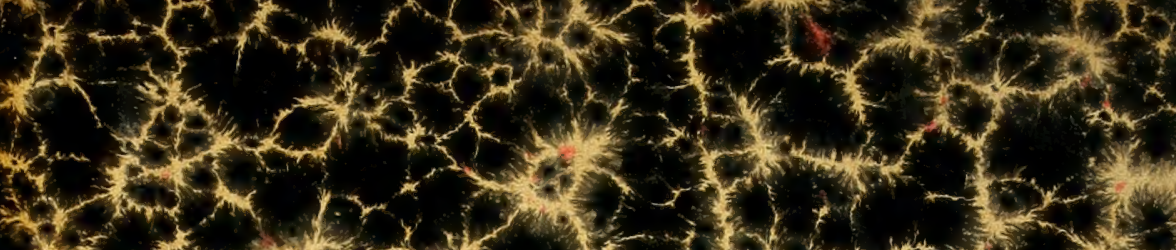

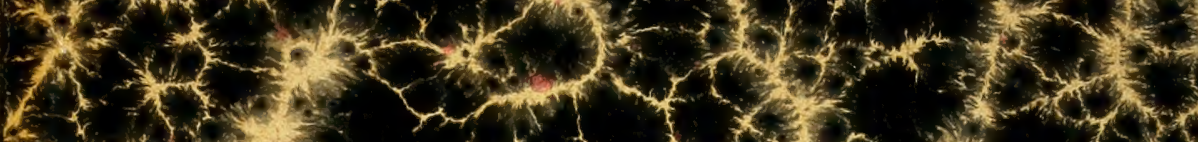

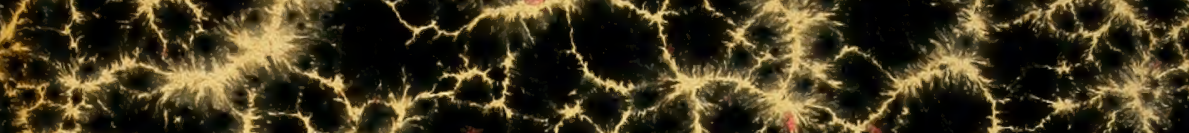

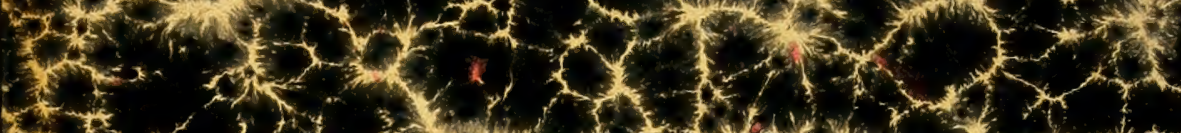

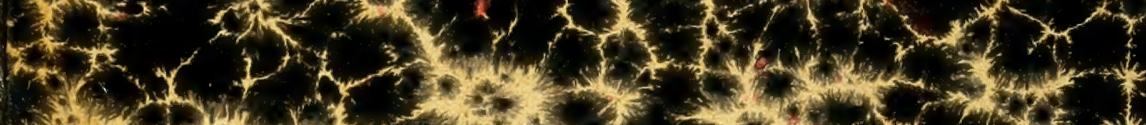

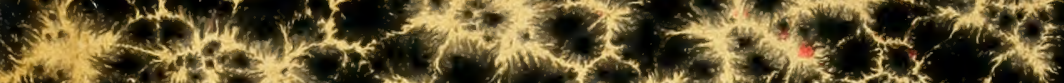

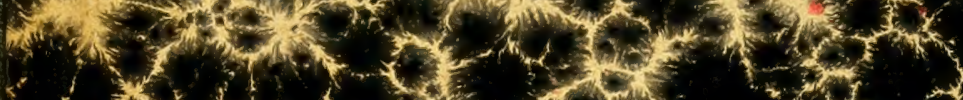

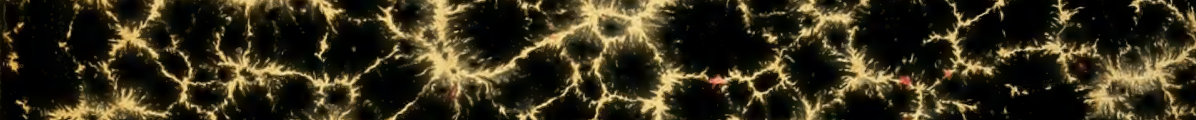

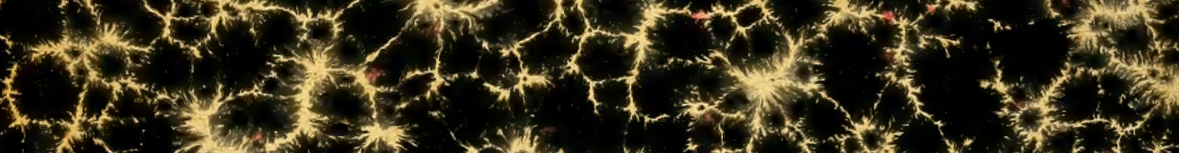

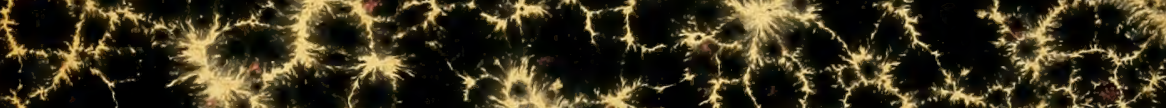

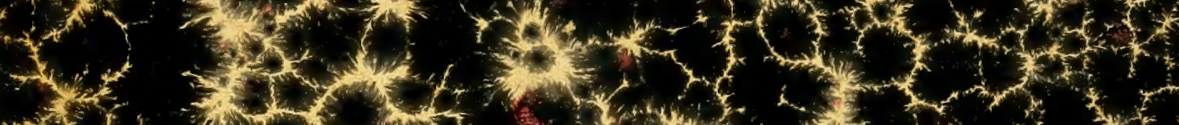

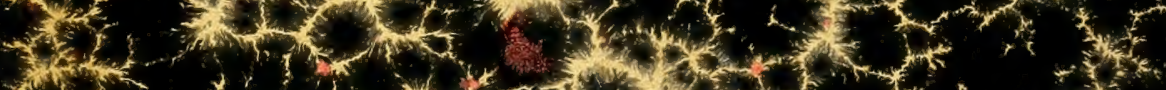
(6)

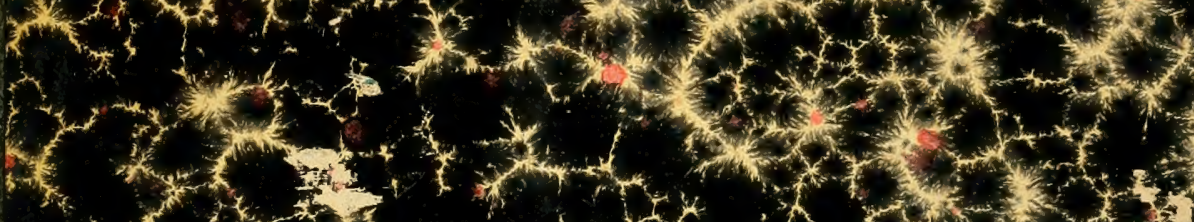

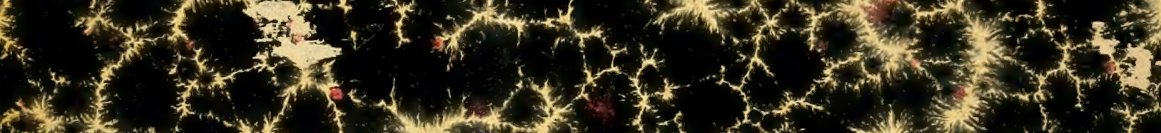

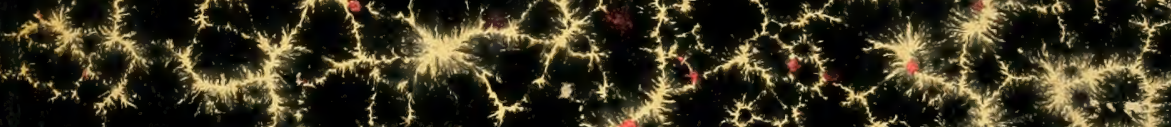

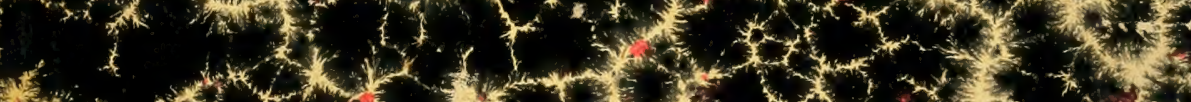

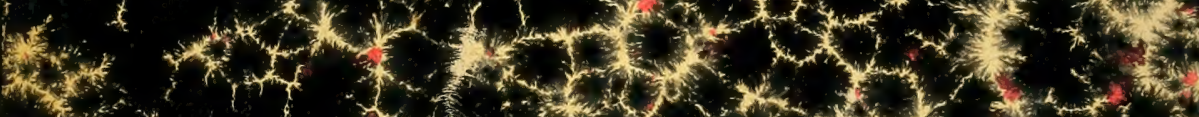
H.

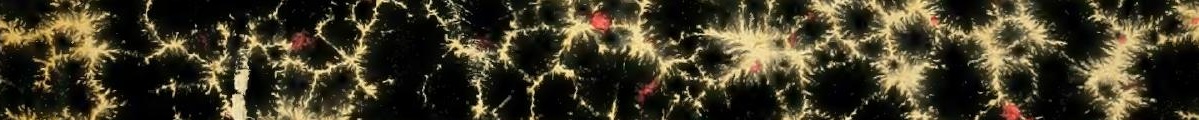

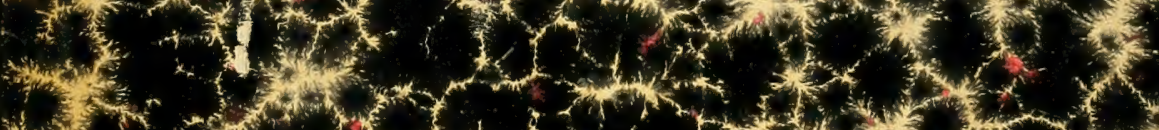
(n) F

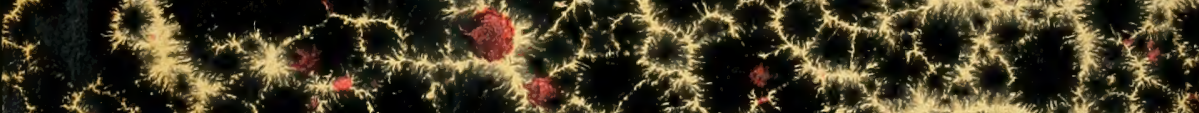

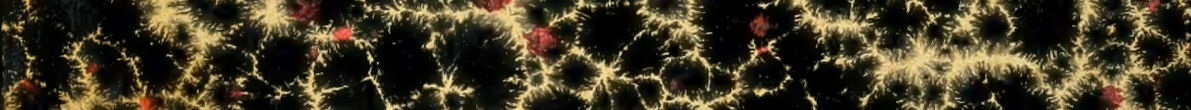
(1. (2) (1) (1) (n)

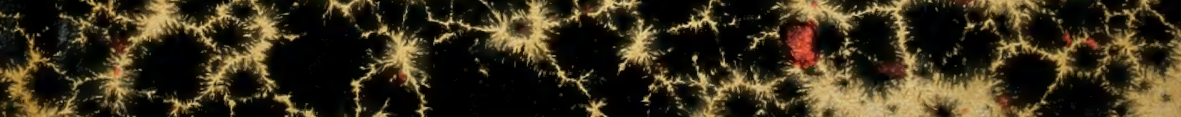

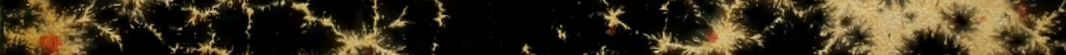




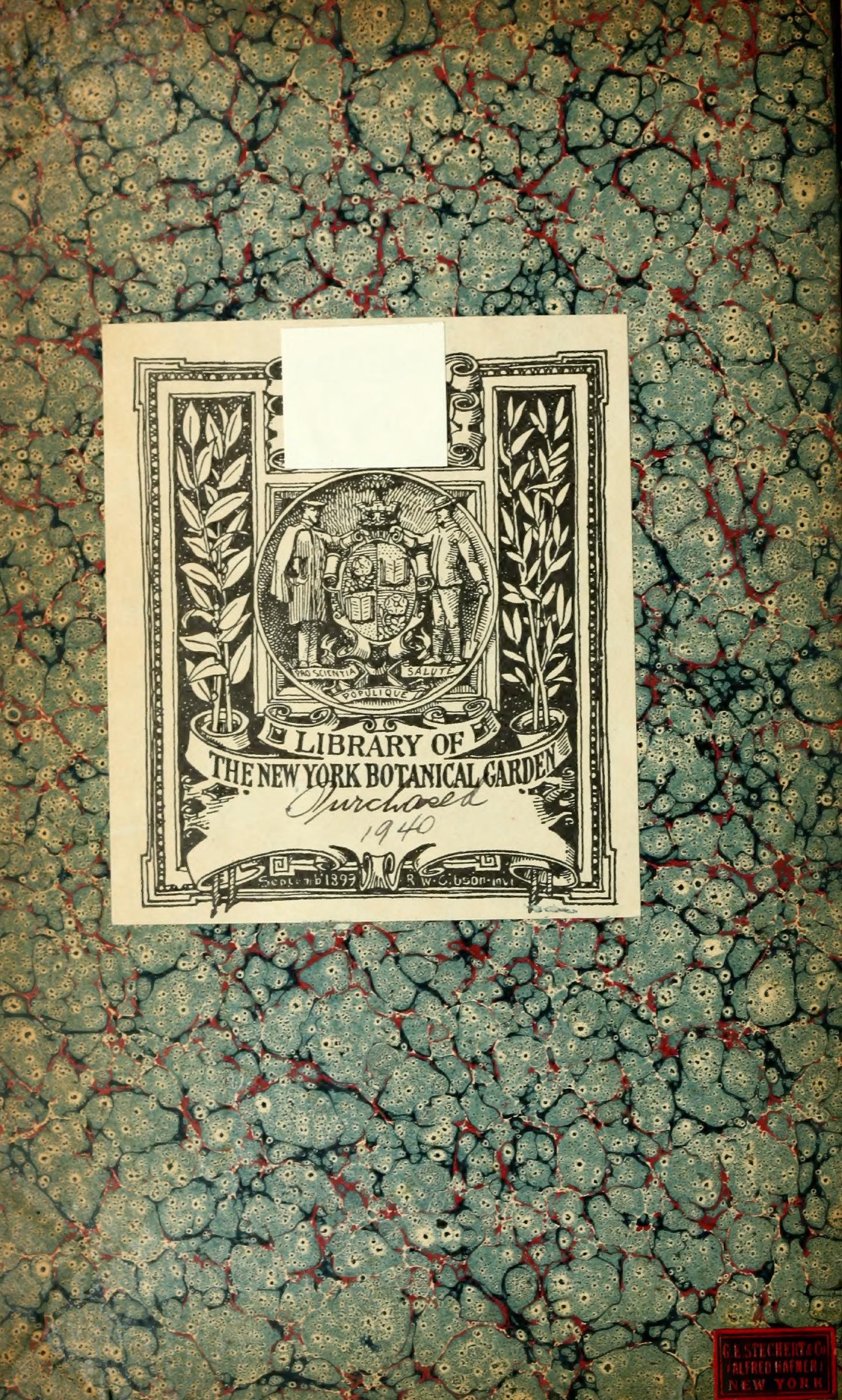


e. 7 rid

2.2.3 frot to

\section{50035}

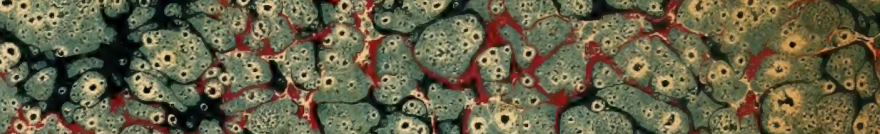

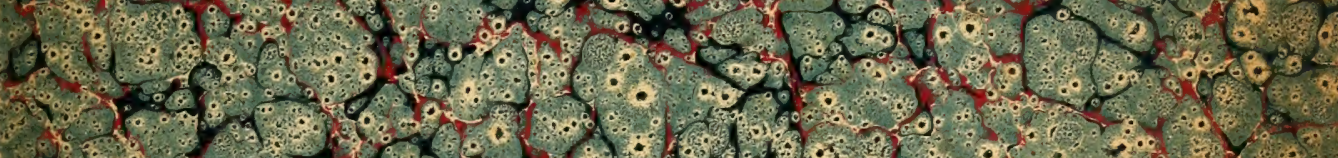

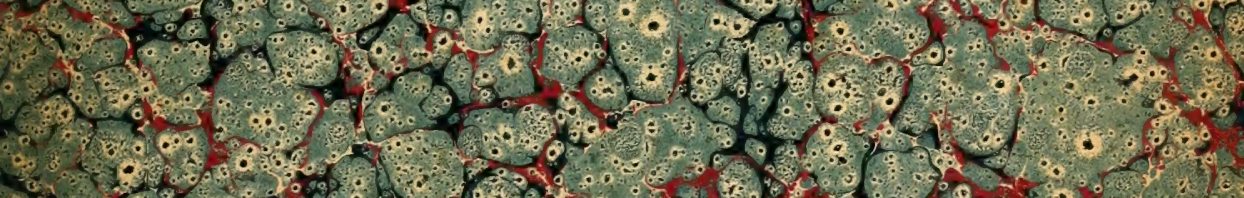

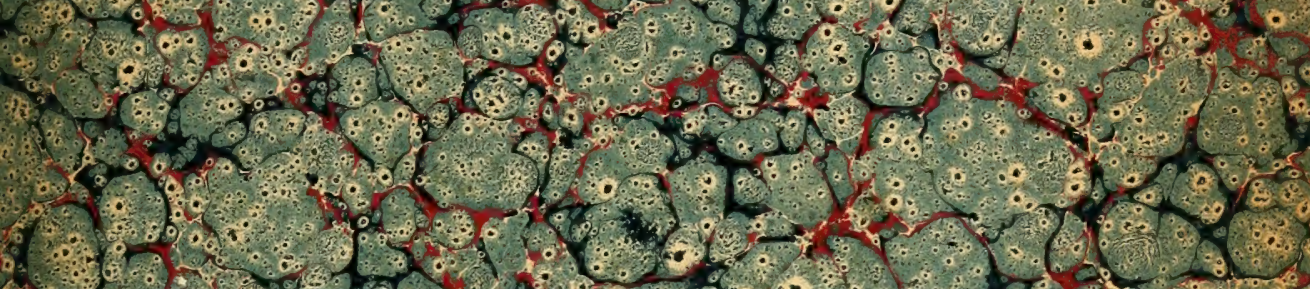

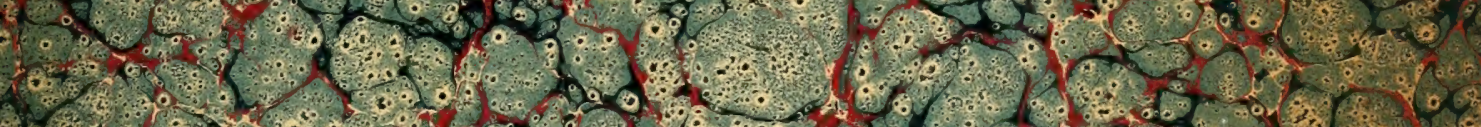

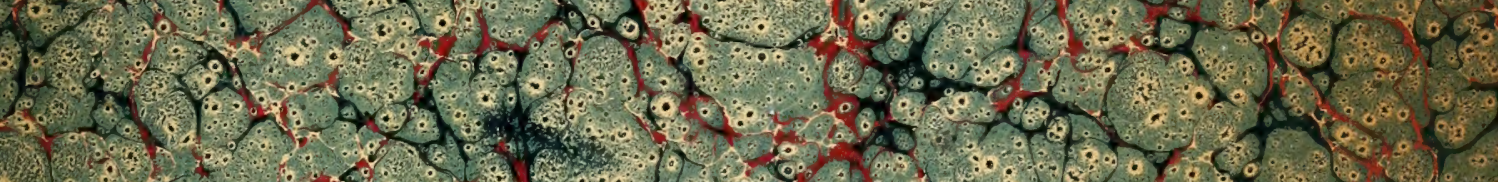

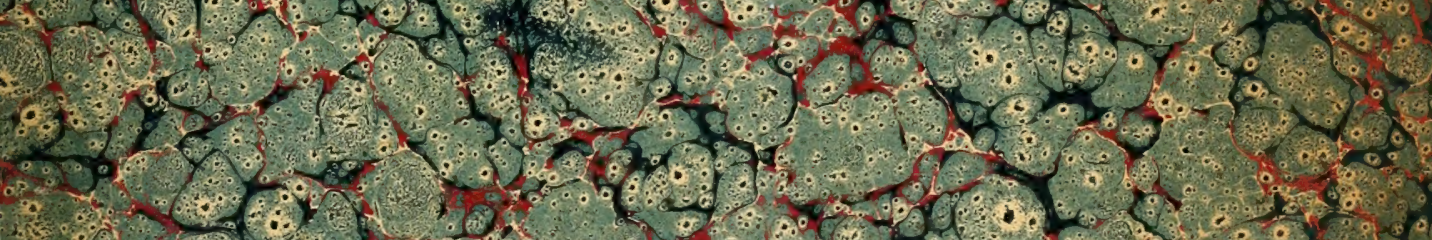

3. Le $x^{2}+f^{2}$

$6 \ln (x+5)$

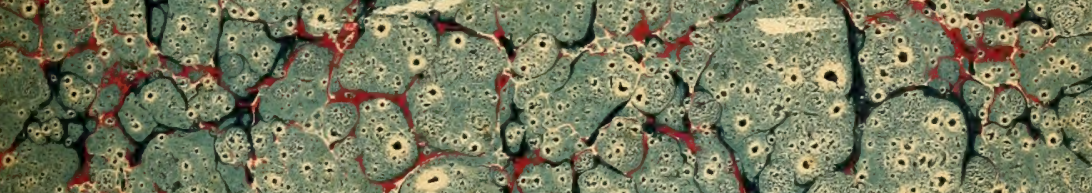

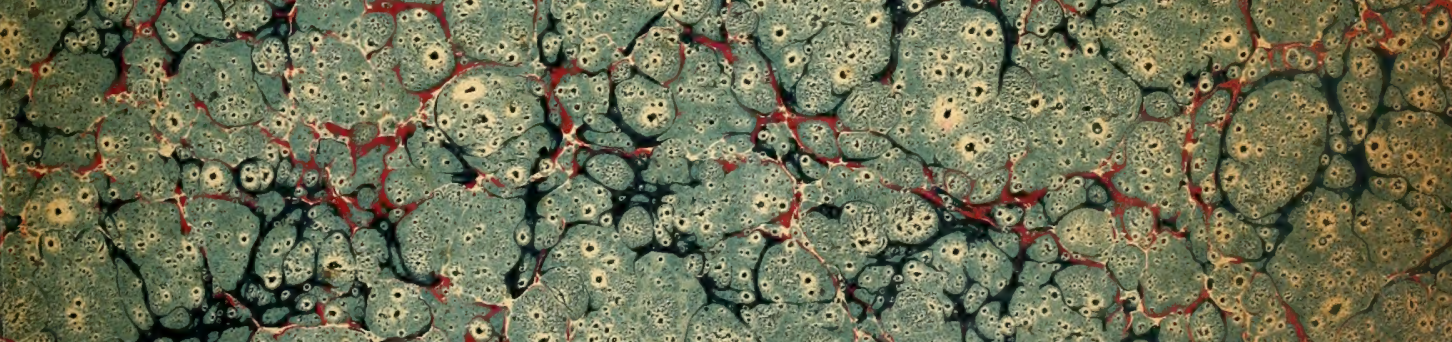
$30023: 409 \times 15$

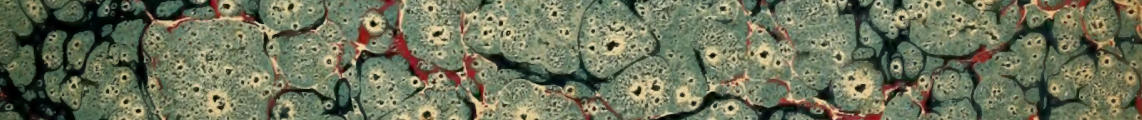
a. $3.42 x^{2} x^{2}$

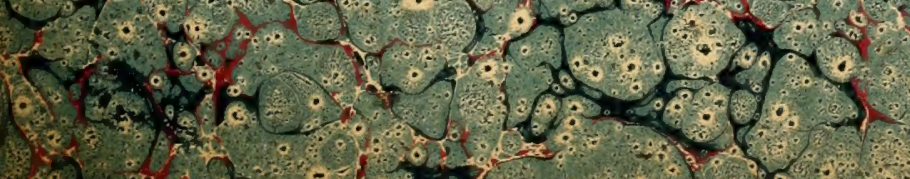

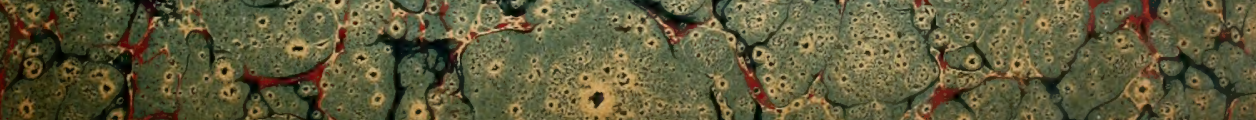







\section{CHAMPIGNONS}

DE LA FRANCE 


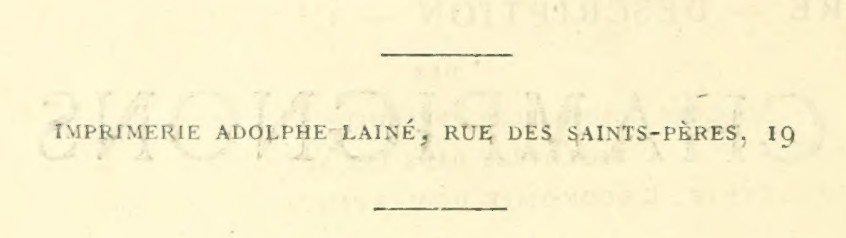




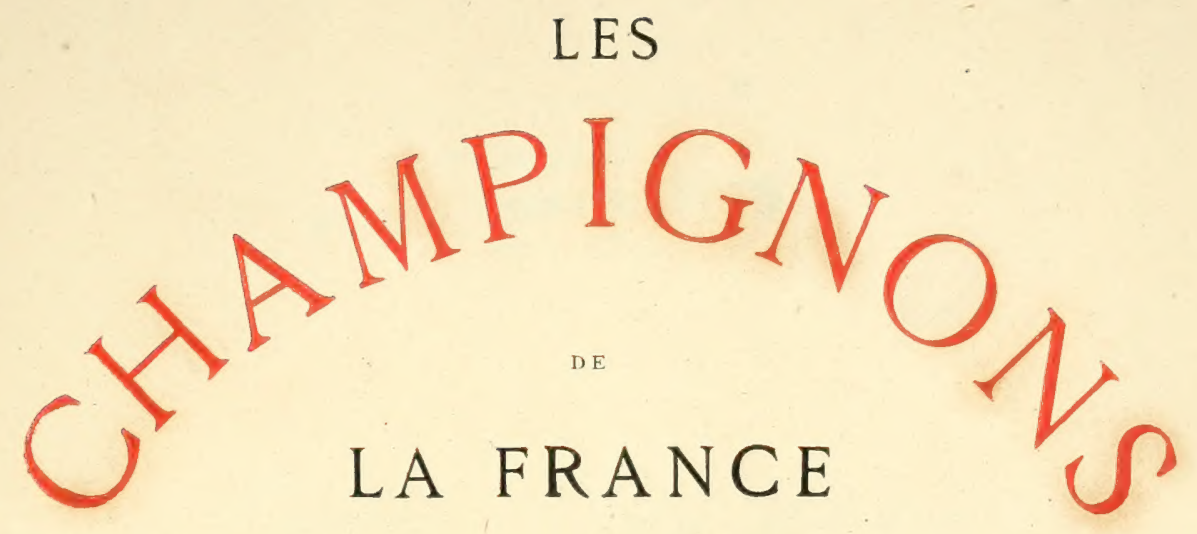

HISTOIRE - DESCRIPTION - CULTURE - USAGES

DES

ESPÈCES COMESTIBLES, VÉNÉNEUSES, SUSPECTES,

EMPLOYÉES DANS LES ARTS,

L'INDUSTRIE, L'ÉCONOMIE DOMESTIQUE ET LA MÉDECINE

P A R

\section{F. S. CORDIER}

Docteur en Médecine, Membre de plusieurs Sociétés savantes

ORNÉ DE VIGNETTES ET DE 60 CHROMOLITHOGRAPHIES DESSINÉES D'APRÈS NATURE PAR A. D. CORDIER

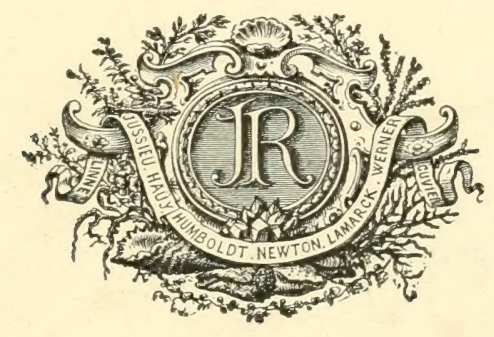

\section{PARIS}

J. ROTHSCHILD, ÉDITEUR

LIBRAIRE DE LA SOCIÉTÉ BOTANIQUE DE FRANCE

43, RUE SAINT-ANDRÉ-DES-ARTS, 43

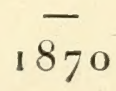

Tous droits réservés 


$$
\begin{aligned}
& \text {. F } 7 \\
& \text { C } 58
\end{aligned}
$$




$$
\begin{gathered}
\text { Ib la dtemaine } \\
\text { de }
\end{gathered}
$$

Ghreicm Henny Persoon

Eréatcuer dela Ścionce mugcologigue

Yon éleve recomnaifsunt,

\%. S. Cordier.

Paris, ce $1^{\text {cr }}$ août 1869. 



\section{INTRODUCTION.}

Les champignons offrant à l'homme tout à la fois des substances utiles aux arts, des médicaments énergiques, des poisons violents, et un aliment des plus agréables et des plus sains, la connaissance de ces végétaux est pour lui du plus grand intérêt. A ne les considérer que sous le rapport alimentaire, il lui serait encore utile de les connaître, puisqu'il en fait journellement usage, et que, dans les temps de disette, il trouve en eux une véritable ressource. Cependant l'étude de ces plantes est généralement négligée, non-seulement des personnes qui n'ont pas à s'occuper de science, mais aussi du plus grand nombre des botanistes.

Elle est négligée d'abord parce qu'elle n'a pas l'attrait de l'étude des plantes phanérogames, pour la plupart si séduisantes par l'éclat, la beauté, le parfum de leurs fleurs, la variété de leurs fruits, de leur feuillage, de leur port; elle l'est surtout à cause de l'extrême ressemblance que présentent entre elles beaucoup d'espèces, ce qui rend leur détermination 
difficile; elle l'est aussi i cause de la quantité prodigieuse de ces especes. On peut dire, en effet, que le nombre des champignons est égal, s’il n’est supérieur, it celui de toutes les plantes phanérogames, puisqu'il est constant que la plupart de celles-ci en nourrissent plusieurs espèces.

En France seulement, on compte plus de six cents espèces d'Agaries, plus de deux cents espèces de Pezizes, et au moins trois cents espèces de Sphéries; et cependant il est certain que toutes les espèces appartenant ì ces divers genres ne sont pas connues; beaucoup d'entre elles n'ont été jusqu'à présent ni figurées ni décrites par les auteurs.

Ce n'est pas toutefois que nous manquions de livres qui traitent des champignons; nous en possédons mème un assez grand nombre. Dans plusieurs figurent it peu près toutes les espèces connues à l'époque où ils ont été publiés; d'antres décrivent les espèces de tel payss, de telle contrée; il y en a même qui traitent d'une manière toute spéciale des champignons alimentaires et rénéneux; mais tous ces livres, soit parce qu'ils coutent cher, soit parce qu'ils manquent de figures ou n'en possèdent pas suffisamment, soit enfin parce fu'ils sont traités d'une manière trop scientifique, restent, malgré tout leur mérite, à peu près inconnus du public et mème de la plupart des savants. Quelques-uns de ces livres, d'ailleurs, sont écrits en langue étrangère; ils ne peurent done être consultés que d'un petit nombre de lecteurs.

C'est le livre qui fait plus particulièrement défaut aux personnes désireuses de se livrer à l'étude difficile des champignons, que nous nous somınes proposé de leur donner, en publiant cette nouvelle édition des 
champignons alimentaires et vénéneux de la France. On trouvera décrites dans ce livre toutes les espèces qui intéressent par leurs propriétés alimentaires ou malfaisantes, Jeur emploi dans les arts et l'industrie. Nous avons tâché de le mettre à la portée du plus grand nombre des lecteurs, tout en nous tenant à la hauteur des connaissances actuelles.

Un mot sur la disposition de ce livre :

La première partie contient des généralités sur l'organisation des champignons, leur physiologie, leur mode de reproduction, leur géographie, l’influence que peuvent exercer sur eux le sol, l'habitat, la saison, le climat; les moyens de distinguer les espèces comestibles des espèces vénéneuses; la possibilité d'enlever à ces dernières leur principe malfaisant; les dommages causés par quelques-unes de ces plantes; la culture, la récolte, la conservation des espèces utiles à l'homme, leur préparation culinaire, leur rôle dans les arts, l'industrie, l'économie domestique; la manière d'agir des espèces malfaisantes sur l'économie animale, le traitement à apporter aux accidents qu'elles déterminent, et enfin l'usage en médecine de ces plantes.

Dans la deuxième partie, nous avons décrit les champignons comestibles, vénéneux ou employés dans les arts, c'est-ì-dire toutes les espèces de France qui offrent de l'intérêt à l'homme. Aux descriptions détaillées, nous avons joint le plus souvent la synonymie des espèces, malheureusement si compliquée dans les auteurs, et la citation des meilleures figures qui en ont été données. Nous ne nous sommes pas contenté de citer les planches des auteurs qui ont écrit avant nous; nous avons donné, dessinées d'après 
nature par $V^{\text {the }}$ Delville-Cordier, les figures d'une ou de plusiems espèces des genres dont nous parlons.

I des descriptions sont prérédées de tableaux synoptiques oiu sont exposés les caractères de la famille et du genre de nos plantes. Dans ces tableaux nous avons fait usage de la méthode dichotomicfue; nous aurions voulu appliquer cette méthode à leur détermination spécificue; nous avons dû y renoncer, à cause de la facilité avec laquelle on peut s'égarer lorsqu'on a à traiter d'un si grand nombre d'espèces.

Nous arons adopté pour la classification des espèces du genre Agaric la méthode de Persoon, suivie par Decandolle, II. Iéveillé et la plupart des botanistes français, de préférence à celle du savant professeur Fries; cette dernière ayant surtout pour base la couleur des spores et le rapport des lames avec l'hyménophore, ce qui n'est pas toujours facile à constater. La classification de Persoon nous a toujours d'ailleurs paru d'un usage plus pratique. Nous avons toutefois tenu compte de la coloration des spores et des autres caractères assignés par Fries.

Nous n'arons pas accepté le partage du genre Agaric de Linné en douze ou quinze genres, comme le fait Fries, par la raison que ces genres sont établis sur des caractères trop peu distincts pour être facilement reconnus par des commençants, lesquels ne peuvent guère voir et ne voient en effet, dans les genres Hygrophorus, Gomphus, Marasmius, Lentinus, etc., que de simples Agarics. Nul doute cependant que la plupart des genres qui ont été créés aux dépens du genre Agaric ne soient plus tard généralement adoptés, la découverte d'espèces nouvelles augmentant charque jour. Quoi qu'il en soit, nous avons 
eu soin d'établir la concordance de la méthode que nous avons suivie avec celle qui a été suivie par le savant Suédois.

Quelques personnes peut-être trouveront trop détaillée la description des espèces dont nous parlons, et eussent préféré, qu'à l'exemple de Persoon dans son Synopsis fungorum, nous nous fussions borné à spécifier seulement les traits caractéristiques qui distinguent une espèce d'une autre espèce. Une description scrupuleuse est rarement trop longue, surtout lorsqu'on a eu l'attention de mettre en lettres italiques, ainsi que nous l'avons fait, les signes que l'on peut regarder comme tout particuliers à l'espèce décrite. Aux noms scientifiques nous avons ajouté les noms vulgaires que porte la plante dans nos anciennes provinces.

Le catalogue des champignons de la France n'ayant pas encore été publié, nous avons cru devoir donner l'énumération de toutes les espèces qui rentrent dans les genres dont nous avons parlé. Cette énumération, disposée par ordre alphabétique, est nécessairement incomplète; mais elle pourra servir de point de repère aux botanistes qui s'occupent de mycologie.

Bien que le nombre de champignons alimentaires, vénéneux, dont nous avons donné la description, soit considérable, il en existe, sans aucun doute, beaucoup d'autres qui certainement sont comestibles, et d'autres encore qui sont vénéneux, mais sur les qualités desquels l'expérience n'a pas encore prononcé. Il nous a semblé inutile de décrire ces espèces, n’ayant voulu parler que de celles dont les propriétés sont bien constatées.

Quoi qu'il en soit, nous croirons avoir atteint le 
but que nous nous sommes proposé si, par la publication de ce live, nous parrenons à propager le gont d'une partie de la botanique toujours trop négligée, et à rendre moins fréquentes les méprises dans la récolte et l'usage des champignons, et, par conséquent, les empoisonnements moins fréquents.

Notre excellent ami, le docteur Léveillé, le plus sirrant peut-ètre des mycologistes français, et savant trop modeste, ayant bien voulu, dans la rédaction de ce livre, nous aider de ses bons conseils, nous sommes heureux de lui adresser ici nos remerciments bien sincères. 


\section{CHAMPIGNONS}

DE FRANGE.

\section{PREMIÈRE PARTIE.}

\section{CHAPITRE PREMIER.}

DE L'ORganisation DEs Chaupignons.

Les champignons sont des plantes terrestres ou parasites d'une consistance charnue, gélatineuse, coriace ou mème tubéreuse, qui portent, sur l'une de leurs faces ou à l'intérieur, des corpuscules infiniment petits auxquels les botanistes ont donné le nom de spores ou séminules, les regardant avec raison comme les organes reproducteurs de la plante.

Ces végétaux, qui tous tiennent un rang des plus humbles dans l'échelle des êtres organisés, se font cependant remarquer par la multiplicité de leurs formes, la variété de leurs couleurs, et quelquefois même par la beauté et l'élégance de leur port.

Ils n'ont jamais ni feuilles, ni fleurs, ni appendices foliacés; ils n'ont ni étamines, ni pistil, et par conséquent pas d'organes sexuels; du moins jusqu'à présent on ne leur 
en a pas découvert avec certitude. Ils germent sans apparence de cotılédons; ils appartiennent donc à la classe des cryptogames de Linné, à celle des acotylédones de Jussieu.

Quoique très-simples dans leur structure ou leur composition générale, ces plantes présentent néanmoins dans la plupart des espèces un appareil d'organes plus ou moins complinuc'. Les plus complexes d'entre eux réunissent tout à la fois ce que les botanistes appellent le nyycélium, le volíu, le collet, le pédicule, l'hrménophore, l'hr)ménium et les spopes.

Voyons d'abord ce que sont ces différentes parties.

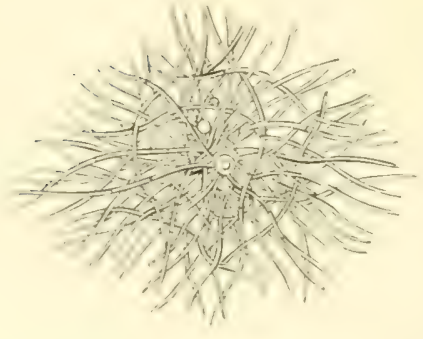

Nycélium, - Filaments grossis.

On donne le nom de mycélium, de carc)the, ou blanc de champignon, aux fibres ou filaments le plus souvent blancs, comme soyeux, presque toujours entrelacés, qui donnent naissance aux jeunes champignons, et au moyen desquels ils adhèrent à la terre ou aux corps sur lesquels ils végètent.

Le volva, volve ou bourse, est une membrane de cou-

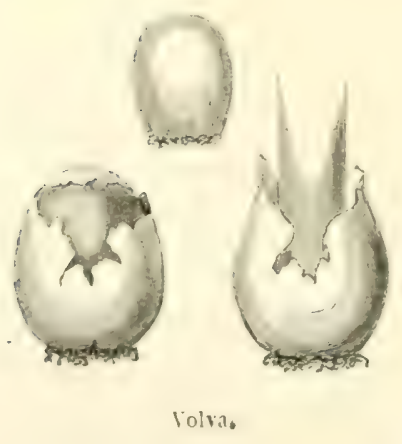
leur blanche qui, dans plusieurs Agarics et dans les Phalloïdes, enveloppe entièrement le champignon dans sa jeunesse. Celuici la déchire en se développant et la" laisse à la partie inférieure du pédicule, complète ou incomplète : complète, lorsqu'il n'en emporte rien ; incomplète, lorsqu'il en entraine avec lui des dé- 
bris qui restent adhérents au chapeau sous la forme de taches blanches ou de squammes.

Le pédicule, que l'on appelle aussi stipe, pied ou tige, est la partie du champignon qui supporte l'hyménophore. Bulbeux ou renflé à sa base, atténué ou dilaté à sa partie supérieure, mais plus souvent cylindrique dans toute sa longueur, le pédicule est charnu ou coriace, tomenteux ou lisse, nu ou pourvu d'un anneau ou collier. Il s'insère tantòt à la partie centrale du chapeau ou hyménophore, ce qui est

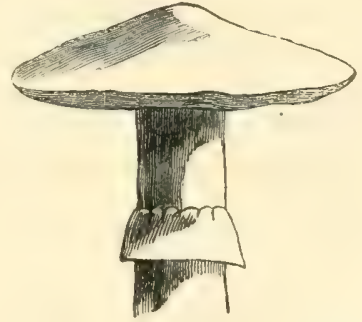

Chapeau, pédicule et collier. le cas le plus fréquent, et tantòt sur un point excentrique ou tout à fait latéral. Lorsqu'il manque, l'espèce est dite sessile.

Ce que l'on nomme anneau, collet ou collier', est formé par une membrane particulière qui, dans le jeune âge de beaucoup d'Agarics et d'un petit nombre de Bolets, part de la base du pédicule, enveloppe celui-ci jusqu'à une certaine hauteur, d'où elle s'étend à toute la circonférence du chapeau, duquel elle se sépare ensuite pour rester attachée à la partie supérieure du pédicule, où, le plus souvent, elle forme une sorte de bourrelet annulaire, presque toujours plissé et rabattu. Le volva et le collier existent quelquefois ensemble sur un mème champignon.

Lorsque le collier est très-mince et que, à l'approche de la maturité de la plante, il se détruit en laissant seulement quelques filaments suspendus aux bords du cha- 
peatu ou adhérents au pédicule, on l'appelle plus parti-

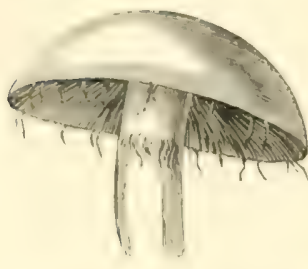

(hapentu, stipe et collier arancéris. culierement cortine ou collet rarachnoüde. Le collier ainsi modifié se trouve plus particulierement dans une section d'Agarics que, pour cette raison, Persono avait désignée sous le nom de Cortinaire.

Le collier, soit consistant, soit aranéeux, et le volva manquent dans beaucoup de champignons; mais alors ces champignons sont presque toujours complétement enveloppés, du moins dans leur trèsjeune âge, d'une sorte de voile, à peine distinct, qui semble tenir lieu de volva et de collier. Ce voile, cette enveloppe générale, est veloutée, comme cotonneuse, quelquefois mème glutineuse.

Jans un grand nombre de champignons, les Russules, les Lactaires, etc., on ne remarque ni volva, ni collet, ni voile d'ancune sorte.

L'hyménophore, appelé le plus souvent chapeau ou piléole, et quelquefois aussi réceptacle, est l'organe du champignon qui porte l'hyménium, membrane sur laquelle naissent les spores. Il est la partie la plus élevée, la plus apparente du champignon, celle qui est supportée par le stipe, lorsque ce stipe existe.

L'hyménophore se présente sous les formes les plus diverses. Tantôt il a celle d'un éteignoir, d'un parasol, d'une coupe ou même d'un entonnoir, selon les espèces, comme dans la plupart des Agarics ; tantòt celle d'un cône arrondi, comme dans les Morilles; celle d'une mitre, comme dans les Helvelles; ou bien celle d'une croûte étalée sur le lieu oil végète la plante, comme dans plusieurs Théléphores, Morilles et Polypores lignicoles; toutefois, la forme hémis- 
phérique est celle qu'il affecte le plus volontiers; il a presque toujours cette forme dans le jeune âge de la plante. Ordinairement régulier, il semble, dans quelques espèces lignicoles, qu'il soit coupé en deux par le milieu, ce que l'on appelle dimidié.

Les bords du chapeau sont entiers ou divisés. Quelquefois, comme dans les Agaries qui ont peu de chair, ils sont marqués de stries longitudinales parallèles aux feuillets.

Dans les espèces coriaces, sessiles, dont la durée est de plusieurs années, telles que les Bolets amadouviers, le chapeau présente une alternative de saillies et de dépressions circulaires, qui sont le résultat de la formation successive de couches annuelles, et qui peuvent servir à faire con naître l'âge de la plante.

Le chapeau, qui pour l'ordinaire est la partie la plus colorée du champignon, n'a pas toujours une coloration uniforme, surtout à la face supérieure, où se voient quelquefois des taches, des marbrures et mème des zones concentriques ou cercles de différentes nuances. Cette mème surface, qui souvent est rendue visqueuse par l'humidité, est glabre ou velue, lisse ou pulvérulente, ou bien encore parsemée de squammes ou papilles produites par l'épiderme qui se soulève sous forme d'écailles imbriquées, et qu'il faut savoir distinguer des squammes ou verrues des Amanites; celles-ci, comme je l'ai dit plus haut, sont des parcelles de la bourse ou volva.

L'hyménophore, ou chapeau, est charnu, gélatineux, subéreux ou coriace, selon les espèces. Il se continue avec le stipe, duquel il n'est pas toujours bien distinct.

L'hyménium, ou organe fructifère des champignons, est cette membrane qui forme en se repliant les lames rayonnées du centre à la circonférence des Agarics, les replis saillants des Chanterelles, les veines des Morilles, les pointes 
ou aiguillons des Hydnes, les tubes des Bolets et des Fistulines, les pores des Polypores, etc.

Dans quelques espèces du genre Théléphore, il semble gue l'hyménium soit placé sur la face supérieure du chapeau. bien qu'en réalité il soit placé sur l'inférieure. Celte disposition apparente est due à ce que plusieurs de ses lobes sont réfléchis en haut.

Dans les Clavaires et les Trémelles, champignons qui n'ont pas de chapeau distinct, I'hyménium parait occuper toute la superficie de la plante.

Dans les Igaries, les Bolets, les Hydnes et la plupart des basidiosporés, l'hyménium est placé à la partie inférieure de la plante: dans les Morilles, les Helvelles, les Pezizes et la plupart des thécasporés, il est placé ì la partie supérieure.

Cette membrane est souvent d'une couleur différente de celle du chapean. Quelle que soit sa couleur, elle devient plus foncée à la maturité des graines.

L'hyménium porte dans quelques auteurs le nom de membrane sporulifiere, mombrane séminifère, membrane gong) lifire.

On désigne sous le nom de spores, sporules ou séminules, et quelquefois sous celui de gongyles, ce qu'on appelle graines ou semences dans

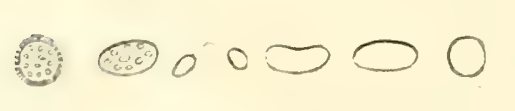
les végétaux d'un ordre plus élevé; c'est-à-dire les Sporres grossies. organes reproducteurs des champignons. La ténuité des spores est telle que, dans le plus grand nombre des cas, elles se dérobent à la vue simple; et leur nombre est si considérable, dans quelques espèces, qu'il semble, à une certaine époque de la vie du champignon, que l'hy- 
ménium tout entier soit formé par leur réunion. Celui-ci s'en trouve recouvert comme d'une poussière fine, ressemblant à ce que dans certains fruits on appelle la fleur.

Les spores, tant qu'elles sont adhérentes à l'hyménium, sont : ou bien libres, isolées et supportées par des filaments qui reposent sur de petits corps saillants appelés basides, basidies ou clinodes; ou bien elles

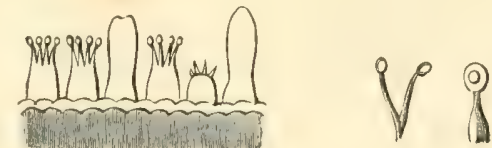

Basides et anthéridies grossis.

sont renfermées en certain nombre dans des utricules auxquelles on a donné le nom de théques.

Les basides, à la maturité de la plante, font saillie à la surface de l'hyménium.

Chaque baside est composé d'une seule cellule arrondie, ovoïde ou allongée, qui porte à son sommet un ou plusieurs filaments désignés sous le nom de stérigmates, à l'extrémité de chacun desquels se trouve une seule spore.

Les spores sont supportées ainsi par des basides dans les genres Agaric, Bolet, Hydne, Phallus, Lycoperdon. Chaque baside, dans ces genres de champignons, porte quatre filaments ou stérigmates, et par conséquent quatre spores. Dans les genres Cantharellus et Scleroderma, ce nombre parait variable; car, si l'on voit le plus ordinairement quatre filaments sur chacun des basides, quelquefois aussi on en compte deux, trois, cinq ou six. Dans les genres Exidie et Tremelle, chaque baside ne porte qu'un filament et qu'une spore.

Les thèques, appelées aussi sporanges ou asci, sont des vésicules, des utricules spéciales, séparables, allongées en forme de massue, ovoïdes ou globuleuses, dans lesquelles les spores sont renfermées en nombre presque tou- 
jours determince, mais variable, selon les genres de cham-

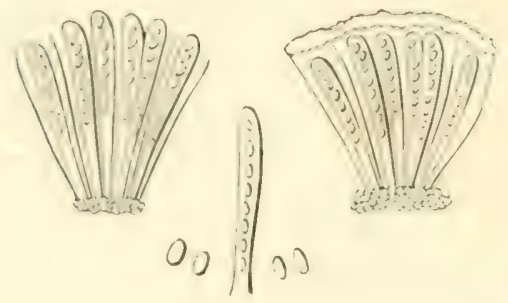

Thèques grossies. pignons, et disposées en séries le plus souvent longitudinales, qui semblent tapisser l'hyménium.

Les theques se voient dans les genres Pezize, Helvelle, Leotia, Géoglosse, etc.; chaque thèque, dans ces plantes, renferme huit spores; elles se voient dans le genre Truffe, ou chacune d'elles en contient de quatre à huit; dans le genre Élaphomyce, où leur nombre varie de une à huit.

On peut se demander si, lorsque dans un mème genre le nombre des spores est variable, soit sur les basides, soit dans les thèques, cette variation ne serait pas due à l'avortement d'une ou de plusieurs spores, ou bien à une soudure intime de plusieurs thèques ou de plusieurs basides.

I)ans les Lycoperdonnés et les Tubéracés, la partie du champignon qui porte les organes de la reproduction n'est pas extérieure, comme dans les autres champignons; elle est renfermée dans une enveloppe particulière, à laquelle on a domné le nom de péridium ou réceptacle. A la maturité du champignon, les basides et les thèques tapissent l'intérieur du péridium.

Les Lycoperdonnés sont pourvus de basides; les Tubéracés le sont de thèques.

Outre les thèques et les basides, on remarque assez souvent à la surface fructifère des champignons des cellules saillantes, arrondies, ovales ou allongées, aiguës, obtuses ou renflées ì leur extrémité libre, auxquelles les mycologistes ont donné le nom de cystides ou anthéridies. Ce nom d'anthẹridies leur a été donné par quelques botanistes, qui 
les avaient regardés, et peut-être les regardent encore, comme des organes destinés à la fécondation des spores, et jouant le rôle que remplissent les anthères dans les plantes phanérogames. Comme on ne voit dans les anthéridies rien qui ressemble ni au pollen, ni à la liqueur contenue dans les grains du pollen, il est difficile d'admettre qu'elles soient les agents fécondateurs des spores. Les anthéridies pourraient bien n'ètre que des basides ou des thèques, dont les spores ou séminules sont avortées, et qui se seront allongées d'une façon anomale. Il est certain, du moins, que les anthéridies ne sont pas disposées avec ordre comme le sont les étamines dans les plantes phanérogames; comme le sont les spores elles-mèmes sur les basides ou dans les thèques. Les anthéridies, d'ailleurs, manquent dans beaucoup d'espèces; on ne les rencontre guère que dans les champignons d'un ordre élevé.

Je dois dire que les basides, les thèques et les anthéridies ne se voient distinctement qu'à l'aide du microscope. Il en est de mème des spores, à moins que celles-ci ne soient accumulées en grand nombre sur une mème surface. Un moyen bien simple toutefois de voir les spores dans la plupart des champignons, consiste à placer leur surface fructifère sur une glace posée horizontalement ou sur une feuille de papier blanc ou noir. Lorsque, après quelques heures, on vient à enlever ces plantes, on trouve la place qu'elles occupaient ternie par une matière pulvérulente entièrement

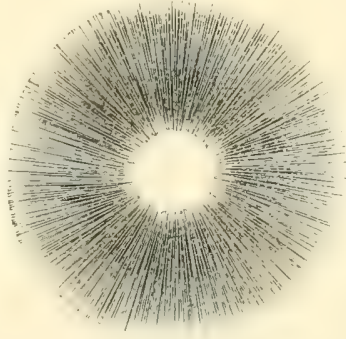

Spores détachées d'un Agaric. composée de spores. Les Agarics et les Bolets, placés comme je viens de le dire, laissent sur la glace ou le papier un dessin assez exact de la surface fructifère. 
CHAPITRE 11.

PROPRIETES PHYSIQTES DES CIIAMPICYOYS.

Bien que certaines especes de champignons paraissent assez compliquées dans leur organisation, toutes ces plantes cependant ne sont, en dernière analyse, composées que d'un seul élément anatomique, le tissu cellulaire; c'est-àdire qu'elles sont uniquement formées de fibres entrelacées les unes dans les autres, et laissant entre elles des espaces ou vacuoles plus ou moins irréguliers, tantòt arrondis, tantòt allongés, qui communiquent les uns avec les autres. Cette disposition en cellules de la trame, ou tissu de tous les organes des champignons, a fait ranger ces plantes dans la classe des végétaux cellulaires.

Les champignons sont intermédiaires entre les algues et les lichens, autres plantes cellulaires. La transition de certains champignons aux algues et aux lichens est même tellement insensible, qu'aujourd'hui encore les botanistes sont dians le doute si telle plante, qui est regardér par quelques savants commé un véritable champignon, ne serait pas plutòt une algue ou un lichen. Linné et d'autres botanistes se demandaient si ces êtres placés sur la limite des deux règnes, végétal et animal, ne devaient pas former un règne à part, que l'on aurait appelé fongique, et tenant le milieu entre les deux autres. 
La création de ce règne peut paraître étrange; l'est-elle beaucoup plus que celle d'un règne humain, proposé dans ces derniers temps par quelques savants, et que d'autres savants ont admis avec empressement?

Si les éléments qui entrent dans la composition des champignons sont d'une simplicité extrême, il n'en est pas moins vrai que ces plantes présentent une grande variété de forme, de taille, de consistance, de couleur, d'odeur et de saveur.

Presque toutes, au sortir de terre ou de l'habitat qu'elles ont choisi ou accepté, sont sphériques; mais, à mesure qu'elles se développent, elles prennent la forme qui caractérise le genre et souvent même l'espèce auxquels elles appartiennent. Elles affectent celle d'une cloche, d'une ombrelle, d'un disque aplati, ou mème d'un entonnoir dans les Agarics; celle d'une coupe, dans les Pezizes; celle d'une massue ou de rameaux imitant le corail, dans les Clavaires; celle d'une mitre dans les Helvelles; celle d'une croûte étalée dans quelques Polypores et Théléphores; celle d'alvéoles dans les Morilles, Favolus, Hexagona; celle d'un grillage dans les Clathres. Les Crathes, les Nidulaires, ressemblent à des nids dans lesquels on croirait voir des œufs: les Spumaires ont l'aspect de l'écume ou d'une gelée blanche. Diverses Tremelles ont l'apparence du cerveau, du mésentère: les Phallus, les Verpa, ont la forme étrange que rappelle leur nom.

Certains champignons atteignent des grosseurs considérables. L’Agaric fausse Oronge, l'Agaric élevé, se font remarquer par leur grande taille. Le Bolet comestible et le Bolet à gros pied, B. pachypus, Fr., se distinguent aussi par leur volume, de même que certains Polypores. Berkeley cite le cas d'un Polypore squammeux qui avait atteint, en trois semaines, une périphérie de 7 pieds 5 pouces anglais, 
"t yui pesait 34 livres. In Polypore du frène, Bull., mesurat 42 pouces anglais en largeur. Le Polypore géant atteint prespue toujours une taille colossale, comme son nom l'indicue. I.e Polypore touffu, P. frondosus, Fr., atteint aussi le plus souvent une taille très-grande : on en a vu qui mesuraient 75 centimètres de largeur et qui pesaient de 9 it ro kilogrammes. In Bolet foie de bocuf, Fistulina hepatica, Fr., avait 60 centimètres de largeur et pesait près de i 5 kilogrammes; quelques espèces de Vesse-de-loup acquièrent aussi une grande dimension, entre autres le Lycoperdon gigantesque, lequel dépasse souvent le volume de la tète d'un homme et va jusqu'à peser plusieurs livres.

I)'autres champignons se font, tout au contraire, remarquer par l'exiguité de leur taille. Je ne parle pas ici de ces espèces à peine visibles à l'œil nu et appartenant à la classe des Torulacés, des Mucorés et des Mucédinés. Je n'ai pas à m'occuper de ces plantes; mais, même parmi les espèces qui nous intéressent comme alimentaires, il en est quelquesunes qui sont d'une taille assez chétive pour que, le plus souvent, on dédaigne de les recueillir : tels sont l'Agaric esculent, Jacq., Ag. perpendicularis, Bull., et l'Agaric disséminé, Pers., Ag. digilaliformis, Bull.

Quant à la consistance de ces plantes, les unes sont charnues, d'autres sont gélatineuses, pulpeuses, d'autres sont dures, coriaces; quelques-unes mème ont la consistance du liége ou celle du bois. Les espèces épiphytes, ou lignicoles, sont généralement plus coriaces que les espèces terrestres; elles présentent aussi plus de diversité dans leurs formes.

La couleur des champignons est extrêmement variée. On peut dire qu'il n'est pas de nuances que ces plantes ne présentent: les botanistes, dans leurs descriptions, sont mème souvent embarrassés pour donner un nom à ces 
nuances. On trouve en elles toutes les dégradations du jaune, de l'orangé, du rouge, du pourpre, du lilas, du brun, du fauve, du chàtain, du bistre, de la terre d'ombre, etc.

Le vert et le bleu sont les couleurs qu'elles affectent le moins souvent. Ise premier ne s'observe que dans quelques Russules, l'Agaric virescent, Schaff., l'Agaric à lames fourchues, Pers., et, dans les variétés vertes des Amanites phalloïdes, Fr. et Mappa, Batsch. Le bleu ne se voit guère non plus que dans l'Agaric odorant, Bull., l'Agaric bleuâtre, Ag. (Cortinarius) cyanites, Fr., et l'Agaric vert-de-gris, Ag. xruginosus, Curt.

Le rouge vif, et toutes les variétés du rouge, se remarquent dans diverses Russules, Agaricus integer, Lin., Ag. emeticus, Fr., Ag. sanguineus, Bull. Le rouge vineux se voit dans l'Agaric rougeâtre, Ag. (Amanita) rubescens, Pers., dans la Clavaire améthyste, Bull., dans les feuillets du champignon de couche. Le violet s'observe dans plusieurs Cortinaires.

Bon nombre de champignons sont entièrement blancs.

Leur couleur n'est pas constante dans toutes les espèces: elle varie quelquefois assez pour laisser des doutes dans la détermination de quelques-unes, surtout de la section des Russules. Cette différence de coloration, tantòt plus faible, tantòt plus prononcée, est due souvent à l'action de la lumière, mais plus souvent encore à l'âge de la plante.

Quelques champignons sont unicolores; c'est-à-dire qu'ils ne présentent qu'une seule couleur, mais nuancée à différents degrés: d'autres ont des couleurs variées dont les tons sont tranchants et forment contraste : plusieurs sont zonés, rayés, marqués de taches de diverses couleurs. Quelques-uns ont un aspect velouté, soyeux, micacé; d'autres sont lisses, luisants. 
La chair, ou ce que l'on appelle la trame, le parenchyme des champrignons, est blanche dans le plus grand nombre des esperes; (dle est jaune dans quelques-unes : l'Oronge, la Chanterelle, divers Bolets; dans d'autres elle est fuligineuse: l'Agaricus (Paxillus) contiguus, Bull. Elle est d'un rouge brun dans la Fistuline hépaticue, Bull.; noire dans la Pezize noire, Bulgaria inquinans. Elle est nuancée de rose a la superficie du chapeau dans plusieurs Russules et dans l'Agaric rougeâtre, Ag. (Amanita) rubescens.

Cette chair, dans quelques espèces de Bolets et d'Agarics, change de couleur lorsqu'on vient à la briser. Il en est de mème des tubes et des feuillets.

Diverses espèces sont tout chair, pour ainsi dire, entre autres le Fistulina hepatica, Fr.; d'autres, au contraire, sont tellement minces qu'elles semblent en manquer absolument: tel est le cas de la plupart des Coprins.

En général, la chair ou le parenchyme des champignons, a moins de consistance dans le jeune âge que dans l'âge adulte.

La saveur des champignons est très-variable. Quelquesuns sont insipides; d'autres sont âcres; caustiques, amers, astringents, nauséeux, etc.

Dans quelques espèces, la saveur, d'abord nulle, ou à peine sensible, se développe peu de temps après qu'on les a màchées, et donne à la bouche une sensation de brùlure et de constriction qui persiste longtemps.

On sait de quelle âcreté cette saveur est douée dans l'Agaric poivré, Scop:, dans l'Agaric controverse, Pers., et dans plusieurs Lactaires.

Elle a quelque chose de vireux et de nauséeux dans l'Agaric bulbeux, Bull., Igaricus Phalloides, Fr, et Mappa, Batsch., et dans la lausse Oronge. Elle est salée dans l'Agaric engainé, Bull.; acide dans l'Agaric du bouleau, Scop., 
l'Agaric cannelle, Ag. (Cortinarius) cinnamomeus, Fr., acide aussi dañs le jeune àge de l'Agaric contigun, Bull., Paxillus involutus, Fr.; elle devient amère lorsque le champignon vieillit. L'Agaric à longue racine, Agaricus radicosus, Bull., a d'abord une saveur agréable, mais, un instant après qu'on l'a goùté, il laisse dans la bouche un goùt d'une âcreté insupportable. L'Agaric échaudé, Bull., et la Clavaire en pilon, Lin., ont une saveur amère déplaisante; il en est de mème de l'Ag. tuberosus, Bull, et de l'Ag. racemosus, Pers., lorsqu'ils sont avancés en âge.

L'odeur des champignons n'est pas moins variable que leur saveur. Celle qui domine dans la plupart d'entre eux est toute particulière à ces plantes et semble n'appartenir qu'à elles seules; c'est plus particulièrement celle qui distingue le champignon de couche.

Quelques espèces sont dépourvues de toute odeur: telles sont le Bolet comestible, Bull., le Bolet livide, Pers., Bolelus lividus, Fr., l'Oronge vraie.

Plusieurs de ces plantes exhalent un parfum des plus agréables, tandis que d'autres sont repoussantes par leur extrème fétidité.

L'Agaric odorant, Bull., répand une odeur qui tient du musc et de l'oillet. L'Agaric camphré, Bull., dont l'odeur est presque nulle et assez semblable à celle du camphre, lorsque le champignon est frais, exhale, lorsqu'il est desséché, l'odeur du mélilot. L'Agaric imbriqué, Bull., a celle de la gentiane; l'Agaric orcelle, Bull., l'Agaric Mousseron, Bull., Ag. Prunulus, Scop., l'Agaric couleur de froment, Bull. et plusieurs autres, celle de la farine récente. Les Agarics Marasmius alliaceus, Jacq., M. prasiosmus, Fr., M. scorodonius, Fr., M. porreus, Fr., sentent l'ail d'une façon très-prononcée; de là leur est venu leur nom spécifique: 
I. Lenlinus sunvissimus, Fr., répand, dit Friès, une oldur tris-anréable, et qui est perceptible a 20 pieds de distance.

Dans le nombre des especes dont l'odeur est fétide, je citerai l'Agaric soufré, Bull., qui, à peine sorti de la terre, a celle du chanvre roui, et qui, devenu adulte, exhale une odeur cadavéreuse; l'Agaric aqueux, Bull., et la Pezize stipitée, Bull. (P. macropus, Pers.), qui sentent la punaise; l'Agaric fétide, Pers., Ag. (Russula) foetens, Fr., doit ce nom à son odeur repoussante; l'Agaric spermatique, Paul., doit le sien à l'odeur toute particulière que ce nom rappelle. Le Satyre impudique, Phallus impudicus, Lin., répand, à sa maturité, une odeur d'une fétidité extrème, qui se fait sentir au loin et qui attire les mouches, comme le ferait la chair corrompue; le Clathre grillé, Clathrus cancellatus, Lin., a une odeur plus repoussante encore.

Le principe odorant de la plupart des champignons est volatil; il se dissipe en grande partie par la dessiccation. Quelques espèces cependant, telles que I'Hydnum suaveolens, Pers., l'Agaric mousseron, Ag. albellus, Dec., I'Agaric camphré, Bull., gardent leur odeur étant desséchées.

Toutes les espèces de champignons contiennent un suc ou fluide aqueux, analogue à la séve des plantes phanérogames; mais, outre ce principe, nécessaire à l'accroissement et à l'entretien de la plante, quelques-unes possèdent un autre suc de nature laiteuse, le plus ordinairement blanc, opaque, lequel s'épanche lorsque l'on vient à blesser la plante, et qui est assez caractéristique pour que l'on ait créé avec ces espèces un sous-genre auquel on a donné le nom de Lactaire.

Les champignons rangés dans la section des Lactaires ne sont pas les seuls cependant qui doment un suc laiteux i la cassure; les dgaricus gralopus, Pers., prasiosmus, Fr., 
crocatus, Pers., de la section des Mycènes, en donnent aussi. C'est dans le pied de ces derniers que ce suc est contenu. Le pied des individus jeunes du Polypore squammeux, Fr., distille aussi un suc de nature laiteuse.

Le suc laiteux est concrescible.

Nous avons vu que les spores, ou organes reproducteurs des champignons, sont des corps d'une petitesse extrème. Leur dimension varie entre quatre à cinq millièmes de millimètre et quelques centièmes de millimètre. Assez ténues pour échapper entièrement au tact lorsqu'elles sont isolées, elles font éprouver, lorsqu'elles sont abondantes, la sensation d'une poussière fine. Leur densité est moindre que celle de l'eau; aussi sont-elles facilement transportées par les vents, les courants d'air.

Leur structure est très-simple. Elles sont formées par une seule cellule ou petite vésicule très-mince, contenant un fluide qui tient des granulations en suspension. Dans quelques espèces cependant, appartenant à des genres tout à fait inférieurs, et dont nous n'avons pas à nous occuper, elles sont cloisonnées et semblent renfermer des sporules ou spores plus petites; mais peut-être ces spores cloisonnées ne sont-elles que des péricarpes ou de véritables siliques renfermant les sporules.

Les spores ont une forme ovale, elliptique ou sphérique, selon les espèces. Elles sont lisses dans la plupart des champignons; mais, dans quelques-unes de ces plantes, les Tubéracés, par exemple, elles sont hérissées d'aspérités.

L'enveloppe de la spore est simple pour Corda; elle se compose, pour MM. Tulasne, de deux membranes difficiles à séparer: l'une externe, qu'ils appellent exospore; l'autre interne, qu'ils nomment endospore. Pour d'autres mycologistes, les spores sont composées d'un épispore et d'un nucleus. L'épispore est formé d'une seule cellule, qui garde 
sur 111 proint de sat suface lat trace de son insertion sur le filament du baside, et probablement aussi celle de son insertion dans la thèque. Le nucléus est le noyau, le centre d. lit spore.

Les spores affectent des couleurs variées qu'olles communiquent presque toujours à l'hyménium; c'est-à-dire à la membrane qui constitue ou revèt les feuillets des Agarics, les aiguillons des Hydnes, les tubes des Bolets. Elles sont blanches, roses, jaunes, ferrugineuses, faures, brun-pourpre ou mème noires, selon les espèces.

Ce n'est pas tout d'abord que les spores prennent leur couleur et qu'elles la domnent à l'hyménium. Dans les Agarics appartenant à la division des Pratelles, les spores, d'abord- lilas ou violacées, deviennent noires à la maturité de la plante; les feuillets suivent leur mode de coloration. Il en est de mème des Coprins, qui, dans leur jeune âge, ont les spores et les feuillets rosés ou d'un gris cendré, et qui plus tard les ont d'un noir foncé. 1)u reste, la couleur de l'hyménium n'est pas nécessairement sous la dépendance des spores; plusieurs Agarics ont les feuillets colorés et les spores blanches.

La couleur des spores, bien que variable selon l'àge de la plante. est assez constante dans les champignons adultes pour que le professeur Fries et d'autres mycologistes aient cru pouvoir fonder sur elle les principales subdivisions qu'ils ont établies dans le genre Agaric.

Les spores de quelques champignons ont une odeur et une saveur particulières.

Par les temps humides, quelques champignons sont recouverts d'une matière visqueuse qui rend leur superficie toute gluante. D'autres, au contraire, se recouvrent à leur maturité d'une sortéde poussiere farinetise, qui n’est pas sans analogie avec l'espere de cire qui recoure certains fruits. 
CHAPITRE 111.

PHYSIOLOGIE DES CHAUPIGNONS.

Bien que les champignons passent généralement pour des plantes agames, c'est-d̀-dire dépourvues d'organes sexuels, quelques botanistes cependant ont cru reconnaitre dans diverses espèces des organes màles et des organes femelles. C'est dans les appendices appelés cystides ou anthéridies, qui se voient seulement dans les champignons d'un ordre élevé, qu'ils ont cru reconnaitre les organes mâles; mais, les anthéridies ne possédant rien qui ressemble au pollen des plantes phanérogames, il est difficile d'admettre que ces corps soient des organes de fécondation; ce sont plutòt, comme je l'ai dit plus haut, des thèques ou des basidies développés avec exagération, et, par cela mème, avortés.

D'autres botanistes pensent avoir constaté l'existence d'organes mâles et d'organes femelles parfaitement distincts, et portés par des individus différents, les mâles sur un pied, les femelles sur un autre pied.

Enfin, d'autres encore auraient vu sur la mème plante des organes séparés d'abord, qui se rapprochent, se réunissent et finissent par se confondre pour produire une spore (Syzjgites megalocarpus, Ehr:). Des zoospores, c'est à-dire 
des spores animes de monvements, se produiraient id la suitede la fecondation.

lims done. il y aurait daus la classe des champignons des especes que l'on pourait regarder comme dioiques, et d'autres qui seraient monoïques. Les observations de ces auteurs auraient besoin peut-être, pour être admises à faire retrancher les champignons de la grande classe des plantes agames, d'ètre appuyées sur de nouvelles observations. La vérité est néanmoins que les basidies et les thèques peuvent ètre considérés comme de véritables ovaires, contenant ou supportant les spores ou séminules; mais, quant aux organes de la fécondation, on peut dire qu'ils sont encore à trouver, leur existence n'étant pas suffisamment démontrée.

Les anciens étaient persuadés que les champignons naissent spontanément.

1)'après Pline, le principe générateur de ces plantes réside dans le limon, dans le suc acescent de la terre humide et dans les racines de presque tous les arbres à gland ( 1 ).

La croyance à leur génération spontanée fut longtemps partagée par les modernes; mais, depuis que Micheli a démontré que les champignons se reproduisent de semences comme les autres végétaux, elle a été généralement abandonnée. Personne aujourd'hui peut-ètre ne croit à la spontanéité de leur génération, mème pour les espèces les plus simples. On a reconnu en effet que les spores ou séminules des champignons, placees dans des circonstances favorables au développement de ces végétaux, germent en quelque façon à la manière des plantes d'un ordre plus élevé.

Ces spores ont besoin pour germer d'une température de

1) Hine, 22-4tis et $22-48$. 
I 5 à I 8 degrés centigrades; celles de certaines espèces germent cependant à une température peu supérieure à celle de la glace. Les froids au-dessous de zéro empèchent le développement de leur germination, comme ils empèchent celui des autres végétaux.

Les spores de quelques espèces peuvent germer aussitòt après qu'elles ont quitté le sporophore ou réceptacle dans lequel elles ont pris naissance; tel est le cas de la plupart des moisissures. Trois heures suffisent à certains Mucors, six à douze heures à certains Urédinés. Les spores de diverses sphéries germent qu'elles sont encore renfermées dans leurs thèques. La germination des grandes espèces, tout au contraire, Agaricinés, Polyporés, etc., ne se produit que longtemps après leur émission; il semble qu'une période de repos soit nécessaire aux spores pour que leur germination puisse s'opérer. Cette période dépassée, si les spores se trouvent placées dans des circonstances d'habitat, d'humidité et de température favorables, les phénomènes de la végétation ne tardent pas à se manifester. En suivant ces phénomènes, on voit d'abord sortir d'un pôle, ou même des deux pôles opposés des spores, un filament ou radicule, qui bientòt se divise et se multiplie en rameaux plus ou moins nombreux, presque toujours blancs, lesquels s'enchevètrent, s'entre-croisent et forment ce que l'on appelle mycélium ou blanc de champignon.

Le mycélium parait jouer dans ces plantes le ròle que jouent les racines dans les plantes monocotylédones et dicotylédones, ou peut-être, et mieux encore, le rôle que joue le placenta dans l'œuf humain et dans celui des autres mammifères; c'est-à-dire qu'il puise là où il a pris naissance les sucs qui doivent servir à la nutrition et au développement du nouvel être.

Toutes les espèces de champignons paraissent pourvues, 
it leur origine. diun mycélium; mais cet organe n'est pas toujours apparent. Mans quelques-unes, il disparait si promptement que l'on pourrait mettre en doute son existence. Tel est le cas de divers champignons parasites, qui semblent n'adhérer aux corps sur lesquels ils régetent que par une sorte d'agglutination, sans apparence de radicules.

Le mycélium dans les champignons hypogés, - les Truffes, par exemple, - se développe sous terre, et presque toujours il échappe à l'observation. Dans lẹs champignons épigés, - les Phalloidés, les Lycoperdonnés, la plupart des Agarics, des Bolets, des Hydnes, etc., - il rampe sous le sol ou à la superficie du sol. Dans les champignons épiphytes ou lignicoles, il vient à la surface des régétaux sur lesquels le champignon doit pousser. Quelquefois mème il pénietre profondément dans leur intérieur.

Le mycélium n'a pas toujours la forme byssoïde ou de blanc de champignon, que tout le monde connait; il prend parfois et garde la forme de radicules ou de racines qui ne seraient pas sans analogie avec les racines des végétaux phanérogames. si elles n'étaient pas entiérement de nature celluleuse. Ces sortes de racines se voient dans les Phallus, les Clathres et quelques Lycoperdonnés. Quelquefois le mycélium est mucilagineux, comme dans le genre Spumaria. D'autres fois il est ferme, compacte, s'il est vrai que les Sclérotium ne soient que des mycélium latents de diverses espèces de champignons.

Sur le mycélium apparait bientòt, lorsque les circonstances sont favorables, le champignon proprement dit, le. quel, à sa naissance, a presque toujours une forme globuleuse ou ovoide, mais qui, en grandissant, prend graduellement celle qu'il doit avoir à l'état parfait.

Tous avons vu que le champignon rudimentaire est dans presque toutes les espèces, entouré, soit d'une membrane 
ou tégument universel, tomenteux, qui disparait bientôt sans laisser de traces; soit d'une membrane ou même de deux membranes, plus ou moins persistantes, et formant ce que l'on appelle-le collet et le volva, et qui, l'une et l'autre, ont pour objet de protéger la plante avant son développement.

Le collet ne serait pas, pour Bulliard, sans analogie avec le calice et les pétales des plantes.

" Le collet, dit-il, parait être aux champignons ce que les pétales et les calices sont aux fleurs des autres plantes; c'est un abri sûr pour les graines qui sont probablement fécondées avant que le collet se détache du chapeau. "

Je me demande si les membranes qui constituent le collet et le volva n'auraient pas une analogie plus grande encore avec les membranes chorion et amnios de l'œuf des mammifères. Le mycélium représenterait alors, comme je l'ai dit plus haut, le placenta des mammifères.

Quoi qu'il en soit, le champignon sort du volva et se détache du collet en déchirant ces membranes, comme le fotus humain déchire celles qui l'enveloppent avant sa naissance, et comme le poulet sort de sa coquille en la brisant.

Le champignon s'échappe mème quelquefois du volva en produisant du bruit, à cause de la résistance que cette membrane lui oppose.

Bulliard dit, en parlant du volva du Satyre fétide, Phallus impudicus, Lin. : "Ce volva se crève toujours avec un certain effort, et quelquefois avec une explosion presque aussi forte qu'un coup de pistolet: il arrive même assez sóuvent que, si on a mis ce champignon dans un vase de verre ou de faience, dont il remplisse toute la capacité, et au fond duquel il y ait un peu d'eau, il brise ce vase quand son volva se crève; ceci se remarque principale- 
ment quand l'air atmosphérique est en mème temps chaud et $\sec (1)$. $)$

1.e froid, meme intense, ne parait avoir d'effet injurieux ni sur les spores. ni sur le mycéliume des champignons. Que les hivers soient rigoureux, en Suède et en Russie, ils n'empechent nullement l'apparition des champignons, lorsque vient la saison ou ils ont coutume de se montrer.

Une chaleur sèche, élevée un peu au-dessus de roo degrés, ne détruit pas, à ce que l'on assure, la faculté germinative des spores de la plupart des especes.

Le mycélium, de mème que les spores de diverses espèces, lignicoles surtout, reste très-souvent à l'état latent, et cela des années entières, attendant que des circonstances favorisent son développement.

Tenu dans un lieu sec, le mycélium ou blanc de champignon garde longtemps sa propriété végétative. Les jardiniers disent en avoir conservé pendant vingt ans qui, mis ensuite sur des couches, a produit quantité de champignons. Les pluies abondantes lui sont préjudiciables; elles le noient en quelque façon.

Mais si le mycélium et les spores résistent à un froid rigoureux et à une température élevée, il n'en est pas ainsi du champignon lorsqu'une fois il a commencé à se développer: un froid intense et une chaleur extrème le tuent; aussi, bien peu d'espèces, surtout si elles sont de consistance charnue, résistent aux gelées d'hiver et à la chaleur ardente d'un été sec. Les espèces à consistance subéreuses, telles que la plupart des Polypores, supportent assez bien la chaleur et un froid extrèmes.

Le champignon en voie de développement a besoin, pour continuer à s'accroitre et marcher régulièrement vers son

1) Bulliard, Hist. des Champ), p.61. 
état parfait, d'un degré de température et d'humidité qui ne doit pas dépasser certaines limites.

A voir la quantité prodigieuse de spores que produisent les champignons, quantité évaluée à plusieurs millions dans une foule d'espèces, et la facilité avec laquelle ces spores si ténues, si légères, sont emportées par les vents, entrainées par les pluies, les courants d'eau, on se demande comment il se fait que la terre ne soit pas entièrement couverte de ces végétaux; mais, si l'on vient à réfléchir qu'une foule de plantes phanérogames produisent, elles aussi, une quantité prodigieuse de semences d'une petitesse extrème, et que cependant ces plantes ne sont pas plus multipliées que tant d'autres végétaux, on cesse de s'étonner de la rareté proportionnelle des champignons. C'est que leurs spores ou semences, comme au reste les semences des autres plantes, ont besoin, pour entrer en germination et se développer, d'ètre placées dans des circonstances toutes particulières de température, d'aération, de lumière et d'habitat. Or, quelle immense quantité de spores sont détruites, avant que toutes ces circonstances soient réunies! Et d'abord, la germination des grandes espèces de clsampignons, telles que les Agarics, les Bolets, les Hydnes, ies Helvelles, etc., ne se fait qu'à des époques déterminées de l'année; si donc à ces époques les spores ne sont pas placées dans les conditions voulues, non-seulement elles ne germent pas, mais encore elles perdent, pour la plupart, leur faculté germinative. Que le mycélium, de toutes les espèces, pour ainsi dire, à l'exception de celui du champignon de couche, soit transporté dans des lieux souterrains, ce mycélium, en l'absence de la lumière et d'un air renouvelé, produira des monstruosités, et nullement des champignons à l'état normal et susceptibles de donner des spores à leur tour. 
Ene seule spore peut-elle produire ces mycélium si complexes qui, dauns quelques espreces, nous frappent par leur étendue; ou bien ces mycélium sont-ils le produit de la germination d'un grand nombre de spores dont les filaments entremilés, confondus ensemble, finissent par produire ces groupes quelquefois si nombreux de champignons?

Ce que l'on sait, c'est que dans les espèces à organisation simple, comme les Mucorés, les Mucédinés, une seule spore suffit pour développer, une moisissure, qui bientòt occupe une surface relativement étendue.

Mais comment s'opèrent les fonctions vitales dans ces plantes?

Nous avons vu, que si les champignons varient beaucoup dans leur structure et leur configuration, ils sont néanmoins composés uniquement de fibres entrelacées et formant, par leur disposition, un tissu réticulaire, dont les cellules, tantòt arrondies, tantòt allongées, communiquent avec les agents extérieurs au moyen de pores d'une ténuité extrème. C'est par ces pores que se font l'absorption et l'exhalation.

Ces plantes n'ayant pas de vaisseaux propres à la circulation de la séve, comme en ont les végétaux d'un ordre plus élevé, c'est dans les cellules mêmes, dont toute la plante parait formée, que sont contenus les fluides nutriciers dont la circulation presque insensible se fait par une sorte d'attraction capillaire.

On admet généralement que les champignons se laissent pénétrer de fluides par endosmose et qu'ils abandonnent ces fluides par exosmose. C'est dans ce double mouvement continu d'absorption et d'élimination que s'accomplissent les phénomènes de nutrition, d'assimilation, d'accroissement et bientòt ceux de reproduction de la plante. 
Arrivé à son état parfait, le champignon donne des semences comme tous les autres végétaux; les semences émises, il y a presque aussitòt arrêt de développement dans la plante; les phénomènes d'exhalation prévalent sur ceux d'absorption, et bientòt survient la cessation de la vie.

La plupart des champignons croissent avec tant de rapidité, que l'on dit en proverbe: Pousser comme un champignon. Il en est qui en quelques heures arrivent à leur complet développement. Le Lycoperdon gigantesque acquiert, en moins d'une nuit, le volume de la tête d'un homme.

Les pluies d'orage surtout favorisent leur apparition. Le lendemain d'un jour de pluie où le tonnerre s'est fait entendre, on est tout étonné de voir des champignons lì où la veille on n'aurait pas soupçonné l'existence de leurs germes. Mais, si ces plantes poussent vite, ellespassent vite aussi. Dans les Coprins, la durée de la vie est éphémère; c'est à peine s'ils ont vécu un jour qu'ils se flétrissent. Dans les espèces charnues, la durée moyenne de la vie est de six à douze jours. Elle est plus longue dans les espèces dont la consistance est coriace, - les Lentinus, les Marasmits, - et dans celles dont la texture est comme tubéreuse, - certains Polypores et certains Hydnes. - Les Polypores à amadou, Polyporus fomentarius et $P$. igniarius, ont une existence dont la durée parait s'étendre à plusieurs années, puisque, tous les ans, une nouvelle couche de pores vient s'ajouter aux couches anciennes; on peut dire, cependant, que la vie réelle de ces champignons ne se prolonge guère au-delà de quelques mois. Ce qui trompe sur cette durée apparente, c'est que, pendant plusieurs années de suite, des couches nouvelles de tubes ou pores se développent sur les couches anciennes qui leur servent d'habitat. Il en est de ces plantes comme de la plupart des 
pulypers. dont les générations successives établissent leurs hathitations les unes atl-dessus des autres.

Nous avons vu que les spores des champignons sont, les unes contenues dans des cellules allongées, appelées thèques, les autres placées au sommet de filaments supportés par ce que l'on appelle des basides. Dans les champignons dont les spores sont renfermées dans des thèques, ces spores, à la maturité de la plante, sont, à des intervalles plus ou moins rapprochés, lancées dans l'espace avec une certaine force, sans doute par la contraction de la thèque; et conme celle-ci contient, en mème temps que les spores, un liquide huileux, ce liquide, projeté dans l'air en même temps que les séminules, se volatilise et forme ces petits nuages tourbillonnants que l'on voit s'élever de temps à autre de la surface de l'hyménium des Pezizes et des Morilles.

Dans les champignons dont les spores sont supportées par des basides, - les Agarics, les Bolets, les Hydnes, il semblerait que ces organes, en se détachant du filament qui les porte, dussent tomber verticalement sur le sol et d'une manière tout à fait passive; il n'en est point ainsi, la plupart sont lancées dans l'espace jusqu'à une certaine distance, et en rayonnant, pour ainsi dire. Ce qui le prouve, c'est que, dans leur chute, les spores tracent, sur le sol ou l'habitat sur lequel le champignon a vécu, un dessin d'un diamètre beaucoup plus grand que le champignon luimème dont elles se sont séparées. La nature a voulu qu'il en fùt ainsi, afin que leur dissémination fùt répartie d'une manière plus étendue.

Halgré le peu de consistance que présentent, en général, les champignons, ces plantes ont pour la plupart une forme expansive de végétation véritablement remarquable. Non-seulement elles poussent avec rapidité, mais encore, 
dans leur croissance rapide, elles peuvent soulever des poids et des masses considérables. Le docteur Charpentier rapporte, dans ses Éléments de physiologie, que, dans le voisinage de Basingstoke, une dalle mesurant 2 I pouces carrés et pesant 83 livres, fut soulevée et sortie de son lit à une hauteur d'un pouce et demi par une masse de Roadstools, - Agarics, - de 6 à 7 pouces de diamètre, et il ajoute que presque tout le pavé de la ville subit un déplacement par la mème cause.

Les Agarics, du reste, ne sont pas les seuls champignons qui puissent déplacer des pavés, des masses de terre : on a vu des dalles, des pierres volumineuses, soulevées par des Lycoperdons.

Diverses espèces de Polypores et d'Hydnes ne se contentent pas de lutter contre les obstacles qui s'opposent à leur développement; elles agglutinent, enveloppent les corps qui se trouvent dans leur voisinage, fragments de bois, herbes mortes ou vivantes; elles les étreignent si fortement qu'il semble que ces corps étrảngers ne fassent qu'un avec leur propre substance.

Le phénomène appelé contractilité se produit dans plusieurs espèces de champignons. Nous venons de voir qu'il existe dans les thèques et les basides, à l'époque de la maturation des spores.

M. Robson, observant le Clathre grillagé, a constaté un mouvement sensible dans une partie des fibres du sommet de la plante, au moment où elle sortait du volva; l'ayant touchée avec la pointe d'une épingle, il a vu avec surprise que le mouvement des fibres était encore plus prononcé.

Les champignons blessés ont une puissance de réorganisation remarquable. Si l'on enleve une partie des tubes d'un jeune Bolet, il les reproduit. Que ces mêmes tubes soient rongés, détruits par les limaces, chez les jeunes indi- 
vilus, ils renaissent; on les trouve reproduits aussi en grande partie dans le's Bolets adultes. In jeune Polypore "st-il coupé en travers, la plaie se cicatrise sans laisser de Irace; il en est de mème des Lycoperdonnés.

l.es champignons, cependant, ne se reproduisent point par scissiparité. Il est sans exemple, je crois, qu'un champignon, divisé en plusieurs fragments, ait donné naissance it des champignons multiples. Il n'en est pas ainsi du mycélium de diverses espèces, entre autres du mycélium du champignon de couche, lequel peut être divisé en fragments qui, dans des circonstances favorables, donneront quantité de champignons.

La nature, en procréant les ètres, a tout fait pour la conservation de l'espèce et de l'individu; mais, comme elle n'attache de l'importance à la vie de celui-ci qu'autant qu'il possède la faculté génératrice, elle ne tarde guère à le laisser périr lorsqu'une fois il a perdu cette faculté. Ce que nous voyons pour les insectes, qui presque tous meurent aussitòt après la fécondation et l'émission des œufs; ce que nous voyons pour les plantes annuelles, qui se fanent, se dessèchent et cessent de compter parmi les êtres vivants peu de temps après la maturation des graines, nous le voyons plus rapidement encore pour les champignons, qui presque tous meurent aussi et se décomposent peu de temps après la maturation et l'émission des spores.

L'existence de ces plantes se prolonge rarement au-dela de quelques jours. La destruction de diverses espèces semble mème nécessaire pour que la dispersion des séminules ait lieu: tel est le cas des Truffes; tel parait ètre celui des Clathres et des Phallus, et peut-être aussi celui des Coprins, bien que ces derniers émettent une partie de leurs semences avant que leur décomposition commence.

Si quelques espèces qui croissent sur les arbres, telles 
que les Bolets Amadouviers, semblent étendre leur vie jusqu'à quatorze el quinze ans, il n'en est pas moins vrai que ces espèces se renouvellent chaque année, ainsi que je l'ai dit plus haut; mais, comme leur consistance presque ligneuse leur permet d'échapper longtemps à la destruction, le nouveau champignon se développe sur l'ancien, qui lui sert de support, et mème, en quelque façon, de nourriture.

Les champignons, après avoir émis leurs spores, entrent, ai-je dit aussi, plus ou moins promptement en décomposition, selon les espèces. Cette décomposition a la plus grande analogie avec celle des substances animales; ce qui semblerait venir à l'appui de l'opinion partagée par divers savants, que les champignons sont des productions plutòt de nature animale que de nature végétale. 


\section{CHAPITRE IV.}

GEORAPHIE DES CHAMPICTONS.

Les champignons, considérés dans leur ensemble, croissent partout ou la végétation peut se manifester. On peut dire qu'il n'est pas de partie du monde où on ne les rencontre; toutefois, comme ils ont besoin pour se développer de se trouver dans des conditions particulières d'habitat, d'humidité, d'air, de lumière et de chaleur, on concoit qu'ils se montrent plus abondamment dans certaines régions. La chaleur sèche et un froid vif nuisent à leur développement; ils sont rares dans les régions équatoriales, à cause de la chaleur extrème qui y règne, et, sous les cercles polaires, à cause de la rigueur du froid.

Jans la zone centrale de l'Europe, où la température est moyenne et où les pluies sont fréquentes, ils sont nombreux en espèces et viennent abondamment. D'après Krombholz, c'est sous les tropiques que les champignons se montrent avec le plus d'abondance, parce que là se trouvent réunies les conditions les plus favorables à leur existence.

Les champignons de petite taille et dont l'organisation est simple, les Iucorés, les Iucédinés, sont répartis sur tout le globe, en bien plus grand nombre que ceux qui 
sont de grande faille, et dont l'organisation est plus complexe; les champignons suivent en cela la loi générale, qui veut que, dans le règne végétal comme dans le règne animal, les espèces d'une petite taille soient plus nombreuses en individus que les grandes espèces.

Les champignons viennent à peu près dans toutes les formations géologiques.

Quelques espèces se rencontrent sur les montagnes, à des altitudes considérables.

L'Agaric fausse Oronge, le champignon de couche et la Chanterelle, ont été trouvés dans les Alpes, à une hauteur de I,624 mètres au-dessus du niveau de la mer. Philippi a trouvé sur l'Etna le Geaster hygrométrique, à une hauteur de I,656 mètres. Le Clavaria crislata, Pers., a été trouvé à celle de I, 820 .

Oswaldheer a rencontré un assez grand nombre d'Agarics et deux Pezizes à une hauteur de 2, Ir I et mème de 2,274 mètres. Un Agaric de la section des Mycènes a été trouvé par M. Agassis sur les bords du glacier de l'Aar, à 2,598 mètres d'élévation.

Junghum a constaté qu'à Java les champignons croissent surtout à une hauteur de 974 à 1,624 mètres au-dessus du niveau de la mer. Plus haut ou plus bas que cette altitude, leur abondance diminue. Il en est de mème sur les montagnes de l'Amérique centrale.

Hooker fils a remarqué que dans la haute Asie les champignons étaient très-abondants à la hauteur de 2,274 à 2,598 mètres au-dessus du niveau de la mer, tandis qu'ils étaient fort rares dans les plaines.

Sur les monts Himalaya, l'apparition de certains champignons ne cesse qu'à une hauteur de i 8, ooo pieds anglais. A la base de ces montagnes viennent les espèces tropicales; à une certaine hauteur, celles que l'on peut appeler sub- 
Mopricales: plus haut, colles du sud de l'Europer, et plus latul encolre colles du nord de l'Europe.

Certaines espèces sont cosmopolites, c'est-à-dire qu'elles croissent sous toutes les latitudes. Parmi celles qui nous intéressent, je citerai le champignon de couche; le Polyports versicolor, lir.; le P. Incidus, Ir.; le P. igniarius,

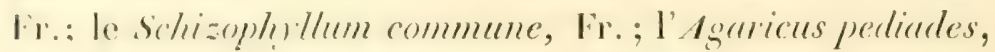
Fr., et nos espéces communes de Vesse-loup, qui se rencontrent à peu près dans toutes les parties du monde, excepté dans les régions extrèmes du Nord.

Il est certaines espèces qui viennent communément chez nous, et que l'on trouve aussi dans des contrées excessivement éloignées de la France. Le Clavaria fastigiata, Lin., a etcobservé a la diuyane; le Geoglossum hirsumu, Pers., a l'Ile de lrance; le Thelephora terrestris, Pers., dans l'A. mérique equinoxiale; le I.coperdon prviforme, Schoff., it la Nouvelle-Grenade, etc.

Dans les contrées les plus lointaines, la Tasmanie, la Nouvelle-Zélande, l'ile de Juan-Fernandez; le Chili, se trouvent des espèces européennes, et mème en assez grand nombre, proportionnellement aux espèces indigènes.

L’Amérique du Nord est très-riche en champignons. Outre les espèces qui lui sont propres, elle en possède une multitude de celles qui viennent en Europe.

Les pays tout à fait au nord n'ont pas pour ainsi dire d'espèces spéciales; ils ne produisent guère que celles des zones tempérées.

Mais, si quelques champignons semblent venir à peu pres partout, beaucoup d'autres, au contraire, sont particuliers à certaines régions, à certaines contrées; ils ont leurs localités d'élection, leur préférence pour tel ou tel sol; vainement on les chercherait ailleurs.

Les Polypores et les Lenzites ont pour centre principal 
les pays tropicaux; les Agarics viennent plus volontiers dans les régions froides; les Coprins se rencontrent sur tout le globe.

Les champignons des contrées boréales sont en général plus charnus et moins coriaces que ceux des régions tropicales. Sous l'équateur, les Russules sont presque subéreuses.

Les forèts vierges des pays tropicaux produisent des champignons toute l'année. En Europe, ce n'est guère qu'en automne que ces plantes se montrent en quantité. Dans cette partie du monde, le nombre des espèces diminue ì mesure que l'on s'avance vers les régions polaires, comme il diminue à mesure que l'on s'élève sur les montagnes.

Les champignons qui viennent sous les arbres conifères ne viennent généralement pas dans les bois d'essence non résineuse.

Les Cortinaires et les Hydnes se plaisent dans les régions boisées; on ne les trouve pas dans les terres cultivées. Les Coprinaires, tout au contraire, de mème que les Pratelles et les Coprins, se plaisent dans les pays de plaine riches en engrais.

Les champignons, si nombreux aujourd'hui en espèces vivantes, ont-ils été trouvés à l'état fossile? L'attention des géologues s'étant jusqu'à présent peu portée vers l'étude des champignons fossiles, le nombre des espèces reconnues comme telles est resté fort limité. Jusqu'alors il n'y a guère que le Bolet oblique, Bull., Polyporus lucidus, Fr., champignon que l'on rencontre vivant à peu près sous toutes les latitudes, que l'on connaisse à l'état fossile. C'est dans les marécages de Cambridgeshire que ce champignon a été trouvé fossilisé.

On a constaté dans l'ambre jaune l'exister̃ce de Penicillium contemporains de ces espèces conifères, perdues au- 
jourd'hui, qui produisaient l'ambre. On a constaté de mème, sur les feuilles de dépòts récents, l'existence de spphériacés.

P'lus tard, sans doute, le nombre des espèces de champignous fossiles se trouvera considérablement augmenté. 


\section{CHAPITRE، V.}

de r'infuence de la saison, du climat, du sol, de L'HABitAT, dE la CULture.

\section{Influence de la saison.}

L'époque de l'année a-t-elle de l'influence sur le danger que peut présenter l'usage des champignons? En d'autres termes, leurs propriétés toxiques ou alimentaires augmentent-elles ou diminuent-elles selon les saisons?

Les espèces toxiques et les espèces comestibles gardent leurs propriétés malfaisantes ou alimentaires, qu'elles viennent au printemps, en été ou en automne.

La variété verna de l'Agaric phalloide, Fr., Agaric bulbeux printanier, Bull., laquelle vient surtout au printemps, comme son nom l'indique, n'est pas moins dangereuse que les autres variétés de ce même Agaric qui viennent en été et en automne. Il en est de mème de l'Ag. Mappa, Batsch., de l'Ag. émétique, Fr., et d'autres espèces malfaisantes qui se montrent assez indifféremment en été et en automne, et qui sont également toxiques dans l'une comme dans l'autre saison. L'Agaricus (Amanita) rubescens, Fr.; l'Ag. (Russula) alutaceus, Fr.; l'Ag. (Russula) cyanoxan. 
thus, Per's., ot lat Chanterelle, que l'on trouve fréguemment an printemps, en clé et en automne, sont comestibles dans toutes les satisons.

Il est d'observation cependant que les exemples d'empoisonnement sont plus fréquents en automne qu'i toute autre époque de l'année; mais cette fréquence n'est nullement due à ce que le principe toxique des espèces vénéneuses serait plus développé dans cette saison; elle tient uniquement à ce que, les champignons croissant alors en plus grande abondance, il s'en fait une plus grande consommation.

Mais, si l'époque de l'année n'a pas une influence bien constatée sur les qualités des champignons, on peut dire qu'il n'en est pas tout à fait de mème de la constitution atmosphérique.

Dans nos contrées, le temps est-il chaud et sec, les champignons alimentaires ont plus de coloration, plus d'arome, plus de fermeté; leurs propriétés alimentaires sont véritablement augmentées, parce qu'elles sont en quelque façon concentrées. La sécheresse et la chaleur concentrent de mème le principe malfaisant des espèces toxiques.

La grande humidité et les pluies abondantes, au contraire, affaiblissent les qualités nutritives des espèces comestibles, de mème qu'elles affaiblissent les qualités délétères des espèces toxiques. Si les pluies sont abondantes, elles lavent, pour ainsi dire, les champignons, en entrainant une partie du principe malfaisant; ou bien elles accumulent ce principe à la partie inférieure du pédicule, comme cela se remarque dans les Amanites, dont la bulbe devient alors la partie la plus active.

Les amateurs de champignons savent tous que l'état de l'atmosphère influe sur les qualités de ces végétaux; aussi 
vont-ils de préférence les récolter le matin, et, autant que possible, par un temps sec.

L'âge des champignons parait aussi n'ètre pas sans influence sur leur principe actif. Arrivées à la maturité, les espèces vénéneuses sont plus dangereuses qu'elles ne le sont dans le jeune âge.

Les espèces comestibles elles-mèmes, trop avancées en àge, deviennent indigestes, et, par conséquent, nuisibles. Le champignon de couche est, comme bien d'autres, dans ce cas; aussi la police, à Paris, défend-elle la vente de ceux dont les feuillets passent au noir.

\section{De l'influence du climat.}

Le climat exerce-t-il une influence sur les propriétés toxiques ou alimentaires des champignons? C'est-à-dire, les propriétés alimentaires ou vénéneuses de ces plantes vont-elles en augmentant ou en diminuant d'intensité, ̀̀ mesure que l'on s'avance vers l'équateur?

Cette question parait résolue pour la plupart des auteurs, puisqu'ils affirment que les espèces malfaisantes, dans les contrées septentrionales de l'Europe, le sont également dans celles du Midi. On serait tenté de croire cependant que le principe de quelques espèces nuisibles perd un peu de sa violence à mesure que l'on s'avance vers le Sud.

La fausse Oronge, poison bien constaté en Russie, en Italie et dans les provinces du nord et du centre de la France, où souvent elle occasionne des accidents graves, dont plus d'une fois j'ai été témoin, est mangée impunément dans le midi de la France. Mais, là comme ailleurs, ce champignon n'est comestible qu'autant qu'on lui a fait subir une préparation culinaire propre à détruire, ou du moins à affaiblir considérablement son principe délétère. 
"Mremellate, dans le Gard, plusieurs familles, dit le docteur de. Sernes, recueillent la fausse Oronge et s'en nourrissent, ayant grand soin de la faire bouillir longtemps et de jeter l'eau; elles utilisent ainsi des quantités considérables de cet Agaric, qui ne leur sont pas disputées (I). »

A Bonneville, vallée de Chamonix, la fausse Oronge serait aussi, d'après une communication faite à II. Chatin par II. Dupont, pharmacien de cette ville, l'un des mets les plus recherchés des habitants. L'usage de cette plante n'est pas cependant sans danger aux environs mèmes de Bonneville, puisque, une fois, M. Dumont l'a vue produire un délire furieux, qui céda à l'emploi de l'émétique suivi d'une potion éthérée (2).

Il est bien certain que la fausse Oronge serait mangée dans le nord de la France, comme elle l'est dans le midi, si on lui faisait subir la préparation à laquelle on la soumet dans le Gard. Ce qui est certain aussi, c'est que l'Agaric bulbeux, Bull., Agaricus phalloides, Fr., est non moins malfaisant dans le midi que dans le nord de la France. On ne cite l'exemple d'aucune personne qui, là pas plus qu'ailleurs, se soit volontairement hasardée à en faire usage comme aliment.

Les champignons, au rapport de MY. Junghum et Leprieur, se succèdent toute l'année, et sans interruption, dans les contrées voisines de l'équateur; et cependant nous ne savons rien ou presque rien de leurs qualités vénéneuses ou comestibles. Les populations sauvages n'en mangent pas, soit que l'expérience leur ait appris à s'en méfier, soit qu'elles trouvent assez de ressources dans ie produit de leurs chasses et dans l'abondance des fruits, qui

(1) Essai de Flore cryptogamique, p. 111.

12) Bulletin de la Société botanique, 1861, n०3. 
y mûrissent en toute saison, pour n'avoir pas besoin de recourir à l'usage alimentaire de ces plantes. Quant aux voyageurs assez nombreux qui ont visité les régions intratropicales, ils ne nous disent rien des vertus de ces plantes, ayant jugé prudent sans doute de ne pas expérimenter sur eux-mêmes les propriétés de végétaux contre lesquels s'élèvent des préventions généralement trop fondées.

La prévention contre l'usage des champignons se retrouve aussi en Algérie. Ils ne sont pas rares dans cette province; l'Agaric comestible, ou champignon de couche, y croît mème assez abondamment pendant une grande partie de l'année, et néanmoins il est négligé des indigènes, de même que les autres espèces d'Agarics et de Bolets. Les Tatares de la Crimée dédaignent aussi ces plantes, tandis que les Russes les recherchent.

A l'appui de l'influence apparente du climat pour atténuer le principe toxique des champignons, on pourrait citer ce que Leguelvel de Lacombe raconte, dans la relation de son voyage à Madagascar, de l'innocuité des champignons qui çroissent dans cette île (I):

“Mes Maronites (ses guides), dit-il, ramassèrent en che“ min une grande quantité de champignons qu'ils nomment “ Houlatches, et parurent étonnés lorsque je leur dis qu'en "Europe il s'en trouvait beaucoup de malfaisants; ils “ m’assurèrent qu'il n'en était pas de mème à Madagascar, “ et qu'on pouvait manger sans crainte tous ceux qu'on « trouvait. En effet, j'en ai mangé depuis presque tous les " jours, et jamais ils ne m'ont fait de mal. "

L'auteur ne nous dit pas, ce qu'il serait bon de savoir, à quelle préparation culinaire les Malgaches soumettent les champignons.

(1) Voyage à Madagascar, t. II, 1. 237. 
11 est a regretter aussi qu'il ne nous ait pas donné la description des especes dont il a fait usage, ou tout au moins ne nous ait pas dit à quel genre ces espèces apparlicuncust.

Je ne sais si l'on peut admettre comme certain qu'il n'y ait pas de champignons malfaisants dans l'ile de Madagascar ; toutefois on aurait tort de conclure du fait raconté par M. Leguelvel qu'il n'en existe pas dans les régions intra-tropicales; car, dans la relation d'un autre voyageur, le commandant Guillain, aujourd'hui gouverneur de la Nouvelle-Calédonie, on voit un exemple d'empoisonnement par ces plantes, arrivé dans l'ile de Mombase, située près de la còte de Zanguebar, au troisième degré, 3o minutes de latitude sud, et, par conséquent, dans une contrée plus rapprochée de l'équateur que ne l'est Madagascar.

Parlant des migrations qui avaient eu lieu de l'intérieur de l'ile vers le littoral, M. Guillain dit: “ Qu'un groupe d'émigrants venus d'un territoire voisin de celui des OuaKouavi, fuyant devant les Oua-Gallais, s'étant avancés dans le sud jusqu'à un endroit nommé depuis Chakalam'guy, virent beaucoup de champignons, dont ils mangèrent; parmi ces champignons, il y en avait de vénéneux, et les individus qui en avaient mangé moururent (I). »

Dans la Nouvelle-Calédonie, colonie française située entre le $19^{\circ}$ et le $22^{\mathrm{e}}$ degré de latitude sud, il existe aussi des champignons malfaisants et des champignons comestibles. Les indigènes se gardent bien de manger les premiers; quant aux espéces alimentaires, ils les récoltent lorsqu'ils les rencontrent, mais ils ne les recherchent pas.

J)ans la basse Cochinchine, autre colonie de France, il

(1) Documen/s sur l'histoire, la géographie et le commerce de l'Afrique orientale, par M. le capitaine de vaisseau Guillain, in-8\%. 
se trouve également des champignons dangereux et des champignons comestibles; l'un des plus estimés est l' $\mathrm{Aga}$ ricus fimetarius, Loureiro, lequel vient sur la fiente des buffles, après les premières pluies (I).

Comme on le voit par ces exemples, l'affaiblissement prétendu des propriétés toxiques des champignons, à mesure que l'on s'avance vers l'équateur, n'est nullement démontré. Ce qui, au contraire, parait bien démontré, c'est que les espèces malfaisantes gardent leurs propriétés toxiques partout où on les rencontre, de même que les espèces comestibles gardent les leurs. Il est certain du moins que l'Agaricus campestris, L., le champignon de couche, lequel semble avoir suivi l'homme partout où il lui a plu d'aller établir sa résidence, et que l'on rencontre aujourd'hui sous les tropiques comme aux confins du pòle arctique, est alimentaire partout. On en peut dire autant de la Chanterelle, Cantharellus cibarius, Fr., champignon cosmopolite aussi, c'est-à-dire qui croìt indifféremment sous toutes les latitudes.

\section{Influence du sol et de P'habitat.}

La constitution géologique du sol, elle aussi, a-t-elle une action sur les propriétés toxiques ou alimentaires des champignons? Augmente-t-elle ou diminue-t-elle ces propriétés?

Si la nature du sol modifie, dans un sens ou dans l'autre, les vertus des champignons, il faut que ce soit d'une manière bien peu sensible, puisque jusqu'alors ces modifications n'ont été signalées par aucun auteur.

Les espèces qui viennent dans toutes les formations géo-

(1) Jouan, Science pour tous, 7 septembre $186 \%$. 
logicues, reconnues alimentaires dans une formation quelconque, restent alimentaires, que le sol appartienne aux terrains primitifs, aux terrains de transition, aux terrains secondaires, tertiaires ou quaternaires; de mème les espèces toxiques gardent leurs propriétés vénéneuses, quelle que soit la nature du sol sur lequel elles poussent. Du reste, rien n'est plus commun que de voir, sur n'importe quelle nature de terrain, un champignon malfaisant croitre à còté d'un champignon alimentaire.

Les espèces épiphytes, c'est-à-dire celles qui poussent sur les arbres, gardent aussi leurs propriétés, qu'elles viennent sur telle ou telle essence d'arbre, lors mème que ces arbres appartiendraient à des genres différents, à des familles différentes.

L'Agaricus ulmarius, Bull., est comestible, qu'il vienne sur le hêtre, le chêne, le peuplier, ou bien sur l'orme; l'Ag. ostreatus, Jacq., venu sur le chène, le noyer ou le hètre, garde ses propriétés comestibles. Il en est de même de l'Ag. salignus, Alb., qui croît sur l'aune et le saule, et de la listuline hépatique, qui croit assez indifféremment sur le chêne, le châtaignier, le noyer et le hètre.

D'un autre còté, l'Agaric (Panus) styptique, Fr., est malfaisant, qu'il croisse sur le chène, le hêtre ou toute autre espece d'arbre, car il vient fort indifféremment sur les plaies de la plupart des arbres morts ou mourants.

Ce que l'on peut dire, c'est que les champignons qui croissent dans les terrains maigres et secs sont en général moins développés que ceux qui viennent dans les lieux gras et humides; mais aussi ils ont, en général, plus de saveur, plus d'arome que ces derniers. 


\section{Influence de la culure.}

Si la constitution géologique du sol n'a pas une influence bien évidente sur les qualités bonnes ou mauvaises des champignons; si le climat et la saison n'en ont qu'une bien faible et même contestée par quelques mycologistes, on peut dire qu'il n'en est point ainsi de la culture à laquelle on a soumis certaines espèces.

On ne saurait affirmer cependant que la culture atténue et fasse disparaître le principe toxique des espèces malfaisantes, puisque jusqu'à présent aucune expérience directe n'a été faite à ce sujet; mais il est certain que la culture change, modifie plus ou moins la forme, la taille, la consistance, la couleur, le gout et l'odeur des champignons alimentaires.

C'est à la culture que l'on doit, sans aucun doute, ce grand nombre de variétés que présente l'Agaricus campestris, Lin., le champignon de couche, variélés assez dissemblables 'de l'espèce primitive pour que quelques botanistes les aient regardées et décrites comme autant d'espèces distinctes, telles que l'Agaricus villaticus, Brond., qui a le chapeau squammeux, le pied pourvu d'une espèce de volva, et dont l'odeur et la saveur ont quelque chose de nauséeux.

L'Ag. sylvicola, Vittad., dont le chapeau est lisse, le pied bulbeux, la chair légèrement fauve;

L'Ag. praticola, Vittad., dont la chair entamée devient tout aussitôt rougeâtre ;

L'Ag.vaporarius, Krombh., champignon qui vient dans les caves, sur le fumier de cheval, et dont la couleur est d'un blanc mêlé de bistre et le chapeau non écailleux.

I.'Ag. setiger, Faul., et l'Ag. arvensis, Schoeff., la Boule 
de neige des auteurs, ne sont probablement non plus que des varietis de l'I garic champetre.

Ine autre variété de ce dernier, peu connue et d'une excellente qualité, dit un journal anglais, laquelle vient sous les arbres, se distingue parce qu'elle répand, lorsyu'elle est divisée, un suc ronge abondant. Cette variété se trouve donc, en quelque sorte, transformée en Lactaire.

M. Lavalle a vu abondamment, au printemps de l'année 1851, dans le jardin botanique de Montpellier, une variété de champignon de couche, Agaricus arvensis, Schœff., pourvue de deux colliers ou de deux membranes enveloppantes, dont l'une, la plus extérieure, rappelait, dit-il, le volva des Amanites (1).

Nais, dira-t-on, comment attribuer à la culture la production de toutes ces variétés? La culture les produit comme elle a produit tant d'autres variétés dans presque toutes les plantes que l'homme a fait passer de l'état sauvage à l'état de domesticité, si je puis employer cette expression; c'està-dire, en faisant que les semences des plantes soient placées dans des conditions de végétation et de nutrition qu'elles ne trouvent pas à l'état sauvage. Ce que l'homme a fait avec intention pour les plantes phanérogames dont il se nourrit, il le fait ici accidentellement, et, pour ainsi dire, it son insu.

Les spores des champignons cultivés, déja modifiées par la culture, venant à ètre transportées par les courants d'air, les pluies ou de toute autre façon, dans des localités inaccoutumées, dans des terrains fumés, travaillés par la main de l'homme, ont produit les variétés dont je viens de parler et cela, comme je le disais, à l'insu mème de l'homme.

Le simple voisinage des animaux domestiques suffirait

(1) Traité pralique des Champignons comest., Iur J. Lavalle, 1852. 
seul, par la nature variée de l'engrais que donnent aux terres leurs fientes, pour amener des variétés dans les espèces de champignons. On remarque en effet que celles qui viennent dans toutes les formations géologiques, et qui par conséquent ne sont pas difficiles sur le choix de l'habitat, telles que l'Agaric engainé, Bull.; l'Ag. alutacé, Fr.; le Bolet comestible, Bull.; le B. scabre, Fr.; le B. subtomenteux, Lin., lesquelles semblent se plaire dans le voisinage de l'homme, présentent un plus grand nombre de variétés que celles qui croissent dans les lieux solitaires et loin de son voisinage.

On remarque aussi que les espèces qui viennent sur les arbres, et qui, par cela même, ne sont pas soumises à l'influence de l'homme, présentent beaucoup moins de variétés que celles qui sont terrestres.

Ainsi donc, il nous faut admettre que des circonstances locales peuvent modifier les individus, et que ceux-ci transmettent à leur descendance les modifications acquises. 11 en est, sous ce rapport, des champignous comme des autres plantes.

On esṫ parvenu, au moyen de la culture, à obtenir des variétés de l'Agaric comestible d'une dimension et d'un poids considérables. Il a suffi à $\mathbf{M}$. le docteur Labourdette d'arroser avec une eau contenant un peu d'azotate de potasse, - sel de nitre, - le champignon cultivé pour obtenir des individus d'une taille extraordinaire, et pesant en moyenne de 5 à 600 grammes.

En Angleterre, M. Ingram, qui s'occupe avec succès de la culture des champignons, ajoute à la fertilité et à la qualité de ces plantes en arrosant les couches qui les produisent avec une faible dissolution de sel commun (I).

1) Berk, Gard. chron. de 1861, 1. 1091. 
C'est assuriment, sous le rapport de l'alimentation, un resultat farorable que celui de l'augmentation de poids et de volume de l'Agaric cultivé; mais n'est-il pas à craindre que l'emploi prolongé des moyens mis en usage pour obtenir cette exagération ne finisse aussi par amener une maladie, oïdium ou autre cryptogame parasite, qui ne serait pas moins funeste à ce champignon que celle que la culture, malheureusement forcée, de la pomme de terre, de la vigne ou du houblon, a produite, et entretient depuis plusieurs années d'une manière fàcheuse sur ces plantes? La nature a des lois qu'il n'est pas permis d'outrepasser, mais que l'homme est toujours disposé à enfreindre.

La culture, ai-je dit, transforme les espèces; le fait est incontestable, s'il est vrai que le Polypore tubérastre, Polyporus tuberaster, Fr., dont le mycélium, englobé dans une masse de terre et de pierres, constitue ce que les Italiens appellent pielra fungaja, champignon cultivé depuis longtemps, et regardé par les botanistes comme une espèce distincte, ne soit en réalité, comme le prétend le professeur Hanne, que le Polypore pied-de-chèvre, P. Pes Capræ, Pers., qui vient en France dans les Vosges, où on le fait servir à l'alimentation (I).

De mème l'Agaric napolitain, Agaricus neapolitanus, Pers., cultivé à Naples sur le marc de café, et regardé jusque dans ces derniers temps comme une espèce nouvelle, ne serait, pour Fries, qu'une variété de son Agaricus Catinus, - Ag. infundibuliformis, Bull.,-lequel vient communément dans nos bois, en septembre et en octobre, plus particulièrement sur les feuilles tombées à terre; mais que l'on ne récolte pas, probablement à cause du peu de chair dont il est revètu.

(1) Hanne, Traité sur les Champ. comest. et vénén., p. כ5. Fries, Epicrisis, p. 72. 
En admettant qu'il reste des doutes sur le type primitif de ces champignons, il est permis d'affirmer que les espèces typiques sont innocentes, tout aussi bien que les variétés obtenues par la culture. 
DES HOYEXS DE DISTINGLER LES CHIUPJGNOXS ALIUEATAIRES DES CHAMPIGTONS IETENI

Les champignons ont, de tout temps, offert a l'homme more ressonec comme aliment; la medecinc, les arts et l'industrie ont su tirer de leur emploi un parti avantageux, lequel ne peut manquer de s'accroitre; cependant il est d'observation que ces plantes, généralement peu connues du vulgaire, et mème de la plupart des savants, sont partout regardées avec indifférence, si ce n'est mème avec dédain, puisque, partout ou l'homme les rencontre, presque loujours il les foule aux pieds et les traite en ennemies.

L'aversion, pour ainsi dire instinctive, que la plupart des hommes ont pour les champignons est fondée sur la facilité avec laquelle on peut confondre, dans leur usage, les espéces toxiques avec les espèces alimentaires, facilité d'autant plus grande que l'on trouve, non-seulement dans un même genre de champignons, les Agarics et les Bolets, par exemple, mais mème jusque dans les sous-genres de ces plantes, les Amanites, les Russules, les Lactaires, tout à la fois des espèces vénéneuses et des espèces comestibles, tellement ressemblantes entre elles qu'on ne peut les distinguer à moins d'en avoir fait une étude spéciale; 
il ne faut donc pas s'étomner si chaque année des erreurs fatales occasionnent la mort de familles entières.

On s'est demandé s'il n'existe pas de caractères généraux, appréciables pour tous, au moyen desquels on pourrait distinguer les champignons vénéneux des champignons alimentaires, et, par conséquent, éviter ces funestes méprises. Malheureusement non, ces caractères n'existent pas.

Ia plupart des auteurs nous disent bien qu'il faut en général se méfier des espéces qui viennent dans les bois ombragés, les lieux sombres et humides, les cavernes, les souterrains; qu’il faut se méfier de celles dont la chair est molle et aqueuse; de celles qui ont une saveur àcre; astrin. gente, acide ou salée; de celles dont la couleur est d'un rouge brillant, verte ou bleue; de celles qui n'ont pas d'odeur ou ont une odeur qui n'est pas celle du champignon de couche; de celles qui sécretent un suc lactescent; de celles qui changent de couleur lorsqu'on les entame; de celles dont les lames ou feuillets sont colorés en brun on noircissent en vieillissant; de celles dont la surface est gluante; de celles dont la chair est mollasse et fibreuse, et enfin de celles qui ne sont attaquées ni par les limaces ni par les insectes ou les vers.

Et ils ajoutent que l'on peut, tout au contraire, regarder comme inoffensifs leś champignons qui se plaisent dans les lieux peu couverts des bois; ceux qui viennent dansles friches, les bruyères, les prairies, les champs cultivés; ceux dont la saveur n'est ni fade, ni acide, ni astringente; ceux qui ont une odeur de champignon de couche ou de farine récente; ceux qui ont une consistance charıue, ferme, cassante, une chair qui ne change pas de couleur à l'air; ceux qui ont une surface sèche, non visqueuse, une couleur rosée, vineuse ou violacée; ceux qui sont attaqués 
far les vers. les insectes of les limaces; ceux qui sont recherehes par les animaux mammiferes.

Sans donte il a a puelpue chose de rrai dans ces renseignements des auteurs; mais accepter comme monens propres à distinguer les champignons alimentaires des champignous vénéneux de tels caractères, serait s'exposer, d'une part, à repousser des espèces comestibles comme espèces malfaisantes; et, de l'autre, à prendre des espèces éminemment toxiques pour des espèces alimentaires.

C'est qu'en réalité aucun de ces caractères n'est exclusivement propre, ni aux champignons vénéneux, ni aux champignons alimentaires.

En effet, les espèces qui viennent dans les parties omloragées des bois ne sont pas toutes malfaisantes, puisque c'est là que naissent de préférence les Clavaires, dont aucune espèce peut-être n'est nuisible, et les Chanterelles, acceptées partout comme aliment. Les champignons qui viemment dans les parties découvertes des bois, dans les friches, les pelouses, les prairies, ne sont pas non plus tous inoffensifs; car, si c'est là que se plaisent l'Agaric comestible, Agaricus campes/ris, Lin.; l'Agaric excorié, Ag.excoriatus, Fr.; l'Agaric élevé, Ag. procerus, Scop.; l'Agaric faux Mousseron, $A g$. (Marasmius) oreades, Bolt. : c'est la aussi que se trouvent le plus souvent l'Agaric brûlant, $A g$. (Marasmius) urens, Bull., espèce fort suspecte, et l'Agaric en demi-globe, Ag. semiglobatus, Batsch., autre espèce trèsdangereuse.

Les champignons dont la chair change de couleur lorsqu'elle est blessée ne sont pas non plus tous vénéneux. A la vérité, le Bolet pernicieux, Boletus luridus, Pers., dont la chair devient bleue ou verdâtre lorsqu'on la casse, et le Bolet Satan, B. Salanas, Lenz, dont la chair devient violette, sont dangereux; mais la chair de quelques Bolets 
inoffensifs change aussi de couleur lorsqu'elle est entamée. Celle du Bolet bleuissant, B. cyanescens, Bull., passe assez promptement au bleu foncé. Celle du Bolet scabre, B. scaber, Fr.; celle de sa variété orangée, B. auranliucus, Bull., prennent une couleur légèrement vineuse, et cependant ces espèces sont comestibles. On en peut dire autant de l'Agaric lactaire doré, $\mathrm{Ag}$. (Lactarius) volemus, Fr., qui devient de couleur légèrement terreuse lorsqu'il est blessé, et de l'Agaric délicieux, Ag. (Lactarius) deliciosus, Lin., qui prend une couleur verdàtre lorsqu'il est meurtri.

Les espèces qui sécrètent un suc laiteux ne sont pas toutes dangereuses; car, si l'Agaric à coliques, $A g$. (Lactarius) torminosus, Schœeff., l'Agaric meurtrier, $A g$. (Lactarius) rufus, Scop., ne sont pas mangés impunément, il n'en est pas de mème de l'Agaric volemus et de l'Agaric délicieux, espèces que je viens de nommer, ni de l'Agaric poivré, Ag. (I actarius) piperalus, Scop., de l'Agaric controverse, Ag. (Lactarius) controversus, Pers., et de l'Agaric douceâtre $A g$. (Lactarius) subdulcis, Bull., lesquels sont tous comestibles.

La saveur âcre, astringente ou acide, n'est pas non plus un signe certain de nocuité, car l'Agaric poivré et l'Agaric controverse, déjà mentionnés plus haut, ont une saveur tellement âcre que la cuisson même ne la détruit pas entièrement, et cependant ces champignons sont mangés tous les jours impunément. On mange aussi le Bolet scabre, Fr., la Fistuline hépatique, Fistulina hepatica, Fr., dont la saveur est acide ; l'Agaric rougeâtre, Ag. (Amanita) rubescens, Fr., et l' Ag. melleus, Vahl., dont la saveur est désagréable; l'Hydne sinué, et la Chanterelle, dont la saveur est piquante.

Quant à l'odeur de champignon de couche, elle est commune à bearcoup d'espèces qui ne passent pas pour 
comestibles : l'oderu de farine aussi est lo propre de certains champignons dont la qualité alimentaire n'est pas constatée; entre autres, l'Agaric livide, Ag. lividus, Bull., et le Bolet du mélèze.

La couleur rouge brillant, verte ou bleue, n'est pas non plus un indice certain de la mauvaise qualité des champignons. A la vérité l'Agaric émétique, $A g$. (Russula) emelicus, Fr., l'Igaric sanguin, 1g. Russula) songumeus, Bull., qui sont d'un rouge vif; la variété verte de l'Agaric bulbeux, 1s. (Amanita) bulbosus, Bull., Is. Mappre, Batsch, et phalloides, Fr., qui est verte, sont dangereux; mais l'Agaric Russule, Ag. Russula, Schoeff.; l'Agaric alutacé, Ag. (Russula) alutaceus', Fr., qui sont d'un rouge vif aussi; l'Agaric verdoyant, Ag. (Russula) virescens, Schoff., dont la couleur est verte, et l'Agaric odorant, $A g$. odorus, Pers., qui se fait remarquer autant par sa coulemr bleue que par son odeur d'anis, sont comestibles.

La viscosité particulière à quelques espèces n'est pas davantage un signe de nocuité. L’Agaric blanc d'ivoire, Ag. (Hygrophorus) elurneus, Bull., est tout gluant par les temps humides; l'Agaric virginal, Ag. (Hygrophorus) virgineus, Jacq., ne l'est guère moins, et cependant ces champignons peuvent se manger.

Is coloration en brun des feuillets, lorsque le champignon vicillit, n'est pas non plus un signe certain de nocuité; le caractère des Agarics de la section des Pratelles est précisément d'avoir des feuillets qui deviennent noirs à la maturité, et cependant plusieurs sont comestibles : c'est mime à rette subdivision qu'appartiennent le champignon de couche et toutes ses variétés.

L'accroissement rapide des Agarics de la section des Coprins, la promptitude avec laquelle leurs feuillets prennent une couleur noire et se dissolvent, ont fait regarder 
pendant longtemps ces champignons comme suspects. On sait aujourd'hui qu'on peut les employer comme aliment, si on a soin de les cueillir avant que leurs feuillets aient pris la couleur noire et aient éprouvé un commencement de décomposition.

Que la chair d'un champignon soit fibreuse et coriace, ou bien qu'elle soit cassante, elle n'en est pas pour cela nécessairement dangereuse ou comestible. Dans les Russules et les Lactaires, elle est cassante, et cependant l'Agaric émétique, l'Agaric sanguin, qui appartiennent à la section des Russules; l'Agaric à coliques et l'Agaric meurtrier, qui appartiennent à celle des Lactaires, sont nuisibles, tandis que l'Agaric élevé, Ag. procerus, Scop.; l'Agaric pied en fuseau, Ag. fusipes, Bull., la Chanterelle, Cancharellus cibarius, Fr., qui sont loin d'avoir la chair cassante, sont comestibles.

On voudrait croire que l'homme peut manger sans danger toutes les espèces qui deviennent la proie des limaces, des vers et des insectes : il n'en est rien; car, s'il est vrai que ces animaux attaquent de préférence les champignons comestibles, il est vrai aussi qu'ils ne respectent guère plus la fausse Oronge et l'Agaric bulbeux, Bull., poisons violents, qu'ils ne respectent la véritable Oronge, $A g$. (Amanita) cæsareus, Scop., et l'Agaric rougeâtre, Ag. (Amanita) rubescens, P'ers., champignons délicats à manger; tandis qu'ils n'attaquent ni la Chanterelle, ni l'Hydne sinué, Hydnum repandum, Iin., champignons reconnus partout pour alimentaires.

L'organisation des insectes et des mollusques est d'ailleurs trop différente de celle de l'homme pour qu'il soit permis de conclure qu'un champignon sera nécessairement alimentaire pour l'homme s'il est attaqué par les insectes, les limaces ou les vers. Ne sait-on pas que certaines che- 
nilles, celle du tithymale, par exemple, se nourrissent de plantes qui sont de violents poisons pour l'homme?

Divers mammiferes, tels que les cerfs, les vaches, les porcs, recherchent avidement certaines especes de champignons. Guidés par leur instinct, ou plutòt par les sens du goùt et de l'odorat, ces animaux savent, lorsqu'ils sont en liberté, faire choix des especes; aussi ne s'empoisonnentils jamais.

Il serait donc bien d'observer quelles sont celles qu'ils recherchent et celles qu'ils dédaignent. L'organisation de ces animaux différant peu de celle de l'homme, il est évident qu'il y aurait plus de sécurité à manger les espèces dont ils font choix qu'à manger celles qui sont attaquées par des animaux tout à fait inférieurs. Il ne faudrait pas toutefois s'y fier entièrement, car on sait que le porc et la chèvre mangent, sans ètre incommodés, divers végétaux qui pour l'homme seraient des poisons, et que les lapins et les cochons d'Inde mangent impunément les champignons vénéneux crus. Les pores mangent de mème la fausse Oronge.

Comme on le voit, ni l'habitat, ni la couleur, ni la saveur, ni l'odeur, ni la consistance, ni la facilité avec laquelle les champignons sont ou ne sont pas attaqués par les limaces, les insectes et les vers, ne peuvent fournir de signes certains et absolus de la qualité de ces végétaux. Quoi qu'il en soit, il sera toujours bien, avant de faire usage d'un champignon sur lequel on aurait des doutes, de faire ce que font les animaux, c'est-à-dire de consulter les organes du goùt et de l'odorat; car il est rare qu'une espèce dont l'odeur plaît et qui, goûtée crue, a une saveur agréable, et qui persiste telle, ne soit pas comestible. Quant à vouloir assigner aux champignons vénéneux des caractères généraux pratiques qui les fassent distinguer des 
autres espéces, et de plus appréciables à tout le monde, la chose me parait impossible.

Tout ce que l'on peut établir d'une manière absolue, c'est que les diverses espèces de Phallus et de Clathres sont malfaisantes; c'est que, dans le genre Agaric, si nombreux en espèces, on n'a, dans les subdivisions auxquelles Fries a donné le nom de Heboloma, d'Inocybe, de Flammula, de Naucoria, d'Hypholoma, de Psilocybe, de Psathyra, de Panaolus, signalé aucune espèce comme comestible; ce qui toutefois ne veut pas dire que toutes celles qui composent ces subdivisions seraient nuisibles, puisque jusqu'alors on n'a pas cherché à constater les propriétés de la plupart d'entre elles.

Ce que l'on sait aussi, c'est que dans la section des Cortinaires, très-nombreuse en espèces, on n'en a pas jusqu’à présent signalé une seule qui soit vénéneuse; toutes cependant ne peuvent pas ètre regardées comme comestibles, puisque plusieurs d'entre elles ont une saveur amère et désagréable.

On peut établir d'une manière absolue que, dans le genre Morille et dans le genre Hydne, il ne se trouve pas d'espèces vénéneuses; que toutes celles du genre Helvelle sont innocentes; qu'aucune espèce du genre Tremelle n'est mentionnée comme malfaisante, et qu'enfin toutes celles du genre Lycoperdon passent pour alimentaires tant que leur chair conserve sa blancheur.

On a cru longtemps, et quelques personnes croient encore, qu'un moyen de reconnaître si un champignon est malfaisant ou comestible est de se servir, dans la préparation de ces plantes, d'une cuiller d'argent ou d'une bague en or; si, dans la cuisson du champignon, la cuiller ou la bague noircissent, il est malfaisant; si elles restent claires, il est innocent. 
C'est là une errear contre lacquelle on ne saurait trop protester: que l'argent ou l'or noircissent ou restent brillants au contact des champignons, on n'en peut rien conclure. J'ai essayé ce procédé avec l'Agaric bulbeux et divers autres Iqarics malfaisants, ils n'ont nullement noirci ni l'or' ni l'argent.

Necker avait avancé que l'oignon blanc, cuit avec les champignons, devient bleuâtre ou brun, s'ils sont vénéneux, tandis qu'il reste blanc s'ils n'ont rien de malfaisant. I a moelle du jonc noircirait aussi dans les mèmes circonstances, s'il fallait en croire les observations de certaines personnes. Nalheureusement ces assertions ne sont pas confirmées par l'expérience.

Le véritable, le seul moyen peut-être d'éviter les méprises, lorsqu'on veut faire usage des champignons, c'est d'apprendre à commaitre les caractères qui sont propres à chaque espèce en particulier; en d'autres termes, c'est d'avoir dans la mémoire ou sous les yeux le signalement précis des espèces; et, pour cela, il faut les étudier dans tous les âges et sous toutes les formes qu'elles peuvent revètir ; car pendant leur croissance beaucoup d'entre elles changent de forme et de couleur, ce qui rend difficile leur détermination. Heureux celui qui, pour étudier ces plantes, peut se procurer cles livres dans lesquels elles sont figurées avec les couleurs et les proportions qui leur sont propres.

Il sera bien néanmoins, tout en consultant les livres qui traitent des champignons, d'avoir recours aux renseignements que peuvent fournir les hommes qui vivent ou travaillent habituellement dans les forêts, tels que les bùcherons, les charbonniers, les marchands de bois, les gardes forestiers; l'expérience et la tradition ayant appris à la plupart d'entre eux à distinguer les espèces vénéneuses des espèces alimentaires. 
CHAITRE VII.

DE LA COUPOSITOY CHIMOUT, DES CHAMPICNONS.

Plusieurs chimistes des plus distingués se sont occupés, en France, de l'analyse chimique des champignons.

Braconnot a fait celle de l'Agaric volvacé, Agaricus (Volvaria) volvaceus, Bull.; celle de l'Ag. poivré, fg. (Lactarius) piperalus, Bull., de l'Ag. styptique, dg. (Panus) st)pticus, Fr., du Polypore squameux, Fr. (Bolet du noyer, Bull.), du P. officinal, Fr. (B. du mélèze, Jacq.), du P. faux amadouvier, P. igniarius, Fr., de la Chanterelle, de l'Hydne sinué, de l'H. hybride, Bull., H. velutinum, Fr., du Bolet visqueux, B. viscidus, Lin., du Salyre impudique, Phallus impudicus, Lin., de la Pezize noire, Bulgaria inquinans, Fr., et celle des spores de l'Agaric atramentaire, Ag. (Coprinus) atramentarius, Bull.

Vauquelin a fait celle du champignon de couche, de l'Agaric bulbeux, Bull., de la fausse Oronge, Bull., de l'Ag. théiogale, Ag. (Lactarius) theiogalus, Bull.

Bouillon-Lagrange, celle du Bolet du mélèze; celle du B. amadouvier, Polyporus fomentarius, Fr.; celle de la Truffe, Tuber cibarium, Lin., laquelle a été aussi analysée par Robert. Enfin, dans ces derniers temps, M. Gobley, M. Jules Lefort et M. Boudier ont répété celle du cham. 
pizmon de conche. II. Boudier a de plus lait l'analy se de l'Isaric bulbeux, de la fausse (Oronge et du bolet comestible.

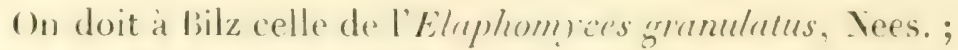
colle de l'E. aculeaus, littad. E. echimanus, Tul.), à II. Bouchardat; celle du seigle ergoté, Sclerotium Clavus, Jec., a été faite par plusieurs savants.

Je ne rapporterai pas en détail ces analyses, qui toutes du reste donnent des résultats assez semblables, pour qu'il soit démontré que les diverses espèces, étudiées jusqu'à présent, possèdent un certain nombre de principes ou éléments que l'on peut appeler constituants, puisqu'ils se retrouvent dans toutes.

Ces éléments sont :

$I^{0}$ Eau de végétation;

$2^{\circ}$ Cellulose ou ligneux qui constitue toute la partie résistante du parenchyme et des membranes de ces plantes ;

$3^{0}$ Trois substances azotées : une insoluble dans l'eau ; une soluble dans l'eau et coagulable à la chaleur; la troi. sième soluble dans l'alcool;

$4^{\circ}$ Une matière grasse analogue à la cire;

$5^{0}$ Deux autres substances grasses, dont l'une fluide à la température ordinaire; l'autre solide, cristallisable à la mème température;

$6^{\circ}$ Sucre ou mannite;

$7^{\circ}$ Iatière colorable en brun par l'action libre de l'air ;

$8^{\circ}$ Substance aromatique;

$9^{\circ}$ Trace de soufre;

$10^{\circ}$ Trace de sels de potasse et de silice.

Ces éléments se retrouvent, disais-je, dans toutes les espèces; mais il s'en faut qu'il y ait identité dans leurs 
proportions, car l'àge, l'habitat de la plante, la saison de l'année, etc., font varier ces proportions.

Outre ces éléments, on a trouvé, dans les espèces analysées, dı mucilage, de la gomme, de la gélatine, de l'albumine, de l'osmazome, de la bassorine, de l'inuline, de la dextrine, de la gélatine, des huiles essentielles, des acides fumarique, citrique, malique, phosphorique, oxalique, des sels de potasse, soude, chaux, etc.

Quelques-unes de ces plantes possèdent en plus certains principes qui semblent leur être propres. Tels sont : l'amanitine de II. Letellier, particulière aux Amanites; la bulbosine et la mycétide de M. Boudier: la première, trouvée par lui dans les Amanites; la seconde, dans divers. Agarics; l'agaricine de M. Gobley, trouvée dans le champignon de couche; et la géine de Braconnot, trouvée par celui-ci dans les spores de l'Agaric atramentaire.

Disons tout de suite que ces diverses substances n'ont pas jusqu'à présent été suffisamment isolées pour pouvoir ètre définitivement considérées comme des principes immédiats de ces végétaux.

L'eau qui entre dans la composition des champignons est évaluée dans quelques espèces à plus des neuf dixièmes du poids de la plante.

La cellulose est la base commune des divers organes des champignons, celle qui reste après qu'on en a séparé les autres éléments par la macération dans l'eau ou par des lotions répétées. C'est une substance plus ou moins blanche, mollasse, insipide, peu élastique, qui brùle avec rapidité lorsqu'elle est desséchée. Ses propriétés la rapprochent de la fibre ligneuse : c'est elle qui donne aux cham. pignons leur consistance et leur forme.

C'est elle aussi qui, avec les principes azotés, le sucre et la mannite, qui entrent dans leur composition, fait de ces 


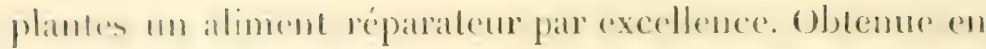
Irailant le champignon patr l'eau bouillante legerement alcalisée, elle perd les qualités malfaisantes qu'elle avail dius quelques especes; il y a plus, elle devient alimentaire.

I a cellulose a pour formule $\mathrm{C}^{12} \mathrm{H}^{29} \mathrm{O}^{19}$.

La cellulose ne se colore jamais en bleu, ni par l'iode, ni par l'acide sulfurique; elle résiste plus longtemps à l'action dissolvante de ce dernier que la cellulose des autres plantes.

Pour les chimistes actuels, le corps que Braconnot ef les premiers chimistes qui ont analysé les champignons appelaient fongine, et que, jusque dans ces derniers temps, on avait regardé comme un élément simple, n'est qu'un mélange de cellulose et de matière grasse. Déjà, pour Vau. quelin, la fongine était une simple modification du tissu ligneux.

Les champignons sont des substances fort azotées et qui participent de la nature des chairs.

MM. Schlossberger et Dopping, voulant apprécier la valeur nutritive des ces plantes, dosèrent l'azote des espèces le phus fréquemment en usage comme aliment; roo parties de champignons desséchés à roo degrés leur donnèrent:

Igaric comestible, azote.... 7-26

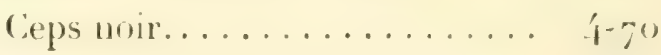

Igaric délicieux......... 4-68

Russule............. 4-2.5

chanterelle.......... 3-2\%

11. Loforl, dans son analyse du champignon de conche n'a tronvé que 2-9I d'azote, quantité de beaucoup infé- 
rieure à celle que MU. Schlossberger et Dopping aviticnt trouvée dans la leur. Cette différence ne tiendrait-elle pas à ce que les champignons cultivés auraient crû dans des * conditious différentes d'engrais ou d'habitation?

Ce mème chimiste a voulu s'assurer si l'azote se trouvait en égale proportion dans toutes les parties du végétal; pour cela, il a analysé séparément les diverses parties du champignon de couche; le chapeau proprement dit, les feuillets avec leurs spores et le pédicule; le tout desséché à 110 degrés, il a obtenu les résultats suivants :

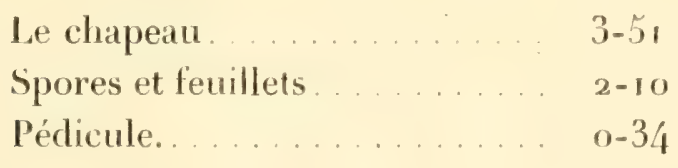

La partie la plus nutritive du champignon serait donc le chapeau; la moins nutritive, le pied ou pédicule. Le cha. peau et le pied présentent du reste des différences assez tranchées de saveur et d'odeur pour expliquer la préférence que, dans l'usage alimentaire, beaucoup de personnes donnent au chapeau sur le pédicule sans se douter peutètre que le pédicule est moins réparateur que le chapeau, en mème temps qu'il est moins sapide.

Le principe toxique des champignons de la section des Amanites, tout au contraire du principe nutritif, serait, d'après des observations répétées, plus concentré dans le pédicule, et surtout dans la partie bulbeuse du pédicule des Amanites, que dans le chapeau lui-même et que dans le reste de la plante. M. Letellier dit cependant que les lamelles des Agarics sont plus actives, comme poison, que les autres parties de la plante. Est-ce à la présence des spores, ou bien parce que les lamelles contiennent en général 
menims d'eall que le reste dur hampignon, gu'elles doivent eolle mocuite plus grande?

Prespue fous les champignoms contiennent de lialloumine. C"est. disent biraconuot et II. Cobles, at lat presenee de ce principe que les champignons doivent la consistance ferme quils premnent a la cuisson; c'est aussi a la présence de l'albumine que l'on doit de les faire servir à la fabrication du bleu de Prusse au lieu de sang.

I a matière sucrée du clampignon de couche ne constitue pas un sucre particulier; elle est pour M. Gobley la mannite. Ce champignon renferme une forte proportion de matières extractives azotées; celle de ces matières qui est soluble dans l'eau et daus l'alcool se rapproche du principe que les chimistes appellent osmazome.

Les champignons, proprement dits, ne renferment pas de matière amylacée. Le suc d'un grand nombre d'espèces contient du sucre fermentescible, susceptible par conséquent de donner de l'alcool. Celui de la Chanterelle, soumis ì la fermentation, a fourni à M. Roussel, pharmacien a Evreux, 5 pour cent d'alcool par distillation, au petit alambic de Salleron.

L'agaricine de II. Gobley est la graisse solide des champignons; elle vient se ranger auprès de la cholestérine, de l'ambréine et des antres matières grasses sur lesquelles les alcalis sont sans action; elle est cristallisable.

La géine a été obtenue par Braconnot en traitant les spores de l'dgaric atramentaire par l'éther, l'eau bouillante, l'acide chlorhydrique, l'ammoniaque, la potasse successivement. Apres ces divers traitements les spores n'avaient pas changé d'une manière appréciable de forme ni de volume; elles avaient conservé leur couleur brun fonce 1 .

(1) Aunules de chimie el de physique 1838, t. LXIX, p. 434. 
La Truffe, Tuber cibarium, Bull., a été analysée par Bouillon-Lagrange et par Robert. Je ne crois pas devoir mentionner en détail ce que ces chimistes rapportent de leur analyse.

Desséchées au bain-marie, les truffes, dit BouillonLagrange, deviennent cassantes et conservent leur arome.

Mises en digestion dans l'huile d'olive, ce liquide ne se charge pas de leur arome; les truffes le conservent tout entier. Mises en digestion dans du vinaigre et retirées après dix jours, elles n'offrent plus à la dent qu'une matière insipide, coriace et ressemblant à la fibre ligneuse; le vinaigre prend l'odeur et la saveur de la salade confite. Une chaleur douce, ajoute-t-il, en sépare un peu d'eau, les dessèche et ne leur fait pas perdre leur parfum. On peut donc pour les conserver employer la dessiccation.

Les acides végétaux, suivant Antoine, pharmacien au Val-de-Grâce, paraissent détruire l'arome des truffes, ou du moins s'opposer à son développement.

Les champignons, ai-je dit, sont des substances fort azotées et qui participent de la nature des chairs. Décomposés par l'action du feu dans des vaisseaux clos, ils donnent les mêmes produits liquides et gazeux que les matières animales.

Outre les divers principes mentionnés plus haut, la plupart des champignons en contiennent d'autres, dont il semble que jusqu'à présent la chimie ne se soit pas occupée sérieusement; je veux parler du principe odorant, du principe sapide et du principe colorant.

La plupart de ces plantes exhalent une odeur particulière, plus ou moins analogue à celle du champignon de couche, et que l'on pourrait appeler fongique, parce qu'elle est propre aux champignons.

Quelques-unes de ces plantes exhalent une odeur déli- 
cieuse. Mul doute que les parfumeurs ne cherchent un jour a tirer parti de leur principe odorant. D'autres exhalent une odeur de farine récente; d'autres une odeur alliacée; d'autres encore une odeur fétide. Enfin il en est qui n'ont absolument aucune odeur.

Le principe odorant des champignons est dù, selon toute vraisemblance, à une huile essentielle ou à une substance résineuse. La chimie n'a pas jusqu'alors cherché à isoler ce principe.

La saveur de ces plantes est très-variable. Il en est de fades et d'insipides; il en est d'âcres, de caustiques, d'acides, de styptiques, de nauséeuses, etc.

Cette variété dans la saveur indique nécessairement une varicté dans les principes qui la leur donnent. Ces principes aussi auraient besoin d'être plus particulièrement étudiés.

Beaucoup de champignons se font remarquer par l'éclat de leur couleur. Leur matière colorante pourrait ètre utilisée dans les arts : déjà les teinturiers ont su tirer parti de celle de divers Polypores, entre autres du Polyporus hispidus, Bull., du P. igniarius, Bull.

L'action de la lumière est sans doute pour beaucoup dans le plus ou le moins de coloration des champignons. On remarque que cette coloration est plus prononcée chez les individus qui vivent au grand air que chez ceux qui viennent à l'ombre. Il est d'observation aussi qu'elle est plus intense dans les tissus qui sont le plus rapprochés de la superficie du chapeau.

II. Filhol, directeur de l'École de médecine de Toulouse, est parvenu à isoler la matière colorante rouge d'une espèce de Russule. Un jour viendra sans doute où les différents principes qui donnent aux champignons des odeurs, des saveurs, des couleurs si variables, selon les espèces, seront isolés et probablement utilisés. 
Les Agarics de la section des Lactaires répandent, quand on les brise, un suc laiteux ordinairement blanc; mais, dans quelques espèces, jaune ou roussâtre, qui tient en suspension des résines. Ce suc, très-abondant dans les temps humides, l'est beaucoup moins dans les temps secs. La sécheresse diminue sa quantité en le concentrant. Dans diverses espèces le suc s'épanche alors en partie sur la tranche des feuillets, où il se concrète sous la forme de grumeaux caséeux.

Les Lactaires ne sont pas les seuls Agarics qui donnent un suc laiteux; quelques espèces de la section des Mycènes sont dans le même cas; tels sont l'Agaricus galopus, Schrad., l'Ag. sanguinolentus, Alb. et Schw., l'Ag. crocaıus, Schrad., champignons de petite taille et qui par cela mème sont rarement observés. C'est dans la cavité de leur pied seulement que se trouve ce suc. Une variélé du champignon de couche donne aussi, par un effet de la culture, comme je l'ai dit plus haut, un suc coloré. Le Fistulina. hepatica, Fr., donne pareillement un suc rouge.

Le suc des Lactaires est miscible à l'eau. Il a, daus quelques espèces, une saveur excessivement âcre; dans d'autres, cette saveur est douce. Dans les espèces où l'âcreté prédomine, le sıc laiteux emprunte cette qualité à un principe particulier que l'on retrouve dans d'autres espèces. Ici, le principe âcre n'est que mèlé au suc laiteux ; il n'en fait pas partie essentielle.

Le principe âcre des Lactaires n'est enlevé entièrement ni par l'infusion à froid dans l'eau, mème pendant plusieurs jours, ni par les lavages à l'eau froide répétés, ni par la macération dans les alcalis, l'alcool, les acides faibles; il ne l'est pas d'avantage par l'ébullition et la cuisson.

Dans les Agarics de la section des Russules, et dans plusieurs autres espèces, le principe âcre, n'étant pas mêlé au 
suc laiteux, est facilement enlevé par l'ébullition, par la matcération dauns les acides faibles, l'alcool, la potasse et les alcalis en solutions.

Quelques champignons, tels que l'Agaric styptique, $A g$. (P'anus) sinpticus, Fr., I'Ig. amer, Ig. fascicularis, Huds. I'Ag. elcodes, Fr., le Bolet chicotin, B. felleus, Bull., etc., contiennent un principe amer dont les propriétés ne sont pas bien connues, ce principe n'ayant pas été jusqu'alors suffisamment étudié. Dans d'autres espèces, c'est le principe acide qui domine. Nous avons vu que les acides malique, citrique et fumarique existent dans plusieurs champignons; l'acide oxalique s'y trouve aussi quelquefois.

Quelques champignons changent assez promptement de couleur lorsqu'on vient à les briser : tel est le cas de divers Lactaires et de plusieurs Bolets.

La chair et les feuillets de l'Agaric volemus, $A g$. (Lactarius) volemus, Fr., prennent une couleur terreuse, si on les endommage; la chair et les feuillets de l'Ag. délicieux, Ag. (Lactarius) deliciosus, Lin., deviennent verdâtres. La chair et les tubes du Bolet rubéolaire, B. luridus, Schœff., des $B$. radicans et cyanescens, Bull., passent rapidement au bleu; la chair du B. Satanas, Lenz, rougit ou devient violette lorsqu'on la brise ; celle du Bolet scabre, Fr., devient d'un vineux clair. Le $B$. luridus, laissé à l'air libre, redevient jaune après un certain temps et quelquefois rougeâtre.

On ne sait pas encore quelle est la cause de ce phénomène.

D'après les épreuves de Saladin, il n'est dù ni à l'action de l'air, ni à celle de la lumière, puisqu'il se produit aussi bien lorsqu'on brise le champignon dans l'eau ou dans l'huile, dans le gaz hyddrogène, dans l'acide carbonique, qu’à l'air libre. 
L'ozone joue, à ce que l'on suppose, un rôle dans ce changement de coloration.

Selon M. Phipson, la matière colorante qui existe dans les Bolets, et qui change lorsqu'on vient à les entamer, s'y trouve à l'état incolore, soluble dans l'alcool et difficilement miscible à l'eau; elle se résinifie à l'air. Elle possède les propriétés de l'aniline et donne lieu, avec les agents oxydants, aux mêmes colorations que l'aniline et ses autres combinaisons salines (I).

Plusieurs espèces de champignons sont phosphorescentes, c'est-à-dire qu'elles sont lumineuses dans l'obscurité. L'Agaric de l'olivier, Ag. olearius, Dec., qui vient, en France, au pied des oliviers, du charme et du peuplier blanc, jouit de cette propriété : la nuit il donne une lueur assez vive pour permettre de lire des livres imprimés en petits caractères. Ce sont ses feuillets surtout qui projettent de la lumière.

Sous les tropiques, le phénomène de la phosphorescence est particulier à beaucoup de champignons. En Australie, à Amboyne, au Brésil, il s'en trouve dont la lueur surpasse en éclat celle de l'Agaric de l'olivier. Gardner (M.) a vu au Brésil, dans le voisinage de Villa da Natividade, un bel Agaric dont la lumière phosphorescente, de couleur vert pâle, permettait de lire dans une chambre non éclairée. Des enfants jouaient avec ce champignon. Cet Agaric, qui n'a guère que trois à quatre centimètres de diamètre, vient sur les feuilles en décomposition d'une sorte de palmier, ce qui l'a fait appeler par les habitants du pays Fleur de coco.

L'Agaricus noctilucens, Lév., qui vient à Manille, est également phosphorescent.

(1) Comptes rendus, $1860,2^{e}$ semestre, t. L, p. 107. 
Ine autre espece de champignon, d'une grande dimension, ot phosphorescente aussi, a été trouvée en tustralie dans la colonie de la Rivière du Cygne.

Les Agarics ne sont pas du reste les seuls champignons qui émettent de la lumière visible la nuit. Pline parle d'un champignon blanc, odorant, qu'il appelle Agaric, sans doute le Polypore officinal, luisant dans les ténèbres, signe qui le faisait reconnaitre, et que pour cette raison on récoltait la nuit $(\mathrm{I})$.

Le Polypore soufré, $P$. sulfureus, Fr., qui est très-voisin du Polypore officinal, a été tronvé tout lumineux sur un vieux chène du bois de Boulogne. Il ressemblait, dit Paulet, à des flammes de feu dans l'obscurité (2).

Une autre sorte de champignon, appelé Rhizomorphe, à cause de sa ressemblance avec une racine, et que l'on regarde aujourd'hui comme une monstruosité d'un champignon qui vient naturellement en plein air, mais dont le développement a été contrarié par la privation d'air renouvelé et de lumière, croìt abondamment dans les mines souterraines. Ce champignon, dans quelques-unes de ces mines, couvre la voûte, les parois, les piliers, de ses rameaux noirs, fibreux, entrelacés, lesquels donnent une lumière phosphorescente qui éblouit presque l'oeil du spectateur, et va jusqu'à donner aux galeries l'apparence d'un palais enchanté pour une fète de nuit.

On a remarqué aussi des mycélium qui avaient un aspect. lumineux ; celui de la Truffe est dans ce cas; il émet quelquefois une lueur phosphorescente.

Les feux follets aperçus, la nuit, dans les marécages, les vieux bois humides, ne sont, pour quelques personnes,

(1) Pline, 1. XVI, 13.

(2) Paulet, t. II, p. 100. 
que la lumière vacillante de champignons à l'état de décomposition.

Peut-être aussi est-ce à la présence d'un mycélium que certaines souches de bois et de racines d'arbres coupés doivent la propriété lumineuse qu'elles gardent plusieurs jours de suite.

On ne nous dit pas ce qui donne aux champignons cette propriété. Ne serait-elle pas due à la présence du phosphore dans ces végétaux? Ce corps s'y trouve, au moins à l'état de combinaison, puisque la présence de phosphates a été constatée dans presque tous les champignons qui ont été soumis à l'analyse.

L'explication la plus plausible du phénomène de la phosphorescence des champignons est que le phosphore que renferment ces plantes se consume lentement en se dégageant de ses combinaisons actuelles. La phosphorescence de l'Agaric de l'olivier ne peut guère cependant être rapportée à la décomposition du champignon, puisqu'elle est, dit M. Léveillé, d'autant plus prononcée que le champignon a plus de vigueur.

L'opinion commune est que les champignons, comme la plupart des autres végétaux, contribuent puissamment à purifier l'air des lieux où ils croissent. Il paraitrait tout au contraire, d'après les expériences des physiciens, qu'ils vicient l'air au lieu de le purifier, car ils absorbent une grande quantité d'oxygène, et dégagent en retour du gaz acide carbonique. Ils exhalent aussi, d'après quelques expérimentateurs, du gaz azote et du gaz hydrogène, substances qui, de même que l'acide carbonique, sont de nature à vicier l'air plutôt qu'à l'assainir.

Placés sous l'eau, ils dégagent un gaz, composé d'hydrogène 'et d'azote. Exposés sous une cloche, à la lumière, ils n'exhalent pas d'oxygène, comme font les plantes phané- 
rogames pourrues de feuilles; loin de là, ils l'absorbent en quantité pour le convertir en acide carbonique par une sorte de respiration. En général, ces plantes contiennent une grande quantité d'azote. On peut mème dire que, de toutes les productions végétales, ce sont celles qui sont le plus fortement azotées.

Les champignons, après avoir émis leurs spores ou séminules, entrent presque tous plus on moins promptement en décomposition. La plupart d'entre eux exhalent, en se décomposant, une odeur fétide que l'on pourrait appeler cadavéreuse.

Les espèces à consistance presque ligneuse, comme sont plusieurs Polypores, divers Hydnes et mème divers Agarics (Marasmius), se décomposent lentement et le plus souvent sans exhalaison fétide. Toutes ces plantes, en se désorganisant, laissent sur le sol un détritus singulièrement propre à favoriser la végétation d'autres plantes, qui, l'année suivante, viendront là où les champignons ont laissé leurs dépouilles.

Après avoir parlé des différents principes dont la chimie a constaté la présence dans les champignons, j'arrive enfin à celui de tous qui doit nous intéresser davantage, mais sur lequel cette science ne nous a malheureusement presque rien appris, bien que des recherches sérieuses aient été faites à ce sujet : je veux parler de leur principe toxique.

Et d'abord, ce principe est-il le même dans toutes les espèces malfaisantes? Cela est plus que douteux, puisque, comme nous le verrons plus loin, les effets toxiques sont différents selon les espèces. Dans les unes, ce principe agit comme poison narcotique; dans d'autres, comme poison âcre, irritant; et, dans d'autres encore, tout à la fois comme poison âcre et narcotique.

Différent par son mode d'action sur l'économie animale, 
l'élément toxique doit différer aussi par ses propriétés chimiques.

Ce que nous savons du principe narcotique, c'est qu'il est soluble dans l'eau, dans l'alcool, dans l'éther et les acides faibles, au moyen d'une macération plus ou moins prolongée; qu'il n'est détruit ni par l'ébullition, ni par la dessiccation, et, de plus, qu'il n'est décomposé ni précipité par les acides, les alcalis faibles, l'acétate de plomb, la noix de galle ou le tannin; que, de plus, il n'a ni odeur ni saveur.

Ce principe est généralement regardé comme un alcaloïde. Il est permis toutefois de mettre en doute si véritablement c'est un alcaloïde, puisque l'on n'est pas parvenu encore à l'isoler entièrement, et que jusqu'à présent il n'a pas été possible de l'obtenir cristallisé. Comme il se rencontre plus particulièrement dans la section des Amanites, M. le docteur Letellier, savant mycologiste, a cru devoir, il y a bien des années déjà, lui imposer le nom d'Amanitine.

On ne sait pas si l'amanitine n'existe que dans les Amanites, ou si ce n'est pas cette mème substance qui donne aux Clathres et aux Phallus les propriétés déléteres et narcotiques qui caractérisent aussi ces champignons.

M. Boudier, mycologiste et chimiste distingué, pense avoir trouvé dans l'Amanite bulbeuse un autre principe toxique qu'il regarde aussi comme étant de nature alcaloïde, et qu'il propose d'appeler Bulbosine, principe qui serait tout à fait différent de l'amanitine de M. Letellier, ce que celui-ci conteste. Je le répète, l'amanitine et la bulbosine n'ont pas été jusqu'alors suffisamment séparées des autres éléments, pour que l'on puisse prononcer si elles constituent un seul et même principe ou des principes différents, et mème si le principe toxique est véritablement un alcaloïle. 
Schrater, de son citte, a trouré dans la fausse Oronge une substance colorante, rouge, âcre, soluble dans l'eau et l'esprit-de-vin, qu'il regarde comme le poison, parce qu'elle a tué des oiseaux.

Le principe âcre, caustique, existe dans les Lactaires, les Russules et d'autres Agarics, comme aussi dans divers bolets. Quelques especes semblent, comme je le disais plus lıaut, réunir tout à la fois le principe narcotique et le principe âcre, puisque ces espèces produisent sur l'économie les effets des poisons âcres et ceux des poisons narcoliques.

Le principe âcre est-il une matière grasse, une matière résineuse, ou bien un principe indépendant de la graisse et de la résine?

Vauquelin était porté à croire que la propriété malfaisante des champignons réside dans leur matière grasse. Braconnot pensait que celle de l'Agaric styptique était due à l'efflorescence farineuse et de nature résineuse qui, dans les temps secs surtout, recouvre le chapeau des individus avancés en âge, et qui, comme toutes les matières résineuses, est soluble dans l'alcool bouillant. Il attribuait celle de l'Agaric (Volvaria) volvacé à une substance trèsfugace. La propriété drastique du Bolet du mélèze, Polyporus officinalis, Fr., est due aussi, selon toute vraisemblance, à une résine fixe.

La chimie, en mème temps qu'elle cherchait à isoler le principe toxique des champignons, a di chercher l'antidote du poison. Elle l'a cherché dans le sucre, le vinaigre, le suc du citron, l'eau salée, l'éther, l'ammoniaque, l'eau iodurée, le quinquina, la noix de galle, le tanniu, la magnésie, le charbon, et bien d'autres substances, mais toujours sans résultats définitifs, ni même bien sensibles.

Cette science, comme on le voit, ne nous a, malgré les 
progrès incessants qu'elle fait chaque année, rien appris de bien positif touchant le principe toxique des champignons, mais elle n'a pas dit son dernier mot; espérons qu'elle parviendra un jour à isoler ce principe et à trouver des réactifs qui permettront de reconnaitre sa présence au sein mème de nos organes. Tant qu'elle n'aura pas obtenu ce résultat, il sera difficile au médecin légiste, appelé à prononcer si la mort est le résultat ou non d'un empoisonnement par ces plantes, d'éclairer la justice.

En l'absence des ressources que la chimie ne peut offrir, MM. Boudier et Reveil ont pensé que l'on pourrait, par l'examen microscopique des matières rejetées par le vomissement et celui des déjections alvines, reconnaitre, d'après la couleur et la forme des spores, la nature mème du champignon, et par conséquent constater l'espèce, ou tout au moins la section à laquelle appartient le champignon. Sans doute il ne serait pas impossible d'arriver à cette constatation: mais quelle habitude du microscope ne faudrait-il pas posséder, quelle étude de la mycologie ne faudrait-il pas avoir faite, pour parvenir à prononcer avec certitude sur l'espèce qui a causé l'empoisonnement!

Un moyen plus certain, peut-être, de reconnaître si l'empoisonnement est causé par un champignon, est de faire manger à un chien les matières que le malade a rejetées. Si le chien est malade, et surtout s'il meurt, il est évident que le champignon était malfaisant. 


\section{CHAPITRE VIII.}

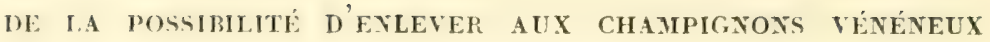
LEUR PRINCIPE TOXIQUE.

On sait que les populations russes recueillent assez indifféremment toutes les espèces de champignons qu'elles veulent conserver pour l'hiver. Elles les entassent dans des vases, les recouvrent d'une certaine quantité de sel et les laissent ainsi jusqu'au moment d'en faire usage.

M. Germann dit que, dans l'Ukraine, on mange impunément, après leur avoir fait subir cette préparation, le Boletus luridus, Schœff., la fausse Oronge, les Agarics (Lactaires) torminosus, Schœff., scrobiculatus, Scop., et diverses autres espèces qui passent pour malfaisantes.

La conservation des champignons dans le sel, tout simple que paraisse le procédé, permet, comme on le voit, de manger impunément des espèces qui sans cette préparation auraient agi comme poison.

De temps immémorial, pour ainsi dire, on savait aussi que l'on peut, au moyen de la macération dans l'eau avec addition de sel ou de vinaigre, enlever aux champignons leur principe toxique; Bulliard, Paulet, Pouchet, et la plu- 
part des auteurs qui ont écrit sur les champignons comestibles, mentionnent ce fait : je l'avais mentionné moi-mème dans la première édition de ce livre; mais ce qu'aucun auteur peut-être n'avait dit, c'est le temps précis pendant lequel les champignons doivent séjourner dans l'eau salée ou vinaigrée pour pouvoir ensuite ètre mangés impunément.

Les expériences nombreuses tentées, il y a quelques années par Frédéric Gérard, lui ont démontré que trois à quatre heures d'immersion peuvent suffire pour rendre comestibles des espèces très-malfaisantes, à la condition toutefois qu'après les avoir retirées de cette eau on les fera blanchir, c'est-à-dire qu'on les fera bouillir dans de nouvelle eau, que l'on jettera comme la première. Les champignons, lavés ensuite et ressuyés, on peut leur donner tel ou tel assaisonnement, et les manger en pleine sécurité. Ce fait étant bieu constaté, Gérard et sa famille, fort nombreuse d'ailleurs, n'ont pas craint de faire un usage fréquent de champignons traités de la sorte.

Voici du reste le procédé usité par Gérard, tel qu'il le décrit lui-mème :

"Pour chaque 500 grammes de champignons coupés en morceaux d'assez médiocre grandeur, - en quatre pour les moyens, en huit pour les plus gros, - il faut un litre d'eau acidulée par trois cuillerées de vinaigre ou deux cuillerées de sel gris, si on n'a pas autre chose : dans le cas où on n'aurait que de l'eau à sa disposition, il faut la renouveler une ou deux fois. On laisse les champignons macérer pendant deux heures, puis on les lave à grande eau; ils sont alors mis dans de l'eau froide qu'on porte à l'ébullition, et après un quart d'heure, ou mieux encore une demi-heure, on les retire, on les lave, on les ressuie, et on les apprête, soit comme un mets spécial, - et ils comportent les mêmes 
assaisonnements que les autres, - soit comme condiment (I). ")

Ce procédé a été expérimenté par F. Gérard lui-mème, en présence des membres que le Conseil de Salubrité avait désignés pour constater son efficacité : ces membres étaient MII. Beaude, Flandin et Cadet de Gassicourt; sur l'invita tion de ce dernier, je me suis joint à la commission.

J'ai tout d'abord vérifié que parmi les espèces que Gérard avait préparées se trouvaient quelques pieds de fausse Oronge, Agaricus muscarius, Lin., et d'Agaric bulbeux, Agaricus bulbosus, Bull., champignons essentiellement délétères. Gérard a mangé de ces champignons en présence de la commission; sa famille en a mangé, plusieurs membres de la commission en ont goùté, j'en ai fait autant, personne n'a été incommodé.

Les expériences de Gérard confirment donc ce que l'on savait d'ancienne date de la possibilité d'enlever aux champignons leurs propriétés délétères, par une macération prolongée dans une eau acidulée ou salée, et peut-être mème dans de l'eau pure, et les traitant ensuite par l'ébullition et le lavage. Je dis peut-être même dans l'eau pure, car il n'est pas démontré que le sel ou le vinaigre soient absolument nécessaires pour enlever le principe toxique; Bulliard dit positivement qu'on affaiblit le principe en lavaut les champignons dans deux ou trois eaux, et en les faisant cuire ensuite dans plusieurs eaux que l'on jette à mesure qu'ils acquièrent différents degrés de cuisson. Dans le Poitou, on mange, ajoute-t-il, la fausse Oronge préparée ainsi (2).

Le procédé Gérard n'est donc guère, comme on le voit,

(1) Rerue scienlifique et industrielle, 1851.

(2) Planles vénéneuses de la France, p. 75. 
que celui qui était en usage dès les temps les plus anciens.

Il n'est pas besoin d'ajouter que le liquide dans lequel on a fait macérer les champignons, se chargeant du principe actif sans le neutraliser, devient un poison violent qui, essayé sur des animaux, leur donne presque toujours la mort. M. Pouchet, de Rouen, a fait bouillir dans un litre d'eau, pendant un quart d'heure, six fausses Oronges; la décoction, donnée à un chien, le tua peu d'heures après, tandis que les champignons eux-mèmes furent mangés sans inconvénient par un autre chien. Cette expérience, répétée un grand nombre de fois, soit avec la fausse Oronge, soit avec l'Agaric bulbeux, Bull., lui a toujours donné des résultats semblables (I).

Je dois faire observer ici que le simple fait de blanchir les champignons, suffisant peut-être pour enlever entièrement le principe malfaisant de la fausse Oronge, ne l'enlève complétement ni à l'Agaric Panthère, Ag. pantherinus, Dec., ni probablement à l'Agaric bulbeux, puisqu'on cite des exemples de personnes qui sont mortes, et qui cependant avaient traité ces champigons par l'eau bouillante, jeté cette eau et ressuyé les champignons avant de les assaisonner. Le blanchiment ne suffit pas non plus pour détruire entièrement le principe actif de l'Agaric nébulaire, Ag. pileolarıus, Bull., je le sais par expérience.

Tout satisfaisant que paraisse le procédé préconisé par Gérard, la prudence conseille de ne pas faire un usage alimentaire habituel de champignons toxiques traités par cette méthode, puisqu'il suffirait de l'oubli d'une portion trèspetite de certaines espèces, de l'Agaric bulbeux, par exemple, que par mégarde on n'aurait pas soumise à la macé-

(1) Journal des connaissances médicales, 1838-1839, t. VI, p. $34 \%$. 
ration, pour produire les accidents les plus graves. Toutefois il sera bien de recourir an procéde pour peu que l'on ait des doutes sur les qualités des champignons que l'on se propose d'employer comme aliment.

L'action de faire macérer dans l'eau les champignons, et de les blanchir ensuite, a le tort très-grand, aux yeux des amateurs, d'enlever aux espèces aromatiques presque tout leur parfum. On pourrait dire cependant que l'inconvénient est suffisamment compensé par la sécurité qu'elle donne. Les cuisiniers, d'ailleurs, possèdent tous plus ou moins l'art de donner de l'arome aux aliments qui en sont le plus dépourvus. Un moyen simple d'ailleurs de restituer à ces plantes la saveur dont les a privées la macération aqueuse prolongée, c'est de les assaisonner au moyen de l'espèce de conserve ou saumure, préparée avec le suc de champignons, et d'un usage si fréquent en Angleterre où clle porte le nom de Ketchup.

II. Gobley, dans son intéressant mémoire sur le champignon comestible, considéré sous le rapport chimique, reconnait un autre tort au procédé de macération plus ou moins prolongée: c'est de faire perdre aux champignons la plus grande partie de leurs qualités nutritives, en les privant de la matière alibile qui se trouve en grande quantité dans ces plantes, lesquelles alors ne seraient plus réellement formées que de fibres végétales (1). M. Boudier est d'avis aussi que les champignons perdent par la macération la plus grande partie de leurs principes nutritifs. L'opinion de MII. Cobley et Boudier, toutefois, n'est pas partagée par le célèbre mycologiste anglais Berkeley. Celui-ci regarde ce que Braconnot appelait fongine, c'est-à-dire la cellulose, autrement ce qui reste des champignons après que les prin-

(1) Recherches chimiques sur les champignons vénéneux. 
cipes solubles en ont été enlevés par des lavages successifs, comme gardant toujours à un haut degré sa propriété nutritive (1). Quoi qu'il en soit, la macération dans l'eau salée ou vinaigrée des champignons, comme moyen préventif de l'empoisonnement, nous paraît d'une utilité bien démontrée.

On s'est demandé s'il ne serait pas possible aussi de détruire le principe toxique de ces plantes par l'addition de certaines substances à leur cuisson.

Les anciens s'accordent pour attribuer aux queues de poires et aux bourgeons du poirier la propriété de détruire ce principe.

Selon Celse, les champignons perdent toute leur qualité nuisible si on les fait bouillir dans de l'huile ou avec de jeunes branches de poirier (2).

Pline, de son côté, dit qu'il y a sécurité à manger ces plantes, si on les fait cuire avec des queues de poires.

Cesalpin (3) et Ambroise Paré, d'accord en cela avec Celse et Pline, croyaient aussi que l'on peut trouver dans l'écorce du poirier et dans ses fruits un remède préventif contre l'action délétère de ces végétaux.

“ On apprestera, dit A. Paré, les champignons sans qu'ils " fassent mal, sçavoir, les faisant cuire avec poires sau" vages, au défaut desquelles on pourra user des poires " domestiques, pourveu qu'on prenne de celles qui sont " plus aspres, sans regarder si elles sont fresches ou seichées “ au soleil; et non seulement les poires, mais aussi les " feuilles et escorces du poirier tant sauvage que domes" tique, y sont bonnes. Ainsi accoustrez les faut jeter aux

(1) Gardner's Chron., nov. 1859.

(2) Celse, 1. V, c. 27, 17.

(3) Cesalpin, ch. 40. Né en 1519, mort en 1603. 
" prises, et pourtant ne feront $n u l$ mal; car la vraye con" trepoison du champignon, c'est le poiricr (1). „

Ces mots : "Ainsi ascoutrez les faut jeter aux privez, » font supposer cependant que 1. Parc n'etait pas bien convaincu de l'efficacité du procédé.

Les médecins modernes, n'ayant pas grande confiance aux vertus du poirier et de ses productions, ont renoncé depuis longtemps à leur emploi comme contre-poison.

Il y a, je l'avoue, peu à se fier à la décoction de queues de poires, comme moyen préventif; comme aussi aux feuilles, aux bourgeons et à l'écorce du poirier.

J'ai fait cuire douze grammes d'Agaric bulbeux, variété verte, Ig. Phalloides, Fr., et autant d'Ag. puntherinus, Dec., avec de la viande; j’ai versé dans ce mélange une décoction concentrée de queues de poires et de queues de cerises; j’ai donné ce mélange à un jeune chien, lequel a présenté des symptòmes d'empoisonnement peu de temps après, et a succombé le deuxième jour.

Chansarel a prouvé, dit Lenz, que l'on détruit immédiatement le principe vénéneux des champignons, si l'on ajoute une décoction de noix de galle aux espèces que l'on a fait cuire.

Il est douteux que la décoction de noix de galle soit un moyen sûr de détruire le principe toxique de ces plantes, puisque la poudre de noix de galle et le tannin lui-mème, ajoutés aux champignons, n'empêchent pas leurs fâcheux effets de se produire.

Ces substances, autant du moins que j'ai pu en juger par mes expériences, atténuent ces effets, mais ne neutralisent pas le principe toxique.

J'ai donné à des chiens des Amanites malfaisantes, l'Agø-

(1) Ambroise Paré, OEurres, I. XXI, c. 43. Mort en 1590. 
ricus phalloides, l'Ag. Mappa, l'Ag. muscarius, l'Ag. pantherinus, soit mélangées de tannin, soit mélangées de noix de galle en poudre, les chiens n'en ont pas moins été malades; un de ces chiens est mort après trois jours de souffrance.

J'ai donné à d'autres chiens le tannin ou la poudre de noix de galle immédiatement après l'ingestion du champignon vénéneux; le résultat a été le mème, les chiens ont été malades.

Si le tannin et la noix de galle, mèlés aux champignons ou donnés immédiatement après leur ingestion, n'empèchent pas les effets du poison de se manifester, il ne faut pas espérer qu'ils auront un meilleur résultat donnés trois ou quatre heures après l'ingestion, et lorsque déjà les symptòmes de l'empoisonnement sont évidents. Administrés alors ils pourront bien, comme dans les cas précédents, amoindrir les effets du poison, mais non neutraliser le principe vénéneux; ni le tannin, ni la noix de galle, ne peuvent d'ailleurs s'employer comme moyens préventifs par leur mélange dans la préparation des champignons, soit pendant, soit après la cuisson, car alors ils donneraient à ces plantes un goût insupportable.

Le café contient du tannin, mais probablement en quantité trop faible pour atténuer d'une manière bien prononcée l'action toxique des champignons.

Krapf dit qu'ayant avalé un petit morceau d'Agaricus (Russula) inleger, Fr., bien cuit et bien pressé, il en éprouva beaucoup de mal, bien qu'il en̂t pris, presqu'aussitôt après, du café; moi-mème j'ai été incommodé, une partie de la journée, pour avoir mangé à déjeuner trois pieds d'A garicus nebularis, Batsch., et cependant j'avais, pour compléter mon déjeuner, pris une tasse de café au lait.

$\mathbf{M}^{1 \mathrm{le}}$ Boyer, ayant mangé à son dìner de l'Agaric bul- 
beux, 1E.phalloides, variété verte, se trouva empoisonnée. Les premiers symptómes déclarés, on lui donna du café. Elle fut calme jusqu'à trois heures du matin, après quoi d'autres symptòmes plus graves survinrent. Le médecin appelé la soumit à un traitement des plus rationnels; elle succomba néanmoins quarante-huit heures environ après l'ingestion du champignon. $\mathrm{NI}^{\mathrm{me}}$ Boyer qui, elle aussi, avait mangé de ce champignon et n'avait pas pris de café, est morte quelques heures après sa fille (I): donc le café n'est uullement l'antidote du poison.

Le thé aussi contient du tannin ; ses propriétés sont à peu près celles du café; combien de personnes cependant en ont pris après avoir mangé des champignons malfaisants et n'ont été que médiocrement soulagées!

On a prétendu que le suc de citron, employé comme assaisonnement, pouvait rendre comestibles les champignons malfaisants; il n'en est rien.

J'ai donné à un chien un mélange de vingt grammes d'Agaric bulbeux, variété blanche, et d'Agaricus pantherinus, Dec., cuits avec de la viande; j'ai exprimé dans ce mélange du suc de citron, en quantité plus grande que celle que l'on emploie dans l'assaisonnement des mets; ce chien est mort trois jours après.

J'ai donné à un autre chien quatre-vingts grammes d' Agaricus pantherinus, cuit avec de la viande et du citron, suc et écorce; à un autre chien pareille quantité de fausse Oronge, préparée de la même manière. Les chiens goùtèrent ce que je leur apportais et le laissèrent tout aussitòt; j'eus beau tortiller le mélange dans de la viande nouvelle, ils refusaient cette viande; c'est à peine si je pus leur faire manger la moitié de ce que j'arais préparé pour l'un et pour

(1) Journal de chimie médicale, année 1846. 
l'autre. Tous les deux furent malades assez sérieusement; le lendemain cependant ils paraissaient tout à fait remis. Le Grec Nicandre, grammairien, poëte et médecin tout à la fois, lequel vivait un siècle avant notre ère, regardait le vinaigre comme l'assaisonnement et l'antidote des champignonś Il dit que, apprêtés au vinaigre ou à l'oxymel, ils perdent leurs mauvaises qualités.

L'expérience a appris que le vinaigre ne détruit nullement leur principe toxique. Il y a plus : ce principe étant soluble dans les acides affaiblis, le vinaigre, mêlé aux champignons dans leur préparation comme aliment, développerait leurs funestes effets plutòt qu'il ne les atténuerait.

L'huile, le beurre, la graisse, le sel, employés comme assaisonnement dans cette même préparation, ne détruisent point et même n'affaiblissent point leur principe malfaisant. II en est de mème de la dessiccation et de l'ébullition, du moins pour ce qui est des Amanites. 


\section{CHAPITRE IX.}

DE L'EMPLOI DES CHAMPIGNONS DANS L'INDUSTRIE ET L'ÉCONOMIE DOMESTIQUE.

Les champignons n'intéressent pas l'homme seulement sous le rapport alimentaire, ils l'intéressent aussi sous le rapport de l'industrie et de l'économie domestique et pharmaceutique.

Parlons d'abord de leur emploi dans l'industrie et l'économie domestique; plus tard nous les considérerons comme poisons et comme agents pharmaceutiques.

Le Bolet amadouvier, Polyporus fomentarius, Fr., est généralement employé à la fabrication de l'amadou. Voici comment on procède à cette préparation. On prend les jeunes individus, on les monde de leurs tubes et de leur écorce, après les avoir ramollis en les tenant dans une cave où dans un lieu frais, s'ils sont secs. On les coupe par tranches ou lames minces, que l'on bat avec un maillet, sur une pierre ou sur un morceau de bois, afin de les distendre : on mouille ces lames de temps à autre, on les bat de nouveau, et on les frotte entre les mains jusqu'à ce qu'elles aient acquis un certain degré de mollesse et de donceur. Ainsi préparées, elles constituent ce que l'on apelle Agaric des chirurgiens, substance employée pour 
arrêter les hémorrhagies. On obtient l'amadou proprement dit, cette autre substance dont on se sert pour se procurer instantanément $\mathrm{du}$ feu, en faisant bouillir, pendant environ une heure, dans de l'eau à laquelle on ajoute une certaine quantité de salpêtre, les tranches de bolet préparées comme je viens de le dire, après quoi on les retire pour les faire sécher à l'ombre, et les battre de nouveau. Cinq cents grammes de salpêtre (azotate de potasse) suffisent pour un grand chaudron plein de tranches de champignons. L'addition du salpêtre dispose l'amadou à s'enflammer plus facilement. Quelques fabricants sont dans l'usage de soumettre les tranches du champignon à l'action de plusieurs ébullitions. Les habitants de la campagne ne les font pas toujours bouillir dans l'eau nitrée ; ils se contentent le plus souvent de les mettre deux ou trois fois dans la lessive de cendres dont on se sert pour le blanchiment du linge. Quelquefois aussi ils les baignent dans une eau qui tient en dissolution de la poudre à canon : ce dernier mode de préparation a l'inconvénient de les noircir.

La fabrication de l'amadou forme une branche de commerce assez considérable, tant est grande la consommation qui s'en fait, bien qu'aujourd'hui les allumettes phosphorées qui s'enflamment par l'effet seul du frottement en aient bien fait restreindre l'usage.

Les habitants de la Sibérie, du Kamtchatka et d'autres contrées asiatiques se servent de cette substance pour façonner des moxas auxquels on donne la forme de cônes ou cylindres, qu'ils brùlent sur la peau pour remédier aux maladies articulaires devenues chroniques.

Le Bolet de Sologne, qui n'est qu'une variété du Bolet amadouvier, sert, aux environs d'Orléans, aux mêmes usages que celui-ci. Il en est de même, en Autriche, de l'Agaric de chêne, Drdalea quercina, Fr. En Italie, ce 
Dadialea, au rapport de Cesalpin, est employé par les baigneurs comme lrosse à decrasser la tete. Quelques personnes s'en servent aussi comme d'une étrille pour les chevaux.

Le Polyporus igniarius, lir., est fréguemment employé dans les campagnes pour transporter le feu.

L'amadou sert aux artificiers à faire les boulets ou mèches d'Allemagne qui brùlent sans répandre ni fumée, ni mauvaise odeur.

Les habitants de la Franconie, au rapport de Gleditsch, ont trouvé le moyen de préparer cette substance comme une peau de chamois, et d'en faire une sorte d'étoffe qui leur sert à confectionner des vètements très-chauds et trèsdoux.

Lenz a fait un excellent amadou en trempant du Rncodium cellare, Pers., dans de l'eau contenant du salpêtre en dissolution.

Nul doute qu'on ne puisse retirer l'amadou d'un trèsgrand nombre de champignons. Palisot de Beauvois conseille d'en faire avec le Bolet oblique, Bull. Polyporus lucidus, Fr.; Bulliard et Ventenat conseillent d'en faire avec la Vesse-loup des bouviers, Lycoperdon Bovista, Lin., la Vesse-loup ciselée, L. cælatum, Bull., et toutes les grandes espèces du genre Lycoperdon. Bulliard indique même la manière de procéder à la préparation de la Vesse-loup des Bouviers.

"Pour cela, dit-il : $I^{0}$ On froissera entre les doigts cette substance filandreuse jusqu'à ce qu'il n'en sorte plus de poussiere. $2^{\circ}$ On la coupera par tranches de deux lignes d'épaisseur ou environ. $3^{\circ}$ On passera un fil à travers plusieurs de ces tranches, comme pour en faire un chapelet. $4^{\circ}$ On aura de l'eau dans laquelle on aura fait dissoudre quelques grains de poudre à tirer, ou mieux de salpètre; 
on y mettra un peu de farine, et l'on fera tremper dans cette eau, pendant une heure ou deux, ces tranches ainsi enliassées; on les fera sécher ensuite, et l'on pourra s'en servir de la mème manière que de l'amadou préparé avec le Bolet ongulé (Polyporus fomentarius). Si l'on s'apercoit que cet amadou se consume trop vite, on le trempera une seconde fois dans la mème eau, à laquelle on ajoutera une plus grande quantité de farine; si, au contraire, il ne conserve pas l'étincelle, on fera dissoudre dans cette eau un peu plus de poudre. "

Les habitants des îles Fidji se font avec un champignon, - espèce de Rhizomorpha, - des ceinturons, qu'ils garnissent de franges et qu'ils ornent à profusion de grains de collier. Ces ceinturons frangés, qui souvent constituent le seul vêtement des naturels, sont fort recherchés. Ils sont plus particulièrement en estime chez les pècheurs de la côte, parce qu'ils supportent bien l'immersion dans l'eau, surtout quand on les a graissés avec de l'huile de $\operatorname{coco}(\mathrm{I})$.

Je ne serais pas surpris que l'on fit servir à un usage semblable le Polyporus fomentarius, espèce européenne.

Angos raconte que, dans les bois de la Nouvelle-Zélande, il pousse, sur les arbres, une espèce de Polypore assez grande et assez résistante pour que l'on en fasse des siéges commodes (2). Mais ce n'est pas seulement à la NouvelleZélande, chez les antipodes, que l'on utilise ainsi les Polypores; Gleditsch dit qu'il a vu chez des chasseurs de l'Ukraine le $P$. fomentarius employé en guise de siége.

Nous avons vu figurer à l'Exposition universelle, dans le pavillon réservé de la Société protectrice des animaux,

(1) Gardn., Chron.

(2) Hussey, v. P. Dryadeus. 
des Polypores creusés pour servir de nids artificiels aux oiseaux.

Bulliard, que j'ai occasion de citer souvent, dit, en parlant de la Vesse-loup étoilée, Geaster hysgrometricus, Pers., qu'elle mérite toute l'attention du naturaliste, en ce qu'elle lui offre un hygromètre aussi sùr qu'invariable, par la faculté qu'elle a de refermer les divisions de son volva dès qu'il fait sec, et de les étendre sitòt qu'il vient à pleuvoir ou que l'atmosphère se trouve chargée d'humidité.

Le Bolet squameux, Polyporus squamosus, Fr., sert, en Angleterre, à fabriquer d'excellents cuirs à rasoir et que l'on dit supérieurs à tous les autres. Pour cela, on choisit, en automne, des individus de grande taille, exempts de toute attaque de vers; on les sèche avec soin, afin de prévenir l'action de la moisissure; après quoi, on les coupe en tranches longitudinales auxquelles on donne une forme convenable : chaque tranche, polie avec la pierre ponce, est ensuite collée sur un bois d'une forme appropriée à l'usage que l'on en veut faire ( I). Le bolet du Bouleau, Polyporus belulinus, Fr., peut être employé au même usage.

Les Suédois se servent du Bolet subéreux, Bull., Polyporus nidulans, Fr., pour faire des bouchons (2).

On peut faire, avec diverses espèces de Polypores à fibres ligneuses, des estompes, qui sont préférables peut-ètre à celles que l'on fait avec le liége.

Le Bolet amadouvier, Poly por'us fomentarius, Fr., et le Bolet faux amadouvier, Polyporus igniarius, Fr., sont employés, en Bohème, comme vases à fleurs dans les appartements. On place ces champignons contre le mur ou tout

(1) Gardn., Chron.

(2) Id., nov. 1860, p. 975. 
autre point d'appui, mais renversés, c'est-à-dire le côté de la fructification en dessus, et la partie qui adhérait à l'arbre au point d'appui. Dans ces champignons, préalablement creusés, on place des plantes à rameaux retombants, géranium, cactus, etc. On les fait servir également comme étagères.

On retire un principe colorant de beaucoup de champignons. Les teinturiers emploient pour teindre en noir brun le Polyporus igniarius, qu'ils nomment Agaric de chêne. Les gantiers font un usage fréquent du Bolet hispide, Bull., Polyporus lispidus, Fr., pour teindre les peaux en couleur marron fauve. Pour cela, ils font bouillir le champignon dans de l'eau; ils plongent dans cette eau les peaux qu'ils foulent aux pieds, afin qu'elles s'imprègnent mieux de la matière colorante. Celle-ci est assez abondante pour que les menuisiers, les ébénistes, puissent la faire servir à teindre le bois. Mis en poudre, ce même champignon sert à teindre la soie, la laine et le coton.

Les étoffes plongées dans la décoction alunée du Bolet du mùrier blanc, Hexagona mori, Poll., dit Duchesne, prennent les diverses couleurs, jaune verdâtre, jaune-chamois, jonquille, etc., suivant le temps de la macération des tissus, la proportion du Bolet, la température du bain, etc. Les couleurs que donne ce Bolet sont touies très-solides. C'est surtout dans l'Italie supérieure que l'on fait servir ce champignon à la teinture.

Le Bolet sulfurin, Polyporus sulfureus, Bull., sert aux teinturiers à_teindre en jaune.

Les Arabes du cercle de Laghouat emploient, pour teindre en jaune, un Polypore d'une assez grande dimension, à pores excessivement petits, qui vient sur le pistachier térébinthe. Les indigènes appellent ce champignon 
Semra ou Cerra. I’ai vu au musée d'Alger des spécimens de colle plante.

Dans les Canaries, on teint la lane et la soie aree les spores du Pohsaccum corrssipes, Dec., P. linclorium, Poir., espéce de Lycoperdon. Les paysannes de Bologne, dit II. Barla, emploient de même cette plante pour teindre la laine dont elles font leurs vêtements. A Massoine, et dans quelques localités des environs de Nice, elle est également en usage pour teindre le fil et la laine. Ce champignon donne une très-belle couleur brune qu'on extrait par l'ébullition.

L’Agaric charbonné, Bull., Ağ (Russula) nigricans. Fr., donne une couleur brun foncé, dont les arts et l'industrie pourraient tirer parti. Ce champignon, qui passe à la couleur noire à mesure qu'il avance en âge, arrivé au terme de son dépérissement, se dessèche, et reste longtemps sur le sol sans se décomposer; il est donc d'une conservation facile.

Bulliard a retiré de la variété violette de la Tremelle mésentériforme, par la seule infusion dans l'eau, une couleur d'un beau bistre rougeâtre, très-solide, et qui porte sa gomme avec elle. Cette plante donne par l'ébullition une couleur plus foncée. On pourrait, selon lui, tirer de ce champignon et de la Tremelle verticale, Tremella fimbriata, Pers., un parti avantageux dans l'art de la teinture. Si l'on veut, ajoute Bulliard, empècher la teinture de Tremelle de se courrir de moisissure, lorsqu'elle est exposée à l'air, il suffit de faire bouillir dans le liquide quelques clous de girofle.

J'ai dit que M. Filhol, chimiste distingué, et doyen de la Faculté des sciences de Toulouse, a obtenu une belle couleur rouge des Agarics (Russules) à chapeau rouge : probablement on obtiendrait aussi une belle couleur bleue de 
l'Agaric odorant, Agaricus odorus, Bull., de l'Agaricus (Cortinarius), čerulescens, Fr., de l'Ag. (Cortinarius) cyanites, $\mathbf{F r}$.

Bulliard, on le sait, est parvenu à faire une encre bonne pour le lavis avec le suc d'un Agaric que, pour cette raison, il a appelé atramentaire, $A g$. (Coprinus) atramentarius. I) u reste on peut faire de l'encre avec l'eau provenant de la décomposition de la plupart des Agarics du sous-genre Coprin, laquelle est formée, presque entièrement, de spores qu'elle tient en suspension. Il suffit pour cela de faire bouillir le chapeau du champignon et de filtrer la liqueur que donne l'ébullition. En ajoutant à cette liqueur des clous de girofle, ou une petite quantité de sublimé corrosif, on l'empèche de moisir.

Desmazières a fait aussi avec plusieurs espèces de Stilbospores, une encre qui peut remplacer celle de la Chine, pour le lavis et le dessin. Mais les Stilbospores sont de trop petites espèces de champignons pour que l'on puisse en tirer un parti avantageux.

Vaillant dit que la Clavaire muscoïde, Clavariu muscoïdes, Lin., plongée dans l'eau lorsqu'elle est sèche, la teint, en un instant, en jaune de safran (I).

Le bois imprégné naturellement du mycélium de la Pezize bronze, Peziza xruginosa, Fl., Dan., garde une belle couleur verte qui le fait employer comme ornemènt par les tourneurs de Tunbridge Wells.

Si l'art de la teinture a su tirer parti des champignons, celui du parfumeur pourrait aussi utiliser ces plontes. L'Agaric à odeur suave, Agaricus suaveolens, Schum., l'Agaric odorant, Ag. odorus, Bull., le Bolet suave, Trametes odorutu, Fr., et d'autres champignons exhalent une

(1) Botan., t. VIII, p. 9. 
odeur délicieuse. Il n'en est pas, an rapport de Linné, qui plaise davantage aux Lapons que celle de ce dernier; aussi les jeunes gens qui vont voir leurs maitresses en portent-ils toujours sur eux afin de se rendre plus agréables: Les femmes laponnes, par réciprocité, portent aussi sur elles ce précieux Bolet.

A cette occasion, Linné s'écrie : “ $O$ Vénus! toi à qui suffisent à peine, dans les contrées étrangères, les diamants, les pierres précieuses, l'or, la pourpre, la musique, les spectacles, ici tu es satisfaite d'un simple champignon! ”

La poudre de ce mème Bolet, mise dans les habits, en éloigne les insectes par son odeur, bien que les insectes mangent le champignon lorsque son odeur est dissipée.

La fausse Oronge doit, comme l'on sait, son nom latin, Agaricus muscarius, Lin., à la propriété qu'elle a de tuer les mouches, et cela par un procédé bien simple. Le champignon, étant divisé en petits morceaux, est saupoudré de sucre; on verse dessus de l'eau, de la bière ou dı lait, que l'on expose dans les chambres où les mouches abondent ; celles-ci viennent sucer le liquide et périssent. Toutes cependant ne meurent pas, car souvent elles ne sont que narcotisées, ainsi que l'a observé Seyffert; quelques-unes reviennent à la vie et s'envolent; aussi conseille$\mathrm{t}$-il de les ramasser pendant leur sommeil et de les jeter au feu $(\mathrm{I})$.

Allioni dit, de ce mème Agaric, qu'il met en fuite les punaises, si on en frotte les meubles ou les murailles.

L'homme n'a pas craint, 'dans diverses contrées, de faire usage de cet Agaric, tout dangereux qu'il est, dans l'intention de se procurer des jouissances. Les Ostiocks,

(1) Seyffert, de Fungis, p. 19. 
les Kamtchadales et d'autres habitants de la Russie asiatique le mangent cru ou boivent sa décoction, afin de se jeter dans une sorte d'ivresse. Trois ou quatre champignons secs, délayés dans une décoction d'Epilobium angustifolium, Lin., on de Vaccinium oxycoccos, Lin., ou dans une boisson quelconque, sont suffisants pour une société nombreuse. Quelquefois cependant les champignons sont avalés secs, sans aucun mélange. Leurs propriétés enivrantes se communiquent à l'urine des personnes qui en font usage : aussi arrive-t-il quelquefois que ces mèmes habitants du Nord de l'Asie boivent cette urine pour continuer leur orgie (1). Ainsi donc l'intoxication produite par cette plante, de mème que celle de l'alcool, ne va à rien moins qu'à òter à l'homme l'usage de son libre arbitre.

Du reste, l'homme ne s'est pas contenté de s'enivrer du poison du champignon; il a été, daus certaines régions de l'Ouest de l'Afrique, jusqu'à faire un dieu d'une espèce de Bolet, que pour cette raison Afzelius a appelé sacré, Boletus sacer (Polyporus sacer, Fr.). Les nègres de la Guinée rendent à ce champignon, remarquable toutefois par sa beauté, un véritable culte; ils le vénèrent comme ils vénèrent divers autres objets naturels, qu'ils regardent comme des divinités tutélaires.

D'après les analyses chimiques de Braconnot, on peut retirer de l'Agaric poivré et des autres Agarics de la section des Lactaires, une matière grasse analogue à la cire, et qu'à la rigueur on pourrait convertir en bougies diaphanes. Reste à savoir quel serait le prix de revient de ces bougies.

Les expériences de Enslein, Beffort et Goetling démon-

(1) Damaze de Raymond, Tubleau de l'empire de Russie, „1. II, p. 631. - Lindley, reget. Kingdom. 
trent que l'on peut, dans la préparation du bleu de Prusse, employer les champignons au lieu de sang. Ces plantes, de mème que les matières animales, fournissent de l'acide prussique.

Les champignons contenant une grande quantité d'azote, comme le démontre l'analyse, et comme du reste le prouve la vigueur avec laquelle l'herbe pousse là où ils s'étaient montrés l'année précédente, pourraient être recueillis avec avantage pour servir d'engrais. J'appelle sur la propriété fertilisante des champignons l'attention des cultivateurs. Il y a des années où l'Agaric contigu de Bulliard, Ag. (Paxillus) inwolutus, Fr., qui vient à peu près dans tous les terrains, l'Agaricus melleus, Fl., Dan., qui pousse sur les souches coupées au niveau du sol, les $B$ olelus luteus, et $B$. granulatus, Lin., qui viennent surtout sous les pins et les sapins, et tant d'autres champignons, se montrent en nombre si prodigieux qu'un enfant pourrait facilement en ramasser un hectolitre dans sa journée. L'homme va chercher le guano bien loin, tandis qu'il a peut-ètre sous la main un amendement du sol qui ne lui coùterait rien, pour ainsi dire, à recueillir.

Les bêtes à corne mangent, comme on le sait, quantité de champignons; ces plantes, si elles étaient mieux connues, pourraient aussi être recueillies et apportées dans les étables pour servir à la nourriture de ces animaux ; mais il serait essentiel de ne leur donner que les espèces dont on sait qu'ils font choix, parfaitement saines, et de plus exemptes d'insectes et de larves d'insectes.

Les champignons, comme on le voit par les citations précédentes, ont rendu de véritables services aux arts, à l'industrie, à l'économie domestique. Il est certain que, lorsqu'ils seront mieux connus, ils en rendront davantage encore. 


\section{CHAPITRE $X$. \\ DOMIAGES CAUSÉS PAR LES CHAMPIGNONS}

Les maladies d'une foule de plantes qui intéressent l'homme ont pour cause le parasitisme de végétaux appartenant à la classe des champignons; le plus souvent, il est vrai, d'un ordre tout à fait inférieur, mais dont les effets n'en sont pas moins préjudiciables, - les Urédinés. -

I)'une taille extrèmement ténue, très-simples dans leur organisation, mais par cela même se multipliant avec une rare facilité, ces champignons nuisent aux plantes sur lesquelles ils vivent; soit parce que, se nourrissant de leur suc, ils les épuisent; soit parce que, bouchant les pores de la plante, ils empèchent la circulation, l'absorption et l'exhalation de se faire librement.

Ce que nos cultivateurs appellent Nielle, Charbon ou Embrun, maladie qui, sous la forme d'une poussière noire, attaque les enveloppes florales, et ensuite les ovaires de presque toutes les graminées : - le froment, l'orge, l'avoine le millet, - et nuit conséquemment beaucoup aux récoltes, surtout dans les années pluvieuses, est produite par l'Uredo carbo, Dec. (Lsilago segelum, Ditm.).

La Carie, qui envahit le grain du froment et le transforme, presque sans le déformer, en une poussière noire, 
fitide lorsquiclle est fraiche, est produite par l'teredo (aries, Dec. (Tilletia caries, Tul.).

La Rouille, autre maladie qui attaque les feuilles, les gaines des feuilles et jusqu'aux tiges des graminées, principalement celles du froment, qu'elle épuise mème quelquefois, est produite par l'Uredo rubigo vera, Iec. (Tricholuasis rubigo vera, Lév.).

L'Ergot, qui transforme le grain des céréales, et plus particulièrement celui du seigle, en une substance compacte, d'une nature sèche et grumeleuse, d'un noir violacé à sa surface, tandis que l'intérieur reste blanc, mais d'un blanc terne, est regardé, par quelques botanistes, comme un Sclérote, Sclerolium clavus, Dec., sorte de champignon, qui jusqu'à présent n'a pas donné de spores; et par $\mathbf{H}$. Léveillé comme une altération du grain devenu malade par la présence du Sphacelia segelum, Lév., autre sorte de champignon.

Le Meunier, le Givre, le Blanc du pêcher, du rosier, du houblon, etc., sont dus à des Érysiphes et à des Oidium.

Ces champignons parasites, qui presque tous ont l'apparence de moisissures, avaient jusque dans ces derniers temps assez peu attiré l'attention des cultivateurs; mais depuis quelques années que l'Oidium Tuckeri, Berkl., attaque la vigne avec tant d'opiniâtreté, et qu'un autre champignon microscopique attaque avec non moins de persistance la pomme de terre, l'attention de l'homme s'est portée davantage sur ces plantes cryptogamiques : il a dû chercher à prévenir et à détruire la cause de maladies qui lıri causent tant de préjudice. Heureusement il a trouvé dans le chaulage un moyen de prévenir ou du moins de restreindre l'apparition du Charbon et de la Carie, et dans le soufre un remède à peu près certain contre l'Ö̈dium de la vigne et le Blanc du pêcher; mais, jusqu'à présent, il 
n'en a pas trouvé, de certain du moins, contre la maladie de la pomme de terre.

Les arbres malades ou languissants, ceux dont le tissu ligneux est mis à nu parce que la hache l'a mutilé dans quelques-unes de ses parties, ou parce que la violence du vent a séparé du tronc quelqu'une de ses principales branches, servent très-souvent d'habitat à des champignons, - Agarics, Polypores, Hydnes, - qui, se reproduisant presque toujours plusieurs années de suite dans ces plaies, trop lentes à se cicatriser, semblent hàter la destruction de l'arbre.

Mais c'est surtout le mycélium de certains champignons qui est préjudiciable aux arbres, aux arbustes et mème à beaucoup de plantes vivaces, dont il attaque les racines. Les ravages du mycélium sont d'autant plus graves que souvent son existence souterraine est méconnue, rien extérieurement ne la mettant en évidence.

Un arbre languit et meurt sans cause apparente de maladie: il meurt parce que le mycélium, le blanc d'un champignon, a attaqué ses racines. On remplace cet arbre par un arbre très-sain, il est vrai, de la même espèce que celui que l'on a été obligé d'enlever, le nouvel arbre languit et bientòt meurt aussi. On suppose presque toujours qu'il n'a pas prospéré parce que le sujet qu'il remplace avait épuisé le sol des principes nécessaires à sa nutrition. Sans doute l'épuisement du sol peut nuire à l'arbre nouvellement planté; mais plus souvent encore celui-ci ne prospère pas et meurt parce que du mycélium resté en terre sur des débris de racines de l'arbre enlevé a communiqué une maladie mortelle à l'arbre qui l'a remplacé.

On sauve les arbres qui languissent sous l'influence du mycélium en retranchant en entier la partie de la racine qui est attaquée, ou bien en la lavant avec une forte solu- 
tion de sublimé corrosif, de sulfate de cuivre, ou de toute autre substance capable de détruire le mycélium sans faire du tort à l'arbre.

On prévient l'apparition de la maladie sur le sujet que l'on veut planter en ne laissant dans le sol aucune des racines envahies par le mal, et même en brùlant ces racines ou en les emportant au loin afin qu'elles ne puissent étendre ce mal à d'autres plantes.

Des champs de fraisiers ont été détruits par des mycélium.

Les Rhizoctonia, champignons souterrains, mal déterminés scientifiquement, nuisent aussi à beaucoup de plantes Le Rhizoctonia crocorum, Dec., connu sous le nom de Mort du safran, attaque les bulbes de cette plante et les fait périr, si l'on n'arrète ses ravages en creusant un fossé d'environ trente centimètres de profondeur tout autour des endroits qui sont infectés de la contagion.

Le Rhizoctonia medicaginis, Dec., nuit également d̀ la luzerne, qu'il finit par faire périr. Enfin, une autre espèce de Rhizoctonia tue, en Angleterre, les racines de l'asperge.

I.e Merulius lacrymans, Schum., attaque les bois de construction et les rend bientòt impropres à tout usage; car, bien que ce champignon entretienne la ou il végète une humidité presque constante, il n'en est pas moins vrai qu'il finit par convertir le bois en une masse poudreuse, sèche et friable. On arrète ses ravages en arrosant le bois avec une solution de sulfate de cuivre ou en l'imprégnant, au moyen de lotions plusieurs fois répétées, de goudron provenant des usines à gaz.

On sait avec quelle facilité les moisissures, - Mucorés. et Mucédinés, - se propagent sur les fruits, les confitures, le pain, la viande, les provisions de toutes sortes, végé- 
tales ou animales. On peut dire qu'il n'est pas un seul de nos mets que les moisissures respectent, et cela se conçoit. Les spores de ces plantes flottant sans cesse dans l'air, sont transportées partout, pour ainsi dire; il n'est donc pas étonnant qu'elles s'établissent et se multiplient sur toutes les substances fermentescibles. Qui ne sait d'ailleurs avec quelle rapidité les moisissures germent et se développent.

On garantit les fruits, les viandes de l'atteinte des moisissures en les plaçant dans des endroits secs et aérés, ou secs et bien fermés. On en garantit les confitures en les couvrant d'un feuille de parchemin que l'on a trempée dans de l'eau-de-vie ou tout autre liquide spiritueux.

Le vin exposé à l'air se recouvre d'une végétation para. sitaire, très-simple, connue vulgairement sous le nom de fleurs, et que les botanistes appellent Mycoderma vini. Cette végétation que l'air apporte dans le vin donne à ce liquide un goût amer dont on ne le débarrasse qu'en détruisant la vitalité des germes, en chauffant le liquide à une température de soixante à soixante-quinze degrés.

Le Mycoderma aceli, autre végétation du même genre, mais ayant la forme d'une gelée, connue sous le nom de Mère du vinaigre, transforme le vin en vinaigre.

Mais ce ne sont pas seulement les végétaux qui ont à souffrir de l'injure des champignons parasites; plusieurs de ces plantes, d'un ordre tout à fait inférieur aussi, vont jusqu'â s'attaquer à des insectes vivants.

La Muscardine, maladie contagieuse qui attaque les vers à soie et les tue, est produite par une plante cryptogamique, le Botrytis bassiana, Bals. (Stachylidium bassianum, Mont.), dont le mycélium traverse complétement les tissus de l'animal. 
Le Mucor melitlophthorus, Rabenh. se développe sur l'abeille et la tue également.

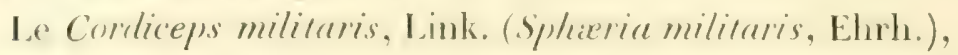
et le Cordiceps entomorrhiza, Fr., vivent sur les insectes à l'état de chrysalides et peut-citre mome les attaquent-elles lorsqu'elles sont encore à l'état de chenille.

Une autre espèce de Cordiceps se développe, en Amérique, sur une guêpe à l'état parfait, qui, bientòt appesantie par le poids de la plante parasite, tombe et meurt.

Il y a plus, certaines plantes cryptogamiques iraient jusqu'à établir leur domicile sur l'homme, s'il est vrai, comme l'ont avancé dans ces derniers temps des médecins distingués qui se sont occupés plus particulièrement des affections cutanées, qu'une foule de maladies du derme, du cuir chevelu et mème des membranes muqueuses, dartres, teignes, muguet, etc., soient produites par des végétaux cryptogamiques, - Achorion, Trichophton, Vicrisporon, Oidium, - difficiles à voir à la vue simple, mais caractérisés par l'existence de filaments mycodermiques et de spores visibles au microscope.

Mais si les champignons portent préjudice à beaucoup de végétaux et 'même d'animaux, ils ont à leur tour de nombreux ennemis. Sans parler de l'homme qui les recherche pour sa nourriture ou qui, par aversion, les foule aux pieds, nous avons vu qu'ils sont recherchés par les vaches, les cerfs, les chèvres, les porcs, etc., et qu'ils sont dévorés par les limaces et une foule d'insectes. Ce sont ces derniers surtout qui, soit à l'état de larve, soit à l'état parfait, leur font une guerre constante.

La quantité d'espèces d'insectes qui attaquent les champignons, à tous les âges de la plante, est vraiment prodigieuse. La plupart des Agarics et des Bolets charnus sont à peine sortis de terre que déjà ils sont la proie de larves 
de toutes sortes, et que bientôt ils tombent sur le sol entiè rement décomposés. Les espèces les plus malfaisantes pour l'homme, telles que l'Agaric bulbeux, la fausse Oronge; les espèces les plus âcres, telles que l'Agaric poivré, Bull., ne sont pas à l'abri de leurs attaques; les Polypores à consistance ligneuse ne le sont pas davantage; il n'est pas jusqu'aux truffes, ces champignons souterrains, qui ne trouvent aussi des ennemis dans les insectes. Peut-être les champignons doivent-ils à leur nature animalisée d'ètre recherchés par tant d'ètres différents.

Les insectes qui à l'état de larve ou à l'état parfait vivent aux dépens de ces plantes appartiennent à des tribus, à des familles, à des genres très-différents.

Une quantité prodigieuse de coléoptères trouvent en eux leur vie et leur habitat. La tribu des sylphiens, celle des hélopiens, des cantharidiens, des diapériens, des piméliens, des sténélytres, des xylophages, etc., en comptent une multitude; mais ce sont les staphyliniens surtout que l'on y rencontre en plus grand nombre.

La tribu des diptères compte une multitude de muscides et de tipuliens qui se nourrissent de champignons. Quelques larves de lépidoptères de la famille de tinéides vivent de mème à leurs dépens. Enfin, on rencontre fréquemment dans les champignons des acarus, des cloportes, des scolopendres, soit que ces animaux se nourrissent de la plante elle-mème, soit qu'ils aillent chercher leur proie parmi les hôtes qu'elle recèle.

Morts et desséchés, les champignons ne sont pas même épargnés par les insectes : ceux-ci les attaquent et finissent par les détruire entièrement : ils les attaquent jusque dans les herbiers, ce qui rend si difficile au botaniste la conservation de ces plantes.

Quelques espèces de champignons cependant sont géné- 
ralement épargnées par les insectes et les limaces; telles sont les Mérules, les Hydnes, les Coprins, privilége qu'elles doivent probablement à la présence de tel ou tel principe que l'analyse chimique ne nous a pas encore fait connaitre.

Le savant docteur Léveillé a donné, dans le Dictionnaire d'histoire naturelle de d'Orbigny, une liste excessivement nombreuse des insectes qui vivent aux dépens des champignons ou qui y établissent leur domicile; cette liste, à laquelle j'ai contribué, est si multiple que l'on pourrait la croire complète, et cependant de nouvelles observations permettraient d'y ajouter encore de jour en jour.

Les champignons morts ou vivants ne sont pas attaqués seulement par les insectes : ces plantes sont à peine en voie de décomposition que l'on voit se développer sur elles une foule de végétaux cryptogamiques : Mycobanche, Sporotrichum, Melanconium, Sepedonium, Dematium, Botrytis, Trichoderma, Fusidium, etc., et mème des champignons d'un ordre plus élevé que les Mucorés et les Mucédinés, entre autres le Nyclalis asterophora, Fr., le N. parasitica, Fr., l'Agaricus loveianus, B., et le Boletus parasilicus. 
CHAPITRE XI.

DE LA RÉCOLTE DES CHAMPIGNONS.

La récolte des champignons doit se faire par un temps sec et le matin de préférence à tout autre moment de la jour. née. Une chose essentielle dans cette récolte, c'est de ne se point méprendre sur la détermination des espèces; il faut donc les examiner avec soin dans toutes leurs parties, et s'assurer si elles ont les caractères botaniques que les naturalistes leur ont reconnus. Avec de l'habitude, on parvient à distinguer une espèce de toutes ses congénères.

En général, il vaut mieux couper ces plantes à fleur de terre, et sur tige, que de les arracher. En les arrachant, on s'expose à les salir et à faire entrer dans les feuillets, les pores ou les alvéoles, de la terre ou du sable, dont ensuite on les nettoierait difficilement. De plus, en les arrachant, on enlève presque toujours les jeunes individus qui se trouvent au pied du champignon adulte, et dont plus tard ou aurait pu tirer parti : le plus souvent aussi on laisse en terre un volva, qui offre un caractère certain pour reconnaître diverses espèces, et enfin on détruit le mycélium, qui aurait permis, l'année suivante, de retrouver la plante au mème endroit.

Il faut, autant que possible, les cueillir avant leur entier 
developpement, parce que, trop avancés on itge, ils sont d'une digestion difficile, et que d'ailleurs, a peine arrivés à leur maturité, ils entrent presque tous en putréfaction, d'après cette loi générale que ce qui croît promptement dure peu et s'altère promptement. On doit laisser ceux qui sont attaqués par les insectes ou leurs larves. Outre le dégoùt qu'inspirent ces larves, nous ne savons pas si, mélées aux aliments, elles n'auraient rien de nuisible.

Les truffes ne se trouvant pas à la surface du sol, comme les autres champignons, leur recherche exige une attention toute particulière et une certaine habitude. C'est ordinairement dans les terrains légers, humides et ombragés, d'argile sablonneuse et ferrugineuse, dans les bois de chènes et de chàtaigniers, et dans le voisinage de ces bois qu'elles se plaisent. On en rencontre dans toute l'Europe, excepté peut-ètre en Suède. En France, elles viennent surtout dans les provinces méridionales : c'est là aussi qu'elles acquièrent plus de parfum.

Le terrain qui les recèle présente des gerçures et quelquefois de petites éminences à sa surface. Lorsqu'on le frappe, il rend un bruit sourd; cet indice de leur présence trompe rarement. Un indice plus certain encore, c'est l'odeur particulière qu'elles exhalent et qui se fait sentir à quelque distance; odeur qui n'est pas toujours sensible pour l'homme, mais qui l'est extrêmement pour les cochons, animaux qui recherchent les truffes avec une avidité extrême, et dont l'homme a su tirer parti pour se procurer ces plantes. Voici de quelle manière.

On conduit ces animaux, dressés le plus souvent d'avance à cette chasse, dans les terrains où l'on sait qu'il y a des truffes; aussitôt que l'on s'aperçoit qu'ils fouissent la terre en un lieu plus particulièrement, on accourt, on les éloigne, et avec une petite bèche on soustrait la truffe à 
leur gloutonnerie. Pour ne pas décourager l'animal, on lui donne un gland, une châtaigne ou une pomme de terre. Le cochon sent la truffe à une distance de trente à cinquante mètres; il la sent de mème à près d'un mètre de profondeur.

Bruyerin dit que, de son temps, on entourait d'une courroie le groin des cochons employés à la recherche des truffes, afin de les empècher de dévorer ces plantes (I). Cette sorte de muselière n'est plus en usage aujourd'hui. Quoi qu'il en soit, comme avec les porcs il faut une grande surveillance, et que souvent il arrive qu'ils ont dévoré les turbercules avant que l'on ait eu le temps d'accourir, et qu'il faut mème quelquefois les leur disputer, on a imaginé de dresser des chiens barbets à cette sorte de chasse. Rarement ces animaux montrent du goùt pour les truffes; cependant, comme avec quelques soins on parvient à les accoutumer à leur usage, quand une fois ils en mangent avec plaisir de cuites et de crues, on peut les conduire à la recherche de ces végétaux. Avec le chien, cette chasse est facile et ne diffère guère de celle que l'on fait avec le cochon. Lorsque le chasseur voit qu'il flaire plus particulièrement certain endroit, et que déjà il gratte avec ses pattes, il écarte l'animal et, avec un outil, il enlève les truffes. Pour ne pas décourager le chien, on lui donne les plus petites à manger.

Il y a des insectes qui peuvent aussi servir à découvrir le lieu d'habitation de ces plantes. L'un est une espèce de tipule décrite et figurée par de Borch (2); les autres sont des Hélomyces, insectes de la famille des Muscides, décrites et figurées par M. Laboulbène. Ces insectes, dont les

(1) Bruyerinus, 1. 范.

(2) De Borch, Lettres sur les truffes du Piémont, pl. 3, f. 10. 
larves se nourrissent de la substance de la truffe, soit qu'ils sortent de l'état de larve, soit qu'ils veuillent déposer leurs aufs dans les truffes, se tiennent assez constamment dans leur voisinage. A la fin de l'automne, au temps de la maturité des tubercules, le matin, lorsque par un temps serein, on voit ces insectes se balancer en colonnes dans l'air ou voltiger en troupes, puis se poser sur le sol, on peut ètre certain qu'en creusant la terre là où on les a vus voltiger et se reposer, on découvrira des truffes, mais qui trop souvent seront gâtées, parce qu'elles ont servi à la nourriture de l'insecte.

Enfin, il est des hommes dont le coup d'œil est si exercé, qu'ils peuvent dire, à l'inspection d'un terrain, s'il y a là des truffes et quelle est leur qualité.

C'est le plus souvent à la profondeur de dix à quinze centimètres que ces plantes se trouvent enfoncées dans la terre; quelquefois cependant on en trouve à sa surface, qu'une force élastique semble en avoir fait sortir.

Les truffes ne venant pas toutes à la même époque, on en fait plusieurs récoltes. La première a lieu en août; la seconde, en octobre; la troisième et dernière en décembre et janvier. C'est dans ce dernier mois qu'elles ont plus de parfum. Les truffes précoces sont fort estimées : en Italie on les appelle aoútuines. 


\section{CHAPITRE XII.}

de la Culture des Champignons.

Le goût que montrent la plupart des hommes pour les champignons a dû naturellement les conduire à rechercher s'ils ne pourraient pas les faire croître et les multiplier à leur gré, comme tant d'autres plantes qui servent à la nourriture : c'est aussi ce qu'ils ont fait. La culture de ces plantes n'est pas du reste un art moderne; elle était déjà pratiquée chez les anciens. Du temps de Dioscoride, et probablement bien avant lui, on multipliait artificiellement les espèces comestibles, et, comme de nos jours, on en faisait venir sur couches.

D'après cet auteur, il suffisait, pour avoir des champiguons, de répandre de l'écorce de peuplier, réduite en poudre, sur une couche de terre bien fumée.

Selon Ménandre, un des procédés mis en usage chez les Grecs consistait à couvrir de fumier une souche de figuier et à l'arroser fréquemment.

On obtenait un résultat semblable, selon Tarentinus, en maintenant constamment humides des cendres de végétaux exposées en plein air.

Ce même Tarentinus nous dit qu'au moyen d'un mélange de vin et d'eau chaude dont on arrose des souches de peu- 
plier noir on biane. on oblent tres-promptement le cham-

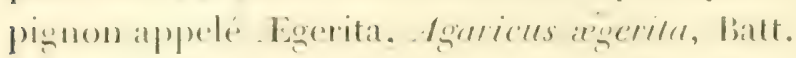

trepuis te temps de Cialien jusqua la Renaissance, les auteurs ne nous parlent guere dre champignons, of par conséquent se taisent aussi sur leur culture. Césalpin et Lécluse, qui vivaient au commencement du seizième siecle, sont les premiers, je crois, qui rompent ce silence. Le peuplier blanc et le peuplier noir, dit le premier, produiront toute l'année des champignons, si l'on saupoudre de leur écorce réduite en petites parcelles des terres engraissées dé fumier, et plus sûrement encore, sil'on emploie l'écorce du peuplier des montagnes, Populus montana, que Pline appelle Lybien, arbre renommé pour ses champignons (I).

Le procédé indiqué par Césalpin est, comme on le voit, à peu prés celui de Dioscoride.

Lécluse dit que le peuplier blanc, coupé au niveau de terre et jusqu'à la racine, arrosé ensuite d'eau chaude dans laquelle on a délayé du levain de champignon (du mycélium), produit en moins de quatre jours des champignons excellents à manger.

De nos jours, M. Desvaux a cultivé l'Agaric atténué, Aguricus atterualus, Dec., variété Ag. cylindraceus, Fr. qui vient sur les vieux troncs de saule et sur ceux de peuplier. Cette espèce, qui est très-voisine de l' Egerita des anciens, si ce n'est la mème, est cultivée aujourd'hui dans le midi de la France par bon nombre de personnes.

Voici, du reste, ce que M. Desvaux dit de la culture de l'Agaric atténué :

"Ce champignon vient en groupes plus ou moins nombreux. Ayant reconnu cette espece, on se procure une rondelle de bois de peuplier de la plus grande étendue possi- 
ble et de trois à quatre centimètres d'épaisseur; on l'enfouit jusqu'à fleur de terre dans un lieu frais, découvert, et on frotte la surface de cette rondelle avec l'Agaricus altenuatus, le plus possible. Si l'on a procédé au printemps, on peut ètre assuré qu'à l'automne suivant on aura une récolte abondante de cet Agaric, dont les produits devront ètre récoltés promptement, en été, par la raison que plusieurs espèces de coléoptères mycétophages, de mème que leurs larves, les piquent et les mangent rapidement. En automne et au printemps, on pourra laisser prendre un peu plus de développement aux nombreux individus qui couvriront le bois (I). »

I. Desvaux a obtenu jusqu'à huit et neuf récoltes de ce champignon dans les années humides.

M. Auguste Saint-Hilaire dit, de son còté, de l'Agaricus rgerita, appelé Pivoulade par les Languedociens, qu'on peut le cultiver et se le procurer abondamment dans presque toutes les saisons de l'année. Il suffit pour cela de recouvrir d'une couche de terre des tranches de peuplier que l'on arrose de temps en temps pour activer la végétation.

Il est à regretter que des procédés aussi simples que ceux qui étaient mis en usage par les anciens, et que celui dont parlent Desvaux et Auguste Saint-Hilaire, ne soient pas plus généralement connus, ou que du moins on ne les mette pas plus fréquemment en usage.

Il est une espèce de champignon que nous faisons naitre à peu près à notre volonté, partout où il nous plait et dans toutes les saisons : c'est l'Agaric de couche, Agaricus compestris, Lin., que, de temps immémorial, on a cultivé sur couche.

A Paris, et dans presque toutes les grandes villes, ce

(1) Desvaux, Mémor, encyclop., 11. 109, janv. 18.40, 1. 43. 
champignon, venu artificiellement, est, pour ainsi dire, le seul que l'on mange.

Les jardiniers ont plusieurs manières de construire les couches à champignons; toutes cependant se réduisent à peu de choses près, à celle que je vais indiquer.

On creuse dans un jardin, au midi ou au levant, et de préférence dans un terrain sec et sablonneux, une fosse profonde de six centimètres, large de soixante à soixantequinze, sur telle longueur que l'on voudra. On la borde d'une partie de la terre de la fouille. Dans un terrain humide on fait la fosse plus profonde, mais l'on remplit l'excédant de pierrailles que l'on recouve d'un peu de terre et de sable. On remplit cette fosse d'un mélange de terreau, de bon fumier pourri et de crottin d'un cheval qui ne soit pas nourri de son. On foule aux pieds le mélange et on l'élève à la hauteur de soixante-cinq à quatre-vingts centimètres, en lui donnant la forme d'un dos d'âne; sur ce mélange, ainsi battu, on met, d'espace en espace, des morceaux de mycélium, - blanc de champignon, - pris dans une bonne couche actuellement en activité, ou mème du blanc que l'on aura conservé à l'ombre ou dans une cave. On recouvre le tout d'un lit de terreau ou de bonne terre végétale de deux à trois centimètres d'épaisseur, que l'on recouvre, lui-mème, de cinq centimètres environ de paille ou de fumier non consommé; ce dernier se nomme chemise.

Vingt à vingt-cinq jours après qu'une couche, comme celle que je viens de décrire, a été établie, elle produit des champignons en quantité, si l'on a soin de l'arroser, non pas abondamment, mais fréquemment, ce qu'il faut faire surtout en été. Dans cette saison, lorsque la température de l'atmosphère est fort élevée, la couche n'a pas besoin du lit de paille ou de fumier, appelé chemise, et 
même dans un autre temps, lorsque ce fumier donne trop de chaleur ou d'humidité, il faut le renouveler ou le diminuer d'épaisseur.

La chaleur la plus convenable est celle de vingt à vingthuit degrés centigrades. Il faut veiller à obtenir constamment cette température. On y parrient facilement en épaississant ou en amincissant la chemise. Du reste, il sera bien de changer celle-ci de temps à autre, surtout si elle venait à se pourrir par trop d'humidite et de chaleur.

La récolte des champignons se fait tous les trois ou quatre jours, selon leur abondance. On les cueille au fur et à mesure de leur venue. Il vaut mieux les couper par le pied que de les arracher; car en les arrachant, on s'expose à entrainer du mycélium et des champignons qui ne sont pas encore développés.

Quelques personnes préparent les couches à champiguons sans avoir la précaution d'y mettre du mycélium, et cependant il arrive fréquemment que ces couches sont productives. La raison en est que très-souvent les fumiers qui entrent dans la composition de la couche, renferment des spores qui n'attendaient que des circonstances favorables pour se développer. Le plus sùr, néanmoins, est de garnir toujours la couche de blanc de champignon.

Les couches à champignons durant plusieurs anvées, l'hiver, on peut les transporter à la cave ou dans une serre; il est mème des jardiniers qui ne les établissent jamais ailleurs, parce que là elles se trouvent à l'abri des orages, des pluies, de la sécheresse, du froid et du chaud excessifs. La température des caves étant à peu près constante, les couch€s que l'on y établit, exigent peu de soins et réussissent mieux que celles que l'on établit à l'air libre. Mais on a remarqué que les champignons qu'elles produisent ont moins de saveur et de parfum que ceux qui 
vienuent sur couche dans 131 jatrdin; it plus forte raison an ont-ils moins ancore que cenx qui natssent spontanement daus les friches o les paiturages. Const done de próférence au grand air et dans un lieu où le soleil pénètre qu'il convient de construire les couches.

Pour entretenir la fécondité d'une couche, il faut l'arroser avec de l'eau qui a servi à laver les champignons dont on a fait usage, et laisser sécher sur pied quelques individus qui, arrivés à leur maturité, répandront autour d'eux les spores ou corpuscules reproducteurs. Lorsque la couche s'épuise, on renouvelle le fumier.

Le printemps et le commencement de l'été sont les sai. sons les plus favorables à la construction des couches; elles sont d'ordinaire en plein rapport un mois ou deux après qu'elles ont été faites. Celles que l'on construit à la fin de l'été produisent en hiver; celles que l'on établit en décembre ne produisent qu'au mois de mai suivant.

Il arrive quelquefois qu'une couche à champignons ne produit rien, ou mème qu'elle produit des champignons d'espèces tout à fait différentes de celles dont on s'était proposé la culture.

La stérilité de la couche tient alors, ou bien à ce que le mycélium dont on s'est servi pour la féconder était altéré d'avance, et par conséquent ne pouvait rien produire, ou bien encore à ce que la faculté végétative du mycélium ou des spores aura été détruite par une fermentation trop active de la couche. Si d'autres espèces, telles que des Coprins, ont pu se montrer sur la couche, cela tient à ce que leurs spores, placées plus superficiellement, ont résisté à la fermentation, et par conséquent ont pu donner des produits. Il faut savoir faire choix du mycélium et reconnaitre s'il n'est pas altéré.

Lorsqu'une couche ne produit rien ou produit des cham- 
pignons autres que le champignon de couche, ce qu'il y a de mieux à faire, c'est de la détruire et d'en reconstruire une autre; ce que l'on devra faire aussi si les iules, les scolopendres, les cloportes, envahissent la litière.

Le blanc de champignon, ou mycélium, a la propriété de se conserver un grand nombre d'années. Cl. Tollard dit en avoir vu qui a produit de très-bons champignons, après vingt années de conservation.

Les couches en plein air donnant des champignons de meilleure qualité que celles que l'on établit dans des caves ou dans des carrières souterraines, il sera bien d'aérer, autant que possible, les caves et les carrières où l'on cultive ces plantes.

En France, on ne cultive guère que le champignon de couche, et dans quelques provinces du Midi l'Agaric atténué et l'Agaric ægérite, dont je parlais tout à l'heure. La culture de plusieurs autres espèces pourrait cependant ètre tentée, et sans doute elle le serait avec succès.

I)'après une note attribuée au docteur Thore, et rapportée par plusieurs auteurs, on sème, dans le département des Landes, l'Agaric Palomet, Agaricus (Russula) virescens, Schrff., et le Bolet comestible, Boletus edulis, Bull.

"Pour cela, dit-il, on se contente d'arroser la terre d'un bosquet planté en chênes, avec de l'eau dans laquelle on a fait bouillir une grande quantité de ces deux espèces de champignons. La culture n'exige d'autres soins que d'éloigner de ce lieu les chevaux, les porcs et toute espèce de bètes à cornes, qui sont très-friandes de ces deux plantes; ce moyen ne manque jamais de réussir. Nous laissons aux physiciens, ajoute-t-il, à nous expliquer pourquoi l'ébullition ne fait pas mourir les germes. $)$

Il est douteux en effet que l'eau dans laquelle on a fait bouillir des champignons puisse servir à leur multiplica- 
tion: car, bien que les spores supportent une température seche très-élevée, l'ébullition, du moins si alle est prolongée, détruit leur faculté germinative. Il serait préférable, ce me semble, d'employer seulement l'eau qui a servi à laver l'Agaric palomet et le Bolet comestible, comme on se sert, pour féconder des couches préparées d'avance de l'eau dans laquelle on a lavél'Agaricus campestris, le champignon de couche.

Du reste, M. Réveil regarde comme apocryphe la note attribuée à Thore; car, assure-t-il, personne, ni dans les Landes, ni à Dax, ne fait usage du procédé dont aurait parlé Thore. M. Réveil a répété pendant plusieurs années de suite, et dans plusieurs départements, le procédé indiqué ci-dessus et toujours sans aucun succès. Des épluchures de champignons semées par ce savant dans les localités ou se trouvent habituellement certaines especes, n'ont pas non plus propagé ces espèces.

Micheli a semé des Agarics sur des feuilles tombées d'arbres de différentes sortes. Il plaçait sur ces feuilles des champignons de couche debout, par conséquent les lames du chapeau tournées en dessous; il jetait les champignons lorsqu'il supposait qu'ils avaient déposé leurs semences sur les feuilles; il portait ensuite celles-ci dans des lieux ombragés, où il y avait d'autres feuilles à demi décomposées et propres à produire des champignons. Au bout d'un certain temps, pendant lequel il avait plu plusieurs fois, il a vu des champignons sortir de ces feuilles. Il est vrai que, dans ses essais, Micheli n'a pas toujours vu la mème espèce se reproduire.

Seyffert, plus heureux que Réveil et Micheli, ayant répandu des semences d'Agaric sur un terreau ligneux et putride, en vit sortir des champignons de l'espèce qu'il avait semée. 
Un ami de Willdenow a cultivé pendant plusieurs années, dans son jardin, non-seulement le champignon de couche, mais aussi l'Helvelle en mitre, Helvella mitra, Bull., et mème le Satyre fétide, Phallus impudicus, Lin.; ce dernier infectait tellement le jardin, que le cultivateur finit par trouver que sa reproduction était trop prospère.

Mazzoli dit aussi avoir semé avec succès ce mème Satyre fétide; peu de personnes seront tentées de l'imiter, tant l'odeur de cette plante est repoussante.

Pourquoi les jardiniers ne tentent-ils pas la culture d'une foule d'autres espèces, plus grandes de taille et tout aussi estimées que le champignon de couche?

La culture des champignons pourrait aussi être rendue plus productive qu'elle ne l'est. Nous avons vu que le docteur Labourdette obtient des champignons de couche d'une grosseur prodigieuse, en arrosant, de temps à autre, la conche avec une solution d'azotate de potasse (sel de nitre), dans la proportion de deux grammes d'azotate de potasse par mètre carré.

Le champignon se développe en très-peu de jours. L'action du sel de nitre se fait sentir pendant plusieurs années.

Nous avons vu aussi que, en Angleterre, M. Ingram a obtenu un résultat semblable, en arrosant ces plantes avec une solution légère de chlorure de sodium (sel de cuisine).

N'est-il pas à craindre, comme je l'ai dit plus haut, que l'espèce, ainsi forcée dans sa culture, ne dégénère et ne donne plus tard que des champignons de médiocre qualité. La culture du chanpignon de couche a déjà produit de nombreuses variétés, qui se perpétuent, mais qui n'ont pas toujours les bonnes qualités de l'espèce primitive?

En Italie, on soumet à une sorte de culture le Bolet tubérastre, Polyporus tuberaster, Fr., champignon très-dèlicat et, fort recherché. Ce Bolet, qui croit spontanément aux 
covirons de Naples, a pour mycilium une sorte de racine tubéreuse, grande, spongieuse et vivace qui, dans ses accroissements successifs, embrasse et lie tres-fortement ensemble de la terre, des fragments de bois, de pierre et autres corps qui se trouvent dans son voisinage, de manière à former des masses quelquefois assez considérables pour peser près de cent livres; ces masses, retenant constamment à leur superficie des semences ou du blanc de tubérastre, se recouvrent, tous les deux ou trois mois, de champignons. Ce sont ces masses fongiferes, appelées pierres it champignons, Pietra fungaja, par les Italiens, que les amateurs de champignons enlèvent et placent dans un lieu chaud et humide où, ayant l'attention de les arroser de temps à autre, elles se recouvrent de champignons, comme elles feraient à l'air libre.

La pietra fungaja se transporte d'un pays dans un antre; mais on s'est assuré que, dans les climats froids, elle dégénère et finit par ne plus produire. Transportée en Suède, elle y a réussi, mais elle ne s'y est pas acclimatée. A Naples et à Florence, on la garde à la cave; en France, on pourrait la conserver dans des serres. Berkeley a vu en Angleterre, à Hammersmith, dans le jardin de Sée, des spécimens de Bolet tubérastre qui étaient venus de mycélium importé.

La pietra fungaja est connue depuis bien longtemps. Bruverin, médecin de François $I^{\mathrm{er}}$, auteur du traité $D e$ re cibaria, s'écrie dans ce livre : "Qui ne verrait pas avec admiration des champignons sortir d'un fragment de roche, et qui, détachés de la pierre, sont toute l'année remplacés par d'autres; car il semble qu'une partie de leur pédicule se pétrifie pour grossir la pierre qui en est ensemencée; phénomène qui nous découvre une vie d'un nouveau genre! ” 
En Italie, on cultive aussi, pour l'usage culinaire, une autre espèce de champignon, l'Agaric napolitain, Agaricus neapolitanus, Pers., qui vient sur le marc de café brûlé.

Voici ce que Ténore disait de ce champignon dans une lettre écrite à Persoon, ce savant père de la mycologie, en lui envoyant plusieurs individus de cette espèce.

"Le champignon que vous trouverez ci-joint se développe sur le marc de café pourri et gardé dans un endroit humide, pendant huit à dix mois. Ce n'est que depuis peu d'années que le hasard le fit découvrir. Des jeunes religieuses d'un couvent de Naples l'ont trouvé sur un tas de marc de café ramassé dans un coin ombragé de leur jardin. Dès lors elles en ont répandu la nouvelle, et, à présent, on se le procure artificiellement; car ici, on a pris l'habilude de ramasser ce marc pendant quelque temps, en employant aussi celui des bontiques, pour en faire une provision plus considérable. On fait pourrir le marc dans un pot de terre cuite, non vernissé, déposé à l'ombre, et arrosé pour entretenir une humidité constante. Les champignons parais. sent au bout de six mois environ; ils sont bons à manger et d'assez bon goùt (1). ”

Dans la culture de l'Agaric napolitain, il n'est pas nécessaire de recourir à l'emploi de mycélium. Les spores de ce champignon seraient à peu près répandues partout si, comme le pense Fries, cet Agaric n'est autre chose que son Agaricus cutimus, on I'Ag. infundibuliformis, Bull., Ag. suavis, Pers., si commun dans nos bois. Il est donc à présumer que la culture de ce champignon réussirait en France.

Les Italiens cultivent encore une autre espèce de Polypore dont on pourrait aussi tenter la culture en France;

(1) Persoon, Myc. europ., t. II, 1. 74. 
cest te Polypore du coudrier, Polyporus corylinus, Mauri, qui vient surtout dans la Campagne de Rome, et qui est tellement apprécié, que rarement il va jusqu'aux marchés de Rome, étant le plus souvent envoyé en présent, comme champignon de choix.

Ce champignon croit principalement sur les vieux troncs de noisetiers, qui accidentellement ont été brûlés. Les paysans, instruits par l'observation du résultat que produit cette combustion, font, sur les vieux troncs des noisetiers, un feu léger jusqu'à ce qu'il y ait un commencement de carbonisation. Après cette opération, les champignons, si les circonstances sont favorables, poussent en si grande quantité qu'ils couvrent toute la souche. Les paysans veulentils obtenir une troisième récolte, ils renouvellent la légère combustion sur le mème tronc.

Le Polypore du coudrier continuant à se développer, bien que transporté à de grandes distances, il serait facile de faire venir d'Italie des souches de noisetiers déjà chargées de champignons, ou tout au moins de mycélium.

La culture de ces espèces étrangères procurerait aux gourmets de France une.jouissance nouvelle.

Mais ce n'est pas seulement en Europe que l'on se.livre à la culture des champignons. Rumphius rapporte qu'à Amboine, et dans d'autres îles voisines, on cultive deux sortes de champignons : le Bolet du muscadier, Boletus moschocaryanus, et le Bolet du sagoutier, B. saguarius. Le premier vient sur les tas de brou de noix muscades, abandonné sur le sol, comme n'étant d'aucune utilité; l'autre, pousse sur les débris du bois de sagou, Sagus farinacea, qu'on entasse exprès dans les jardins. Le Bolet du muscadier est un mets très-recherché des amateurs, et qui ne figure que sur la table des riches; le Bolet du sagoutier sert de mème à lit nourriture de l'homme, mais il vient assez 
abondamment pour qu'on l'emploie aussi à engraisser les porcs et les poules (I).

Quelques espèces de champignons exotiques, transportées en germes avec des plantes venues de pays lointains, se sont plus d'une fois montrées sur la terie qui nourrissait ces plantes ou sur la caisse qui les contenait, entre autres un Aséró, apporté de la Nouvelle-Hollande en Angleterre, et un Stilbum; aucune d'elles ne s'est naturalisée. Une espèce exotique cependant paraît s'ètre acclimatée en Europe : c'est l'Agaricus cæpæstipes, Sowerb., laquelle vient dans les serres et s'y multiplie, si l'on a soin de l'arroser d'eau chaude. Ce champignon, établi depuis longtemps en Angleterre, est originaire de l'Amérique méridionale, où on le rencontre dans les bois parmi les feuilles. I'Angleterre il a passé en France, où il réussit également dans les serres. Il est comestible, mais pourvu de peu de chair.

L'Agaricus (Marasmius) hæmatocephalus, Mont., qui vient dans les parties les plus chaudes des deux Amériques, et que l'on cultive dans les maisons au Brésil, s'est montré il y a peu d'années à Kew, dit Berkeley, dans un pot contenant une espèce de Cardulovica; cette plante n'a pu s'y établir d'une manière permanènte.

Ce savant mycologiste a essayé, il y a quelques années, d'introduire en Angleterre une très-belle espèce d'Agaric dont le mycélium avait été apporté de la rivière du Cygne, en Australie; sa tentative n'a pas réussi. Il en a été de même avec l'Agaricus fabaceus, Berk., dont la culture a été tentée aussi en Angleterre, à cause de ses excellentes qualités, avec du mycélium venu de la Caroline du Sud.

Le peu de succès de ces tentatives ne doit pas décourager.

(1) Herb. Ambon. 
Les champignons sont, comme on le voit, des ètres délicats dont la transplantation est difficile. (guelques-unes de nos espèces cependant, telles que les Amanites et les Coprins, transportées dans un lieu frais avec un peu de la terre sur laquelle elles croissent, contimuent à se développer. les paysans lorrains connaissent cettr propriété aussi, lorsqu'ils rencontrent une Oronge à peine sortie de son volva, ont-ils soin de l'emporter avec un peu de la terre sur laquelle elle a crû, et de la placer sous leur évier, lieu toujours frais, où le champignon continue à grandir. Cette pratique a cela de fâcheux qu'elle ne permet pas au champignon de répandre ses spores dans un lieu propice à sa reproduction.

Presque toutes les autres espéces de champignons se flétrissent, peu de temps après qu'elles ont été enlevées à leur sol natal. 
Les personnes qui font profession de cultiver la truffe ne sont nullement d'accord avec les botanistes sur l'origine et la nature de cette production; car, tandis que les botanistes regardent les truffes comme des champignons souterrains, se reproduisant de spores comme tous les autres champignons, la plupart des cultivateurs, tout au contraire, ne voient dans ces productions que des excroissances végétales de la nature des noix de galle. Telle est du moins l'opinion émise par M. Bonnet et par M. Martin Ravel, à qui l'on doit des travaux intéressants sur la culture de la truffe.

Pour ce dernier surtout, la truffe n'est qu'un accident produit dans la végétation de divers arbres, et plus particulièrement du chêne, par la piqûre que fait une mouche, qu'il appelle truffigène, aux racines chevelues de l'arbre. Selon cet auteur, la mouche truffigène pénètre dans la terre, atteint les racines chevelues, les pique à leur extrémité et dépose là ses œufs. Introduit dans la plaie, l'œuf fait affluer sur ce point les sucs nourriciers; une excroissance, qui est la truffe naissante, s'élève, grandit; la radicule piquée par la truffigène ne tarde pas à mourir; la 
Iruffe alors s'on detache : abandonnce à elle-mème, elle continur at grossir ot a se développer avec le secours de la terre et de l'air.

Il est doutcux qu'une mouche puisse pénétrer dans la terre jusqu'à la profondeur de huit, dix, et quelquefois mème de vingt centimètres, pour déposer ses oufs dans les radicules du chène et d'autres arbres, et produise ces excroissances que plus tard on appellera truffes. S'il en était ainsi. on devrait trouver dans toutes les truffes des larves, des chrysalides, des insectes parfaits, ou tout au moins des traces du séjour de l'insecte auquel on attribue leur origine, et cependant il n'en est rien; la plupart des truffes sont parfaitement intactes lorsqu'on en fait la récolte.

Une hypothèse qui me parait très-vraisemblable touchant la reproduction de ces végétaux, c'est que, lorsque les spores de ce champignon, appelées truffinelles par Turpin, entrent en germination après la destruction de la truffe mère, leur mycélium ayant besoin pour s'accroitre et nourrir la jeune plante de puiser dans l'organisation d'un ètre vivant les éléments nécessaires à sa nutrition, ce mycélium s'attache au chevelu des racines du chène et d'autres arbres qui lui fournissent les premiers éléments de l'assimilation. Plus tard, le tubercule se détache des racines aux dépens desquelles il a vécu quelque temps, et trouvant dans le sol les éléments nécessaires à la continuation de son existence, il croit, se développe, le plus souvent isolé, et ne gardant aucune trace de son adhérence aux spongioles de la racine de l'arbre.

I)éjà, si je ne me trompe, MVI. Tulasne avaient admis que les Élaphomyces pourraient bien ètre des plantes parasitaires; si les Élaphomyces sont véritablement parasites, il y a grande apparence qu'il en est de mème des truffes. 
Mais, que la truffe soit un champignon parasite, ou bien qu'elle soit une espèce de galle provenant de la piquire d'un insecte, comme les bédéguars et les noix de galle, voici à peu près quel est le procédé de culture conseillé et mis en usage par M. Bornholz et par M. Ravel :

Les truffes ne prospérant guère que dans les terrains calcaires ou argilo-calcaires, un peu humides, et plus particulièrement sur la lisière des bois ou dans les endroits qui forment clairière, mais qui pourtant sont ombragés de grands chênes, c'est dans les terrains qui réalisent à peu près toutes ces conditions qu'il faut établir les truffières.

Trouve-t-on ces conditions réunies dans un bois, dans un bosquet ou mème dans un jardin anglais : vous élaguez, dit Bornholz, le bas taillis et les broussailles, après quoi vous creusez d'un mètre trente centimètres ou d'un mètre soixante centimètres tout le terrain destiné à la truffière; vous remplissez la fosse avec de la terre choisie dans la forèt, et alors vous êtes en mesure; il ne s'agit plus que d'implanter les tubercules dans la couche.

Les truffes perdant, à ce qu'il parait, leur propriété germinative aussitòt qu'on les a enlevées à leur sol natal, pour peu qu'elles aient été soumises à l'action de l'air ou du soleil, leur extraction ou leur transport demande certaines précautions.

Par un jour pluvieux on humide, ou par un ciel couvert, on extrait du sol les truffes, de manière à les laisser enveloppées de la terre qui les entoure et les garantit du contact de l'air; si, par suite de l'absence de pluie, le sol était sec, il faudrait l'arroser quelques heures avant de tenter l'extraction des tubercules.

On fait choix de truffes de grosseur moyenne, pleines de force vitale, et parvenues à leur entier développement. Trop avancées en maturité, elles auraient perdu leur fa- 


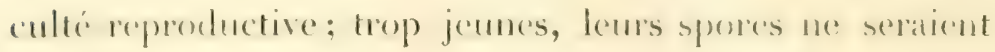
pats sulfisimment mires. Les tuberenles, aiusi garnis de ferre, sont placés dans des caisses, et pour empecher quils ne soient ballottés dans le transport et prévenir tout frottement, on remplit de nouvelle terre humide, que l'on prend sur le terrain, les intervalles qui peuvent exister entre eux; on les transporte ainsi là où l'on veut les planter.

Irrivées au lieu de destination, on ouvre les caisses à l'ombre; le soir de préférence. On humecte un peu la terre si cela est nécessaire, et l'on plante les truffes le plus promptement possible. On les enterre à cinq, dix et quelquefois vingt centimetres de profondeur, selon la nature du terrain que l'on a préparé d'avance; on les recouvre ensuite de la terre environnante. Comme la plante vient de préfércnce au milieu du chevelu des racines des arbres, il sera bien d'en mettre près des radicules de ces arbres, et plus particulièrement près des radicules du chène.

(Quelques cultivateurs pensent qu'il vaut mieux placer les truffes ensemble dans un petit espace, que de les éparpiller sur toute la couche. "Tout le plant, dit Bornholz, se recouvre ensuite de branches de chène, de hêtre ou de charme, jetées de distance en distance. On plante également tout le terrain consacré aux truffes de jeunes arbrisseaux de la mème espèce, — chènes, hètres, charmes, - mais à une certaine distance les uns des autres, de manière qu'ils ombragent le terrain sans arrèter la circulation de l'air. ”

On voit que Bornholz, sans se déclarer partisan de l'opinion de ceux qui veulent que la truffe soit le produit de la piquire faite par un insecte aux racines des arbres, recommande d'en planter sur les couches destinées à produire des truffes.

" Le meilleur moment de l'année pour la plantation des truffes, ajoute-t-il, est le printemps et le commencement de 
l'automne, parce que c'est alor's (ju'on trouve les meilleures truffes à cet usage. Vers ce temps, d'ailleurs, la terre est d'ordinaire assez humide pour qu'on n'ait pas besoin de l'arroser; mais, le cas échéant, par une sécheresse prolongée, il ne faudrait pas omettre les arrosements extraordinaires, lesquels doivent toujours se faire avec précatition pour ne pas inonder et déranger les germes qui se développent. Il est inutile de rappeler que, l'automne arrivé, on couvre les plantes d'une couche de feuilles de chène."

Les truffières ainsi disposées, on les laisse absolument tranquilles; on laisse croitre librement les petites herbes, n'arrachant que les végétations plus grandes qui pourraient épuiser le sol, lequel doit toujours être conservé dans un état de fraicheur.

Les couches préparées au printemps produisent déjà en automne des truffes de la grosseur d'une noisette ou d'une noix. Leur apparition est un signe que le plant a réussi et qu'il prospérera.

Quelques persomes, craignant d'exposer à l'air les truffes qu'elles se proposent de faire servir à l'établissement de truffieres artificielles, transportent dans la fosse ou tranchée préparée d'avance des blocs de terre prise, par un temps humide, dans une truffiere naturelle, et que l'on suppose contenir des truffes ou des germes de truffes. Les expériences faites à ce sujet ont eu quelques résultats avantageux; malheureusement, lorsque l'on opère ainsi, on n'est pas toujours sùr que les blocs de terre que l'on transporte contiennent des truffes ou des germes de truffes.

Une truffière en activité donne des produits depuis le commencement du printemps jusqu'à la fin de l'automne. C'est en aoùt, septembre et octobre, que les truffes viennent en plus grande abondance. Elles sont de meilleure qualité si l'automne est chaud et humide. 
I.'humblité est nécessanire a la truffe; la plante meurt quand la sécheresse est grande et dure longtemps; une quantité d'eau trop grande aussi lui est nuisible; elle la fait dépérir en la chargeant de moisissure.

Lne premiere tentative a-t-elle échoué, il ne faut pas pour cela se décourager ; le terrain est préparé pour l'année suivante. Il est rare que l'on echoue une seconde fois, si l'on transporte dans la couche de nouvelles truffes. Pour plus de sureté encore, on peut faire plusieurs plantations dans le mème terrain, en différentes saisons.

s'il faut en croire les cultivateurs de truffes, tout propriétaire d'une ferme, d'un jardin ou d'un bosquet où sont plantés des chènes, des hètres, des chàtaigniers et autres arbres, peut établir des couches et cultiver la truffe. Il suffit pour cela de choisir un emplacement qui se trouve dans les conditions de celui dont on aurait fait choix dans le bois. On creuse, comme l'a dit plus haut Bornholz, à $\mathrm{I}^{\mathrm{m}}, 30$ ou $\mathrm{I}^{\mathrm{m}}$, 5o de profondeur le terrain destiné à la truffière. On remplit la fosse que l'on a creusée par de la terre choisie dans la forèt, ou, à défaut de celle-ci, par de la terre végétale retirée des endroits où ont vécu de temps immémorial des groupes d'arbres. On traite ensuite cette couche comme on aurait traité celle qui aurait été établie dans un bois; ainsi on plante de jeunes chènes, de jeunes hètres sur la truffière; on recouvre celle-ci chaque automne d'une couche épaisse de feuilles de chène, et l'on a soin d'arracher de dessus la truffière toutes les grandes herbes qui pourraient donner trop d'ombrage. Il sera bien de re. tourner les terres de la truffière après les avoir engraissées, non avec du fumier, il lui serait contraire, mais avec des feuilles de chène.

Il faut, autant que possible, éloigner des truffières les animaux qui sont les ennemis de la truffe. 
Dans les bosquets, les truffes ont surtout à souffrir des attaques des souris, des loirs, des mulots, des limaces rouges et noires, des vers provenant de grosses mouches, des larves de hanneton, des scolopendres, des cloportes. Dans les grands bois, elles ont à souffrir de celles des sangliers, des cerfs, des chevreuils et des écureuils.

Pour détruire, ou du moins diminuer le nombre des insectes, il sera bien de remuer de temps à autre, mais superficiellement, le terrain avec une petite bêche, et d'y mêler une certaine quantité de bonne cendre ou de chaux.

En France, le nombre des espèces de truffes est plus considérable qu'on ne le croit communément; il se monte à une quinzaine, dont cinq ou six sont alimentaires, et dont trois, à ce qu'il parait, sont confondues sous le nom de truffes noires.

Les truffes noires ne végètent qu'au milieu du chevelu des racines des arbres, et en particulier du chevelu de trois espèces de chêne : le chêne rouvre, Quercus robur, Lin., appelé dans quelques endroits chène femelle; le chêne yeuse, $Q$. ilex, Lin., et le chène kermès, $Q$. coccifera, Lin. Elles acquièrent sous ces arbres un parfum qui leur manque lorsqu'elles viennent entre les racines du charme, du hêtre, du châtaignier, etc., au pied desquels on les rencontre quelquefois.

La truffe noire, dite du Périgord ou de haute Provence, est celle que l'on cultive de préférence. Elle vient surtout dans les bois de chène rouvre, arbre qui se distingue de ses congénères par ses fruits sessiles. C'est dans les terrains tertiaires et de transport à base calcaire, argileuse, marneuse, mêlés de cailloux, qu'elle se plaît. Et, comme je l'ai dit des truffes en général, elle vient plus volontiers sur la lisière des bois ou dans les endroits qui ne sont pas trop ombragés. 
Chaque espèce de truffes parait du reste avoir une préfirence margue pour les racines et l'ombrage de certains arbres. Les différentes espèces de chène donnent, à ce que l'on assure, des espèces différentes de truffes.

I ans le Midi de la France, on cultive le chêne tout exprès pour faroriser la multiplication de la truffe; le voisinage de cet arbre lui etant pour ainsi dire indispensable. La truffe noire qui vient sous le chêne rouvre est cultivée de préférence.

Les tubercules se rencontrant presque toujours au pied des chênes qui en ont donné les années précédentes, on marque ces arbres d'une ċroix blanche, afin de les reconnaître, et rendre plus facile la recherche du tubercule. Les arbres sont-ils devenus trop grands, ils ombragent trop fortement le sol et le garantissent de la pluie; le sol cessant alors d'être favorable à la végétation du champignon, il faut renouveler le taillis par coupes.

La culture de l'espèce ou variété qui vient sous le chêne yeuse, de mème que celle qui vient sous le chène kermès, ne pourraient pas être tentées dans le Nord de la France, puisque ces arbres n'y viennent pas.

Une autre espèce, peut-être, de truffe, paraît se plaire dans le.voisinage des racines de coudrier. Des plantations de cet arbuste ont mème été proposées dans le Midi de la France, dans le but de multiplier ce tubercule. Les coudriers étant abondants dans les provinces du Nord, il est à présumer que la culture de cette truffe y réussirait.

11 est rare, en France, de trouver des truffes sous les conifères; en Algérie, le Terfezia Leonis, Tul, sorte de truffe comestible, vient à l'ombre des pins et des cèdres.

A Carpentras, on vend annuellement, dit Martin, du premier décembre à la fin de février, sur le marché, pour deux millions de truffes, qui sont envoyées dans l'Europe en- 
tière. Le Périgord en fait aussi un commerce considérable.

Les truffes ont été cultivées de vieille date; elles l'étaient déjà du temps de François $\mathbf{I}^{\text {er }}$, car Bruyerin, son médecin, dit, dans son traité De re cibaria, que dans certaines contrées humides, les truffes que l'on exportait étaient le produit de la culture (r): Quibusdam locis acceptontur riguis et seruntur.

(1) Bruerinus, p. 3ั4ว̈. 
CHALITRE, XIV.

MOYENS DE CONSERVATION DES CHAMPIGNONS.

Les champignons étant devenus un objet de luxe pour quelques personnes, et pour d'autres un aliment de première nécessité, on a dû chercher de bonne heure les moyens de les conserver pour les saisons de l'année où la nature se refuse à les produire.

Le plus simple et celui qui a dù se présenter le premier à l'esprit, est la dessiccation qui se fait, soit en les laissant sur une claie ou dans un panier à jour, à l'ombre et dans un lieu sec, entiers, s'ils sont petits, coupés par tranches, s'ils sont volumineux; soit en les suspendant à un courant d'air, enfilés en chapelet sur de gros fils, et de façon qu'ils ne se touchent pas. On peut aussi les dessécher en les mettant dans un four, après qu'on en a retiré le pain; mais il ne faut pas que le four soit trop chaud, car on a remarqué que, desséchés avec rapidité, ils valent moins que lorsqu'ils sont desséchés lentement. Certaines espèces perdent en grande partie leur arome par la dessiccation; mais toutes du moins conservent leurs qualités nutritives.

Avant de dessécher les grandes espèces, on les débarrasse de leur partie fructifère, de la pellicule du chapeau et de leur pédicule, si celui-ci est coriace. Une fois secs, les 
champignons sont mis dans des sacs de toile ou de papier que l'on suspend dans un lieu aéré. Il faut avoir l'attention de les secouer de temps à autre, afin d'empècher qu'ils ne se couvrent de poussière ou mème de moisissure.

Ainsi desséchés, on les réduit quelquefois en poudre, au moyen d'une rape ou d'un moulin à café, ou bien encore en les pilant dans un mortier. La poudre se garde dans des flacons bien bouchés. Les Mousserons sont faciles à pulvériser; réduits en poudre, ils se gardent mieux que lorsqu'ils sont entiers.

Quelques personnes, pour conserver les champignons, les font bouillir un instant dans l'eau avec du sel, et les dessèchent ensuíte; ils ne sont plus alors attaquables par les insectes. D'autres les conservent dans l'eau salée; d'autres encore les font confire dans du vinaigre avec du sel, du poivre et de l'ail. Ce dernier procédé s'applique très-bien aux Clavaires et à l'Hydne coralloïde. Pour cela, on les blanchit d'abord, c'est-à-dire qu'on les passe à l'eau bouillante, on les essuie et on les met dans le vinaigre. L'expérience a pronvé que cette manière de les conserver est trèsbonne.

En Italie, l'Oronge, fraîche ou desséchée, se conserve dans l'huile; ainsi préparée, elle y devient mème un objet de commerce.

En Russie et en Allemagne, où l'on fait sans beaucoup de choix, dit-on, de grandes provisions de champignons pour la consommation d'hiver, on les garde dans une espèce de saumure ou dans du vinaigre. Le premier procédé consiste à mettre dans un vase une couche de champignons, puis une couche de sel, et ainsi de suite, jusqu'à ce que le vase soit plein. Le second procédé se réduit à laisser les champignons dans des tonneaux avec du vinaigre.

Les champignons, lorsqu'ils sont cuits, peuvent se gar- 
dep dans des vases en y mettant assez de benrre fondu pour qu'il dépasse le champignon de deux doigts de hauteur. Le vase doit ètre fermé hermétiquement. Le beurre et les champignons sont excellents à manger.

Les truffes se gardent bien dans leur terre natale, si cette terre est privée d'humidité; clles se gardent assez bien aussi enterrées dans du sable ou de l'argile réduite en poudre, après les avoir nettorées avec une brosse rude. Trop mires, ou pas assez mùres, elles se gardent difficilement. Toutes doivent être saines; une seule qui serait endommagée suffirait pour gàter toutes les autres. L'espece la plus apte it la conservation est la truffe noire.

Le vinaigre, la saumure, et même l'eau-de-vie, ont été employés à leur conservation; mais, retirées de ces divers liquides auxquels elles cèdent presque tout leur principe odorant, elles'ne peuvent plus guère servir que comme assaisonnement.

Lne excellente manière de conserver les truffes bonnes et agréables à manger, c'est de les mettre dans l'huile d'olive; ainsi conservées, on les appelle, quoique improprement, Truffes marinées. Dans certains pays, avant de les mettre dans l'huile, on les fait cuire dans du vin.

On aurait tort de laver les truffes que l'on veut conserver; l'humidité leur est préjudiciable, en ce qu'elle favorise leur' putréfaction. Le son, la bourre, les étoupes dont on s'est servi quelquefois, s'imprégnant facilement d'humidité, sont plutòt propres? à accélérer qu'à prévenir leur décomposition. Les cendres les altèrent. La graisse et la cire dont quelques personnes les entourent, empêchant le mouvement d'absorption et d'exhalation qui se fait en elles, nuisent à leur conservation.

Coupées par tranches et suspendues, à l'air libre, sur des fils, on peut les dessécher à la manière des autres 
champignons. En l'absence du soleil, on peut aussi les sécher dans une serre de chaleur tempérée; mais, quel que soit le procédé que l'on mette en usage dans un but de conservation, jamais les truffes ne sont si bonnes que lorsqu'elles sont fraiches.

En Italie, les truffes se conservent aussi par le procédé Appert.

On choisit une certaine quantité de truffes fraiches et sans taches. On les plonge dans l'eau et on les essuie. On en met ensuite trois ou quatre dans de petits vases en cristal, faits tout exprès pour cet usage; on verse dans ces vases ce qu'il faut de vin blanc pour couvrir les truffes, après quoi on bouche les flacons avec des bouchons sans défauts et enveloppés d'une toile humectée d'un peu de colle faite avec de la farine et de l'eau. On lie le bouchon au col des flacons avec un fil de fer; on met ensuite ces flacons entourés de paille ou d'un mauvais linge dans un récipient (un chaudron), à trois pieds, dans lequel on verse de l'eau fraìche qui arrive jusqu'au col des flacons. On met le chaudron sur le feu; mais à peine commence-t-il à bouillir, qu'on le retire sur le coin du fourneau, où on lui fait subir une ébullition très-lente pendant une demi-heure, car une ébullition forte, dégageant trop de vapeur, pourrait faire éclater les flacons. On laisse refroidir ceux-ci dans l'eau même; après quoi, pour plus de sûreté, on goudronne le bouchon. Les flacons se conservent dans un lieu frais et sec.

Les champignons desséchés, ou conservés par les procédés énoncés ci-dessus, forment une branche de commerce assez considérable. Le Midi de la France expédie à Paris ses Ceps (Bolets) en grande quantité, coupés par tranches et desséchés. L'Allemagne et surtout la Bavière lui envoient leurs Morilles, leurs Pezizes, leurs Agarics, etc., mêlés tous ensemble. 
Veut-on employer, comme condiment ou comme assaisonnement, les champignons ainsi desséchés, on les laisse tremper dans l'eau pendant plusieurs heures; apres quoi, on leur donne la préparation que l'on juge convenable.

Les Anglais soumettent à une certaine préparation le suc de champignon, qu'ils gardent ensuite, et dont ils font un usage fréquent. Cette préparation, appelée par eux Ketchup (I), est à peine connue en France. Voici, d'après $\mathbf{u}^{\mathrm{rs}}$ Hussey, comment se fait cette préparation.

Les champignons étant coupés par tranches et saupoudrés de sel, on laisse écouler leur jus à travers un tamis sans les presser; on laisse reposer ce jus pendant quelques heures, après quoi on le transvase avec beaucoup de soin, afin de le séparer de tout sédiment; on le met ensuite dans de petites bouteilles, en ayant l'attention d'y laisser assez de place pour recevoir un peu d'un spiritueux dans lequel on a fait infuser des substances aromatiques.

Le ketchup se garde admirablement, dit-on, et conserve tout son arome, lequel néanmoins se dissipe, si le ketchup vient à fermenter, ou si, dans une préparation culinaire, il est soumis à une ébullition trop prolongée (2).

Les marchands gardent fréquemment dans des barils les champignons salés, avant d'en extraire le ketchup; le mieux est d'extraire de suite le suc du champignon; la conservation en est plus sûre.

Un bon moyen de conservation aussi est de mettre le kelchup dans de petites bouteilles en grès, capables de supporter un bon degré de chaleur sans faire sauter le bouchon.

Dans la préparation du ketchup, on emploie indifféremment toutes les variétés du champignon de couche. Ia

(1) Cr mun w d'misue orientale. En allemand il sierit Catsup.

(2) Gardn., Chron., déc. 1861. 
meilleure pour cet usage est celle qui vient dans les friches, les bruyères. Le ketchup se prépare aussi avec d'autres espèces que le champignon de couche. L'Agaric rougeâtre, Agaricus (Amanita) rubescens, Fr., est souvent employé à sa confection. Il en est de mème de l'Agaric chevelu, Agaricus (Coprinus) comatus, Fl. Dan., qui, comme les autres Coprins, donne un suc très-abondant.

Un mot maintenant sur la conservation des champignons sous le rapport scientifique.

Les plantes phanérogames, gardant presque toutes leur facies dans un herbier, peuvent être consultées chaque jour avec avantage; il n'en est pas ainsi des champignons. Ceuxci, en effet, y figurent assez mal, les uns à cause de leur volume, les autres à cause du changement de couleur et de la déformation que leur dessiccation occasionne, et qui, presque toujours, les rend méconnaissables; mais surtout à cause de la facilité avec laquelle ils sont attaqués par les insectes, qui souvent les détruisent entièrement. Quelques espèces d'ailleurs ne peuvent pas prendre place dans les herbiers à cause de leur prompte décomposition; tels sont la plupart des Coprins.

Quoi qu'il en soit, veut-on conserver en herbier les champignons charnus, on les expose à l'air libre pendant quelques heures, afin de chasser une partie de leur humidité. On les met ensuite entre des feuilles de papier sous une pression modérée, en ayant soin, dans les premiers jours, de les changer de papier matin et soir. Comme il est bon de faire voir la disposition des tubes, des aiguillons et surtout le rapport des feuillets avec le pédicule, et la disposition intérieure de celui-ci, on coupe le champignon perpendiculairement par le milieu avant le dessécher. La dessiccation obtenue, on dispose le champignon dans l'herbier. 
Les especes charnues trè-épaisses, la plupart des Bolets, des IIylnes, des Agarics, et celles qui se liquéfient facilament, doivent ètre choisies avant leur entier développement. Les Tremelles ot autres champignons gélatineux se collant au papier, on les laisse se sécher d'eux-mêmes; veut-on ensuite les examiner, on les humecte.

Les champignons coriaces, subéreux ou ligneux, perdent facilement le peu d'humidité qu'ils possedent; tels sont divers Polypores, Hydnes, Téléphores. Il suffit pour les en priver de les placer dans un lieu sec et aéré. Il faut avoir soin de faire choix d'individus qui ne soient pas attaqués par les insectes. On fait périr les cufs et les larves en desséchant le champignon au four ou en l'exposant à un soleil ardent.

Pour préserver les champignons desséchés des attaques des insectes, on les plonge à diverses reprises dans une solution de sublimé, d'acide arsénieux ou de sulfate de cuivre, ou bien on les imbibe plusieurs fois de cette solution. On peut substituer au sublimé, à l'acide arséuieux et au sulfate de cuivre la décoction de quassia amara, Picrana excelsa, Dec., ou d'écorce de simarouba, Simaruba officinalis, Aubl., à la quantité de soixante grammes dans cinq cents grammes d'eau; ou mème l'infusion de tabac, à laquelle on a ajouté quelques clous de girofle (I).

Les espèces de champignons qui sont minces, aplaties et d'une consistance coriace, se dessèchent aisément dans de vieux livres ou dans du papier. Celles qui sont épiphylles se dessèchent avec la feuille même qui leur sert d'habitat. Les espèces fragiles se conservent dans des boites au fond desquelles on a mis un peu de coton.

Les Lycoperdonées doivent être recueillies avant leur

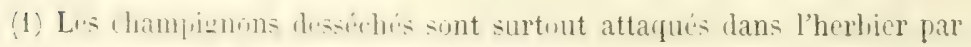
.es dermestes, les ptines, les bostryches, etc. 
maturité. On les laisse à part pendant un jour ou deux, afin qu'elles aient le temps de perdre l'eau qu'elles émettent par une sorte de fermentation; après quoi on les dessèche dans du papier sans trop les presser.

Les Geaster se peuvent mettre immédiatement sous presse.

Les Morilles se gardent facilement entières, et, si l'on veut, avec leur forme naturelle. Pour cela, on fait un trou à l'extrémité inférieure du pédicule; on remplit le champignon, lequel est creux, comme l'on sait, de sable fin, et on le suspend la tête en bas; lorsqu'il est sec, on fait tomber le sable. Le champignon préparé de la sorte conserve à peu près sa forme et son volume.

Les Pezizes et les Helvelles se dessèchent facilement aussi en les laissant séjourner pendant quelques jours dans du sable sec.

On peut conserver les champignons dans de l'alcool étendu d'eau, mais ce moyen est dispendieux. Ces plantes d'ailleurs perdent leur couleur dans l'alcool; en outre, le liquide se trouble, ce qui met dans la nécessité de le renouveler de temps à autre.

On emploie divers procédés pour conserver les truffes. Elles se gardent assez bien dans leur terre natale, si on les couvre de sable ou d'argile desséchée et pulvérisée, de manière qu'elles ne se touchent point. On les enferme alors dans une caisse dont on lute les bords pour empêcher que l'air n'y pénètre. C'est ainsi qu'on nous envoie les truffes du Piémont. On les emballe aussi dans du son, dans des étoupes, dans de la cendre, ou bien on les entoure de cire, de graisse, d'une peau fine; d'autres les font mariner et les enferment ensuite dans des bocaux de verre hermétiquement fermés. Lorsqu'on les lave, l'humidité s'insinue dans leurs pores et hâte leur décomposition. 
Ainsi que les Nousserons et les Oronges, on peut les conserver en les coupant par tranches, qu'on enfile et qu'on expose à une douce chaleur dans un poêle, dans un four ou dans une étuve. Mais, dans cet état de dessiccation, elles perdent presque tous leurs principes odorants. On les conserve encore assez bien dans l'huile, après les avoir fait passer à un feu doux, afin de leur enlever leur humidité. Dès que l'huile parait bouillonner dans le vase et que la surface se couvre d'une espèce d'écume, il faut les òter et s'en servir. Les truffes ainsi marinées ont perdu leur parfum; mais l'huile, en revanche, s'en est emparée. La salade, l'omelette, les oeufs brouillés, les asperges, le poisson qu'on assaisonne avec cette huile, ont un goût de truffes.

La conservation par les procédés suivants est plus particulièrement à l'usage des naturalistes voyageurs.

Les champignons spongieux, flasques ou charnus, se conservent, dit Barelle, $\mathrm{I}^{\circ}$ soit dans un liquide formé de deux parties d'eau pure et d'une partie d'esprit-de-vin rectifié auquel on a ajouté une quantité de sulfate de cuivre cristallisé, suffisante pour donner au liquide une très-légère couleur bleue; $2^{\circ}$ soit dans un liquide formé de huit litres d'eau pure, un litre d'esprit-de-vin rectifié, que l'on filtre après y avoir fait fondre huit grammes d'acétate de plomb, cristallisé.

On met seulement une. espèce de champignon dans chaque bocal. Celui-ci doit avoir une ouverture large, ètre exactement rempli de liquide, afin qu'il y reste le moins d'air possible. On le ferme d'un bouchon enduit de poix ou recouvert d'une vessie vernie, ou bien encore d'une lame d'étain ou de plomb qui recouvre exactement les bords du vase.

La liqueur de la deuxième recette conserve mieux que l'autre les couleurs délicates. 
Lorsqu'on ne veut que transporter avec soi les champignons intacts, sans avoir l'embarras d'emporter des bocaux remplis de liquide, on met dans un vase de terre une couche de mousse, une couche de champignons, et successivement jusqu'à ce que le vase soit plein ; ensuite on y verse de la liqueur première tant que la mousse continue à s'en imbiber, et enfin on bouche le vase.

Si l'on se propose d'expédier, pour un trajet d'un jour ou deux seulement, des champignons frais, on se contente de les placer dans une boîte ou dans un panier, séparés les uns des autres par un lit de mousse sèche, et de mettre le tout à la poste ou au chemin de fer.

Quant aux herbiers mycologiques, le meilleur, sans contredit, serait le dessin en couleur du plus grand nombre d'espèces possibles; mais il n'est pas donné à tout le monde de savoir dessiner, et d'ailleurs il faut dessiner sans retard les champignons, car, du jour au lendemain, la plupart changent de forme, et beaucoup sont en voie de décomposition. 


\section{CHAPITRE XV.}

DE L'EMPLOI ALIMTATAIRE DES CIIAMPIGNONS.

J)ans tous les siècles et chez toutes les nations arrivées à un certain degré de civilisation, les champignons ont figuré sur la table des riches comme sur celle des pauvres : chez les riches comme un objet de luxe peut-ètre, mais chez les pauvres comme aliment de première nécessité.

Les Grecs, et surtout les Romains, avaient pour ces végétaux une passion singulière. Les hommes adonnés de longue main aux plaisirs de la table, veteres voluptuarii, portaient, dit Pline, le raffinement si loin, qu'ils ne s'en reposaient que sur eux-mèmes du soin de leur préparation. Ils les apprêtaient dans des vases d'argent, comme chose précieuse, les coupaient et les servaient avec des instruments de ce métal ou d'electrum (alliage d'or et d'argent).

Les deux espèces qu'ils recherchaient de préférence étaient la truffe, qu'ils appelaient Tuber, et notre Oronge vraie, qui chez eux portait le nom de Boletus. Ils appréciaient singulièrement cette dernière.

Tous les auteurs latins qui en ont parlé accompagnent son nom d'une épithète flatteuse. Martial, qui dans ses écrits en fait l'éloge à chaque instant, va jusqu'à dire que 
de son temps on lui donnait la préférence sur l'or (I). Juvénal, dans sa satire sur les parasites, dit qu'à la table de Vircon, l'Oronge était servie au maitre de la maison, et les champignons de second ordre aux convives subalternes.

L'Oronge cependant ne conserva pas toujours à Rome la haute estime dont elle jouissait. L'empereur Claude, qui en était très-gourmand, ayant été empoisonné par Agrippine, son épouse, qui lui en fit servir un plat dans lequel se trouvait un poison préparé par la trop célèbre Locuste, cela jeta pour un temps de la défaveur sur ce champignon, que Néron, faisant allusion à la mort de Claude et à son apothéose, appelait avec une ironie cruelle un manger des dieux; mais cette défaveur ne dura guère, tant l'Oronge avait d'attraits pour les palais voluptueux.

L'empereur Claude n'est pas, du reste, le seul souverain qui ait eu un goût prononcé pour les champignons. Le pape Clément VII avait, dit Bruyerin, une telle passion pour les champignons qui viennent au printemps, - les Mousserons ou les Morilles sans doute, - que tous les jours il s'en faisait servir des plats entiers. Il avait rendu un édit qui défendait à tous les sujets de l'État romain d'en cueillir, dans la crainte d'en voir manquer l'espèce. Il mangeait aussi des melons immodérément. Sa mort prématurée fut invoquée comme une preuve certaine que la manière de vivre a de l'influence sur la durée de l'existence. Tombé malade par suite d'abus de ces aliments, tout l'art de Curtius, médecin des plus savants de cette époque, ne put, ajoute Bruyerin, lui conserver la vie.

Quelques personnes aujourd'hui encore vont jusqu'à risquer leur existence pour satisfaire leur appétit pour les

(1) Argentum atque aurum facile est lænamque togamque

Mittere: boletos mittere difficile est.

(Mart., epigr. 48, ter. 13.) 
champignons, tandis que d'autres, tout an contraire, n'en voudraient manger pour rien au monde, tant le danger des méprises les effraie.

Le savant L'Écluse (Clusius), qui a écrit sur les champignons et a mème donné des détails sur la manière de les préparer, avait horreur de ces plantes. Il n'avait pas voulu en goùter une seule fois, disait de lui Balthesen de Balthion; il lui eût donc été difficile de se prononcer sur leur saveur.

Nombre de personnes aussi n'en mangent point, prétendant que ces plantes n'ont en elles rien de nutritif et ne sont bonnes qu'à lester les organes de la digestion ou à les fatiguer imutilement. Opinion erronée et tout à fait contraire à ce que démontrent l'observation et l'expérience de tous les jours. Car, si l'on veut bien examiner qu'une foule d'hommes, livrés habituellement à des travaux pénibles, en font pour ainsi dire leur nourriture exclusive; que les Tartares, les Russes, les Hongrois, les Toscans, n'en ont pour ainsi dire pas d'autre durant tout le temps du Carème; que de toute antiquité ces plantes ont été d'un usage alimentaire, il faudra bien reconnaitre qu'elles ne sont pas, moins que tant d'autres substances végétales employées chaque jour, propres à nourrir et à réparer les forces. L'analyse chimique d'ailleurs, nous l'avons vu précédemment, ne permet pas d'élever des doutes sur leurs propriétés nutritives.

Je ne nierai pas toutefois que les espèces de champignons, mème les plus salubres, n'aient produit quelquefois des accidents; mais, le plus souvent, ces accidents auraient pu être évités. Qu'un homme, après une longue abstinence, mange en quantité excessive des champignons mal cuits; qu'il les mange précipitamment, sans mastication, il aura une indigestion des plus completes. Il en au- 
rait eu une de mème s'il avait mangé du porc, des œufs, du poisson ou tout autre aliment, sans plús de précaution. Il y a des espèces qui, bien que comestibles, sont coriaces; les habitants des villes, avec leur estomac faible, délicat, auront une indigestion, mème une dyssenterie, s'ils mangent de ces champignons, tandis que ces mèmes espèces seront digérées par les hommes de la campagne, habitués à une nourriture grossière. Ceux-ci n'appréhendent mème pas de les manger crus. Les habitants des environs de Nuremberg les mangent ainsi avec leur pain noir, assaisonné d'anis et de carvi.

I. Schwægrichen, professeur de botanique à Leipzig, imita ces bonnes gens, si bien que, pendant plusieurs semaines, il ne mangea que des champignons crus avec du pain, et, de plus, il ne but que de l'eau; ceux auxquels il donnait la préférence étaient le Bolet comestible, le Bolet roux, Boletus rufus, Pers., l'Agaric champètre, l'Agaric élevé, la Clavaire coralloïde. Sous l'influence de ce régime, il sentit ses forces s'accroitre.

Willdenow aussi raconte que, durant des semaines entières, il n'a vécu que de champignons et de pain grossier, et que cependant il a joui d'une excellente santé.

On cite l'exemple d'un montagnard de la Thuringe qui, pendant trente ans, n'a vécu que de champignons, et qui est mort centenaire.

Les champignons ont été appelés quelquefois la manne des pauvres, et cela avec juste raison; car ils poussent si vite, et quelquefois si abondamment, que, comme autrefois la manne des Hébreux, il semble qu'ils soient tombés du ciel en une nuit.

Nous avons vu qu'à Madagascar on les mange à peu près sans choix.

En Cochinchine, on fait un très-grand usage de l'Hel- 


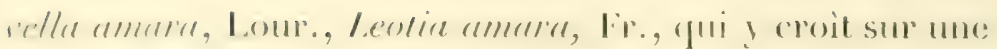
espece de melalengure. Co champignom est tris-amer, mais l'eau lui fait perdre son amertume (1.). Commerson dit que l'on trouve, à l'lle de France et à l'lle Bourbon, un champignon qui vient sur le tronc des palmiers appelés Areca, lorsque cet arbre pourrit sur la terre. Ce champignon donne un goùt agréable de Morille à la soupe et aux ragoùts. Lamarck l'appelle Agaricus lacinialus (2).

Jivers champignons qui naissent sous terre sont mème d'un usage fréquent dans beaucoup de pays. Sans parler de la truffe et autres tubéracés, si généralement recherchés en Europe, je mentionnerai le Mrlitta australis, Berk., champignon hypogée, - sorte de Rhizopogon, — devenu le pain naturel des Anglais, native bread, dans l'Australie et la Tasmanie (3).

En Chine, on mange une espèce de Pachyma, probablement le Pachyma hoelen, Fr, champignon souterrain ayant la forme d'un Sclerotium (4). Les habitants des îles Aleutiennes font usage, comme aliment, du Bromicolla aleulica, Eichwald., autre champignon souterrain qui vient assez abondamment dans ces îles, et qui probablement est un Sclerotium ou le mycélium d'une Clavaire (5).

L'usage des champignons est, on le voit, répandu partout. Les peuples qui vivent tout à fait à l'état sauvage sont les seuls qui dédaignent l'usage de ces plantes, lesquelles pourtant seraient pour eux une ressource certaine quand les produits de la chasse, ceux de la pêche et les fruits dont ils se nourrissent viennent à leur faire défaut, ce qui arrive trop fréquemment.

(1) Journ. de Pharmacie, année 1833.

(2) I.umal'k, Dictionn., t. IV, p. 12't.

(i) B.rhul., Annal. hist. nat., 18:3!!. 32ti, t. VII, f. -2.

(4) Percira, Matière médic.

(i) Eichuslil. Floin. 
La Terre de Feu est peut-ètre l'unique contrée du monde où les populations sauvages fassent un usage habituel d'un champignon comme nourriture : c'est le Cyttaria Darwinii, genre nouveau, voisin du Bulgaria, et décrit par Berkeley. Ce champignon, de forme globuleuse, d'un jaune brillant, pousse en grande abondance sous les hètres. Arrivé à sa maturité, il est recueilli en quantité par les femmes et les enfants. Il se mange cru. Heureux les habitants de cette terre stérile de pouvoir mêler quelquefois une substance végétale à leur nourriture!

Le Cyttaria Darwinii vient aussi au Chili (I).

(1) Mrs Hussey, t. II. 


\section{CHAPTRE III.}

DE LI PREPARATION CLLIMAIRE DES CIIIUPIR, GOYT.

On peut dire qu'il n'est pas de sorte d'apprêt culinaire que l'on n'ait fait subir aux champignons, tant sont nombreuses dans tous les pays les diverses manières de les préparer pour le service de la table.

L'assaisonnement et la cuisson ne sont pas cependant absolument indispensables a l'usage de toutes ces plantes. Il en est quelques-unes que l'on peut manger crues et sans aucun apprêt, entre autres le champignon de couche et ses variétés, l'Agaric élevé, Ag. procerus, Scop., l'Agaric volemus, l'Agaric cyathiforme, Ag. suavis, Pers., l'Agaric piedfu, l'Agaric virginal, le Bolet comestible, le Clavaire coralloide.

En Lorraine, les enfants ne mangent jamais l'Agaric volemus, qu'ils appellent Viau, autrement que cru. Pour moi, je l'ai toujours mangé ainsi au milieu des bois, au moment mème où je venais de le cueillir, et constamment je lui ai trouvé un goùt excellent. Je suis persuadé que ce champigıon ne peut que perdre par la préparation culinaire.

Le véritable moyen de prévenir toute méprise dans l'usage des champignons, et par conséquent tout accident fàcheux, serait, sans aucun doute, de les manger tels que 
la nature nous les présente. En effet, les espèces insalubres ayant presque toujours dans leur état naturel un goût désagréable, et souvent une odeur repoussante qui nous avertissent de nous en défier, ces espèces rebuteraient bientôt si l'on voulait les manger crues. C'est l'art seul des cuisiniers qui cause les empoisonnements; cependant, comme cet art sert à multiplier et à varier nos jouissances, on y aura toujours recours. Il est d'ailleurs des champignons auxquels la cuisson est nécessaire pour qu'on puisse les manger avec plaisir ou sans inconvénient; tels sont l'Agaric rougeâtre, l'Agaric engainé, l'Agaric virescent, le Bolet rude, le Bolet orangé, le Mérule chanterelle et quelques autres. Il serait même impossible de manger crues certaines espèces, telles que l'Agaric poivré, l'Agaric controverse, dont la saveur est tellement âcre que la cuisson même ne peut pas la détruire entièrement.

Règle générale, il ne faut jamais faire usage de champignons que l'on ne connaît pas parfaitement. Pour peu donc que l'on ait le moindre doute sur la nature et la qualité d'une espèce, on devra s'en abstenir, ou du moins ne procéder à sa cuisson et à son assaisonnement qu'après l'avoir coupée par tranches et l'avoir laissée tremper pendant plusieurs heures dans de l'eau à laquelle on aura ajouté un peu de vinaigre ou de sel commun; encore après cela sera-t-il prudent de les blanchir.

Il faut faire choix de champignons qui soient sains, vi. goureux et jeunes, car la plupart, lorsqu'ils sont vieux, deviennent coriaces, et, par conséquent, de digestion difcile. C'est pour avoir usé de champignons trop mùrs ou près de se décomposer que souvent des personnes ont été incommodées et se sont crues empoisonnées par des espèces réellement salubres. Mais, s'il est prudent de rejeter tous les individus qui se fanent de vétusté, il ne l'est pas 
moins de s'alsstenir de ceux qui sont déjà la proie des vers ou des larves d'insectes, car rien ne prouve que ces larves ne soient pas nuisibles, et d'ailleurs les champignons qui en contiennent ne sauraient être mangés qu'avec répugnance.

Si les champignons sont propres et tout à fait intacts, on peut se dispenser de les baigner ou de les laver; mais s'ils sont salis par de la terre ou du sable, il faut les laver à grande eau, ensuite les essuyer et mème les presser.

On peut faire cuire certains champignons entiers et sans en rien retrancher, tels que l'Oreille de chardon, $A g$. Eryngii, Dec., l'Agaric virginal, Ag. (Hygrophorus) virgineus, Jacq., l'Hydne sinué, la Chanterelle et les Clavaires.

On rejette le stipe ou pied des champignons, quand ce pied est coriace comme celui de l'Agaric élevé, de l'Agaric piedfu, du Bolet scabre. On enlève la pellicule du chapeau des Agarics qui se laissent peler; on enlève de mème les tubes des Bolets, ce que quelques personnes appellent le foin. Cette dernière précaution est utile lorsqu'ils sont avancés en âge.

La saveur acerbe de quelques espèces se dissipe entièrement par la cuisson; mais d'autres espèces conservent en grande partie cette saveur. La consistance ferme de plusieurs champignons se dissipe aussi par la cuisson, tandis que d'autres conservent leur dureté malgré une cuisson prolongée; la Chanterelle, le Polyporus frondosus, Fr., le $P$. intrbaceus, Fr., sont de ce nombre.

Beaucoup de champignons préparés par une main habile sont véritablement un aliment exquis et apprécié partout. Les plus recherchés sont: l'Oronge vraie, l'Agaric rougeåtre, l'Agaric ovoïde, le Mousseron du printemps, $A g$. albellus, Dec., le Mousseron d'automne, Ag. Prunulus, Scop., l'Oreille de chardon, le champignon de couche, 
l'Agaric virescent, l'Agaric cyanoxanthe, les Bolets comestible, scabre, orangé et bronzé.

Certaines espèces manquent de parfum ou sont d'une nature trop ferme pour être jamais un aliment délicat; mais elles servent utilement à la nourriture des hommes forts et robustes, et surtout des habitants de la campagne, telles que les Clavaires, les Hydnes, les Pezizes, l'Agaric piedfu, la Chanterelle.

I)ivers champignons, bien que comestibles, sont de trop petite taille ou ont trop peu de chair pour pouvoir être mangés en quantité ; aussi ne les emploie-t-on guère que comme assaisonnement. Je citerai parmi ceux-ci l'Agaric alliacé, l'Agaric odorant, l'Agaric esculent, le faux Mousseron, $\boldsymbol{A g}$. (Marasmius) Oreades, Bolt.Ce dernier est néanmoins très-recherché en Angleterre.

Il est de ces plantes qui se prètent à toutes sortes de préparations culinaires; tels sont les champignons de couche, les Mousserons, le Bolet comestible, etc. Il en est d'autres auxquelles tels ou tels procédés paraissent mieux convenir. On conçoit que les modes de préparation ne peuvent pas être les mèmes pour toutes les espèces, puisqu'elles different de consistance, de nature, de goût, etc.

En général, les champignons n'exigent pas une cuisson très-longue; moins d'une demi-heure suffit à la plupart. Les Polypores et les Chanterelles exigent un temps beaucoup plus prolongé.

N'étant, je l'avoue, nullement versé dans l'art culinaire, j’ai dû puiser un peu à droite et à gauche, dans les livres qui traitent de cet art, les formules de préparation que je donne ici. J'ai choisi celles qui m'ont paru les plus simples et le plus généralement employées, laissant de còté les préparations dans lesquelles le raffinement et le luxe des Vatel et des Carème prédomine, et qui, par conséquent, ne sont 
pas a la portée de toutes les bourses. Je dois dire que j'ai puise surtout dans les ourrages de Roques et de Paulet. Les recettes culinaires que je donne sont variées, et elles ont dii l'itre, car, si les champignons citaient constamment préparés de la mème façon, ils finiraient par inspirer cette satiété dont se plaıgnait, dans les contes de La Fontaine, ce serviteur anquel son maitre faisait manger tous les jours du pàté d'anguilles.

Quelques personnes pourront s'étonner de voir que, dans un ouvrage scientifique, je me sois permis tant de détails sur les diverses manières de préparer les champignons. L'étude de ces plantes n'ayant en définitive pour objet, aux yeux de beaucoup de personnes, que leur emploi alimentaire, j’ai cru utile de donner ces nombreuses formules de préparation. Sans doute j'aurais pu renvoyer le lecteur aux ouvrages qui traitent plus particulierement de l'art culinaire; mais tout le monde n'a pas entre ses mains le Cuisinier impérial ni même la Cuisinière bourgeoise; beaucoup de personnes ne savent mème pas que ces livres existent. Je crains seulement, comme chaque jour, pour ainsi dire, les modes changent, même en préparations alimentaires, qu'on ne trouve un peu surannées queldues-unes de celles que jai données.

\section{PREPUR ITIOSS CILINIRES DES CHIUPICVOTS.}

Champignons sur le gril. -- La manière la plus simple de préparer les champignons, et la plus communément usitée à la campagne et chez les pauvres, consiste à les faire cuire entiers sur le gril et à les assaisonner d'un peu de beurre frais, de sel et de poivre.

Champignons aux fines herbes. - Une autre manière, qui u'est guère moins simple, ni moins usitée, consiste à les 
assaisonner de beurre ou d'huile, de sel, de poivre et de fines herbes, persil, ciboule, échalote, ainsi que leurs pieds hachés, et à les faire cuire sur le plat ou dans une tourtière que l'on couvre d'un peu de braise ou de cendres chaudes. On y ajoute quelquefois de la chapelure.

Une demi-heure au plus suffit à leur cuisson.

IINIERE DE PRÉP IRER IE CHIUPIGTOY DE COICHE ET I I PIIPART DES AGARICS.

Champignons en fricassée de poulet. - "Après avoir épluché et coupé les champignons, s'ils sont trop grands, on les lave à l'eau froide, et on les passe à l'eau bouillante, ce qu'on appelle blanchir : celix les ramollit un peu, et leur ôte une partie de leur parfum, trop fort ou trop âcre pour certaines personmes. Pour leur donner de la fermeté, on les remet dans l'eau froide, et on les essuie bien; après quoi on a un morceau de beurre fin qu'on fait fondre dans une casserole sur le feu; on y ajoute les champignons qu'on mèle bien avec le beurre, pour qu'ils s'en imbibent, ce qu'on appelle faire revenir, en terme de cuisine. Les uns alors (et ce n'est point la meilleure méthode ou la plus saine) y ajoutent une pincée de farine qu'ils font cuire avec les champignons, après quoi ils les mouillent soit avec de l'eau tiède, soit avec du bouillon du pot; d'autres les font cuire de mème, mais sans addition de farine, et en les assaisomnant tout simplement avec le persil, le poivre, le sel, et quelquefois une pincée des quatre épices; lorsqu'on doit retirer le persil, on le met en bouquet. Quand ils sont cuits, on fait, en les retirant tout bouillants et hors du feu, une liaison avec des jaunes d'œufs délayés dans l'eau, ou bien avec de la crème, et on les sert. La sauce alors est rarement blanche; pour la blanchir, on ajoute à la liaison 
une ou deux tranches de citron sans écorce; c'est la maniere la plus usitée à Paris. "(Paulet.)

Champignons à la bourgeoise. - Nettoyez deux cent soixante-quinze grammes de champignons; coupez-les en petites tranches; mettez ensuite quatre-vingt-dix grammes de beurre et trente grammes d'huile dans une tourtière; faites frire doucement les champignons; sautez-les, ajoutez-y un peu de sel et de poivre, et, après dix minutes, saupoudrez-les d'une pincée de persil trituré avec deux gousses d'ail ; servez-les ensuite avec du citron, à part.

Champignons frits ou en beignets. - Salez des deux còtés des chapeaux de champignons bien nettoyés; après cinq minutes, essuyez-les avec une serviette; cela fait, coupez-les en deux, roulez-les dans la farine et jettez-les dans la friture bouillante. Lorsqu'ils auront pris une belle couleur, égouttez-les et apportez-les sur un plat avec une serviette, après les avoir garnis de persil frit non haché.

Dans le pays de Liége et dans le Luxembourg, les paysans font un usage fréquent de ces beignets.

Croquettes de Champignons. - Coupez en forme de petits cubes six chapeaux de champignons bien nettoyés, que vous ferez frire doucement dans une casserole avec soixante grammes de beurre pendant trois minutes; versez dessus trois verres de béchamelle maigre; ajoutez-y trois jaunes d'oufs cuits durs et hachés, un gramme de noix muscade, un peu de sel et une petite poignée de fromage râpé; faites bouillir doucement le tout pendant huit minutes, le remuant de temps en temps. Ensuite, retirez la casserole du feu; ajoutez-y deux jaunes d'œufs crus et versez le tout dans un plat pour le faire refroidir. Faites-en ensuite des boulettes, et terminez comme il est dit des autres croquettes.

Croûte aux Champignons. - Épluchez des champignons, 
fendez en quatre les plus gros, et les moyens en deux; mettez-les dans une casserole avec un morceau de beurre, un bouquet de persil et ciboule, passez le tout au feu; ajoutez un morceau de beurre manié de farine et mouillez avec du bouillon ; assaisonnez de poivre et de muscade râpée ; peu de sel, à cause du bouillon qui est salé; faites bouillir et ensuite cuire à petit feu; au moment de servir, retirez le bouquet et mettez une liaison de jaunes d'œufs délayés avec de la crème; mettez dans le milieu de votre plat la croûte d'un petit pain chapelé, dont vous aurez òté la mie et que vous avez mise un instant sur le gril, après l'avoir beurrée des deux còtés; versez votre ragoùt de champignons sur cette croûte.

Croûte aux Champignons à la Provençale. - "Prenez une certaine quantité de champignons et lavez-les sans les peler; mettez quelques cuillerées de bonne huile dans une poêle et faites-les cuire ainsi sur un fourneau très-vif pendant sept à huit minutes; ajoutez-y pendant qu'ils cuisent du sel, du poivre et de la muscade, des échalotes et du persil, le tout haché; versez-les dans le plat et sur une croûte de pain beurrée et séchée sur le gril. » (Le Parfail (uisinier.)

Ragoût de Champignons. - "Passez les champignons bien épluchés au beurre, avec un bouquet de persil et ciboule, mettez ensuite un peu de farine; mêlez-la et mouillez avec de bon bouillon, autant de vin, et du jus, si vous en avez (I). Faites cuire pendant une bonne heure; liez la sauce avec du jus ou avec un peu de beurre manié de farine. "(Albert.)

Purée de Champignons. - "Faites bouillir des champi-

(1) Ce que les cuisiniers appellent jus est une sorte d'extrait de suc de viande : le bouillon peut remplacer le jus. 
guons bien lavés et épluchés; faites-les égoutter, ensuite hachez-les bien fin, attendu qu'on ne peut pas les passer, et pressez-les dans un linge blanc. Passez vos champignons hachés dans une casserole avec un morceau de beurre et le jus d'un citron. Lorsque le beurre sera en huile, mouillez avec du jus blond (jus que l'on fait avec des viandes blanches, et qu'on ne laisse pas colorer), et autant de bouillon; faites réduire jusqu'à ce que la purée ait acquis une bonne consistance. Vorez si elle est assez assaisonnée. „ (Albert.)

Gufs aux Champignons. - «Pour les préparer, il suffit, lorsqu'ils sont suffisamment cuits, comme on vient de l'indiquer, de les presser à travers une étamine, pour en extraire le jus qu'on bat avec des oufs (sur une chopine de jus, il faut cinq œufs dont on a òté deux blancs); on passe de nouveau à l'étamine, et on les fait prendre au bainmarie dans de petits pots. Si l'on veut les préparer au maigre, on met du lait en place de bouillon lorsqu'on les les fait cuire, et on observe les proportions indiquées. ” (Paulet.)

Tourte aux Champignons. - " Pour la faire, on commence par couper du beurre par tranches dont on couvre le fond d'une tourtière; sur ce beurre, on met une couche de mie de pain bien fine, et sur cette mie de pain une autre couche de champignons dont on a òté la peau et les tiges; on couvre ces champignons de beurre coupé de mème par iranches; on ajoute du poivre, du sel et des fines herbes, comme persil, etc., et de la mie de pain dont on fait une autre couche un peu épaisse, sur laquelle on fait un second lit de champignons semblable au premier, et qu'on recouvre encore de beurre, de mie de pain, de fines herbes, etc. On fait jusqu'à trois couches ou lits, placés alternativement entre ceux de beurre et de mie de pain, etc., de manière 
que les champignons soient placés immédiatement sur un lit de mie de pain et sous une couche de beurre, et que le tout soit recouvert d'une couche de mie de pain trèsépaisse (de l'épaisseur du doigt environ). On convre la tourtière de son couvercle ou four de campagne, on met le feu dessus et dessous, et on fait cuire; c'est l'affaire d'une heure. La tourte cuite, on la sert dans la tourtière. Cette manière est principalement usitée dans le Bourbonnais. n (Paulet.)

On fait entrer les champignons de couche et la plupart des autres Agarics dans la préparation des salmis, des gibelottes, des vols-au-vent; on en fait des salades, des potages; on les mêle aux viandes; on les cuit à l'eau, au lait, au vin, à l'huile, etc.

On en fait des beignets, en les jetant dans l'huile ou le beurre chauds, après les avoir fait bouillir à l'eau et les avoir roulés dans la farine.

Champignons à la crème. - Pelez et nettoyez bien dix beaux chapeaux de champignons, mettez-les ensuite entiers dans un poèlon avec deux verres de crème fraîche, une pincée de sel, une moitié d'échalote et deux feuilles de persil liées; faites-les bouillir doucement pendant une demi-heure; mettez-les ensuite sécher sur un plat; cela fait, délayez dans une terrine trois jaunes d'œufs avec trente grammes de beurre, un gramme de noix muscade râpée et une pincée de persil haché; amalgamez le tout dans la crème, en l'agitant, sans la laisser bouillir; vous la versez ensuite sur les chapeaux. C'est un plat délicieux.

Champignons en matelotte. - Cette manière consiste à achever de cuire, dans la sauce d'une matelote, les champignons déjà passés ou revenus dans le beurre, manière qui se rapproche le plus de celle des anciens, qui les faisaient cuire dans l'huile et le vin. 
Champignons à l'Anglaise. - Enlevez la pellicule a six gros chapuan de champignons blancs; incisez-les légerement avec la pointe d'un couteau, faites-les ensuite macérer pendant une petite heure dans une terrine avec de l'huile, le jus d'un citron ou du verjus, du sel, un gramme et demi de poivre, un petit bouquet de persil. Vous les saupoudrez ensuite légèrement de pain et les mettez sur le gril avec un feu très-lent, les retournant plusieurs fois; après dix-huit minutes environ de cuisson; servez-les en couronne, en versant dessus une sauce chaude à la maitred'hòtel.

Champignons á l'Italienne. - Pelez un kilogramme et demi de beaux champignons blancs; lavez-les avec de l'eau tiède; essuyez-les ensuite et coupez-les en tranches minces; cela fait, mettez dans une casserole cent vingt grammes de beurre, trente-deux grammes d'huile d'olives, deux anchois nettoyés de leurs écailles et que vous triturerez avec deux gousses d'ail ou d'échalote; faites-les frire un instant; jetez-y les champignons avec le jus d'un citron, du sel, un gramme de poivre et un demi-verre de bouillon. Couvrez la casserole, faites-la bouillir à petit feu en mèlant de temps en temps les champignons avec une cuiller de bois, et après un petit quart d'heure d'ébullition, ajoutez-y une pincée de persil avec une feuille de menthe broyée; saupoudrez le tout de sel.

Servez-les ensuite sur un plat, entourés de quelques croûtons frits dans du beurre et glacés.

Champignons à la Languedocienne. - $~$ Prenez de gros champignons de couche, coupez les queues très-court et enlevez une petite peau blanche qui les recouvre; mettez-les sur une tourtière, la queue en haut, avec un peu d'huile; saupoudrez-les de sel fin, gros poivre et muscade râpée, persil et ciboule hachés; arrosez-les d'un peu 
d'huile; ne les retournez pas; quand ils sont cuits, dressez-les sur un plat. Ils doivent ètre imbibés d'huile. » (Albert.)

Champignons a la Lombarde. - Nettoyez six gros chapeaux de champignons; coupez-les en tranches minces dans leur largeur; plongez-les dans un ceuf battu, ensuite roulez-les dans la farine, puis mettez-les dans une tourtière sur cent vingt grammes de beurre fondu. Placez la tourtière sur un feu modéré, et, aussitòt qu'ils seront teints d'une couleur blonde d'un còté, retournez-les de l'autre; salez-les, et, après deux minutes, ajoutez-y une pincée de persil trituré avec une demi-gousse d'ail. Faites-les sauter et servez-les sur un plat en couronne, après les avoir arrosés d'un peu de leur graisse, et servant un citron à part.

Moutarde aux Champignons. -- On prépare en Italie, suivant Sterbeeck, sous le nom de moutarde aux champignons, une sorte d'assaisonnement dont l'usage est assez répandu.

Pour faire cette moutarde, dit Paulet, on prend des amandes pelées qu'on pile dans un mortier avec un peu d'eau; on y ajoute de l'ail, du gros poivre concassé, de l'huile d'olive et du jus de citron; on donne au tout la consistance de la moutarde, et on la sert avec les champignons cuits.

MANIÈRE D'APPRÊTER L'ORONGE.

" La meilleure manière d'apprèter l'Oronge consiste, après l'avoir dépouillée de sa peau et enlevé sa tige, à la faire cuire sur un plat, ou la lèchefrite ou autre vaisseau, sa cavité garnie de fines herbes, de mie de pain, d'ail, de poivre, de sel, et des hachures de sa tige, le tout arrosé 
d'huile. C'est ce qu'on appelle a la barigoule ou a la proven-

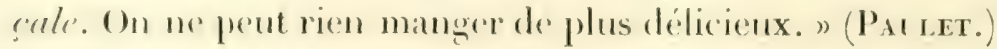

Il faut manger les Oronges fraiches, car elles ne se gardent pals au-delit de un ou denx jours.

Oronges á la Chapsal. - Ayant supprimé la pellicule du chapeaul de six Oronges, et les ayant bien nettoyées, mette\%-les entieres dans une tourtiere, dans laquelle vous aurez mis un bon demi-verre d'huile, en semant dessus une trituration de deux anchois bien nettoyés, une pincée de persil, et une gousse d'ail avec un peu de sel et de poivre; versant ensuite dans la tourtière une demi-bouteille de vin blanc. Couvrez-les avec une feuille de papier arrondie et graissée d'huile. Mettez-les ensuite dans un four chaud pendant vingt minutes environ, ou bien avec de la cendre rouge sous la tourtière et sur le couvercle. Disposez-les en couronne sur un plat, enlevez l'excès de graisse et ajoutez le jus de la moitié d'un citron; le tout bien réduit, vous couvrez les champignons et les servez fumants.

HIYITE IOPPRITER IOREHLE IOE CHIRDOS.

"Les Provençaux et les Languedociens font beaucoup de cas de ce champignon; ils le mangent apprèté avec de l'huile, du sel, du poivre, du persil et de l'ail, qui est l'assaisonnement ordinaire des champignons, et qui a mème donné son nom à deux sauces semblables, qu'on y appelle à la barigoule, à la baligoule; mais cette plante est encore meilleure en fricassée de poulet, et plus délicate que le champignon de couche. 11 n'y a rien à òter dans celle dont il est question. Tournefort et Garides, entre autres, en ont fait l'éloge. n (Paulet.) 
MANILRE D APPRÈTER LES MOUSSEROYS.

Ragoût de Mousserons. - "Après avoir épluché et lavé vos Mousserons, passez-les au lard fondu avec bouquet, sel et poivre; mouillez de jus de veau et faites mitonner; dégraissez ensuite et liez d'un coulis de veau et de jambon. »

Groute aux Mousserons. - « Vous faites un ragoût de mouton; vous mettez une croûte bien sèche et bien chapelée au fond du plat; servez votre ragoût dessus. On peut préparer d'une autre manière cette croûte aux Mousserons; à cet effet, on prend un pain bien chapelé; on en coupe les croûtes de la grandeur d'un écu; on les fait tremper dans du lait et frire de belle couleur; après les avoir égouttées, on les dresse dans un plat et on verse par dessus le ragoût de Mousserons.

“ On peut aussi apprèter les Mousserons à la crème, en faire des beignets, etc.

“ Un habile cuisinier saura préparer un potage au gras ou au maigre auquel notre champignon communiquera tout son parfum.

"Quand on mange le Mousseron, venant de le cueillir, la meilleure manière et la plus simple de le préparer consiste à le laver à l'eau froide et à le mettre à la casserole avec du beurre frais ou de l'huile d'olive, du poivre, du sel et un jus de citron. „ (Nouket et Dassier.)

La poudre de Mousserons desséchés s'emploie pour assaisonner tous les ragouts.

MANIÈRE D'APPRÊTER LES RUSSLLES.

Les Russules sont très-recherchées en Lorraine où elles sont connues sous les noms de Franc-vert, Fayssé, Charbon- 
nier; colles se preparent en genéral a la maniere du champiEnon de couche.

Dans le haut Languedoc, on fait cuire l'Agaric virescent, appelé Verdette dans le Midi, sur le gril, avec de fines herbes et de l'huile. Dans le Nord on le fait cuire avec du beurre, du poivre, du sel et quelquefois un peu de bouillon. On en fait aussi un hachis avec de fines herbes et un peu de lard; on le passe au beurre et on l'introduit dans une omelette.

Les Russules desséchées servent à faire des purées ou des coulis, qui donnent une sorte de relief au ròti et au bouilli de la veille.

IIVIRE II IPPRETER LES LICTMRES.

Les enfants, en Lorraine, mangent presque toujours cru l'Agarieus V olemus, qu'ils appellent Viau. En Allemagne, on le mange assaisonné avec du beurre et du persil, ou cuit avec de la crème ou du beurre, et assaisonné de sel et de fines herbes.

L'Agaric poivré et l'Agaric controverse sont, malgré leur saveur âcre, mangés communément par les charbonniers et les bucherons. Ils se contentent de les cuire sur le gril ou sur les charbons, et d'y ajouter du sel et du poivre. La cuisson détruit en grande partie l'àcreté de ces plantes, mais elle n'en fait jamais un aliment agréable.

Plenck dit de l'Agaric délicieux, qu'il est excellent dans les ragoùts. En Allemagne, on en fait des provisions pour l'hiver, et on le conserve confit dans de la saumure ou dans le vinaigre.

Dans certains pays on fait sécher les Lactaires après les avoir coupés par tranches; dans d'autres, on les conserve 
dans des tonneaux avec du vinaigre et du sel, comme le précédent.

MANIL̀RE D'APPRÊTER LES CHANTERELLES.

“ Le laboureur, les hommes qui vivent au milieu des champs, pourront apprèter simplement les Chanterelles avec du beurre, de l'huile ou de la graisse, du poivre ou du sel. En y ajoutant des tranches de pain grillé, ils auront un plat suffisant pour une famille entière. On peut aussi incorporer ces champignons dans une omelette après les avoir passés à l'eau bouillante, ou bien les méler avec des oufs brouillés. ") (Roques.)

Ce champignon demande à être cuit longtemps et lentement, à l'étuvée; il est bien meilleur si on l'a d'abord laissé tremper pendant quelques heures dans du lait. Il ne faut pas, dans la cuisson, élever trop haut la température, ce qui le rendrait coriace et dissiperait son arome.

Autre procédé. - "Après avoir lavé et épluché les Chanterelles, on les passe à l'eau bouillante : ensuite on les fait cuire avec du beurre frais, un peu d'huile d'olives, de l'estragon, du poivre, du sel et un peu de zeste de citron. Lorsqu'elles sont cuites, on les laisse mijoter sur un feu doux pendant quinze ou vingt minutes, et on les arrose de temps en temps avec du bouillon ou de la crème, ou bien on les lie avec des jaunes d'œuf. ") (Rogurs.)

“ On peut également préparer les Chanterelles avec de la volaille, des tendons de veau ou toute autre viande, en ajoutant à l'assaisonnement ordinaire un peu de jus de citron. »

Dans nos départements du sud, on les marie avec des cuisses d'oie confites.

Quelques mycophiles préfèrent la Chanterelle réduite 
(21) purre et serve sous mone noix de veau ou sous un filet de lexuf. Cette purée s'allie à merveille alsec la tomate ansatisoméne de jus de citron et de fines herbes. Si vons employez l'estragon, il est mieux qu'il soit fraichement cueilli et non conservé.

Desséchées, les Chanterelles servent d'assaisonnement aux ragoùts.

IUNIRE DE PREPARER IES CEPS OI BOLETS

Toutes les préparations auxquelles on soumet le champignon de couche conviennent aux Bolets.

On peut, lorsque ces plantes sont fraichement cueillies, les mettre en ragoùt, en tourte, en fricassée de poulet, etc. On est dans l'usage de les passer à l'eau bouillante, puis de les essuyer, après quoi on les fricasse. Quelques personnes se contentent de les faire revenir dans du beurre; elles ajoutent ensuite du sel et du poivre. D'autres les font d'abord cuire à l'eau, puis les mettent dans une sauce faite avec de l'huile, de l'ail, de l'échalote et du persil que l'on chauffe sur le plat.

Dans les fermes des Basses-Pyrénées, les maitres, les domestiques et les ouvriers se régalent avec des Ceps cuits au four sur un plat, et assaisonnés d'huile, d'ail et de persil. C'est quelquefois leur principal repas.

Il se fait un grand commerce de ces champignons dans nos départements méridionaux, et surtout à Bordeaux.

Ceps aux fines herbes. - "Après avoir épluché les Ceps, on les laisse mariner pendant quelque temps dans l'huile avec du poivre et du sel. Ensuite on les fait cuire sur le plat ou dans la tourtière, avec du beurre frais, des ciboules, des échalotes, du persil et de l'estragon hachés menu, du gros poivre, du sel et de la chapelure de pain. 
"A la campagne, on les mange cuits simplement sur le gril et assaisonnés de beurre, de sel et de poivre, ou bien on les fait frire dans la poèle avec du beurre, du saindoux ou de l'huile. C'est un mets populaire dans les cantons voisins des grandes forêts. "

Potage aux Ceps. - "Coupez par tranches une demidouzaine de Ceps épluchés avec soin; mettez-les dans une casserole avec du sel, du gros poivre, un peu de muscade, une livre de maigre jambon éminci, une demi-livre de croûte de pain et quatre onces de beurre frais. Faites cuire le tout sur un feu vif pendant une heure, et mouil. lez de temps en temps avec de l'excellent bouillon. Passez ensuite à travers une étamine. Remettez votre purée sur un feu doux, en ajoutant du bouillon pour l'éclaircir; laissez mijoter pendant vingt minutes, et versez le tout dans votre soupière, après y avoir mis des croùtons passés au beurre. Surtout que le potage soit chaud et d'un bon goùt.

"Dans les pays où ces champignons abondent, on les coupe par tranches, qu'on enfile et qu'on fait sécher. Ailleurs, on les passe au four ou à l'étuve, et on les conserve pour l'hiver. On en reçoit, tous les ans, ì Paris une grande quantité du département de la Gironde. Lorsqu'on veut en faire usage, on les fait revenir dans de l'eau tiède ou dans $d u$ bouillon, et on les apprète ensuite comme les Ceps nouveaux. Quelques auteurs les râpent et en font des coulis, des potages, des crèmes, etc. "(Rogues.)

Geps à la Bordelaise. - On choisit les plus jeunes individus, ou du moins ceux dont la chair est ferme, blanche, parfumée, et après en avoir retranché l'hyménium ou la partie poreuse, ainsi que le pédicule, on les fait revenir pendant quelques instants sur le gril pour en dégager l'humidité surabondante. Puis on les presse légèrement 
entre deux linges; on les essuie, et on les fait cuire avec dr. l'hule d'olives, du porsil et dre l'ail haché, du poire et du sel. On ajoute, vers la fin, un peu de jus de citron.

Autre procédé. - " On prend une partie des tiges les plus saines, et on en compose, avec de l'ail, du persil, du poivre et du sel, un hachis qu'on a fait revenir dans l'huile d'olives fraiche. Puis on ajoute les Ceps passés sur le gril, et leur cuisson se termine dans ce condiment. ")

Hâtelettes de Ceps à l'Italienne. - “ Faites revenir vos Ceps sur le gril; pressez-les dans un linge, et les coupez en quatre, six ou huit morceaux, suivant leur grosseur. Ayez autant de petites lames de lard. Enfilez tour à tour un morceau de Ceps et un morceau de lard, jusqu'à ce que vos hatelettes (brochettes) soient garnies. Assaisonnez-les avec du sel, du poivre et du persil hachés; trempez-les dans l'huile et panez-les. Faites-les cuire sur le gril, et arrosez-les de temps en temps avec l'huile qui a servì à l'assaisonnement. )' houts.

Manière de préparer le Bolet foie-de-bœuf(Fistulina hepatica.) - Ce champignon, dont la chair est épaisse, veinée et rougeâtre, est quelquefois assez volumineux pour qu'un seul pied puisse fournir amplement de quoi faire un bon repas. Sans odeur sensible, il a un goùt vineux, un peu acide. On recherche, pour l'usage, les jeunes individus, car, avec l'âge, sa surface devient visqueuse, sa chair se durcit et tend mème à passer à l'état ligneux. Trop avancée d'ailleurs, elle altère et échauffe un peu.

Il. y a, dit Paulet, deux principales manières de manger le Bolet foie-de-bœuf : ou cuit sous la cendre, et coupé ensuite par tranches avec une liaison; ou bien apprêté en fricassée de poulet; c'est-à-dire, qu'après l'avoir lavé, épluché et bien essuyé, on le fait revenir à l'eau bouillante, et on le fait cuire dans le beurre avec un peu de persil, de 
ciboule, poivre, sel, etc., et on fait une liaison avec les jaunes d'œufs. L'assaisonnement un peu piquant est toujours nécessaire à cause de sa viscosité, lorsqu'il est un peu avancé. On a éprouvé que le vinaigre se marie mal avec cette espèce, et gâte sa sauce. Ce champignon, qui a une saveur de truffe, altère, échauffe mème un peu, lorsqu'on en mange trop, mais ne nuit jamais. Lorsqu'il n'est que naissant, il ne produit pas cet effet.

On le mange également cuit sous la cendre, coupé par tranches, en $y$ ajoutant une liaison.

A Vienne, en Autriche, et dans d'autres parties de l'Allemagne, on coupe le Bolet foie-de-bouf par tranches minces et on le mange cru en guise de salade, avec la chicorée et la mâche. Si on y ajoute, dit Berkeley, quelque peu de jeunes truffes, on a un mets excellent.

$\mathbf{M}^{\text {rs }}$ Hussey dit que pour faire un bon plat, le Bolet foie-de-bøuf, coupé menu, doit ètre mélangé avec de la viande de veau ou de poulet, et assaisonné avec du jus de citron et du poivre de Cayenne : on le cuit délicatement à l'étuvée ou bien sur le gril.

On le cuit de mème avec de la viande de veau, en y ajoutant de la crème et du jus de citron.

On retire de cette plante un suc abondant, de couleur brune, lequel est excellent avec les biftecks et d'autres viandes grillées.

\section{MANIÈRE D'APPRÊTER LES HYDNES.}

L'Hydne sinué est de très-bonne qualité. La cuisson dans l'eau, dit Paulet, parait nécessaire pour le ramollir, étant de substance un peu ferme. Il n'y a rien à ôter pour préparer ces champignons. On les coupe par morceaux; on les fait revenir un peu dans l'eau bouillante, et on les 
ficisse avec du beure et du persil, du poivre, du sel, ete. Hais l'expérience m'a prouvé qu'après les avoir passés à l'eau houilante, la meilleure maniere de les appriter, c'est de les faire cuire, sans les essuyer, à la graisse et au bouillon : ils sont meilleurs qu'avec le beurre, avec lequel ils sont toujours un peu coriaces. Élant très- peu aqueux par eux-mèmes, ils ont besoin d'un véhicule liquide un peu abondant.

Selon Berkeley, la meilleure manière peut-ètre de préparer l'Hydne sinué est, après l'avoir plongé dans l'eau chaude, de le faire cuire lentement à l'étuvée avec une petite quantité de jus de veau auquel on ajoute un peu de sel, de poivre de Cayenne et un brin de macis. Quand le champignon est tendre, une petite quantité de persil, de cerfeuil, avec un peu d'ail, est ajoutée en mème temps que de la bonne crème. Le tout est servi chaud avec des tranches de pain frit.

On mange aussi ce champignon cuit sur le gril avec de fines herbes, à la manière des Agarics.

L'Hydne hérisson s'accommode comme le champignon de couche, dont il a le goût.

\section{MANIERE D'APPRÊTER LES CLAVAIRES.}

"Après les avoir lavées et épluchées, c'est-à-dire ôté la terre du bas, on les fait ramollir sur un feu doux dans une casserole, avec un morceau de beurre; quand elles sont ramollies, on jette l'eau qu'elles ont rendue, et on les saupoudre légèrement de farine; on les mouille avec du bouillon, et on fait la liaison avec les jaunes d'œufs, quand elles sont cuites; c'est l'affaire d'une heure.

"I'autres les font cuire, après les avoir epluchées et lavées, avec du lard qu'on met dessus et dessous, et du 
bouillon, en ajoutant sel, gros poivre, un morceau de jambon et un peu de persil. Il faut environ une heure de cuisson ; après cela, on les met dans une sauce faite avec du coulis ou du jus de viande, ou en fricassée de poulet, sans les remettre sur le feu. On a soin de couvrir la casserole avec du papier, sur lequel on met le couvercle; c'est le moyen de retenir leur parfum, de les conserver blanches, et d'empêcher la sauce de s'épaissir trop.

“ On coufit encore les Barbes-de-chèvre (les Clavaires) au vinaigre, de la mème manière que les cornichons et la perce-pierre, Crythmum maritimum, etc. Pour cela, on les blanchit d'abord, c'est-à-dire on les passe à l'eau bouillante, on les essuie et on les met dans du vinaigre. L'expérience a prouvé que cette manière de les conserver est trèsbonne. "(Paulet.)

Les grandes espèces de Clavaires demandent à ètre cuites à l'étuvée pendant au moins une heure. Ce qu'il y a de mieux, c'est d'ajouter à leur cuisson un mélange de fines herbes et de jambon auquel il est indispensable de joindre des cives, des échalotes et une petite portion d'ail.

Lorsqu'on fait cuire les petites espèces de Clavaires, elles doivent être liées en bottes, comme les asperges. C'est le plus souvent à la sauce blanche qu'on les prépare. I.es Clavaires de couleur jaune sont moins délicates que les blanches.

Ces plantes; même celles qui sont de petite taille, sont pour la plupart d'excellents articles de nourriture.

\section{MANIÈE D'APPRÉTER LES MORILLES.}

Les Morilles sont les bienvenues du printemps. De quelque manière qu'on les apprête, dit Paulet, elles sont toujours bonnes, étant moins huileuses et d'une chair moins 
compacteen ginéral que les Champignons, les Mousserons et les Truffes; elles sont aussi plus légères sur l'estomac, et n'incommodent jamais.

Pour les apprêter, on commence, après les avoir épluchées, par les laver et les battre daus plusieurs caux, d'une casserole a l'autre, pendant quelque temps, pour leur iter toute la terre qu'elles sont sujettes à contenir dans leurs cavités. Cette opération faite, on les égoutte bien en les essuyant, et on les met dans une casserole sur le feu, avec du beurre, du gros poivre, du sel, du persil, et, si l'on veut, un morceau de jambon. Une heure de cuisson leur suffit. Comme elles ne rendent pas beaucoup d'eau, on est obligé de les humecter souvent, et, pour cela, on préfère le bouillon. Lorsqu'elles sont cuites, on ajoute des jaunes d'œufs, pour faire la liaison, en les otant du feu. Il y en a qui y mettent un peu de crème. On les sert seules, ou sur une croùte de pain rissolée et imbibée de beurre.

Morilles farcies. - On préfère pour les farcir les Morilles fraiches et les blondes. On les ouvre au bout de la tige, et après les avoir bien lavées, battues et essuyées, on les garnit d'une farce fine, et on les fait cuire entre des bandes de lard. On les sert dans une sauce semblable à celle des Morilles à l'italienne.

A Vienne en Autriche, on farcit les Morilles avec de la chapelure de pain, de la viande de volaille, des sardines, des écrevisses et d'autres assaisonnements.

On mange encore ces champignons frais, grillés, ou cuits sous un four de campagne.

Morilles à l'I talienne. - « Épluchez, lavez et laissez égoutter vos Morilles; coupez-les en deux ou trois parts, suivant leur grosseur, et placez-les dans une casserole sur du feu vif, avec de l'huile d'olive, poivre, sel et un bouquet de fines herbes. Faites-les sauter quelques instants, ensuite 
y ajoutez du persil haché, de la ciboule et une pointe d'ail. Continuez la cuisson sur un feu modéré; mouillez avec un bouillon et un verre de vin blanc; et, lorsque la cuisson est parfaite, servez avec du jus de citron et des croûtons bien rissolés.

* Dans nos départements méridionaux, on apprète les Morilles à la manière des Ceps, ou bien on les mange farcies comme les aubergines. Ailleurs, on les farcit avec de la volaille, des anchois, de la chapelure de pain, quelques fines herbes, et on les fait cuire entre deux bardes de lard. On aime à les savourer dans les pâtés chaùds, la fricassée de poulet, l'émincé de volaille. Enfin, rien n'est si délicat qu'une noix de veau entourée de Morilles, convenablement assaisonnée et cuite au four dans son jus. " (Rogues.)

Morilles en hâtelettes. - Après les avoir lavées, coupées en deux, et passées au feu, pour leur faire rendre leur eau, on les met avec du beurre, de l'huile, du sel, du poivre, du persil, de la ciboule hachée et des échalotes : ainsi marinées, on les embroche avec de petites brochetes, et on les fait griller après les avoir légèrement panées. On les arrose avec leur sauce, et on les sert avec ce qui reste.

Morilles à la crème. - "Après les avoir passées sur le feu, avec du beurre, du sel, un bouquet de fines herbes et un petit morceau de sucre, on les mouille, quand elles out perdu leur eau, de bon bouillon, en ajoutant quelques pincées de farine; on y mêle ensuite de la crème et on les sert avec des croùtes de pain. " (PAulet.)

Ragoût de Morilles. - Épluchez, coupez en deux et lavez vos Morilles; égouttez-les bien en les essuyant. Ensuite, mettez-les dans une casserole avec du beurre fin. Faites sauter sur un feu assez vif, et, lorsque le beurre est fondu, exprimez-y le jus d'un citron. Donnez encore quelques tours; ajoutez ensuite sel, gros poivre et un peu de mus- 
cade ripres. Laissez cuire vos Horilles pendant une heure, et nourrissez-les par intervalles avec du bouillon ou du consommé. Lorsqu'elles sont cuites, liez-les avec des jaunes d'oufs.

Morilles aux croutons. - " Passez vos Morilles sur le feu avec du beurre, du sel, du gros poivre et un bouquet de fines herbes; faites sauter et ajoutez un peu de farine. Mouillez-les avec de l'excellent bouillon f faites-les cuire et réduire sur un feu doux. Supprimez ensuite le bouquet de fines herbes. Prenez des croutons que vous aurez fait frire d'avance dans le beurre; faites une liaison avec trois jaunes d'œufs et une pincée de sucre en poudre que vous mèlez à vos Morilles, et versez le tout sur vos croùtons. ” (Rogues.)

I.es Morilles sèches reviennent facilement dans l'eau. Séchées au four ou autrement, on les râpe ainsi que certains Ceps et les Mousserons, pour en avoir la poudre, qu'on met dans les sauces au besoin.

MIMITE D'APPRETER LES HELIELLES.

Toutes les Helvelles, dit Roques, fournissent un aliment sain et d'un goùt agréable. On n'en connait encore aucune qui soit d'une nature vénéneuse ou mème suspecte.

Après les avoir épluchées, on les lave à l'eau tiède et on les fait cuire avec du persil, du sel et un peu d'eau. On peut y ajouter, avant de les servir, du lait ou des jaunes d'ceufs.

II ne faut pas, dit M. Berkeley, les laisser tremper trop longtemps dans l'eau ni les laver plusieurs fois, ce qui détruirait leur arome délicat, bien qu'il soit toujours prudent de les diviser et de les plonger un instant dans l'eau chaude, afin de les débarrasser des limaces et autres hòtes 
qu'elles pourraient loger, et du gravier. La meilleure façon de les assaisonner est peut-ètre de les préparer avec du veau ou du poulet hachés menu et enveloppés dans des tranches de lard minces, après que, d'abord, on les a fait cuire à l'étuvée jusqu'à ce qu'elles soient tendres et convenablement assaisonnées.

Les Helvelles peuvent être préparées à peu près de la mème façon que les Morilles. Comme celles-ci, elles devraient toujours être recueillies par un temps sec, car la moindre humidité les fait moisir, et la putréfaction s'ensuit rapidement.

MANIÈRE D'APPRÊTER LES VESSE-LOUP.

Toutes les grandes espèces de Vesse-loup peuvent se manger, tant que, coupées en travers, elles restent d'un blanc pur : si elles offrent des taches jaunes ou commen. cent à prendre une couleur cendrée, elles sont trop vieilles; il faut les rejeter. Mais toutes les espèces de ce genre, dit Berkeley, ne sont certainement pas, quoique jeunes et préparées avec soin, délicates à manger, entre autres le $L y$ coperdon cælatum et le Bovistu plumbea.

On fait subir aux Vesse-loup la même préparation qu'aux champignons ordinaires.

La Vesse-loup gigantesque est un champignon excellent quand elle est cueillie-jeune et préparée convenablement.

Voici comment mistress Hussey conseille de la préparer.

Coupez-les en tranches d'un demi-pouce d'épaisseur; ayez des herbes hachées, du poivre, du sel, etc., tout prêt, comme pour une omelette ordinaire; trempez les tranches dans un jaune d'œuf, recouvrez-les des herbes et de l'assaisonnement; faites-les frire dans du beurre frais et servez-les immédiatement. Elles sont plus légères et de 
plus ficile digestion que les omelettes aux reuls, et ressemblent à des beignets de cervelle.

En Italie, on coupe la Vesse-loup gigantesque par fragments, ainsi que la Vesse-loup ciselée; on les passe à l'eau bouillante, puis on les fait frire avec de l'huile, en y ajoutant l'assaisonnement nécessaire.

Du temps de Césalpin, les Vesse-loup étaient déjà d'un usage alimentaire. On les faisait cuire, nous dit cet auteur, dans leur jus, et on y ajoutait de la menthe, ou bien on les faisait frire dans de l'huile, après les avoir coupées par tranches. C'était, ajoute-t-il, un aliment des plus agréables et qui n'offrait aucun danger.

MANIERE D'APPRÉTER LES TRIFFES.

Les grosses Truffes sont les plus estimées : celles qui viennent dans le Périgord passent pour les meilleures.

La Truffe noire, Tuber cibarium, est la plus usitée en France. La Truffe blanche, T. magnatum, beaucoup plus rare que la noire, est tellement agréable au goùt et à l'odorat, qu'en tout temps elle se vend à un prix élevé.

Les Truffes peuvent se manger de mille manières différentes, crues ou cuites, assaisonnées ou sans accommodement, seules ou mélangées à d'autres aliments.

Elles sont excellentes dans toutes sortes de ragout, soit hachées, soit coupées en tranches après les avoir pelées. C'est sans contredit un des meilleurs assaisonnements que l'on puisse servir en cuisine.

On en farcit fréquemment les volailles, auxquelles elles communiquent leur parfum en mème temps qu'elles favorisent leur conservation.

IIses dans le lait, ces plantes lui communiquent leur 
odeur et hâtent sa coagulation; on peut de cette manière obtenir des fromages à la Truffe.

"On préfère avec raison l'huile ou le beurre à toute autre substance pour assaisonner la Truffe. Après l'huile, le vin est l'ingrédient ou le véhicule qui lui convient le mieux, et lorsque ces deux substances sont mariées ensemble, alors l'assaisonnement est parfait. Voilà pourquoi un ragoùt de Truffes n'est bon et bien agréable que lorsque la sauce a pour base l'huile et le vin. Ainsi, pour faire un bon ragoût, après les avoir bien lavées et bien brossées pour enlever toute la terre, on les fait tremper un peu dans l'eau, ou, ce qui est mieux, dans l'huile, on les coupe ensuite par tranches, et on les met sur le plat avec de l'huile ou du beurre, un peu de vin, du sel et du gros poivre; il y en a qui ajoutent des anchois et de petits oignons. C'est l'affaire d'une heure de cuisson; on fait une liaison avec des jaunes d'œufs. Quand les Truffes sont de bonne qualité, ce ragoût est délicieux. Quelques personnes ajoutent un peu de bouillon pendant la cuisson. " (Paulet.)

D'autres les mangent cuites dans du vin et dans du consommé, assaisonné de sel, de poivre, d'un bouquet de fines herbes, de racines et d'oignons. On ne les met cuire dans ce bouillon qu'après les avoir fait tremper dans l'eau tiède. Quand elles sont cuites, on les sert pour entremets sous une serviette.

Truffes cuites sous la cendre. - Avec un couteau, on fait des fentes à la Truffe en plusieurs endroits pour pouvoir $\mathrm{y}$ introduire poivre, sel et assaisonnement; on la plonge dans de l'huile; on la recouvre ensuite de papier huilé, puis on l'enveloppe de nouveau avec du papier mouillé, pour la faire cuire une heure au moins sous la cendre bien chaude.

Autre procédé. - «Prenez de belles Truffes lavées et 
brosseres aree soin. Sampoudrez chacume d'elles de sel et de gros poivre. Enveloppez-les dans plusieurs donbles de papoier. garnis de bardes de lard. Nouillez kigrement ces caisses, et mettez-les sous une cendre rouge. Faites cuire pendant une bonne heure. Otez le papier, essuyez vos Trulfes, et servez-les chaudement dans une serviette. " (Rogues.)

Truffes au vin de Champagne. - On lave plusieurs fois les 'Truffes dans l'eau tiède, on les brosse et on les met dans une casserole foncée de bardes de lard, avec du sel, une feuille de latrier et une bouteille de vin de Champagne. On couvre hermétiquement la casserole, on fait bouillir une demi-heure, et on sert les Truffes sous une serviette. Les Truffes acquièrent ainsi une propriété excitante très-marquée; mais, si elles réveillent les tempéraments inertes, elles échauffent et irritent les sujets bilieux et sanguins.

Truffes à la vapeur de vin. - “On cuit les Truffes à la vapeur de vin, en mettant dans une casserole deux verres de vin blanc, un petit verre d'eau-de-vie et tel aromate que l'on veut. On place les Truffes sur un clayon dans la casserole, que l'on recouvre de son couvercle, et l'on fait bouillir; aussitòt que l'ébullition commence, on pose sur le couvercle un linge mouillé; les vapenrs se condensent et retombent bouillantes sur les Truffes; lorsque celles-ci sont cuites, on les retire et on les laisse un instant se ressuyer a l'air: on sert sur une serviette. " (Paulet).

Truffes à la Périgord. - 11 y a deux manières de préparer les Truffes à la Périgord : l'une consiste à les faire bouillir entières dans le vin et à les assaisonner; l'autre à les bien cuire d'abord sous la cendre et à les fricasser ensuite.

Truffes á la maréchale. - Prenez de grosses Truffes bien brossées et lavées; ajoutez à chaque une pincée de sel et 
de gros poivre; enveloppez-les de plusieurs morceaux de papier, et mettez le tout dans une petite marmite converte de cendres chaudes où vous les laisserez une heure. On les sert en cet état.

Truffes à la Piémontaise. - On fait mariner les Truffes dans l'huile; on les coupe par lames très-minces, et on dispose un lit de ces Truffes émincées sur un plat d'argent avec de l'huile, du sel, du gros poivre et du fromage de Parmesan râpé. Après avoir fait ainsi plusieurs couches, on met le plat sur la cendre chaude et sous le four de campagne. Un quart d'heure suffit pour leur cuisson.

On prépare aussi les Truffes en croustade. On les choisit alors d'une forte dimension, on les couvre de bardes de lard, et on les dispose dans de la pâte brisée, dont on forme une espèce de tourte qu'on met au four. Dans une heure elle est cuite.

Truffes du Piémont à la Rossini. - "Vous émincez fine ment des Truffes du Piémont. Vous mettez ensuite dans un saladier de l'huile d'Aix, de la moutarde fine, du vinaigre, un peu de jus de citron, du poivre et du sel. Vous battez ces divers ingrédients jusqu'à parfaite combinaison, et vous mêlez vos Truffes.

"On peut servir de même nos Truffes noires, en ajoutant à cet assaisonnement deux jaunes d'œufs et une pointe d'ail, afin de leur donner le goût et le moelleux des Truffes du Piémont. » (Roques.)

Truffes a l'Italienne. - “Prenez des Truffes moyennes, épluchées et coupées par tranches; mettez-les dans une cas. serole aveć un peu d'huile, de sel, de poivre, de persil, de ciboule, d'échalotes hachées, et deux gousses d'ail piquées d'un clou de girofle. Laissez-les un peu mariner et mettez-les quelques moments sur les cendres chaudes. Égouttez-les, et ajoutez de bon bouillon, ou du vin blanc, 
Ine cronte de pain beurrée et maniée dans la farine; faites bouillir le tout; dégraissez et servez vos Truffes avec un peu de jus de citron ; la sauce doit ètre perlée. » (Paulet.)

Truffes blanches ou noires à l'Italienne. - Après avoir plongé dans l'eau et bien brossé deux cent cinquante grammes de Truffes, pelez-les, si elles sont noires. Coupez-les par tranches sur un plat, mèlez ensuite cent cinquante grammes de beurre et soixante grammes d'huile d'olives dans une tourtière avec deux anchois nettoyés et triturés, avec une pincée de persil et une gousse d'ail ou d'échalote. Faites frire légèrement le tout pendant une minute, ensuite jetez-y les Truffes avec une pincee de sel ; retournez-les deux ou trois fois ; versez-les sur un plat, entourées de croùtons de pain frits dans le beurre et glacés, en faisant dégoutter dessus deux cuillerées ì louche de bouillon concentré. Servez-les fumantes avec un citron à part.

Truffe blanche ou grise. - Autre procédé. - Cette production souterraine, dit M. Barla, est tellement agréable au goùt et à l'odorat que, mème à l'époque ou elle est la plus commune, on la vend encore à un prix élevé. Les Truffes les plus affinées sont celles qui ont une forme arrondie et la chair foncée et odorante; celles qui sont comprimées ou lobées sont moins recherchées.

On coupe cette Truffe en tranches très-minces avec un couteau fait exprès, et on la mange ordinairement crue en salade, après l'avoir assaisonnée• avec de l'huile, du vinaigre et du jus de citron. En Piémont, on la mange le plus souvent avec des cardons crus et une sauce composée d'huile et d'anchois. On s'en sert aussi pour parfumer divers ragoûts.

Truffes à l'Espagnole. - "Coupez les Truffes en quatre morceaux après les avoir lavées et épluchées; faites-les 
sauter dans un peu d'huile, en y ajoutant ciboules hachées, poivre, sel, épices et laurier. Quelques tours suffisent pour les cuire. Un peu avant de les sortir du feu, vous mouillez votre sauce d'un peu de vin de Madère, et vous achevez par une liaison avec un peu de farine et un jaune d'œuf. » (MM. Moynier.)

Ragoût de Truffes. - “Après avoir lavé et bien brossé des Truffes d'un bon parfum, on les fait mariner dans l'huile; on les coupe ensuite par tranches épaisses de deux lignes, et on les met sur un plat qui aille au feu ou dans une casserole, avec de l'huile ou du beurre, du sel, du gros poivre et un peu de vin blanc. Lorsque les Truffes sont cuites, on les sert avec du jus de citron, ou bien on les lie avec des jaunes d'œufs. ”

Autre procédé. - "Prenez de moyennes Truffes et coupez-les en tranches; mettez-les dans une petite casserole; vous les passez avec très-peu de beurre et de muscade râpée; vous les mouillez avec de l'espagnole et du consommé, et, après les avoir dégraissées, vous incorporez un verre de vin de Champagne réduit. „ (Le Parfait Cuisinier.)

Pouding aux Truffes. - "Épluchez deux livres de moyennes Truffes, et les émincez en lames de deux lignes d'épaisseur; sautez-les dans une casserole avec quatre onces de beurre tiède, une grande cuillerée de glace de volaille dissoute, un demi-verre de madère sec, le sel nécessaire, une pincée de mignonnette et une pointe de muscade râpée.

“Vous prenez un bol d'entremets, ayant à peu près quatre pouces de profondeur sur sept de diamètre; vous le beurrèz légèrement à l'intérieur, vous le foncez de pâte brisée, et vous y placez les Truffes avec leur assaisonnement. Vous humectez ensuite le tour de la pâte, et vous la couvrez d'une abaisse ronde dont vous soudez parfaitement 
les bords, afin que le parfum des Truffes ne s'évapore point à l'ébullition; puis vous enveloppez le bol daus une serviette, rons le liez arec une ficelle, et vous le placez daus une marmite d'eau bouillante. Après une heure et demic d'ébullition, le pouding est cuit. Iu moment de servir, vous l'égouttez, vous en détachez la serviette, et vous le disposez sur le plat d'entremets.

"Les Truffes mises dans du lait hâtent sa coagulation et lui communiquent leur parfum. On peut de cette manière obtenir des fromages aux Truffes. „ (Roques.)

Emincie de Truffes. - Coupez des Truffes en tranches minces, passez-les au beurre, ajoutez des échalotes et du persil haché, sel et gros poivre; mouillez avec du bon vin blanc et deux cuillerées de jus. Au moment de servir, mettez une cuillerée d'huile ou un petit morceau de beurre.

Ratafia de Truffes. - « On prend deux livres de Truffes moyennes, d'un tissu ferme et bien parfumées. On les coupe par fragments, et on les fait macérer à froid pendant vingt jours dans deux pintes de bonne eau-de-vie, en ajoutant à la macération trois gros de vanille du Mexique, découpée. On passe le mélange, et on l'édulcore avec deux livres de sucre fondu dans une livre d'eau de rivière. On filtre ensuite la liqueur, et on la conserve dans des flacons hermétiquement bouchés.

«Cette liqueur, prise suivant les règles de l'hygiène, c'est-à-dire avec modération, égaie les esprits attristés, réveille les organes languissants. „ (Roques.)

Truffes au court-bouillon ou au vin de Champagne. - Plongez dans l'eau une douzaine de grosses Truffes, et brossez-les bien. Faites frire doucement, pendant deux minutes, dans une casserole, un petit morceau de beurre, avec trois morceaux de ciboule, une carotte, un bouquet de thym et de basilic, mêlez le tout dans une grande bouteille de vin 
blanc, trois clous de girofle, une feuille de laurier, un peu de sel, une pincée de persil entier.

Faites bouillir doucement le tout pendant une petite heure; passez-le ensuite par le tamis dans une autre casserole, dans laquelle vous déposerez les Truffes, les couvrant avec un rond de papier graissé de beurre. Faites-les cuire pendant une demi-heure environ, et mettez-les bouillantes au milieu d'une serviette sur un plat.

Voulant ensuite les cuire au vin de Champagne, au lieu du court-bouillon, vous ferez usage d'une bouteille de champagne et d'un peu de sel. Faites-les cuire et servez-les comme ci-dessus. On les sert aussi froides mises en pyramide sur une serviette, a vec une sauce à l'huile, à part.

Truffes en salade. - Après avoir bien brossé et essuyé des Truffes, blanches de préférence, coupez-les par tranches sur un plat muni d'une serviette, au moment de les porter sur la table, afin que l'on puisse jouir de tout leur agréable parfum. Vous servez, à part, une sauce composée de la manière suivante : faites délayer dans une terrine deux anchois nettoyés, triturés avec une gousse d'ail et passés aux tamis avec le jus d'un citron, un gramme de poivre et de sel; mélez-y un demi-verre d'huile très-fine et versez dans la saucière. Servez aussi du citron à part.

Truffes en pâte. - "Lavez et brossez de grosses Truffes, que vous arrangez dans un morceau de pâte brisée pour en former une tourte. Couvrez les Truffes de quelques bandes de lard; recouvrez la tourte et faites-la cuire l'espace d'une heure. » (Paulet.)

Omelette aux Truffes. - "Cassez et battez les œufs comme ¿ l'ordinaire. Épluchez de petites Truffes, que vous coupez en morceaux carrés et que vous assaisonnez de poivre, de sel et d'un peu d'épices. Faites fondre dans une casserole un bon morceau de beurre : si vous avez lard et jambon à 
mettre dans l'omelette, faites-les revenir dans le beurre; ajoutez-y ensuite les Truffes et fitites-les sauter jusqu'a ce qu'elles soient entierement cuites; retirez alors les Truffes. Ajoutez un peu de beurre, s'il n'en reste pas assez dans la casserole ; versez-y les œufs battus; lorsqu'ils sont un peu pris, sans cependant qu'ils se soient attachés au fond de la casserole, vous y versez les Truffes et achevez l'omelette comme à l'ordinaire. Au moment de servir, vous pouvez l'arroser avec de l'essence et mettre à l'entour du plat des Truffes très-chaudes, cuites au vin, accompagnées d'un citron partagé en deux. Pour les aufs brouillés et l'omelette sans lard ni jambon, vous procédez d'une manière tout à fait semblable. Ces mets ne doivent pas manquer de beurre.

"Il est à remarquer que les Truffes, en cuisant avecles œufs, ne veulent avec elles ni oignons, ni ciboules, et généralement aucun herbage. » (IM, Moynier.)

Préparation de la Truffe appelée Tersez (Tuber niveum, Desf.) chez les Arabes. - "Les trabes, dit Fries, mangent comme un mets délicieux et avec juste raison la Truffe qu'ils appellent Tersez. Mise d'abord sur la braise, ensuite nettoyée et arrosée d'un jus gras, c'est un aliment délicat et recherché. lls la mangent aussi cuite à l'eau ou avec du lait. ” (Fies, S) st. myc., p. 29.)

Manière de préparer les Truffes chez les anciens. - Suivant Apicius, après avoir fait cuire les Truffes dans l'eau, on les traverse d'un petit bâton, et on les présente un instant devant le feu; on les met ensuite dans un poèlon avec de l'huile, un peu de jus de viande, du chervis, du vin, du poivre et du miel, dans des proportions convenables. Lorsque la sauce est bouillante, on fait une liaison avec un peu de farine et on les sert en cet état.

Pline dit qu'on les lave dans du vin, qu'on les fait 
cuire ensuite sous la cendre et qu'on les sert chaudes, saupoudrées de poivre et de sel.

Apicius et Platine nous ayant laissé des détails assez étendus sur la cuisine des anciens, je renvoie à ces deux auteurs les personnes qui seraient curieuses de savoir comment de leur temps on assaisonnait les champignons.

Manière d'apprêter les Ghampignons desséchés. - Les Champignons desséchés sont, dans certains pays, d'une grande ressource pour l'hiver et le temps du carême.

Cesplantes se préparent à peu près de la mème manière que si elles étaient fraiches. Mais il faut, lorsque l'on veut en faire usage, commencer par les ramollir en les tenant plongées pendant quelques heures dans de l'eau tiède ou dans du lait. On préfère le lait pour les Chanterelles et les Clavaires, et l'eau pour les Agarics, les Morilles et les Bolets. "Lorsqu'on veut faire usage des Cèpes (Bolets), dit M. Paulet, on les fait revenir dans l'eau tiède, où on les laisse infuser toute la nuit sur les cendres chaudes, la veille du jour où l'on veut les manger. On conserve cette.eau chargée d'une partie de leur parfum. Les uns les font bouillir ensuite légèrement dans l'eau, et, après les avoir essuyés et avoir jeté cette ean, ils les font cuire dans le beurre avec du persil, du sel, du poivre, c'est-à-dire avec l'assaisonnement ordinaire; ils les nourrissent pendant leur cuisson avec la première eau dont on a parlé : c'est l'affaire d'une heure environ. La liaison se fait avec des jaunes d'œufs ou de la crème. D'autres les mangent à l'oignon, qu'on fait roussir d'abord sur le feu, dans le beurre; quand ils commencent à roussir, on ajoute les champignons qu'on achève de faire cuire. Il y en a qui ajoutent de la chapelure de pain, de la muscade ou des quatre épices.

* En Hongrie, on fait avec ces plantes des coulis ou soupes qu'on y mange avec plaisir. Pour cela, on les fait 
revenir avec de l'eau tiède, comme il a été dit plus haut; on se sert de cette eau dans laquelle on fait bouillir des ròties de pain. Après un temps suffisant, on passe le tout pour en faire un coulis épais de consistance de purée, auquel on ajoute les Champignons qu'on a fait cuire à part dans le beurre, avec l'assaisonnement convenable. On mêle le tout pour en faire un plat d'abondance. »

La poudre des Champignons desséchés peut servir à assaisonner tous les aliments dans la préparation desquels on fait entrer ces plantes : elle remplace mème avec avantage les Champignons frais, du moins quant au parfum et à la saveur. 


\section{CHAPITRE XVII.}

DE L'EFFET DES CHAMPIGNONS VÉNÉNEUX SUR L'ÉCONOMIE ANIMALE.

La plupart des champignons vénéneux sont des poisons subtils, qui, pris même en petite quantité, - Agarics et Bolets, - peuvent donner la mort dans l'espace de quelques heures. Les exemples de ce genre d'empoisonnement ne sont malheureusement que trop communs. On peut dire qu'il ne se passe pas une année sans que les journaux apprennent au public que des familles entières ont succombé pour avoir mangé imprudemment des champignons délétères ; et, ce qui est regrettable, c'est que presque jamais ces journaux ne nous disent par quelles espèces les accidents ont été occasionnés.

Sans vouloir rapporter ici des exemples particuliers d'empoisonnement, et je pourrais en rapporter un grand nombre, je dirai que plusieurs personnages, illustres par leur rang et leur naissance, au nombre desquels, disent les auteurs, il faut compter l'empereur Jovien, le pape Clément VII, l'empereur Charles VI, la veuve du czar Alexis, un Borromée de Naples, périrent empoisonnés par des champignons. 
The méprise fatale dans l'usage de ces plantes causa, au rapport de Pline, la mort d'Anneus Serranus, capitaine des gardes de Néron.

En I 75 r, la princesse de Conti, étant à Fontainebleau, prit de fausses Oronges pour de véritables Oronges; elle les cueillit elle-mème et s'en fit servir un plat. Après en avoir mangé, elle éprouva des accidents très-graves; sa vie mème fut en danger.

Le seul toucher, l'odorat même de diverses espèces de champignons, ont suffi, au témoignage de quelques personnes, pour produire des symptòmes d'empoisonnement.

Bauhin raconte qu'ayant manié le champignon qu'on appelait alors Fungus albus acris, Agaricus (Lactarius) zonarius, Bull., et s'en étant frotté les yeux par hasard, il en éprouva une vive irritation.

Rhasis parle d'un champignon dont la poudre mise sur un bouquet empoisonne lorsqu'on le flaire. Hilden cite un cas d'empoisonnement de ce genre. Ces auteurs ne nous disent pas quelle espèce de champignon aurait fourni cette poudre fatale. Il est certain que la poudre des champignons malfaisants ne serait pas respirée impunément.

Clusius (l'Écluse) raconte qu'on lui avait présenté à Amsterdam plusieurs individus du Phallus Hadriani, Vent., et que, toutes les fois qu'il le serrait dans la main, il éprouvait un engourdissement. Cette espece aurait-elle disparu? aucun mycologiste ne dit l'avoir rencontrée.

Il est certain qu'il.y a des espèces à odeurs pénétrantes, qui, fraiches ou mème desséchées, étant laissées dans une chambre à coucher, ont occasionné de violents maux de tète à la personne qui y avait passé la nuit.

Pennier de Longchamps dit qu'ayant récolté au pied d'un chène un champignon qu'il garda une nuit dans sa 
chambre, le lendemain en s'éveillant il se sentit suffoqué par une odeur fétide (I).

MI. Tulasne disent aussi que s'étant imprudemment enfermés, pendant la nuit, dans une chambre étroite où se trouvait l'Agaric annulaire, Bull., Ag. melleus, Fl. Dan., l'air fut tellement vicié par l'odeur putride et les exhalaisons du champignon qu'ils en furent comme asphyxiés.

Lenz aussi fut incommodé pour avoir laissé neuf pieds du Bolet satan, dans sa chambre.

Plus d'une fois, j'ai eu des maux de tête pour avoir séjourné trop longtemps dans une pièce où j’avais déposé diverses espèces de champignons.

Bassius dit qu'une espèce de Phallus qu'il décrit, et qu'il propose d'appeler Phalloidustrum Bononiense alpinum, exhalait une odeur tellement forte qu'il en éprouva un violent mal de tête.

La femme d'un médecin, M. J. Busson, ayant goûté par distraction d'un champignon désséché, fut obligée de le rejeter aussitôt après l'avoir mâché : une demi-heure après, bien qu'elle eût rincé sa bouche, elle sentit du malaise; prise de nausées, elle fit des efforts pour vomir et ressentit une douleur violente à l'estomac : heureusement elle vomit. On offrit de ce champignon à un chat qui refusa d'en manger; on lui en présenta d'autres, il les dévora.

Les plus dangereux de tous les champignons sont sans contredit ceux qui appartiennent au sous-genre Amanite des Agarics : ce sont ceux du moins qui occasionnent les accidents les plus graves et les plus fréquents; ceux qui, chaque année, pour ainsi dire, causent la mort de familles entières.

La plus pernicieuse des espèces d'Amanites est l'Aga-

(1) P. de Longchamps, p. 50 et 57.

(2) Tulasne, Select. fung. Carpol. 
ricus phulloiles, Fr. Agaric bulbeux Bull. Son principe malfaisunt est assez actif pour que des personnes qui n'en araient mangé qu'un seul pied aient succombé. D'apres mes expériences répétées, donné it des chiens, al l'état frais, il les tue à la dose de vingt-cing à trente grammes; donné à l'état sec, il les tue à une dose moins forte encore. Un jeune chat, qui avait rongé quatre grammes seulement de ce champignon frais, est mort le cinquième jour. Cette Amanite tue, tantòt de vingt-quatre à trente-six heures après l'ingestion, et tantôt après avoir fait languir trois ou quatre jours.

L'Agaricus Mappa, Batsch, champignon qui ressemble tellement au Phalloüle que pendant longtemps les botanistes les avaient confondus et n'en faisaient qu'une seule - espèce, Agaric bulbeux, Bull. Amanita venenosa, Pers., est un peu moins actif que le Phalloide, et néanmoins plus d'une fois il a donné la mort. L'Agaricus pantherinus, Déc., tue aux mèmes doses que le Мappa.

L'Agaricus muscarius, Lin., ou fausse Oronge, est un poison peut-ètre moins violent que les précédents. Plus d'une fois, cependant, il a mis aussi la vie en danger. Il occasionne surtout de graves accidents nerveux, lesquels, il est vrai, se dissipent le plus ordinairement après avoir donné, pendant un jour ou deux, les plus vives inquiétudes.

Nous avons vu plus haut que l'urine de ceux qui ont fait usage de ce champignon acquiert des propriétés enivrantes. La chair des rennes qui ont été tués peu de temps après en avoir mangé est pareillement enivrante ( 1 ).

A ces faits j'ajouterai que l'on a des exemples d'enfants qui, allaités par des femmes empoisonnées pour avoir mangé des champignons vénéneux, ont succombé, empoisonnés eux-mèmes par le lait de la nourrice.

\section{(1) Langsdorf.}


Les Agarics de la section des Amanites agissent à la manière des poisons narcotico-âcres, c'est-à-dire que leurs effets sont ceux de l'opium et des solanées.

Le suc de ces champignons appliqué sur la peau dénudée produit, par absorption, le narcotisme et des accidents nerveux, sans apparence d'inflammation extérieure. Celui de l'Agaric phalloïde, inoculé sous la peau d'oiseaux de petite taille, les a tués dans les vingt-quatre heures, d'après mes expériences.

Les Agarics du sous-genre des Russules agissent à la façon des poisons âcres caustiques, et cependant, comme les Amanites, ils produisent quelquefois des effets narcotiques.

Les Russules les plus évidemment toxiques sont l'Aga. ricus ruber, Fr., l'Agaricus emeticus, Pers., et l'Agaricus sanguineus, Bull.

Ces champignons ont une saveur extrêmement âcre. Lorsqu'on les mâche, ils impriment à la langue et à la bouche une sensation brûlante. Lenz, Krombholz et plusieurs personnes ont éprouvé des coliques et des vomissements pour avoir seulement goûté de l'Agaricus integer.

Prises comme aliment, les Russules provoquent des nausées, des évacuations alvines excessives, une soif ardente, de l'anxiété, de l'oppression, une sensibilité extrême de l'épigastre, une altération profonde du visage, enfin tous les symptòmes de l'inflammation de l'estomac et des intestins. Ces divers symptômes s'accompagnent quelquefois de coma et autres accidents nerveux, ce qui permet de supposer que la présence du principe canstique n'exclut pas celle du principe narcotique. En général, les symptômes d'empoisonnement par les Russules se manifestent plus promptement que ceux que produisent les Amanites.

Le suc des Russules, mis sur la peau dépouillée de l'épi- 
derme, occasionne une inflammation locale, sorte d'érysipèle, exempt de symptòmes généraux.

Les Agarics du sous-genre Lactaire agissent sur l'économie à peu près à la manière des Russules.

La saveur de quelques Lactaires est d'une âcreté insupportable et qui persiste pendant longtemps. La moindre parcelle du champignon, mise sur la langue, semble emporter la bouche. Pris à l'intérieur, les Lactaires déterminent, de même que les Russules, une inflammation des roies digestives, accompagnée quelquefois d'un assoupissement profond et d'autres accidents nerveux.

Il n'est pas jusqu'aux spores de quelques espèces de champignons qui ne soient malfaisantes. Celles de l'Agaricus vellereus, Fr., goùtées, même en petite quantité, déterminent des nausées et d'autres symptômes graves. Le docteur Badham fut sérieusement incommodé, et cela pendant plusieurs heures, pour aroir simplement gonté les spores d'un Agaric laiteux, qu'il ne nomme pas, mais qui était probablement ce même Agaricus vellereus.

Un chien, qui avait déchiré en jouant un pied de ce champignon, en éprouva des douleurs presque incroyables, qu'il témoignait par une vive agitation. Est-ce à la matière résineuse qu'ils contiennent que les Lactaires doivent leur propriété toxique, ou bien à l'amanitine qui alors se trouverait mélée à ce principe?

Les Lactaires ont une grande analogie de structure et de vertu avec les Russules. Ce qui les différencie plus particulierement, c'est que celles-ci perdent en grande partie leur saveur âcre lorsqu'on les laisse macérer dans l'eau, tandis que les Lactaires gardent la leur.

J'ai jadis, sur la foi des auteurs qui donnent l'Agaricus nebularis, Batsch, de la section des Gymnopes, pour comestible, mangé de ce champignon : j'en ai été incom- 
modé. Une dame, qui en avait mangé le mème jour que moi, en fut incommodée plus sérieusement que je ne l'avais été. Il occasionna chez elle du malaise, des selles nombreuses, des douleurs abdominales, de l'inappétence. Elle fut deux jours avant de revenir à l'état normal.

Dans la section des Pleuropes, l'Agaric styptique, Bull., Panus styplicus, Fr., est malfaisant. Mais sa petite taille, sa chair molle et coriace en même temps, et sa saveur acerbe sont cause qu'on n'est pas tenté de le faire servir à la nourriture; aussi a-t-il rarement occasionné des accidents. Ses effets sont ceux des champignons âcres.

L'Agaric de l'Olivier, Agaricus olearius, Dec., autre Pleurope, est donné par Micheli comme vénéneux, et par Battarra comme comestible. La propriété phosphorescente de ce champignon suffirait pour le rendre suspect. La vérité est qu'il est malfaisant.

Plusieurs Bolets sont dangereux.

Le Bolet satan, Boletus Satanas, Lenz, expérimenté par Lenz, mérite le nom qui lui a été imposé. Ce savant mycologiste fut fortement incommodé pour avoir seulement goûté un morceau cru de ce champignon. Il ressentit des douleurs dans tous les membres. Le mal, il est vrai, se dissipa assez promptement.

Une personne qui, aussi, s'était contentée d'en mâcher un fragment, eut des vomissements vingt fois répétés, et, de plus, de la fatigue et de la faiblesse, qui durèrent jusqu'à la fin du deuxième jour. D'autres personnes cqui en avaient mangé très-peu ont été fortement incommodées : elles ont éprouvé des vomissements nombreux qui leur ont fait rejeter les boissons et les médicaments qu'on leur avait prescrits. Eiles ont eu du dévoiement, des selles sanglantes et glaireuses : leur pouls était faible, leur ventre affaibli; tout leur corps était froid. Ces mêmes personnes avaient 
cependant trouvé bon goùt à ce champignon malfaisant. Le Bolet satan est assez rare en France; nous devons nous en féliciter.

Le Bolet pernicieux, Bull., Boletus luridus, Schæff., est au contraire très-commun dans nos contrées, surtout en automne. Il occasionne des accidents analogues à ceux que produit le Satanas, mais généralement moins graves. Pris a l'intérieur, c'est sur les voies digestives surtout qu'il agit. Il est nuisible aux animaux ainsi qu'à l'homme.

Le Satyre fétide, Phallus impudicus, Lin., champignon qui n'est pas rare en France, sent, lorsqu'il est jeune, la pomme de reinette; mais, en vieillissant, il exhale une odeur infecte et comme cadavéreuse tellement repoussante qu'un seul pied apporté dans une chambre la rendrait inhabitable.

Un botaniste, dit Badham, ayant laissé par mégarde un de ces champignons dans sa chambre à coucher, fut bientòt éveillé par les émanations insupportables qu'il exhalait : aussi s'empressa-t-il d'ouvrir la fenètre et de le jeter. 11 pensait être débarrassé de l'odeur en mème temps que du champignon, mais celle-ci persista plusieurs heures encore après qu'il eut été jeté. l'ai constaté cette persistance de l'odeur.

Le gaz qui s'échappe du volva du Phallus au moment de sa rupture, recueilli par Godefroy, tua presque aussitòt un moineau qu'il avait plongé dans un volume d'air dont ce gaz formait la quinzième partie.

Le Clathre treillagé, Clathrus cancellatus, Iin., exhale une odeur plus fétide encore que celle du Phallus. Ce champignon, si singulier danis sa forme, est délétère comme ce dernier.

Le docteur Badham, cité plus haut, raconte qu'étant resté dix minutes dans une pièce où se tronvait un pied de 
Clathre, il y était resté dix minutes de trop; il ne dit pas ce qu'il a ressenti.

Paulet raconte, d'après le témoignage d'Ayman, médecin, qu'une jeune personne, ayant mangé un morceau de ce champignon, éprouva, deux heures après, une tension douloureuse au bas ventre, avec des convulsions violentes. Elle perdit l'usage de la parole et tomba dans un assoupissement qui se prolongea au-delà de cinquante-deux heures. On parvint à dissiper ces accidents, en lui donnant un vomitif qui lui fit rendre un fragment du champignon avec deux vers et des matières muqueuses teintes de sang. Elle fut plusieurs mois à se rétablir complétement.

Les paysans des Landes sont, dit-on, si bien persuadés de ses propriétés malfaisantes qu'ils vont jusqu'à croire qu'il peut donner le cancer, et qu'il suffit de le toucher pour attraper la gale; aussi ont-ils soin, lorsqu'ils le rencontrent dans les bois de pins, où il se trouve plus communément, de le couvrir de feuilles ou de mousses. Son odeur infecte, son aspect repoussant et la sensation de chair crue qu'il fait éprouver lorsqu'on le touche, ont bien pu donner lieu à cette croyance superstitieuse.

Les Lycoperdons (Vesses-loup) sont alimentaires dans leur premier àge; ils deviennent nuisibles lorsque leur chair passe au jaune-verdâtre, et commencent à se ramollir.

Leur poussière respirée fortement cause des éternuements violents et quelquefois des hémorrhagies. Lancée dans les yeux, elle provoque le larmoiement, de la cuisson, de la rougeur et même des inflammations violentes.

Vaillant dit que le Scleroderma verrucosum, Pers., pris intérieurement, est mortel.

L'Elaphomyces granulatus, Fr. (Scleroderma cervinum, Pers.) est recherché par les bètes fauves et surtout par les 
cerls, quile mangent avec avidité. Son odeur, presque virulente, le rend suspect. Persoon le dit mème pernicieux aux hommes. Il n'est pas prouvé que jusqu'alors il ait occasionné des accidents. MII. Tulasne en ont fait prendre des quantités assez considérables à des oiseaux et à des grenouilles; ces animaux leur ont semblé n'en souffrir aucunement.

Les Moisissures, - Mucedinées et Mucorinées, - ont l'inconvénient de domner un gout désagréable aux aliments : quelques-unes, en outre, les rendent malsains, mème vénéneux.

Doit-on attribuer aux moisissures les accidents qui surviennent fréquemment quand on mange des viandes qui en sont couvertes? Il sera toujours difficile de dire quelle est la part qu'il faut attribuer à des végétaux introduits dans l'économie animale avec des viandes qui ont déjà éprouvé un commencement de décomposition.

Le pain moisi ne peut être mangé sáns danger pour l'homme et pour les animaux.

Le docteur Vesteroff dit avoir vu deux enfants qui, après avoir mangé du pain de seigle moisi (Mucor Mucedo, Lin.), ont eu le visage rouge, gonflé, le regard animé, effaré, la langue sèche, le pouls faible, accéléré, des étourdissements; une soif inextinguible, puis des envies de dormir, de l'abattement, de l'indifférence à tout, etc. Ces accidents cédèrent à l'emploi d'un émétique.

L'exemple suivant prouve que la moisissure qui vient sur les biscuits peut tuer les poules.

M. Simon, avoué à Arlon (Luxembourg belge), avait reç, il y a quelques années, une caisse de vin de Champagne dans laquelle se trouvaient des biscuits de Reims. La caisse fut descendue à la cave avec les biscuits, car on ne savait pas qu'elle en contenait. Lorsqu'on l'ouvrit, après 
quelques mois de séjour dans la cave, on trouva les biscuits entièrement couverts de moisissure. On les jeta dans la basse-cour à des poules, qui s'empressèrent de les manger, mais qui bientôt furent malades et moururent.

Le fait m'a été rapporté par une dame qui en a été témoin.

Les moisissures qui viennent sur les fruits sont moins dangereuses peut-être que celles qui viennent sur les produits des céréales. Un matin j'ai mangé la moisissure du Penicillium glaucum, Link., venue sur un pot de confitures d'abricot; n'en ayant pas été incommodé, j'ai mangé, le lendemain, celle qui se trouvait sur de la confiture de groseilles; toujours sans en être incommodé. Un autre jour, j'ai mangé celle qui recouvrait la grande moitié d'une orange; je n'en ai pas non plus éprouvé d'effet sensible. Toutefois il ne faudrait pas conclure de ces expériences que les moisissures qui viennent sur les fruits et les confitures, pour n'avoir pas produit sur moi des effets bien prononcés, ne sont pas nuisibles, et que les enfants pourraient les manger impunément. Peut-être ce que j'en ai mangé n'était-il pas en quantité suffisante pour incommoder un adulte, et aurait incommodé un enfant. On sait du reste que certaines substances ne sont malfaisantes que lorsqu'on en fait un usage prolongé.

La Carie du blé, Uredo Caries, Dec. Tilletsia Caries, Tul. n'est pas malfaisante : je l'ai expérimentée sur moi il y a déjà bien des années.

En novembre 1822 , je délayai dans un peu d'eau sucrée quatre grammes de cette poussière, que j'avalai, le matin, à jeun. Je lui trouvai une saveur particulière avec une faible odeur de marée : sa couleur étendue tirait sur le roux. Cette substance n'ayant produit aucun effet sur moi, le surlendemain je triplai la dose, que je délayai dans un 
preu d'alcool affaibli. Je la pris sans en rien éprouver non plus.

On n'avait, jusque dans ces derniers temps, reconnu à la Carie du blé que le grave inconvénient de donner a la farine et au pain une couleur grisàtre et un goùt désagréable. Il faudrait lui en reconnaitre un beaucoup plus fàcheux si, comme le pense le docteur Costallot, la pellagre, maladie signalée d'abord dans le midi de la France, mais qui, depuis quelques années, se serait montrée dans le nord, notamment à Reims, où elle a été constatée par le docteur Landouzy, est le résultat d'un empoisonnement occasionné par l'usage du pain préparé avec du blé affecté de carie; do mème que daus les provinces du sud-ouest de la France cette maladie aurait pour cause, ainsi que le prétendent Balardini, médecin italien, le docteur Costallot, et d'autres médecins, l'usage du mais, altéré par la moisissure appelée Verdet, Verderame (Sporisorium maydis), Link., qui se produit sur le mais avant sa maturité et après qu'il est desséché.

S'il est douteux que dans le nord la pellagre soit véritablement produite par l'usage du blé affecté de carie, il ne l'est pas moins que dans le midi elle ait pour unique cause l'usage du mais affecté de Verdet, puisque, en Espagne, la pellagre a été observée dans des contrées où l'on ne fait pas usage du mais. On peut admettre cependant que la Carie du blé et le Verdet du maïs, innocents lorsqu'on ne fait pas un usage habituel d'aliments qui en contiennent, ne le sont plus lorsque cet usage est longtemps prolongé, et, dans ce cas, s'ils ne sont la cause unique de la maladie, ils contribuent du moins à sa production.

Dans le midi de la France, le Stemonitis ovata, Pers., moisissure noirâtre, et l'Ustilago hypodytes, Trél., viennent sur les roseaux après qu'ils ont été coupés : le ma- 
niement de ces roseaux fait venir des boutons au visage des ouvriers qui les travaillent, et leur occasionne la maladie particulière appelée par eux maladie des roseaux (I). Dans la province d'Alger, où cependant les roseaux (Arundo donax et Mauritanica) sont cultivés en grand et journellement employés à la fabrication de clôtures, de paniers, de corbeilles, etc., on n'a pas remarqué qu'ils donnent la maladie des roseaux.

L'Urédo du maïs, Dec., Ustilago maydis, Tul,, ne serait pas malfaisant, au rapport de Imhoff. Il en a pris quatorze jours de suite une drachme, délayée dans de l'eau, sans en éprouver le moindre inconvénient. Il en a appliqué une certaine quantité à la surface d'une plaie, sans changer aucunement la condition de la plaie, sans augmenter ni diminuer la souffrance (2). W'après le témoignage du docteur Dugès, qui exerce la médecine au Mexique, cette substance y serait d'un usage alimentaire; elle y porte le nom de Cuervo, à cause de sa couleur noire.

La Rouille, Uredo Rubigo vera, Dec., Trichobasis Rubigo vera, Lév., serait moins innocente que l'Urédo du mais, s'il faut en croire certains auteurs. Treize agneaux sur cent seraient morts, dit l'un de ces auteurs, pour avoir mangé des herbes qui en étaient infestées.

Il est certain, dit Tessier, que, dans les années où il y a beaucoup de blé rouillé, il a régné une grande mortalité sur les chevaux, soit qu'on doive en attribuer la cause aux feuilles, soit qu'elle dépende d'autres circonstances (3).

I. Magne, professeur à l'École d'Alfort, cependant ne regarde pas la Rouille comme aussi malfaisante qu'on le suppose : il a nourri, pendant trois mois, un lot de mou-

(1) E. Maurin, Moniteur des hôpitaux, 26 mars 1859.

(2) Gardn., Chron., déc. 1859, p. 973.

(3) Tessier, Malad. des grains, p. 212. 
tons aver de lat paille de blé fortement rouillée, et, nonseulement ils ne sont pas tombés malades, mais mème ils ont pris du poids et de la graisse.

Toutefois M. Plasse, médecin-vétérinaire à Niort, accuse les champignons microscopiques des fourrages avariés d'ètre la cause unique de la fievre typhoide du cheval, qu'il compare à celle de l'homme (I).

L'Ergot du seigle, Sclerotium Clavus, Dec., qui sert de base au Sphacelia segetum, Lév., est, on le sait, donné journellement, à la dose de quatre grammes, it des femmes en travail d'enfantement, pour provoquer les contractions de l'utérus et accélérer l'accouchement. Donné ainsi occasionnellement, il ne détermine pas d'accidents, tandis que l'usage prolongé de la farine qui en contient finit par occasionner l'ergotisme, maladie grave, qui rend les digeslions difficiles, affaiblit les facultés intellectuelles, produit un engourdissement incurable, entraine quelquefois la gangrène des extrémités inférieures, et, dans tous les cas, amène la dégénérescence non-seulement des individus, mais de familles entières.

L'Ergot n'est pas particulier au seigle : dans les années pluvieuses, il vient sur beaucoup d'autres graminées. En Angleterre, les épis du ray-grass (ivraie vivace), ceux du dactyle aggloméré, de l'avoine jaunâtre, en sont quelquefois tout chargés, en octobre. Lorsqu'il est abondant dans les pâturages, les prairies, il produit l'avortement chez les vaches qui s'en nourrissent. Il sera donc prudent d'éloigner des prairies qui en sont infestées les vaches et les brebis pleines, jusqu'à ce que l'herbe, étant fauchée et mise en grange, l'ergot s'en soit détaché.

Il est à peu près certain que des veaux et des agneaux 
apportent en naissant une mauvaise constitution, qui a pour cause l'usage, dans la nourriture donnée á la mère, de plantes ergotées.

L'Ustilago maydis possède aussi des propriétés abortives, qui, dit-on, ont été constatées sur des vaches et des chiennes (I).

Les Érysiphées aussi seraient nuisibles."

Un jeune enfant, dit le docteur Perrachet, après avoir mangé des groseilles à maquereaux couvertes d'Érysiphées, fut pris de coliques, de frissons, de maux de tête, d'anxiété et de mouvements convulsifs suivis de prostration.

M. Boudier a observé un cas à peu près analogue sur la mère et les deux enfants d'une famille de cultivateurs qui présentèrent tous les symptômes d'une véritable cholérine pour avoir mangé des cerises couvertes de la moisissure verdâtre connue sous le nom de vert-de-gris, le Cladosporium herbarum, Link., des botanistes (2).

J'ai dit précédemment que des médecins distingués, qui s'occupent plus particulièrement des affections cutanées, ayant, dans ces dernières années, reconnu, à l'aide du microscope, la présence de filaments mucédinés et de spores dans diverses maladies du derme, du système pileux et des membranes muqueuses, ont considéré ces productions végétatives comme la cause même de ces maladies.

Pour ces médecins, le muguet, maladie qui attaque la bouche, la langue, le pharynx des enfants en bas âge, serait produit par l'Oidium albicans, Ch. Rob.

L'Achorion Schonleinii, Remak., serait la cause de la teigne faveuse, maladie qui attaque l'orifice dermique des

(1) Bouchardat, Répertoire de pharmacie, mai 1861.

(2) M. Boudier, des Chump., 1866. 
follicules pilcux du cuir chevelu et mème de ceux de la face.

Le Trichoph)ton tonsur(uns, Habrust, produirait la teigne tondante.

Le Microsporon Audouini, Grub., serait la cause de la teigne décalvante ou pellade, maladie qui n'est accompagnée d'aucune altération du derme, le cryptogame bornant aux cheveux son action destructive.

Le Microsporon mentagrophytes, Grub., donnerait naissance à la maladie appelée mentagre; si touttefois il est autre chose qu'un Trichophyton tonsurant.'

Le Nlicrosporon furfur, Sluyt., déterminerait sur l'homme les taches hépatiques, des éphélides lenticulaires, des pityriasis, etc.

Deux espèces nouvelles de végétaux parasites, Aspergillus flasus, Wred., et A. nigricans, Wred., observées par II. Wreden, se développeraient, selon lui, dans la menbrane du tympan et seraient la cause d'une maladie particulière de l'oreille, très-opiniâtre, et qu'il combat par l'hypochlorite de chaux et l'arséniate de potasse (I).

Des Algues mème auraient été trouvées dans l'intérieur du corps de l'homme et vivant au milieu des matières sécrétées, entre autres des Leptomitus, des Leptothrix, des Merismopodia, etc.

Je crois que les spécialistes ont été trop loin en attribuant tant de maladies différentes à des productions végétales.

Et d'abord, ces plantes cryptogamiques sont-elles réritablement la cause des maladies qu'on les accuse de produire, ou bien ne se montrent-elles dans ces maladies que comme complication, et seulement parce que des spores,

1) Congrès médical de $186 \%$, 
flottant dans l'espace, se trouvant transportées sur un organe malade, s'y sont développées, le nouvel habitat, bien qu'insolite, n'étant pas tout à fait contraire à la germina. tion de la plante?

Je me demande aussi si ces productions végétales, regardées par les médecins qui les ont observées comme constituant des espèces nouvelles, tout à fait distinctes et mème appartenant à des genres qu'il leur a fallu créer, ne sont pas de simples modifications, ou plutòt des altérations d'espèces de Mucédinées bien connues; modifications ou altérations provoquées par la nature mème de l'habitat sur lequel les spores de ces plantes se seraient développées.

D'autres maladies que des affections du cuir chevelu, du derme ou des membranes muqueuses, ont été attribuées à des plantes cryptogamiques.

La carie périphérique des dents, par exemple, nom auquel Klenke substitue celui de carie végétative, serait occasionnée, selon Nedden, par une production parasitaire cryptogamique dont il décrit les effets ( 1 ).

La syphilis, d'après Custano, ancien médecin-major de l'armée d'Orient, est le résultat de l'introduction dans l'économie d'un végétal fongiforme parasite, qui, en se développant, appelle autour de lui des fluides anomaux, au milieu desquels il se développe, en même temps qu'il refoule les tissus sains, dont il prend la place. Les caustiques et les antisyphilitiques métalliques, si fréquemment mis en usage dans cette maladie, n'agiraient, selon lui, qu'en taisant périr les spores, ou en les rendant impropres à la germination (2).

(1) Gazette hebdom., t. IV, p. 812.

(2) Comptes rendus, 28 février 1855 , vol. XL, p. 478. 
Ce qui parait bien démontré, c'est que les spores de la levure de bière, inoculées sous la peau par le docteur Lowe, ont produit la maladie cutanée appelée porrgo lupınosa.

Le docteur Thiersch admettait que le choléra pouvait se transmettre, de l'homme a l'homme, par des cryptogames résultant de la fermentation, lesquels se trouveraient répandus dans l'air et porteraient li. ferment par la bouche et les fosses nasales jusque dans l'estomac ( $\mathbf{I}$ ).

Bien d'autres maladies assurément que la carie dentaire et la syphilis pourraient, si l'on ne consultait que l'analogie, être attribuées à des productions cryptogamiques. Le cancer, les ulcères atoniques, par exemple, ne pourraient-ils pas être regardés comme produits par une plante qui, se multipliant sans relàche, rongerait lentementl'organe sur lequel elle se serait fixée?

La rage elle-mème ne pourrait-elle pas ètre considérée comme occasionnée par le développement plus ou moins tardif de spores d'un végétal d'une nature toute particulière, qui, inoculées avec la bave de l'animal affecté de rage, resteraient plus ou moins longtemps à l'état d'incubation, selon la constitution de l'individu, mais qui, un jour, faisant effort pour se développer, produiraient cette maladie fatale? Je ne serais pas surpris que l'on trouvât des spores dans la bave des animaux affectés de la rage, puisque déjà, en 1841 , Laugenbek a trouvé dans l'écoulement nasal d'un cheval morveux des filaments mycodermiques et des spores brunàtres, réunies en chapelet. Ce serait donc en détruisant les spores par une cautérisation prompte, et avant qu'elles soient absorbées, que l'on prériendrait l'apparition de l'hy drophobie rabique et celle de la morve. 
Nous avons vu que la plupart des champignons exhalent en se décomposant une odeur fétide : beaucoup d'entre eux répandent alors des miasmes putrides qui vicient l'air, et qui, au dire de quelques personnes, seraient la cause de ces fièvres de mauvais caractère qui sévissent plus particulièrement en automne, et qui, dans certains villages, situés au milieu des bois humides, jettent si souvent la désolation dans les familles.

Je ne sais si l'accusation portée contre les champignons en décomposition est fondée, mais il est certain qu'on préviendrait les effets qu'on leur attribue, si, dans un but d'économie domestique, on enterrait ces plantes pour les convertir en fumier, comme le conseille M. Lavalle. Ce procédé si simple, tout en conservant la santé, la vie aux hommes, produirait un engrais qui probablement ne le céderait en rien à celui que donnent les animaux domestiques.

On a accusé plus d'une fois d'avoir occasionné des accidents graves, des espèces de champignons qui, au su de tous, sont alimentaires. La Morille, la Chanterelle, le champignon de couche lui-mème, toutes les espèces reconnues pour comestibles, auraient été la cause d'empoisonnements.

On conçoit que les champignons, mème les plus salubres, occasionnent des accidents s'ils ont été cueillis trop vieux, s'ils ont subi un commencement de décomposition, si leur cuisson est insuffisante, ou si l'on en mange avec excès.

Des Morilles, altérées par l'état humide et pluvieux de la saison, et, de plus, mal nettoyées avant la cuisson, oc= casionnèrent des accidents sérieux dans une famille composée du père, de la mère et de quatre enfants. Ce mème champignon, conservé pendant plusieurs jours, soumis à l'action d'une température élevée et probablement ayant 
subi un commencement de fermentation, fut cause de l'empoisonnement de deux femmes, qui, heureusement, n'en moururent pats. Des champignons de couche, récoltés depuis plusieurs jours, peuvent aussi déterminer des accidents. C'est dans le but de prévenir ces accidents qu'd Paris la police interdit la vente de champignons dont les feuillets ont perdu leur couleur lilas.

Du reste, les champignons ne conviennent pas à tous les estomacs. Il en est de cet aliment comme du lard, des choux, des pois, des lentilles, etc., dont tant de personnes se nourrissent habituellement, tandis que d'aurres sont incommodées si elles se hasardent à en manger.

Une indigestion causée par l'usage de champignons reconnus pour comestibles fatigue le malade, le fait souffrir, mais rarement constitue un danger réel et jamais un véritable empoisonnement. 


\section{CHAPITRE XVIII.}

DES SYMPTOMES DE L'EMPOISONNEMENT PAR LES CHAMPIGYONS.

En général les champignons malfaisants ne produisent pas chez l'homme leurs effets immédiatement après l'ingestion : presque toujours il se passe plusieurs heures avant que les symptômes d'empoisonnement se déclarent. Du reste, ces effets sont plus ou moins prompts, plus ou moins violents, selon l'espèce de champignon et selon la quantité dont on a fait usage. On conçoit que leur manière d'agir sur l'économie soit différente, suivant que c'est le principe àcre ou le principe narcotique qui prédomine dans ces plantes.

Les premiers symptômes d'empoisonnement par les champignons à principe àcre ne se manifestent guère que deux ou trois heures après l'ingestion; les espèces à principe narcotique sont plus tardives encore dans leurs effets: souvent il se passe huit heures, dix heures et mème davantage, avant qu'aucun accident se déclare : jusque-là le malade reste ignorant du danger qui le menace.

Les espèces qui sont caractérisées par la présence d'un principe âcre, telles que les Russules, les Lactaires, l'Agaric styptique, Ag. (Marasmius) st)pticus, Bred., le Bolet livide, $\boldsymbol{B}$. luridus, fr., le Bolet Satan, fr., occasionnent, peu de temps après leur ingestion, une tension dans la région de 
l'estomac et de l'anxiété, signes précurseurs de l'inflammation de cet organe et du tube intestinal; inflammation caractérisée bientôt par de la douleur à l'épigastre, de la sécheresse à la gorge, une soif ardente, de la fréquence dans le pouls, des vomissements répétés, des selles nombreuses, une agitation extrème et quelquefois des mouvements convulsifs. Ces champignons paraissent agir sur l'économie à la manière des acides ou des alcalis concentrés. Il n'est pas rare qu'ils tuent après deux ou trois jours de souffrance; mais, si le traitement a été prompt et bien dirigé, rarement ils vont jusqu'à donner la mort.

Quant aux champignons qui contiennent un principe narcotico-dere (l'amanitine), tels que l'Agaric hulbeux, Bull., et ses variétés, verte, blanche, jaunâtre, Ag. (Amanita) Phalloides, fr., Ag. (Amanita) Mappa, Batsch, l'Agaric panthere, Ag. (Amanita) pantherinus, 1)ec, l'Agaric fausse Oronge, leur action est plus lente à se manifester que celle des précédents. D'ordinaire, il se passe quatre heures, six heures, douze heures et souvent davantage avant que les premiers symptômes se déclarent.

Ceux-ci débutent par de la pesanteur de tète, un peu de trouble dans les idées, des douleurs vagues, de l'abattement, de la stupeur; puis viennent des nausées, des vomissements, auxquels succèdent la diarrhée, la cardialgie, les douleurs abdominales, l'anxiété, l'oppression, une soif vive. Le malade a le visage pâle, décomposé; il éprouve des accidents nerveux, tels que des convulsions violentes, un délire taciturne ou un délire gai; quelquefois mème il a des visions fantastiques, mais plus souvent encore, il tombe dans un assoupissement comateux dont il est difficile de le tirer. Le malade a des défaillances fréquentes: le pouls, devenu petit, dur, serré, s'affaisse de plus en plus; une sueur froide se répand sur tous ses membres. 
Enfin la mort, presque toujours prévue et annoncée par le malade lui-même, vient mettre un terme à ses souffrances. Il meurt tantôt dans les angoisses d'une convulsion déchirante, tantôt plongé dans une léthargie profonde.

Le plus souvent les malades succombent dans les quarante-huit heures qui suivent l'empoisonnement, mais quelques-uns languissent cinq ou six jours et finissent par succomber. On comprend, du reste, que le poison ait des effets variables selon la quantité de champignons qui a été ingérée et selon la constitution des individus. Mais combien de personnes ont trouvé la mort, qui n'avaient mangé qu'un seul pied de champignon du sous-genre Amanite!

Un fait bien digne de remarque dans l'empoisonnement par ces végétaux, c'est que presque toujours les personnes qui en ont fait usage les ont mangés avec plaisir; rien, une fois qu'ils sont assaisonnés, ne trahissant leurs mauvaises qualités.

A l'ouverture du corps des individus qui ont succombé à l'empoisonnement par les champignons à principe narcotique, on ne voit souvent aucune trace d'inflammation de l'estomac et des intestins, bien que le malade ait eu des vomissements, des selles répétées et des douleurs abdominales, indices presque toujours certains d'une inflammation des voies digestives. Chez ceux-ci, le foie est le plus ordinairement volumineux, pâle, sans consistance; la vésicule du fiel est vide.

Réveillé-Parise, qui avait eu bien des fois occasion d'ouvrir des cadavres de soldats morts pour avoir mangé des champignons du sous-genre Amanite, a le plus souvent observé que l'action toxique avait été seulement stupéfiante : la membrane muqueuse, gastrique et intestinale, étant tout à fait saine. L'action toxique s'était portée plus particulièrement sur le système nerveux. 
Daus les cals d'empoisonnement par les champignons à principe àcre, on trouve que l'estomac, pour l'ordinaire vide d'aliments, et les intestins vides de matière fécale, mais distendus par des gaz fótides, ou contractés sur euxmèmes, sont constamment phlogosés, et prespue toujours parsemés à leur intéricur de taches livides et ulcérées, plus ou moins étendues; on trouve même quelquefois que des portions considérables d'intestins sont frappées de sphacèle. Tous les viscères abdominaux participent plus ou moins à cet état morbide. Le foie, la rate, le mésentere, sont gorgés d'un sang noir; il en est de même des poumons. Des taches inflammatoires ou gangréneuses sont disséminées sur divers points des membranes séreuses; de semblables taches se sont rencontrées dans les ventricules du cerveau, dans l'œesophage, sur le mésentère, la vessie, la matrice, et mème sur le foetus d'une femme enceinte, disent les auteurs d'un rapport fait à la Faculté de Bordeaux sur les empoisonnements par les champignons. Extérieurement, on remarque sur les téguments des taches violettes, nombreuses et très-étendues.

L'empoisonnement par les champignons ne présente pas, comme on a pu le voir, de symptòmes qui lui soient essentiellement propres; tous ceux dont j'ai fait mention peuvent se rencontrer dans l'empoisonnement par d'autres substances végétales : il en est de mème des lésions organiques que constate l'autopsie. 
CHAPITRE XIX.

DES MOYeNS DE REMÉdIER AUX ACCIDENTS PRODUITS PAR LES CHAMPIGNONS DÉLÉTÈRES.

Les personnes qui ont mangé des champignons vénéneux étant presque toujours vouées à une mort certaine, si elles ne sont promptement secourues, on doit, aussitôt que les premiers symptòmes de l'empoisonnement se manifestent, leur donner tous les secours que réclame leur position. En l'absence d'antidotes bien constatés, ce que le médecin a de mieux à faire, c'est de débarrasser l'économie de la substance ingérée, afin de soustraire le malade à son influence pernicieuse. On le fera donc vomir au plus tôt, que le champignon appartienne à la classe de ceux dont les effets sont surtout narcotiques ou à la classe de ceux dont l'action particulière est de déterminer des désordres inflammatoires. Mais comme d'ordinaire, lorsque les premiers symptòmes se déclarent, le poison se trouve déjà en partie dans le canal intestinal, il convient, en mème temps que l'on fait vomir, de procurer des évacuations alvines.

L'ípécacuanha, délayé dans l'eau, à la dose de 5o centigrammes à I gramme et plus, selon l'âge de la personne, ou l'émétique, à celle de 5 ou 1 o centigrammes en solu- 
tion dans une tasse du mème liquide, sont des mọ ens presque toujours sûrs de provoquer le vomissement. Si l'on ajoute à ces substances de 15 à 3o grammes de sulfate de potasse, de soude ou de magnésie, que l'on administre par fractions, à des intervitles plus ou moins rapprochés, on produit le double effet du vomissement et de la purgation. On secondera les efforts du vomissement, en faisant boire abondamment de l'eau tiède; et, si les effets de la purgation tardaient à se manifester, il faudrait faire prendre au malade des purgatifs un peu actifs, tels que le séné, la rhubarbe, la casse, en décoction; l'huile de ricin, mêlée au sirop de nerprun ou au sirop de fleurs de pêcher, les sels neutres en solution. Ces mèmes substances, prises en lavement, pourraient être d'une grande utilité.

Si l'on n'avait pas à sa disposition les médicaments dont je viens de parler, comme l'on perdrait des moments précieux en restant inactif et en abandonnant le malade à lui-mème pendant le temps que l'on mettrait à se les procurer, il faudrait chercher à provoquer le vomissement, en faisant boire au malade de l'eau tiède en quantité, après quoi on introduit le doigt jusqu'au fond de la gorge, ou mieux encore la barbe d'une plume imbibée d'huile ou trempée dans une infusion légère de tabac, avec laquelle on chatouille toute l'arrière-bouche. On a recours de préférence à l'huile à brûler, comme plus nauséeuse : fumer est, pour les personnes qui ne sont pas habituées à l'usage du tabac, un assez bon moyen d'exciter des vomissements et quelquefois des selles. La décoction d'une pincée de tabac haché ou en corde dans 250 grammes d'eau, donnée en plusieurs fois, produit assez constamment le romissement : cette décoction le provoque, mème prise en lavement. Toutefois il ne faudrait pas dépasser la faible quantité que je viens d'indiquer, le tabac pris à forte dose 
étant lui-mème un poison violent. On a fait vomir des malades en leur présentant ou en leur faisant avaler un objet qui leur répugnait beaucoup.

Nous avons vu que les champignons vénéneux agissent les uns à la manière des poisons âcres, irritants : tels sont les Bolets, les Kussules, les Lactaires ; les autres à la manière des poisons essentiellement narcotiques, la fausse Oronge, par exemple, et quelques autres tout à la fois comme des poisons âcres et narcotiques, tels que l'Agaric bulbeux et l'Agaric panthère.

Les symptômes d'empoisonnement différant selon que le champignon agit comme poison irritant ou poison narcotique, le traitement ne doit plus être le mème, après que l'on a provoqué le vomissement et des évacuations alvines.

Si l'empoisonnement était accompagné d'accidents nerveux, sans qu'il y eût apparence d'inflammation, on ferait usage des antispasmodiques et des sédatifs. L'éther sulfurique s'est acquis une certaine réputation contre ces diverses sortes d'accidents. Je dois faire observer ici que, comme cette substance a la propriété de dissoudre le principe actif des champignons, on ne doit recourir à son emploi que lorsque le champignon est rejeté en entier, ou tout à fait absorbé. Il en est de mème des acides, tels que le vinaigre, les sucs de citron, d'orange, de verjus, etc., dont l'utilité, de mème que celle des dérivatifs, est bien reconnue lorsqu'il y a stupeur et engourdissement.

Le coma, l'assoupissement, dans les empoisonnements par les champignons narcotiques, est quelquefois si profond, et la constriction des mâchoires si grande que l'on ne peut rien faire avaler au malade. On a proposé, dans ce cas, de se servir d'une sonde en eaoutchouc, longue de 
50 à 60 centimétres, pour ingérer dans l'estomac une potion émétisée, ou un éméto-cathartique. On introduit la sonde dans la bouche, au défaut d'une dent, ou bien on l'engage dans l'espace qui reste libre entre les deux dernières molaires et l'arcade dentaire. On fait pénétrer la sonde dans l'cesophage et mème jusque dans l'estomac; on chasse alors, an moyen d'une seringue qui s'adapte à celle-ci, le liquide que l'on a soin de pousser lentement.

On peut craindre dans cette opération de faire pénétrer la sonde dans le larynx; on évite cet accident en dirigeant en arrière l'extrémité de celle-ci. On pourrait aussi faire pénétrer la sonde par les narines; quoi qu'il en soit, ces divers procédés opératoires exigent une main exercée.

Chantarel assure avoir employé avec avantage la décoction de noix de galle, comme antidote des champignons.

La noix de galle, de mème que le tannin, expérimentés par moi, ne m’ont donné aucun résultat avantageux. II. Réveil, les ayant expérimentés de son còté, dit que ces substances, de même que la décoction de quinquina, sont d'une complète inutilité.

Le café néanmoins est d'une utilité bien démontrée dans les cas d'empoisonnement par les champignons narcotiques; mais c'est bien moins peut-être à cause du tannin qu'il contient que parce qu'il possède une propriété stimulante, dont l'effet essentiel est de tirer les malades de l'assoupissement dans lequel les plongent si souvent ces espèces, qu'il agit.

M. Boudier pense que le tannin et l'infusion de noix de galle peuvent être donnés avec avantage, mais il préfère, après que les vomissements ont été provoqués, donner de temps en temps aux malades, et par cuillerées, une solution très-légère d'iodure iodé de potassium : cette solution, dit-il, précipite le poison des Amanites mieux que le taunin 
et l'infusion de noix de galle, et pénètre plus facilement dans la circulation (1).

Dans l'empoisonnement par les champignons à principe âcre, lorsqu'une fois on est parvenu à provoquer l'expulsion de la substance nuisible, ou bien lorsqu'il s'est écoulé un temps fort long depuis le moment de son ingestion, et que l'on peut raisonnablement supposer qu'elle a été toute absorbée, et ne se trouve plus dans les voies digestives, c'est aux moyens jugés propres à combattre l'inflammation qui s'est développée sur l'estomac, les intestins et souvent dans d'autres organes, qu'il faut avoir recours; inflammation qui se reconnait à la sécheresse de la langue, l'intensité de la soif, la fréquence et la petitesse du pouls, la chaleur de la peau, la douleur et la tension du ventre.

Ces moyens sont : les saignées générales et locales, que l'on est quelquefois obligé de réitérer; les boissons mucilagineuses, telles que la décoction de gomme arabique, l'infusion de racine de guimauve, de graine de lin ; les boissons émulsives, le lait d'amandes, le lait coupé, le blanc d'œuf battu dans de l'eau, les boissons dites délayantes et rafraichissantes, la décoction d'orge, de gruau ou de fécule, les sirops d'orgeat, de groseille, de limon, de vinaigre, étendus d'eau; le petit-lait, l'oxymel, la limonade avec le citron ou l'orange. Généralement les acides végétaux sont employés avec avantage à cette période de la maladie. Un pharmacien de Bordeaux a préconisé l'ammoniaque liquide.

Si les boissons étaient rejetées par les vomissements, comme il arrive quelquefois lorsque l'inflammation est fort intense, il faudrait les faire prendre seulement par cuillerées à la fois, et insister sur l'emploi des saignées, des

(1) Des Champignons, etc., p. 122. 
bains, des fomentations émollientes sur le ventre, des lavements adoucissants, et tenir lo malade it une diete sévère.

Si le malade se refroidit, il faut rappeler la chaleur, activer, autant que possible, la circulation par l'usage des boissons chaudes, le thé, le café, l'infusion de menthe, de mélisse, etc.; les frictions légères; les sinapismes.

Dans la longue convalescence qui suit généralement l'empoisonnement par les champignons, on donnera au malade des aliments de facile digestion, des crèmes de riz ou d'orge, des fécules, de la bouillie, des panades, des laits de poule, des légumes, des fruits cuits, des viandes légères, un peu de vin rouge ou plutòt de la bière, et dans l'intervalle des repas de l'eau sucrée. Si les forces tardaient trop à revenir, on lui ferait prendre des amers, des toniques, des préparations de quinquina, de fer, etc., et des aliments succulents.

Lorsque l'empoisonnement est occasionné par le mélange de champignons à principe narcotique et de champignons à principe âcre, on conçoit que le traitement doit être mixte. Le plus rationnel sera toujours de faire vomir, si l'on suppose que le champignon séjourne encore dans l'estomac, après quoi on s'attachera à combattre les symptòmes prédominants $(\mathrm{I})$.

Une indigestion causée par l'usage de champignons reconnus pour comestibles ne présente pas généralement de gravité. On y remédie en provoquant le vomissement avec de l'eau tiède, après quoi on fait prendre au malade du thé, du café léger, ou une eau légèrement alcoolisée. Pres-

(1) Je renvoie, pour le traitement des maladies cutanées: dartres, teignes, etc., attribuées à des végétaux parasites : achorion, trichophyton, etc., aux ouvrages spécialement consacrés aux maladies de la peau. 
que toujours le malade se remet promptement de son indisposition.

Du traitement de l'empoisonnement par les champignons chez les anciens.

Le traitement auquel chez les anciens étaient soumises les personnes qui avaient mangé des champignons malfaisants parait aujourd'hui quelque peu empirique; aussi est-il généralement abandonné. Peut-être serait-il convenable cependant de reprendre, ne fùt-ce qu'à titre d'essai, l'emploi des remèdes usités par eux, car, selon toute vraisemblance, c'était l'expérience qui leur avait appris à faire choix de telle substance plutôt que de telle autre.

Le raifort, Cochlearia armoracia, Lin., dit Pline, est, d'après le témoignage de Nicandre, utile contre les empoisonnements par les champignons ( 1 ).

Si l'on a fait usage, dit Celse, de champignons malfaisants comme nourriture, il faut manger du raifort (radicula), assaisonné d'oxycrat ou de sel et de vinaigre.

Galien dit, à son tour, que l'on donnait, en quantité, des radis (raphani) crus aux personnes qui étaient malades pour avoir mangé des champignons. On leur faisait prendre aussi du vin pur, de la lessive de cendres de sarment, du nitre dissous dans du vinaigre, de la lie de vin brûlée, délayée dans de l'eau et donnée en boisson, ou de l'absinthe avec du vinaigre, ou bien encore de la rue, Ruta graveolens, Lin., en poudre, délayée dans du vinaigre. La rue, ajoute-t-il, mangée seule fait du bien aussi (3).

(1) Pline, $\mathbf{X X}, 13$.

(2) Celse, 1. V, sect. 27-1\%.

(3) Galien, t. XIV, c. 7, p. 140. 
Lit rue, dit Pline, est utile contre l'empoisonnement par ces plantes, soit qu'on la donne en boisson, soit qu'on la domne en substance ( $\mathrm{I}$ ).

I a graine de rue des montagnes, Ruta monlana, Dec., dit de son côté Dioscoride, bue dans du vin, à la dose de I 5 drachmes ( 67 gram. 5 o centigr.), est un puissant remède contre tout empoisonnement. I.es feuilles de rue, mangées seules, à jeun, ou avec des noix et des figues sèches, amortissent toute espèce de venin. On donnait la préférence à la rue des jardins sur celle des montrgnes; celle-ci, plus active, causait la mort si l'on en mangeait trop (2).

Les anciens, comme l'on voit, faisaient un cas tout particulier de la rue : elle leur servait de médicament et d'aromate. Aujourd'hui encore on l'emploie, en Italie, comme condiment dans les salades. L'emploi de cette plante à haute dose étant dangereux, c'est avec circonspection qu'il faut en faire usage.

La fiente de poule, dit Galien, a soulagé promptement des personnes qui étaient comme asphyxiées pour avoir mangé des champignons. Après avoir réduit la fiente en poudre, on la délayait dans trois ou quatre tasses d'oxycrat ou d'oxymel: peu de temps après en avoir pris, les personnes vomissaient et étaient complétement débarrassées.

Serait-ce uniquement comme vomitif que la fiente de poule agirait, ou bien est-ce en vertu de l'urate de chaux qu'elle contient? De nos jours encore quelques personnes ont recours à l'usage de cette fiente de poule dans maintes maladies, seulement elles font choix du blanc de cette

(1) Pline, $\mathbf{X x}, 51$.

(2) Dioscoride, livre III. 
substance. Délayée dans du vin, la fiente de poule prend, à Montmorency, le nom de vin de poule.

Apollodore, au rapport de Pline, parle de l'emploi du suc de choux pour remédier aux accidents causés par les champignons. 


\section{CHAPITRE XX.}

DE I' EMPLOI DES CHAMPIGNOYS EN MÉDECINE.

$\Lambda$ pres avoir parlé assez longuement des propriétés malfaisantes des champignons, je crois devoir dire quelques mots des propriétés médicales attribuées à plusieurs de ces plantes.

La médecine en faisait autrefois un usage assez fréquent, aujourd'hui cet usage est à peu près entièrement abandonné ; mais sans doute on y reviendra, car le plus souvent la médecine, après avoir longtemps délaissé, sans trop savoir pourquoi, l'usage de tels ou tels médicaments, un jour vient qu'elle les sort de l'oubli où elle les avait laissés.

Parlons d'abord de l'emploi que les anciens faisaient de ces plantes.

Selon Pline, le champignon que de son temps on appelait Agaric, et que les pharmaciens continuent à appeler de ce nom, le Bolet du Mélèze, Polypore officinal des mycologistes, pris en boisson, à la dose de trois oboles (I) (2 gramm. 25 centigr.), dans un cyathe (o litre $0 / 45$ ) de

(1) Obole, la sixième partie de la drachme. Cyathe, la douzième partie du patarin. 
vin vieux, guérissait la strangurie et la splénite. Ce champignon, donné de la même façon et aux mêmes doses, guérissait le nerf appelé platys (le tendon d'Achille?) et la douleur d'épaule. On le donnait aussi réduit en poudre à la dose de 4 oboles ( 3 gramm. 45 centigr.) dans deux cyathes (o litre og) de vinaigre.

Les anciens distinguaient l'Agaric mâle et l'Agaric femelle, tous les deux de couleur blanche et croissant sur les arbres. Le mâle, dit Pline, est plus dense, plus amer; il cause de la céphalalgie. L'Agaric femelle, moins consistant que le mâle, a une saveur d'abord douce, mais qui bientôt devient amère.

Nous ne savons pas trop si ce que les anciens appelaient Agaric màle et Agaric femelle étaient deux espèces distinctes, ou s'ils n'étaient pas, ce qui est très-vraisemblable, de simples variétés d'une même espèce. Quoi qu'il en soit, l'Agaric qui venait de la Gaule passait pour plus faible que celui que l'on recueillait aux environs du Bosphore.

On les employait contre les flux de ventre. On les faisait entrer dans la préparation des médicaments appelés ophthalmiques, dont on se servait pour bassiner les yeux. On les employait pour faire disparaitre les lentilles (lentigines), les taches de rousseur et autres taches qui viennent sur le visage des femmes. On les employait contre les éruptions et ulcères sordides de la tête, contre la morsure des chiens, comme aussi pour réprimer les excroissances qui viennent au fondement ( $\mathrm{I}$ ).

Voyons maintenant quel usage la médecine a fait des champignons dans des temps plus rapprochés de nous, et quel usage elle en pourrait faire encore.

La fausse Oronge, administrée en poudre, à l'intérieur,

(1) Pline, 1. 22-58; 1. 25-57; 1. 26-48. 
a été 'mplovée arec succes, assure-t-on, contre l'épilejsie et d'autres maladies nerveuses. Bernardet et Whisling attestent son succès ( 1 ).

Plenck faisait prendre sa poudre intérieurement contre l'épilepsie. Il la donnait à la dose de cinquante grammes à un gramme, trois fois par jour, dans de l'eau, ou à celle de quatre grammes, une fois seulement dans la journée, administrée dans du vinaigre, comme plus efficace.

Employé à l'intérieur et à l'extérieur, en même temps, ce champignon aurait guéri les engorgements chroniques (tumeurs et indurations), les scrofules, et des ulcères fistuleux de mauvais caractère.

Sa poudre, répandue sur les ulcérations de la cornée, les excoriations du bout du sein, les ulcères sanieux ou compliqués de carie, aurait guéri ces maladies.

La fausse Oronge était cueillie avant sa maturité, puis séchée à l'ombre ou dans un four. Les médecins employaient de préférence la poudre obtenue du pied du champignon; attendu qu'il contient, comme nous l'avons dit, plus de principe actif que le chapeau.

La teinture de ce champignon a été vantée contre la teigne, les impétigos, les dartres et le catarrhe chronique avec crachats muqueux et puriformes. Elle se donnait, étendue d'eau ou de vinaigre, à la quantité de douze à quarante gouttes, répétée trois fois par jour.

La fausse Oronge aurait aussi, à ce que l'on prétend, arrèté des diarrhées et des sueurs trop abondantes.

On sait que les habitants du Kamtschatka emploient ce champignon non pas comme médicament, mais dans le but de se plonger dans une sorte d'ivresse.

Tantôt ils le mangent desséché et tantôt infusé dans du

(1) Whisling, Dissert, de virtut. Agarici muscarii. 
suc de Vaccinium uliginosum, ou bien encore ils en préparent, avec les feuilles d'une espèce d'épilobe et de l'eau, une boisson qu'ils boivent comme du vin. La fausse Oronge produit sur eux l'effet du vin, et, comme celui-ci, elle provoque, chez quelques-uns la joie, l'exaltation, les chants, la danse; tandis que chez d'aatres elle amène la tristesse, la violence, les excès. Je ne recommanderai pas le procédé kamtschatkale comme moyen propre à préserver des maladies.

Ce champignon n'a jamais, que je sache, été employé en médecine à titre de sédatif; ses propriétés nárcotiques cependant sont bien connues. Pourquoi ne l'emploierait-on pas comme succédané de l'opium? Il y aurait mème de l'avantage sous le rapport pécuniaire; car il ne demande pas de culture; on sait qu'il est peu de contrées boisées où on ne le trouve abondamment, en automne.

Il serait facile d'en faire des extraits, des sirops, des teintures alcooliques ou éthérées, etc.

Son suc, de même que celui de plusieurs autres Amanites, appliqué sur la peau dénudée, produisant par absorption le narcotisme, ou pourrait, sous cette forme, l'employer à faible dose, comme on emploie la morphine et autres préparations opiacées.

Tout récemment le $\mathrm{D}^{\mathrm{r}}$ Curtis a proposé l'emploi thérapeu. tique des champignons vénéneux contre le choléra, la maladie de Bright et les fièvres intermittentes. C'est la teinture d'Agaric bulbeux dont il a fait usage contre ces maladies : malheureusement ses observations sont trop peu nombreuses pour ètre concluantes; toutefois il sera bon de les répéter.

L'Agaric poivré, Agaricus acris, Bull. (Lactarius pipera. tus, Fr.), a été d'usage en médecine. Son suc laiteux, pris avec le sirop d'althæa, passait pour provoquer l'excrétion de l'urine et briser les calculs. 
La mème propriété était attribuée à l'Agaric zoné, $A g$. (Lactarius) zonarius, Fr. autre lactaire. Vaillant dit que le suc de ce champignon, pris arec le sirop d'althea, brise le calcul, d'après une expérience certaine, en même temps qu'il provoque l'urine. Il dit aussi que par le frottement il fait disparaitre les verrues.

Au rapport de MY. Noulet et Dassier, les paysans du Languedoc emploient aujourd'hui encore cet Agaric pour cautériser ces excroissances. Son suc agit à la manière du lait de la chélidoine et du réveil-matin.

Césalpin attribue au Polypore tubérastre, champignon cultivé à Naples sur la pietra fungaja, la vertu de provoquer la sortie de l'urine et des graviers; comme aussi celle de dissiper les douleurs d'estomac, de guérir l'ictere et le flux de ventre (1).

Pour en revenir à l'Agaric poivré, ce champignon aurait guéri la phthisie pulmonaire, lorsque déjà cette maladie était accompagnée de fièvre hectique et de vomique du poumon. M. Dufresnoy le réduisait en poudre, après l'avoir lavé, puis desséché dans un four : il en composait ensuite un opiat ou électuaire de la manière suivante.

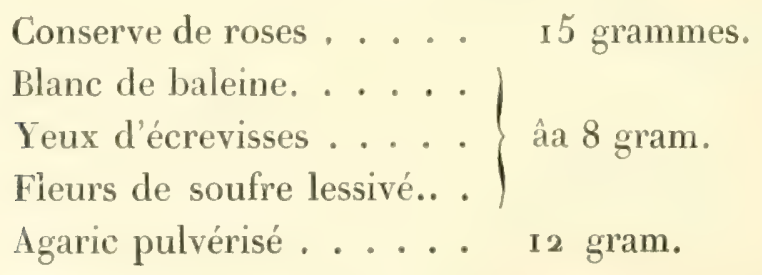

Miel de Narbonne, quantité suffisante pour composer un électuaire dont on faisait prendre deux grammes et demi, trois fois par jour, délayé dans une infusion de mille-feuille sucrée.

(1) Cisalpin, 4x. 
L'Agaricus (Lactarius) corminosus, Fr., était quelquefois substitué à l'Agaric poivré : on l'ajoutait à l'électuaire, mais à la quantité d'un gramme cinquante centigrammes seulement. Le quinquina aussi y était quelquefois ajouté, à la dose d'un gramme, et l'opium à celle -de vingt centigrammes.

Le Pecq de Cloture faisait usage de ce même électuaire dans les mèmes circonstances. Cette préparation, délaissée aujourd'hui, pourrait être essayée de nouveau dans les cas de catarrhes chroniques et de phthisie non trop avancée.

Pourquoi aussi ne tenterait-on pas la guérison des ulcères atoniques par l'application sur les plaies de la pulpe, du suc ou de la poudre d'Agarics de la section des Lactaires et des Russules? Nous avons vu que le suc de quelques-unes de ces plantes, mis en contact avec la peau dénudée, produit par son âcreté une inflammation limitée qui ne détermine pas d'accidents généraux. La chair écrasée de ces Agarics ne pourrait-elle pas aussi être utilisée pour produire la rubéfaction de la peau?

L'Agaric amer, Bull., Ag. elæodes, Fr., croît, pour ainsi dire, toute l'année, en touffes considérables, sur les souches d'arbres à demi pourries. Ce champignon, qui n'est jamais attaqué, ni par les insectes, ni par les limaces, provoque, pris en petite quantité, des vomissements et des selles abondantes; on pourrait donc le prescrire en médecine comme vomi-purgatif, en substance, en infusion, en décoction.

D'autres Agarics, tels que l'Agaric fasciculaire, $\mathbf{A g}$. fascicularis, Huds., l'Agaric rouge-brique pâle, Ag. sublaleritius, Schæff., jouissent des mèmes propriétés que l'Agaric amer. Une fois introduits dans les officines, ces champignons y prendraient place à côté de la rhubarbe, du séné, de l'aloès, du nerprun, de la mercuriale, etc. Toute. 
fois leur emploi devrait ètre réglé par la médecine, car l'Igaric amer tue un chien a la dose de soixante grammes.

On pourrait anssi utiliser, comme médicament, l'Agaric styptique, Ag. (Panus) stypticus, Fr., qui, comme on le sait. purge violemment les animaux auxquels on le donne, mais ne les tue pas.

Sertorius est le premier qui ait prescrit le Bolet odorant, Boletus sulicinus, Bull. (Trumetes suareolens, Fr.), contre la phthisie pulmonaire. 11 le donnait en poudre à la dose d'un gramme trente centigrammes, deux ou trois fois par jour.

Les professeurs Schmidel et II endst rapportent des exemples de guérison de cette fatale maladie, obtenue par l'emploi d'une cuillerée à café d'électuaire de ce champignon donnée dans du miel, trois fois par jour.

Le Bolet du Mélèze, Polyporus officinalis, Fr., était vanté, il y a peu de temps encore, contre les sueurs colliquatives des phthisiques. C'est en poudre et en extrait qu'on l'administrait. Son usage exige de la prudence, à cause de ses effets drastiques.

Ce Bolet contient, d'après les analyses de Braconnot et de Bonillon-Lagrange, une grande quantité de résine âcre, à laquelle il doit sans doute ses propriétés purgatives. Tromsdorff regardait ce purgatif comme préférable à la résine de jalap. Les paysans suisses s'en servent pour purger les vaches.

Haller rapporte que les habitants du Piémont prennent un petit morceau de ce champignon, avec addition d'un peu de poivre, quand ils ont avalé quelques-unes de ces petites sangsues dont les eaux de leur pays abondent. Les habitants de Balen l'emploient réduit en poudre, dit Bomare, pour guérir les pustules, les furoncles de leur bétail. 
Fouquier avait préconisé le Bolet du Mélèze contre les sueurs nocturnes des phthisiques. Ce champignon est un purgatif violent qui autrefois était très-employé, mais dont aujourd'hui l'usage est très-restreint : il doit, à ce qu'il paraît, sa propriété cathartique à un principe résineux.

Un autre Bolet, Polyporus serpenıarius, Pers. (P. annosus, Fr.), qui peut-être ne vient pas en France, est employé par les paysans de la Suède contre la morsure des serpents. Ils exposent à la fumée du champignon le membre qui a été blessé ; la guérison, au rapport de Fries, ne se fait pas attendre. Fries dit aussi avoir vu arrêter, dans un court espace de temps, par l'application de ce même Polypore, le sang qui coulait de la bouche d'un chevreau qui avait été blessé.

Ce que l'on appelle amadou et Agaric des chirurgiens se retire, comme nous l'avons vu, du Polyporus fomentarius, Fr., et de plusieurs autres Polypores.

L'amadou est usité surtout dans le pansement des plaies pour arrêter les hémorragies des petits vaisseaux, à cause de sa propriété absorbante. On l'emploie aussi, comme la flanelle, et mieux que la flanelle, pour conserver le calorique sur les parties du corps qui ont besoin d'une chaleur permanente. Nous avons dit plus haut que l'on en fait des vêtements.

En Angleterre, les médecins font usage de plaques d'amadou pour prévenir les ulcérations qui surviennent si fréquemment aux parties déclives du corps, le sacrum, le trochanter, chez les personnes qu'une longue maladie condamne à l'immobilité pendant des semaines entières : telles que les fractures, les luxations. Ils l'emploient de même pour exercer une pression légère sur les veines variqueuses et réprimer leur dilatation.

L'odeur de l'amadou brûlé, préparé avec l'azotate de 
potasse, est un excellent calmant pour les personnes atteintes de maux de nerfs.

La décoction dans le lait de la Pezize oreille de Judas, Exidia auricula Judx, Fr., et son infusion prolongée dans le vinaigre, étaient autrefois fréquemment employées en gargarismes contre les esquinancies, le gonflement des amygdales et autres maladies de la bouche et de la gorge; aujourd'hui quelques personnes ont recours à leur usage dans les mèmes circonstances.

En Allemagne, ce champignon, trempé dans l'eau de roses, est souvent usité dans la médecine du peuple pour combattre les inflammations oculaires. On prétend qu'on l'a administré avec succès aux hydropiques, de mème que le Bolet du Mélèze.

L'Oreille de Judas passe pour purgative; il est douteux qu'elle le soit en effet, car elle est employée, ou du moins une espèce qui lui ressemble singulièrement, est employée comme aliment dans diverses parties du monde.

Avant que la ligature des artères fùt devenue d'un usage vulgaire, on employait la poussière de la Vesse-loup gigantesque, Lycoperdon giganteum, Batsch, et celle de la Vesseloup ciselée, L. cælatum, Bull., pour arrêter le sang. On s'en servait, comme on se sert aujourd'hui de poudre de colophane, de toile d'araignée ou de linge brûlé. En Angleterre, c'est encore aujourd'hui un remède populaire contre les coupures et les saignements de nez. Le vulgaire, dit Murray, en fait usage, en Allemagne, contre l'état chassieux des paupières des chevaux et des bêtes de trait, et aussi contre leur diarrhée, dit Loesel (I). Valmont de Bomare assure que les barbiers d'Allemagne ont toujours dans leurs boutiques de la poudre de Vesse-loup gigan-

(1) Laselius, Flora Prussica, p. 82 . 
tesque, qu'ils mettent sur les coupures des rasoirs pour arrêter le sang.

Les expériences de Lafosse prouvent combien son efficacité est grande, puisque, chez le cheval, après que l'on avait coupé l'artère crurale, on a arrêté la perte du sang à l'aide de la compression faite avec un fragment du champignon, recouvert de sa poussière séminale. Je ne sais, dit Ascherson, si l'on ne devrait pas recourir à l'emploi de ce moyen, dans les cas d'hémorragies gangréneuses, lorsque le chirurgien, ne parvenant pas à les arrèter, croit n'avoir plus de ressources que dans l'amputation.

Les spores de la Vesse-loup géante, mèlées avec du lait, sont un remède populaire en Italie contre le cours de ventre des bœufs.

La fumée des Lycoperdons passe pour posséder des propriétés anesthésiques, c'est-à-dire de nature à abolir la sensibilité générale. On l'emploie depuis longtemps, en Angleterre, avec succès, pour stupéfier les abeilles lorsqu'on veut prendre leur miel sans les détruire. On a mème fait usage de ces plantes comme substitut du chloroforme. Des opérations, dit Berkeley, auraient été tentées avec succès sous leur influence ( 1 ).

Le $\mathrm{D}^{\mathrm{r}}$ Richardson a pu endormir des chiens pendant plusieurs heures et produire la suspension momentanée de la sensibilité, en les exposant à la vapeur de la combustion de la poussière de Lycoperdons. C'est par le dégagement de gaz acide carbonique et d'oxyde de carbone que la fumée opère; ce n'est donc pas à la manière de l'éther ou du chloroforme. Du reste, ce procédé ne fait-il pas courir les mêmes dangers et peut-être même des dangers plus grands que ceux auxquels sont exposées les personnes

(1) Berkeley, Garden. Chron., 1860, p. 289. 
que l'on soumet ì l'action de ces dernières substances?

Les habitants de Java, dit Zippelius, se servent de la poussière du Lycoperdon kakava, Lév., pour se guérir de coliques flatulentes.

La Truffe du Cerf, Elaphomyces granulatus, Fr., servait autrefois à colorer le baume apoplectique. Elle passait pour alexipharmaque, c'est-à-dire comme moyen propre à expulser du corps les poisons, les virus, 'qui s'y seraient introduits. On lui accordait aussi la propriété de provoquer la sécrétion du lait et d'accélérer l'accouchement. Si elle possède réellement cette dernière propriété, on pourrait la substituer au seigle ergoté. Il est vrai que celui-ci se trouve plus communément dans les pharmacies.

Gleditsch parle d'un paysan qui, pour rézeiller en lui les désirs vénériens, prenait tous les jours huit grammes d'esprit-de-rin dans lequel il avait laissé macérer la Truffe du Cerf, Elaphomyces granulatus, Fr. Il vantait cette liqueur comme ayant la vertu merveilleuse de ranimer ceux qui étaient affectés de langueur maritale. Il en cédait largement et gratuitement à tous les pauvres. Quelques charlatans, moins généreux, vendaient, au poids de l'or, cette teinture à des jeunes gens blasés et à des vieillards maniaques. Aujourd'hui encore la Truffe du Cerf est usitée dans quelques pays comme aphrodisiaque.

Ia Truffe comestible, Tuber cibarium, Sibth., et la Truffe blanche, Rhizopogon albus, Fr., Hymenogaster Klotschii, Tul., jouissent aussi à un haut degré de la réputation de porter aux plaisirs de l'amour, réputation qui pourrait bien ètre usurpée, car bon nombre de personnes en ont mangé, et mème en assez grande quantité, sans avoir constaté la propriété spéciale qu'on leur attribue. Quoi qu'il en soit, les Truffes paraissent être un restaurant efficace dans les cas d'épuisement et de faiblesse d'estomac. 
L'estime que l'on faisait de ces plantes, comme aphrodisiaques, et la croyance où l'on était qu'elles ne venaient point de semences et qu'elles n'en donnaient point, a inspiré à un poëte, dont le nom est resté ignoré, le distique suivant :

Semina nulla damus; sine semine nascimur ullo, At qui nos mandit semen habere putat (1).

Le Satyre fétide, Phallus impudicus, L., réduit en poudre, est regardé, dans plusieurs cantons, comme un remède qui porte aussi aux plaisirs de l'amour.

Beckmann dit qu'on le donne aux bestiaux pour les exciter à l'accouplement. Ascherson a vu un cheval de dix-sept ans se montrer très-ardent en amour après avoir mangé de ce champignon. Quelques personnes prétendent qu'il détermine de fréquents avortements chez les vaches, ce que d'autres nient. Gleditsch dit qu'on le cueille avant qu'il soit entièrement développé, car il parait qu'il ne produit son effet que lorsqu'il est encore dans son volva. Alors il n'a pas l'odeur fétide qu'il aura plus tard. On le dessèche et on l'emploie réduit en poudre. Hertwig l'a donné à des chiens et à des chevaux; il n'en a rien obtenu. Ne serait-ce pas la forme même de ce champignon qui lui aurait fait accorder la vertu stimulante qu'on lui attribue? Beaucoup d'autres champignons, les Bolets, les Agarics et les Morilles, en particulier, jouissent de la réputation de posséder cette mème vertu. La propriété aphrodisiaque de ces plantes est fortement contestée aujourd'hui.

Le Phallus Mokusin, Lin. (Lysurus Mokusin, Cib.), en Chine, et le Lycoperdon carcinomale, Lin. (Podaxon carci-

(1) « Nous ne provenons pas de semence, nous ne donnons pas de semence, et celui qui nous mange pense en obtenir de nous. ) 
nomalis, Fr. , près du cap de Bonne-Espérance, sont, dit Iadliam, employés par les habitants de ces pays en applications extérieures contre les plaies cancéreuses.

Les Chinois saupoudrent ces ulcères de la cendre du Phallus Mokusin jusqu'a ce que toute la malignité du mal ait disparu. Ils le mangent quelquefois, mais non sans danger, car c'est un véritable poison ( 1 ). Ce champignon et le Lycoperdon carcinomale produiraient donc un effet tout contraire à celui que les habitants des I andes attribuent au Clathre grillagé.

Le Satyre fétide est encore dans quelques pays un remède populaire contre la goutte; aussi, en Allemagne, on l'appelle Champignon de la goutte. En Hollande, au rapport de Greville, on l'emploie en cataplasmes contre les douleurs rhumatismales.

Les Pachyma, champignons souterrains qui viennent dans les contrées les plus chaudes du globe, sont usités en médecine.

Le Pachyma Tuber regium, Rhumph., qui vient à Amboine, dans les ìles Moluques, est vanté contre la diarrhée, les maux de gorge, les fièvres, etc. Le $P$. Hoelen, Fr., que l'on trouve en Chine, est un médicament précieux dont on fait usage, à la manière du thé, pour rétablir les forces. On l'emploie contre la phthisie. Le Pachema C'ocos, Schwein., plante de la Caroline, est de même employé par les indigènes dans le traitement des maladies. On ne nous dit pas quelles sont les maladies contre lesquelles on en fait usage (2)

On sait quel usage fréquent, on pourrait mème dire quel abus, les accoucheurs et les sages-femmes font aujourd'hui

(1) Fries, Systema mycol., II, P. 286.

2) Frin's, Systema myc., II, 1. 2'?2. 
du seigle ergoté pour ranimer les contraclions de l'utérus dans les cas d'inertie de cet organe, accélérer l'accouchement, favoriser la délivrance, arrêter les pertes atoniques qui surviennent quelquefois après le travail de l'enfantement. On administre cette substance, réduite en poudre, à la dose de cinquante centigrammes à deux grammes; et en infusion à celle de quatre grammes pour cinq çents grammes d'eau. Qui aurait pensé, il y a un demi-siècle à peine, que l'ergot du seigle, poisọn lent lorsqu'il est mèlé au pain, prendrait place dans la matière médicale et deviendrait d'un usage général, comme médicament? Ajoutons que si cette substance a rendu des services, son abus a occasionné plus d'une fois la mort des enfants, et n'a pas èté sans nuire à la mère.

Wiggers, à qui l'on doit l'analyse la plus complète du seigle ergoté, y a trouvé un principe particulier, doué de propriétés narcotiques, qu'il appelle ergotine, et que l'on administre à peu près dans les mèmes circonstances que l'ergot, mais à de moins fortes doses.

Nous avons vu que les champignons renferment une forte proportion de matières extractives azotées, solubles dans l'eau. Ces plantes ne contenant pas d'amidon, ou du moins n'en contenant qu'une quantité à peu près inappréciable, et ne renfermant du sucre qu'à l'état de mannite, et cela dans une très-faible proportion, pourraient, de préférence, ètre données comme nourriture aux personnes affectées de diabète sucré; s'il est vrai, ce qui est mis en doute aujourd'bui, qu'il faille dans cette fâcheuse maladie s'abstenir surtout d'aliments féculents, dans la crainte de transformer la fécule en sucre. 



\title{
CHA MPIGNONS
}

\author{
DE LA FRANCE.
}

- जबिकाष

DEUXIEME PARTIE.

Tableau synoptique des familles de Champignons.

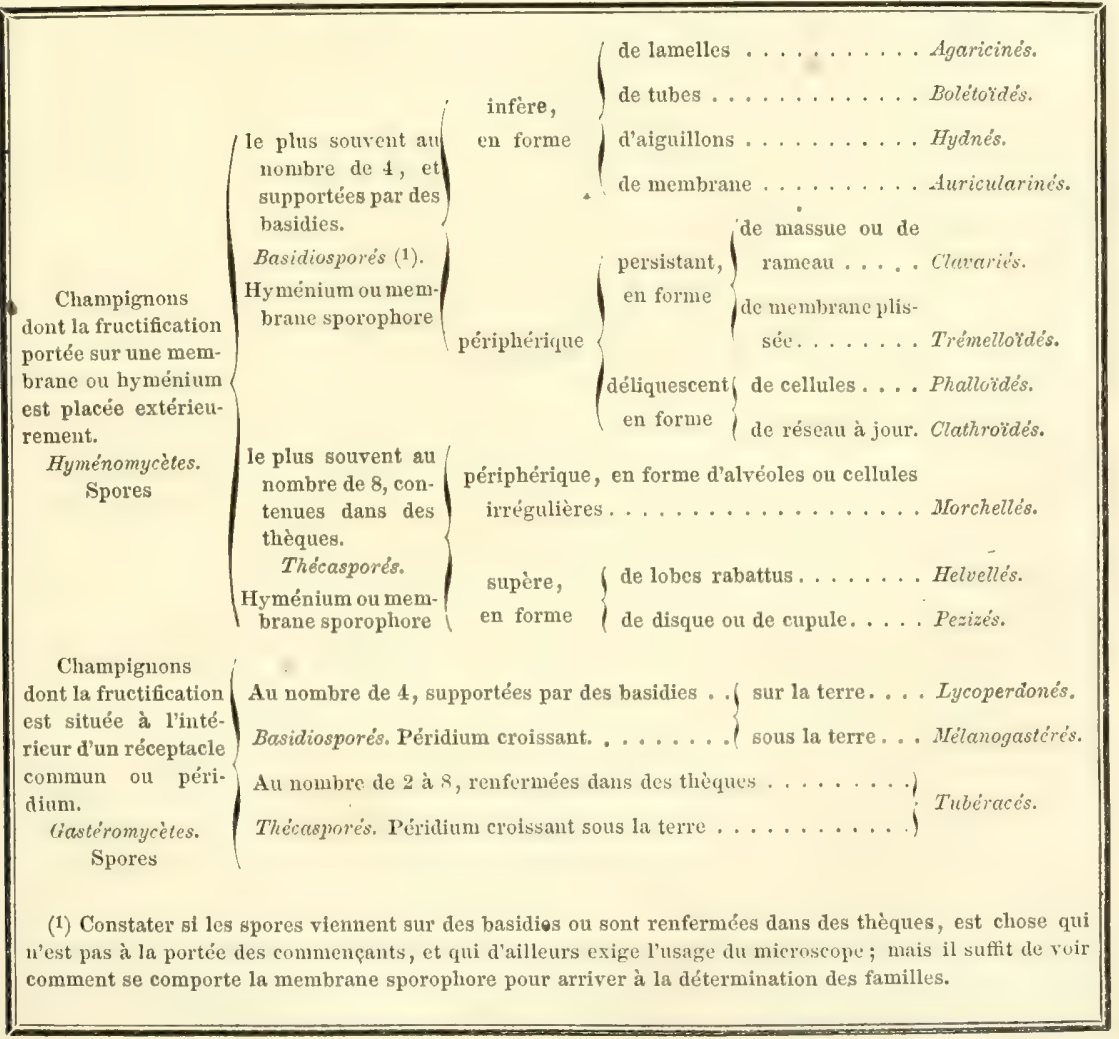


bivision dichotomigue du stenre Msaric.

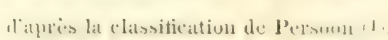

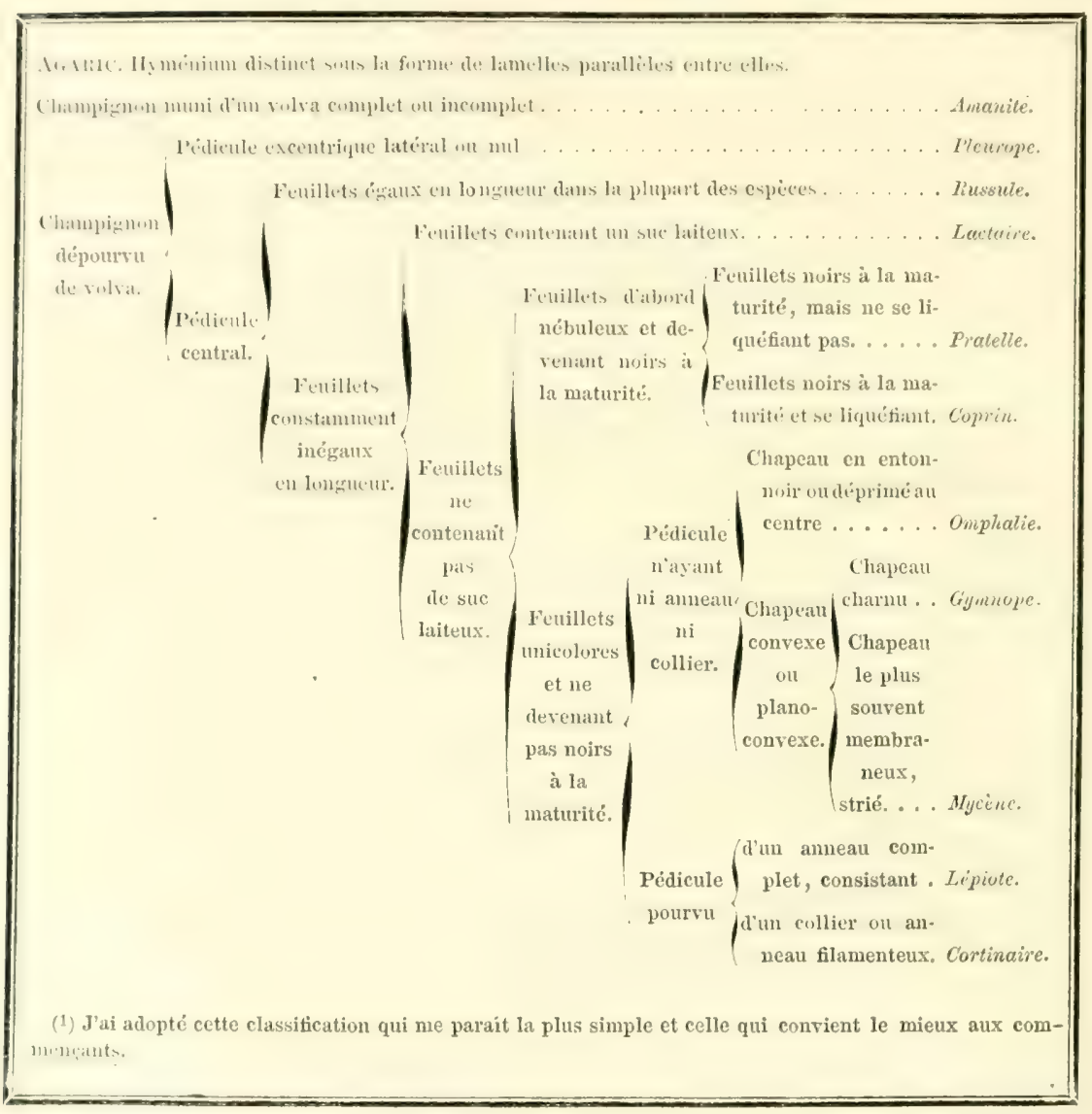




\section{Classe Ire - HYMÉNomyCĖTES.}

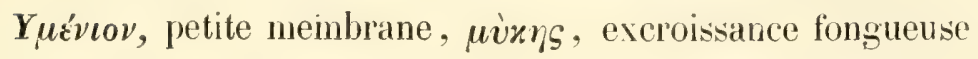

hYMENIUM a SURface OU MEMBRANE SPOROPHORE PLACÉE EXTÉRIEUREMENT.

Spores portées sur des basides. Basidiosporés.

ORdRE Ier. - AGARIGINÉS (Agaricini).

Hyménium infère, formant des feuillets ou lamelles, pouvant se partager en deux membranes, lesquelles rayonnent d'un centre commun.

\section{Section Ire. - AGARIC (Agaricus).}

'A jaoıนóv, d'Agaria, ville de la Sarmatie.

Chapeau doublé en dessous de feuillets à bords aigus, et qui ne sont presque jamais anastomosés les uns avec les autres.

\section{Ś́RIe Ire. - AMANITE (Amanita).}

'Apavirns, sorte de champignon chez les Grecs. Genre pour quelques auteurs.

Champignons charnus, sortant d'un volva ou bourse qui se déchire et laisse quelquefois des lambeaux sur le chapeau, mais toujours à la base du pédicule, lequel est central et pourvu ou non d'un collier; hyménophore distinct du pédicule. Tous croissent sur la terre et le plus ordinairement dans les bois.

Les champignons les plus délicats et les plus vénéneux appartiennent à la série des Amanites. 


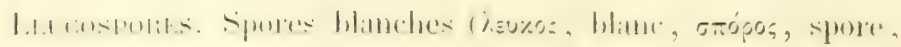
semence).

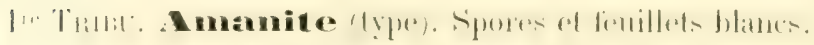

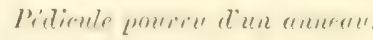

Ag. (Am.) Oronge. Ag. (Am.) cosarens, Scop., Fl. Ciarn., 419.

(P]. I).

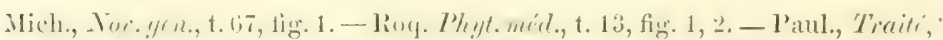

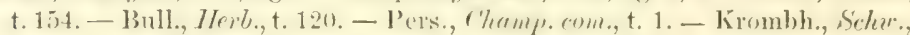
t. 8. - Vittad., Fung. mang., t. 1. - DC., Fl. fr., 562, - Fr. Epicr., 1.

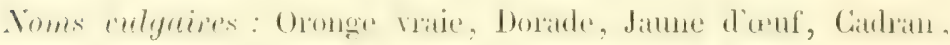

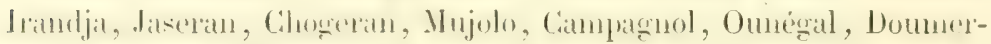
sial, Romminel, Dorgher.

LOronge en d'une frelle conlenr jaune-oranger ; dle a un chapean presque plane, orbiculaire, large de 10 à 15 centimètres, dont les bords striés et souvent incisés se recourbent en dessous, et dont la superficie n'est ni visqueuse ni tachetée de verrues; ses feuillets sont larges, épais, inégaux, jaunâtres, très-adhérents à la chair, mais non arthérents au pédicule, lequel est jaune en dehors, blanc en dedans, lisse, long de 8 à 15 centimètres, plein, bulbeux, pourvu d'un anneau jaune, large, renversé. Ce champignon, lorsqu'il est jeune, se trouve renfermé tout entier dans un volva de couleur blanche, ce qui Ini donne alors l'apparence d'un cuf; pour lui livrer passage, le volva se déchire et reste complet à la partie inférieure du pédicule.

L'Oronge croît à la fin de l'été et en automne dans les bois, et surtout dans les bois de pins; elle a une odeur faible et une saveur des plus agréables; c'est un manger délicieux et recherché partout. II faut tien se garder de la confondre avec la fausse Oronge (Ag. muscarius), décrite plus loin.

Ag. (Am.) élevé. Ag. (Am.) cxcelsus, Fr., Epicr., 16.

l'aul., Sur. mint., t. 12. - Kirombh., t. 29, fig. 14-17. - Berkl., Outl., t. 3̈, fig. 3. Amanita ampla, Pers., Syn., 15.

Cie champignon est d'une taille élevée, comme son nom l'indique. Son pédicule atteint 16 et 18 centimètres, et son chapeau 12 à 15 centimètres de largeur. Ce chapeau est charnu, fragile, d'abord sphéri- 
que, puis faiblement convexe ou même plane, de couleur gris blanchâtre (gris de souris) ou gris fauve, plus foncé au centre, parsemé de squames ou verrues, larges, enflées, qui disparaissent bientôt. Ses bords sont lisses et quelquefois substriés dans un âge avancé.

Les feuillets, inégaux, ventrus, libres, arrondis en arrière, étroits, épais, à bord très-finement crénelé, ne laissent pas de stries sur le pédicule, lequel est cylindrique, un peu bulbeux à sa base, écailleux au-dessous d'un collet, blane, rabattu, finement strié. Le volva, ordinairement fugace, est d'un blanc terreux, et presque toujours caché sous terre.

L'Ag. excelsus, dont la chair est blanche, ferme, appétissante, est assez rare; il vient dans les bois montueux; son odeur n'est pas désagréable. Par la saveur, il rappelle le champignon de couche, et cependant il est vénéneux. Cette proprièté, déjà connue, a été confirmée par les expériences de M. Tulasne.

Ag. (Am.) Mappa. Ay. Mappa, Batsch.

$$
\text { (II. III, Iim. } 1 \text { ) }
$$

Paul., Ch., t. 158, fig. 1, 2. - Vittad, Funy. many., t. 11. - Krombl., t. 28,

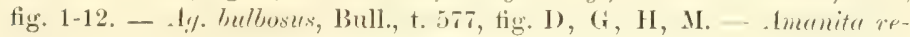
nenosa, Pers., Champ. com., t. 2, fig. 3. - Fr., Epricr., 11.

Var. A. Chapeau de couleur blanche. Roq., Phyt., t. 15, fig. 3. - Schæff., t. 241. "B. " verdâtre. Krombh., t. 28, fig. 1-10.

"C. „ jaune paille ou citron. Schæff, t. 20. - Roq., t. 15, fig. 1.

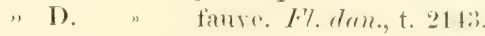

Chapeau d'abord convexe, puis plane, latge de: 8 it 10 contimetres, ordinairement de couleur jaune-soufre, mais quelquefois verdàtre, blanc, grisâtre ou fauve, non visqueux, à bord strié ou à peine strié. Cie chapeau porte des verrues blanches, débris du volva. Ses lamelles sont blanches, inégales, elles atteignent le pédicule. Celui-ci, long de 10 à 12 centimètres, devient fistuleux avec l'àge, il est blanc, cylindrique ou un peu atténué à son extrémité supérieure, pourvu d'un anneau membraneux, renflé en bulbe à sa partie inférieure, où se voit une simple trace en forme de marge, laissée sur cette base par le volva. Pellicule du chapeau se séparant difficilement.

Ce champignon est commun en automne; il croît dans les bois. D'odeur faiblement vireuse, de saveur désagréable, il est aussi dangereux que l'Ag. phalloides, dont il diffère si peu, qu'on les consirlérait comme ne formant qu'une seule et même espèce. Plusieurs 


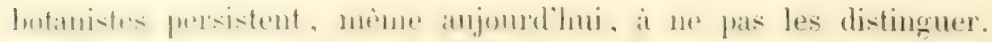
L'Ag. Mappa et l'Ag. phalloides sont les deux espèces qui occasionnent les accidents les plus graves et les plus fréquents.

Ag. (Am.) fausse Oronge. Ag. (Am.) muscarius, Lin.

(Pl. II).

Mich., t. 78 , fig. 2. - solleff., t. 27, 2R. - sow., ('ol. fig., t. 286. - fircv.,

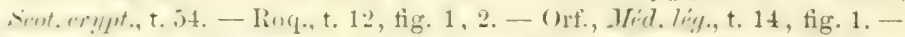

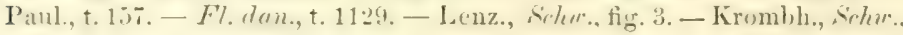
t. 9. - Tittad., t. 5. - Hoffim., t. 1. - DC., Fl. fr., 561. - Fr., Epricr., 7. - $1 \%$ mermentiarus, Bull.. t. 12\%.

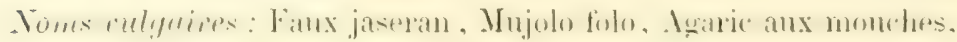
Tue-mouches.

La fausse Oronge, remarquable par son élévation et sa beauté, a un chapeau de couleur rouge écarlate, plus prononcée au centre, large de 10 à 18 centimètres, convexe ou à peu près plane à la maturité, presque constamment moucheté de verrues blanchàtres, peu nombreuses, anguleuses, formées par. les débris du volva, adhérentes an chapeau, qui est un peu visqueux et à bord faiblement strié. Ses feuillets, blanchàtres, larges, droits, inégaux, non adhérents au pédicule, sont coupés brusquement à leur terminaison. Le pédiculè est entièrement blanc ou blanc jaunâtre, long de 12 à 18 centimètres, plein, cylindrique, bulbeux à sa base, où se trourent à peine quelques vestiges d'un volva écailleux; le collier est large, blanc, ordinairement rabattu.

La fausse Oronge, assez commune dans les bois, en septembre ef en octobre, vient le plus souvent solitaire. Elle n'affecte pas désagrẻaJlement l'odorat, mais sa sareur a quelque chose de vireux. Confondue avec la véritable Oronge, elle a causé de nombreux accidents; c'est un poison des plus actifs.

Ag. (Am.) Oronge blanche. Ag. (Am.) ovoideus. DC., Fl. fr., suppl., p. 53. Vittad., t. 2, - Ag. ovoides albus, Bull., t. 364. - Amanita alba, Pers., Champ. com., p. 177.

Noms vulgaires: Boulé, Coucoumèle blanche, Coquemelle.

L'Agaric Oronge blanche est de grande taille et de couleur blanche dans toutes ses parties. Son chapeau, orbiculaire, presque plane, lisse, dépourvu de squames ou en portant seulement quelques vestiges floc- 
culeux, a des bords scillants, infléchis, non striés, auxquels sont souvent suspendus des débris de l'anneau; il peut acquérir 14 ou 15 centimètres de largeur; ses feuillets, blancs, saillants, atteignent à peine le pédicule, ils ne sont pas atténués aux extrémités, les plus courts étant arrondis, coupés brusquement; le pédicule est long de 8 à 10 centimètres, plein, ferme, cylindrique, à peine renflé à sa base, comme tomenteux, pourvu d'un anneau peu consistant; le volva est grand et mince.

On trouve l'Oronge blanche dans les forèts de chènes, en été et en automne; elle est commune dans les parties méridionales de la France, et fournit un aliment des plus délicats; son odeur est faible, sa chair épaisse, ferme, d'un goùt très-agréable.

L'Ag. ovoideus n'est pas sans ressemblance avec la variété blanche de l'Ag. bulbeux, plante délétère, avec laquelle il faut éviter de le confondre.

L'Ag. Coccola, Scop. - Fr., Epicr., 2. - Batt., t. 4, f. D, que l'on rencontre quelquefois dans le midi de la France, ne diffère guère de l'Ag. ovoideus que par ce qu'il est strié sur ses bords; pour quelques auteurs, il n'en est qu'une variété. L'Ag. Coccola est comestible.

Ag. (Am.) Panthère. A!l. (.ti.) putherims, DCi., Fl. fi., suppl., p. 52.

S̈chæff., t. 90. - Vitlad., t. 39.-Fl. dan., t. 1911, fig. 2.- Krombh., t. 29, fig. 10-13. - Paul., ('h., t. 160, fig. 2. - Śoc. méd., t. 14. - Staude, t. 10. fig. 3, 4. - Roq., t. 20, fig. 2, 3, et t. 21, fig. 2, 3. - Letell., Suppl., t. 639, fig. B-D. - Fr., Eprirr., 8. - Amanita umbrina, Pers., syn., 12, pl. 3, fig. "…

Noms vulgaires : Fausse golmelle; Faux missie, en Lorraine.

Le chapeau de ce champignon est toujours de couleur fuligineuse ou fauve, livide, un peu brunâtre, visqueux par les temps humides; d'abord convexe, puis plane, large de 6 à 9 centimètres, tacheté, surtout au centre, de squames blanches, petites, assez régulières, faiblement strié sur les bords; sa chair est blanche sous la cuticule; ses feuillets, dont les plus courts coupés à angle presque droit, et les plus longs à peine adhérents au pédicule, sont d'un blane pur. Le pédicule de cet Agaric est blanc, cylindrique, long de 6 à 10 centimètres, plein, pourvu d'un collier et tubéreux à sa base, qu'entoure un volva tomenteux peu distinct.

Quoiqu'il serve d'aliment aux vers, ce champignon est très-vénéneux; je l'ai expérimenté sur des chiens, qui en sont morts. 
Commun en antume dans les hois montuenx, lig. puntherimes est charnu et de saveur vireuse. On a pu le confondre avec l'Ag. $r u$ bescens et l'Ag. vaginatus; mais il n'a pas le pied et le chapeau rougeatres du premier, ni la taille élancée et le volva bien distinct du second, lequel d'ailleurs n'a pas de collier.

Ag. Am. phalloïde. A\% Am.) phalloides, Fr., Epicr.. 4 ot 5.

(II. IV).

Vilill. Jient. Par., t. 14, fig. 5. - Stande, t. 10, fig. 1, 2. - Vivian., Fungh., t. 15. - Vittad., t. 17. Ag. bulbosus, Bull., t. 2.

Var. A. Chatpean de conlenr blancle. Ay. remus, Bull, t. los. - Panl., t. 156, fig. 3, 4. - Pers., Champ. com., t. 2, fig. 1. - Bolt., Fung., t. 48. Roq., t. 23, fig. 5. - Fr., Epier., 4.

Var. B. Chapeau de couleur jaune. Amanita citrina, Pers., Champ. com., t. 2 , fig. "2.

Var. C. Chapeau verdâtre. Ag. virescens. Fl. dan.,-t. 246. - Roq., t. 23, fig. $1,2$.

Var. D. Chapeau olivâtre. Krombh,, t. 69, fig. 10-17.-Pers., Champ. com., t. 2 , fig. 3 .

Ce champignon, le plus dangereux de tous peut-être, a un chapeau charnu, convexe, aplati, glabre, visqueux par les temps humides, large de 8 à 10 centimètres, à bord orbiculaire non strié, rarement recouvert des débris du volva. Sa couleur, jaune le plus souvent, prend avec l'àge une teinte verdàtre, quelquefois vert-olive ou fauve, plus pâle sur les bords. La variété qui vient au printemps est blanche. Les lamelles de cet Agaric sont blanches, inégales, nombreuses; les plus courtes coupées brusquement, les plus longues s'arrètant à quelque distance du pédicule, lequel est blanc, long de 8 à 12 centimètres, plein d'abord, mais devenant ensuite creux au sommet, cylindrique, un peu renflé à sa base, pourvu à sa partie supérieure d'un anneau membraneux peu consistant. Le volva est assez ample, lache, à moitié libre, persistant en grande partie.

L'Ag. phalloüde vient dans les bois, en été et en automne; il est malheureusement très-commun. Son odeur est faible; sa saveur, d'abord peu prononcée, laisse bientôt dans la bouche quelque chose d'àcre. Une grande partie des accidents qu'il occasionne est due à son aspect séduisant.

Le champignon de couche ( $\mathrm{Ag}$. campestris), avec lequel on pourrait confondre l'Ag. phalloüde, se distingue de ce dernier par ses feuillets plus ou moins roses et par l'absence d'un volva. 
Ag. (Am.) rougeâtre. Ag. $(A m$.$) rubescens, Pers., Syn., 13$.

Paul., Soc. méd., t. 13; Champ., t. 161. - Vittad, t. 41.-Krombh., t. 10, fig. 1-5. - Huss., I, t. 23. - Staude, t. 10, fig. 5. - Schæff., t. 91 et 261. - Fr., Epier., 13. - Ag. verrucosus, Bull., t. 316.

Noms vulgaires: Grolmelle ou Golmotte franche, en Lorraine, et Missie dans quelques cantons.

Cette espèce a le chapean d'abord convexe, puis presque plane, large de 8 à 10 centimètres, d'un rouge fauve peu prononcé ou d'un rouge vineux, plus coloré au centre, non striẻ ou à peine strié sur les bords, parsemé de squames d'un blanc rougeàtre. Ses feuillets sont larges, nombreux, droits, inégaux, les plus courts coupés àssez brusquement, mais terminés en s'arrondissant, non décurrents, d'un blanc pur. Le pédicule, bulbeux à sa base et à peu près cylindrique dans le reste de son étendue, est long de 8 à 12 centimètres, ordinairement fistuleux, d'un rouge vineux, plus foncé à sa partie inférieure, où se voient à peine quelques débris du volva, couvert dans sa longueur de petites peluchures, pourvu d'un anneau large de la couleur du pédicule et conservant le plus souvent l'empreinte des feuillets. La chair en est cassante, blanche, rougeñtre au-dessous de la pellicule.

L'Ag. mubescens croît à terre dans les parties découvertes des bois, en été et en automne, le plus souvent solitaire; il n'est pas rare. Son odeur est nulle; sa saveur, d'abord fade, devient ensuite âcre et comme salée.

C'est un manger des plus délicats, et dont il se fait une grande consommation en Lorraine.

Ag. (Am.) solitaire. Ag. (Am.) solitarius, Bull., t. 48.

$$
\text { Fr., Epicr., } 16 .
$$

Cette grande et belle espèce, voisine de la précédente, atteint 12 ef 15 centimètres de diamètre. Le chapeau, régulièrement arrondi, est d'abord convexe, puis plane et mème un peu déprimé au centre, parsemé d'un grand nombre d'écailles ou verrues proéminentes, formées par les débris du volva. De couleur blanche ou quelquefois d'un bistre pàle, l'Ag. solitaire a des feuillets larges, épais, entièrement blanes, laissant leur empreinte sur le pédicule, qui est blane, cylindrique, long de 12 à 15 centimètres, portant un collier membraneux, comme 


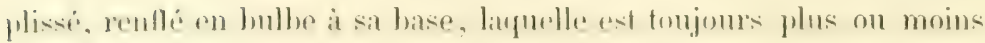
garnie d'écailles ou de pellicules, vestiges du volva.

Cet agaric, assez rare, vient en été dans les bois; sa chair est blanche, 1 im !roit excquis.

Ag. (Am.) Forme de pin. Ag. (Am.) strobilifomis, Vittad., t. 9.

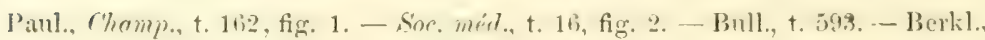
Outl., t. 3, fig. 2. - Fr., Epicr., 9.

Entierement blanc et de grande taille, l'Ag. strobiliformis a le chapeau charnu, convexe d'abord, puis étalé, à surface comme satinée, a marge non striée, chargé de squames ou verrues anguleuses, fortement adhérentes, grises, formées des débris du volva, qui se déchire de bonne heure et laisse à peine quelques traces à la base du pédicule. Les feuillets sont inégaux, les plus courts arrondis à leur extrémité, les plus longs libres. Le pied est gros, solide, floconneux, pourvu dans le jeune àge d'un anneau fugace, renflé en bulbe d̀ sa base, où il est marqué d'un sillon circulaire.

Ce champignon, dont l'odeur est peu prononcée, la saveur agréable, un peu aigrelette, est assez rare : il est comestible. Les limaces l'attaquent fréquemment. Il croìt dans les bois montueux en automne.

\section{fumean mel on oblitritr.}

Ag. (Am.) insidieux. Ay. (Aw.) insirliosus, Letell.. Sirpl. i Bulliand, t. 631 .

Le chapean de cet Agaric est fauve jaunâtre ou jaune verdâtre, plane, à stries radiées. Il a des lamelles blanches; un pédicule blanc, nu, haut de 8 à 12 centimètres, rétréci vers le haut, bulbeux à sa base; un volva, entier, grand, contournant le bas du pédicule; la chair mince.

L'Ag. insidiosus est solitaire, et vient, en été, dans les bois. Il est rinimentr.

L'Ag. maleficus, signalé par Roques comme dangereux, et connu aux environs de Bordeaux sous le nom de gendrame, est probablement lo minte que l'. ly. insidiosus. 
Ag. (Am.) à tête lisse. Ag. (Am.) leiocephalus, DG., Fl. fr., suppl., p. 53.

$$
\text { Fr., Epicr., } 531 .
$$

Cette belle espèce, entièrement blanche, mème dans un àge avancé, a le chapeau charnu, d'abord convexe, puis plane, arrondi, pouvant acquérir jusqu'à 18 et 20 centimètres de diamètre, sec à la superficie, lisse, comme satiné; les feuillets inégaux, nombreux, serrés, non adhérents au pédicule, qui est ferme, assez court, haut de 8 à 10 centimètres, épais à sa base, sans collier; le vỏlva très-grand.

L'Ag. leiocephalus est comestible; on le vend au marché de Montpellier; sa chair est ferme, son odeur agréable.

Il ressemble à l'Ag. ovoideus et à l'Ag. regius, Porta; mais il diffère du premier en ce qu'il manque de collier et que son chapeau est lisse; du second, en ce que ses feuillets sont blancs, tandis que l'A $\mathrm{A}$. regius a les feuillets couleur de chair.

Ag. (Am.) Gris de souris. Ag. (Am.) murinus, Roq., p. 359.

Morel, Traité des champig., t. 10.

L'Ag. murinus ressemble beaucoup à l'Ag.vaginatus, avec lequel on l'a confondu.

Son pédicule, haut de 10 centimètres, est nu, d'un blanc mat, creux, aminci au sommet, bulbeux à sa base, où se montrent quelques débris du volva. Le chapeau, d'abord conique, devient plane, même légèrement concave, mais avec le centre mamelonné; il est uni, satiné, d'un gris argenté ou de souris, d'une teinte plus foncée au milieu, quelquefois taché de plaques blanches, strié sur les bords. Ses lamelles sont très-minces, inégales, d'un blanc mat.

On le trouve, à la fin de l'été, dans les bois. Il est peu charnu, d'une saveur fade, d'une odeur un peu nauséense, dit Roques; d'une odeur et d'une saveur agréable de noisette, dit M. Bertillon, et cependant nuisible, puisque celui-ci en ayant, ainsi que son frère, mâché et avalé quelques bouchées, tous deux en furent fortement incommodés (Bertillon, Union médicale, 1861, p. 570).

Un Agaric, de la section des Collybia, portant déjà łe nom de murimus, celui de Roques derrait être changé. 
Ag. (Am.) engaîné. Ag. (Am.) vaginatus, Bull., t. 98 et 512.

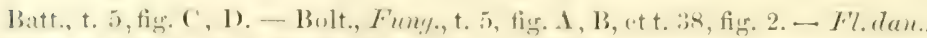

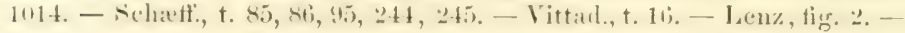
Krombh., t. 1, fig. 1-5. - Paul., t. 151, fig. 1, 2. - Fr., Epicr, 26, pl. 5, fig. $1,2$.

Var. 1. Fulva. Amanita spatiena, Pers, syn., 2. - Krombh., t. 10, fig. 6-8.

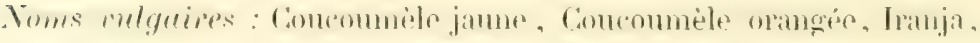
Iritujarlit.

Var. B. Plumbea, Chapeau brun, livide, bleuâtre. Amanita livida. Pers., Sym., 1.

Nons vulgaires : Concoumèle grise, Concoumèle grisette, Grisette.

I a perdicule de co champignom est long de 10 a 15 centimetres. grèle, fragile, fistuleux à la maturité, cylindrique, non bulbeux, dépourvu de collet, souvent peluché à sa base, laquelle est entourée d'un volva persistant, plus ou moins allongé en forme de gaine. Le chapeau, mince, peu charnu, est large de 6 à 8 centimètres; d'abord convexe, puis presque plane, de couleur gris de plomb ou gris cendré, jaune fauve, quelquefois livide à un âge avancé, plus foncée an centre, à superficie lisse, souvent chargée de pellicules, débris du volva; il est. constamment striẻ sur les bords. Ses feuillets sont inégaux, rétrécis à leur base, blanes et adhérents au sommet du pédicule, dans la première variété; d'un blanc grisâtre et non adhérents au pédicule, dans la dernière.

Ciette plante est un aliment délicat. On la trouve le plus souvent solitaire, dans les bois et sur le bord des bois, de juin à novembre; elle est commune, très-variable quant à sa couleur, sa forme ę ses dimensions; sa chair est fragile, inodore.

Rhodospores ('Póbov, rose, omópos, semence). Spores et feuillets roses.

2. Tribu. Volvaria (Volva, enveloppe des champignons).

Ag. (Am.) soyeux. Ag. (Am.) bombycinus, Schæff., t. 98.

Mich., t. 76, fig. 1. - Krombh., t. 23, fig. 15-21. - Barla, t. 25, fig. 1-5. - Fr., Epicr., 532. - Amanita incarnata, Pers., Syn., 3.

Le chapeau de l'Ag. bombycinus est blanc ou légèrement fauve, couvert de petites écailles ou fibrilles soyeuses; d'abord conique, puis 
convexe, plane, légèrement mamelonné, large de 10 à 15 centimètres, un peu visqueux. Les feuillets d'abord blancs, puis d'une couleur rosée, inégaux, libres, larges, sinueux, sont frangés à leur bord; le pied est nu, plein, flexueux, long de 8 à 16 centimètres, glabre, un peu plus gros à sa base. Volva très-large, d'un blanc jaunâtre ou fauve.

Cé champignon, assez rare, croit en été et en automne dans les bois, les jardins et les champs; sa chair est très-blanche, tendre; il a une odeur faible, une saveur agréable. Il est comestible; on le mange en Toscane.

Ag. (Am.) à petit volva. Ag. (Am.) parvulus, Weinm.

(Pl. Vl, fig. 2).

Pers., Obs. myc., t. 4, fig. 4, 5. - Ay. volvaceus minor, Bull., t. 330. - Fr., Epicr., 535. Amanita pusilla, Pers., Syn., 5.

Nom vulgaire : Agaric à petite coiffe.

Ce champignon vient en automne dans les serres, les jardins, les pâturages ; il passe pour très-dangereux; mais sa petite taille n'est pas de nature à le faire rechercher. Son chapeau est peu charnu, hémisphérique, bombé au centre, sec, blanchâtre, à superficie recouverte d'une fine peluchure: ses lames sont inégales, larges, épaisses, assez distantes du pédicule et de couleur rosée. Le pédicule est court, plein, égal, comme soyeux : le volva, grisâtre, persistant, se déchire en plusieur's lanières.

Ag. (Am.) royal, Ag. (Am.) regius, Porta.

Fr., Epicr., 536. - Paul., t. 153, fig. 3-5.

Nom vulgaire: Coucoumelle, en Languedoc.

Cette espèce est peu commune, puisqu'elle n'a été figurée que par Paulet, encore ses desseins sont-ils des plus médiocres. Selon cet auteur, elle croit dans les départements méridionaux, où elle est recherchée. La seule différence qu'elle présente avec l'Ag. leiocephalus, c'est que ses feuillets sont roses, tandis que les feuillets de l'Ag. leiocephalus restent blanes.

L'Ag. regius a la chair blanche, ferme, d'odeur et de saveur agréables; le chapeâu charnu, compacte, convexe d'abord, puis plane, large de 8 à 10 centimètres, glabre, lisse, d'un blanc tirant légèrement sur le roux; les feuillets couleur de chair ou rose très-tendre, 


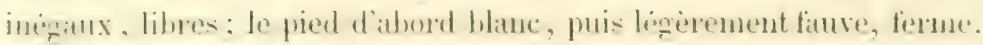

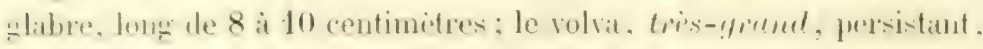

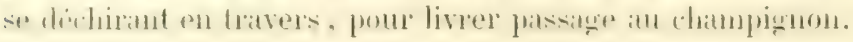

Ag. (Am.) spécieux. Ag. (Am.) speciosus, Fr., Epicr., 537 et 540.

(PI. VI, fig. 1).

Fl. dan., t. 1737. - Krombh., t. 26, fig. 1-8. - Berkl., t. 7, fig. 3. - Barla, t. 26.

Letell., t. 645, fig. C, E, H. - Ag. gloiocephalus, DC., Fl. fr., 6, p. 52.

On reconnait ce champignon à son chapeau charnu, gluant sur toute sa surface par les temps humides, lisse et brillant par un temps sec, d'abord convexe, puis plane, toujours mamelonné au centre, d'un blanc gris de souris, ne portant pas de débris de volva, strié légèrement sur ses hords; à ses feuillets, inégaux, d'abord blancs, puis rosés, n'atteignant pas le pédicule, qui est glabre, plein, cylindrique ou grossissant insensiblement par le bas, blane, roussâtre, dépourvu de collier, long de 9 à 11 centimètres, épais de 2 centimètres environ; au volva, blanc, petit, membraneux, déchirẻ en plusieurs lobes inégaux, villeux, de mème que la base du pédicule.

Cette espèce, qu'il ne faut pas confondre avec l'Ag. vaginatus, est d'odeur nauséabonde et vénéneux. Ses propriétés malfaisantes ont été constatées par M. Letellier. Il est assez rare, et croit dans les prés et les champs, en octobre.

Ag. (Am.) à grand volva. Ag. (Am.) volvaceus, Bull., t. 262.

Letell., t. 623. - Ventur., Stud., t. 8, fig. 72, 73. - Vivian., t. 10. - Barla, t. 25, fig. 6-13. - Sow., t. 1. - Paul, t. 151, fig. 8. - Fr., Epicr., 533. Amanita virgata, Pers., Syn., p. 249.

Duns sa jeunesse, ce champignon est enveloppé tout entier d'un volva complet, de couleur gris fauve, làche, persistant, se déchirant à son sommet en cinq ou six segments inégaux. Le chapeau est d'abord convexe, puis presque plane, peluché, d'un gris cendré, rayé ensuite de lignes noires, droites, divergentes, large de 6 à 8 centimètres, assez charnu, non visqueux. Les feuillets sont pulvérulents, d'un rouge de chair ou couleur de brique, inégaux, larges, atteignant à peine le pédicule; celui-ci est plein, subcylindrique, nu, glabre, blanchàtre, long de 5 à 6 centimètres, épais de $11 / 2$ centimètre.

Ce chanpipnon ust rineruen. Sa chair, blanche, cassante, a une saveur àcre. 
L'Ag. volvaceus croit par groupes, en été et en automne, sur le tan et le terreau, dans les serres et les étables. Il est vénéneux. Sa chair, blanche, cassante, a une saveur âcre.

L'Agarie vipérin, Ag. (Am.) viperinus, Fr., Ag. conicus, Pico, est malfaisant aussi; il a occasionné des accidents très-graves. Il vient en Piémont et très-probablement en France.

\section{A M A N T T E.}

Volva ou enveloppe générale distincte de la pellicule du chapeau.

\section{Leucospores.}

1re Trubu. - Amanite (type).

Ag. (Am.) ì verrues arrondies. Iy. (Am.) baccatus, Mich., t. 80, f. 4. - Fr., Epicr., 29. - Dans le midi de la France; rare.

Ag. (Am.) Oronge. Ag. (Am.) coesareus, Scop. (décrit).

Ag. (Am.) Coccola. Ag. (Am.) Coccola, Scop., f. 2. - Batt., t. 4, f. D. - Fr., Epicr., 2. -. Dans les régions humides qui avoisinent la Méditerranée. N'est probablement qu'une simple variété de l'Ag. ovoiders.

Ag. (Am.) élevé. Ag. (Am.) excelsus, Fr. (décrit).

Ag. (Am.) perlé. Ag. (Am.) gemmatus, Paul., t. 158, f. 3. - Fr., Epicr., 28. Dans les bois des environs de Paris; saveur non désagréable.

Ag. (Am.) insidieux. Ag. (Am.) insidiosus, Letell. (décrit).

Ag. (Am.) tête lisse. Ag. (Am.) leiocephalus, DC. (décrit).

Ag. (Am.) gris de souris. Ag. (Am.) murinus, Rog. (décrit).

Ag. (Am.) lenticulaire. Ag. (Am.) lenticularis, Lasch. - Lin., no 18. - Paul., t. 149. - Fr., Epicr., 22. Dans les forêts épaisses ; rare. Effets douteux.

Ag. (Am.) Mappa. Ag. (Am.) Mappa, Batsch (décrit).

Ag. (Am.) moucheté. Ag. (Am.) muscarius, Lin. (décrit).

Ag. (Am.) facette de diamant. Ag. (Am.) nitidus, Fr., Epier., 15. - Batt., t. 6, fig. B. - Paul, t. 162. - Dans les bois et les pelouses ombragées; rare. Probablement vénéneux.

Ag. (Am.) ovoïde. Ag. (Am.) ovoideus, DC. (décrit).

Ag. (Am.) Panthère. Ag. (Am.) pantherinus, DC. (décrit).

Ag. (Am.) phalloïde. Ag. (Am.) phalloides, Fr. (décrit).

Ag. (Am.) porphyre. Ag. (Am.) porphyrius, Fr., Epicr., 6. - Alb. et Schw., t. 11, f. 1. Ag. ophytes, Lév. et Paul., t. 152 , f. 2. - Dans les lieux humides plantés de pins, les Alpes et même les environs de Paris; rare. Propiétés inconnues.

Ag. (Am.) Oronge tannée. Ag. (Am.) pretorius, Schwein. - Paul., t. 153, f. 1, 2. -- Schæff., t, 245 . - Dans les forêts épaisses; rare. Suspect.

Ag. (Am.) déchiré. $A g .(A m$.$) recutitus, Fr., Eipier. 12. Variété : A g$. bulbosus, Bull., t. 577, f. E, F. - Dans les bois de pins, en été et en automne; rare. Vénéneux.

Ag. (Am.) rougeâtre. Ay. (Am.) rubescens, Schæff. (décrit).

Ag. (Am.) solitaire. (Ag. (Am.) solitarizes, Fr. (décrit).

Ag. (Am.) épais. Ag. (Am.) spissus, Fr., Epier., 17. - Krombl., t. 1, f. 7, et t. 29, f. 1-5. - Dans les buis de plaines. Suspect. 


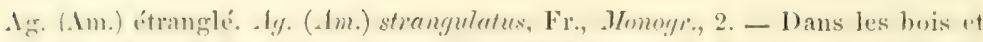
le's pelonses ch automme; rare. Proprevités incommes. Est-ce une variété do: 1'A\%. solitarius?

Is. (Am.) forme de pomme de pin. Ay. (Lm.) strobiliformes, Vittad. (derrit).

Ag. (Am.) engâne. A\%. (Am.) vayinatus, 13nll. (dérit).

Ag. (Am.) valide. Ag. (Am.) validus, Berkl. - Fr., Epicr., 14. Krombh., t. 2 , f. 18-21.

Ig. (Am.) printannier. Ag. (Am.) vernus, Fr. (décrit). Variété du phalloides.

Ag. (Am.) vireux. Ag. (Am.) virosus, Paul., t. 155, fig. 1-4. - Fr., Epicr., 4. 1g. bulbosus, Bull., t. 2. - Dans les bois, en automne. Est-ce peut-être une varicité de l'. Iy. phalloides?

$$
\text { 2е Тивв: - Volvaria. }
$$

Ag. (Am.) soyeux. Ag. (Am.) bombynius, Schæff. (décrit.)

Ag. (Am.) à chapeau gluant. Ag. (Am.) gloiocephalus, DC., est l'Ag. speciosus, $\mathbf{F}_{1}$. $\Lambda g$. (Am.) medius. $A g .(A m$.$) medius, Schum. Dans les bois. Vénéneux.$

Ag. (Am.) à petit volva. $A g .(A m$.) parvulus, Weinm. (décrit $)$.

Ag. (Am.) royal. Ag. (Am.) regius, Porta. (décrit).

Ag. (Am.) spécieux. Ag. (Am.) speciosus, Fr. (décrit).

Ag. (Am.) à grand volva. Ag. (Am.) volvaceus, Bull. (décrit).

\section{Ś́ra II. - LÉpIOTE (Lepiota).}

$\Lambda \varepsilon \pi i \varsigma$, écaille, pellicule.

Champignons charnus, recouverts dans le jeune âge d'une membrane, qui, en se déchirant, laisse un anneau persistant sur le pédicule; feuillets ne noircissant pas; absence de volva.

Aucune espèce de Lépiote n'est signalée comme étant certainement malfaisante.

Leucospores. Spores blanches.

1re Tribu. Cepiota (type). Chapeau ou hyménophore distinct du pédicule. Champignons terrestres.

Ag. âpre. (Ag. asper), Pers., Syn., p. 256.

Vittad., t. 43. - Fr., Epier., 18.

L'Ag. asper vient, à terre, dans les bois. Il a le chapeau d'abord convexe, puis plane, large de 6 à 7 centimètres, fauve rougeâtre ou fauve brun, parsemé de squames ou aspérités nombreuses, petites, droites, persistantes, grises, à bord lisse; les feuillets blancs, arrondis en arrière, adnexes nombreux; le pied allongé, sub-bulbeux, 
sub-fibrilleux ou squameux, d'un blane fauve ou cendré, long de 6 it 7 centimètres, d'abord plein, puis creux, portant vers le sommet un anneau entier.

Reveil, qui l'a expérimenté sur des chiens, dit qu'il est vénéneux.

On pourrait le confondre arec l'Ag. mbescens; il s'en distingue en ce qu'il a la chair de couleur fauve sous la cuticule, et non rougeâtre, comme l'Ag. rubescens.

Quelques botanistes rangent cette espèce dans la section des Amanites.

Ag. à tige d'oignon ( $A g$. cepestipes), Weinm.

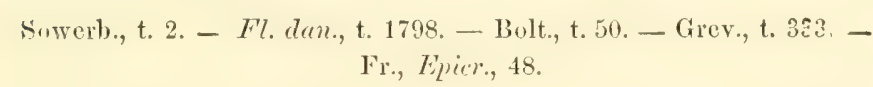

Cie champignon, d'origine exotique, à ce que l'on croit, vient en touffes et rarement solitaire, sur le tan et la terre de bruyère, dans les serres et dans les jardins, en automne; il a le chapeau mince d'abord blanc, puis d'un jaune-soufre ou légèrement fuligineux, ovale, étalé avec l'àge, mamelonné, couvert de petites écailles farineuses, strié ou plie sur les bords; les feuillets, inégaux, blancs, larges, libres, n'atteignant pas le pédicule, qui est creux, velouté, long do 12 à 15 centimètres, renflé dans le bas comme une tige d'oignon, légèrement bulbeux, pourvu d'un anneau fugace. Saveur un peu amère, sub-vireuse. Comestible.

Son peu de chair fait qu'il ne sera jamais recherché conme aliment.

Ag. clypéolaire (Ag. clypeolarius), Bull.

P'aul., Ch., t. 136. - Bull., t. 405 et 50h, fig. 2. - Fr., Epicr., 10.

Noms vulgaires: Coulemelle d'eau, Fausse golmelle.

Ce champignon, qui est assez commun et varie beaucoup d'aspect, croît solitaire, dans les lieux humides et ombragés des bois, en été et en automne. Sa consistance est molle, son odeur faible, sa saveur à peu près nulle. Le pédicule, blanc, grêle, le plus souvent fistuleux, non bulbeux à sa base, est long de 8 à 10 centimètres, comme cotonneux au-dessous du point d'insertion du collier, lisse supérieurement; ce collier, peu consistant, ne se voit guère que dans les jeunes individus. Le chapeau est large de 5 à 10 centimètres, d'abord ovoïde, 
puis plane et quelquefois concave par le redressement des bords, mais toujours proéminent au centre. La surface blanchâtre est parsemée de mouchetures roussatres, fort nombreuses dans la jeunesse, et plus multipliées au centre du chapeau. Les lames sont larges, Jlanches, inégales, non adhérentes au stipe.

L'Ag. clypeolarius a de la ressemblance avec l'Ag. excoriatus; il en diffère en ce qu'il a le pied squameux et l'anneau fugace. Il passe pour vénéneux. M. Letellier dit l'avoir mangẻ sans en être incommodé. Plusieurs personnes ont assuré à cet auteur qu'elles l'avaient mangẻ arec plaisir sans éprouver aucun accident. Les animaux le rejettent peu de temps après s'en être nourris, mais quelquefois, dit Paulet, ils ne ressentent aucun mal. Reveil le signale comme suspect; il sera donc prudent de s'en abstenir. L'Ag. procerus, avec lequel on pourrait peut-ètre le confondre, est de dimension beaucoup plus grande.

Ag. en crête (Ag. cristatus), Fr., Epicr., 41.

Batsch., f. 205. - Grev., t. 176. - Sow., t. 176. - Krombh., t. 25, fig. 26-30. Huss., I, t. 48. - Ag. colubrinus, Var.; Pers., Syn., 2.

Chapeau peu charnu, à surface blanchâtre, grise ou jaunâtre, mamelonné, d'abord lisse, soyeux, ensuite recouvert de petites écailles, sub-granuleuses, brunes ou noires; lames écartées du pédicule, blanches, de longueur inégale, plus larges vers la marge du chapeau; pied fistuleux, cylindrique, droit, lisse, pourvu d'un anneau peu consistant, qui s'en sépare de bonne heure, glabre, excepté à la base, de couleur blanche au-dessus de l'anneau, et grisâtre en dessous.

Cet agaric, comestible et même délicat à manger, a la saveur et l'odeur agréables; il croit vers la fin de l'été et en automne, à terre, dans les bois, les prés, les jardins.

Quoique ressemblant beaucoup à l'Ag. clypeolarius, il en est distinct. Il n'est pas non plus sans ressemblance avec l'Ag. (Am.) excelsus, espèce dangereuse.

Ag. tête hérissée (Ag. echinocephalus), Vittad., Fung. mang., 346.

Paul., Soc. méd., t. 16, fig. 4; Champ., t. 163, fig. 3.

Champignon blane, charnu, convexe, puis plat, lisse, parsemẻ de vermes pyramidales, aiguës, qui se détachent facilement, dont les feuillets, de longueur inégale, sont très-serrés, larges vers la marge 
du chapeau, aigus à l'autre extrémité, adhérents par une dent au pédicule, d'abord blancs, puis d'un blanc verdâtre. Le pédicule, plein, blanc, floconneux, devient creux avec l'àge, se prolonge en une pointe qui s'enfonce en terre, est pourvu d'un anneau, blanc, large, qui ne persiste guère que sous forme de débris.

Cet agaric, vinéneux ì un haut degré, ì l'odeur du champignon de couche. Il est assez rare, et vient à terre, dans les bois, en automne, solitaire ou en groupes de trois ou quatre individus.

Ag. excorié (Ag. excoriatus), Schæff., t. 18, 19.

Paul., t. 135 bis. - Vittad., t. 35. - Kroml,h., t. 24, fig. 24 - 30. - Pers., Sign, p. 257, - Fr., Epicr., 34 .

L'Ag. excoriatus diffère peu de l'Ag. procerus; on ne l'en distingue que par sa dimension, qui est constamment plus petite, et par son pied, qui est plus court et rarement bulbeux. Le chapeau, large de 5 à 6 centimètres, d'abord convexe, puis plane, mais à centre proéminent, est de couleur fauve cendré. L'épiderme mince se relève en petites écailles. Les feuillets, d'un blanc pàle, très-nombreux, minces, inégaux, larges, saillants, quelquefois dichotomes, n'atteignent pas le pédicule. Celui-ci est cylindrique, parfois bulbeux à sa base, creux, glabre, lisse, blanc ou de la couleur du chapeau; il a un anneau, large, mobile, persistant.

Cie champignon est comestible. Il croìt, en été et en automne, dans les bois, les champs et les terres cultivées. Sa chair est blanche, molle; sa saveur fongique; son odeur presque nulle.

Ag. mastoïde (Ag. mastoideus), Fr.

Fl. dan., t. 2144. - Krombh., t. 24, fig. 17-18. - Batt, t. 10, fig. A. - Berk1., Mag. zool. et Bot., t. 2, fig. 1. - Fr., Epier., 36.

Cet agaric a le chapeau de couleur blanc alutacé, peu charnu, mou, convexe, fortement mamelonné, à cuticule mince, se déchirant en papilles ou écailles minces, éparses; les feuillets très-écartés, d'un blanc pâle; le pédicule creux, faible, sub-villoso-squameux, à peu près cylindrique, bulbeux à sa base, pourvu d'un anneau entier, mobile.

On le trouve dans les hois. - Il est comestible, mais peu estimé. 
Ag. chètif $(A y$. naucinus), lis.

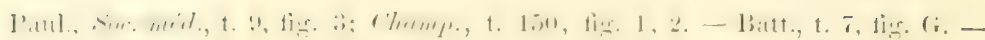
Vittad., t. 40. - Krombl., t. 24, fig. 20-23. - Fr., Epicer., 47.

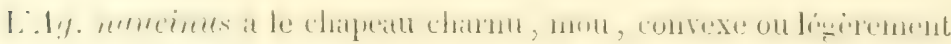

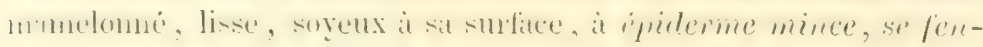
dillant en granulations très-fines, qui le recouvrent, excepté au sommet; les feuillets, nombreux, libres, inégaux, d'un blanc pâle, passant au rose; le pied plein ou légèrement creux, atténué de bas en haut, bulbeux à la base, fibrilleux, blane, pourvu supérieurement d'un anneau mince; la chair, ferme, blanche; l'odeur et la sareur fongiques.

Est peu commun et comestible; vient à terre dans les bois gazonneux et les champs.

Ag. couleuvré (Ay. procerus), Scop., p. 418.

(PI. VII.)

Scheff, t. 22, 23. - $F l$. dan., t. 772. - Curt. Lond., t. 69. - Vittad., t. 24. - Lenz, fig. 5, 6. - Paul., Champ., t. 135. - Sow., t. 190. - Ag. colubrinus, Bull., t. 78 et 583. - Pers., Syn., p. 257.- Fr., Epicr., 31.

Coms mlynires: Cornelle, Grisette, Coulenvelle, Clorosse, Cinl d'ours, Houpale, Saint-Martino, Brugaizello, Capellon, Coche, Cocherelle, Parasol, Bouterot, Paturon, Coulsé, Colombette, Escumelle, Chic à la bague (Loire), Commère (Indre-et-Loire), Cloroson (Creuse), Golmelle et Golmotte de Voyen (Meuse).

Cie champignon, remarquable par sa beauté, s'élève quelquefois à plus de 30 centimètres; son pédicule, renflé en bulbe à sa base, est grèle, cylindrique, fistuleux, traversé de taches blanches et brunes, muni d'un collet mobile et persistant; son chapeau, d'abord ovoïde, puis étalé, ordinairement proéminent au centre, peut atteindre jusqu'à 25 et 30 centimètres de diamètre; il est recouvert d'écailles imbriquées, formées par l'épiderme qui se soulève, de couleur bistre ou fauve cendré sur fond blanchâtre; ses feuillets sont d'un blanc pâle, inégaux, peu serrés, n’atteignant pas le pédicule, qui est reçu dans une dipmesion du chapeau.

L'Ag. procerus vient à la fin de l'été et en automne, dans les endroits découverts des bois et dans les champs sablonneux. Il est alimentaire et d'usage très-répandu; son odeur et sa saveur sont agréables. On rejette le pédicule comme trop coriace. 
L'Ag. rachodes, Vittad., t. 20, ressemble beancoup à l'Ag. procerus; pour quelques auteurs, il n'en est même qu'une variété. Fries dit que le rachodes a une saveur désagréable et n'est pas comestible; M. Hussey dit, au contraire, qu'il est le vice-roi du procemus. Au marché de Londres on les vend contondus ensemble.

Ag. de Vittadini (Ag. Vittadinii), Moretti, Bot. ital., t. 1.

Vittad., Amen., t. 1. - Krombh., t. 27. - Huss., I, t. 85. - Fr., Epierr., 43.

Champignon de très-grande taille, robuste, épais, entièrement blane, ayant le chapeau charnu, obtus, large de 12 à 15 centimètres, convert d'écailles vermqueuses, serrées; les feuillets libres, ventrus, épais ; le pied solide, long de 15 à 18 centimètres, épais de 3 , pourvu, à sa partie supérieure, d'un anneau ample, au-dessous duquel il est couvert de squames réfléchies, concentriques, jamais bulbeux et sans traces de volva. Il vient dans les bois; est rare.

Vénéneux, il cause de l'irritation à la gorge, de la chaleur dans tout le corps et des étourdissements.

On peut le confondre avec l'Ag. (Am.) excelsus, espèce malfaisante aussi : il en diffère surtout par l'absence d'un volva.

2. Tribu. Armillaria (Amilla, bracelet). Chapeau ou hyménonophore se continuant avec le pédicule; anneau restant adhérent a ce dernier.

Ag. orange (Ag. cuentius), Schirff., t. 37.

Barla, t. 13, fig. 1-10. - Fr., Elpirr., 6ht.

L'Ag. aurantius est un champignon de taille moyenne, qui vient tard dans les bois de sapins. Il exhale une odeur forte, nauséabonde, analogue à celle de l'huile de ricin. Son goût est un peu àcre et amer. M. Barla le dit comestible; mais il est de qualité médiocre. Selon cet anteur, on le rencontre solitaire, en automne, dans les bois et sur la lisière des bois.

Le chapeau est charnu, de couleur orangée faible, convexe, puis plane, obtus, couvert de petites écailles adhérentes, visqueux. Le pied solide, égal, tacheté au sommet de squamules de couleur orangée, est muni d'un anneau peu apparent. Les feuillets sont nombreux, sinueux, adnexes, blancs. 
Ag. chaussé ( $A g$. caligatus), Viviani, t. 35 .

Barla, t. 9 et 10 .

Nom vulgaive: Cinssetta.

(a) Ahmpignon vint solilaire on par petits groupes sous les pins,

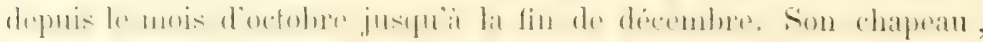
d'abord convexe, puis plane, est de couleur rouge briquetẻ ou rouge brun, plus foncé au centre qu'à la circonférence. Il a les spores d'un blanc jaunatre, ovoïdes, les bords tonjours roulés en dessous, la surface comme satinée, couverte de petites peluchures, brunes, filamenteuses, les feuillets, blanes, inégaux, arquẻs, atténués vers les bords du chapeau, adnés, arrondis et échancrés près de leur insertion au pédicule. Cie pédicule est charnu, plein, ferme, filandreux, long de

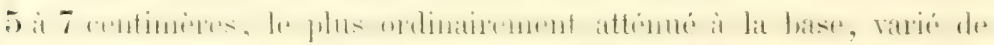
taches circulaires, irrégulières, interrompues, de la couleur du chapeau, mais blanc et parsemé de petites écailles ou papilles blanches au-dessus de l'anneau, lequel est le plus souvent persistant, blanc à l'intérieur, varié à l'extérieur de teintes fauves ou rongeâtres.

L'Ag. caligatus a la chair tendre, compacte, blanche, prenant, lorsqu'on l'entame, une teinte rose, variée de jaunâtre; l'épiderme se détache facilement du chapeau, de mème que les feuillets; l'odeur est peu sensible, la saveur légèrement acide, peu agréable arant la cuisson. Il est comestible, et très-recherché par les habitants des environs de Nice.

Ag. couleur de miel (Ag. melleus), Fl, dan.

(PI. VIII.)

Vahl, Fl. dan., t. 1013. - Mich., t. 81, fig. 2. - Vittad., t. 3. - Lenz, fig. 7. (iper., t. 332. - Krmul,l, t. 1, fig. 13, et t. 43 , fig. :3-6. - Sum., t. 101 . - Batt., t. 11, fig. B, F. - Berkl., t. 4, fig. 1. - Staude, t. 9, fig. 4, 5. Fr., Epier., 73. - Ag. anmularius, Bull., t. 540, fig. 3, et t. 377. - Ay. polymyces, Pers., Syn., 19.

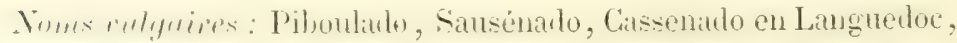
Souquarel (Tarn).

Champignon peu charnu, concolore, dont le pédicule jaunâtre, lavé d'un peu de noir à la base, est long de 8 à 12 centimètres, cylindrique, un peu tordu sur lui-mème, légèrement courbé à sa base, plein dans le jeune âge, fistuleux dans la vieillesse, garni vers le sommet 
d'un collier entier, d'abord évasé en godet, puis rabatlu. Le chapeau, fauve jaunâtre, mêlé parfois de verdàtre, est convexe, à centre proéminent, plus coloré que le reste, tacheté de petites écailles brunâtres, à bord mince, étalé, faiblement strié. Les feuillets sont blancs ou légèrement jaunâtres, inégaux, larges, peu serrés ; ceux qui atteignent le pédicule, un peu décurrents.

L'aspect terreux de cette plante ne prévient pas en sa faveur. Le pédicule étant coriace, on ne fait usage que du chapeau, dont la chair, blanche, jaunâtre, se sépare facilement de la pellicule, a une odeur forte et un peu vireuse, la saveur nulle, le plus souvent âcre et désagréable.

L'Ag. melleus est comestible; on le vend sur les marchés de Vienne.

Bien que la cuisson lui fasse perdre son àcreté, il n'est nullement recherché en France; on ne le mange guère que dans le Languedoc. On le trouve, en été et en automne, dans les bois, au pied des vieux trones coupés au niveau de terre, par groupes de dix, quinze et vingt individus; très-commun.

Ag. muqueux (A . mucidus), Schrad.

Tratt., t. 14, fig. 27. - Fr., Epier., 82. - Ag. nitidus, Fl. dan., t. 773, 1130 et 1372 .

Champignon de taille moyenne, entièrement blane, le plus souveı,t en groupes, en automne, sur les trones de hètre languissants ou coupés depuis peu. Le chapeau est large de 4 ou 5 centimètres et plus, convexe, étalé, mince, mou, visqueux, d'un blanc pur, mais quelquefois de teinte cendrée ou légèrement fuligineuse. Les feuillets, inégaux, distants, d'un blanc pur, sont arrondis vers un pédicule cylindrique, grêle, recourbé, plein, légèrement renflé à sa base, épais de 4 à 5 millimètres, pourvu au sommet d'un anneau, prononcé, réfléchi. Très-peu charnu, inodore; comestible, selon Chevallier.

Ag. rude (Ag. scruposus), Fr., Epicr., 69.

Batsch., t. 5, fig. 19, et t. 19, fig. 101. - Paul., t. 51, fig. 2-4, et t. 94, fig. 1-4.

Noms vulgaires: Darmas, Macaron des prés (Paulet).

Le chapeau de cet agaric est charnu, convexe d'abord, puis plane, à surface glabre, inégale, brune, marquée de rides contoumées. Ses 


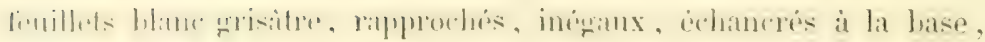

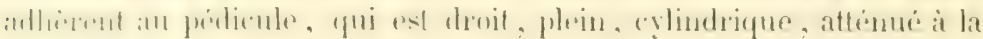
lase, glabre, de la couleur du chapeau, pourvu d'un anneau blane, fingace, étroit, placé à la partie supérieure.

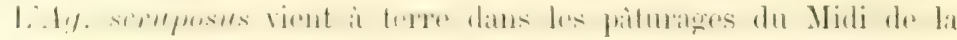
France. Sa chair ferme, blanche, délicate à manger et recherchée, a une odeur de farine récente, un goût et une saveur agréables.

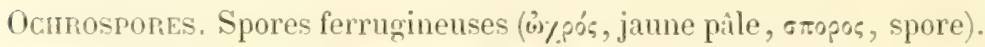
Dermini, de Fries.

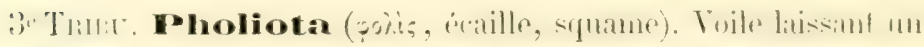
anneau sur le pédicule.

Ag. Egerite (Ag. Egerita), Fr.

liatt., t. ti, fig. L. - I'anl., t. 145. - Fr., Elicr., fist.

Noms vulgaires: Champignon du peuplier, Pivoulade.

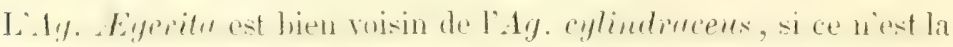
mème espèce. Il croìt, en automne, en touffes, au pied du peuplier noir, et de plusieurs autres arbres, dans le Midi de la France.

Chapeau charnu, d'abord convexe, puis plat, et mème à bords relevés arec l'ìge; surface lisse, un peu soyeuse et sèche, de coulemr faure dans un âge arancé, sujette à se gercer ; feuillets inégaux, serrés, d'un blanc tirant sur le fauve ou le roux, aigus vers la marge du chapean, arrondis, échancrés à l'autre extrémité, et adhérents par une dent à un pédicule, cylindrique, blanchàtre, d'abord plein, puis se creusant, glabre, ferme, muni très-près des feuillets d'un annean membraneux, blane, persistant.

C'est un excellent champignon, que les anciens mème recherchaient; odeur et saveur agréables.

Ag. cylindracé (Ag. cylindraceus), DG., Fl. fr., VI, p. 51.

L.etcill, t. 63\%. - Noul. et Dass, t. 32. - Fr., Epier., 653.

Var. A. Ag. attenuatus, DC., Fl. fr., VI, p. 51. - Fr., Epier., 653. - Batt., t. 6 , fig. $C$.

Noms vulgaires: Champignon du saule Pivoulade, Pihoulade, Saiizénado. 
Cet agaric croit au printemps et en automne, le plus souvent en touffes, sur les vieux troncs de saules, et mème de peupliers.

Le chapeau est charnu, sec, glabre, convexe, large de 10 à 12 cenfimètres, d'un blanc sale ou un peu roussâtre, souvent irrégulier, à bords repliés en dessous dans le jeune âge. Ses feuillets, d'abord blanchâtres, plus tard d'un brun fauve sale, sont adhérents au pédicule et décurrents, seulement lorsque le pédicule est excentrique, ce qui arrive quand le chapeau est gêné dans son développement. Ce pédicule, plein, charnu, blanchâtre, plus ou moins courbé ou tordu, long de 6 à 10 centimètres, cylindrique, aminci à sa base dans la variété attenuatus, est muni au sommet d'un anneau rabattu, peu consistant, d'un blanc fauve et placé très-près des feuillets.

Comestible. On mange ce champignon à Toulouse et à Montpellier. Sa chair, blanche et délicate, a une odeur particulière, une saveur fongique.

Ag. précoce $(A g$. procox $)$, Pers., Syn., p. 420.

Schift, t. 217. - Letell., t. 1. - Berkl., t. 8, fig. 1. - Batt., t. 20, C. - Fi. Epicr., 647 .

Chapeau charnu, mou, convexo-plane, doux au toucher, lisse, large de 5 centimètres environ, d'un blanc jaunùtie ; feuillets émarginés, adnexes, arrondis, inégaux, serrés, d'un blanc fuscescent, brunissant à la longue; pied plein, ensuite creux, cylindrique, d'abord farineux-pubescent, plus tard devenant lisse, blanc, de mème que la bague dont il est pourru, laquelle est entière, striée en dessus.

Vient à terre, ešt commun au printemps, dans les jardins et lieux abondants en herbe.

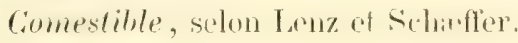

Ag. pudique (Ag. pudicus), Bull., t. 597, fig. 2, R, S, L, O.

Batt., t. 8, fig. A. - Huss., I, t. 31. - Letell., t. 664. - Fr., Epicr., 652.

D'abord blanc, le chapeau de cette espèce devient d'un blanc faure; il est charnu, globuleux, convexe, enfin plane, arrondi, large de 8 à 10 centimètres, lisse, sec, glabre. Les feuillets sont ventrus, arrondis en arrière, libres, adnexes, inégaux, blanchâtres, puis d'un blanc fanve. Le pied, quelquefois excentrique, courbé à la base, haut de 5 
à 8 centimètres, solide, plein, à peu près égal, lisse, est muni d'un anneau étalé, entier, persistant.

Cet agaric serait comestible, selon M. Berkeley.

Il vient solitaire ou en touffes, sur les vieux trones des arbres.

Ag. remarquable (Ag. spectabilis), Fr., Epicr, 661.

Ag. aureus, Bull., t. 92. - Ag. thabarbarinus, Krombh., t. 3, fig. 3.

Cet agaric a le chapeau compacte, convexo-plane, sec; la cuticule, déchirée en squames ou en fibres soyeuses, de couleur doré pàle ou fauve; les feuillets, adnés-décurrents, serrés, étroits, d'un jaune ferrugineux; le pédicule ferme, ventru, assez court, enveloppé en bas par l'anneau, farineux en dessus.

11 croit, dans les bois, au pied des troncs de chènes.

Son goùt est salé, amer. - Comestible, selon M. Letellier.

Ag. écailleux ( $A g$. squarrosus), Müller.

Batsch., fig. 114. - Schæff,, t. 61, 80. - Sow., t. 284. - Grev., t. 2 - - Fl. dan., t. 831. - Paul., t. 292. - Huss., I, t. 8. - Ag. squamosus, Bull., t. 6ibi. - Fr., Epier., b60.

L'Ag. squarrosus, commun en automne, vient en touffes plus ou moins nombreuses, au pied de différents arbres, et surtout du pommier; il est comestible (je l'ai mangé plusieurs fois); a la chair ferme, d'un blanc jaunâtre; l'odeur faible; la saveur fongique, agréable; se pèle difficilement.

Son chapeau, large de 6 à 8 centimètres, de ouleur fauve clair, est recouvert, ainsi que le pédicule, de squames nombreuses qui se redressent de la circonférence au centre du chapeau, un peu plus foncées en couleur vers le centre de ce chapeau, lequel est d'abord arrondi, hémisphérique, puis aplani, à bords légèrement recourbés en dessous. Les feuillets sont d'un blane pâle, arqués, inégaux, droits, nombreux, atteignant le pédicule mais non décurrents, finement mortilés de blanc à leur tranchant. Le pédicule, long de 6 à 10 centimètres, est cylindrique, flexueux, atténué à sa base, plein ou fistuleux, pourvu à sa partie supérieure d'un anneau peu consistant, squameux au-dessous de cet anneau, non squameux en dessus. 


\section{LEPOTA.}

1re Tribu. - Lepiota (type).

Voile universel continu avec la pellicule du chapeau. Hyménophore distinct du pellicule.

Ag. à écailles aigues (Ag. acutesquamosus), Weinm. - Fr., Epier., 38. - Dans le gazon des jardins ou des bois. Comestible, selon Mich.; suspect, selon - Vittad.

Ag. couleur d'amiante (Ag. amianthinus), Scop. - Batsch, fig. 97. - Fr., Epicr., 50. - Dans les prairies. Est peut-être une variété de l'Ag. granulosus.

Ag. âpre (Ag. asper), Pers. (décrit).

Ag. tige d'oignon (Ag. cepestipes), Weinm. (décrit).

Ag. archarias (Ag. archarias), Pers., Icon., t. 5, fig. 1-3. - Fr., Epicr., 50. Dans toutes les forêts de pins. Est peut-être une variété de l'Ag. granulosus.

Ag. en bouclier (Ag. clypeolarius), Bull. (décrit).

Ag. en crête (Ag. cristatus), Fr. (décrit).

Ag. tête hérissée (Ag. echinocephalus), Vittad. (décrit).

Ag. herminé (Ag. ermineus), Fr., Epicr., 42. - Krombh., t. 25, fig. 34, 35. Dans le midi de la France, en automne; rare; saveur de radis.

Ag. excorié (Ag. excoriatus), Fr. (décrit).

Ag. de Fries (Ag. Friesii), Lasch, 9. - Lin. - Fr., Epicr., 37. - Variété pro-è bable de l'Ag. acutesquamosus. - Dans les bois; très-rare. Comestible.

Ag. des fours (Ag. furnaceus), Letell., Suppl., t. 653. - Sous un four à pain à Saint-Leu.

Ag. granuleux (Ag. granulosus), Batsch, fig. 24. - Fr., Epier., 50, - Commun dans les bois, bruyères et pacages. Vénéneux, selon Duchesne.

Ag. mastoïde (Ag. mastoideus), Fr. (décrit).

Ag. de moyenne taille (Ag. mesomorphus), Bull., t. 506, fig. 1. - Fr., Epicr., 54. - Dans les gazons, çà et là, en automne.

Ag. chétif (Ag. nazeinus), Fr. (décrit).

Ag. de Paulet (Ag. Pauletii), Paul., t. 163, fig. 1, 2, - Fr., Epicr., 49. - Dans les bois des environs de Paris. Suspect.

Ag. couleuvré (Ag. procerus), Scop. (décrit).

Ag. raboteux (Ag. rachodes), Vittad., t. 20. Voisin de l'Ag. procerus. - Dans les serres; rare. Suspect.

Ag. de Vittadini (Ag. Vittadinii), Moretti (décrit).

\section{2 e Tribu. - Amillaria.}

Voile partiel annulé; hyménophore continu avec le pédicule.

Ag. orangé (Ag. aurantiuss), Schæff. (décrit).

Ag. de Crouan (Ag. Crouanii), De Guernisac-Crouan, Fl. fin., p. 82. - Sur le terreau, dans une serre.

Ag. chaussé (Ag. caligatus), Viv. (décrit).

Ag. noirâtre (Ag. denigratus), Pers., Syn., p. 267. - Fr., Epicr., 76. - Sur les trones d'arbres; très-rare.

Ag. gris brun (Ag. griseo-fuscus), DC. - Fr., Epicr., 78. -Variété de l'Aq. melleus, selon de Seyne. 


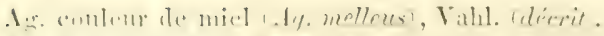

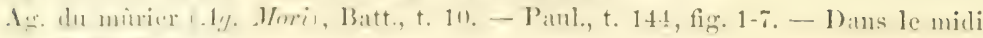
de lat lianter; ratre.

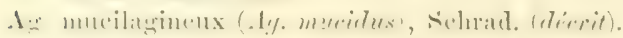

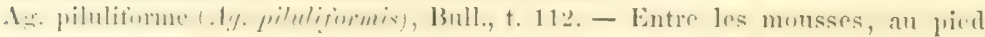
de's arbers.

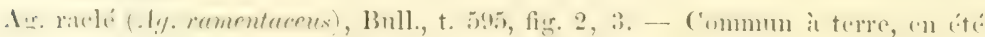
et en automne. Suspect.

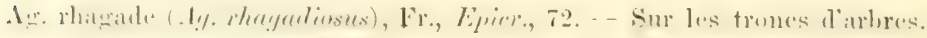

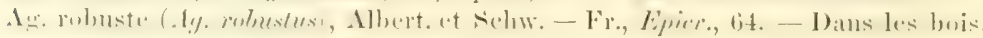

$\Lambda$ g. mde (Ag. scruposus), Fr. (décrit).

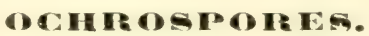

;е Trли: - Pholinta.

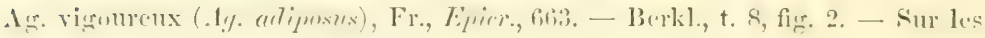
trones de hêtres languissants ou récemment coupés.

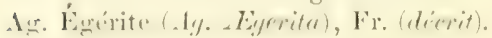

Ag. atténué (Ag. attematus), DC., Fl. fr., VI, p.51. - Letell., t. 632. - Va-

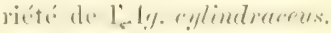

Ag. doré (19. aureus), Matt. - Fr., Epier., 638. - Sow., t. 77. - Sur les trones murts, en antomne: commun. Siexpect dipries Reveil et Letellier.

- $\Lambda$ g. rouille (Ag. aurivellus), Batsch, fig. 115. - Schæff., t. 209. - Fr., Epier., 659. - Sur les trones des arbres touffus, surtout des saules.

Ag. des mites (Ag. blattarius), Fr., Epier., 645. - Dans les jardins et les lieux cultivés.

Ag. coronille (Ag. coronilla), Bull., t. 597, fig. 1. - Fr., Epicr., 649. - Paul., t. 104. - Solitaire dans les gazons; commun.

$\Lambda$ g. cylindracé (Ag. cylindraceus), DC. (décrit).

Ag. destructeur (Ag. destruens), Brond., t. 6. - Fr., Epier., 656. - Sur le tronc des peupliers.

Ag. luxuriant (Ag. luxurians), Batt., t. 23, fig. B. - Fr., Epior., 655. - Sur les trones de chênes.

Ag. marginé (Ag. marginatus), Batsch, fig. 207. - Fr., Epier., 676. - Sur le trone et le bois pourni des pins.

Ag. murex (Aq. muricatus), Fr., Epicr., 669. - Sur les trones pourris de hêtre.

Ag. couleur de belette (Ag. mustellinus), Mich., t. 80, fig. 6. - Fr., Epicr., 677. Sur le bois de pin.

Ag. changeant (Ag. mutabilis), Schæff., t. 9. - Fr., Epicr., 675. - Bull., t. 543, fig. O, P, R. - Huss., II, t. 27. - Berkl., t. 8, fig. 3. - Sur les trones d'al'bres; rarement à terre; commun au printemps et en automne. Comestible, dit Fries, mais à dédaigner.

Ag. mycénoïde (Ag. mycenoides), Fs., Epicr., 680. - Dans les marais tourbeux.

Ag. pieu (Ag. paxillus), Batt., t. 11, fig. D. - Bull., t. 553, fig. Q. - Fr., Epier., 671. - Sur les trones courerts de feuilles.

Ag. phragmatophylle (Ag. phragmatophyllus), de Guern.-Crouan, Fl. fin., p. 76. - Sur la terre, au pied des arbres.

$\Lambda$ g. précoce (Ag. prepex), Pers. (décrit).

$\Lambda$ g. pudique (Ag. pudicus), Bull. (déerit).

Ag. racine de navet (Ag. radicosus), Bull., t. 160. - Fr., Epicr, 651. - Dans

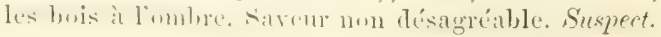


Ig. remarquable (.1\%. spectabilis), Fr. (dicriti.

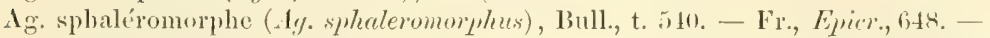
Dans les endroits humides.

Ag. écailleux (Ag. squarrosus), Miiller (décrit).

Ag. en toge (Ag. togularis), Bull., t. 595, fig. 2. - Fr., Epicr., 642. - Dans les gazons,

\section{SÉRIE III. - GYMNOPE (Gymmopus).}

(Tup.vórous, yui a le pied nu).

Point de volva, point d'anneau, ni de collier; pédicule central plein; feuillets ne noircissant pas en vieillissant; chapeau charnu, à centre proéminent.

Leucospolits. Spores blancher.

1 re Trubu. Tricholoma ( 0 p $\xi$, cheveu, sou, frange). Pied charnu; lamelles sinuées ou échancrées en arrière.

Ag. acerbe (Ay. acerbus), Bull., t. 571, fig. 2.

Pers., Myc., 279. - Vittad, p. 350. - E'r., Evicr., 160.

On reconnait ce champignon à son chapeau charnu, large de 7 à 9 centimètres, convexe, étalé, obtus, glabre, lisse, de couleur blanche, teintée de jaune, et enfin d'un roux fauve, assez souvent tacheté ef comme tigré, strié, mince au bord, fortement roulé en dessous; à ses feuillets, droits, inégaux, serrés, d'un jaune pâle, un peu décurrents. Le pied, long de 4 à 5 centimètres, est plein, nu, solide, d'un blanc jaunâtre, tacheté au sommet de très-petites écailles, cylindrique, mais quelquefois épaissi à sa base.

If croit à terre, assez tard, en groupes de deux ou trois individus.

Comestible. Vittadini dit qu'on le mange aux environs de Milan.

Ag. mousseron blanc (Ag. albellus), DG., Fl. fr., 469.

$$
\text { (I'1. IX, fig. 1.) }
$$

Schæff., t. 50. - Roq., t. 16, fig. ${ }^{4}, 5$. - Sow., t. 122. - Paul., t. 94, et t. 95, fig. 1-8. - Fr., Epier., 147.

Noms vulgaires: Mousseron, Misseron, Moussaïron, Champignon muscat, Braquet. 
Le chapean de ce champignon est charmu, comprate, convexe, sul)mamelonné, quelquefois irrégulièrement arrondi, glabre, large de 8 à 10 centimètres, d'abord blanc, puis d'un gris légèrement fauve, souvent parsemé de taches squameuses non persistantes, à bord mince, lisse, replié en dessous. Les feuillets sont nombreux, inégaux, blancs, les plus longs sont adhérents au pédicule et terminés par une dent. Le pédicule, nu, blanc, fibrilleux, plein, sous-ventru à sa base, enfoncé en partie dans la terre, est haut de 3 à 4 centimètres.

On a donné à cet agaric le nom de Mousseron, parce qu'il vient dans les mousses. L'Ag. albellus, dit Paulet, est le Mousseron le plus fin, le plus délicat que l'on connaisse; selon Bosc, c'est un manger délicieux, qui échappe à toute comparaison. On le trouve plus fréquemment dans les départements du Midi que dans ceux du Nord. Sa chair, blanche, ferme, cassante, se pèle difficilement. La dessiccation ne détruit pas son odeur agréable et musquée. Il apparait au premier printemps, sur les pelouses et le bord des bois.

L'Ag. Georgii, Lin. et Clus. - Fr., Epicr., 146, appelẻ ainsi, en Angleterre, parce qu'il vient à l'époque de la Saint-George (23 avril), est considéré par M. Léveillé comme une simple variété de l'albellus, et par M. Berkeley comme une variété du gambosus.

Ag. à 'tête blanche (Ag. albus), Fr., Epicr., 159.

Batt., t. 20, fig. I. - Berkl., t. 4, fig. 6. - Bult., fir. 153. - 1y. leucocephalus, Bull., t. 428 et 536. - Pers., Myc., 184, 185, 189.

Ce champignon, qui croît, au printemps el en automne, solitaire ou par petits groupes, à terre, dans les bois, est entièrement blanc dans sa jeunesse. Plus tard, il a le chapeau nu, peu jaunâtre ou fauve au centre.

Ce chapeau, d'abord convexe, plane ensuite et ordinairement mamelonné, lisse, sec, charnu, large de 6 à 7 centimètres, a les bords parfois sinueux. Les feuillets sont nombreux, inégaux, minces, larges, comme festonnés sur leur tranchant, un peu adhérents au pédicule, qui est long d'environ 8 centimètres, nu, plein, fibreux, cylindrique ou atténué à sa base, quelquefois flexueux.

L'Ag. albus passe à tort pour vénéneux, dit M. Letellier. Quoi qu'il en soit, son odeur particulière, faible, vireuse, sa saveur, âcre et amère, ne préviennent nullement en sa faveur. 
Ag. couleur d'améthyste (Ag. amethystinus), Scop., 437.

Paul., t. 95, fig. 9-11. - Fr., Epicr., 150.

Noms vulgaires: Mousseron, Palomet, Palombette, Blavet.

Son chapeau est charnu, peu épais, fragile, large de 7 à 8 centimètres, d'abord convexe, puis plane, irrégulièrement arrondi, glabre, lisse, humide, d'une couleur mélangée, dans la jeunesse, de bleu, de blanc et de vert au centre (gorge de pigeon), se changeant ensuite en roux, à bord d'un blanc sale, sub-rigueux. Les feuillets blancs deviennent un peu roussâtres avec l'àge, ils sont décurrents, subadnés, de longueur inégale, fins, serrés. Le pédicule, plein, nu, fibreux, ne s'élevant pas à plus de 4 centimètres, est légèrement renflé à sa base.

Cet agaric est comestible, d'un goût exquis; aussi le mange-t-on quelquefois cru. Il croit dans le Midi de la France, en automne, à terre, dans les bois, les friches, sur le gazon, parmi les mousses, ordinairement solitaire. Il a la chair blanche, ferme, l'odeur agréable, et ressemble au Mousseron par son port et sa forme.

Ag. des sables (Ag. arenarius), Laterrade.

Paul., Champ., t. 85, fig. 1, 2. - Ag. sinuatus, var. B. Arenarius, Laterr. Léveil., Ann. d. sc. nat., $1^{\text {re }}$ série, t. IX, p. 119.

Cette espèce est de couleur jaune, rutilante. Elle a le chapeau charnu, d'abord convexe, obtus, puis étalé, glabre; les feuillets, inégaux, peu nombreux, aigus aux deux extrémités, mais plus larges vers le pédicule, à la partie supérieure duquel ils sont adhérents; le pédicule cylindrique, nu, le plus souvent bulbeux à sa base, glabre, fibreux, plein.

L'Ag. arenarius croit, en automne, dans les sables des bois. Paulet dit qu'on le mange ả Bordeaux, oủ il est très-recherché. Il n'est pas rare dans la forêt de Fontainebleau: Il ressemble à l'Ag. sulfureus, espèce nuisible, dont il diffère surtout par sa chair blanche, son odeur douce et sa saveur agréable.

Ag. doré (Ag. auratus), Krombh., t. 63, fig. 10-12.

$$
\text { Paul., Champ., t. 43. - Fr., Epicr., } 93 .
$$

L'Ag. auratus, qu'on recherche comme aliment, dans le Midi de la France, est assez rare, il croit à terre dans les bois de pins. On le 


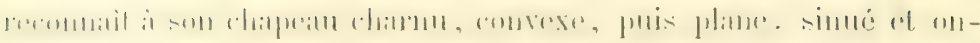

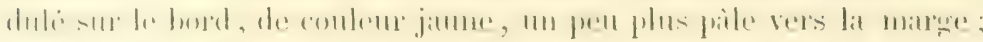

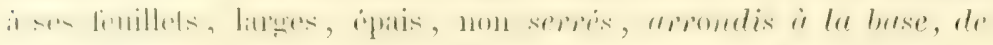

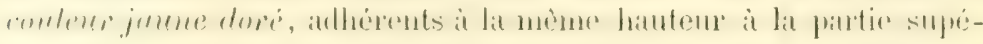
rieure du pédicule : ce pédicule est court, nu, épais, ferme, inégal, libreux, glabre, de la couleur du chapeau. La saveur de ce champignon est agréable.

Ag. trapu (Ag. brevipes), Bull., t. 521, fig. 2.

Buxh., t. 31, fig. 1. - Paul., t. 44, fig. 1, 2. - Fr., Eipicr., 172.

Cet agaric a le chapeau large de 6 à 7 centimètres, d'abord concave, puis plane, avec un mamelon très-obtus, souvent échancré, à superficie bien lisse, de couleur gris brun; les feuillets d'un gris cendré, nombreux̃, inégaux, aigus vers la marge du chapeau, échancrés i leur insertion au pédicule, lequel est court, nu, plein, de la couleur du chapeau, glabre, cylindrique, assez souvent renflé à sa base.

L'Ag. brevipes est comestible et mème délicat, selon Paulet. Reveil le donne pour suspect; peut-être ne l'a-t-il pas expérimenté. L'odeur de cet agaric est faible, sa sareur légèrement astringente, sa chair, fragile, d'un blanc sale ou un peu rougeàtre. C'est un champignon charnu, qui vient assez tard, en automne, dans les gazons des bois et sur le bord des chemins.

Ag. colombette (Ag. columbetta), Fr, Epicr., 108.

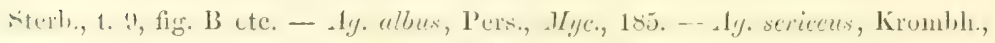
t. 25, fig. 6,7 .

(a) chanpignon, entierenent blane, se distingue encore par les catractères suivants: chapeau charnu, convexe, étalé, humide, rigide, sub-flexueux, d'abord glabre, ensuite soyeux, fibrilleux ou squamuleux, large de 6 à 8 centimètres, à bord légèrement enroulé; pied solide, nu, fort, inégal, strié, sub-glabre, long de 4 à 5 centimètres; leuillets presque libres, odeur et sareur peu prononcées.

Il n'est pas très-commun, et croit solitaire dans les bois de chênes et les bruyères. Comestible.

L'Ag. spermaticus, Paul., 1. 45, f. 1-3. - Fr., Epicr., 92, ressemble beaucoup au Columbetta. Fries dit que l'Ag. spermaticus est vénéneux; d'après M. Léveillé, ses propriétés sont incertaines. 
Ag. jambu (.ty. gambosus), Fr., Epier., 145.

Krombh., t. 63, fig. 18-22. - Stande, t. 9, fig. 2, 3. - Berkl., t. 4, fig. 5. Macq., t. 2, fig. 13. - Sow., t. 281. - Huss., I, t 83. - Ag. Pomonce, Lenz, Schw., p. 23, t. 2, fig. 7. - Ay. Georgii, Lin.

Ce champignon de grande taille, mais variable en dimension, blanc ou légèrement ocracé, a le chapeau charnu, trés-épais, d'abond convexe, puis plane et ondulé, humide, glabre, tacheté et enfin gercé, à bord roulé en dessous dans le jeune àge, velouté, de mème que le sommet du pied; les feuillets émarginés, ventrus, serrés, d'un blanc jaunâtre, adhérents au pédicule, lequel est nu, ferıne, solide.

L'A $g$. gambosus a une odeur forte de farine récente; il vient au printemps, dans les bois, les champs et les prés, tantòt seul, tantòt en groupes, le plus ordinairement formant un cercle.

Comestible. Il est d'un usage assez fréquent en Scandinavie. Lenz l'a souvent mangé cru ou cuit.

Ag. géminé ( $\mathrm{Ag}$.geminus), Paul., t. 40.

$$
\text { Fr., Epicr., }-26 .
$$

Paulet dit que cette espèce est très-bonne à manger. On la trouve en groupes peu nombreux et souvent composés de deux individus, d'où lui est venu le nom de geminus. On la distingue par son chapeau charnu, compacte, de couleur rousse, large de 3 à 5 centimètres, sec, convexe, onduleux, quelquefois finement crevassé, à bord infléchi en dessous, mince; ses feuillets, minces, nombreux, serrés, d'un blanc roussàtre, aigus à la marge; son pied court, épais, fibreux, nu, plein, de la couleur du chapeau. Pare.

Ag. pied rayé (Ag. grammopodius), Bull., t. 548 et 585 , fig. 1 .

Huss., II, t. 41. - Fr., Eyicr, 169. - 1\% tuthlaris, Pers., Mye., 110.

Agaric solitaire, dont le chapeau charnu, d'abord en cloche, puis convexe, plane et enfin déprimé, légèrement manelonné, lisse, humide, est large de 6 a 8 centimètres, gris brun ou fauve roux; les feuillets sont inégaux, arqués, serrés, blancs, non décurrents, adhirents à un pédicule, ferme, épais, plein, nu, cylindrique, long de 5 à 8 centimètres, glabre, marqué de petites raies noiratres, un peu renflé à sa base. On le trouve dans les bois ombragés, vers la fin de l'automne. 


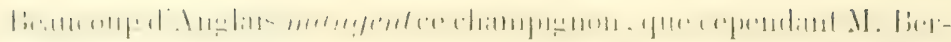

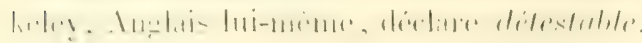

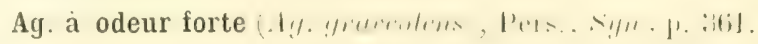

$$
\text { (II. II, Ii . 2.) }
$$

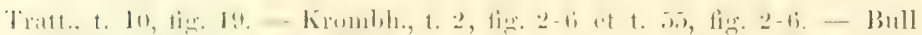

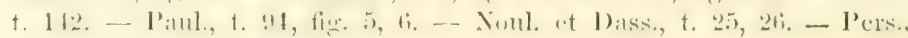

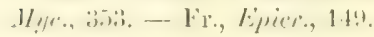

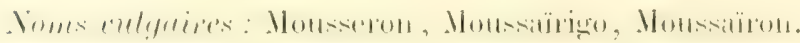

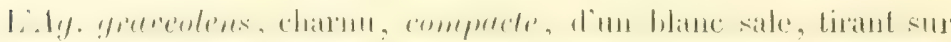

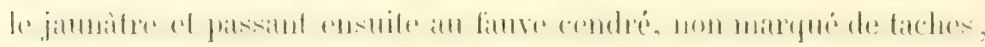

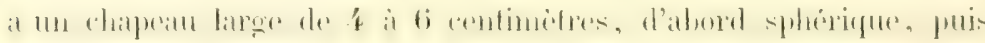

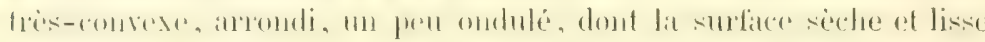

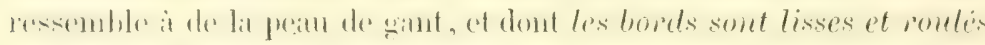
an dessems: less fenillets termines an pointe anx deux extremités. nombreux, inẻgaux, arqués, minces, adhérents au pédicule, d'abord blancs, ensuite d'un blanc sale ou roussâtre, fuligineux ; le pédicule blanc, nu, lemm, long de 3 it 4 centinctres, épais de 12 a lis millimetres, cylindrique, fibrilleux; la chair blanche, cassante, épaisse, à odeur pénétrante, se rapprochant de celle de la farine.

Il croit au commencement du printemps dans les bois, les friches et les prés sees. C'est un manger délicàt, dont on fait un fréquent usage dans le Midi de la France, surtout comme assaisonnement. On lo conserve souvent desséché; il se pèle dificilement.

Ag. imbrique (.ty. imbriculus), lir., Epricr., 109.

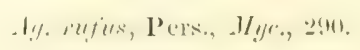

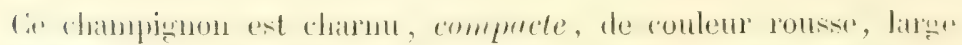

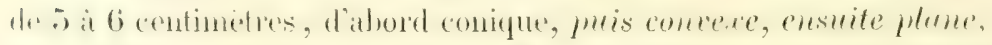

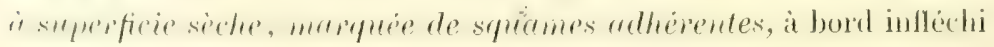
dlans les jeunes individus, pubescent, moins foncé en couleur. Il a les lamelles serrées, d'un blane roussâtre, émarginées, adnexes; le prod plein, court, roussâtre, nu, d'un blanc pulvémulent au sommet; dit dhair ferme, d'une saveur donce.

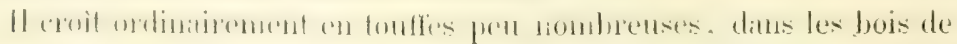

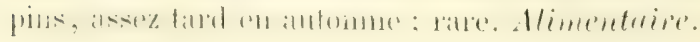


Ag. nu (Ay. mudus), Bull., t. 439.

Buxb., t. 12, fig. 1. - P'aul., t. 78, fig. 3. - Krombh., t. 71, fig. 27-29.Fr., Epier, 162.

Cet agaric, commun dans les bois, en èté ct en automne, vient le plus souvent en groupes peu nombreux; il a le chapeau d'abord convere, puis tplati, mais d'ordinaire faiblement mameloné, irrégulièrement concave ou sinué, large de 5 à 8 centimètres, lisse, do couleur violet-tendre ou lilas grisâtre, quelquefois violet fauve, charnu seulement au centre, $\dot{a}$ bord légèrement recourbé en dessous; les feuillets, nombreux, inégaux, bleus ou d'un violet roussâtre, aigus vers la marge du chapeau, arrondis à leur base et adhérents au pédicule par un léger prolongement; le pédicule, plein, élastique, cylindrique, nu, long de 5 à 6 centimètres, de la couleur du chapeau, sub-farineux au sommet, légèrement tomenteux à sa base.

Il est comestible, très-bon et délicat ; odeur faible, saveur agréable; chair cassante, d'un blanc un peu violacé.

Ag, travesti (Ag. personatus), Fr., Epicr., 161.

Fl. dan., t. 1133. - Sow., t. 209. - Bolt., t. 147. - Huss., II, t. 40. - Berk1., t. 5, fig. 1. - Iy. bicolur, Pers., Myr., 386 .

Son chapeau est compacte, charnu, régulier, large de 7 à 8 centimètres, et mème davantage, feonvexe, glabre, lisse, lumide, de couleur violacée, lilas, plus souvent cendrée ou fauve pàle, à bord excédant, recourbé, tomenteux. Les feuillets serrés, d'un blanc terne ou d'un violacé sale, sont arrondis en arrière et libres. Pédicule épais, pulvérulent ou tomenteux, lilacé ou violacé, un peu renflé à sa base, plein d'abord et enfin creux.

A la première vue on prendrait cet agaric pour ún Cortinaire; aussi a-t-on pu le confondre avec le Cortinarius violaceus. Il n'est pas non plus sans ressemblance avec l'Ag. nudus. Il vient presque toujours solitaire dans les bois, les gazons, les pâturages, et quelquefois dans les jardins. Non rare. Comestible; il se vend sur les marchés de Londres et d'Alger. Il est très-estimé dans le Midi de la France.

Ag. russule (Ag. Russula), Sehæff., t. 58.

'Tratt., t. G. - Krombh,, t. 63, fig. 1-9. - Bull., t. 509, fig. 3. - Letell., t. 616. - Barla, t. 13, fig.11, 12. - I'ers., Hyc., 296. - Fr., Eprer., 99.

Cé champignon sert d'aliment, surtout en Autriche. On pourrait 


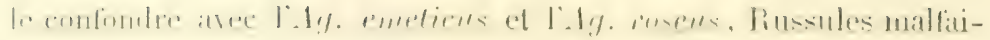
santes, si leurs feuillets n'ofrraient des diflérences essentielles. Ces deux demiers agarics ont les feuillets de longueur égale, tandis que ceux de l'Ag. Russula sont inégaux.

Le chapeau est charnu, de taille assez grande, large de 8 à 10 centimètres, d'abord convexe, puis plane et même un peu déprimé au centre, visqueux, gramuleux ou parsemé de petites peluchures brunes et écailleuses. Les feuillets, inégaux, blancs, peu serrés, arrondis, larges de 6 à 7 millimètres, sont à peu près libres. Le pied est $n u$, ordinairement cylindrique, court, d'un rouge rosé, plein, ayant le sommet granuleux et risqueux.

On trouve l'Ag Russula dans les bois; assez rare; solitaire.

Ag. couleur de soufre (Ag. sutphureus), Bull., t. 168.

Sowerb., t. 44. - Fl. dan., t. 1910, fig. 1. - Paul., t. 85, fig. 3, 4. - Berkl.,

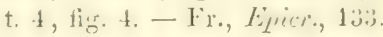

Plante toute de couleur jaune-soufre, dont le pédicule est long de 6 à 8 centimètres, nu, cylindrique, ordinairement flexueux; plein, glabre, légèrement strié. Le chapeau, charnu, large de 4 à 8 centimètres, quelquefois un peu fauve, à superficie d'abord conique, puis convexe, avec le centre parfois un peu déprimé, est charnu, à surface sèche, ne se pelant pas. Les feuillets sont inégaux, larges, distants, terminés en pointe, adhérents au stipe, et quelquefois faiblement décurrents.

L'Ag. sulphureus a la chair jaune, l'odeur et un peu le goût du chènevis pourri, il vient solitaire, dans les bois, en automne. On le trouve toujours à terre. Commun. Vénénenx.

2e Tribu. - Clytocibe ( $x \lambda$ ítos, penché, $x \cup \beta \eta \eta n$, tète). Pied fibreux élastique; lamelles décurrentes ou fortement adnées, non enduites de viscosités, atténuées en arrière, mais non échancrées; chapeau à marge primitivement enroulée.

Ag. oreillette (Ag. Auricula), Fr., Epicr, 192.

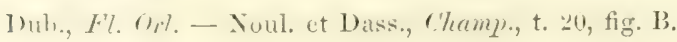

Noms vulgaires: Oreillette, Escoubarbe, Courdelou.

Un chapeau charnu, compacte, irrégulièrement arrondi, convexe, n'ayant guère dans son entier déreloppement que 4 ou 5 centimètres 
de diamètre, d'un gris plus ou moins foncé ou cendré fauve, lisse, d'abord convexe, puis plane, dont les bords sont un peu roulés en dessous; des feuillets d'un blanc pàle, décurrents sur un pédicule, court, plein, atténué à la base et de la couleur des feuillets, tels sont les signes distinctifs de l'Ag. Auricula.

Il vient ordinairement solitaire, en été et en automne, dans les clairières des bois et sur les pelouses; est comestible, de très-bon goût et de facile digestion, a l'odeur de la farine récente, ne se pèle pas et se dessèche facilement.

Pour M. Léveillé, l'Ag. Auricula pourrait bien n'ètre qu'une variété de l'Ag. prunulus.

Ag, de Garidel (Ag. Garidelli), Fr., Epicr, 243.

Paul., t. 63, fig. 2-4.

Noms vulgaires: Pinedo, en Provence.

Ce champignon n'est signalé que par Garidel et Paulet. Il est tout entier de couleur de chair. Son chapeau est charnu, d'abord convexe, puis déprimé au centre, lisse, à marge recourbée en dessous, large d'environ 8 centimètres. Les feuillets sont inégaux, nombreux, aigus aux deux extrémités, décurrents. Pied nu, glabre, plein, inégal, renflé à sa base.

Il vient à terre, dans les bois de pins en Provence, où il est recherché; il a la chair blanche, l'odeur et la saveur agréables. Comestible.

Ag. gymnopode (Ag. gymnopodius), Bull., t. 601, fig. 1.

Noul. et Dass., Champ., t. 23. - Fr., Eipicr., 735.

Nom vulgaire: Cassenado, en Languedoc.

Cet agaric croit, en automne, dans le Midi de la France, par groupes de quinze à vingt individus, à terre, dans les bois. Les paysans le confondent avec l'A $g$. socialis; il en diffère en ce qu'il vient à terre, au pied des arbres, et non sur les souches pourries ou au pied des yeuses, comme l'Ag. socialis. Sa chair, épaisse, blanche et très-ferme, a une odeur et une saveur.agréables.

Son chapeau est charnu, large de 6 à 8 centimètres, d'un brun ferrugineux, d'abord campanulé, puis convexe, puis plane, strié et souvent fendu sur les bords, mamelonné au centre, qui est comme hé- 


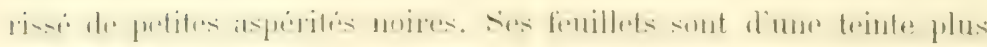

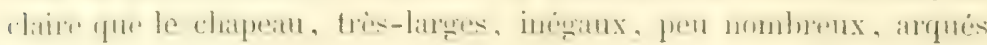

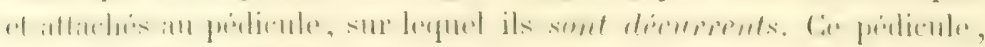

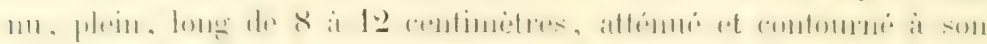

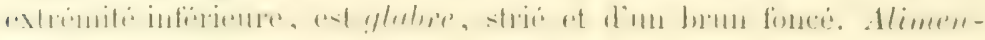
lini, 'in.

Ag. nébuleux (Ag. nebularis), Batsch, fig. 193.

Fl. dan., t. 1734. - Grev., t. 9. - Paul., t. 79, fig. 1-5. - Huss., II, t. 9. -

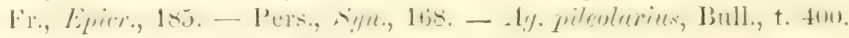

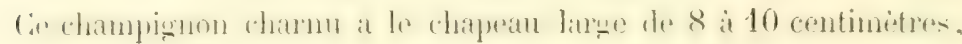
convexe d'abord, puis plane, rarement régulier, avec le centre presque toujours proẻminent, de couleur gris cendré, plus foncée au centre, les bords étant minces, légèrement recourbés en dessous, la superficie sub-furineuse chez les jeunes individus, lisse plus tard. Les feuillets sont d'un blanc pàle, inégraux, nombreux, minces, étroits, aigus aux deux extrémités, se prolongeant sur un pédicule long de 4 ì 8 centimètres, blanc ou grisâtre, peu épais, cylindrique, quelquefois flexueux, plein, substrié longitudinalement, tomenteux à sa base. Sa chair est blanche, son odeur fongique, sa saveur particulière.

A la fin de l'été et en automne on le trouve fréquemment solitaire ou en groupes, et formant souvent des trainées irrégulières à terre, dlans les bois, parmi les feuilles, auxquelles il adhère par une sorte de bivsus.

Bien que les auteurs donnent l'Ag. nebularis comme comestible, il est malfuisant. Paulet l'arait signalé comme suspect. M. Berkeley dit qu'on le mange en Angleterre; mais, ajoute-t-il, c'est une des espèces qui peuvent devenir offensives arec l'àge, et qu'il faut choisir saines, non viciées. Ayant voulu l'expérimenter, j'ai cueilli moimème des individus jeunes et sans défaut; ils m’ont incommorlé, ainsi qu'une personne qui asait partagé mon repas. Il est donc proJable que si des personnes en ont fait usage impunément, elles l'ont mangé dans de très-faibles proportions.

Il est facile de le confondre avec l'Ag. geotropus.

Ag. odorant (Ag. odorus), Bull., t. 556, fig. 3, et t. 176.

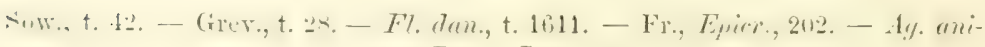
satus, Pers., Synn, 122.

Nom mulgaire: Bise verte (Vosges). 
Ce champignon exhale une odeur agriable, pénérante, qui se rapproche de celle de l'anis. Son chapeau, peu charnu, est large de 4 à 8 centimètres, glabre, non visqueux, de couleur gris bleu clair ou vert terne bleuâtre, d'abord convexe, puis plane, mais légèrement mamelonné au centre, avec des bords sub-sinueux et quelquefois même relevés. Les feuillets, dont un tiers à peine atteint le pédicule, sont adnés, sub-décurrents, non serrés, d'un blanc pâle très-légèrement incarnat. Le pédicule est grèle, cylindrique, plein, nu, long de 3 à 5 centimètres, de la couleur du chapeau, mais affaiblie.

Il vient à terre, dans les bois, sur les feuilles mortes, auxquelles il adhère par une sorte de duvet.

Comestible et de saveur agréable; on pourrait l'employer comme condiment. Suspect pour Reveil.

Ag. social (Ag. socialis), DG., Fl. fr., VI, p. 48.

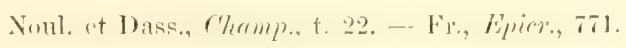

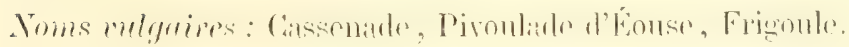

L'Ag. socialis croit, par touffes de quinze à vingt individus, sur les vieilles souches du chène yeuse, de mème que l'Ag. ilicinus. Son chapeau charnu, presque plane, fauve ou roussâtre, à centre plus fonce, un peu mamelonné et peluché, a les bords un peu roulés en dessous. Ses feuillets sont roux, très-décurrents sur un pédicule cy-lindrique, long de 12 à 15 centimètres, tortillé sur lui-même, d'un roux pâle, noirâtre à sa base, plus large là oủ s'insèrent les fenillets. Chair blanche, ferme, d'une odeur agréable. Comestible.

Il est en grande réputation dans le bassin pyrénéen; mais on ne mange que le chapeau, et non le pied, qui est coriace.

Cet agaric ressemble à la variété $A g$. contortus, Bull., t. 36 , de l'Ag. fusipes; mais ses feuillets très-décurrents sont de couleur ferruginense. 
3. Thror. Collybia (xokiußos, triespetite piese de monnaie). Pied

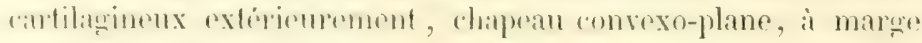

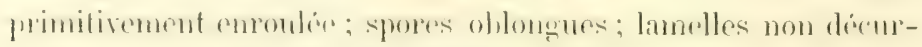
renter non colnites de viscosite et se dechirant fatcilement.

Ag. clou (Ag. Clavus), Lin.

Pers., MIyc, 243. - Bull., t. 148, fig. $\Lambda$, B, C, E. - Bolt., t. 39 B. - Vaill., t. 11, fig. 19, 20, - Fr., Epricr., 339.

Champignom de putite taille, a pen pres plane, qu'on trouve, solitaire, au printemps, sur les trones d'arbres et au pied des arbres, de couleur orangé rougeâtre brillant, ayant une saveur faible de radis, sans mauvais goût; un chapeau peu charnu, obtus, lisse, glabre, un peu jaunattre, large de $11 / 2$ centimètre à peine, coriace, non strié; des feuillets libres, nombreux, serrés, blancs, adnexes, émarginés; le pied plein, mince, glabre, cylindrique, à racine allongée, villeuse, long de 7 centimètres.

L'Ag. Clavus est tout voisin de l'Ag. esculentus. Comme celui-ci, il n'a.ni mauvais goùt ni mauvaise odeur; mais il croìt de préférence au pied des arbres et son pédicule est plein, ce qui les différencie.

Ag. dryophile (Ag. dryophilus), Bull., t. 343.

Suw., t. 127. - Sichaft., t. 255. - Ifuss., T, t. 39. -- Fr., Epicr., 334.

L'Ag. dryophilus varie de forme, de dimension et de couleur. Il est implanté sur les feuilles mortes par une base filamenteuse, sorte de byssus, agglomérant les débris qui l'entourent. Sa saveur est nauséeuse. Mistress Hussey le dit très-pernicieux : il a occasionné un empoisonnement en Angleterre. Extrèmement commun, dans tous les bois, du printemps à la fin de l'automne.

Il a le chapeau peu charnu, presque plane, obtus, quelquefois déprimé au centre, de couleur roux pâle ou fauve jaunàtre, lisse, large de 4 à 5 centimètres; les feuillets sinueux, serrés, étroits, d'un blanc pâle, adhérents, à peu près libres ou ayant une dent décurrente; le pied fistuleux, lisse, nu, de la couleur du chapeau ou un peu plus pâle, blanc au sommet. 
Ag. esculent (Ag. esculentus), Jacq., t. 14, fig. 4.

Tratt., t. F. - Lenz, fig. 18. - Vaill., t. 11, fig. 16-18. - Fr., Epicr., 330. - Ag. perpendicularis, Bull., t 422, fig. 2. — Schæff., t. 59. - Pers., Myge, 243.

L'Ag. esculentus, dont le chapeau est large à peine de 3 centimètres, peu charnu, à peu près plane, obtus, lisse, non strié, de couleur fauve ou jaune terreux, a une saveur légèrement amère; il vient, aủ printemps, dans les pàturages, les bruyères et les bois de haute futaie, soit solitaire, soit en touffes formées d'individus rapprochés, mais non soudés. Ses feuillets blancs, assez serrés, souples, adhèrent à un pédicule, long de 5 à 8 centimètres, fistuleux, grêle, trèsglabre, tenace, fortement enraciné, de la couleur du chapeau.

Comestible. Malgré sa petite taille, il est fort estimé en Autriche comme assaisonnement; on le porte au marché de Vienne. Partout ailleurs il est négligé : on le conserve desséché.

Ag. pied-fu (Ag.fusipes), Bull., t. 106 et 516 , fig. 2, et t 36 .

(PI. X.)

Sow., t. 129. - Schæff, t. 87, 88. - Fl. dan., t. 1607. - Krombh., t. 42, fig. 9 à 11. - Huss., II, t. 48. - Berkl., t. 5, fig. 5. - Paul., Champ., t. 51. Fr., Epier., 292.

Nom vulgaire: Chènier ventru (Paulet).

Cette espèce, dont les feuillets sont blanchàtres dans la jeunesse, est toute de couleur fauve ou marron lorsqu'elle est adulte. Son pédicule, nu, lisse, sillonné, long de 6 à 12 centimètres, est tortueux, renflé au milieu et terminé en pointe, ce qui lui donne la forme d'un fusceau, la partie inférieure plus colorée que le reste. Le chapeau, globuleux dans le jeune âge, plus tard irrégulièrement convexe, quelquefois fendillé en dessus, a 8 centimètres et plus de large. Les feuillets sont un peu écartés, inégaux, larges vers le pédicule, où ils se terminent parfois brusquement par un petit crochet décurrent.

L'Ag. fusipes croît en été et en automne, par touffes de sept ou huit individus, quelquefois solitaire, dans les bois, au pied des arbres et sur les trones pourris; il n'est désagréable ni au goût ni à l'odorat. Comestible; on rejette le pied comme trop coriace.

L'Ag. øedematopus, Schæff., et l'Ag. daucipes, Pers., Myc., 236, sont pour Fries de simples variétés de l'Ag. fusipes; l'Ag. contortus, Bull., t. 36, n'est peut-ètre non plus qu'une variété du fusipes. 
Ag. des devins (Ag. hariolorum), Bull, t. 585, fig. 2.

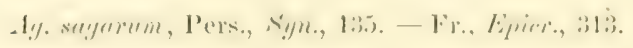

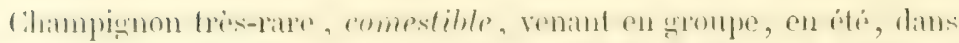
les bois, sur les fonilles pourries. Il a, dit Bulliard, un gont tresagréable et presque pas d'odeur. Dans quelques pays le peuple superstitieux craint de le fouler aux pieds, ce qui, peut-être, lui a fait domer le nom d'unuric des devins.

C'est un champignon de couleur jaune pâle, dont le chapeau, peu charnu d'abord, convexe, puis plane et quelquefois mème légèrement

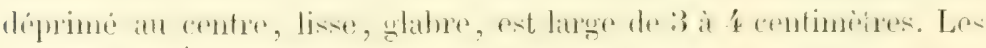
feuillets, inégaux, écartés, presque toujours tortueux, sub-émarginés,

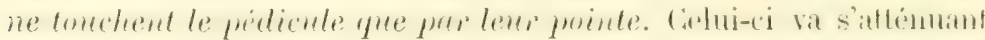
par en haut, et se continue avec la chair du chapeau; il est long de 3 i 4 centimètres, nu, villeux, coriace, plein dans la jeunesse, fistuleux dills 113 itge asancé.

Ag. d'yeuse (Ag. ilicinus), DG., Fl. fr., V, p. 48.

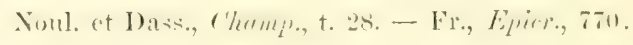

Noms vulgaires: Pivonlade d'éouse, Piboulado, Saüsenado, Cassinado,

On trouve cet agaric, à la fin de l'été, par touffes de dix et quelquefois trente individus, sur les vieilles souches et au pied du chêne vert ou yeuse. Le chapeau est charnu, très-convexe dans la jeunesse, puis presque plane, sec, non peluché, d'un roux fauve, quelquefois divisé sur les bords, de 3 à 4 centimètres de diamètre. Les feuillets, d'un roux pàle, inégaux, adhérent au pédicule sans être décurrents. Le pédicule est nu, roussâtre, presque cylindrique au sommet, nu. aminci en pointe à sa base, plein ou irrégulièrement fistuleux, long de 8 à 10 centimètres.

On mange, à Nontpellier, l'Ag. ilicimus, confondu avec l'Ag. socialis, sous le nom de pivoulade d'éouse. La chair est blanche, d'un gout exquis; elle a une odeur agréable. Le chapeau seul sert d'aliment, le pédicule étant trop coriace.

II. de Seynes, d'accord avec Delile, ne le regarde guère que comme whe rariete de l'dy fusipes. 
4n Tribu. Hygrophorus (ùypos, humide, "pope, action de porter). Genre pour quelques auteurs.

Hyménophore ou chapeau se continnant avec le pédicule, et dont la trame pénètre dans les feuillets, lesquels sont très-souvent rameux à leur base; chapeau et feuillets visqueux.

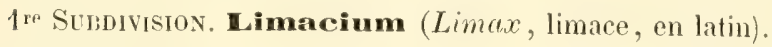

Ag. blanc d'ivoire (Ag. eburneus), Bull., t. 118 et 551, fig. 2.

PI. XI, fig. 1.

Buxb., t. 30, fig. 2. - Schæff., t. 39. - Lenz, fig. 8. - Batt., t. 4, fig. 2. Berk., t. 15, fig. 1. - Noul. et Dass., t. 21, fig. B. - Ag. jozzolus, Scop., Fl. carn. - Hygrophorus eburneus, Fr., Epicr., 3.

L'Ag. ebumeus est tout d'un blanc d'ivoire, luisant, très-visqueux par les temps humides.

Il a un chapeau, d'abord hémisphérique, puis plane et même quelquefois concave, mais toujours proéminent au centre, large de 5 i 8 centimètres, charnu, lisse sur ses bords, qui, dans le jeune âge, sont recourbés en dessous; les feuillets, étroits, inégaux, nombreux, légèrement prolongẻs sur un pédicule nu, plein, cylindrique, ordinairement court, parfois grêle et allongé, couvert sur le sommet de petites écailles ou aspérités brunâtres. Il croìt communément dans les bois en automne.

Comestible. Il a une odeur et une saveur agréables.

L'Ag. penarius, Fr., Epicr., 6, ressemble quelque peu à l'Ag. ebrineus; il est comestible aussi et vient probablement en France.

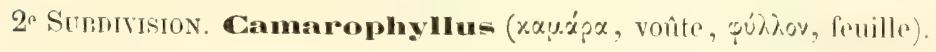

Chapeau charnu, humide, ì peine visquenx; voile nul; pied légèrement lisse.

Ag. des prairies (Ag. pratensis), Pers, Syn., 87.

Sow., t. 341. - Schæff., t. 313. - Fl. dan., t. 1735, fig. 1. - Grev., t. 91. Krombh., t. 43, fig. 7-10, - Huss., II, t. 40. - Hoffim., t. 5. - Ag. ficoides Bull., t. 587, fig. 1. - Hygrophorus pratensis, Fr., Epier., 24.

Ce champignon, fauve roussâtre et quelquefois cendré ou blanchàtre, a le chapeau charnu, d'abord convexe, puis aplati, avec le centre proéminent, glabre, humide, à bords minces ; les fenillets, peu nombreux, arqués, inégaux, épais, distants, de la couleur du chapeau ou blanchâtres, très-décurrents sur un pédicule court, plein, blanchâtre, lisse, attemur on bas. 


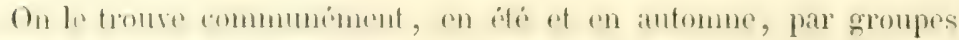
pent nombromx, dims les pros ef les pritmages.

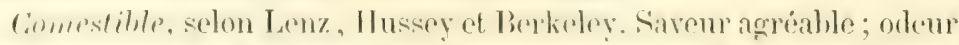

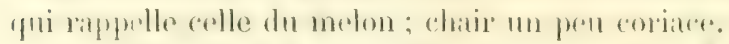

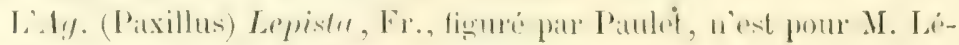

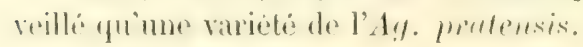

Ag. virginal (Ag. virgineus), Jacq., Misc., 2, t. 15, fig. 1.

$$
\text { (Pl. XI, fig. 2). }
$$

Suw., t. 32. - Battar., t. 19, fig. II. - Batsch, fig. 200 - Grev., t. 166. - Ay. ericeus, Bull., t. 188. - Hygrophorus virgineus, Fr., Epicr., 25.

Noms vulgaires: Oreille, Oreillette, Mousseron, dans quelques provinces; guiche, dans les Vospers.

Cet agaric, d'un blane de neige dans toutes ses parties, croit par petites peuplarles, vers la fin de l'été, dans les bruyères, les friches, les pâturages.

Son chapeau, d'abord convexe, plane à la fin, obtus, est large de 4 centimètres environ, à bords quelquefois aréolés ou fendillés, faiblement roulés en dessous, sec dans les lieux découverts, mollasse dans les lieux humides; il prend, en vieillissant, une légère teinte de gris ou de fauve. Ses feuillets sont inégaux, décurrents, peu nombreux, assez épais. Son pédicule n'a guère que 2 à 3 centimètres; il est ferme, plein, cylindrique, plus épais vers le sommet qu'à la base, mais non squarreux au sommet comme l'Ag. eburneus.

Alimentaire. Il a un goût agréable, une odeur faible, une chair mince, à demi transparente.

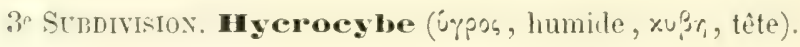

Chapeau mince, aqueux, fragile; voile nul.

Ag. écarlate (Ag. coccineus), Schæff., t. 302.

Batt., t. 19, fig. B. - Sow., t. 381. - Fl. dan., t. 715. - Huss., I, t. 61. Ag. scarlatinus, Bull., t. 570, fig. 2.- Hygrophorus coccineus, Fr., Epicr., 38.

Champignon élégant de forme, peu charnu, fragile, ayant un chapeau mince, convexe, obtus, visqueux, glabre, d'un rouge écarlate, tournant au jaune; des feuillets adnés, décurrents avec une dent, 
marqués de veines de différentes couleurs (pourpre à la base, jaune au milieu, glabre sur le tranchant); un pied creux, comprimé, jaunâtre, écarlate à sa partie supérieure. Très-commun, en automne, dans les prés, les pâturages. Comestible, d'après Mistress Hussey ; saveur très-agréable:.

L'Ag. coccineus a de la ressemblance avec les $A g$. miniatus, Fr., puniceus, Fr., psittacinus, Fr., ceraceus, Fr., et même avec l'A $g$. conicus, Fr., tous de la section des Hygrophores de cet auteur, mais dont les propriétés n'ont pas été étudiées.

Ag. gris de souris (Ag.murinaceus), Bull., t. 520

Krombh., t. 72, fig. 6-18. - Batt., t. 19, fig. 8. - Sow., t. 106. - Hygrophores murinaceus, Fr., Epicr., 50.

Son chapeau, d'abord campanulé, puis étalé, mamelonné, mince, large de 7 à 8 centimèlres, est soyeux, légèrement squameux à la surface, souvent crevassé sur les bords, cendré fuligineux. Ses feuillets sont peu serrés, larges, à bords sinueux, un peu plus pâles que le chapeau, ceux qui sont dimidiés coupés court, les plus longs aảnés, échancrés à leur base. Pédicule grèle, ordinairement flexueux, fistuleux, nu, grisàtre, non glabre.

Selon Duchesne et Morel, cet agaric est vénéneux. On le rencontre, en automne, dans les bois et les puiturages. Il a une odeur particulière, forte; une saveur fongique.

\section{Rhodospores. Spores roses.}

5 e Tribu. Entoloma (Ẻvros, en dedans, $\lambda(\omega) \mu$, , frange, bordure).

Chapeau ou hyménophore se continuant avec le pédicule; lamelles adnexées au pédicule par une sinuosité.

Ag. en bouclier (Ag. clypeatus), Lin.

Fr., Epicr., 573. - Bolt., t. 69. - Buxb., c. 4, t. 6. - Huss., II, t. 42 . Berkl., t. 7, fig. 6. - Ag. phonospermus, Bull., t. 534. - Ag. fertilis, Alb. et Schw. - Vaill., p. 53.

Le chapeau de ce champignon est peu charnu, hygrophane, d'abord d'une forme campanulée, il s'aplatit ensuite irrégulièrement, se creuse même dans le centre, mais reste mamelonné; ses bords sont ondulés ou sinues; sa surface est, sèche, lisse et soyeuse, rayée ou tachetée et comme pulvérulente, de couleur gris jaunàtre ou rous- 


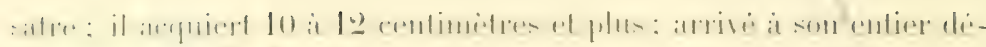

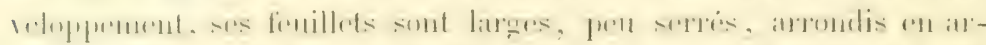

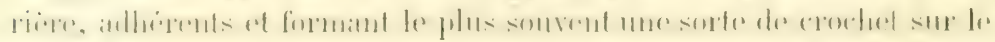

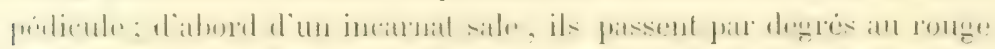
mat en vieillissant; son pédicule est ferme, fibreux, plein d'abord,

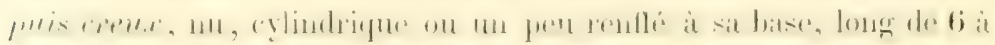
8 centimètres, quelquefois blane, mais plus souvent grisàtre et ordinairement marqué de stries rougeàtres, pulvérulent au sommel.

Il croit au printemps, surtout dans les lieux boisés et découverts, sur les pelouses et dans les allées des jardins, solitaire ou en touffes jeu nombreuses. Sa chair est blanche, cassante, inodore.

l'ris, mème en petite quantité, ce champignon est un poison dont les ellets sont narcotiques. In Auglais, W. O. Smith et sa famille, en ayant mangé, en furent assez sérieusement malades. Pour Reveil il cost suspect.

Ag. rose grisâtre (Ag. rhodopolius), Fr., Epicir., 474

I'aul., t. 99, fig. 1. - Bolt., t. 6. - Fl. dan., t. 1736. - Krombh., t. 55 , fig. 17-22.

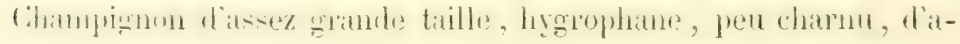
bord campanulé, puis étalé, plat ou déprimé, à centre mamelonné, à Jords flexueux ; surface lisse, comme satinée, d'un gris pàle lorsqu'il est sec, d'un gris noiràtre ou basané lorsqu'il est humide, large d'environ 8 centimètres; feuillets inégaux, espacés, aigus vers la marge, très-larges vers le pédicule, auquel ils adhèrent par un petif crochet, rosés dans le jeune âge, plus foncés en couleur en vieillissant, pédicule creux, cylindrique, allongé, glabre, blane, pruiné en baut. Croit au printemps et en automne dans les bois.

Chair blanche, aqueuse, fragile: saveur presque nulle, odeur analogue à celle de la farine fraiche.

Comestible. Paulet et M. Léveillẻ l'ont vu manger abondamment. Il fitut eviter de le confondre avec l'dy. chyperotus.

Ag. sinué (Ag. simuatus), Fr.

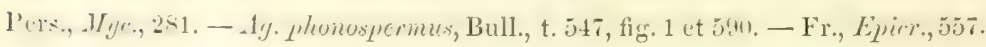

Noms vulgaires: Videau, Jaunet, Champignon jaune des Sables (Gironde). 


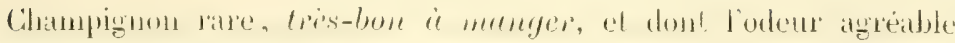

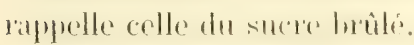

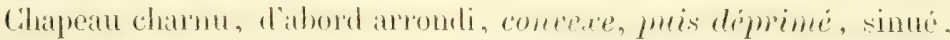
lisse, glabre, d'un bistre clair ou blane jaunàtre; large de 40 à 15 centimètres, feuillets très-larges, nombreux, roussitres, libres, obtus et émarginés à leur partie postérieure; pédicule plein, nu, ferme, compacte, d'abord fibrilleux, ensuite glabre, blane, tacheté de roux, égal ou un peu renflé à sa base, long de 5 à 7 centimètres.

Il croît à terre, au printemps et en automne, dans les bois liumides:

Cette espèce ressemble quelque peu à l'A $\boldsymbol{g}$. clypeatus $\mathrm{Fr}$, avec lequel il serait dangereux de la confondre.

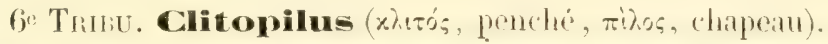

Chapean ou hyménophore se continuant ave un pédicule charnu ou fildreux: lamelles plus ou moins décurrentes.

Ag. orcelle (A 9. Orcella $)$, Bull., t. 573, fig. A, B, et t. 591 .

(Pl. XII, fig. 1).

Batt., t. 3!, 1, B. -- Batsch, t. 216. - Vittad., t. 12, fig. 2. - Fr., Epicr., 582.

Ciet agaric vient, en automne, solitaire ou en petits groupes, dans les bois, sur les pelouses, au bord des chemins; rarement il est attiqué par les vers; il a une forte odeur de farine récente; une saveu non désagréable; une chair cassante. Son chapeau, charnu, blanc, devenant un peu grisàtre en vieillissant, lisse avec l'aspect du satin ou d'une peau de gant glacé, visqueux par les temps de pluie, large de 6 à 9 centimètres, est d'abord convexe, puis plane et quelquefois déprimé au_centre, irrégulièrement arrondi ou mème lobé, à bord roulé dans les jeunes individus; ses feuillets sont nombreux, droits, inégaux, serrés, d'un blanc légèrement incarnat, terminés en pointe, sur un pédicule court (3 à 4 centimètres), nü, plein, blanc, s'élargissant an sommet, presque toujours excentrique et ordinairement recourbé. Comestible.

Ag. prunulus (Ay. Primules), Scop.

(Pl. Nil, fig. 2.)

Śchaft., t. 78. - Sow., t. 143. - Krombh., t. 55 , fig. 9, 10. -- IIuss., II, t. 47. Berk., t. 7, fig. 7. - Barla, t. 28, fig. 1-6.

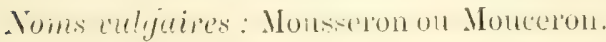




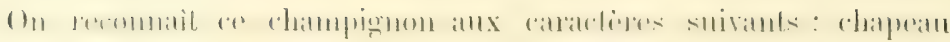

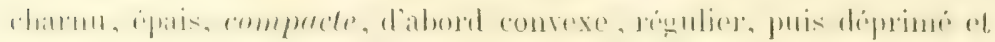

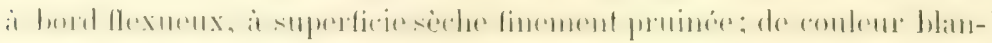

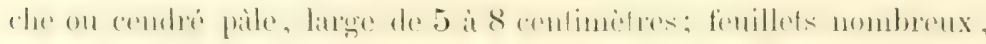

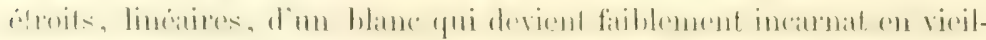

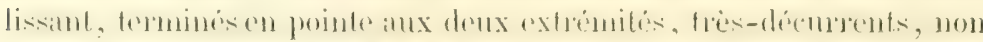

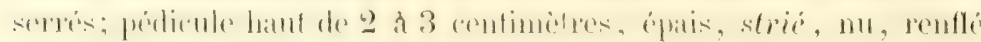

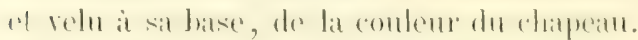

On le troure dans les bois et les friches, au printemps (avril et mai).

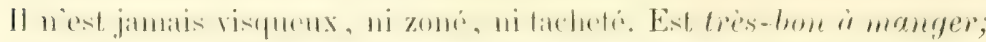
la chair, ferme, blanche, cassante, exhale une odeur de farine récente, forle al itgriathlo.

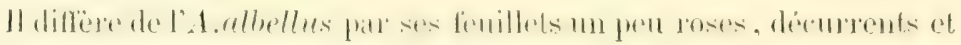
terminés en pointe aux deux extrémités.

Vittadini et M. Léveillé regardent l'Ag. prunulus et l'Ag. orcella comme ne formant qu'une mème espèce. D’après M. Léveillé, l'Ag. auricula Dub. rentrerait dans cette mème espèce.

Ochrospones. Spores ferrugineuses.

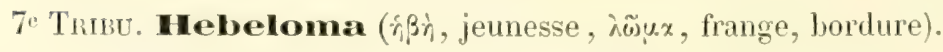

Pédicule charnu; fenillets sinueux, émarcrinés, non décurrents.

Ag. nauséabond (Ag. fastibilis), Schxff, t. 221.

Batt., t. 15, fig. D. - Fr., Elnier., 714.

Var. Ag. pruinosus, Paul. et Léveil., t. 53, fig. 2.

Chapeau compacte, charnu, d'abord convexe, puis plane, sinueux, oltus, lisse, glabre, ochracé, pàle où blanchàtre, large de 5 à 8 centimètres, à bord enroulé; feuillets émarginés, peu serrés, d'abord d'un blanc pâle, puis de couleur cannelle; pied solide, ferme, épais, subbulbeux, d'un blanc pâle, fibro-squameux, long de 6 à 8 centimetres, sourent flexueux, pourvu d'une cortine blanche, floconneuse. Cie champignon vient ordinairement en petites touffes, dans les bois, dans les champs. Il a une odeur de radis, une sareur légèrement amère, désagrẻable. Il est malfaisant, dit Kickx. M. Léreillé le tient au moins pour suspect. Il diffère peu de l'Ag. crustuliniformis.

Aucune espèce de la division des Hebeloma n'est signalée comme comestible. 
Ag. échaudé (Ag. crustuliniformis), Bull., t. 308 et 546.

(Pl. XIII, fig. 1.)

Batsch, fig. 195. - Paul., Champ., t. 52, fig. 1-3. - Berkl., t. 9, fig. 1.

Fr., Epicr., 724.

Chapeau charnu, consistant, convexe, ensuite plane et sinueux sur le bord, large de 5 à 8 centimètres, à superficie unie, luisante et très - gluante par les temps humides, de couleur blanc ocracé on jaune roux; feuillets nombreux, d'un roux pâle ou incarnat terreux, crénelés sur leur tranchant et comme larmoyants, ceux qui sont entiers laissant un intervalle entre eux et le pédicule, lequel est nu, plein, cylindrique, sub-bulbeux, long de 5 à 10 centimètres, blanc, glabre à sa base, granuleux ou tacheté de petites peluchures dans le milieu.

Ce Champignon est commun de juillet à novembre, dans les bois et les prairies, et vient par groupes, formant quelquefois des cercles et d'autres fois des bandes sinueuses ayant jusqu'à 100 mètres de longueur. Par sa forme et sa couleur, il a quelque ressemblance avec un échaudé, d'où lui est venu son nom. Sa chair est blanche, assez ferme, sa saveur désagréable; son odeur a quelque chose de la rave.

Vénéneux. Il a incommodé des animaux auxquels on en avait donné à manger.

Ag. crevassé (Ag. rimosus), Bull., 388 et 599.

(PI. XIII, fig. 2.)

Sow., t. 323. - Grev., t. 128. - Batsch, t. 20, fig. 107. - Krombh., t. 44, fig. 10 à 12. - Pers., Myc., 331. - Berkl., t. 8, fig. 5. - Fr., Epicr., 699.

Ciette espèce, dont le chapeau est large de 5 à 8 centimètres, peu charnu, d'abord conique puis plane avec le centre proéminent, peluché ou marqué de fibres soyeuses, rayonnantes, de couleur fauve clair, irrégulièrement crevassé de fentes longitudinales, a les feuillets inégaux, sinueux, nombreux, libres, fauves ou gris rougeàtre, le pédicule, nu, plein, cylindrique, grèle, long de 6 à 9 centimètres, d'un blanc sale ou fauve, comme farineux $\dot{\alpha}$ son sommet, un peu renflé à sa base.

Elle est très-commune, à terre, dans les bois, en été et en automne. Odeur terreuse; saveur amère; chair blanche. 
L'Ag. rimosus passe pour vénéneux. Selon M. Berkeley, il n'aurait ni bonnes ni mauvaises qualités; mais Reveil le dit malfaisant, et Balljis rapporte qu'il a empoisonné toute une famille.

\section{GXMNOF:}

\section{jre Tumst. - Tricholoma.}

I'ied charnu; fenillets sinués en arrière.

Ag. accrhe (.1\%. acertur.

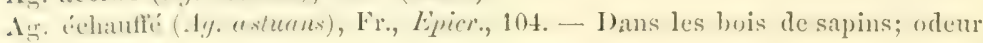
nulle.

Ag. Mousseron (Ag. albellus), DC. (décrit).

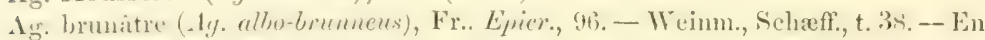
automne, dans les bois de pins et de chênes, sur les montagnes.

Ag. blane (Ag. albus), Fr. (décrit).

$\Lambda \mathrm{g}$. améthyste (Ag. amethystinus), Seop. (décrit).

$\mathrm{Ag}$. des sables (Aq. arenarius), Laterrade (décrit).

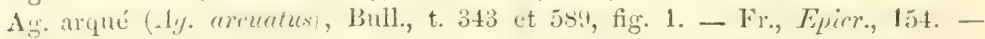

Dans les prés où il y a beaucoup d'herbages, groupé sur un même pied; cn automne; rare.

Ag. argenté (Ag. agyracens), Bull., t. 423, fig. 1. - Variété de l'Ag. terreus.

Ag. couleur d'or (Ag. auratus), Krombh. (décrit).

Ag. trapu (Ag. brevipes), Bull. (décrit).

Ag. des crapauds ( $A g$. bufonins), Pers., Syn., 188. - Bull., t. 545, fig. 2, et t. 168. - Variété de l'A. sulfureus, pour Fries. - Dans les bois de pins sur les montagnes; odeur fétide; suspect.

Ag. couleur de chair (Ag. carners), Bull., t. 533, fig. 1. - Dans les bois, les gazons, sur le bord des chemins.

Ag. cartilagineux (Ag. cartilagineus), Bull., t. 589, fig. 2. - Fr., Epicr., 120. Dans les endroits couverts de gazons; en automne; rare.

Ag. couleur de cire (Ag. cerinus), Pers., Syn., 119. - Fr., Epicr., 139. - Dans les bois de sapin.

Ag. tête jaune (Ag. chrysenterus), Bull., t. 556. - Fr., Epicr., 138. - Dans les bois de hêtres, entre les feuilles.

Ag. blanc cendré (Ag. cinerascens), Bull., t. 428, fig. 2. - Fr., Epicr., 167. Dans les bois.

$\Lambda$ g. odeur de chair rôtie (Ag. Cnista), Paul., t. 37, fig. 4-6. - Fr., Epicr., 168. —Dans les bois de hêtres exposés au soleil; rare; odeur de farine. Probablement comestible?

Ag. Columbetta (Ag. Columbetta), Fr. (décrit).

Ag. feuillets en coin (Ag.cuneifolius), Fr., Epicr., 124. - Batsch, fig. 206. Bull., t. 580, fig. A, B. - Dans les gazons; odeur de farine.

Ag. pied dense (Ag. dasypus), Pers., Syn., 348. - En groupes, près des trones de chênes.

Ag. équestre (Ag. equestris), Lin. - Schæff,, t. 41. - Dans les bois de pins; rate; tardit.

Ag. jaune brun (Ag. flavo-brunneus), Fr., Epicr., 95. - Schæff., t. 62. - Dans les bois humides; très-commun, surtout dans les bois de pins; odeur de farine. 
Ag. couleur de froment (.1y. frumentaceus), Bull, t. 571, fig. 1. - Daus les lienx humides des bois; rare.

Ag. obseur (Ag. furvus), Fr., Epicr., 113. - Dans les mousses humides des campagnes et des bois.

Ag. furdé (Ag: fucatus), Fr., Epicr., 90. - Sous les pins, au bord des chemins.

Ag. jambu (Ag. gambosus), Fr., Epier. (décrit).

Ag. geminé (Ag. geminus), Paul. (décrit).

Ag. de la Saint-Greorge (Ag. Georgiï), Lin. - Paul., t. 94, fig. 13-18. Var, de l'Ag. gambosus. - Dans les pays boisés, vers le milieu d'aviil. Comestible.

Ag. pied rayé (Ag. grammopodius, Bull. (décrit).

Ag. de Guemisac (Ag. Guemisaci), Crouan, Fl. fin., p. 81. - Sous les pins maritimes.

Ag. à odeur forte (Ag. graveolens), Pers. (décrit).

Ag. humble (Ag. humilis), Fr., Epicr., 173. - Dans l'herbe des torrains humides, en automne.

Ag. imbriqué (Ag. imbricatus), Fr. (décrit).

Ag. ionide (Ag. ionides), Bull., t. 533, fig. 3. - Fr., Epier., 141. - Dans les gazons des bois humides.

Ag. lascif (Ag. lascivus), Fr., Epicr., 135. - Dans les bois de chênes et les plantis.

Ag. tête blanche (Ag. leucocephahus), Fr., Epricr., 160. - Krombh., t. 62. - Commun dans les bois; odeur et saveur de farine récente.

Ag. blane noir (Ag. melaleucus), Pers., Syn., 180. Ay. leucophceus, Pers., MIyc., no 280.-Buxb., t. 12, fig. 2. - Fr., Epicr., 171. - Commun par les temps de pluie, dans les bois, le long des chemins, dans les gazons; sorte de protée.

Ag. Méléagre (Ag. Meleagris), Sow., t. 171.-Fr., Epier., 122. - Sur les couches.

Ag. clignotant (Ag. nictitans, Fr., Epicr., 94. - Bull., t. 574, fig. 1. - Dans les bois à feuillage épais; rare; sans odeur. - Variété Ag. fulcellus, Fra, Epier., 94. Ag. fulvus, Bull., t. 552, fig. 2. - Dams les bois de hêtres.

Ag. nu (Ag. nudus), Bull. (décrit).

Ag. des montagnes (Ag. oreinus), Fr., Epier., 155. Ag. testudineus, Pers., Myc., t. 23, fig. 1-2. - Dans les bruyères des montagnes, au printemps; odeur faible, acidule. Comestible.

Ag. de Pelleticr (Ag. Pelletieri), Léveillé; Crouan, Fl. fin., p. 81. - Dans les chemins creux.

Ag. prétentieux (Ag. portentosus), Fr., Epicr., 88. - Dans les bois do pins.

$\Lambda \mathrm{g}$, travesti (Ag. personatus), Fr. (décrit).

Ag. pied de chèvre (Ag. pes capra), Clus. - Sterb., t. 9. - Schæff., t. 14. Fr., Epicr., 152. - Dans les gazons; odeur de farine. Comestible.

Ag. tête brune (Ag. phaiocephalus), Bull., t. 555, fig. 1. - Fr., Epior., 113. - A terre, au printemps et à l'automne. Suspect.

Ag. à feuillets nombreux (Ag. polyphyllus), DC. - Fr., Epicr., 111. Ag. phecochrous, Pers., Myg., 312. - Dans le Midi de la France; dans les serres, sur le tan.

Ag. roussâtre (Ag. Russula), Schæff. (décrit).

Ag. cinq parts (Ag. quinquepartitus), Lin. - Paul., t. 55, fig. 2, 3. - Dans les bois de pins; rare. Odeux nulle; saveur douce.

Ag. rutilant (Ag. rutilans), Schæff., t. 219. - Sous les arbres verts.

Ag. de Schumacher (Ag. Schumacheri), Fr., Epicr., 153. Ag. pullus, Pers, Myc., $n^{\circ} 144$. - Dans les bois de hêtres, à la fin de l'automne. Vénéneur, sclon Duchesne. 
Ag. odeur de savon (Ag. saponaceus), Fr., Epier., 118. - Sow., t. 81. Ag. argyrespermus, Bull., t. 602. Commun; fin de l'automne et hiver, dans les buis, lorsque l'atmosphère est humide. Odeur caractéristique de savon.

Ag. émarginé (Ag. sejunctus), Sow., t. 126. - Fr., Epicr., 87. - Dans les forêts ; when de farine.

Ag. sordide (Ag. sordidus), Fr., Epicr., 178. - Fl. dan., t. 1843, fig. 2. - Dans les jardins, les vergers.

Ag. spermatique (Ag. spermaticus), Paul, t. 45, fig. 1-3. - Fr., Epier., 92. Dans les bois à feuillage épais; odeur vireuse. Vénéneux ou du moins fort surpect.

Ag. couleur de soufre (Ag. sulfureus), Bull., (décrit).

Ag. terreux (Ag. terreus), Schæff., t. 64. - Sow., t.76. - A terre, dans les bois et les champs, pendant l'automne et l'hiver.

Ag. tigré (Ag. tigrinus), Schæff., t. 89. - Fr., Epicr., 151. - En groupes, sous les pins dont le pied est couvert de gazon. Comestible; peu estimé.

Ag. triste (Ag.tristis), Scop. - Fr., Epier., 114. - Dans les champs, les haies.

Ag. enflé (Ag. tumidus), Pers., Syn., p. 350. - Krombh., t. 72, fig. 1-5. - Fr., Epicr., 128. Ag. robustus, Letell. - Dans les bois de pins; rare.

Ag. des vaches (Ag. vaccinus), Pers., Iconograph. et descript., t. 2, fig. 1-4. Dans les bois de pins.

Ag. panaché (Ag.variegatus), Scop., Fl.carn., p. 434. - Fl. dan., t. 1910. fig. 2. - Très-voisin de l'Ag. rutilans.

Ag. rayé (Ag. virgatus), Fr., Epicr., 130. - Lasch. - Weinm., p. 26. - Dans les bois, sur les montagnes solitaires, au Midi; en automne; rare.

$2^{\text {e } T r i b u . ~-~ C l y t o c i b e . ~}$

Pied élastique à écorce fibreuse; fevillets décurrents ou aigus à leur annexion.

Ag. Ag. ample (Ag. amplus), Pers., Syn., 139. - Fr., Epier., 217. - Dans les bois; très-rare.

Ag. d'Augé (Ag. Augeanus), Mont. - Odeur de farine.

Ag. petite oreille (Ag. Auricula), Fr. (décrit).

Ag. blanc de céruse (Ag. cerussatus), Fr., Epicr., 279. - Fl. dan., t. 1796. Dans les bois.

Ag. pied en clou (Ag. clavipes), Pers., Syn., 176. - Fr., Epicr., 217. - Dans les bois; très-rare.

Ag. pied court (Ag. curtipes), Fr., Epier., 195. - Dans les gazons.

Ag. blanchi (Ag. dealbatus), Sow., t. 123. - Pers., Myc., 189. - Fr., Epicr., 215. - Dans l'herbe des champs, en automne; odeur agréable. Probablement comestible.

Ag. enfumé (Ag. fumosus), Pers., Syn., 165; Icon. pict., t. 7, fig. 3. - Fr., Epicr., 189. - Dans les bois de pins, sur les montagnes; odeur nulle. Vrai protée. - Pris quelquefois pour l' $\mathrm{Ag}$. nebularis.

Ag. de Garidel (Ag. Garidelli), Fr. (décrit).

Ag. gymnopode (Ag. gymnopodius), Bull. (décrit).

Ag. hirnéole (Ag. hirneolus), Fr., Epier., 196. - Weinm., p. 223. - Pers., Myc., 131. Ag. undulatus, Bull., t. 535, fig. 2, - Dans les mousses et le long des chemins.

Ag. des jardins (Ag. hortensis), Pers., Syn., 194. - Batt., t. 21, fig. D. - Fr., Epicr., 222. - Dans les jardins du Midi de la France. 
Ag. bronzé (Ag. molybdinus). Bull., t. 523. - Fr., Epicr., 218. - Dans les bois feuillus.

Ag. des lieux humides (Ag. humosus), Fr., Epicr., 223. - Sur la terre, dans les terrains humides.

Ag. nébuleux (Ag. nebularis), Batsch (décrit).

Ag. odorant (Ag. odorus), Bull. (décrit).

Ag. opaque (Ag. opacus), With. - Sow., t. 142. - Pers. Myc., nos 162, 170, 190. - Fr., Epicr, 228. - Dans les bois.

Ag. social (Ag. socialis), (décrit).

Ag. à odeur suave (Ag. suaveolens), Schum. - Fl. dan., t. 1912, Ag. hedeosmus, Pers., Myc., 121. - Parmi les mousses.

Ag. vert (Ag. viridis), Scop. - Bull., t. 176. - Fr., Epicr., 201. - Dans les bois. N'est probablement qu'une variété de l'Ag. odorus, Bull.

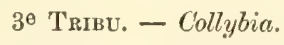

Pédicule cartilagineux extérieurement; marge du chapeau d'abord enroulée; feuillets non décurrents.

Ag. en touffes (Ag. acervatus), Fr., Epicr., 333. - Dans les bois de pins, à la base des trones.

Ag. anthracophile (Ag. anthracophilus), Lasch. - Ag. ambustus, Fr., Epicr., 352. - Sur la terre brûlée.

Ag. aqueux (Ag. aquosus). Bull., t. 12. - Dans les mousses humides.

Ag. butireux (Ag. butyraceus), Bull., t. 572. - Dans les bois, en novembre.

Ag. garni de franges (Ag. cirratus), Schum. - Batsch, fig. 95. - Fr., Epier., 321. - Parmi les feuilles mortes dans les bois.

Ag. clou (Ag. Clavus), Bull. (décrit).

Ag. des collines (Ag. collinus), Scop. - Schæff., t. 220. - Ag. arundinaceus, Bull., t. 403. fig. 1. - Sur les collines couvertes de gazon.

Ag. concolore (Ag. concolor), Del., Iconog. Très-voisin de 1'Ag. cedematopus.

Ag. confluent (Ag. confluens), Pers., Syn., 207; Icon. pict., t. 5, fig. 1. - Dans les bois.

Ag. des cônes (Ag. conigenus), Pers., Syn., 245. - Buxb., t. 57, fig. 2, - Dans les bois de conifères, sur les pommes de pins et de sapins.

Ag. tortu (Ag. contortus), Bull., t. 36. - N'est probablement qu'une variété de l'Ag. fusipes. - Sur le trone des arbres.

Ag. blanc de cygne (Ag. cycneus), Lév. et Paul., t. 93, fig. 4, 5. - A terre, en automne, dans les bois.

Ag. dryophile (Ag. dryophilus), Bull. (décrit).

Ag. comestible (Ag. esculentus), Jacq. (décrit).

Ag. extubérant (Ag. extuberans), Batt., t. 28, fig. 1. - Fr., Epier. 336. Ag. ocior., Pers., Myc., 244. - A terre, sur les trones, au printemps et en été.

Ag. pied en fuseau (Ag. fusipes), Bull. (décrit).

Ag. des devins (Ag.hariolorum), Bull. (décrit).

Ag. de l'yeuse (Ag. ilicinus), Dec.(décrit).

Ag. pied en forme de lance (Ag. lancipes), Paul., t. 118. - Krombh., t. 42, fig. 6-8. - Dans les bois, à terre; rare.

Ag. long pied (Ag. longipes), Bull., t. 232 et t. 515, fig. M. - Dans les bois ombreux, en automne.

Ag. maculé (Ag. maculatus), Alb. et Schw. - Fr., Epicr., 293. - Dans les lieux humides plantés de pins. 
Ag. souris (Ay. murinus), Fr., Epicr., 354. - Dans les endroits sauvages des bois, ì terre,

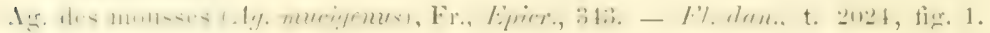
- Dans les mousses des champs, et au bas des trones d'arbres.

Ag. nummulaire (A\%. nummularius), Bull., t. 56. - Dans les feuilles; les pailles.

Ag. occllé (Ag. ocellatus), Fr., Epicr., 340. - Bull., t. 569, fig. 1. - Dans les bois; au bord des chemins; sur les gazons.

Ag. pied gonflé ( 1 g. codematopus), Schæff, t. 259. - Krombl., t. 42, fig. 6-8. 1\% fusiformis, Bull., t. 76, - - Sur les bois pourris. N'est peut-être qu'une vitivite d. l. 1.y insijus.

Ag. parasite (Ag. parasiticus), Bull., t. 574, fig. 2. - Sow., t. 127. - Nyctalis parasitica, Fr., Epior., 5. - Berkl., Outl., t. 19, fig. 2. - Sur l'Ag. Russula adustus.

Ağ. pied châtain (Ay. pheopodius), Bull., t. 532, fig. 2. - Fr., Epicr., 297. Dans les bois.

Ag. à feuillets plats (Ag. platyphyllus), Fr., Epicr., 288, - Paul., t. 97, fig. 1, 2. Ag. grammocephalus, Bull., t. 594. - Autour et sur les trones de bouleaux, de hêtres, etc. cariés.

Ag. è picd entrelacé (Ag. plexipes), Fr., Epicr., 350 et 351. Ag. fuliginarius, Batsch, fig. 40. - Sous les hêtres, parmi le gazon.

Ag. rameux (Ag. ramosus), Bull., t. 102. - Fr., Epicr., 303. - Sur les trones d'ormes.

Ag. en grappes (Ag. racemosus), Pers., Disput., t. 3, fig. 8. Ag. globulites, Brond., t. 6, fig. 6, 7. - Sur les agaries putréfiés.

Ag. cmraciné (Ag.radicatus), Relhan. - Sow., t. 48. - Fr., Epicr., 285. - Au pied des trones d'arbres.

Ag. des tiges (Ag. stipitarius), Fr., Epicr., 310. - Lasch, Ag. caulicinalis, Bull., t. 522, fig. 1. - Sur les tiges et les racines des graminées, en touffes.

Ag. tenace (Ag. tenacellus), Pers., Syn., 244 ; Icon. pict., t. 1, fig. 3. - Dans les bois, automne et hiver. Odeur nulle; saveur agréable.

Ag. tubéreux (Ag.tuberosus), Bull., t. 256. - Sur les champignons pourris; commun, en novembre.

Ag. pied velouté (Ag. velutipes), Curt., Fl. lond., t. 70. - Sow., t. 384, fig. 3. IIuss., I, t. 46. - Fr., Epior., 305. Ag. nirripes, Bull., 344, et t. 519, fig. 2. - Sur les trones d'arbres.

Ag. ventru (Ag. ventricosus), Bull., t. 411, fig. 1. - Dans les forêts épaisses du Midi; sur la terre, les fumiers.

te Ti:ut. - Higroplutur.

Ifymenium continu avec le pédicule et pénétrant dans les feuillets; chapeau et feuillets visqueux ou humides.

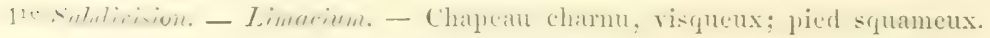

Ag. (Hyg.) dent d'or (Ag. Hyg. chrysodon), Batseh, fig. 212. - Fr., Epicr., 2. Dans les bois,

Ag. (Hyg.) Cossus (Ag. Hyg. Cossus), Sow., t. 121. - Fr., Epier., 4. - Dans les bois de pins.

Ag. (Hyg.) forme de disque (Ag. Hyq. discoideus), Pers., Syn., 200. - Fr., Epier., 17. - Dans les endroits herbagés, sur les chemins des bois de pins; rare.

Ag. (Hyg.) ivoire (Aı. Ilyy. ebumeus), Bull. (décrit). 
Ag. (Hyg.) rougissant (Ag. Hyg. erubescens), Fr., Epicr., 8. - Dans les lieux sauvages et les bois de pins.

Ag. (Hyg.) glutinifère (Au. Hyg. glutinifer), Bull., t. 258 et 539, fig. B. - Paul., t. 87, fig. 1, 2. - Fr., Epicr., 10. - Dans les bois touffus, du Midi surtout.

Ag. (Hyg.) à feuillets soufrés (Ag. Hyg. hypothejus), Fr., Epior., 13. - Krombh., t. 71, fig. 24, 25. - Alb. et Schw., t. 10, fig. 3. - Sow., t. 8. - Dans les bois de pins, les bruyères.

Ag. (Hyg.) blane brun (Ag. Hyg. leucophceus), Bull., t. 539, fig. C, E. - Variété de l'Ag. glutinifer.

Ag. (Hyg.) gluant (Ag. Hyg. limacinus), Scop. - Paul., t. 77, fig. 3. - Fr., Epicr., 17. - Dans les pays de bois de plaines.

Ag. (Hyg.) blane livide (Ag. Hyg. livido-albus), Fl. dan., t. 1904, fig. 2. - Fr., Epier., 16. - Dans les bois chargés de feuilles; rare.

Ag. (Hyg.) blanc olivacé (Ag. Hyg. olivaceo-albus), Fr., Epier., 14. - Schæft., t. 312. - Dans les bois de pins de montagnes, été et automne.

Ag. (Hyg.) de l'office (Ag. Hyg. penarius), Fr., Epicr., 6. - Schæff., t. 238. Dans les bois mixtes, les bois de hêtres surtout. Comestíble.

Ag. modeste (Ag. pudorinus), Fr., Epicr., 9. - Pers., Myc., 168. - Sous les sapins.

Ag. (Hyg.) pustulé (Ag. Hyg. pustulatus), Pers., Syn., 178. - Dans les bois de pins.

\section{Hygrophores.}

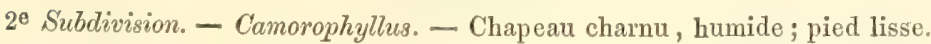

Ag. (Hyg.) des bois (Ag. Hyg. nemoreus), Lasch. - Dans les bois rabougris et épais.

Ag. (Hyg.) blane de neige (Ag. Hyg. niveus), Scop. - Schæff., t. 232.-Krombh., t. 24, fig. 1-3. - En automne, dans les prairies mousseuses.

Ag. (Hyg.) des pacages (Ag. Hyg. ovinus), Bull., t. 580. - Fr., Epicr., 30. Huss., II, t. 50. - Dans les prairies des pays de plaines. Duchesne le dit comestible.

Ag. (Hyg.) des prés (Ag. Hyg. pratensis), Lin. (décrit).

Ag. (Hyg.) virginal (Ag. Hyg. virgineus), Jacq. (décrit).

\section{HYGROPHORLS}

$3^{e}$ Subdivision. - Hygrocybe - Champignon entièrement aqueux; fragile.

Ag. (Hyg.) céracé (Ag. Hyg. ceraceus), Fr., Epicr., 37. - Sow., t. 20. - Wulf., II, t. 15, fig. 2. - Dans les prés couverts de mousses, et les pâturages en automne.

Ag. (Hyg.) chlorophane (Ag. Hyg. chlorophanus), Fr., Epicr., 45. - Dans les gazons et les mousses.

Ag. (Hyg.) écarlate (Ag. Hyg. coccineus), Schæff. (décrit).

Ag. (Hyg.) conique (Ag. Hyg. conicus), Scop. - Schæff, t. 2. - Sow., t. 381.Bull., t. 50, et t. 524, fig. 3. Ag. dentatus, Lin. - Dans les gazons et les herbes, en automne.

Ag. (Hyg.) riant (Ag. Hyg. latus), Pers., Syn., 141. - Dans les prés couverts de mousses.

Ag. (Hyg.) vermillon (Ag. Hyg. miniatus), Fr., Epior., 39. - Fl. dan., 1009, fig. 2. - Krombh., t. 1, fig. 21. - Dans les lieux humides, pendant tout l'été. 
Az̈. (Iy.r.) gris de somis (Ay. IIyg. murinaceus), Bull. (decrit).

Ag. (IIyer) dore brillant (A\%. IIy. obrusseus), Fr., Eypiry, 43. - Batt., t. 19, fig. 1). - sur le bord des bois, en automme; rare.

$\Lambda$ g. (Iyg.) perroquet (Ag. Hyg. psittacinus), Schrff., t. 301. - Grev., t. 74. Batt., t. 21, fig. E. - Sow., t. 82. - Huss., I, t. 41. - Bull., t. 545, fig. 1. - Dans les pâturages et les tourbières.

Ag. (Hyg.) rouge pourpre (Ag. Hyg. puniceus), Bolt., t. 67, fig. 2 et t. 43. Fr., Epicr, 42. - Dans les prés où croissent les mousses.

Ag. (Hyg.) brun bai (Ag. Hyg. spadiceus), Scop. - Fr., Epicr., 47. - Dans les gazons de montagnes.

Ag. (Hyg.) chapeau rose (Ag. rhodocephalus), Léveil. - De Guernisac-Crouan, Fl. fin.

\section{RHODOSPOItES.}

5e Tribu. - Pluteus (en latin, parapet, cloison).

Chapeau ou hyménophore distinct du pédicule; lamelles absolument libres; enveloppe générale nulle ou confondue avec la pellicule du chapeau. Épiphytes.

Ag. couleur de cerf (Ag. cervinus), Schæff., t. 10. - Sow., t. 108. - Fr. Epicr., 541. - Ag. pluteus, Krombh., t. 2', fig. 7. - Commun, au printemps et à l'automne, sur les troncs d'arbres, dans les bois et même sur les toits en chaume. Suspect.

Ag. jaune brun (Ag. chrysophreus), Schæff., t. 253. - Berkl., t. 7, fig. 5. - Fr., Epier., 554. - En automne, sur les bois tombés à terre, le hêtre surtout.

Ag. velu (Ag. ephebeus), Fr., Epier., 543. - Bull., t. 214. - Sur les trones d'arbres, dans les lieux ombragés; rare.

Ag. couleur de lion (Ag. leoninus), Schæff., t. 48. - Pers., Icon. et descript., t. 1, fig. 3, 4, - Berkl., t. 7, fig. 4. - Fr., Epicr., 553. - Ag.pyrospermus, Bull., t. 547, fig. 3. - Sur les trones de hêtres gâtés.

Ag. nain (Ag. nanus), Pers., Syn., p. 537. - Bull., t. 547, fig. 3. - Fr., Epicr., 548. - Sur les trones d'arbres, du hêtre surtout.

Ag. blanc rosé (Ag. roseo-albus), Fl. dan., t. 1679. - Fr., Epier., 552. - En mars, sur les trones cariés du peuplier, dans la France méridionale ; odeur de farine.

Ag. du saule (Ag. salicinus), Pers., Syn., 160. - Fr., Epicr., 544. - Sur les saules creux.

Ag. ami de l'ombre (Ag. umbrosus), Fr., Epicr, 542, - Weinm. - Pers., Icon. et descript., t. 2, fig. 5, 6. - Sur les troncs d'arbres et la terre, dans les pays très-ombragés.

be Тигів: - Entolone.

Hyménophore continu avec le pédicule charnu ou fibreux; feuillets sinués.

Ag. ardoisé (Ag. ardosiacus), Bull., t. 348. - Fr., Epicr., 565. - Dans les prés humides, les bois.

Ag. en bouclier (Ag. clypeatus), Lin. (décrit).

Ag- bicolore (Ag. dichrous), Pers., Syn., 156. - Fr., Epier., 571. - Paul., t. 114, fig. 4, 5. - A terre dans les gazons.

Ag. bleu-grisâtre (Ag. griseo-cyaneus), Fr, Epicr., 570. - Dans les pays montagneux, les pâturages. 
Ag. chevelu (Ag. jubatus), Fr., Epicr., 568. - Parmi les mousses.

Ag. livide (Ag. lividus), Bull., t. 382. - Fr., Epicr., 558. - Dans les bois, à terre. Odeur de farine. - Ag. pluteus, Batsch. - Paul., t. 134, fig. 3. Serait-ce une variété de l'Ag. cervinus?

Ag. humide (Ag. madidus), Fr., Epicr., 564. - Fl. dan., t. 2148. - Dans les mousses des ruisseaux, à l'ombre; odeur fétide. Suspect.

Ag. placenta (Ag. Placenta), Batsch, fig. 18. - Fr., Epicr., 560. - Dans les haies humides. Tard, en automne.

Ag. prunuloïde (Ag. prunuloides), Fr., Epicr., 559. - Sur la terre, dans les collines.

Ag. rose blane (Ag. rhodopolius), Fr., Epier., 574. - Bolt., t. 6. - Krombh., t. 55, fig. 17-22. - En automne, dans les endroits humides des bois, surtout plantés de hêtres. Comestible (décrit).

Ag. rubicond (Ag. rubellus), Scop. - Fr., Epicr., 566. - Dans le Midi, en automne.

Ag. des haies (Ag. sepium), Noul. et Dass., t. 26. - Dans les bois taillis.

Ag. satiné (Ag. sericeus), Bull., t. 413, fig. 2. - Fr., Epier., 578. - Commun au printemps et en automne, dans les prairies, les gazons.

Ag. légèrement soyeux (Ag. sericellus), Fr., Epicr., 572. - Commun, à terre, dans les endroits couverts de gazon.

Ag. sinué (Ag. sinuatus), Pers. (décrit).

\section{ze Tribu. - Clitopilus.}

Chapeau continu avec le pied charnu ou fibreux; feuillets décurrents.

Ag. à feuillets blanes de chair (Ag.carneo-albus), With. - Fr., Epicr., 587. Dans les bois.

Ag. à lamelles safranées (Ag. croceo-lamellatus), Letell., Suppl., t. 617.

Ag. orcelle (Ag. Orcella), Bull. (décrit).

Ag. prunulus (Ag. Prunulus), Scop. (décrit).

8e Tribu. - Leptonia ( $\lambda \varepsilon \pi \tau \omega s$, mince).

Pied à écorce cartilagineuse, marge du chapeau d'abord recourbée; lamelles libres ou adnées au pédicule, mais se retirant.

Ag. couleur de canard (Ag. anatinus), Lasch, no 561. - Fr., Epicr., 595. Dans les pâturages exposés au soleil.

Ag. des sources (Ag. aquilis), Fr., Epicr., 605. - Bord des ruisseaux et des rivières.

Ag. des lieux arides (Ag. asprellus), Fr., Epicr., 609. -- Dans les prés secs, montueux.

Ag. couleur d'acier (Ag. chalybous), Pers., Syn. 158. - Fr., Epicr., 601. Krombh, t. 2, fig. 11, 12. - Ag. glaucus, Bull., t. 521. - Sur les collines gazonnées, dans les prés, en automne.

Ag. grisonnant (Ag. incanus), Fr., Epicr., 606. - Ag. murinus, Sow., t. 162.Dans les gazons exposés au midi, en automne; rare.

Ag. de Kervernike (Ag. Kervernii), de Guern. - Crouan, Fl.fin., p. 76. - Dans les garennes marécageuses.

Ag. pied brillant (Ag. lampropus), Fr., Epicr., 597. - Sur les coteaux gazonnés.

Ag. lazulin (Ag. lazulinus), Pers., Icon. pict., t. 4, fig. 3, 4. - Fr., Epicr., 602. - Dans les gazons des collines. 
Ag. non dentelé(-1\% netiens), Fr., lifier., 611. - Dans les gazons et les herbes, surtuut des marais,

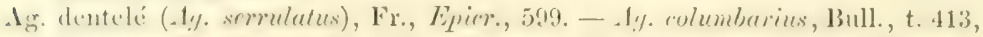
fig. 1. - Ilulmsk., t. 38. - Sur le gazon, dans le's buis et les cullinos.

9e Tribu. - Nolanea (en latin, nola, elochette).

l'ied cartilagineux; marge du chapeau d'abord droite, pressée contro le pédicule; lamelles adnexes, sub-libres.

Ag. fluet (Ag. exilis), Fr., Epicr., 629. - Dans les endroits frais et gazonnés des bois, entre les feuilles.

Ag. des marécages (Ac. junceus), Fr., Epicr., 618. - Dans les sphaignes des marais.

Ag. papillé (Ag. mammosus), Lin.-Fr., Epicr, , 616. - Bull., t. 526. - Batsch, fig. 3. - Commun dans les gazons exposés au soleil.

Ag. pied noir (Ag. nigripes), Trog, p. 527. - Fr., Epier., 619.-- Dans les marais, parmi les jones; odeur forte.

Ag. des pâturages ( 1 g. pascuus), Pers. - Schrff., t. 229. - Bolt., t. 35. Commun dans les pâturages et les forêts.

Ag. plein pied (Ag. pleopodius), Bull, t. 556, fig. 2. - Fr., Ëpicr., 624. \& En touffes, en automne, dans les pâturages; rare.

\section{0e Tribu. - Hebeloma.}

Pied charnu, feuillets sinués.

Ag. tête jaune (Ag. auricomus), Fr., Epicr., 700. - Batsch, fig. 21. - Sur les terres brûlées. Variété de l'Ag. descissus.

Ag. échaudé (Ag. crustuliniformis), Bull. (décrit).

Ag. lacéré (Ag. deglubens), Fr., Epier., 695. - Sous les pins.

Ag. fendillé (Ag. descissus), Fr., Epicr., 700. - Batt., t. 18, fig. F. - Dans les bois.

Ag. noble (Ag. elatus), Batsch, t. 108. - Fr., Epicr., 725. - Puimi les feuilles tombées, dans les bois.

Ag. prétentieux (Ag. fastibilis), Pers., Syn. 127. - Fr., Epier., 714. - Schæff., t. 221. - Dans les bois; odeur de rave. Suspect. Vénéneux, dit Kickx.

Ag. en faite (Ag. fastigiatus), Schæff., t. 26. - Fr., Epicr., 698. - Dans les champs, aux bords des chemins.

Ag. ferme (Ag. firmus), Pers., Icon. et deser., t. 5, fig. 3, 4.-Ag. Clavus, Batsch, fig. 199. - Paul., t. 53, fig. 1. - Fr., Epier., 717. - Dans les bois de pins. Suspect.

Ag. floculeux (Ag. flocculentus), Pall. - Fr., Monogr., p. 336. - Ag. lanuginosus, Fr., Epier., 685. - Vaill., t. 13, fig. 4-6. - Bull., t. 370. - J)ans les terrains plantés de hêtres, les bosquets, en automne.

Ag. ¿̀ feuillets terreux (Ag. geophyllus), Low., t. 124. - Bull., t. 522, fig. 2. Fr., Epicr., 709. - Très-commun dans les bois.

Ag. odeur d'anis (Ag. gratus), Weinm., p. 194. - Dans les garsns.

Ag. hérissé (Ag: hirsutus), Laseh. - Fr., Epior., 684. - Dans Iẹ bois Limides.

Ag. déchiré (Ag. lacerus), Fl. dan., t. 1846, fig. 1. - Fr., Epicr., 692. - En touffes, sur la terre nue, dans les bois de pins de montagies; préusce. 
Ag. lanugineux (Ag. lanuginosus), Bull., t. 370. - Sur les souches et à terre, dans les bois.

Ag. à longue tige (Ag. longicaudus), Pers., Syn., 136. - Batt., t. 21, fig. F. - Fr., Epicr., 726. - Berk1., t. 9, fig. 2. - Dans les futaies.

Ag. noeturne (Ag. lucifugus), Fr., Epicr., 710. - Pers., Icon, et deseript., t. 15, fig. 2. - Dans les bois de pins.

Ag. dartreux (Ag. petiginosus), Fr., Epier. 722. - Ag. mufipes, Pers., Icon. pict., t. 1, fig. 5. - A terre, dans les bois.

Ag. odeur de poire (Ag. piriodorus), Pers., Syn., 81. - Bull., t. 532, fig. 1. Fr., Epicr., 689. - Le long des chemins, dans les bois.

Ag. projeté en arrière (Ag. relicinus), Fr., Epicr., 682. - Dans les bois de pins de montagnes et les mousses de chênes.

Ag. ondulé (Ag. repandus), Bull., t. 223, fig. 2. - Laseh. - Pers., Mye., 280. - Dans les bois sablonneux, sur le bord des chemins. Très-suspect.

Ag. crevassé (Ag. rimosus), Bull. (décrit).

Ag. odeur de sureau (Ag. sambucinus), Fr., Epicr., 705. - Sow., t. 414. - Pers., Myc., 194. - Dans les bois de pins, les gazons, le long des chemins; odeur forte, vireuse.

Ag. odeur de moutarde (Ag. sinapizans), Paul., t. 82. - Fr., Epicr., 72, - Dans Ies lieux humides des bois.

\section{$11^{\text {e }}$ Trubu. - Flammule (en Iatin, petite Hanme).}

Pédicule charnu; feuillets adnés au pédicule ou décurrents, non échancrés.

Ag. de l'aune (Ag. alnicola), Fr., Epicr., 754. - Paul., t. 147. - Ag. amarus, Bull., t. 147. - Sur les trones de vieux arbres. Saveur amère. Vénéneux.

Ag. apieré (Ag. apicreus), Fr., Epior., 758. - Ag. lignatitis, Bull., t. 554, A. Sur les trones.

Ag. austère (Ag. austerus), Fr., Epicr., 759. - Sur les trones du pin et du sapin.

Ag. des charbonniers (Ag. carbonarius), Fr., Epicr., 750. - Weinm. - Sur la terre brûlée, été et automne.

Ag. pulvérulent (Ag. connissans), Fr., Epier., 756. - Ay.pulverulentus, Bull., t. 178. - Sur les trones de saules, en groupe. Vénéneux, selon Reveil.

Ag. à grand réseau (Ag. cortinatus), DC., Fl. fr., VI, p. 51. - Fr., Epicr., 752. - Sur le bois de chêne yeuse, au printemps et à l'automne; rare. - Vaviété $A g$. cortinellus, DC., $i d$. - Sur les saules.

$\Lambda$ g. flave (Ag. Alavidus), Schæff., t. 35. - Fr., Epicr, 755. - Sur les trones de pins, en groupe, au mois d'octobre.

Ag. fuseau (Ag. fusus), Batsch, t. 189. - Fr., Epicr., 751. - A terre et sur les vieux trones abattus.

Ag. à pied nu (Ag. gymnopodius), Bull., t. 601, fig. 1. - Fr., Epicr., 735. - Comestible.

Ag. flexible (Ag. lentus), Pers., Syn., 52. - Fr., Epicr., 743. - Entre les feuilles mortes, de hêtres principalement.

Ag. lubrique (Ag. lubricus), Fr., Epicr., 744. - Weinm. - Dans les bois, à la base des trones; dans les gazons vigoureux.

Ag. mixte (Ag. mixtus), Fr., Epicr., 746. - Bull., t. 556, fig. F, O. - A terre, dans les bois de pins de montagnes.

$\Lambda$ g. de Nees (A 7 . Neesiz), Barla, t. 23, fig. 1-4. - Sur les trones du pin; rare.

$\Lambda$ g. du sapin (Ag. sapineus), Fr., Epier., 765. - Sur les trones pourris du sapin. 
$\Lambda$ g. il bords ciliés (.1\%. strigireps), Fr., Epier., 739. - Ay. gnaphaliocephalus, Bull., t. 576, fig. 1. - Entre les feuilles mortes.

Ag. vincux (Ay. vinosus), Bull., t. 84. - Fr., Eyirr., 736. - Non dangereux; goût salé, comme vineux; à terre.

\section{2 'Tribu. - Nancoria (naucus, zeste de noix).}

Pédicule cartilagineux extérieurement; chapeau plus ou moins convexo-plane; à marge d'abord recourbée.

$\Lambda$ g. des moissons (Ag. arvalis), Weinm. - Batt., t. 28, fig. D. - Dans les terres cultivées et humides.

Ag. cerodes (Ag. cerodes), Fr., Epicr., 791. - Ag. muscomim, Hoffm., Nom., t. 573. - Sur la terre, entre les mousses.

Ag. à odeur de concombre (Ag. cucumis), Pers., Obs. - Fr., Epier., 779. - Sur la terre dans les jardins; le bord des chemins.

Ag. arrosé (Ag. conspersus), Pers., Icon. et descr., t. 12, fig. 3. - Fr., Epier., 815. - Krombh., t. 3, fig. 12. - Dans les bois, les lieux frais, les marécages surtout.

Ag. hérisson (Ag. erinaceus), Fr., Epicr., 813. - Ag. aridus, Pers., Myc., 327. - Sur les rameaux tombés à terre, à la fin de l'été; rare.

Ag. poudreux (Ag. furfuraceus), Pers., Syn., 379. - Ag. squarrosus, Bull., t. 593, fig. 3.-Batsch, fig. 98. - A terre, sur les sciures, les rameaux coupés, les feuilles, etc.

Ag. des graminées (Ag. graminicola), Nees, f. 186. - Fr., Epier., 821. - Sur les tiges, les chaumes des graminées.

Ag. locataire (Ag. inquilinus), Weinm. - Fr., Epier., 808. - Sur les bois cariés, les chaumes, les rameaux tombés à terre.

Aq. hilaire (Ag. hilaris), Fr., Epicr., 776. - Ag. xanthopodius, DC., Fl. fr., 49. - Dans les bois, en octobre.

Ag. horizontal (Ag. horizontalis), Bull, t. 324. - Sow., t. 341. - Sur les écorces de poirier, d'orme, au printemps et à l'automne.

Ag. limbé (Ag. limbatus), Bull., t. 563, fig. 2. - Fr., Epicr., 818. - A terre.

Ag. couleur de coing (Ag. melinoides), Bull., t. 560, fig. 1. - Berkl., t. 9, fig. 3. - Dans les bois exposés au soleil, les prés, les gazons, au printemps et ì l'automne.

Ag. des plaines (Ag. pediades), Fr., Epicr,, 799. - Schæff., t. 203. - Toute l'année, dans les champs, d'où son nom rebíov, plaine.

Ag. pygmée (Ag. pygmaus), Bull., t. 525, fig. 2. - A la base des trones d'arbre.

Ag. demi-orbiculaire (Ag. semi-orbicularis), Bull., t. 422. - Berkl., t. 9, fig. 4. - Fr, Epicr., 800. - Sur les pelouses, au bord des chemins.

Ag. sidéroïde (Ag. sideroides), Bull., t. 588. - Fr., Epicr., 794. - Sur les chemins; dans les débris de bois; sur les trones de pins.

Ag. vêtu (Ag. siparius), Pers., Myc., 258. - Fr., Epicr., 814. - Weinm. - Ag. vestitus, Chev., t. 6, fig. 9. - Sur la tige des fougères, les branches pourries du chêne, au printemps et en automne.

Ag. couleur de tabac (Ag. tabacinus), DC., Fl. fr., VI, p. 46. - Le long des chemins, en automne; rare.

Ag. tenace (Ag.tenax), Fr., Epicr., 803, - Parmi les feuilles de sapin. 
13 Triвu. - Galera (en latin : bonnet de peau).

Pédicule cartilagineux extérieurement; chapeau plus ou moins campanulé, à marge d'abord droite et rapprochée du pédicule.

Ag. antipus (Ag. antipus), Lasch. - Fr., Epier., 837. - Dans les bois.

Ag. entassé (Aq. confertus, Bolt., t. 18. - Fr., Epicr., 833. - Dans les serres, sur le terreau.

Ag. à tête conique (Ag. conocephalus), Bull., t. 563, fig. 1. - Fr., Epicr., 839. - Dans les terres grasses.

Ag. des mousses (Ag. hypnorum), Batsch, fig. 96. - Bull., t. 560, fig. 1, C-E. - Dans les mousses. La variété sphagnorum de ce champignon est commune dans les marais, toute l'année.

Ag. couleur de brique (Ag. lateritius), Batt., t. 28, fig. T. - Fr., Epicr., 832. $F$. dan., t. 1840, fig. 2. - Dans les gazons, les terres grasses.

Ag. ovale (Ag. ovalis), Berkl., 297. - Fr., Monogr., p. 389. - Ag. campanulatus, Bull., t. 563, fig. 1.-Dans les terres fumées.

Ag. transparent (Ag. pellucidus), Bull., t. 555, fig. 2. - Sur les feuilles de hêtres, les chemins.

Ag. couleur de farine (Ag. siligineus), Schæff., t. 70, fig. 1-5. - Fr., Epicr., 834. Dans les gazons, les terres fumées, au bord des chemins.

Ag. grêle (Ag.tener), Schæff., t. 70, fig. 6-8. - Fr., Epicr., 833. - Sow., t. 33. - Ag. foraminulosus, Bull., t. 535, fig. 1. - Dans les herbes, sur les détritus, les trones, au printemps.

\section{SÉrie IV. - MYCENE (Mycena).}

(Múxrs, champignon).

Absence de volva et de collier; chapeau campanulé, rarement étalé, jamais ombiliqué; pédicule central, grêle; feuillets ne noircissant pas en vieillissant, presque sans suc; quelques-uns ayant le pédicule lactescent. Espèces fragiles, à peine charnues, et de trop petite taille pour être recherchées comme aliment.

\section{Leucospores. Spores blanches.}

\section{1re Tribu. Mycène (type).}

Pied fistuleux; chapeau mince, le plus souvent campanulé, primitivement droit et pressé contre le pédicule.

Ag. $\operatorname{pur}$ (Ag. purus), Pers., Myc., 408.

Sow., t. 72. Fl.dan., t. 1613, 1673. - Batsch, fig. 20. - Labr., t. 13, fig. 4. - Schæff., t 303. - Paul., t. 119. - Huss., II, t. 49. - Fr., Epicr., 373. - Ag. roseus, Bull., t. 507.

Cet agaric, peu charnu, de couleur rose, pourpre ou rougeâtre, a le chapeau d'abord conique, puis campanulé et quelquefois aplati, mais 


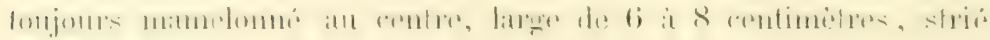
sensiblement sur les bords, un peu humide à la superficie; les feuillets, inégaux, peu nombreux, larges, saillants, arrondis, adnexes, non-décurrents, de la couleur du chapeau, mais plus pàles, veinés ou réticulés à leur insertion au pédicule, qui est long de 6 à 10 centimètres, fistuleux, assez grèle, glabre, brillant, de la couleur du chapeau, mais moins foncé, cylindrique ou atténué par le haut, velu à sa base.

L'Ag. purus est très-variable de taille et de couleur; le plus souvent rose ou lilas, il est quelquefois incarnat, gris bleuàtre, pâle et mème blanc.

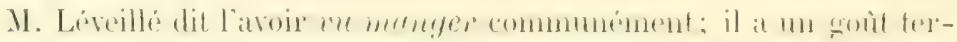
reux, et une odeur faible de radis.

On le trouve très-fréquemment, en été et même très-tard en automne, dans les bois, parmi les feuilles tombées, dans les prés mousseux, les bruyères, en groupes peu nombreux.

Ag. couleur d'étain (Ag. stanneus), Vaill., p. 70, nº 1 .

Fr., Epicr., 407. - 1\%. griseus, Pers., Myc., 439.

Chapeau entièrement membraneux, campanulé, étalé, glabre, large de 2 à 3 centimètres, hygrophane, strié, lisse, d'un soyeux luisant lorsqu'il est sec, de couleur grise, derenant couleur d'étain arec l'àge; feuillets inégaux, adnés, peu serrés, d'un gris blanchàtre, veinés, décurrents au moyen d'un denticule; pied long de 5 à 8 centimètres, épais de 2 à 3 millimètres, iisse, fistuleux.

L'Ag. stanneus se trouve dans les gazons des bois, il est inodore.

Est comestible, selon Reveil; mais trop peu charnu pour que l'on en fasse usage.

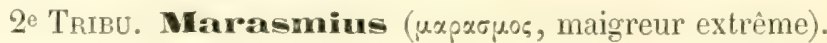

Pied cartilagineux; chapeau ou hyménophore coriace, mince, se continuant avec le pied; feuillets épais, sub-coriacés, à bord tranchant. Champignons épiphytes, non-putrescents, et pouvant reprendreleur forme lorsqu'ils sont humectés. Genre pour quelques auteurs.

Ag. alliacé (Ag. alliaceus), Jacq., t. 82.

Fl. dan., t. 1251. - Mich., t. 78, fig. 4. - Paul., t. 122 his, fig. 1. - Mfurasmius alliaceus, Fr., Epicr., 36.

Nom mlymier. Isaric porream (Tosges). 
Le nom donné à cet agaric dit assez qu'il a une odeur très-forte d'ail. Son chapeau, très-peu charnu, est sub-membraneux, flexible, d'abord campanulé, puis étalé, mais conservant un mámelon peu prononcé, lisse, légèrement marqué de stries dans un âge avancé, blanc grisâtre ou un peu roux, large seulement de 2 à 3 centimètres. Les feuillets sont inégaux, aigus vers la marge du chapeau, arrondis et libres à l'autre extrémité, distants les uns des autres, d'abord blanc et enfin d'un blanc fauve. Pied coriace, fistuleux, grêle, allongé, droit cylindrique, nu, noirâtre, velouté ou comme couvert de givre, à base terminée en racine.

Ce Champignon comestible, qui croit en automne, dans les bois montueux sur les feuilles, est si peu substantiel, qu'il ne peut servir que de condiment.

Ag. faux mousseron (Ag. oreades), Bolt., t. 151.

(Pl. XIV, fig. 3).

Śow., t. 247. - S'chæff., t. 77. - Paul., t. 103, fig. 1-4. - (trev., t. 323. Vittad., t. 10, fig. 1. - Krombh., t. 43, fig. 11-16. - Staude, t. 9, fig. 1. - Bull., t. 144, et t. 528, fig. 2. - Noul. et Dass., t. 27, fig. B. - Berkl., t. 14, fig. 5. - Huss., t. 38. - Ay. caryophylleus, Pers., Myc., 234. Marasmius oreades, Fr., Epiar., 7.

Noms vulgaires: Faux Mousseron, Mousseron godaille ou de Dieppe, Mousseron d'automne, Mousseron pied dur; Sécadon, en Languedoc.

Cet agaric ne ressemble guère au véritable Mousseron que par sa couleur toute d'un jaune pâle, tirant sur le roux.

Son pédicule est nu, cylindrique, plein, long de 4 à 5 centimètres, non velu à sa base, grèle, tenace et se tordant par la dessiccation. Le chapeau, d'abord hémisphérique, puis conique et quelquefois plane, souvent mamelonné au centre, peu charnu, est large seulement de 3 à 4 centimètres.

Feuillets inégaux, peu nombreux, d'un blanc pâle, plus colorés sur la tranche, n'adhérant pas au pédicule.

Il croît, à la fin de l'été et en automne, dans les prés secs, les endroits des bois découverts, le plus souvent en petits groupes, et quelquefois traçant des cercles ou des séries. Commun.

C'est surtout comme assaisonnement qu'on l'emploie. En Angleterre, il s'en fait une grande consommation; on le dessèche quelquefois pour le manger en hiver. Sa chair, dépourvue de suc, se déchire avec peine; elle a une odeur faible et une saveur agréable. Peu recherché en France à cause de sa petite taille. 
Ag. chaussé (Ay. peronatus), Bolt., t. 58.

(Pl. XIV, fig. 2.)

Sow., t. 37. - Fl. dan., t. 2018, fig. 2. - Berkl., t 14, fig. 4. - Marasmizs peronatus, Fr., Epicr., 2.

L'Ag. peronatus est assez voisin de l'Ag. urens, pour que Persoon ait été tenté de les regarder comme ne faisant qu'une même espèce. II ne diffère guère, en effet, de celui-ci, que par son chapeau plus large, plus ridé lorsqu'il est vieux, et que par son pied, garni à la base d'un duvet jaunâtre, comme laineux, ce qui lui a valu le nom qu'il porte. Saveur poivrée.

II. Letellier donne ce Champignon comme vénéneux.

Ag. à odeur de poireau (Ag. porreus), Pers., Myc., 210.

Sow., t. 81. - Ag. alliacens, Bull., t. 158, et t. 424, fig. 1. - Marasmius porreus, Fr., Epicr., 3.

Nom vulgaire: Agaric alliacé (Vosges).

Cet agaric exhale une forte odeur d'ail, qui persiste quelquefois pendant des années, lorsqu'il est desséché. Il est comestible, et s'emploie surtout comme assaisonnement.

Il croît, le plus souvent en groupes, dans les bois, assez tard en automne, sur les feuilles sèches, tombées à terre, surtout sur celles du chêne, et généralement sur la nervure du milieu.

Le chapeau membraneux, sec, coriace, lisse, de couleur jaune pâle ou roussâtre, est d'abord convexe, puis plane, orbiculaire, large de 3 à 4 centimètres, opaque, légèrement strié sur ses bords. Les lamelles adhérentes au chapeau sont écartées, fermes, arrondies et comme tronquées. Le pied, d'abord plein, puis fistuleux, nu, grêle, long de 7 à 9 centimètres, épais de 2 à 3 millimètres, est coriace, roussâtre, tomenteux ou pubescent, plus velu dans le bas, et grossissant à ses deux extrémités.

Ag. odeur d'échalotte (Ag. scorodonius), Fr.

(PI. XIV, fig. 1.)

Mich., t. 72, fig. 2. - Fl. dan., t. 1251. - Sv. Bot., t. 173. - Schæff., t. 79. - Paul., t. 122 bis, fig. 2, 3. - Lenz, fig. 17. - Pers., Myc., 211. - Marasmius scorodonius, Fr., Epier., 21.

L'Ag. scorodonius exhale une odeur d'ail très-prononcée, il croît, à la fin de l'été, sur les collines exposées au soleil, les rameaux tom- 
bés à terre, les chaumes des céréales, dans les bruyères et les pâturages secs. Son chapeau, peu charnu, mince, convexe ou plane, est. d'abord lisse, puis légèrement rugueux ou plissé, large de un à deux centimètres et demi, rơux, pâle ou terreux. Ses lamelles, crispées , blanchàtres, un peu écartées, adhèrent à un pédicule fistuleux, cylindrique, long de 2 à 3 centimètres, épais de 2 millimètres, glabre, luisant, roussâtre, devenant brun avec l'âge.

Il est comestible et d'un usage fréquent dans la Lusace comme assaisonnement; plus rare que l'Ag. alliaceus.

Ag. brûlant (Ag. Mar. urens; , Bull., t. 528, fig. 1

$$
\begin{aligned}
\text { Fl. dan., t. 2018, fig. 1. - Berkl., t. 14, fig. 3. - Marasmius urens, } \\
\text { Fr., Epicr., 1. }
\end{aligned}
$$

Ce Champignon vient, çà et là, dans les bois et les pàturages, en été et en automne, sur les feuilles mortes, ordinairement en touffes peu nombreuses.

Saveur âcre et poivrée. Chapeau large de 4 à 5 centimètres, con-vexe d'abord, puis plane, un peu charnu, membraneux, coriace, uni dans la jeunesse, et plus tard comme ridé ou sillonné, assez régulier, jaune-terreux ou roussâtre, avec les feuillets roussâtres, ètroits, peu serrés, les plus longs terminés régulièrement, à un ou deux millimètres du pédicule; ce pédicule, de la couleur du chapeau, est plein, solide, nu, cylindrique, un peu plus épais et velu à sa base, légèrement rayé de fauve, long de 10 à 12 centimètres. Chair mince, ferme, blanche.

Il est généralement regardé comme dangereux. MM. Noulet et Dassier disent que si on l'administre à des chiens, il produit des vomissements et des selles accompagnées de mouvements nerveux, mais qu'il n'amène pas la mort. Reveil le déclare malfaisant. En Angleterre, il ne passe pas pour vénéneux; M. Léveillé doute aussi qu'il le soit. Jusqu'à ce que ses propriétés soient mieux constatées, il sera prudent de s'en ahstenir.

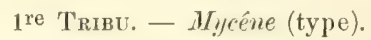

Ag. acicule (Ag. acicula), Schæff., t. 222. - Fr., Epicr., 422. - Dans les bois de hêtres.

Ag. adonis (A\%. Adonis), Bull., t. 560, fig. 2. - Fr., Epirr., 375. - Dans les gazons des bois, par touffes. 
Ar. alcalin (.1\%. alualinus), Fr., Epier., 401. - Weinm. - Schrft, t. 31, 32. sur le trunc des arbres et à terre.

Ag. ammoniacal (Ag. ammoniacus, Fr., Epier., 402. - Sur la terie, dans les champs.

Ag. bleu foncé (A\% atrocyeneus), Batsch. - Fr., Fpurr., 399. - I terre, sur les aiguilles du pin.

Ag. capillaire (Ag. capillaris), Schum. - Fl. dan., t. 2142.-Ag. lacteus, Bull., t. 601, fig. 2. - Sur les feuilles tombées, surtout celles du hêtre.

Ag. jaune citron (Ag. citrinellus), Pers., Icon. et descr., t. 11, fig. 3. - Fr., Epier, 483. - Dans les bois de pins, en octobre surtout.

Ag. chlorotique (Ag. chlorantus), Fr., Epier., 376. - Fl. dan., t. 1614, fig. 2. Dans les endroits herbagés des bois.

Ag. cladophylle (Ag. cladophyllus), Lév., Ann. des sc. nat., 1843, t. 7, fig. 1.

Ag. claviculaire (Ag. clavicularis), Fr., Epicr., 430. - Bull., t. 80. - Dans les lieux humides des bois; rare.

Ag. adhérent ( $\mathbf{A} g$. cohcerens), Alb. et Schw. - Ag. ceratopus, Pers., Myc., 459. - A terre et sur les rameaux ligneux.

Ag. des écorces (Ag. corticola), Schum. - Lin. - Mich., t. 74, fig. 8. - Ag. pusillus, Hoffm., t. 34. - Ag. corticalis, Bull., t. 519, fig. 1, A, B, C. Automne et hiver, commun sur l'écorce et dans les mousses des arbres.

Ag. en coupelle (Ag. craterellus), DR. et Lév., Expl. scient. de l'Algérie, Bot, p1. 31. - Sur les rameaux de différents arbustes, dans les bois au printemps et à l'automne; au midi de la France.

Ag. couleur de safran (Ag. crocatus), Schrad. - Fl. dan., t. 2024, fig. 1. - Fr., Epicr., 426. - Sur les feuilles humides du hêtre tombées à terre; commun.

Ag. sanguin (Ag. cruentus), Fr., Epier., 424. - Sowerby, t. 385, fig. 2, 3. Dans les lieux humides sous les pins et les sapins.

Ag. débile (Ag. debilis), Bull., t. 518, fig. P. - Fr., Epicr., 415. - Dans les mousses des champs.

Ag. dilaté (Ag. dilatatus), Fr., Epicr., 436. - Bull., t. 363, fig. R, S. - Sur les bois putrides et les chaumes, dans les lieux humides.

Ag. discopus (Ag. discopus), Lév., Ann. des sc. nat., 1841, t. 14, fig. 4. - Sur les fruits tombés du coudrier.

Ag. epipterygius (Ag. epipterygius), Scop. - Sow., t. 92. - Fr., Epicr., 429. - Très-commun à terre, sur les mousses, les feuilles tombées, les chaumes, les trones.

Ag. pied menu (Ag. flopes), Bull., t. 320. - Fr., Epier., 411.-Commun, dans les endroits couverts de feuilles.

Ag. fauve-blane (Ag. flavo-albus), Fr., Epicr., 380. - Ag.pumilus, Bull., t. 260. - Assez commun, à terre et sur le trone des vieux arbres.

Ag. en casque (Ag. galericulatus), Scop. - Schæff,, t. 52. - Bull., t. 518, fig. C, D, E. - Fr., Epicr., 391. - Commun sur les trones, de novembre à décembre; variable.

Ag. pied laiteux (Ag. galopus), Schrad. - Fl. dan., t. 1550, fig. 2. - Batt., t. 28, fig. Q. - Fr., Epicr., 428. - En touffes, sur la terre couverte de mousse humide, en automne; commun.

Ag. gris (Ag. griseus), Fr., Epicr., 476. - A terre, dans les gazons, en automne.

Ag. couleur de plâtre (Ag. gypseus), Bull., t. 563, fig. 4. - Ag.-ochraceus, Pers., Myc., 459. - A terre et sur les rameaux ligneux.

Ag. pied couleur de sang (Ag. hematopus), Pers., Syn., 228. - Sur les trones d'arbres. 
Ag. d'hiver (Ag. hyemalis), Osbeck. - Fr. Epirr., 442. - Ag. corticalis, Bull., t. 519, fig. 1. - Sur les écorces; tard.

Ag. modeste (Ag. integrellus), Pers., Icon. et descr., t. 13, fig. 5. - Fr., Epicr., 480. - A terre, sur le bois qui pourrit et les feuilles en décomposition.

Ag. des jones (Ag. juncicola), Fr., Epicr., 446. - Bull., t. 148, fig. D. - Sur les chaumes, surtout du jonc articulé.

Ag. conleur de lait (Ag. lacteus), Pers., Syn., 257. - Ag. nanus, Bull., t, 563, fig. N, O. - Commun, à terre, en novembre et décembre, dans les bois de pins.

Ag. tête menue (Ag. leptocephalus), Pers., Icon. et descr., t. 14, fig. 4. - Fr., Epicr., 400. - Sur les trones et la terre; très-rare.

Ag. rayé (Ag. lineatus), Bull., t. 522, fig. 3. - Fr., Epicr., 377. - Dans les prés et les bois.

Ag. jaune blane (Ag. luteo-albus), Bolt., t. 38, fig. 2. - Fr., Epicr., 379. Dans les lieux ombragés et humides, en automne.

Ag. limité (Ag. metatus), Weinm. - Fr., Epicr., 403. - Ag. lavigatus, Pers., Syn., 230. - A terre, dans les mousses, dans les bois de pins.

Ag. mucor (Ag. mucor), Batsch, fig. 82, - Fr., Epicr., 437. - Près des feuilles pourries.

Ag. livide (Ag. pelianthinus), Fr:, Epicr., 361. - Batt., t. 19, fig. F. - Pers., Myc., 395.-Dans les bois de hêtres et de chênes, sur les feuilles tombées.

Ag. à cent raies (Ag. polygrammus), Bull., t. 395 et 518, fig. H. - Commun, sur les trones d'arbres, et, à terre, sur les feuilles tombées.

Ag. ptérigène (Ag. pterigenus), Fr., Epicr., 349. - Sur la nervure des feuilles pinnées, et surtout des fougères.

Ag. pur (Ag. purus), Pers. (décrit).

Ag. rosacé (Ag. rosellus), Pers., Syn., 255, et t. 5, fig. 3. - Fr., Epicr., 372. - Fl. dan., t. 2025, fig. 2. - Dans les bois de pins, entre les feuilles et les mousses.

Ag. rubro-marginé (Ag. rubro-marginatus), Fr., Epicr., 370. - Sur le bois, les chaumes.

Ag. rugueux (Ag. rugosus), Bull., t. 518, fig. K, M. - Fr., Epicr., 389. - Sur le trone et près du tronc des arbres.

Ag. sanguinolent (Ag. sanguinolentus), Alb. et Schw. - Fr., Epicr., 425. Bull., t. 518, fig. P. - Entre les feuilles et les mousses humides, en antomne.

Ag, pied soyeux (Ag. setipes), Fr., Epicr., 477. - Ag. variegatus et Ag. hypnicola, Pers., Ag. tentatula, Bull., t. 560, fig. 3. - Dans les mousses et les broussailles humides.

Ag couleur d'étain (Ag. stanneus), Vaill. (décrit).

Ag. des pommes de pin (Ag. strobilinus), Sow., t. 197. - Fr., Epicr., 375. Sur les cônes de pins à demi pourris.

Ag. supin (Ag. supinus), Lin. - Fr., Epicr., 418. - Hoffm., t. 6, fig. 3. - Sur les trones mousseux des hêtres, en groupes.

Ag. stylobate (Ag. stylobates), Pers., Syn., t. 5, fig. 4. - Fr., Epicr., 455. Sur les feuilles et les chaumes renversés; toujours solitaire.

Ag. clochette (Ag. tintinnabulum), Paul., t. 122, fig. 3. - Sur les trones renversés du hêtre; tard, en automne.

Ag. tressé (Ag. vitilis), Fr., Epier., 416. - Ag. fistulosus, Bull., t. 518, fig. O. - A terre, parmi les mousses et les chaumes renversés; tard, en automne.

Ag. vulgaire (Ag. vulgaris), Pers., Syn., 258. - BerkI., Outl., t. 6, fig. 2. Dans les bois, sur les feuilles pourries. 


\section{2e Trine. - Marasmius.}

Mg. Mar. alliacé ( $1 \mathrm{~g}$. Mar. alliaceus), Jacq. (décrit).

Ag. Mar. réuni (Ag. Mar. amadelphus), Bull, t. 850, fig. 3. - Fr., Epier., 37. - En touffes, sur les rameaux; automne et hiver; sans odeur.

Mg. Mar. Androsace (.1\%. Mar. Androsaceus), Lin. - Bolt., t. 32. - Sow., t. 94. - Fl. dan., t. 1551, fig. 1. - Aq. epiphyllus, Bull, t. 569, fig. 2. - Sur les feuilles mortes, en décembre et en janvier, et sur les écorces, mais plus rare.

Ag. Mar. beau pied (Ag. Mar. calopus), Pers., Syn., 218. - Bull., t. 550, fig. 1. - Sur les pailles, les racines des graminées.

Ag. Mar. à odeur d'oignon (Ag. Mar. cepaceus), Fr., Epicr., 6. - Larb., t. 14, fig. 3. - Dans les champs.

Ag. Mar. des feuilles mortes (Ag. Mar. epiphyllus), Fl. dan., t. 1194, fig. 1. Tratt., fig. 22. - Sow., t. 93. - Fr., Epicr., 51. - Sur les feuilles et les pailles.

Ag. Mar. pied rouge (Ag. Mar. erythropus), Pers., Syn., 206. - Fr., Epicr., 18. - Sur les trones et les feuilles tombées du hêtre, en automne, dans le midi; rare.

Ag. Mar. alvéolaire (Ag. Mar. faveolaris), Mont. - Fr., Epier., 45. - Sur les pailles, les feuilles, dans les Ardennes.

Ag. Mar, à odeur de fenouil (Ag. Mar. foniculaceus), Fr., Epicr., 5. - Sur le bord des chemins et les gazons des bois; rare.

Ag. Mar, infect (Ag. Mar. foetidus), Sow., t. 21. - Fr., Epior., 26. - Sur les branches en pourriture.

Ag. Mar. fauve pourpré (Ag. Mar. fusco-purpureus), Pers., Icon. et descr., t. 4, fig. 1-3. - Fr., Epicr., 13. - Sur les feuilles tombées du hêtre.

Ag. Mar. des graminées (Ag. Mar. graminum), Lib. - Berkl., t. 14, fig. 8. Sur les feuilles des graminées.

Ag. Mar, d'Hudson (Ag. Mar. Hudsoni), Pers., Syn., 248. - Sow., t. 164. Fr., Epicr., 49. - Sur les feuilles du chêne vert.

Ag. Mar. greffé (Ag. Mar. insititius), Fr., Epier., 48. - Sur les feuilles tombées du chêne, de la ronce etc.

Ag. Mar. brodequin (Ag. Mar. mulleus), Fr., Epier., 4. - Vaill., p. 63, n 16. Pers., Myc., 215. - Sur les trones d'érables etc.

Ag. Mar. faux mousseron (Ag. Mar, oreades), Bolt. (décrit).

Ag. Mar. perforant (Ag. Mar.perforans), Hoffm., t. 4, fig. 2. - Batsch, fig. 10.Schæff., t. 239. - Fr., Epicr., 47. - Sur les feuilles de sapin, les feuilles et les fruits de hêtre; odeur fétide.

Ag. Mar. chaussé (Ag. Mar. peronatus), Batt., t. 58 (décrit).

Ag. Mar. à pied comprimé (Ag. Mar. plancus), Fr., Epicr., 8. - Paul., t. 103, fig. 5, 6. - Dans les bois feuillus ; rare. Comestible; odeur nulle.

Ag. Mar. odeur de poireau (Ag. Mar. porreus), Pers. (décrit).

Ag. Mar. odeur de ciboule (Ag. Mar. prasiosmus), Fr., Epior., 11. - Bull., t. 524, fig. 1. - Sur les feuilles, dans les bois de chênes et de hêtres; tard, en automne.

Ag. Mar. pyramidal (Ag. Mar. pyramidalis), Scop., p. 433, - Fr., Epier., 9. Vaill, , no 54.

Ag. Mar. des rameaux (Ag. Mar. ramealis), Bull., t. 336. - Fr., Epicr., 28, sur les petits rameaux des arbres; très-commun; inodore.

Ag. Mar. rotule (Ag. Mar. rotula), Scop. - Mich., t. 74, fig. 5. - Fl. dan. t. 1134. - Bull., t. 64, t. 569, fig. 3. - Très-commun, au printemps et en automne, sur les trones et les feuilles. 
Ag. Mar. saccharin (Ag. Mar. saccharinus), Batsch, fig. 83. - Fr.; Epicr., 50. - Sur les feuilles, les pailles.

Ag. Mar. odeur d'échalotte (Ag. Mar. scorodonius), Fr. (décrit).

Ag. Mar. lamelles en collerettes (Ag. Mar. torquatus), Fr., Epicr., 35. - Paul., t. 124, fig. 2, 3. - Sur les pailles et les feuilles.

Ag Mar. brûlant (Ag. Mar. urens), Bull. (décrit).

Ag. Mar. de Vaillant (Ag. Mar. Vaillantii), Fr., Epier., 24. - Vaill., t. 11, fig. 21, 23. - Sur les pailles, le bois mort, les feuilles tombées.

\section{SÉrie V. - OMPHALIE (Omphalia).}

('Oupaìse, nombril).

Chapeau en entonnoir ou déprimé au centre; pédicule le plus souvent coriace; feuillets décurrents, ne noircissant pas.

LEU GOS P ORE S. Spores blanches.

\section{1re Tribu. Omphalia (type).}

Espèce terrestre, de petite taille; feuillets à bord non-denté, ne se détachant pas facilement du chapeau; absence de collier.

Ag. en bassin (Ag. Catinus), Fr., Epier, 247.

(PI. XV, fig. 1.)

Ag. infundibuliformis, Bull., t. 286. - Ag. neapolitanus, Pers., Myc., 112.

Cet agaric est tout entier d'un blanc pâle, prenant une nuance incarnat par les temps pluvieux. Il a le chapeau mince, fragile, glabre, lisse, toujours creusé en entonnoir, large de 5 à 8 centimètres, à bords devenant irréguliers avec l'âge; les feuillets inégaux, minces, étroits, serrés, blancs, décurrents, terminés en pointe aux deux extrémités; le pied élastique, long de 3 à 5 centimètres, plein, fibreux, cylindrique ou légèrement renflé à sa base, laquelle est villeuse.

Il vient dans les bois, en septembre et en octobre, sur les feuilles mortes, qu'il pénètre au moyen de ses fibres radicales.

Sa chair blanche a une odeur agréable, un goùt de champignon.

Fries regarde l'Ag. neapolitanus, Pers., cultivé à Naples sur le marc de café, comme une simple variété de l'Ag. Catinus. 
Ag. cyathiforme (Ag. cyathiformis), Bull., t. 575, fig. H, M. P, Q.

Vaill., t. 14, fig. 1-3. - Bult., t. 145) - IJulmsk., 2, t. H1. - Sow., t. 363.

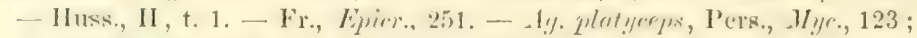
L!\%. tardus, id., 124; Ay. areus, id., 128.

Ce Championom, commun a la fin de l'antomme dams les bois, parmi les mousses, a une odeur faible, une saveur presque nulle; il se pèle sans difficulté ; rarement il est attaqué par les insectes ou les vers.

Il est entièrement de couleur fauve ou roussâtre (terre d'ombre); mais ses feuillets sont un peu plus pâles que le reste de la plante. Le chapeau membraneux, arrondi, large de 4 à 5 centimètres, lisse, lıumide, luisant par les temps de pluie, a les bords sinueux, réfléchis. Les feuillets sont droits, étroits, inégaux, distants, faiblement décurrents sur un pédicule plein, grèle, cylindrique, élastique, fibrilleux, réticulé, atténué par le haut, long de 5 à 7 centimètres.

Comestible. Son peu de chair est cause qu'il n'est pas recherché.

Ag. flasque (Ag. fluccidus), Sow., t. 185.

Pers., Myc., 82. - Fr., Epicr., 241. - Ag. infundibuliformis, Bull., fig. N.

Chapeau à peine charnu, mince, flasque, déprimé, puis en forme d'entonnoir, lisse, large de 6 à 7 centimètres, de couleur fauve, ferrugineux ou roussâtre; feuillets nombreux, décurrents, étroits, arqués, jaunâtres; pédicule d'un jaune clair, court, plein, inégal, ordinairement flexueux, velu à la base.

Commun dans les bois, où il vient le plus souvent en touffes parmi les feuilles. Suspect d'après Paulet et Reveil. Peut-ètre n'est-il qu'une variété de l'Ag. inversus.

Ag. fragrant (Ag. fragrans), Sow., t. 10.

(PI. XV, fig. 2.)

Pers., Myyc. t. 27, fig. 5. - Krombh., t. 1, fig. 34-38. - Fr., Epicr., 268.

Champignon d'une odeur agréable se rapprochant de celle de l'anis.

Chapeau charnu-membraneux, d'abord convexe, puis plane et enfin déprimé, d'un blanc sale, unicolore, lisse, glabre, hygrophane; pied glabre, élastique, subflexueux, d'abord plein, puis creux; feuillets faiblement décurrents, peu serrés, blancs.

Dans les bois, en automne, parmi les mousses, le gazon. Commun.

Comestible. On le vante comme condiment. 
Ag. géotrope (Ag. geotropus), Bull., t. 573, fig. 2.

Grev., t. 41. - Huss., I, t. 66. - Sow., t. 61. - Batsch, fig. 204. Fr., Epier., 239.

Ce Champignon a le chapeau charnu, d'abord convexe, puis plane et enfin en entonnoir, mais mamelonné au centre et à bord légèrement replié en dessous, à surface lisse comme du satin, de couleur blanche, tirant quelquefois sur le jaune; la chair blanche; les feuillets très-décurrents, inégaux, simples, assez nombreux, droits, aigus aux deux extrémités, d'abord blancs et enfin de la couleur du chapeau; le pied long de 8 à 10 centimètres; blanc, plein, compacte, fibrilleux, atténué par le haut, parfois velu à la base.

Il croìt communément à terre, dans les bois, en automne. Comestible.

Les Comtois le vendent avec le Mousseron de Suisse. On le mange aussi dans le midi de la France. Badham le regarde comme un des meilleurs et des plus sains.

Il faut éviter de le confondre avec l'Ag. nebularis. Ce dernier est malfaisant ou tout au moins suspect.

Ag. gigantesque (Ag. giganteus), Sow., t. 244 .

Huss., I, t. 79. - Fr., Epicr., 229.

Champignon de grande taille, entièrement d'un blanc alutacé. Son chapeau, en forme d'entonnoir, a quelquefois près de 30 centimètres de diamètre; il est charnu, mince, se fendillant; à superficie d'abord humide, couverte d'un duvet entrelacé, plus tard elle devient squameuse; feuillets très-serrés, légèrement décurrents, passant du blanc au jaune. Pied solide, dur, épais, égal, lisse, long de 6 à 7 centimètres.

On peut le manger en toute sécurité. Odeur faible, mais agréable; saveur douce.

Il vient en septembre, dans les bois, les friches, par groupes, formant le plus souvent des cercles de grande dimension. Assez rare.

Ag. gris cendré (Ag. gilvus), Pers., Syn., 367.

Batsch, t. 37, fig. 204. - Bolt., t. 22. - Letell., t. 670. - Fr., var. splendens. Epicr, 238.

Chapeau charnu, compacte, large de 8 à 10 centimètres, d'abord convexe, puis déprimé, mais à peine infundibuliforme, très-glabre, 
luisint. lnmide par les temple pluvienx, de conlenr fanve gris-cendre; feuillets très-décurrents, serrés, minces, souvent rameux, incarnat päle ou ocracé ne passant pas au roux; pied. charnu, solide, ferme, non élastique, à peu près cylindrique, blanc, glabre, fistuleux avec l'íge, long de 5 à 7 centimètres, villeux à la base.

Cette espèce vient à terre dans les bois, parmi les mousses et les feuilles; sa chair est blanche et d'un goût agréable. Comestible.

Ag. entonnoir (Ag. infundibuliformis), Schæif., t. 212.

Berkl., t. 5, fig. 2. - Fr., Epicr., 231. - Ag. suavis, Pers., MFyc., 85.-

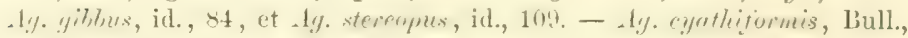
t. 248 , fig. $B, D$, et t. 575 , fig. F, G.

Ce champignon peu charnu, se desséchant facilement, rarement attarqué par les vers, sub-coriace, a le chapeau jaune pâle, tirant sur le cannelle, mince, uni, creusé en coupe ou en entonnoir, mais à centre us peu proéminent, large de 4 à 6 centimètres, à bords sinués; les lamelles d'un blanc pàle, étroites, inégales, minces, terminées en pointe aux deux extrémités, décurrentes sur un pédicule de la couleur blanc pâle des feuillets, assez grêle, nu, plein, long de 4 à 5 centimètres, fibreux, évasé à sa partie supérieure, et légèrement renflé à la base, qui adhère par un duvet assez dense aux feuilles tombées à terre.

On le trouve communément, à la fin de l'été et en automne, dans les bois, solitaire ou en petits groupes, à terre, sur la mousse, les feuilles mortes. Comestible.

Sa saveur est un peu astringente, son odeur agréable.

Eviter de le confondre avec l'Ag. inversus, champignon suspect.

Ag. retourne ( $1 y$. imersus), Scop., Citin., p. 445.

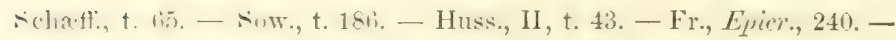

Ag. infundibuliformis, Bull., t. 553 (ex parte).

L'Ag. inversus a le chapeau charnu, fragile, large de 5 à 6 centimètres, convexe d'abord, puis en forme d'entonnoir, lisse, de couleur brun roussâtre d'abord, ensuite couleur de tan, à bord mince, recourbé; les feuillets très-décurrents, simples, peu serrés, d'un blano paile et à la fin de la couleur du chapeau; le pied plein, puis spongieux, puis creux, nu, mince, ferme, lisse, de la couleur du chapeau, quelquefois recourbé; chair pâle, odeur acidule. Non commun. 
Il vient dans les bois, souvent en touffes.

L'Écluse range cet agaric parmi les champignons pernicieux. Paulet et Kickx le tiennent pour fort suspect,.

$$
\text { Ag. laque (Ag. laccatus), Scop. }
$$

Schæff., t. 13. - Grev., t. 249. - Batt., t. 18, fig. G, I. - Krombh., t. 43, fig. 17-20. - Huss., I, t. 47. - Sow., t. 187 et t. 64. - Bolt., t. 41, fig. A, et t. 63. - Berkl., t. 5, fig. 3. - Buxb., t. 30, fig. 1. - Fl. dan., 1249. Fr., Epicr., 279. - Ag. amethysteus, Bull., t. 570, fig. 1.

Cet agaric, de couleur violet-améthyste à sa naissance, devient ensuite roux de chair ou jaunâtre. Son chapeau, large de 4 à 6 centimètres au plus, est d'abord hémisphérique, régulier, ensuite convexe, puis déprimé au centre, à bords sinués, $\dot{a}$ superficie sèche, comme farineuse. Les feuillets sont d'un violet plus ou moins foncé, rares, épais, inégaux, légèrement décurrents sur le pédicule. Ce pédicule, cylindrique, haut de 5 à 7 centimètres, nu, grêle, plein, filandreux, continu avec le chapeau, est garni au bas de fibrilles radicales.

On le trouve fréquemment dans les bois, en automne, soit solitaire, soit plus souvent réuni de deux à quatre ensemble.

Comme il est peu charnu, on le recherche peu, quoiqu'il soit comestible; on rejette le pédicule comme trop coriace.

\section{2e Tribu. Lentimus (lentus, flexible).}

Espèces épiphytes; feuillets à bord denté, ne se détachant pas facilement du chapeau. Plusieurs espèces sont pourvues d'une cortine peu apparente et qui disparait promptement.

- Genre pour quelques auteurs.

Ag. Lent. tigré (Ag. Lent, tigrinus), Bull., t. 70.

Batt., t. 12, fig. A, B, C, D. - Sow., t. 68. - Pers., Myc., 71. - Lentinus tigrinus, Fr., Epicr., 14, 15.

Var. Ag. Dunalii, DC., Fl. fr. - Bull., t. 36. - Saint-Amans, t. 12.

Berkl., t. 15, fig. 2.

Champignon peu charnu, coriace, mince, blanc, dont le chapeau arrondi, mais le plus souvent de forme irrégulière, large de 5 à 8 centimètres, est toujours ombiliqué, c'est-ì-dire creusé en entonnoir, aver les bord rabathos. marpue de petites peluchures ou spumes 
brine's ou yris fanre. comme soyeuses, nombrenses, semblant aller du centre à la circonférence. Les feuillets sont d'un blanc pâle, nombreux, inégaux, étroits, sinueux, finement crénelés sur leur tranchant, les plus courts coupés brusquement, les plus longs terminés en pointe et décurrents sur un pédicule tortueux, long de 4 à 5 centimètres, grèle, à peu près cylindrique, mais s'élargissant pour se continuer avec le chapeau, le plus souvent squameux, et quelquefois pourvu d'une cortine, à peine apparente et qui disparait promptement.

Il croit solitaire ou en touffes parfois nombreuses, en été et en automne, sur les vieilles souches des saules, des peupliers, de l'orme etc.

Comestible; fort agréable au goût et à l'odorat; chair ferme.

L'Ag. (Lentinus) umbellatus, Fr., Epicr., 31, est aussi comestible. Paulet dit l'avoir mangé plusieurs fois, et l'avoir trouvé de très-bon goùt; il est rare en France.

Ochrospores. Spores ochracées.

3e Tribu. Paxillus (paxillus, pieu).

Feuillets se détachant facilement du chapeau; pas de collier. Genre pour quelques auteurs.

Ag. Pax. enroule (Ag. Pax. involutus), Batsch, t. 13, fig. 61 .

Buxb., t. 26. - Schæff., t. 71, 72, et t. 252. - Sow., t. 98. - Berkl., t. 12 , fig. 5. - Batsch, t. 13, fig. 61. - Paul., t. 62 et.t. 63 , fig. 1. - Ag. contiguus, Bull., t. 240 et t. 576, flg. 2. - Paxillus involutus, Fr., Epicr., 4. - Rhimovis involuta, Rabh.

Champignon entièrement de couleur fauve sale ou jaune terreux, à pédicule cylindrique, plein, nu, charnu, solide, souvent tortueux, et quelquefois excentrique, long de 4 à 5 centimètres, continu et s'élargissant avec le chapeau. Le chapeau, d'abord convexe, puis plane et enfin déprimé au centre, souvent irrégulier, a 12 à 14 centimètres de diamètre, les bords, dans le jeune âge, roulés en dessous, tomenteux et marqués de stries ou comme cannelés. Les feuillets, un peu plus pâles que le reste de la plante, sont nombreux, inégaux, droits, quelquefois anastomosés, minces, atténués aux deux extrémités, un peu décurrents sur le pédicule, se détachent aisément de la chair du chapeau, avec laquelle ils semblent n'ètre que contigus; moniliformes à leur base. 
Il croit solitaire ou en petits groupes dans les bois, en été et en automne; très-commun. La chair et les feuillets deviennent de couleur fauve terreux, lorsqu'ils ont été meurtris; chair de la couleur du chapeau; odeur fongique; saveur faible.

Il est comestible. On le mange en Allemagne et en Russie; je l'ai mangé plusieurs fois. Dans certaines années, on le trouve en si grande abondance, qu'il pourrait être une ressource pour les pauvres.

\section{OMPIIALIA.}

1re Tribu (type).

Ag. de l'automne (Ag. brumalis), Fr., Epier., 260. - Bull., t. 278, - Dans Ies bois et les bruyères, surtout en novembre.

Ag. en marmite (Ay. cacabus), Fr., Epror., 246. - Sous les sapins̀.

Ag. campanelle (Ag. campanella), Batsch. - Schæff., t. 230. - Nees, fig. 191. - Sur les trones du pin.

Ag, en bassin (Ag. catinus), Fr. (décrit).

Ag. tirant sur le blanc (Ag. candicans), Pers., Syn., 385. - Bull. t. 575, fig. E. Fr., Epier., 214. - Dans les endroits humides des bois, sur les feuilles tombées.

Ag. couleur de cerf (Ag. cervinus), Hoffm., t. 2, fig. 2. - Nees, Syst., fig. 174. Fr., Epicr, 242. - Dans les mousses, tardivement.

Ag. blanc verdâtre (Ag. chrysoleucus), Fr., Epicr., 447. - Ag. mollis, Bull., t. 38 . - Sur les trones pourris.

Ag. contractile (Ag. clusilis), Fr., Epicr., 356. - Ag. unbilicatus, Bull, t. 411, fig. 2. - Bolt., t. 17. - Dans l'herbe des bois, les feuilles tombées.

Ag. cupule (Ag. cupularis), Bull., t. 554, fig. 2. - Sur la terre.

Ag. en coupe (Ag. cyathiformis), Bull. (décrit).

Ag. des bruyères (Ag. ericetorum), Bull., t. 551, fig. 1. - Fr., Epicr., 249. Commun près des chemins, dans les champs exposés au soleil.

Ag. epichysium (Ag. epichysium), Pers., Icon. pict., t. 13, fig. 1. - Fr., Epicr., 459. - Sur les bois humides.

Ag. pâlissant (Ag. expallens), Pers., Syn., 394. - Ag. cyathiformis, Bull, t. 575, fig. G, I. - Fr., Epicr., 252. - A terre, dans les lieux sauvages. Variété probable de l'A $g$. cyathiformis.

Ag. fichet (Ag. Fibula), Bull., t. 186 et 560, fig. 1. - Fr., Epicr., 478. - Dans les lieux humides, au printemps et en été, les mousses, les gazons

Ag. flasque (Ag. flaccidus), Sow. (décrit).

Ag. vacillant (Ag. Aluxilis), Fr., Epicr., 524. - Sur les mousses des trones d'arbres.

Ag. parfumé (Ag. fragrans), Sow. (décrit).

Ag. géotrope (Ag. geotropus), Bull. (décrit).

Ag. gigantesque (Ag. giganteus), Sow. (décrit).

Ag. gris cendré (Ag. gilvus), Pers. (décrit).

Ag. effilé (Ag. gracillimus), Weinm. - Vaill., p. 71, no 6. - Fr., Epicr., 479. Dans les lieux marécageux, sur les chaumes.

Ag. gris pâle (Ag. griseo-pallidus), Desm., no 120. - Ag. griseolus, Pers., Myc., 137, t. 28, fig. 3. - A terre, le long des chemins, dans les champs, les jardins. 
Ag. hépatique (.1\% hequlims), Batseh, fig, 211. - Fr. Eprer., 457. - Dans les champs, sur les chemins.

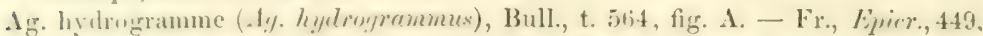
- Ag. streptopus, Pers., Myc., 127. - Sur les feuilles du hêtre, dans les licux humides.

Ag. en entonnoir (Ag. infundibuliformis), Schæff. (décrit).

$\Lambda$ g. retourné (Ag. inversus), Scop. (décrit).

Ag. laque (Ag. laccatus), Scop. décrit).

Ag. tris-grand (Ay. marimus), Alb. et Schw. - Buxb. - Fr., Epicr., 230. Ag. stereopus, Pers., Myc., 109. - Dans les bois, sur les feuilles mortes; odeur agréable.

Ag. dicolore (Ag. metachrous), Fr., Epicr., 262. - Weinm. - Krombh., t. 2 , fig. 22. - Dans les bois très-secs, au milien des feuilles; odeur nulle.

Ag. des murailles (Ag. muralis), Swartz. - Fr., Epicr., 466.

Ag. jarre (Ag. obbatus), Buxb. - Bull,, t. 248, fig. C. - Fr., Epicr., 253. Dans les plantis.

Ag. cloporte (Ag. Oniscus), Fr., Epicr., 462. - Dans les endroits tourbeux et mousseux, en groupe; rare.

Ag. analogue (Ag. parilis), Fr., Epier., 237. - Ag. obliquus, Pers., Icon. pict., t. 13, fig. 3. - Aq. cimicarius, Pers., Myc., 136, t. 26, fig. 7. - Dans les bois; plus grand pendant l'été qu'à la fin de l'automne.

Ag. phyllophile (Ag. phyllophilus), Pers., Fl.dan., t. 1847. - Schæff., t. 207. Fr., Epicr., 211. - Sur les feuilles tombées, surtout celles du hêtre.

Ag. poli (Ag. politus), Pers., Syn., 463. - Dans les bois.

Ag. pruipeux (Ag. pruinosus), Lasch. - Bull., t. 568, fig. 1. - Fr., Epicr., 256. - Sur les trones et dans les bois de pins, où il y a de la mousse, en automne, tard.

Ag. en boîte (Ag. pyxidatus), Bull., t. 568, fig. 2. - Dans les champs, sur les chemins, en automne.

Ag. rustique (Ag. mesticus), Fr., Epicr., 463. - Dans les bruyères, les lieux incultes.

Ag. scyphiforme (Ag. scyphiformis), Fr., Epicr., 464, - Sur la terre nue ou parmi les mousses.

Ag. scyphoïde (Ag. scyphoides), Fr., Epicr., 455. - En groupes, dans les terres couvertes d'herbe et de mousse.

Ag. sphagnicole (Ag. sphagnicola), Berkl., Outl., p. 131. - Sur les sphaignes.

Ag. brillant (Ag. splendens), Pers., Syn., 375. - Fr., Epicr., 238. - Variété de l'Ag. gilvus.

Ag. à petites écailles (Ag. squamulosus), Pers., Syn., 369. — Fr., Epicr., 232. De bonne heure, dans les bois de pins, les gazons, sur le bord des chemins.

Ag. odeur suave (Ag. suaveolens), Schum., Fl. dan, t. 1912, fig. 1. - Fr. Epicr., 259. - Ag. hedeosmus, Pers.; Myc., 121. - Dans les mousses, et plus souvent dans les prairies.

Ag. trompette (Ag.-Tuba), Paul., t. 65, fig. 2-6. - Fr., Epicr., 248. - Dans les feuilles, celles du pin surtout.

Ag. ombellifère (Ag. umbelliferus), Lin. - Fr., Epier., 467. - Ag. pseudo-androsaceus, Bull., t. 276. - Sur les bois cariés, dans les haies épaisses, les marais tourbeux.

Ag. ombiliqué (Ag. umbilicatus), Schæff., t. 207. - Fr., Epicr., 450.-Ag. phoophthalmus, Pers., MYyc., 108. - A terre et sur les racines des arbres.

Ag. ombratile (Ag. umbratilis), Fr., Epicr., 474. - Weinm. - Sur les bords des fossés. Vénénerux. 
Ag. tremblotant (Ag. ventosus), Fr., Epicr., 448. - Bull., t. 564, fig. B. - Sur les bois de hêtres.

Ag. stigmatisé (Ag. vibecinus), Fr., Epicr., 258. - Ag. cyathiformis, Bull., t. 575. fig. K, L. - Dans les mousses, surtout dans les bois de pins, au bord des marais, en groupe.

2 e Tribu. - Lentinus (Leucospores).

Ag. Lent. colimaçon (Ag. Lent. cochleatus), Fr., Epicr., 35. - Sow., t. 168. BerkI., t. 19, fig. 4. - Sur les trones de différents arbres.

Ag. Lent. de Delastre (Ag. Lent. Delastris), Lév., Ann. des se. nat., 1844.

Ag. Lent. de Dunal (Ag. Lent. Dunalii), DC. - Fr., Epicr., 15. - Batt., t. 12 , fig. A. - Berkl., t. - 5, fig. 2. - Sur les saules, les peupliers. - Variété de I'Ag.tigrinus, pour M. de Seynes.

Ag. Lent. humidifère (Ag. Lent. humescens), Lév., Ann. des sc. nat., 1848, 121. - Dans la France méridionale.

Ag. Lent. gracieux (Ag. Lent. lepideus), Sow., t. 382. - Fr., Epier., 16. Schæff., t. 29, 30. - Sur les vieux bois de pins.

Ag. Lent. d'apparence ligneuse (Ag. Lent. suffrutescens), Fr., Epicr., 32. Schæff., t. 249. - Sur les bois travaillés.

Ag. Lent. tigré (Ag. Lent. tigrinus), Bull. (décrit).

Ag. Lent. couleur de renard (Ag. Lent. vulpinus), Fr., Epicr., 39. - Sow., t. 361. - Sur les vieux trones d'orme.

$$
\text { 3е Tribu. - Paxillus (Ochrospores). }
$$

Ag. Pax. noir tomenteux (Ag. Pax. atrotomentosus), Batsch, fig. 32. - Paul., t. 33, fig. 2-3. - Fr., Epicr., 6. - Dans les bois, à terre et sur les trones. Suspect.

Ag. Pax. filamenteux (Ag. Pax. filamentosus), Scop. - Fr., Epicr., 5. - A terre, dans les bois.

Ag. Pax. enroulé (Ag. Pax. involutus), Batsch (décrit).

Ag. Pax. en aiguière (Ag. Pax. Lepista), Fr., Epicr., 1. - Paul., t. 47, fig. 3, 4. - Dans les bois et les lieux humides. Peut-être variété de l'Ag.pratensis.

$$
\begin{aligned}
& \text { SÉrie VI. - PLEUROPE (Pleuropus). }
\end{aligned}
$$

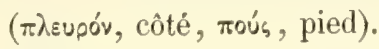

Champignons à pédicule nul, latéral ou excentrique; feuillets décurrents. La plupart croissent sur les bois et les arbres malades.

Leucospores. Spores blanches.

1 re Tribu. Pleuropus (type). Champignon charnu, non coriace.

$$
\begin{gathered}
\text { Ag.du houx (Ag. Aquifolii), Paul., t. } 38 . \\
\text { Fr., Epicr., } 498 .
\end{gathered}
$$

Cet agaric n’a été signalé que par Paulet, qui le décrit ainsi : Chapeau charnu, mou, d'abord convexe, ensuite plane ou déprimé, large 
de 12 i 15 centimetres, rarement régnalier, uni, sec, shlabre, quelInefois crevatsé, de couleur de buis, lenillets ipres, lurges, éloignes les uns des antres, inciganx, plus fonces en coulener que le chapean, décurrents et s'insérant à la même hauteur à une espèce de bourrelet, autour d'un pédicule le plus souvent excentrique, droit, plein, solide, blanc, nu, et un peu aplati.

Il vient à terre, en automne, dans les buissons de houx; a une chair fine et délicate, un parfum agréable et une saveur qui invitent $\dot{a}$ le manger. Ce serait un des meilleurs champignons que l'on connaisse. Fries est tenté de regarder l'Ag. Aquifolii comme une variété de l'Ag. Eryngii.

Ag. du chêne (Ay. dryinus), Pers., Comment., 96.

Schæff., t. 233. - Nees, Syst., t. 22, fig. 177. - Paul., t. 18, fig. 3, 4. Huss., II, t. 29, 33. - Pers., Myc., 46. - Fr., Epicr., 485.

Var. gibbosus, Paul., t. 20, fig. 1.

Le chapeau de cette espèce est dimidié, convexe d'abord, et bientòt aplati, oblique, dur, compacte, large de 6 à 8 centimètres, blane, parsemé d'écailles formant des taches noirâtres, son bord est tranchant, un peu replié en dessous; les feuillets sont étroits, d'inégale longueur, arqués, d'un blanc pur, devenant avec l'âge d'un jaune pâle, décurrents sur un pédicule sublatéral, ferme, plein, subsquameux, long de 3 à 4 centimètres et plus, de la couleur du chapeau, garni dans le jeune âge d'un voile blane, fugace, déchiré, rarement apparent.

Comestible. Ce champignon, dont la chair est blanche et prend une teinte légèrement jaune lorsqu'elle est coupée ou brisée, a un goût et une odeur agréables; il croît en automne, ordinairement solitaire, sur le tronc et les branches du chène, du pommier et d'autres arbres.

Ag. de l'éryngium (Ag. Eryngii), DG., Fl. fr., VI, no 462.

Mich., t. 73, fig. 2. - Paul., Champ., t. 39. - Vittad., t. 10, fig. 2. - Noul. et Dass., Champ., t. 21, fig. A. - Fr., Epicr., 499.

Noms vulgaires: Ragoule, Gingoule, dans le nord de la France; Brigoule, Ringoule, Bérigoule, Boulingoule, dans le midi ; Béigoula, Couderlo, en Languedoc; Oreillette, Oreille de chardon, dans le Nivernais; Corgne, Panichaon, en Provence. 
Cet agaric est plus délicat que le champignon de couche, quoique peu odorant et peu savoureux. Il croit, en octobre, sur les racines mortes du chardon Roland (Eryngium campestre), dans les terrains sablonneux et secs; son chapeau charnu, lisse, de couleur roux pâle ou gris fauve, est large de 5 à 8 centimètres, arrondi ou irrégulier, d'abord convexe, puis un peu déprimé au centre, avec les bords roulés en dessous; ses lames sont blanchâtres, inégales, peu serrées, aiguës aux deux extrémités et décurrentes sur le pédicule, lequel est nu, court, plein, ferme, blanchâtre, droit, cylindrique, central, mais plus souvent excentrique. Rare.

Ag. géogène (Ag. geogenius), DC.

Mich., t. 65, fig. 2. - Fr., Epicr., 507. - Ag. leporinus, Pers., Myc., 39, et Ag. Auricula, id., Myc., 67.

Var. alba, Paul., t. 25, fig. 1, 2.

Champignon presque membraneux, glabre, luisant, sub-visqueux par les temps humides, haut de 6 à 7 centimètres, large de $5 \dot{a}$ 6 , de couleur fauve ou terre d'ombre, dimidié, dont les bords latéraux, en se rapprochant, forment un entonnoir fendu jusqu'à la base, et sont ondulés, irréguliers, réfléchis. Ses feuillets, très-nombreux, surtout à la circonférence, inégaux, minces, serrés, blancs, se prolongent en petit nombre jusqu'à la naissance d'un pédicule latéral, court, recourbé, canaliculé en dessus, tubéreux ou un peu renflé à la base.

L'Ag. geogenius, qui ressemble beaucoup à l'Ag. petaloides, se mange dans les environs d'Aigues-Mortes, dit M. de Seynes, confondu sous le nom de Bérigoule avec l'Ag. Eryngii; il est même estimé comme aliment. Néanmoins ce champignon serait dangereux, s'il est le même que l'Ag. geogenius de Paulet, var. alba, lequel, expérimenté par cet auteur, aurait fortement incommodé un chien.

Ag. de l'olivier (Ag. olearius), DG., Fl. fr., VI, suppl., p. 368.

Batt., t. 13, fig. A, B, et t. 14, ftg. B. - Larbr., t. 20, fig. 6. - Paul., t. 23, et t. 24, fig. 1-7. - Vivian., t. 50. - Pers., Myc., 62. - Tulasne, Ann. des sc. nat., t. 20, fig. 1-10. - Barla, t. 24, fig. 1-6. - Fr., Epier., 854.

Nom vulgaire: Champignon de l'olivier.

Cet agaric, entièrement de couleur orange ou roux doré vif, quelquefois un peu brun en dessus, est charnu. Son chapean, d'abord con- 


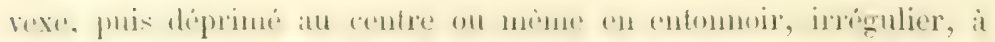
borts replies an desoms, ext latre de 7 it 10 rentimetres, et prisente une surface lisse, sèche, douce au toucher. Les feuillets sont inégaux, plus pâles que le chapeau : larges, serrés, très-décurrents sur un pédicule, plein, de la couleur du chapeau, à chair filandreuse, central ou plus souvent excentrique, atteignant à peine 6 à 8 centimètres, presque toujours courbé, plus large à sa partie inférieure.

Il croit le plus souvent en groupes, sur les racines à fleur de terre de l'olivier, du charme, de l'yeuse, de plusieurs autres arbres ou arbrisseaux. On le trouve communément dans les provinces méridionales de la France.

Est vénéneux. Il a une odeur non désagréable; une saveur légèrement amère ou styptique; la chair d'un blanc jaunâtre ou orange, cassante, ferme, celle du pédicule étant filandreuse. Les docteurs Destrems et Mierge ont vu des exemples bien caractérisés d'empoisonnement causé par ce champignon, qui purge violemment, même lorsqu'il n'est que mâché.

Ses feuillets deviennent phosphorescents la nuit, et communiquent une lueur phosphorescente aux doigts qui les ont touchés; aucune odeur n'accompagne cette phosphorescence.

Persoon et M. Léveillé considèrent l'Oreille du chêne vert, Paul., t. 24, fig. 3-4 Ag. (Panus) farneus, Fr., Epicr., 1, et l'Oreille du charme, Paul., t. 24, fig. 5-7. - Barla, t. 24, fig. 7-9 (Ag. Carpini, Fr., Epicr., 865) comme de simples variétés de l'Ag. olearius.

Ag. ostrace (Ag. ostreatus), Jacq., t. 288.

Sowerby, t. 241. - Curt., t. 116. - Tratt., fig. 40. - Fl. dan., t. 892. Vittad., t. 4. - Lenz, fig. 19. - Krombh., t. 41. - Huss., II, t. 19. Ag. dimidiatus, Bull., t. 508. - Letell., 695. - Fr., Epicr., 503.

Var. A. Ag. glandulosus, Bull., t. 426. - Paul., t. 28.

" B. Ag. gyrinus, Pers., Myc., t. 25, fig. 2.

Noms vulgaires : Couvrose, Poule de bois (Vosges), Oreille de nouret ou Nouret.

Ce champignon comestible est d'un usage assez général dans les Vosges. Sa chair est ferme, blanche; son odeur faible; sa saveur non désagréable.

Il croît en touffes, et le plus souvent imbriqué sur le tronc des arbres languissants, plus spécialement sur le pommier, au printemps et dans les antommes phuienx; sot commun. 
Il a le chapean chatron, lisse, substimidie, en forme de conque,

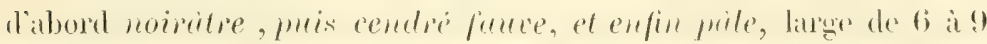
centimètres of davantage, à bords recoubés en dessous; les fenillets, décurrents, droits, inégaux en longueur, d’un blanc pàle, non serrés,

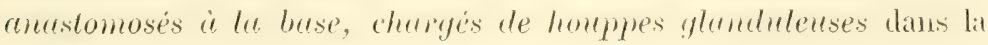
variété $A$, le plus petit nombre de ces feuillets atteignant le pédicule, qui est latéral, court, épais, maigre à la base.

M. Léveillé ne serait pas éloigné de regarder l'Ag. dimidiatus de Bulliard conme distinct de l'ostreatus; ils sont d'ailleurs alimentaires l'un et l'autre.

Ag. pétaloïde ( $A g$. petaloides), Bull., t. 226 et 557, fig. 2.

Batt., t. 9, fig. L. - Pers., Iyc., 34. - Frr., Eivir., 508.

Var. Ag. spathulatus, Pers., Obs., t. 4, fig. 1 , et $M_{y y c .,} \mathrm{n}^{0} 35$, t. 25 , fig. 5 .

Champignon dimidié, peu charnu, mince, large de 6 à 7 centimètres, de couleur fauve pàle ou cendrée, à superficie sèche et comme farineuse, à bords sinués, rabattus, ayant la forme d'une spatule ou d'un pétale dont l'onglet serait prolongé; les feuillets's d'un blanc cendré ou faiblement jaunâtre, nombreux, droits, inégaux, étroits, décurrents sur un pédicule, latéral, blanc, nu, comprimé, long de 1 à 3 centimètres, continu avec la chair du chapeau, creusé en gouttière en dessus et marqué en dessous de veinules longitudinales, qui sont la continuation de la décurrence des feuillets.

Il croit à terre et sur les souches enterrées, dans les parties arides des bois et le long des chemins, en septembre et en octobre, solitaire ou en groupes de deux ou trois individus.

Il a l'odeur de la farine récente; une saveur qui n'est pas désagréable; se pèle facilement; chair cassante. Comestible.

Ag. du saule (Ag. salignus), Hoffm. - Pers., Syn., 428.

Tratt., t. 4, fig. 8. - Paul. et Lév., t. 17, 18, et t. 20, fig. 2, 3. - Fr., Epicr., 504. - Ag. allochrous, Pers., Myc., 44.

Il est de grande taille, a le chapeau large de 16 à 20 centimètres, sub-imbriqué, charnu, dimidié ou dilaté en éventail, convexcplane, glabre, lisse, quelquefois gercé, de couleur noisette ou café au lait, déprimé à sa base. Les feuillets, assez rapprochés, sont minces, larges, d'inégale longueur, blancs ou nuancés, de la couleur du cha- 


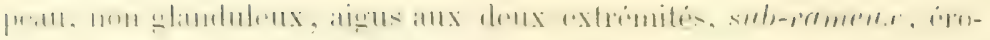

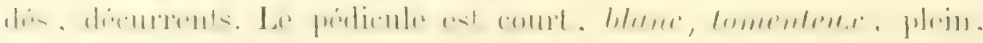
li inte.

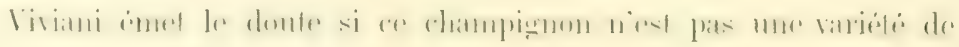
l'Ag. ostreatus On le trouve non communément dans l'arxiere-saison, solitaire ou par groupes peu nombreux, sur les vieux troncs d'arbres, ot plus particulièrement sur les trones de saules, de peupliers et de noỵers. Jeune, il est délicat à manger, et recherché des amateurs; vicux, il devient noir et coriace.

Ag. marquetẻ (Ag. tessulatus), Bull., t. 513, fig. 1.

(Pl. XVIII, fig. 1.)

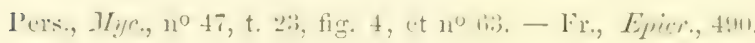

Comme l'Ag. ulmarius, l'Ag. tessulatus a le chapeau charnu, conrexo-plane, glabre, arrondi dans la jeunesse, plus déreloppé d'un còté rue de l'autre à la maturité; il en diffère surtout par un chapeau moins large, jaune fave ou ferrugineux, avec des taches ou marquetures d'un jaune plus clair, presque hexagonales. Les feuillets, blancs ou blane jaunàtre, larges, inégaux, serrés, adhérents au pédicule, sont échancrés à leur base. Ce pédicule, long de 6 à 8 centimètres, blanc, nu, plein, chamu, cylindrique, un peu excentrique, est toujours recourbé pour donner au chapeau une position horizontale.

L'Ag. tessulatus croit, en automne, le plus souvent solitaire, sur les arbres languissants, et surtout sur les vieux troncs du pommier et du cliène,

Sa chair, un peu coriace, peut s'employer comme aliment. La saveur n'est pas désagréable; l'odeur se rapproche de celle de la farine récente. Reveil le dit suspect, mais sans preuve.

Ag. ulmaire (Ag.ulmarius), BulI., t. 510.

(Pl. VIII, fig. 2.)

Sow., t. 67. - Vittad. t. 23. - Noul. et Dass., t. 12, fig. B. Per., Itye., bit-ibi. - Fr., Epier., 489.

Vums inelgnires: Oreille dorne, Comprarol doulne, Aoureillo d'oulmé.

Cet agaric croit en octobre, novembre et décembre, solitaire ou en touffes, sur le tronc de différentes espèces d'arbres, et plus particulierement sur le trone des ormes languissants. 
Son pédicule est cylindrique, toujours arqué pour tenir le chapeau dans une position horizontale, nu, d'un blane sale ou grisàtre, sub-tomenteus, long de 6 a 9 entimetres, chatru, plein, ferme, continu avec la chair du chapeau, auquel il s'insère un peu latéralement. Ce chapeau est charnu, compacte, glabre, il peut acquérir jusqu'i 50 centimètres de diamètre, mais le plus souvent il en a de 12 à 18 seulement; il est comme arrondi, d'un blanc pâle ou gris, mais assez souvent marqué de taches arrondies, plus foncées en couleur. Les feuillets sont nombreux, larges, inégaux, échanciés à leur base, adhérents au pédicule, d'abord blanchàtres, ensuite d'un jaune sale. Rarement attaqué par les vers.

Comestible. La chair, dont la consistance est ferme, compacte, a uno odeur et une saveur agréables. Cée champignon se pèle difficilement.

\section{Pleuropus. (Leucospores).}

2. Tribu. Panus (nom employé par Pline).

Champignon charnu, mais coriace, se desséchant avec l'àge et se conservant par la dessiccation. Genre pour quelques auteurs.

Ag. (Pan.) en conque (Ag. Pan. conchatus), Bull, t. 298, ct $A g$. dimidiatus, t. 517, fig. 25.

$$
\text { (Pl. XIX, fig. 1.) }
$$

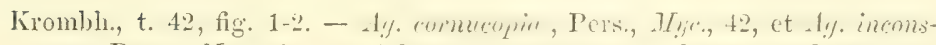

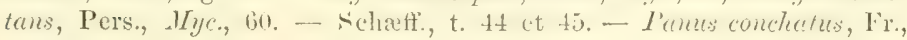
Epicr., 5.
}

Chapeis charnu, mince, irrégulier, excentrique, dimidié, en forme de conque ou d'entonnoir, d'abord blanc roussìtre ou couleur cannelle pâle, glabre, lisse, et enfin légèrement squameux : feuillets décurrents, sub-rameux, d'un blane de chair ochracé, quelques-uns anastamosés, aigus aux deux extrémités; pédicule ferme, court, inégal, à base pubescente.

Sur les troncs et les rameaux des arbres en touffes.

Chair ferme, substance coriace, non putrescente; saveur et odcur agréables. Comestible. 


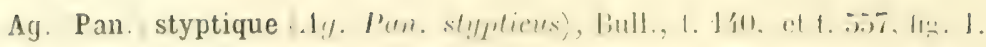

$$
\text { (I) IIS. Ii; : 2.) }
$$

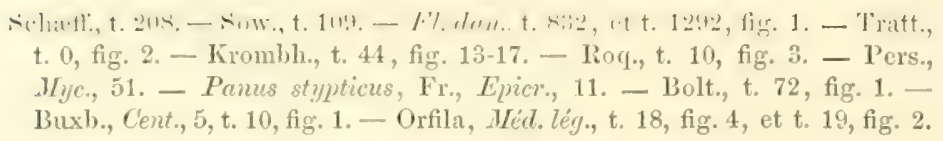

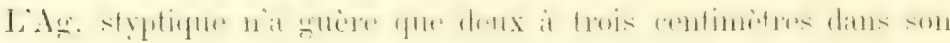
plus grand dianètre, est entièrement de couleur cannelle ou faure clair. Il a un pédicule nu, latéral, plein, long d'environ 2 centimètres, qui s'érase à son sommet et se continue avec le chapeau; celui-ci est un peu oblong ou réniforme, quelquefois lobé, arec les bords roulés en dessous, parsemé de squames furfuracées, qui s'en détachent facilement. Ses lames sont étroites, brunâtres, minces, serrées, inégales, les plus longues se terminant quelquefois toutes à une ligne circulaire, qu'aucune ne dépasse.

Il est assez commun, dans les bois, en automne et en hiver, quelquefois groupé par étages, sur les trones d'arbres coupés transversalenent.

Il n'a pas d'odeur; mais sa saveur, d'abord fade, devient bientòt nau sécuse, puis âcre et brulante à la bouche et à la gorge. Chair peu épaisse, jaunâtre. Coriace.

Vénéneux. Il purge violemment les animaux, mais ne les tue pas.

Ag. (Pan.) cintré (Ay. Pan. tomulosus), Pers., Syn., 422.

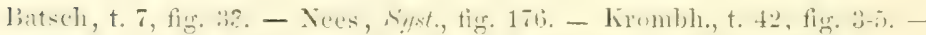

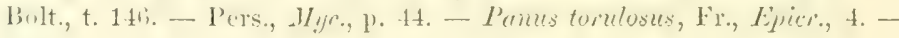
Paul, t. 26, fig. 3,4 .

Nom vulgaine: Cllair de Bavière.

Chapeau dimidié, se déprima:ut en entonnoir, charnu, mince, coriace, large de 5 à 8 centimètres, lisse, couleur de chair tirant sur le roux, à marge repliée en dessous. Feuillets inégaux, peu serros, légèrement crispés, un peu plus pàles que le chapeau, ensuite coulcur de tan, aigus aux deux extrémités, décurrents sur un pied court, olslique, épais, reconvert d'un duvet grisâtre.

Cet agaric, assez rare, croit à la fin de l'été et en automne, assez sonvent, en touffes, sur les vicux troncs de diverses espèces d'arbres, 
et principatement sur les trones de boulean. Sa coulenr varie quelquefois, mais elle a toujours quelque chose de rougeâtre.

Il est très-bon à manger; on en fait un fréquent usage en Allemagne; recherché surtout en Bavière.

Ochrospores. Spores de couleur fermgineuse.

3" Tiniu. Crepidotus (xprisis, pautouflle, oũs, oreille).

Ag. transparent (Aq. translucens), DG.-Fl. Pr.. Silppl., p. 43.

$$
\text { Fr., Epier, } 862 .
$$

Nom vulgaire: Pivoulade de saule, à Montpellier.

C'lamprignon sub-membraneux, it demi-timensparent, sescile on pourvu d'un pied, nu, très-court et latéral, ayant le chapeau d'un blanc légèrement roussàtre, arrondi ou irrégulier; les feuillets libres, inf́gaux, d'abord pâles, puis d'un lilas roussàtre.

Il est comestible, et croit sur les vieux troncs de saule, d'orme et de peuplier, aux environs de Montpellier. Les paysans, dit De Candolle, le mangent, confondu avec d'autres sous le nom de Pivoulade de saule.

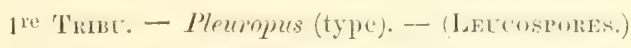

Ag. algide (Ay. alyidus', Fr., Epricr., 523. - Fl. dan., t. 1552 ct 155h, fig. 2.A\%. trichotis, Pers., Myr., 3, t. 26 , fig. 9. - Sul les bois putrides of les trones morts du bonleat.

Ag. appliqué (Ag. applicatus), Batsch, fig. 125. - Bull., t. 581, fig. 2. - Sow. t. 301. - Fr., Epicr., 528. - Sur les bois cariés.

Ag. du houx (Ag. Aquifolii), Paul. (décrit).

As. armoricain (Ay. armoriemus), ('ouan, Fl. fin., p. 77. - Sur les branches mortes du chêne.

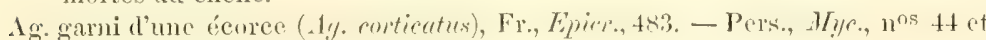
59. - Sur les vienx trones. Rave.

Ag. ondulé (Ag. craspedius), Fr., Epier., 483, - Paul., t. 44, fig. 3. - A la basc des trones en décomposition.

Ag. on gondole (A\%, cyphelleformis), Berk1., t. 15, fig. 3. - Fr., Epicr., 526. Sur les tiges mortes de diverses plantes.

Ag. du dactyle (Aq. Dactyli), Crouan, Fl. fin., p. 77. - Sur les tiges et les fenilles du dactyle gloméré mourant.

Ag. racine maillée (A\%. dietyorhizus, DC.). - Fl. dan., t. 1552, fig. 2. - Sur la terre et les bois putréfiés.

Ag. du chêne (Ag. dryinus), Pers. (décrit).

Ag. de l'eryngium (A\%. Errmyii), DC. (dérrit).

Ag. frangé (Ay. fimbriatus), Bult., t. 61. - Fr. Epric., 494, - A la base des trones cariés du hêtre.

Ag. géogène (Ay.geogenius), DC. (décrit). 


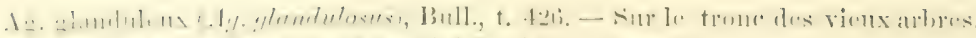

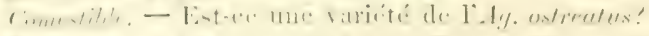

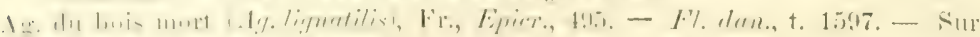

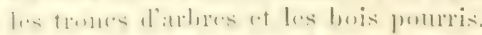

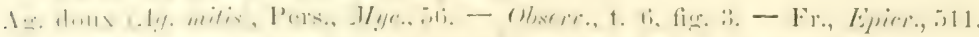

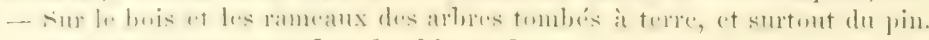
(ommun en automne et dans les hivers doux.

. Ig. nidulant (Ag. nidulans), Pers., Ieon. et deser., t. 6, fig. 4. - Fr., Eprim., 519.

- Assez commun sur les bois qui se pourrissent, le pin, le hêtre.

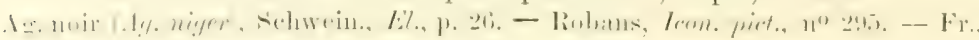
Lipier., 527. - Sur les trones de bois pouri.

Ag. des olivicrs (A\%.olearizs), DC. (dérit).

Ag. en coquillo (Ag. ostreatus), Jacq. (dérit).

Ig. miniature (Ag. perpusillus), Fr., Epier., 530. - Fl. dan., t. 1295, fig. 1. Sur les rameaux tombés.

Ig. pétaloïde (Ag. petaloides), Bull. (décrit).

Ag. des vergers (Ag. Poneti), Paul., t. 33, fig. 1. - Sur les trones pourris, dans les jardins fruitiers.

Ag. du saule ( $1 \%$ saliynus), Fr. (décrit).

Ag. septique (Ag. septieus), Fr., Epier., 520. - Sow., t. 321. - Sur Ic bois et les rameaux pourris.

Ac. tartif (A\% serotinus), Schrad. - Fr., Epicr, 510. - Fl. dan., t. 1693, fig. 2. - Sur les trones des arbres à feuillage épais, automne et hiver.

Ag. Blanc cendré (Ag. spodoleucus), Fr., Fiper., 501. - Paul., t. 22. - Sur les trones du hêtre ete.

Ig. légèrement strié (Ag. striatulus), Fro, Epricr., 529. - Sur les bois et les rameaux tombés ì terre.

Ig. marqueté (Ay. tessulatus), Bull. (décrit).

Ag. tromblant (Ag. tremulus), Schæff,, t. 224. - Fr., Epicr., 514. Sur la terre et les mousses.

Ig. de l'orme (Ag.ulmarius), Bull. (dérrit).

Ag. onguiculaire (A\%. unguicularis), Fr., Eprer., 525. - Pers., Mye., t. 26, fig. 9. I)ans les fentes d'écorces d'arbres, pendant les hivers doux.

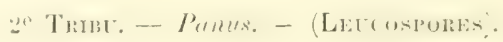

Ag. (Pan.) en conquo (Ag. Pan. conchatus), Bull. (déerit).

Ag. (Pan.) en forme de coupe (Ay. Pan. cyathiformis), Schref., t. 252. - Fro, Evier., 2. - Sur les trones de pins.

Ag. (Pan.) de Delastre (Ag. Pan. Delastrii), Mont. - Fr., Epirc., 16. - Sur l'écoree de divers arbres vivants.

Ag. (Pan.) farneur (A\%. Pan. farneus), Paul., t. 24, fig. 3-4. - Fr., Epror., 1. simple variété de l'Ay. olearius, poux Persoon et Léveillé. - Sur les trones d'yeuse, dans le Midi. - Suspect.

Ag. (Pan.) puanteur (Ag. Pan. fotor), Corda. Ag. Pan. foetens, Seer. - Bull.,

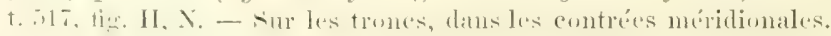

Ag. (Pan.) de Lamy (Ag. Pan. Lamyanus), Mont., Syll., 460. - Sur les trones des chênes, en automme, dans le Limousin.

Ag. (Pan.) styptique (A\%. Pan. stypticus), Bull. (décrit).

Ag. (Pan.) cintré (Ho. Pan. torulosus), Nees (déerit). 


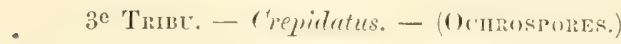

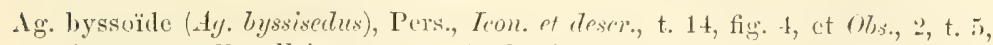
fig. 8, 9. - Fr., Eprier., 866. - sur les bois pourris.

Ag. pleureur (1\%. depluns), Batseh, fig. 122. - Fr., Epire., 865. - - sur la terre, sur les mousses, dans les serres.

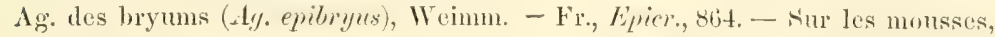
rare.

Ag. épais (A\% rrassus), Batt., t. 25, fig. (†. - Paxillus rrasuse. - Fr., Equir., 8. - Sur les peupliers, eñ automne.

Ag. jonquille (Ag. jonquilla), Lév, et Paul, t. 20, fig. 4. - Sur les vioux trones de chêne. Est très-voisin de l'aly. mollis.

Ag. mou (Ag. mollis), Schæff., t. 213, - Sow., t. 97. - Huss., I, t. 74. - Berkl., t. 9, fig. 6. - Sur les trones pourris des arbres, le bouleau, lo hêtre et même le sapin.

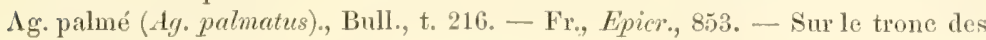
arbres, en automne. Est bien yoisin de l'A $\mathrm{g}$. ulmarius et de l'd\%. tessulatus.

Ag. pannoïde (Ag. pannoides), Fr. - Pers., Myc., nos 61, 15, 17. - Ag. lameblirugue, DC., Fl. fir., suppl., p. 4t. - Pers., Myr., 9. - sur les vieuxtrones. la sciure, en automne.

Ag. forme de pezize (Ag. pezizoides), Nees, t. 6, fig. 18. - Fr., Epicr., 868. N'est pas sans analogie avec l'A $\mathbf{g}$. violaceo-fulrus.

Ag. en trompe (Ag. proboscideus), Fr. Epicr., 860. - Fl. dan., t. 1072. - Sur le bois et les rameaux tombés à terre et putréfiés.

$\Lambda$ g. transparent (Ag.translucens), DC. (décrit).

Ag. variable (Ag. variabilis), Pers., Obs., t. 5, fig. 12. - Berkl., t. 10, fig. 1. Huss., I, t. 5. - Dans les bois, sur les trones et les ramcanx tombés à terre, en automne et en hiver; commun.

Ag. roux violacé (Ag. violaceo-fulvus), Batsch, fig. 39. - Fr., Epicr., 867. Ay. elatinus, Pers., Myc., t. 24, fig. 4. - Sur le bois de pin. 


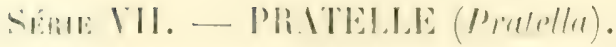 \\ $(1)(111111)$, f110.
}

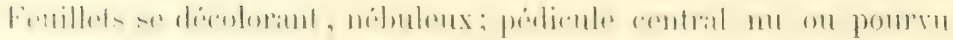

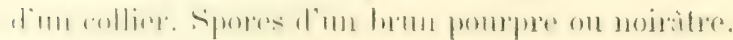

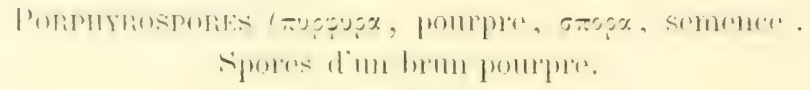

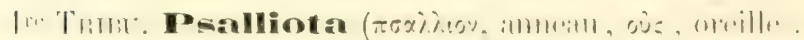

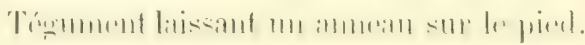

Ag. des jacheres (4\%, amensis), Schaff., t. $310,31 \%$

1. XY, Iiw. 2.)

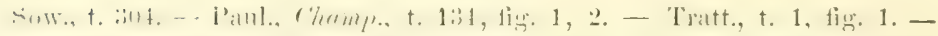

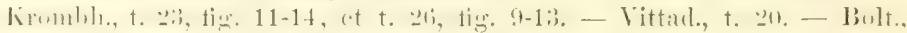

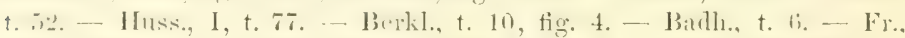

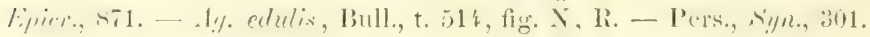

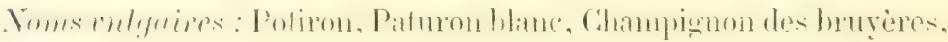
limle de migne.

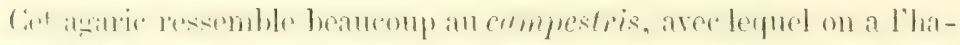

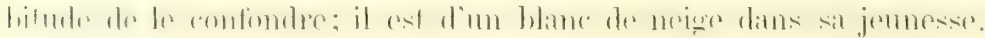

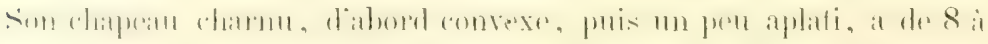
10 contimètres de largeur, la superficie d'abord tomenteuse ou farinouse, glabie ensuile et siche. Les fenillets, libres, inéganx, plus larges vers la circonférence, de couleur rose tendre ou lilas, devicnnent plus tard d'un noir violacé. Le pied ferme, creux ou spon-

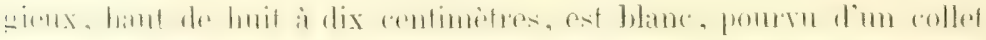

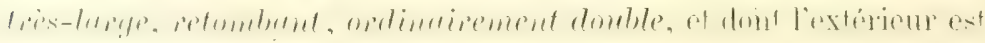
parfois fendu en rayons.

On le trouve fréfuemment, en automne, dans les prés, les pâturages, les lieux découverts des bois. Odeur et saveur agréables.

Il est comestible comme l'A $\mathrm{l}$. cumpestris, dont il se distingue par sa couleur d'un blanc pur, ses feuillets plus pâles, sa chair blanche, ne changeant pas de conleur lorsqu'elle est entamée, ses lamelles longtemps pàles, sèches et ne derenant nullement déliquescentes avec l'àge. Malqué ces différences, il est permis de douter que cette espèce 
soit bien distincte de l'Ag. campestris, le passage de l'une à l'autre étant insensible. Persoon, dans une note manuscrite, dit, en parlant de l'Ag. amensis: Solummodo varietas Ag. campestris videtur. Aucune espèce d'ailleurs ne prèsente peut-être autant de variétés de dimension, de forme, de couleur, que l'Ag. campestris.

Ag. champêtre (Ag. campestris), Lin.

(PI. XX, fig. 1.)

Schrff., t. 33. - Sow., t. 305. - Trer., t. 161, - Tratt., t. K. - Batt., t. 45. - Fl. dan., t. 704. - Nees, t. 24, fig. 195. - Vent, t. 5, fig. 38-41. Viv., t. 6-8. - Hartz, t. 9 et 60. - Berkl., t. 10, fig. 2. - Huss., I, t. 90. - Vittad, t. 6-8. - Krombl., t. 23, fig. 1-8, et t. 26, fig. 14, 15. - Paul., t. 130. - Barla, t. 27, fig. 1-13. - Ag. edulis, Bull., t. 134, et t. 514, fig. L, M. - Fr., Epicr, 870 .

Noms velquares: Champignon de eouche, Champignon des prex. C'hampignon du fumier, Paturon, Potiron, Envinassa, Pradélos, Caberlas, Rougetto, Bousiquet, Campagnola, Campagnoulé, Vinois, Misseron, Saussiron, en Lorraine.

Ce champignon, dont l'usage est répandu partout, a un chapean charnu, convexo-plane, de couleur roussâtre ou brun bistre, et quelquefois jaunâtre ou mème entièrement blanc, large de 6 à 7 centimètres, à superficie sèche; un peu squameuse ou peluchée, rarement lisse; des feuillets non adhérents au pédicule, droits, inégaux, serrés, couleur de chair dans les jeunes individus, puis d'un rouge vineux et enfin noirâtres dans la vieillesse, et sub-déliquescents; le pédicule plein, charnu, cylindrique ou quelquefois renflé à sa base, long de 4 à 6 centimètres, blanc, ordinairement glabre, pourvu dans son milieu d'un anneau blanc, plus ou moins complet et plus ou moins persistant.

Cet agaric, à peu près cosmopolite, vient dans les bois peu couverts, les friches, les champs cultivés, les jardins, les écuries, le plus ordinairement en touffes, depuis le mois de mai jusqu'en octobre. On le cultive sur couche dans tonte l'Europe.

Il est employé sous toutes sortes de formes comme aliment et comme assaisonnement. Odeur et saveur agréables; chair un peu changeante lorsqu'elle est divisée.

On doit se garder de le confondre avec l'Ag. bulbosus et l'Ag. pantherimus, qui sont des poisons; ces deux agaries ont toujours les feuilfols blanes of sont pouren diun volva. 


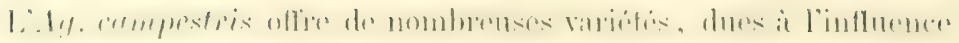

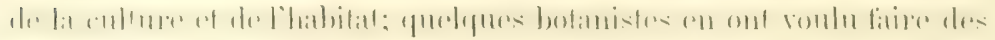

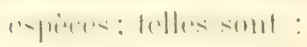

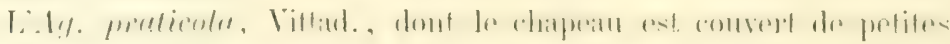

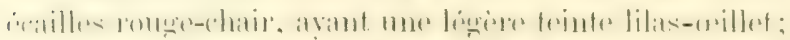

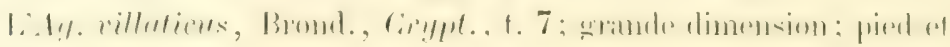
chapeau très-squameux;

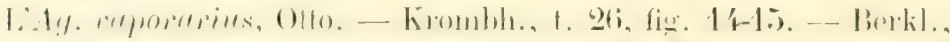

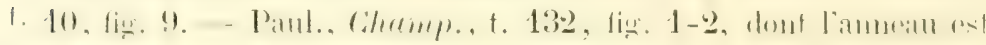

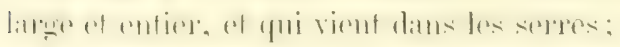

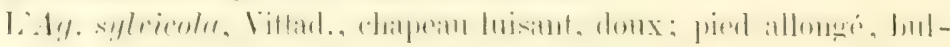
lin+1x.

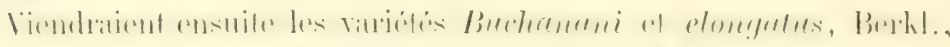

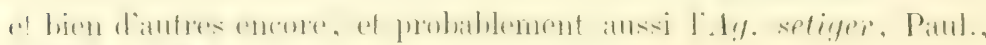

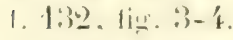

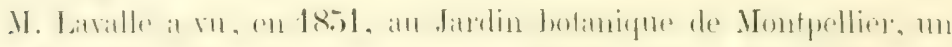

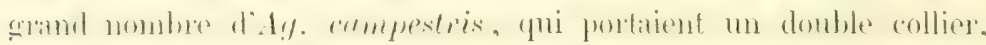
formé par une double membrane, dont l'extérieur rappelait le rolra des Amanites. M. de Seynes, de son côté, rapporte des exemples de ce même champignon priré de collier, ou n'en présentant que des lambeaux attachés au chapeau.

Ag. crétacé $(A g$. cretaceus $), \mathrm{Fr}^{\mathrm{r}}$.

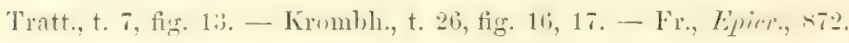

C'e champignon, entièrement d'un blane de craie dans son premier igye, est de taille moyenne. Son chapeau, convexe, plane, charnu, or-

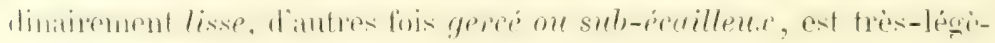
rement fauve à son sommet chez les individus adultes; il a 8 à 9 centimètres de diamètre; ses feuillets, nombreux, inégaux, droits, larges à la circonférence, n'adhèrent pas au pédicule; ils s'en écartent inème légèrement; blancs d'abord, ils se colorent plus tard faiblement en rouge-chair. Le pédicule est cylindrique, un peu renflé à sa hase, le plus souvent creux, haut de 5 à 8 centimètres, parfois flexueux, muni d'un anneau horizontal, large.

Il croit en juillet, août et en automne, dans les jardins, les vignes, les champs cultivés. Il est comestible, de qualité excellente; son odeur est faible, sa savemr agréable; son épiderme, assez épais, se détache farilement du chapean. 
Au premier aspect on prendrait ce champignon pour un Lepiota, à cause de ses feuillets blancs; plus tard ils deviennent incarnats, ot passent au fauve lorsque le champignon se décompose.

Ag. en demi-globe (Ag. semiglobatus), Batsch, fig. 110.

Som., t. 248. - curt., t. 14t. - rrer., t. 328. - Huss., I, t. 39. - Panl.,

t. 150, fig. 4, 5. - Fr., Eprim., 9000. - A\% nitens, Bull., t. 566, fig. t.

In chapean hemispherique, peu charnu, affoignant larement : centimètres, de forme semi-orbiculaire, sub-visqueux, luisant, d'un jaune pàle; des feuillets peu serrés, larges, planes, d'un noir nébuleux, coupés perpendiculairement vers le pédicule, auquel ils sont adhérents; un pédicule droit, grêle, long de 6 à 8 centimétres, d'un jaune très-pâle, fistuleux, glabre, ponctué de noir au sommet, légèrement bulbeux à sa base, pourvu d'un anneau membranenx : tels sont les signes auxquels on reconnait l'Ag. semiglobatus.

Cet agaric, très-commun du mois de mai au mois de décembre, vient le plus souvent en touffes, dans les prés et les parties découvertes des bois, sur le crottin de cheval surtout et le fumier.

Il est vénéneux, mais rarement il va donner la mort. On cite cependant une famille entière qui, en France, est morte pour en aroir mangé. Du reste, il est d'une trop petite dimension pour qu'on le recherche, et que l'on songe à en faire usage. A la rigueur, il peut être confondu avec l'Ag. campestris, puisqu'il vient quelquefois sur couche, mais sa forme et sa petite taille l'en distinguent essentiellement, et avec l'Ag. oreades, mais ce dernier a le pédicule dépourru d'anneau et les feuillets blanes. Il ressemble davantage à l'A $g$. stercorarius, Fr., dont il diffère surtout par son pédicule fistulenx, tandis que celui de l'Ag. stercorarius contient une espèce de moelle. Les propriétés de l'Ag. stercorarius n'ont pas été constatées.

Ag. des bois ( 4 g. sylvaticus), Schmff, t. 242.

Fr., Evire., sit. - 1y. tumesems, Viviani, t. :31.

Cet agaric, qui vient en automne dans les bois, est un de ceux qui ont une grande ressemblance avec l' $A g$. campestris. Viviani le dit pernicieux; il est au moins fort suspect. Une dame de ma connaissance fut incommodée pour en aroir mangé un seul pied, mèlé au champisnon de couche ordinaire (A $\%$. campestris). On le reconnaitra aux signes suivants : 


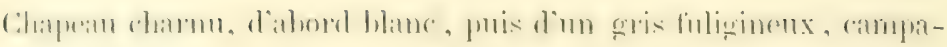

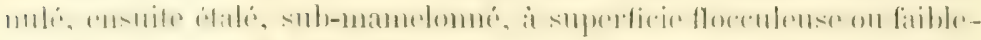

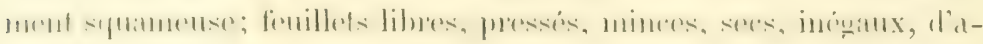

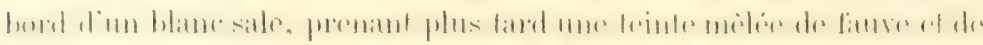

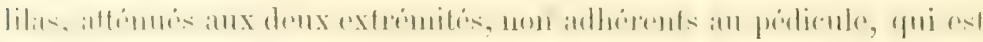
long de 6 à 8 centimètres, ferme, d'abord plein, ensuite sub-lacu-

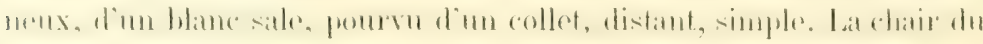

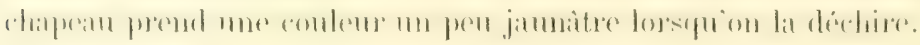

(1) levil forte.

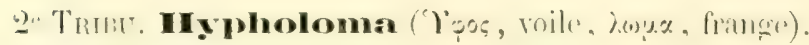

Tŕgument laissant une cortine ou des filaments aranéeux, adluérents it lit matree du chatpeatl.

Ag. en fascicule (1!) fasciculuris), Huds.

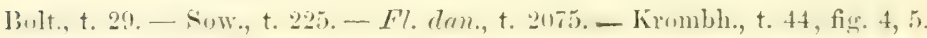

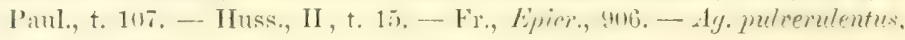
Bull., t. 178.

Chapeau charnu, mince, convexe, sub-mamelonné, glabre, large de \& à 6 centimètres et plus, de couleur jaunàtre, plus foncée au milieu; feuillets adnés, très-nombreux, atténués, étroits; sub-déiqquescents, de couleur de soufre ou fuligineux verdàtre, recouverts dans leur jeunesse par une membrane fugace; pédicule creux, mince, flexueux, fibrilleux, jaune, de mème que la chair du chapeau.

Commun en automne sur les vieux trones, les arbres tombés à terre. Odeur forle, saveur amère. Il ressemble assez à l'Ag. sublatebitius et à l'Ay. colcodes, dont il partage les propriétés pernicieuses.

Ag. rouge de brique pâle (Ag. sublateritius), Schæeff., t. 49, figg. 6, 7.

$$
\begin{aligned}
& \text { Junlw, t. ss. - Huss, I, t. 60. - Kromllh., t. 44, fig. 1-3. - Paul., t. } 149 .
\end{aligned}
$$

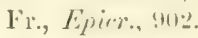

Cet agaric, qui est commun et rarement attaqué par les vers, a le chapeau charnu, convexe, large de 6 à 9 centimètres, à surface sèche, glabre, de couleur brique fauve, plus foncée au milieu, jaune ver's la marge, celle-ci étant repliée en dessous; les feuillets nombreux, inégaux, d'un blane olivacé ferrugineux, devenant noirâtres avec l'âge,

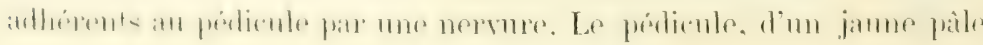


"n haut, de lit couleur du chapeau, presque toujours atténué at lat parlie inférieure, est cylindrique, le plus souvent plein, rarement droit, pourvu d'un collier, placé très-haut et composẻ de filaments fugaces, qui restent attachés à sa circonférence et à la marge du chapeau. Chair blanche.

Il vient en automne, au pied des arbres ou à terre, en groupes quelquefois très-considérables.

Dangereux. Il a incommodé des animaux sur lesquels on l'a expérimenté; rien du reste n'invite à en faire usage. La chair est compacte, l'odeur peu prononcée, la saveur désagréable, nauséabonde.

3e Tripu. Psillocybe ('yìis, mince, xúßr, tète).

$\mathrm{Ni}$ anneau ni cortine; chapeau convexo-plane, à marge primitivement recourbée.

Ag. calleux (Ag. callosus), Fr., Epicr., 939.

Buxb., c. 4, t. 15, fig. 1. - Pers., Myc., t. 27, fig. 3.

L'Ag. calleux est de petite dimension. Son chapeau, peu charmu, est conique, campanulé, obtus, lisse, glabre, see, résistant, large de 2 centimètres, de couleur variable, blanc jaunàtre, livide, avec des f'euillets adnés, ascendants, ventrus, serrés, d'un noir fuligineux; un pied glabre, nu, fistuleux, tenace, pâle, égal, grèle, presque filiforme, long de 5 à 6 centimètres. Il croit dans les gazons, le long des chemins, le plus souvent en groupes.

Cette espèce, dit M. Berkeley, est certainement délétère; mais heureusement sa faille est trop petite pour que l'on songe à en faire usage comme aliment.

$$
\text { 1re Tribu. - Psalliota (Pratelde). }
$$

Ig. érugineux (Ay. oruginosus), C'urt., Fl. Lond., t. 309. - Suw., t. 261. - Fr., Epicr., 891, - Krombl., t. 3, fig. 27, 28, et t. 62, fig. 11-14. - Huss., I, t. 35. - Ag. cyaneus, Bull., t. 170. - A terre et sur les trones d'arbres, dans les plaines couvertes de gazon etc.; commun.

Ag. blane bleuâtre (Ag. albo-cyaneus), Desm. - Pers., Myc., t. 29, fig. 1, 3. Fro, Epicr., 892, - Dans les gazons humides, les prés.

Ag. des champs (Ag. arvensis), Schrff. (décrit).

$\Lambda$. auguste (Ag. augustus), Fr., Epicr., 869. - Dans les bois, tres-rare. Suspect.

$\Lambda$ g. champêtre (Ag. campestrisi, Lin. (décrit).

Ag. crétacé (A\%. cretaceus), Bull. (décrit). 


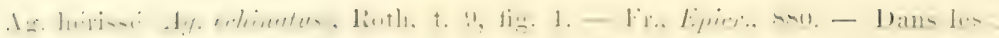
i.mlins it trime.

Ag. ì graines rouges (A\%. humatospermus), Bull., t. 595, fig. 1. - Krombl., t. 3, fig., 21. - Fr., Epricr., 879. - Dans les pâturages de la France méridionale.

Ig. à graine noire (Ay. melanospermus), Bull., t. 540, fig. 1. - Schæff., t. 51, Aff. pheospermus, Fr., Monogr., p. 413. - Dans les plaines et prairies, en automine.

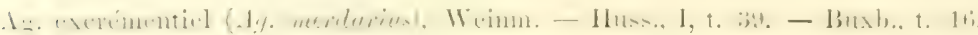
fig. 2. - Grev., t. 341. - Fr., Epicr., 898. - Sur les excréments desséchés rare.

Ig. ohturé (A\%. obturatus), Fr., Epicr., 894. - Dans les terrains argileux, au printemps et en automne; non rare.

Ig. semi-globuleux (Ag. semiglobatus), Batsch (décrit).

Ag. des prés (Ag. pratensis), Schæff., t. 96. Ag. spodophyllus, Krombh., t., 26, fig. 18-22. - Fr., Epier., 873; Monogr., p. 405. - Dans les prés et les bois. - Comestible. - Pour M. Léreillé, variété de l'Ag. campestris.

Ag. soyeux (Ag. setiger), Paul., t. 132, fig. 3, 4. - Fr., Epicr., 875. - Variété de l'ily. campestris, pour de Seynes. - Dans les bois ombragés, en automne. - 1 inne-atil,

Ag. écailleux (Ag. squamosus), Pers., Sym., p. 409. - Weinm. - Fr., Epicr., 896. - Fl. dan., t. 2077, fig. 1, 2. - Berkl., t. 10, fig. 6. - Sur les feuilles tombées, dans les bois, les jardins.

Ig. stercoraire (Ag. stercorarius), Fr., Elicr. 899. - Weinm. - Bull., t. 566 , fig. 4, - Sur les fumiers et la terre végétale.

Ag. saurage (Ag.syleaticus), Schæff. (décrit).

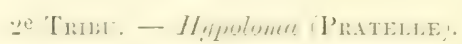

Ig. appendicalé (Ay. appendiculatus), Bull., t. 392. - Fr.s Epicr., 915. A\%. stipatus, Pers., Sym., no 310 . - En touffes, le plus souvent dans l'été et l'automnc, sur les troncs d'arbres pourris, les chemins des bois, dans les jardins.

Ag. de Candolle (Ay. Candollianus), Fr., Epicr., 914. - Fl.dan.,774. - Weinm., 1\%. violaceo-lamellatus, DC., no 406. - Au printemps, à terre, dans les lieux ombragés.

Ig. à lamelles olivâtres (Ag. celceodes), Fr., Epicr., 905. - Paul., t. 108. - Ag. amarus, Bull, t. 30. - Sur les trones d'arbres et à terre; odeur agréable, sareur très-amère. - Suspect.

Ag. épixanthe (Ag. epixanthus), Paul., t. 107. Fr. Epicr., 222. - Sur les troncs dituluis.

Ag. fasciculaire (Ag. fascicularis), Huds. (décrit).

Ag. hydrophile (Ag. hydrophilus), Bull., t. 511. - Paul., t. 110, fig. 1. - Fr., Epier., 916. - Dans les bois, sur les feuilles mortes, les trones, été et automne.

Ag. larmoyant (Ay. lacrymabundus), Bull., t. 194. - Fr. Epier., 911. - Sur la terre et les trones, été et automne.

Ig. piluliforme (Ag. piluliformis), Bull., t. 311. - Fr. Jonogr., p. 428. - Sur les trones, les raneaux mousseux et les feuilles tombées dans les bois.

Ag. silacé (Ag. silaceus), Pers, Syn., p. 307. - Fr., Epicr., 901. - A terre, sulitaire.

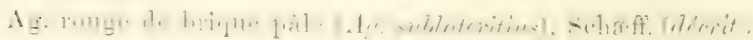


Ag̈. toisommé (A\% relutinus), Pers., Syn., 285. - Fr., Elricr., 912. - Berkl., t. 11, fig. 2. - Dans les graviers, le longdes chemins, dans une terre grasse, et même sur les trones d'arbres.

3e Tribu. - Psilocybe (Pratelle:.

Ig. des sables (Ay. ammophilus), Dur. et Lér. - Dans les sables maritines, isolé ou en groupes peu nombreux, dans le midi de la France, au printemps et en automne.

Ag. roux noir (Ag. atrorufus), Selhæff., t. 234. - Ag. montanus, Pers. - A terre, dans les bois gazonneux et dans les champs pierreux.

Ag. bulleux (Ag. bullaceus), Bull., 556, fig. 2. - Fr., Epier., 932. - Sur les fientes, le long des chemins, au printemps et à l'automne.

Ag. calleux (Ag. callosus), Fr. (décrit).

Ag. courbé (Ag. cernuus), Fl. dan., t. 1005. - Schæff., t. 205. - Fr., Epicr., t. 921. - A terre, sur les feuilles, les bois pourris, ordinairement en touffes, au printemps.

Ag. coprophile (Ag. coprophilus), Bull., t. 566, fig. 3. - Fr., Epicr., 931. - Au printemps, dans les terres fumées et les pâturages, au bord des chemins.

Ag. de la fenaison (Ag. focnisecii), Pers., Icon., t. 1, fig. 1.-BerkI., t. 11. fig. 5. - Huss., I, t. 39. - Fr., Epicr., 925. - En automme, sur Ies pelouses, dans les champs, les jardins.

Ag. phœnix (Ag. phonix), Mich., t. 73, fig. 1. - Fr., Epicr., 918. - Sur la terre fumée.

Ag. physaloïde (Ag.physaloides), Bull., t. 366, fig. 1. - Fr., Epicr., 933. - Paul., t. 99, fig. 7. - Sur les fientes, le long des chemins, au printemps et dans les lieux où crompissent les eaux, pendant l'hiver.

Ag. tête charnue (Ag. sarcocephalus), Fr., Epicr., 929. - Paul, t. 106. -- Sur la terre, dans les bois, les gazons; rare.

Ag. bai-gris (Ag. spadiceo-griseus), Schæff., t. 337. Fl. dan., t. 1673. - Fr., Epicr., 947. - Bull., t. 511. - Sur les trones et près des trons, dans les bois.

Ag. spadicé (Ag.spadiceus), Schæff., t. 60, fig. 4-6. - Fr., Elicr., 920。 - A terre, entre les feuilles, au bas des trones.

Ag. tégulaire (Ag.tegularis), Schum. - Fl. dan, t. 1958. - Fr., Epicr., 938. Sur les terres gazonnées.

Ag. des marais (Ag.udus), Pers., Syn., no 295. - Fr., Epier., 930. - Dans les marais tourbeux.

4e Tribu. - Pscithyoa. (Pratelle). - (!x)upos, fragile.)

Ni anneau, ni cortine; chapeau campanulé, à margo primitivement droite.

Ag. tête conique (Ag. conophilus), Fr., Epicr., 941. - E'. conocephalus, Bull., t. 365. - En novembre, sur les pelouses, dans les jardins.

גg. froncé (Aq. corrugis), Pers., Syn., p. 313. - Fx., Epier., 942. - Ay. pellospermus, Bull., t.561, fig. 1. - Dans les jardins et les forêts ombragées.

Ag. fibrilleux (Ag. fibrillosus), Pers., Syn., no 314. - Fr. Epicr., 952. - Dans les bois humides, à terre, entre les feuilles tombées, rarement sur les arbres.

$\Lambda$ g. pied flexueux (Aq. gyroflexus), Paul., t. 123, fig. 4. - Sehæff., t. 212. - Fr., Eprov, 940. - Daus les gazons humites, sur les racines des arines. 


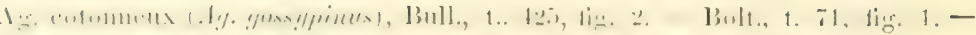

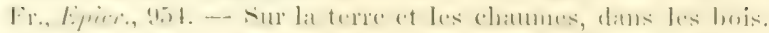

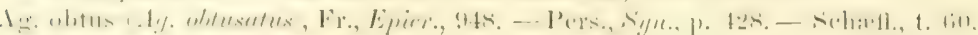

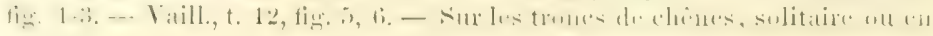
toutles.

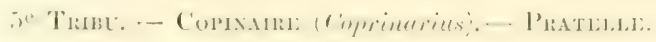

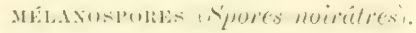

Fenillets nélouleux, un devenant ni fanves ni purpureseents: un pen déliquescents; pied fistuleux; distinct du chapeau.

Les Coprinaires tiennent le milieu entre les Pratelles et les Coprins.

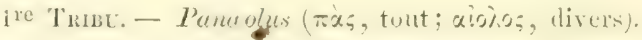

Chapeau peu charnu, strié, à marge excédant d'abord les feuillets, qui sont

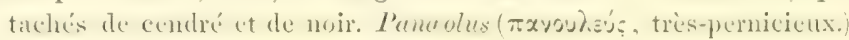

Ig. en pointe (Ay. acuminatus), Batt., t. 22, F. - Fr., Elicr., 967. - Sur le gazon, le bord des chemins.

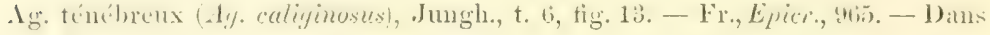
les champs.

Ag. en cloche (Ag. campanulatus), Lin. - Bull., t. 561, fig. 2. - Fr., Epicr., 96. - Sur les terres fumées et les gazons, en automne.

Ag. du fumier (Ag. fimicola), Fr., Elicr., 968. - Bolt., t. 66, fig. 1. - Dans les pâturages, sur les fientes d'animaux, au printemps et en été; rare.

Ig. du terreau (Ag. fimiputris), Bolt., t. 57. - Batt., t. 28, fig. P. - Berkl., t. 11, fig. 6. - Bull., t. 66. - Au printemps et en automne, sur les fumiers, le terreau, la fiente des bêtes de somme.

Ag. papillionacé (Ag. papilionaceus), Bull.. t. 561, fig. 2. - Fr., Epior., 964. Au bord des chemins, sur le fumier et les feuilles mortes, été et automne; commun.

Ag. des phalènes (Ag. phalanarum), Bull., t. 58. - Paul., t. 121, fig. 1. - Fr., Epicr., 959.-Sur le fumier. - Cet agaric serait, selon Seynes, une variété de I'Ag. papilionaceus.

Ag. à amneau distant (Ag. separatus), Lin.- Fr., Epicr., 957. - Bolt., t. 53. Berkl., t. 11, fig. 7. - Ag. nitens, Bull., t. 84. - Commun sur les fumiers.

2e Tribu. - Psathyrella (广aOupos, fragile).

Chapcau membraneux, à bord n'excédant pas les feuillets, qui sont unicolores. Espèce de petite dimension.

Ag. poudré (Ag. atomatus), Fr., Epicr., 977. - Sur le bord des chemins, les gazons.

Ag: tigellé (Ag. caudatus), Fr., Epicr., 975. - Paul., t. 124, fig. 1, 2. - Dans les jardins et les terres fumées; n'incommode pas les animaux.

Ig. disséminé ( $\boldsymbol{A} g$. disseminatus), Pers., Schæff., t. 308. - Sow., t. 166. - Ag. digitaliformis, Bull., t. 22 et 525, fig. 1. - Croît par milliers sur les vieilles souches. Bien qu'il soit comestible, sa taille le fera toujours dédaigner.

Ag. grêle (Ag. gracilis), Fr., Epier., 970. - Dans les broussailles exposées à l'hmmidite ct las giknns, anl printemps. 


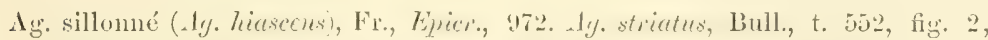
F. $\left(\frac{6}{4}\right.$.

Ag. hydropique (Ay.hydrophorus), Bull., t. 558, tig. 2. - Fr., Épicr., 964. - Dans les jatrdins.

Ag. sombre (1y. subatiatus), Batsel, fig. 89. - Fr., Epricr., 969. - Dans 1es gazons des jardins; non nuisible.

Ag. subtil (Ay. subtilis), Fr., Hyicr., 980. - I'ers., Hye., t. 26, fig. 1. - Iu printemps, sur le fumier de brebis, de chèvres etc.

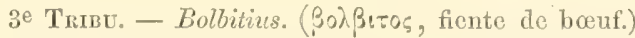

Feuillets d'abord adhérents au pellicule, devenant humides, mais non liquescents : pied fistuleux.

Genve pour quelques auteurs.

Ag. Bolb. de Bolton (Ag. Bolb. Boltonii), Fr., Epricr., 2. - Ay. flavidrs, Bult., t. 149. - Sur le fumier, les tas de feuilles.

Ag. Bolb. fragile (Ag., Bolb. fragilis), Lin. - Fr., Epicr., 3. - Bolt., t. 65. Sow., t. 96. - Au bord des chemins.

Ag. Bolb. jaunâtre (A\%.luteolus), Lasch, no 591. - Fr., Epror., 5. - Sur le gazon des jardins.

Ag. Bolb. chancelant (Ay. Bolb. titubans), Bull., t., 425, fig. 1. - Sow., t. 128. - Fr., Epicr., 4. - Sur la terre ct les feuilles mortes, dans los bois.

Ag. Bolb. jaune d'ouf (Ag. Bolb. vitellinus, Pers., Syn., 272, - Fr., Epicr., 1. Sur le fumier.

\section{SÉRe VII. - GORTINIIRE (Cintinaria).}

(Cortina, tapisserie.)

Fenilde membanenx, pexistant, qui se decolorent en se dexsichant, mais ne noircissent pas; recouverts dans leur jeune âge d'un tégument aranécux, qui laisse des debris, et parfois une cortine on collier filamenteux sur le pédicule. Genre pour quelques auteurs.

Aucune espèce de Cortinaire n'est signalée comme malfaisante; toutes cependant ne poumaient pas servir de nourriture, car plusieurs sont amères.

Les Cortinaires ressemblent aux Pratelles; mais, dans les Pratelles, les feuillets noircissent toujours, ce qui n'arrive pas dans les Cortinaires.

Ochrospores. Spores ochracées.

fre Thut Continaine (type,

Cihapeau convexo-plane; lamelles simples, non décurrentes. 


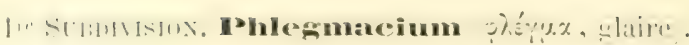

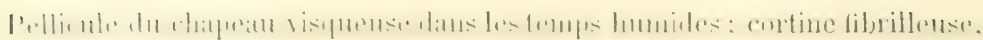

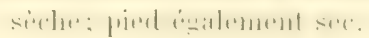

Ag. (Cort.) turbiné (Ag. Coint. turbinatus), Bull., t. 110.

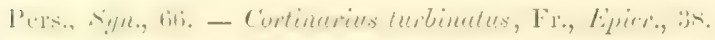

C'cst dans les bois omlragés, les bois de hètres surtout, on été et en

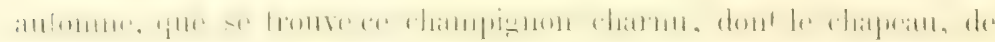
couleur furve pàle, est large de 10 à 12 contimètres, d'abord convexe, puis plan et enfin un peu déprimé, lisse, visqueux et sub-hygrophane par les temps humides. Ses feuillets, nombreux, serrés, tries-entier's, sont terminés en pointe aux deux extrémités, légèrement jimmâtres, puis de couleur baie. Le pédicule, épais, bulbeux à la base, plein, long de 10 à 15 centimètres, blanc ou jaune-paille, glabre, est pourvu d'un collet fugace, aranéeux.

Sa chair, blanche, molle, se pèle assez facilement.

Il est très-agréable au goùt et à l'odorat, dit Bulliard; il semble done qu'on pourrait en manger sans inconvénient.

Réveil néanmoins le tient pour suspect.

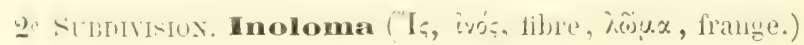

Cilsapeau charnu, sec, soyeux dès le jeune âge, avec des écailles ou des fibres innées; pied charnu, subbulbeux.

Ag. Cort. important (Ag. Cort. proestans), Cordier.

Champignon de grande taille, ayant le chapeau large de 12 à 14 contimètres, charnu, convexe, orbiculaire, sub-satiné, de couleur marron violacé, à bord légèrement recourbé en dessous dans la jeunesse; les fouillets inégaux, peu larges, nombreux, se terminant en rond près du pédicule, arec un petit prolongement en crochet. Leur couleur, d'abor'd blanchàtre, passe au café au lait clair, ou plutòt au cendré clair; le pédicule, fibreux à l'intérieur, blane, ferme, cylindrique, quelquefois sinueux, grossi et presque bulbeux à la base, sub-séricécux, long de 12 à 14 centimètres, large de $21 / 2$ centimètres, pourvu chez les jeunes individus d'un voile aranéeux, blanchâtre, qui disparait chez les individus adultes.

Il croit solitaire ou en groupes peu nombreux, dans les bois, à terre,

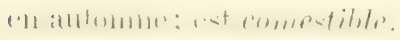




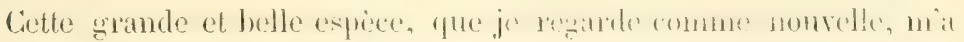
été signalée comme alimentaire par M. Mayeur, percepteur à Ancerville (Meuse). Son odeur est faible, sa saveur un peu prononcée, sa chair d'un blanc terne.

Ag. (Cort.) violacé cendré (Ag. Cort, violaceo-cinereus), Pers., Syn., 1. 279.

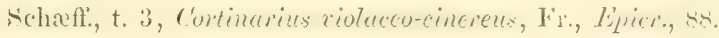

Cie champignon ressemble beancoup au violaceus; comme celui-ci, il est comestible. Il se trouve dans les bois touffus, presque tonjours solitaire. Le chapeau, charnu, convexe, violacé pourpré ou violacé cendré, est couvert de gramulations ou de squames cendrées. Les feuillets, adnés, larges, peu serrés, pourprés, deviennent de couleur cannelle. Le pied, bulbeux, plein, ferme, plus pàle que le chapeau, un peu tomenteux, est muni d'un voile aranćeux, qui disparait bientòt.

Il n'a pas de saveur et son odeur est peu sensible. La chair du chapean est d'un blane sale; celle du pédicule d'un violet rougeâtre. Belle espèce; assez rare.

Ag. (Cort.) violacé (Ay. Cort, violaceus), Lin.

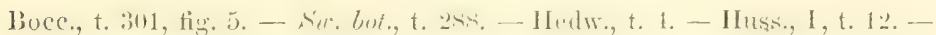
Ag. araneosus violaceus, Bull., t. 250 et 598, fig. 2. - Ag. violaceus, Pers.,

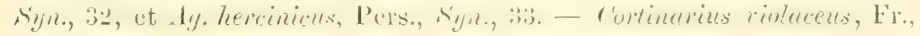
Epicr., 85.

L'Ag. violaceus est charnu, tout entier d'un violet obscur, son chapeau, d'abord convexe, ensuite plan, sec, velu, comme squameux, cos large de 8 à 16 centimètres. Les fenillets, distants, larges, épais, inégaux, presque d'un noir violacé dans le jeune âge, adhèrent au pédicule, qui est cylindrique, plus ou moins renflé à sa base, subtomenteux, large de 8 à 10 centimètres, d'un vivlacé cendré à l'intérieur. Dans la jeunesse, une membrane, si lâche qu'elle semble une toile d'araignée, lie les bords du chapeau au pédicule.

Il croit en aout, septembre et octobre dans les bois. Est comestible. 


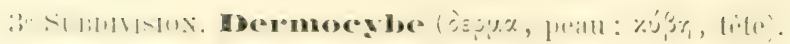

Chapeau mince, d'abord soyeux, ensuite glabre; pied creux, non bulliens.

Ag. (Cort.) cannelle (Ay. Cort. cimamomeus), Lin.

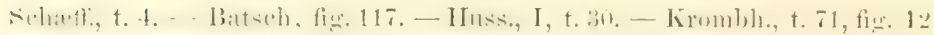
ì 15. - Letell., t. 652. - Vaill., t. 12, fig. 12-14. - Bolt., t. 156. - Sow., t. 205. - Cortinarius cinnamomeus, Fr., Epier., 120.

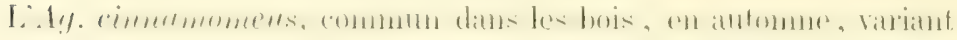
de forme et mème de couleur, a le chapeau charnu, mince, obtus, mamelonné, large de 6 à 8 centimètres, de couleur cannelle claire, d'abord soyeux ou légèrement squamenx, et enfin glabre; les feuillets, adnés, fixés au pédicule par une espèce de dent, larges, serrés, brillants, quelquefois rougeâtres; le pédicule d'abord plein, puis creux, mince, cylindrique, jaunâtre, de mème que le voile, qui est aranéeux; l'odeur aromatique. Comestible; chair jannutre.

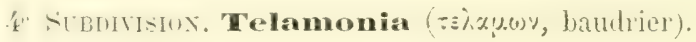

Pied pourvu d'une espèce de voile aranéeux, formant un anneau ou des squanes flocconneuses; chapeau hygrophane.

Ag. (Cort.) à bracelet (Ag. Cort. armillatus), Fr., Epicr., 143.

IIuss., I, t. 19. - Paul., t. 140, fig. 1, 2. - Ag. notatus, Pers., Syn., 7 !. - Ag. aimatochelis, Bull., t. 527, fig. 1, et t. 596, fig. 1.

Cet agaric a le chapeau peu charnu, d'abord convexe, puis plane, large de 8 à 10 centimètres, à surface sèche, fauve clair, et recourate de petites écailles fibrilleuses; les feuillets couleur de rouille ou cannelle pâle, inégaux, peu serrés, arrondis à la base, non décurrents ; lo pédicule, plein, cylindrique, légèrement renflé à sa base, long de 8 ì 9 centinètres, soyeux, fibrilleux, de la couleur du chapeau, marqué duns le milieu de sa longueur d'une tache rouge circulaire. Dans la jeunesse, les feuillets sont recouverts d'un collier aranéeux.

Il croit a terre, ordinairement solitaire dans les bois, surtout dans les bois de liètres, à la fin de l'été et en automne, est comestible, a l'odeur faible, la chair d'un blanc sale, le chapeau facile à peler. 


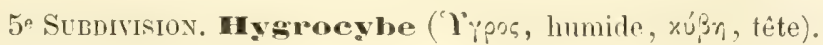

Pied n’ayant ni anneau ni squames floconneuses, séparé du chapeau par une cortine fibrilleuse, mince, adhérente à la marge du chapeau.

Ag. (Cort.) châtain (Ag. Cort. castaneus), Bull., t. 268, et t. 527, fig. 2.

Holmsk., 2, t. 37. - Pers., Syn., 75. - Cortinarius castaneus, Fr., Epicr., 186.

Ce champignon alimentaire, inodore, de saveur agréable, se trouve assez communément en été et en automne, dans les bois, sur la terre nue, en touffes peu considérables.

Son chapeau de couleur marron ou fauve, ordinairement plus pâle sur les bords, est lisse, peu charnu, large de 4 à 5 centimètres, convexe, légèrement mamelonné, souvent concave dans la vieillesse par le redressement des bords, qui alors se fendillent. Ses feuillets sont inégaux, larges, adhérents au pédicule, de la couleur du chapeau, plus páles sur leur tranchant. Le pédicule, long de 3 à 4 centimètres, plein, cylindrique, ferme, de couleur blanche, nuancée de brun violacé, porte les vestiges d'un collier, aranéeux, blane, peu apparent.

Porphyrospores. Spores d'un brun pourpre.

2. Tribu. Gomphidius (royos, gros clou, de sa forme).

Champignon en forme de cône renversé; lamelles décurrentes, légèrement branchues, à bord aigu; hyménophore se continuant avec le pédicule; voile aranéeux.

Genre pour quelques auteurs.

Ag. (Gomph.) visqueux (Ag. Gomph, viscidus), Lin.

(Pl. XXIII.)

Schæff., t. 55. - Sow., t. 105. - Krombh., t. 4, fig. 1-3. - Letell., t. 603 Lq. Cromplues, P'ers., Ieon., t. 13), fig. 1-3; id., Sym., 61. - Gomplidines viscidus, Fr., Epier., 2.

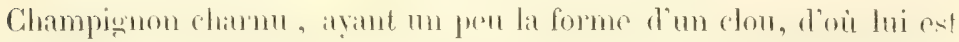
venu le nom de Gomphus ou Gomphidius, imposé par quelques anteurs. Le chapeau, roux fauve ou vineux pàle, large de 6 à 7 centimètres, successivement conique, convexe, plan, est arrondi, mamelonné, sub-visqueux, à bords légèrement recourbés en dessous dans le jeune âge. Les feuillets, un peu plus foncés en conleur que le chapeau, sont distants, droils, decurronts sur un pédicule, plus pale que 


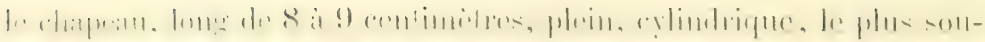

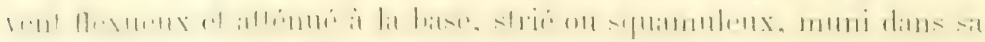

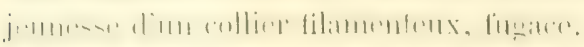

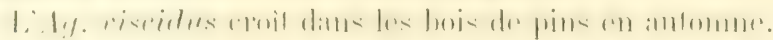

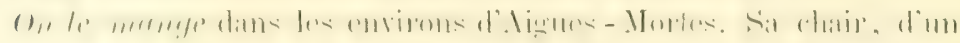
blane roussitre, coriace et nullement délicate, se pèle facilement.

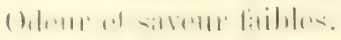

$$
\text { fre Thuв: - Phegmarizur. }
$$

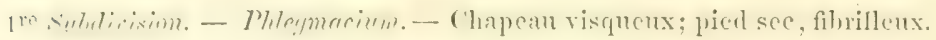

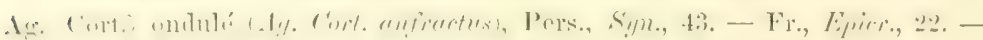
1)ans les bois touftus, les lieux humides couverts de paille.

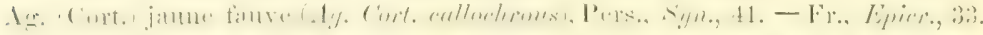

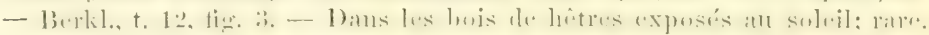

Ag. (Cort.) priđé (Ag. Cort. caperatus), Fr., Epicr., 1. - Fl. dan., t, 165. Dans les bois.

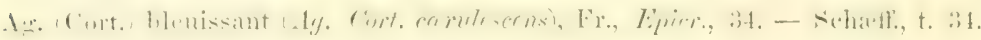
- Dans les bois.

Ag. (Cort.) cristallin (Ag. Cort. cristallinus), Fr., Epricr., 51. - Batsch, fig. 11. - Dans les bois de hêtres; rarc.

$\Lambda$. (Cort.) rent de mer (Ag. Cort. ermatilis), Fr., Epicr., 47. - A $\%$. crocco-coruleus, Pers., Ieon. pict., t. 1, fig. 2. - Dans les bois touffus; rare.

$\Lambda$. (Cort.) brillant ( $\boldsymbol{A g}$. Cort. fulgens), Alb. et Schw. - Scheff., t. 24. - Letell., t. 646. - Fr., Epricr., 40. - Dans les bois de pins, les bois touffus.

Ag. (Cort.) glauque (Ag. Cort. glaucopus), Schæff., t. 53. - Fr., Epicr. 31. Dans les bois de pins de plaine.

Ag. (Cort.) à bord fléchi (Ag. Cort. infractus), Pers., Sym., 283. - Dans les bois ombragés.

Ag. (Cort.) tacheté (Ag. Cort. maculosus), Pers., Sym., no 55. - Fr., Epricr., 5̌5. - Dans les bois de pins; rare.

Ag. (Cort.) miltiforme (Ag. Cort. multiformis), Fr., Epicr., 25.-Dans les bois. $\Lambda$. (Cort.) navet (Ag. Napus), Fr., Epier, 27. - Dans les bois de pins.

Ag. (Cort.) gracicux (Ag. Cort. percomis), Fr., Epier., 15. Dans les bois de sapins.

Ag. (Cort.) purpurin (Ay. Cort. purpurascens), Fr., Epicr., 35. - Dans les taillis.

Ag. (Cort.) turbiné (A g. Cort. turbinatus), Bull. (décrit).

Ag. (Cort.) varié (Ag. Cort. varius), Schæff., t. 42. - Fr., Epicr., 9. - Dans les bois de pins des pays de plaines.

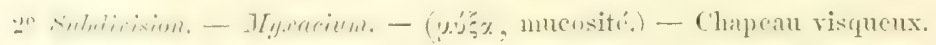

Ag. (Cort.) picd chaussé (Ag. Cort. alutipes), Larch. - Lin., no 303. - Fr., Eyrier., 65. - Dans les bois.

Ag. (Cort.) muquetux (Ag. Cort. collinitus), Pers., Syn., 39. - Buxb., t. 9. -Sow., t. 9. Fr., Epier., 69. - Ag. mucosus, Bull., t. 549, fig. D, F, et t. 596. - Krombh., t. 3, fig. 5, et t. 73, fig. 13-15. - Dans les bois et les bruyères; est mangé à Brescia.

$\Lambda$ g. (Cort.) amptipe (Ay. Cort. elatior), Pers., Syn. - Fr., Epricr., 69. - Dans les loris.

A.. (Cort.) luisant (1g. Cort. nitidus), Sehæff., t. 97. - Sow., t. 126. - Fr.,

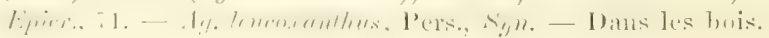


Ag. (Cort.) couleur de la mer (A\%. Cort. saitor), Fr, Epirr., 74. - Dans les bois de haute futaie.

$\Lambda \mathrm{g}$. (Cort.) scintillant (Ag. Cort. vibratilis', Hr., Eipiry, 79. - Sous Ies hêtres.

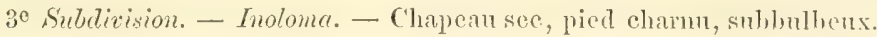

$\Lambda$ g. (Cort.) violet blanchâtre (Alg. ('ort. albo-rivlaceus), Pers., Sym., no 49. Frr, Epicr., 89. - Dans les bois fourrés

Ag. (Cort.) sablé (Ag. Cort. arenatus), Pers., Syn., no 65. - Bull., t. 586. Huss. I, t. 72. - Fr., Epicr, 103, - Dans les bois mélangés des montagnes.

Ag. (Cort.) argenté (Ag. Cort, argentatus), Pers., Syn., no 39. - Krombh., t. 2, fig. 27. - Fr., Epicr., 84. - Dans les bois; rare. - Est peut-être une variété de l'Al\%. albo-riolacens.

Ag. (Cort.) bolaris (Ag. Cort. bolaris) Pers., Syn. et Icon. pict., t. 14, fig. 1. Fr., Epicr., 99.

Ag. (Cort.) de Bulliard (Ag. Cort. Bulliardi), Pers., Syn., no 56. - Bull., t. 431, fig. 3. - Fr. Epicr., 97. - Dans les bois. touffus.

Ag. (Cort.) bleuâtre (Ag. Cort. cyanites), Secret., no 147. - Ag. cyaneus, Pers. Syn., no 30. - Dans les bois humides, plantés de hêtres.

Ag. (Cort.) important ( $\boldsymbol{A g}$. Cort. prestans), Cordier (décrit).

Ag. (Cort.) odeur de bouc (Ag. Cort. traganus), Fr., Epricr., 93, - Schæff., t. 56. - Dans les bois de pins des montagnes.

Ag. (Cort.) violet condré (Ag. Cort. violaceo-cinereus), Pers. (décrit).

Ag. (Cort.) violet (Aq. violaceus), Lin. (décrit)

4e Subdivision. - Demneybe. - Chapean see, sub-strić; pied extériemenon: rigide, creux, non bulbeux.

Ag. (Cort.) anomal (Ag. Cort. anomalus), Fr., Epicr., 115. -Bull., t. 431, fig. 3. Berkl., t. 12, fig. 4. - Ag. eumorpleze, Pers.g Sym., p. 342. - Dans les endroits retirés des montagnes, des bois ete.

Ag. (Cort.) collier aranéeux (Ag. Cort. arachnostrepluss), Letell., Suppt., t. 617.

Ag. (Cort.) tortueux (Ag. Cort. camurus), Bull., t. 431, fig. 4. - Fr., Epicr., 109. - Dans les bois coupés.

Ag. (Cort.) du chien (Ag. Cort. caninus), Fr., Epicr., 111. - Bull., t. 544. Buxb., t. 22. - Dans les bois

Ag. (Cort.) à tête luisante (A\%. Cort. lamprocephalusu), - Bull., t. 544, fig. 2. Ag. lucidus, Pers., Syn., 78.

$\Lambda$ g. (Cort.) couleur de cannclle (Ag. Cort. cimnamoneus), Lin. (décrit),

Ag. (Cort.) blane ochracé (Ag. Cort. ochroleueus), Fr., Epicr., 105. - Dans les bois de chênes: rare.

Ag. (Cort.) orellan (Aq. Cort. orellanus), Fr., Epicr., 121. - Dans les bois; rare - Ag. purpureus, Bull., t. 598.

Ag. (Cort.) raphanoïde (Ag. Cort. raphanoides), Pers., Sym., no 123. - Fr. Epicr., 128. - Dans les bois.

Ag. (Cort.) sanguin (Ag. Cort. sanguineus), Wulf. - Fr., Epicr., 119. - Sow. t. 143. - Bolt., t. 56. - Sur les trones muusseux et sur la terre

Ag. (Cort.) mąqueté (Ag. Cort. subnotatus), Pers. Syn., no 71. - Fr., Epier. 126. - Bull., t. 700, fig. Z, Y. - Dans les bois; rare.

Ag. (Cort.) couleur d'airain (A\%. 'ort. tabularis), lis, Epicr., 108. - Bull., t. 431 fig. 5, - Dans les bois

Ag. (Cort.) des marais (Ag. Cont. uliginosus), Berk1., Dutl.,31. - Dans les marais. sur les splaignes. 


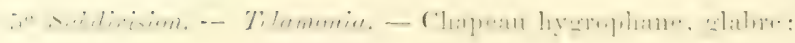
cortine amulifurme.

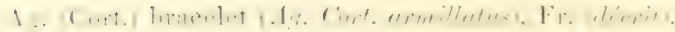

A. (Cort.) ì roile double (A\%.Cor. birelus), Fr., Epicr., 133. - Dans les bois de bouleaux des montagnes.

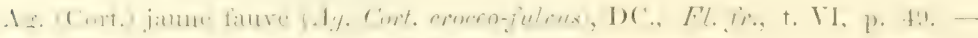
Fr., Epior., 145. - Dans les bois du Midi.

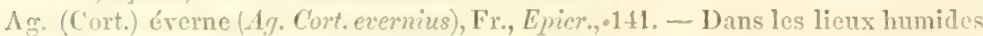
et montueux.

1g. (Cort.) grisâtre (Ay. Cort. helvolus), Bull., t. 521, fig. 1. - Fr., Epier., 147. - Dins les bois.

Ig. (Cort.) fron ( 1 g. Cort. Tinnuleus), Sow., t. 173. - Fr., Epicr., 148. - Ay. helrolus, Pers., Obs., et Il\% punctutus, Pers., Sym. - Bords des hois et des champs.

Ag. (Cort.) demi-chevelu (Aq. Cort. hemitrichuss), Pers., Syn., nº 72. - Fr., Epicr. 166. - Parmi les fenilles tombées et les monsses.

Ag. (Cort.) pied grêle (Af. Cort. ileopolizes), Fr., Epier., 165. - Bull., t. 578 et 586, fig. 2, A, B. - Dans les bris de hêtres, en automne.

Ag. (Cort.) incisé (A $\%$. Cort. incisus), Fr., Eprer., 164. - Bull., t. 586, fig. 2. A terre.

Ag. (Cort.) limonius (Ag. Cort. limonius), Fr., Eipicr., 146. - Holmsk., t. 40. Dans les bois de pins.

Ag. (Cort.) pied rêtu ( $\mathbf{1}$ g. Cort. licinipes), Bull., t. 600, fig. X, IT, T. - Fr., Epier., 136. - Dans les bois de sapins des montagnes.

$\Lambda \mathrm{g}$. (Cort.) ̀̀ tête grenue (A\%. Cort. psammocephalus, Bull., t. 531, fig. 2. - Fr., Evicr., 163. - Dans les bois; commun.

Ag. (Cort.) imposant (Ag. Cort. torrus), Fr., Epicr., 137. - Krombh., t. 73, fig. 19-21. - Ag. araneosus, Bull., t. 600, fig. Q, R, S. - Dans les bois.

Ge Sublivision. - Hygrocybe. - Chapeau hygrophane, glabre; cortine fibrilleuse, mince, fugace.

Ag. (Cort.) aigu (Ag. Cort. acutus), Pers., Sym., 107. - Fr., Epicr., 212. - Dans les lieux humides des bois. Espèce douteuse.

Ag. (Cort.) couleur d'abricot (Ag.Cort. armeniacus), Schæff., t. 81. - Fr., Epicr., 171. - Très-beau daus les bois de pins, moins remarquable ailleurs.

Ag. (Cort.) châtain (Ag. Cort. castaneus), Bull. (décrit).

Ag. (Cort.) quenouille (A $g$. Cort. Colus), Paul., t. 99. - Fr., Epicr., 188. - Dans les buis.

Ag. (Cort.) à bandelette (Ag. Cort. fasciatus), Fr., Epier., 216. - Ag. sidaroides, Bull., t. 588. - A terre, dans les bois.

Ag. (Cort.) ferme (A . Cort. firmus), Fr., Epier., 169. - Bull., t. 96. - Dans les bois ombragés; rare.

Ig. (Cort.) éclatant (4g. Cort. jubarinus), Bull, t. 431, fig. 1. - Fr., Epier., 195. -Dans les bois de pins ete.

Ag. (C'ort.) pied blane (Ag. Cort. leucopus), Fr., Epior., 203. - Ag. leucopodius, 13ull., t. 533, fig. 2. - Au printemps, daus les bois

Ag. (Cort.) sous-fermgincux (A\%. Cort. subfermuineus), Batsch. - Fr., Eprer., 171 
2e Trist: - Gompleres.

Chapean en forme de clou, se continmant avec le pédicule; fenillets décurrents, sul)-rameux.

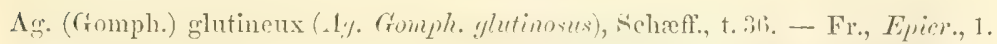
- Ietrll., t. lit7. - Sow., t. 7. - Dans les bois le pins. Comestible. Schummel le dit dangereux.

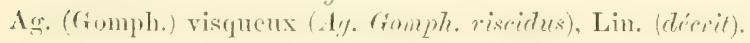

\section{SÉrte IX. - COPRIN (Compimms).}

(Kómpos, excrément.)

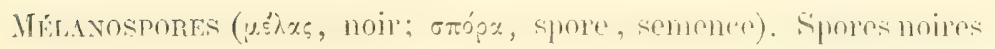

Absence de volva; chapeau peu charnu ou membraneux; feuillets plus ou moins dèliquescents, se fondant en une eau noire; pédicule nu ou pourvu d'un collier, presque toujours fugace, aranéeux; pied fistuleux.

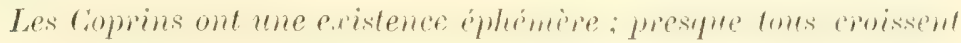
sur le fumier ou les terres riches en engrais.

Chapeau peu charnu ou membraneux; feuillets minces, se liquéfiant en une eau noirâtre; stipe fistuleux; champignons généralement. grêles; spores noires. Coprin. Genre pour quelques auteurs.

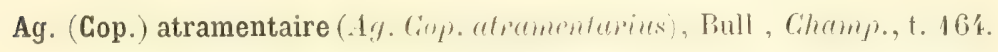

Vaill., Pot., t. 12, fig. 10, 11. - Fl. dun., t. 1370. - Bult., t. 54. - Sow., t. 188. - Schrff., t 67, 68. - Paul., Champ., t. 129. - Coprinus atramentarius, Fr., Epier., 7.

Ce Coprin a le chapeau à peine charnu, presque membraneux, d'abord globuleux, ovale, puis en cloche allongée, large de 5 à 7 centimètres, à bords sinueux et striés, d'abord blane, puis jaunâtre ou fauve pâle, parsemé au sommet de petites taches roussâtres ou bmues; les feuillets inégaux, nombreux, presque tous de même longueur, libres, primitivement blancs, puis d'un pourpre fauve, et enfin noirs; le pédicule lisse, blane, creux; long de 12 à 18 centimètres, épais de 6 millimètres, attenué à sa partie supérieure, où il conserve une empreinte circulaire, vestige d'un anneau fugace.

Il croìt communément en été et en automne, danis les prés, les hois, les jardins, par groupes formés quelquefois de trente ou quarante individus. 


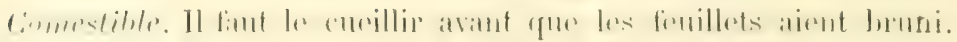

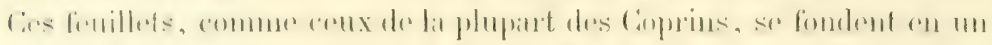

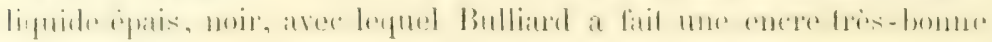
pour le lavis; elle porte sa gomme.

En général, les Coprins sont comestil)les dans leur jeune âge; rien mème ne prouve qu'il y en ait de malfaisants ${ }^{1}$. Les grandes espèces seules sont à rechercher; en Angleterre, elles servent à la préparation du ketchuop.

Observation. L'eau de l'Ag. micacens, Bull., t. 246 et 565, efface l'écriture faite arec de l'encre ordinaire; le suc de l'Ag. atramentavius l'efface également, mais moins bien que l'A $g$. micaceus.

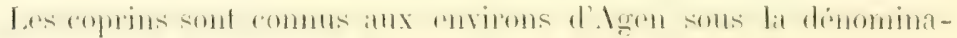

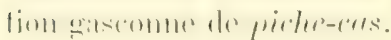

Ag. (Cop.) chevelu (.1\%. (in) comalus), Batt., t. 26, fig. B.

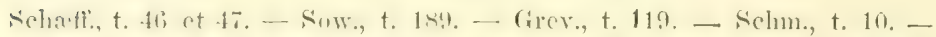

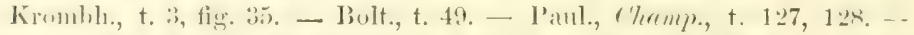

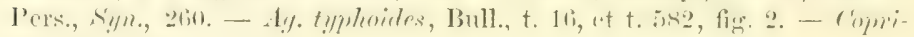
nus comatus, Fr., Epicr., 1.

Simm melyuiere: Quinal d'azé.

Ce champignon, à peine charnu, blanc, avec une teinte légèrement. lilacee ou rousse au sommet, a le chapeau d'abord oroïde, puis cylindrique, même étalé, strié sur ses bords, qui se déchirent et se relèvent, couvert de squames ou peluches nombreuses, larges, soyeuses, allant du sommet à la base, et disposées presque circulairement; ce chapeau acquiert promptement 7 à 8 centimètres de diamètre. Les fenillets sont nombreux, libres, linéaires, presque tous entiers, d'un blanc purpurescent d'abord, puis vineux et enfin noirâtres, et se dissolvant en une matière noire. Le pédicule, blanc, fistuleux, cylindrique, long de 12 à 15 centimètres, atténué à son sommet, pourvu d'un anneau mobile, est un peu renflé à la base, qui se termine par un prolongement en forme de racine.

Il croit en touffes, à la fin de l'été et en automne, dans les bois, les jardins, et en général dans les terrains gras.

Quelques personnes le trouvent très-délicat; il est d'un usage vul-

${ }^{1}$ l'anlet dit cependant que le ropminus fuscesens, Fr., Epicr., 24t, et l'd\%. rufo-candidus, Schrft.; Paul,, t. 125, fig. 1, ayant les feuillets noirs, sont rejetés un vomisomit gar les ehiens, mais sans oceasionmer la mort. 
gaire en Angleterre et aux environs de Lueques; dans les pays rui environnent Toulouse, on le mange frit à la poêle. Il faut le cueillir avant qu'il soit épanoui, et le manger immédiatement, car, du jour au lendemain, comme du reste tous les Coprins, il se décompose en une eau noire, que l'on peut utiliser pour le dessin el le lavis; cette eau est mème plus abondante dans l'Ag. comatus que dans l'Ag. atramentarius.

Ag. (Cop.) it encre (Ay. Cop. atrementarius), Bull. (drerit).

Ag. (Cop.) chevelu (Ag. Cop. comatus), Batt. (dicrit).

Ag. (Cop.) cendré (Ag. Cop. cinereus), Schæff., t. 100 et t. 201. - Fl. dan., t. 1195. - Variété de l'(1\%. timetarins).

Ag. (Cop.) entassé (Ag. Cop. congregatus), Bull., t. 94. -Paul., t. 123, fig. 7, 8. - Fr., Epicr., 30. - A terre, au bord des chemins; est mangé par les

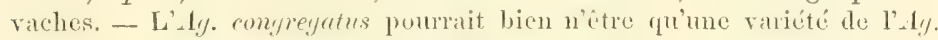
micaceus, de Bull. (note inédite de Persoon).

Ag. (Cop.) déliquescent (Ag. Cop. deliquescens), Fr., Epicr., 28. - Schæff., t. 216. - Bull., t. 558, fig. 1. - S les troncs et entre les feuilles mortes, toute l'année, dans les bois, les jardins, les prés. Suspect, selon Reveil.

Ag. (Cop.) digital (Ag. Cop. digitalis), Batsch, fig. 1. - Bull., t. 437, fig. 2. Frr, Epicr., 29. - Dans les bois, à terre, en automne.

Ag. (Cop.) domestique (Ag. Cop. domesticus), Pers., Sym., no 274. - Fr., Epicr., 40. - Dans les lieux cultivés, au printemps, - en tuffes ; sur les places publiques des villes, des villages; rare, mais remarquable.

Ag. (Cop.) faux éphémère (Ag. Cop. ephemoroides), Bull., t. 582. - Fr., Epicr., 32. - Sur les fumiers.

Ag. (Cop.) éphémère (Ag. Cop. ephemerus), Bull., t. 128, et t. 542, fig. 1, 2. Batt., t. 27, fig. B. - Fl. dan., t. 832, fig. 2. - Fr., Epicr., 43. - Au printemps et ì l'automne, dans les jardins, sur les chemins, les terres fumées.

Ag. (Cop.) érythrocéphale (Ag. Cop. erythrocephahus), Lév. - Ann. des sc. nat., 1841, t. 14, fig. 3. - Sur la terre gypseuse.

Ag. (Cop.) éteignoir (Ag. Cop. exstinctorius), Paul., t. 124, fig. 7. - Bull., t. 437, fig. 1. - A terre, près des racines, dans les terrains fertiles.

$\Lambda$ g. (Cop.) fimetaire (Ag. Cop. fimetarius), Lin. - Sterb., t. 24, fig. A, B. Schæff, t. 100. - Fr., Epicr., 17. - (Ag. cinereus), Bull., t. 88. - Sur les fumiers, les terrains fertiles, humides, ì terre, autour des trones, au printemps.

Ag. (Cop.) it petits flocons (Ag. Cop. flocculosus), DC., Fl. fr., VI, p. 45. Battara, t. 25, fig. A. - Dans les ehamps, les jardins.

Ag. (Cop.) basané (Ag. Cop. fuscescens), Sehæff., t. 17. - Paul., t. 125, fig. 1.A la base des trones d'arbres. D'après Paulet, ce Coprin aurait occasionné des accidents it des chiens. Suspect.

Ag. (Cop.) d'Henderson (Ag. Cop. Hendersonii), Fr., Epricr., 34. - Berkl., t. 24, fig. 8. - Sur les couches, le fumier; très-rare.

Ag. (Cop.) micacé (Ag. Cop. micacens), Fr., Epicr., 22. - Schæff., t. 66, fig. 4 à 6. - Bull, t. 246 et 565. - Grev., t. 76. - Sow., t. 261. - Fl. dan., t. 1193. - Dans les jardins, les prairies, sur les trones pourris ete, de mai ̀̀ novembre.

Ag. (Cop.) des jones (Ag. Cop. juncorum), Crouan. - Sur les tiges mortes du Funcus effisus. 
Ag. (Cop.) nyethemere (Ag. Cop. nzethemerus), Fr., Epicr., 38. - Bull., t. 542 ,

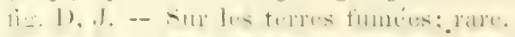

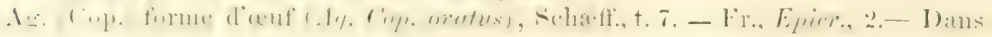
les terrains gras, les gazons; le plus sourent solitaire.

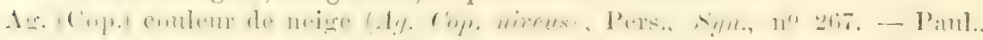
t. 125, fig. 2. - Hoffin., t. 6, fig. 2, - Mich., t. 77, fig. 2. - Sow., t. 262. Fr., Epior., 19. - Commun; an printemps sur les fumiers et dans les bois ombragés; solitaire.

Ag. (Cop.) papillé ((A . Cop. papillatus), Batsch, t. 78. - A terre et sur le fumier.

Ag. (Cop.) pie (Ag. Cop. picaceus), Bull., t. 206. - Fr., Epicr., 12. - Sow. t. 170. - Dans les bois touffus, à terre, les jardins, en septembre et octobre.

1g. (Cop.) pliant (Ig. Cop. plicatilis), Fx., Evicr., 45. - Curt., Fl. Lond., t. 200. Ag. striatus; Bull., t. 552, fig. 2, et t. 80 . - Dans les champs, sur les bords des chemins; commun au printemps et à l'automme.

Ag. (Cop.) rayonnant (Ag. Cop. radians), Desm., Act. des sciene. natur., t. 10, fig. 1. - Sow., t. 145. - Fr., Epicr., 24. - Autour des murs lnumides.

Ag. (Cop.) radié (A\%. Cop. radiatus), Bolt., t. 39. - Fr., Epier., 39.. - Ay. stercorarius, Bull., t. 542, fig. L, E, H. - Sur les fumiers.

Ag. (Cop.) sobolifère (Ag. Cop. soboliferus), Hoffin., Nomencl, t. 3, fig. 2. - Fr., Épier. 9. - A la partic inférieure des trones et dans les serres. - Surpect.

Ig. (Cop.) stercoré (Ag. Cop. stercorens), Scop. - Ag. stercorarius, Bull., t. 542, fig. M, P. - Commun, sur les fumiers.

Ig. (Copr.) Sterculin (Ag. C'op. sterquilinus), Fr., Epicr., 4. - Mich., t. 83, fig. 3. - Sur les bouses de rache.

Ag. (Cop.) tergiversant (Ag: Cop. tergiversans), Fr., Epicr., 21. - Dans les prairies fertiles, en automne.

Ag. (Cop.) drapé (Ag. Cop. tomentosus), Bull., t. 138. - Fr., Epicr., 18. - Mich., t. 75, fig. 3. - Bolt., t. 159. Simple variété de l'Ag. fimetarius, pour de Seynes. Sur la terre fumée dans les jardins, et même dans les endroits sauvages.

Ag. (Copr.) des trones (Ag. Cop. truncorum), Schrff., t. 6. - Fr., Epicr. - Sur la base des trones d'arbres morts.

\section{SÉrie X. - L.ICT.IIRE, Lactarins (lac. lait).}

Genre pour quelques auteurs.

Champignon charnu, à trame vésiculeuse, ferme; chapeau déprimé ou ombiliqué; feuillets lactescents, simples, inégaux, adhérents à un pédicule central; alısence de tégument; suc laiteux, blanc, jaune ou rouge; spores verruqueuses, blanches, jaunattres dans un petit nombre d'especes.

Ag. (Lact.) vènéneux (Ag. Lact. aspideus), $\mathrm{Fr}$.

I’ico, Mrém. de la Société de méd. de Paris, 1780, t. 12. - Paul., t. 72 , fig. 78. Iactarius aspideus, Fro, Epicr., 10.

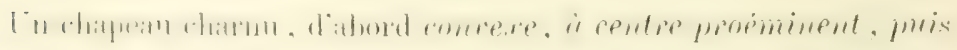

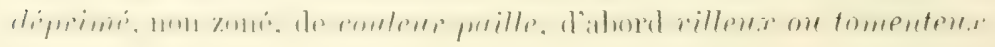


¿l In morge, puis glubre, lisse, blunc; des lanelles pen épaisses. d'un blanc pàle, aiguës aux deux extrémités, adhérentes au sommet du pèdicule, qui est cylindrique, droit, glabre, plein et plus tard fistuleux: tels sont les caractères auxquels on reconnaît l' $\mathrm{Ag}$. (Lact.) aspicleus.

On le trouve dans les bois humides, les saussaies; très-rare.

D'après les observations de Pico, de Turin, ce serait un poison violent. Il a le suc âcre, brûlant, très-caustique, d'un blanc lilas; la chair, ferme, blanche, prenant, de mème que le lait, une teinte violacée au contact de l'air.

Ag. (Lact.) sans zones (Ag. Lact. azonites), Bull., t. 559, fig. 1 .

Noul. et Dass., t. 18, fig. B. - Lartarius anonites, Fr., Epicr., 43.

Bien que, selon Reveil, l'Ag. (Lact.) azonites soit dangereux, il se vend au marché de Toulouse, confondu avec d'autres agarics de la section des Lactaires.

Il est peu délicat au goût, a le chapeau charnu, compacte, d'abord convexe, puis plan et enfin quelquefois déprimé au centre, irrégulier, flexueux ou bosselé, large de 5 à 8 centimètres, à surface lisse, non zoné, de couleur gris bistre ou café au lait; les frillets nombreux, droits, inégaux, d'abord blanes et devenant jaunes avec l'àge, à peine attachés au pédicule, qui est nu, plein, cylindrique, attenué en bas, long de 4 à 5 centimètres, blanchàtre ou jaune-paille; la chair blanche, ferme, de saveur âcre, devenant d'un rouge vineux lorsqu'elle est rompue; le suc d'un blanc de lait.

On le trouve solitaire, en été et en automne, dars les friches et les Jois humides.

Ag. (Lact.) camphré (Ag. Lact. camphoratus), Bull., t. 667, fig. 1.

Krombh., t. 59, fig. 21-24. - Lactarius camphoratus, Fr, Epicr., 52.

Ce Lactaire a le chapeau mince, déprimé, sec, sub-zoné, lisse, large de 3 à 5 centimètres, d'un brun rouge; les feuillets nombreux, d'un jaune rougeâtre; le pédicule cylindrique, plein, souvent flexueux, d'un jaune rougeàtre; le lait, blanc, doux. Il vient dans les bois. Je ne le crois pas malfaisant, quoiqu'il passe pour suspect.

L'Ag. Lact. camphoratus ressemble beaucoup à l'Ag. subdulcis, dont il diffère surtout par une odeur forte de mélilot, qu'il garde même longtemps après aroir été desséché. 
Ag. (Lact.) controverse (Ag. Lact. contruecersus), Pers., Sign., 326.

15.11-1. tig. t. 27. - Barla, t. 18, fig. 1, 2. - Ay. acris, Bull., t. 538, fig. C, 1, L, F, M. - Lactarius controrersus, Fr., Ejpicr., 7.

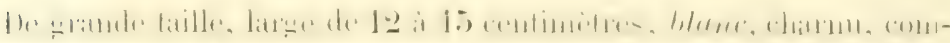

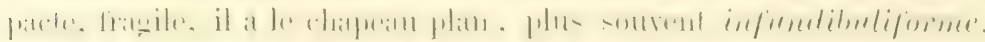
maryué de taches ou zones rosées, à bords ravement régulier's, d'aloord recourbés en dessous, minces, à superficie sub-tomenteuse on sub-risqueuse; les fenillets nombreux, minces, serrés, droits, inégaux, atténués aux deux extrémités, sub-décurrents, nuancés très-faiblement d'incarnat ou de rose clair; ; le pied, long de 4 à 6 centimètres, solide, inégal, atténué en bas, quelquefois excentrique chez les individiss adultes.

Bien que la cuisson ne fasse guère qu'affaiblir son ácreté, ce champignon est d'un fréquent usage dans plusieurs provinces; on le dessèche mème quelquefois pour le manger en hiver. Il est commun, en été et en automne, dans les bois et sur les pelouses, et croit parfois en touffes; son suc, laiteux, blanc, est excessirement âcre.

Ag. (Lact.) délicieux (Ag. Lact. deliciosus), Lin.

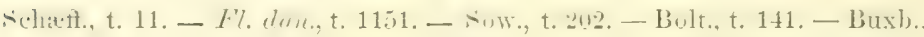
t. 45, fig. 1. - Krombh., t. 11. - Huss., I, t. 63. — Staude, t. 7, fig. 1-3. - Lenz, fig. 9. - Letell., t. 633. - Vittad., t. 42. - Barla, t. 19, fig. 1-5. l'ers., Syn., 332. - Lactarius deliciosus, Fr., Epior., 31.

Noms vulgaires: Rougillon et Rouzillon, en Languedoc; Vache rouge, dans les Vosges; Briqueté.

Le nom de ce champignon parle beaucoup en sa fareur, cependant il est peu recherché en France; les Suédois, au contraire, l'ont en haute estime. En Allemagne, on en fait des provisions pour l'hiver, et on le conserve confit dans la saumure et le vinaigre.

Son pédicule, de couleur jaune ou légèrement tacheté, long de 5 à 6 centimètres, est nu, ferme, épais, d'abord plein, puis creux. Le chapeau, charnu, orbiculaire, large de 8 à 12 centimètres, d'abord convexe, puis plan ou déprimé au centre, à bords réfléchis, sub-visqueux, d'abord jaune, puis fauve et même rougeâtre, est marqué quelquefois de zones jaunâtres. Lames inégales, d'un rouge de brique ou safrané. La chair et les feuillets blessés prennent une couleur vert sointive. 
Ce Lactaire est comestible; il croìt, de juillet à novembre, dans les bois couverts et montueux, et surtout dans les bois de pins.

On pourrait le confondre avec l' $\mathrm{Ag}$. tominosus, l'Ag. zonarius etc.; il s'en distingue par son suc lactescent, rouge orangé ou safrané.

\section{Ag. (Lact.) fuligineux (Ag. Lact, fuliginosus), $\mathrm{Fr}_{1}$.}

Krombh., t. 14, fig. 10-12. - Bull., t. 567, fig. 3. - Hartz, t. 29. - Barla, t. 21, fig. 6, 7. - Lactarius fuliginosus, Fr., Epior.

Champignon de couleur fuligineuse, d'abord convexe, puis déprimé au centre, large de 4 à 5 centimètres, charnu, sub-villeux, très-sec, non zoné, parsemé d'une espèce de givre fuligineux, qui le distingue des espèces voisines, à bords ondulés.

Ses feuillets d'un blanc jaunatre, inégaux, droits, nombreux, adhèrent au pédicule, qui est cylindrique, lisse, d'un blanc sale, ensuite d'un fauve terreux. Le suc laiteux blane, d'abord insipide, devient àcre. La chair, blanche, déchirée, se tache en jaune.

Il croît, en automne, dans les bois; est vénéneux selon M. Barla et Reveil.

Ag. (Lact.) poivré (Ag. Lact. piperutus), Scop.

(Pl. XXVIII , fig. 1.)

Batseh, t. 13, fig. 59. - Roq., t. 6, fig. 2, 3. - Ag. acris, Bull., t. 200. Schæff., t. 83. - Paul., t. 68, fig. 4. - Fl. dan., t. 1132. - Hartz, t. 39. - Krombh., t. 57, fig. 1-3. - Barla, t. 22, fig. 1-5. - Pers., Syn., 325. Lactarius piperatus, Fr., Epicr., 28.

Noms vulgaires: Eauburon, Aburon, Lamburon, Tathyron, Latheron; Poivré; Vache blanche, dans les Vosges; Chavane.

Ce champignon est entièrement blanc, a le chapeau large de 10 à 15 centimètres, d'abord convexe, puis plan et enfin concave ou infundibuliforme, glabre, mais quelquefois comme farineux, non zoné, les bords étant onduleux et recourbés en dessous; les feuillets très-nombreux, étroits, serrés, inégaux, parfois fourchus, blanes, mais prenant une teinte jaunàtre en vieillissant, un peu décurrents sur un pédicule nu, épais, cylindrique, charnu, plein, qui n'atteint guère que 3 à 4 centimètres de hauteur.

Il vient à terre dans les bois, où on le trouve communément, en été et en automne. Chair compacte, ferme; suc blanc, laiteux, excessivement âcre. 


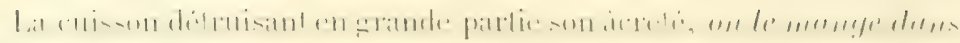

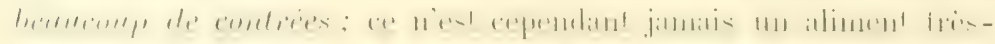

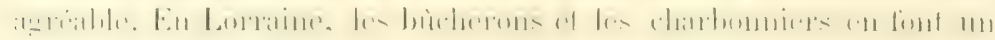
fréquent usage. En Russie, la consonmation en est considérable. Les raches le mangent avec avidité, màis il rend leur latit et leur beur'e nauséeux. En Piémont, on le fait macérer dans l'eau salée.

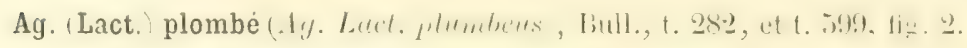

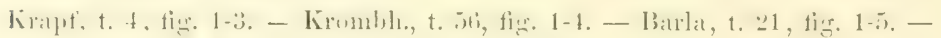
Pers., Syn., 435. - Lactarius plumbeus, Fr., Epier., 24.

Sa chair est blanche, cassante, granuleuse; son lait blane, àcre, piquant; sa saveur amère et désagréable. Le chapeau, d'abord convexe, devient concave ou en entomoir, a la surface sèche, de couleur

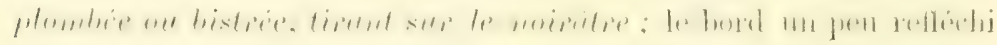
et non zoné. Les feuillets, nombreux, inégaux, étroits, d'un blane jaumitre, sont un peu décurrents sur le pédicule, qui est court, épais, nu, plein.

Commun, dans les bois et les friches, ce lactaire, de médiocre dimension, serait vénéneux d'après M.I. Barla et Duchesne.

Ag. (Lact.) caustique (Ag. Lact. pyroyalus), Bull., t. 529, fig. 1.

Krombh., t. 14, fig. 1-9. - Larbr., t. 18, fig. 13. - Krapf., t. 4, fig. 8. Roq., t. 13, fig. 5. - Noul. et Dass., t. 19, fig. A. - Pers., Syn., 338. - Lactarius pyrogalus, Fr., Eprer., 22.

Son chapeau est charnu, glabre, lisse, un peu humide par les temps pluvieux, large de 6 à 10 centimètres, d'abord convexe, puis déprimé au centre, de couleur jaune terreux ou livide cendré, souvent marqué de zones noirâtres. Les feuillets sont jaune roussutre, écartés, subdécurrents. Le pied, primitivement plein et ensuite creux, de la couleur du chapeau, aminci à la base, est long de 3 à 4 centimètres. Le lait et la chair ne changent pas de couleur.

Cette plante croît solitaire dans les bois et les prés, en été et en automne, est assez commune et vénéneuse. Son suc, laiteux, blanc, douceâtre dans les jeunes individus, devient âcre et caustique à la maturité.

Ag. (Lact.) modeste (Ag. Lact. quietus), Fr., Epicr., 40.

Ag. dygmogalus, Bull., t. 584. - Krombh., t. 40, fig. 1-9.

Cihampignon d'un roux très-pâle, plus obscur dans le centre du chapeau, qui est charnu, large de 6 à 10 centimètres, d'abord vis- 
queux, mais bientôt sec et lisse, parfois marqué de zones grisàtres, arrondi, plan, puis déprimé. Les feuillets sont inégaux, un peu dé-currents, primitivement blancs, puis roussâtres. Le pédicule, nu, spongieux, cylindrique, long de $\mathbf{5}$ centimètres, s'élargit pour se continuer avec le chapeau, auquel il ressemble par la couleur.

Il nait dans les bois, solitaire ou par groupes de deux individus, a le lait blanc, doux; la chair blanche, ferme; est comestible.

On le mange aux environs de Bordeanx.

Ag. (Lact.) roux (Ag. Lact. mufus), Scop.

Krapf, t. 5, fig. 1-4. - Kombl., t. 39, fig. 12-15. - Lenz, t. 1, fig. 17. Huss., I, t. 15. - Paul, t. 69 bis. - Bull., t. 14. - Ag. lactifurs necator, I'crs., Synn., 336. - Lactarius rufius, Fr., Eypier., 56.

Noms vulgaires: Agaric meurtrier; Calalos, dans le Bordelais; Raffoult.

L'Ag. Lact. mufus a le chapeau charnu, ferme, sec, large de 8 à 10 centimètres, d'abord convexe, mamelonné et enfin déprimé en entonnoir, lisse, non zoné, de couleur châtain roux ou bronzé, à bords villeux dans le jeune âge, roulés et ensuite plans; les feuillets nombreux, inégaux, adnés, sub-décurrents, d'un jaune ochracé ou rous-: sâtre; le pédicule, court, plein, plus pàle que le chapeau; le suc lai.. teux, blane, extremement icie.

Il est commun et croìt, en automne, dans les bois et surtout dans les bois de pins; les vers ne l'attaquent jamais; extrêmement vénéneux.

Bulliard dit qu'il est nuisible à la plus petite dose. Krapf rapporte plusieurs exemples de ses effets délétères: il aurait plus d'une fois occasionné la mort.

On l'a confondu quelquefois avec l'Ag. tominosus, qui s'en distingue par son chapeau, dont le bord reste villeux, et son pied creux.

Ag. (Lact.) douceâtre (Ag. Lact. subdulcis), Bull., t. 224, fig. A, B.

$$
\text { (Pl. XXVI, fig. 1.) }
$$

Suw., t. 204. - Bolt., Ł. 3. - Schaft., t. 73 e. purte. - Krombh., t. 40, fig. 13-14. - Lenz, fig. 11. - Barla, t. 20, fig. 4-10. - Lactarius subdulcis, Fr., Epier., 51.

Nom vulgaire: Vache rouge, dans les Vosges.

On trouve communément ce lactaire dans les bois, en été et en automne. Il a le suc blane, laiteux, d'aljord douceâtre, ensuite quelque 
peru atcre; la chair rougeâtre, ne changeant pas de couleur; le chapeau

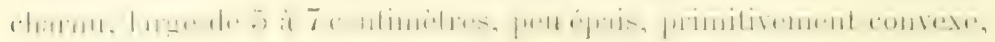
puis dẹpriné au contre, qui reste sub-mamelonné, lissé, non zoné; à superticie sìche, de coulenr fauve rougeütre; les feuillets nombreux, fragiles, inégaux, étroits, presque incarnats et enfin roussàtres, subdécurrents; le pédicule, plein d'ahord, puis creux, cylindrique, long le 3 i 6 centimètres, peu épais, de la conleur du chapean.

J'ai mangé plusieur's fois de ce champignon, et n'en ai pas été incommode; il est done comestible.

L'Ag. mfers, champignon rlangereux, avec lequel on pourrait le confondre, a un lait toujour's excessivement àcre.

Ag. (Lact.) à lait jaune (A\%. Lact. theiogalus), Bull., t. 567, fig. 2.

(I'l. XXYII, fig. 2.)

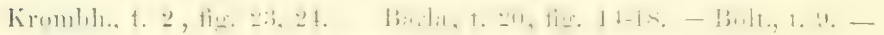
Paul., t. 71. - Lactarius theiogalus, Fr., Epier., 35.

Chapeau de moyeme dimension, charnu, d'alord convexe, plus tard déprimé au centre, souvent un peu irrégulier, glabre, à surface sèche, de couleur roux fauve, ordinairement sulb-zoné. Les feuillets, inégaux, minces, serrés, d'un blanc jaunâtie, adhèrent au pédicule et sont un peu décurrents. Le pédicule lisse, presque toujours plein, nu, de la couleur du chapeau, s'élève au plus à 4 centimètres.

Ce champignon vient, en automne, dans les bois. Son lait est d'un blanc de soufre; sa cliair, jaunaitre, a un goût àcre, amer, une odeur peu prononcee.

L'Ag. theiogalus passe pour vénénerix.

Paulet dit l'avoir donné à des animaux qui n'en ont pas été incommodés. M. Léveillé ajoute qu'on le mange dans quelques campagnes.

Ag. (Lact.) aux tranchées (Ag. Lact. torminosus), Schreff,, t. 12.

$$
\text { (Pl. XXVII, fig. 1.) }
$$

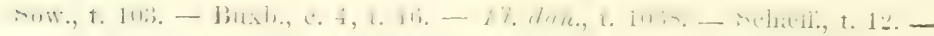
Noul. et Dass., t. 17, fig. B. - Paul., t. 70, fig. 1, 2. - Krombh., t. 13, fig. 15-23. - Ag. necator, Bull., t. 529, fig. 2. - Lactarius torminosus, Fr., Elier., 2.

Xoms vulguires: Morton, Raffoult, Calalos, Mouton zoné.

Plante toute de couleur rouge de chair ou roux pâle, dont le chapeau, large de 8 a 10 centimètres, est d'abord convexe, puis plan et enfin déprimé au centre, à bords roulés en dessous, velus et comme 
frangés. Les feuillets sont d'un blane pâle ou très-faiblement incarnats, étroits, de longueur inégale. Le pied, lisse, plein et bientôt creux, long de 6 à 9 centimètres, est nu, cylindrique, de la couleur du chapeau. La chair, ferme, laisse écouler, lorsqu'on la casse, un suc laiteux, blanc, excessivement âcre.

L'Ag. torminosus se trouve fréquemment dans les bois et les friches, à la fin de l'été et en automne; il n'est presque jamais attaqué par les limaces.

Les noms d'Agaric aux tranchées et d'Agaric meurtrier, qu'on lui a donnés, l'ont fait regarder comme très-dangereux, et cependant presque tous les auteurs s'accordent ì dire qu'on peut le manger impunément; M. Letellier l'a mangé plus d'une fois sans inconvénient; toutefois il est dur et indigeste.

Les mauvais effets qu'on lui attribue ne seraient--ils pas dus à ce qu'on l'a confondu avec l'Ag. mufus, espèce très-dangereuse, ou bien avec l'Ag. scrobiculatus, autre espèce malfaisante, ou du moins fort suspecte? Du reste, le goût très - désagréable de l'Ag. torminosus éloignera presque toujours d'en faire usage.

Ag. (Lact.) sale (Ag. Lact. turpis), Weinm.

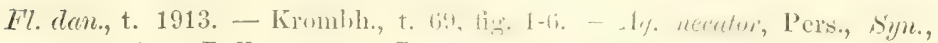
336. - Bull., t. 14. - Lactarizes turpis, Fl., Fpicr., 5.

Le nom de turpis donné à ce champignon est de nature à inspirer une défiance qui n'est pas méritée, car Weinmann et Lenz le donnent pour comestible. On le trouve dans les bois, surtout dans les bois de pins.

C'est une belle espèce, souvent de grande taille, dont le chapeau, de couleur olivacée, terre d'ombre, non zoné ou à peine zoné, compacte, plan, glabre, sub-visqueux, a les bords tomenteux, jaunâtres, un peu enroulés. Les feuillets sont minces, pàles, sub-incarnats. Pied de la couleur affaiblie du chapeau, atténué par en bas, plein, court. Lait blane, âcre.

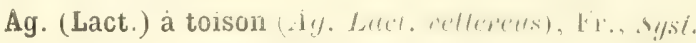

(Pl. XXVIII, fig. 2.)

Sow., t. 104. - Bull., t. 538, fig. G, H, N. - Paul., t. 68, fig. 2, 3. Krombh., t. 57, fig. 10-13. - Huss., I, t. 63. - Plb., t. 4, fig. 3-12. Barla, t. 22, fig. 6-8. - Lucturius vellereus, Fr., Ifprer., 29.

Champignon de couleur blanche, dont le chapeau, large de 12 à 15 centimètres, d'abord légèrement convexe, puis déprimé au centre, 


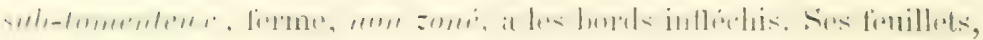

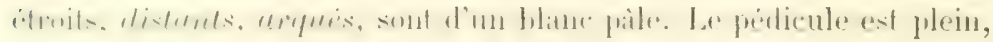

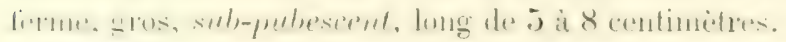

Il croit, en groupes, dans les bois; est assez commun en automne; a la chair compacte, àcre; une odeur faible, non agréable; le lait, blanc, âcre, peu abondant; ce lait devient jaune au contact de l'air, et reprend sa couleur primitive après un certain temps.

Vénéneux, selon quelques auteurs. Badham dit, qu'en ayant goùté, il fut sérieusement incommodé. Un chien, qui en avait déchiré un spécimen, éprouva des tortures presque incroyables. Malgrẻ sa saveur âcre, il serait comestible au rapport de M. Léveillé. M. Barla dit qu'on le mange aux environs de Nice, après l'avoir fait bouillir et macérer dans l'eau.

L'Ag. vellereus ressemble à l'Ag. piperatus; on l'en distingue en ce que ses feuillets sont moins nombreux, qu'il est tomenteux et non glabre.

Ag. (Lact.) vert (Ag. Lact. viridis), Paul., t. 69, fig. 3, 4.

Lactarius viridis, Fr., Epicr., 25.

Cie lactaire croît dans les bois humides, en automne, est rare, compacte, d'assez grande taille, facilement reconnaissable à sa couleur verte, également répandue sur la surface du chapcau, lequel est large de 10 à 12 centimètres, déprimé en entonnoir au centre, glabre, sec, nou zoné, à bords onduleux; a le suc laiteux, blane, àcre; la chair blanche, sans odeur; les feuillets nombreux, serrés, minces, d'inégale longueur, d'un blanc tirant sur le roux, adhérents au sommet du pédicule, qui est droit, cỵlindrique, atténué à sa partie inférieure, d'aJord plein, puis fistuleux, verdatre, glabre.

On le connait dans les campagnes, dit Paulet, sous le nom de Mauvais prévat, ce qui indiquerait des propriétés malfaisantes, et cependant il n'en est rien; ce mycologue l'a donné aux animaux, et luimème en a mangé, sans qu'il en soit résulté aucun inconvénient.

Ag. (Lact.) volemus (Ag. Lact. volemus), Fr.

(1'. XXT1, fig. 2.)

Schrefir, t. 5. - Tratt., t. 20. - Krapf, t. 1, fig. 1-3. - Lenz, t. 3, fig. 12. IIuss., I, t. 87. - Letell., t. 624. - Barla, t. 20, fig. 1-3. - Lactarins rolemus, Fr., Epicr., 47.

Noms vulgaires: Viau, Vachotte, en Lorraine; Vélo, dans quelques parties de la Champagne; Lactaire doré. 
Le chapeau de ce lactaire est large de 8 à 10 centimètres, compacte, ferme, d'abord convexe, puis un peu déprimé au centre, qui cependant reste souvent mamelonné, de couleur jaune-chamois ou fauve clair, non zoné, sec, à épiderme quelquefois fendillé ou sub-pulvérulent.

Les feuillets sont droits, inégaux, quelques-uns parfois bifurqués, les plus courts coupés assez brusquement, les plus longs sub-décurrents, d'un blanc pâle, passant à la couleur du chapeau. Pédicule, nu, cylindrique, plein, ferme, droit ou flexueux, long de 6 à 8 centimètres, de la couleur du chapeau, mais plus pâle, sub-pulvérulent.

Ce champignon est des plus agréables d̀ manger; dans certains pays, on le mange cru aussi souvent que cuit. Ses feuillets froissés prennent bientôt la couleur du chapeau. Le suc est laiteux, doux, blanc, abondant; la chair cassante a une odeur particulière. Il croìt, ordinairement solitaire, dans les bois, en étẻ et au commencement de l'automne.

Ag. (Lact) zoné (Ag. Lact. zonarius), Bull, t. 104.

Vaill, t. 12, fig. 7. Noul, et Dass, t. 19, fig. B. - Venturi, t. 6, fig. 51, 52. - Hartz, t. 43. - Barla, t. 21, fig. 8-12. - Ag. Alexuosus, Pers., Syn., 328. - Lactarius zonarius, Fr., Epicr., 13

Nom vulgaire : Rousillous, dans le Tarn.

Cet agaric vient dans les bois, au printemps, en été et en automne, et passe pour vénéneux. Teinturier dit néanmoins qu'aux environs de Brescia, les habitants de la campagne le mangent sans en être incommodés. Dans le Languedoc, les paysans l'emploient à cautériser les verrues.

Son chapeau, compacte, d'abord arrondi, convexe, s'aplatit ensuite, puis devient déprimé au centre ou infundibuliforme, est d'un jaune tirant sur le roux, marqué de zones concentriqueś de la même couleur, mais plus foncées, acquiert de 8 à 10 centimètres de diamètre, a les bords non velus, légèrement roulés en dessous. Les feuillets sont serrés, inégaux, d'un blanc sale. Le pied, plein, ferme, nu, court, lisse, plus large du haut, d'un blanc jaunâtre, n'est jamais tacheté.

Il a de la ressemblance avec l' $\mathrm{Ag}$. deliciosus, duquel il se distingue surtout par son suc laiteux, blane, àcre, caustique, et par sa chair blanche, qui ne change pas de couleur lorsqu'elle est blessée. 
I. IC'T I I IE.

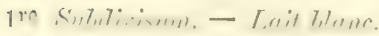

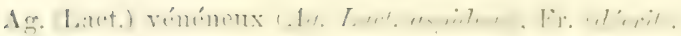

$\boldsymbol{\Lambda}$ g. (Lact.) gluant (Ag. Lact. blennius), Fr., Epior., 15. - Krombh., t. 69, fig. 7, 9. - Sterb.. t. 5, fig. E. - Krapf, t. 4, fig. 11-13. - Dans les bois de hêtres, commun; dans les bois de pins, rarc. - Suspect. Vénéneux, selon liir....

Ag. (Lact.) campylus (Ag. Lact. campylus), Otto. - Fr., Epicr., 4. - Paul., t. 72, fig. 5, 6. - Dans les bois, dे la fin de l'automne; rare.

$\Lambda$ g. (Lact.) lait jaune d'or (Ag. Lact. chrysorheus), Rabh. - Krombh., t. 12, fig. 7-14. - Fr., Epier., 36.

Ag. (Lact.) lait cilice (dg. Lact. cilicioilles), Fr. Epicr, 3. - Ag. crinitus, Schæff., t. 228. - Dans les bois de pins.

Ag. (Lact.) délicieux (Ag. Lact. deliciosus), Fr., Epicr., 31 (décrit).

Ag. (Lact.) controversé (Ay. Lact. controrersus), Pcrs. (décrit).

Ag. (Lact.) fascinant (Ag. Lact. fascinans), Fr., Epicr., 9. - Weinm. - Krombh., t. 50, fig. 17-19. - Dans les bois et les prés couverts de mousses.

Ag. (Lact.) flexucux (Ag. Lact. flexuosus), Schæff., t. 235. - Fr., Epicr., 21. En automne, dans les endroits plantés de pins et les chemins gazonnés. Comestible.

Ag. (Lact.) insipide (Ag. Lact. insulsus), Fr., Epicr., 12. - Krombh., t. 12, fig. 1-6. - Dans les bois. Paraît être comestible.

Ag. (Lact.) pied latéral (Ag. Lact. lateripes), Desm., Cat. plant., 21. - Pers., Iryc., t. 24, fig. 1. - Fr., Epicr., 64. - Sur les trones pourris; rare.

Ag. (Lact.) blême (Ag. Lact. luridus), Pers., Syn., 339. - Paul., t. 70, fig. 3, 4. - Fr., Epier., 19. - Dans les champs, même où il n'y a pas de mousses.

Ag. (Lact.) forme de mamelle (Ag. Lact. manmosus), Fr., Epicr., 58. - Mich., t. 80, fig. 1. - Krombl., t. 40, fig. 26-29, - Dans les bois de pins.

Ag. (Lact.) jutueux (Ag. Lact, musteus), Fr., Epicr., 14. - Dans les bois de pins de montagnes. Vénénerıx.

Ag. (Lact.) pargamenus (A\%. Lact. parqamenus), Batsch, fig. 29. - Schwartz. - Krombh., t. 57, fig. 4-6. - Fr., Epier., 27. - Dans les broussailles, les lieux sauvages.

Ag. (Lact.) poivré (Ag. Lact. piperatus), Scop. (décrit).

$\mathbf{A g}$ (Lact.) couleur de plomb (Af. Lact. plumbeus), Bull. (déerit).

Ag. (Lact.) caustique ( $A$ g. Lact. pyrogalus), Bull. (décrit).

Ag. (Lact.) serifluus (Ag. Lact, serifluus), DC., Fl. fr., VI, p. 45. - Krombh., t. 40, fig. 15-16. - Dans les bois, les bruyères, les lieux humides.

Ag. (Lact.) en creux (Ag. Lact. scrobiculatus), Scop. - Schæff., t. 217 et 228 . Krombh., t. 58, fig. 1-6. - Fr., Epicr., 1. - Dans les bois humides, en novembre. Suspect.

Ag. (Lact.) à coliques (Ay. Lact. torminosus), Schæff. (décrit).

Ag. (Lact.) trivial (A\%. Lact. trivialis), Fr., Epicr., 17. - Krombh., t. 14, fig. 17, 18. - Dans les lieux humides des bois de conifères.

Ag. (Lact.) honteux (A . Lact. turpis), Weinm. (décrit).

Ag. (Lact.) terre d'ombre (Ag. Lact. umbrinus), Pers., Syn., 335. - Paul., t. 69, fig. 1, 3. - Fr., Epier., 53.

Ag. (Lact.) à toison (Ag. Lact. vellereus), Sow. (décrit).

Ag. (Lact.) vert (Ag. Lact, viridisi, Paul. (clécrit).

Ag. (Lact.) zoné (Ag. Lact. zonarius), Bull. (décrit). 


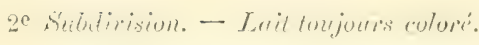

Ag. (Lact.) âcre (A\%. Lnct. (1) is), Bult., t. 190. - Batseh, fig. 68. - Batt., t. 13,

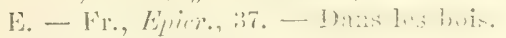

Ag. (Lact.) orangé (Ag. arrantiacus), Fl. danı, t. 1909, fig. 2. -- Batt., t. 16,

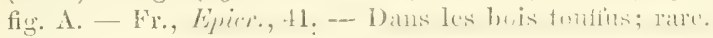

Ag. (Lac.) sans zones (Ay. Lact. azonites), Bull. (décrit).

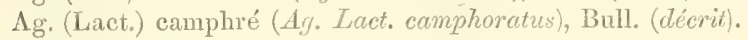

Ag. (Lact.) délicieux (Ag. Lact. deliciosus), Lin. (décrit).

Ag. (Lact.) fuligineux (Ag. Lact. fuliginosus), Fr. (décrit).

Ag. (Lact.) à odeur alcoolique (Ag. Lact. glyciosmus), Lenz, fig. 11. - Huss., I, t. 15. - Fr., Epicr., 59. - Krombh., t. 39, fig. 16-18. - Dans les bois de pins; odeur forte.

Ag. (Lact.) ichoreux (A\%. Lact. ichoratus), Batsch, fig. 60. - Fr., Epicr., 43. Dans les plantis.

Ag. (Lact.) très-doux (Ag. Lact. mitissimus), Fr., Epior., 50. - Krombh., t. 39, fig. 16-18. - Tard, dans los bois. Comestible, selon Letellier.

Ag. (Lact.) pâle (Ag. Lact. pallidus), Pers., Syn., 330. - Krombh, t. 56, fig. 1014. - Fr., Epier., 39. - Dans les bois de hêtres.

Ag. (Lact.) recourbé (Ag. Lact. resimus), Fr., Epicr., 11. - Krombh., t. 58, fig. 11-14. - Dans les bois.

Ag. (Laut.) modeste (Ag. Lact. quietus), Fr. (décrit).

Ag. (Lact) roux (Aq. Lact. rufus), Scop. (déerit).

Ag. (Lact.) à suc couleur de sang (A\%. Lact. sangriflucus), Paul., t. 81, fig. 3-5. - Fr., Epicr., 33. - Dans le La guedoc. Paule le dit très-recherché daus le pays où il croit; trouvé par lui seul.

Ag. (Lact.) douceâtre (Ag. Lact. subdulcis), Bull. (décrit).

Ag. (Lact.) à lait ja:ne (Ag. Lact. theiogalus), Bull. (déerit).

Ag. (Lact.) tithymale (Ag. Lact. tithymalinuts), Scop. - Fr., Epior., 55. Krombh., t. 39, fig. 5-9. - Dans les frêts.

Ag. (Lact.) visqueux (Ag. Lact. uvidus): Fr., Epicr., 20. - Batsch, fig. 202. Dans lis.

Ag. (Lact.) volemus (Ag. Lact. volemus), Fr. (décrit).

\section{SÉrT XI. - RUSSULE, liussula (russulus, rouge).}

Genre pour quelques auteurs.

Champignon charnu, putrescent, d'abord convexe, puis plan ou déprimé, à trame sub-grumeleuse; pédicule central, nu; feuillets ne contenant pas de suc laiteux, égaux entre eux dans la plupart des espèces, souvent anastomosés, bifurqués; absence de volva et de téguments; spores rondes, verruqueuses.

Toutes les espreps de linswules soml terrestres, mois se plaisent dans les bois. 
Ag. (Russ.) alutacé Ag. Russ. alutaceus), Pers., Syn., 349.

(Pl. XXIX, fig. 2.)

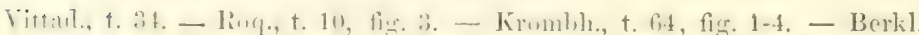
t. 13, fig. 8. - Barla, t. 14, fig. 1-3. - Noul. et Dass., t. 15, fig. $\mathbf{A}, \mathrm{B}$

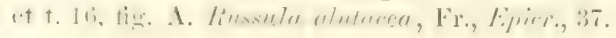

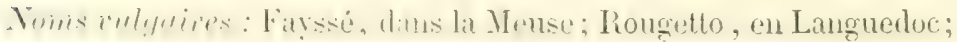
Tiise romer.

Ce champignon a la chair blanche, cassante, agréable au goût; le chapeau large de 8 à 10 centimètres, arrondi, à bord rarement régulier, plan au centre ou déprimé, de couleur rouge violacé ou rouge un peu fauve, mème sanguin, plus foncé au centre, à bord mince, se pelant facilement, finissant par devenir strié et sub-tomenteux; les feuillets droits, peu serrés, égaux en longueur, non décurrents, de couleur ochracé pâle ou blanc jaunâtre; le pédicule long de 4 à 7 centimètres, lisse, plein ou spongieux, blanc, le plus souvent nuancé d'un rouge pâle.

Il croît dans les bois, à la fin de l'été et en automne, est de couleur variable, quoiqu'on puisse lui assigner, à cet égard, des caractères généraux.

La surface de la chair paraît souvent rougeâtre lorsque l'épiderme a été enlevé.

Comestible; très-recherché en Lorraine.

Ag. (Russ.) cyanoxanthe (Ag. Russ, cyanoxanthus), Pers., Syn., 360.

(PI. XXX.)

Bolt., t. 1. - Sterb., t. 5, fig. C, D, E. - Paul., t. 76, fig. 2, 3. - Huss. I, t. \$ - kuw., t. 201. - Krombh., t. 67, fig. 12, - Vittad., t. 27. Schæff., t. 93. - Pers., Syn., 359, 360. - Russula vesca, Fr., Epicr., 10.

Nom vulgaire: Charbonnier, en Lorraine.

Chapeau large de 6 à 10 centimètres, d'abord convexe, puis plan et enfin déprimé au centre, de couleur douteuse, mèlée de violet, de fauve, de brun verdâtre et même bleuâtre, plus foncẻ au centre, non lisse, sub-veiné ou tacheté, non strié sur les bords ou à stries rares. Feuillets d'un blanc pur, épais, droits, peu serrés, plus larges à la circonférence, atteignant presque tous le pédicule, mais non décurrents, quelques-uns parfois bifurqués près du pédicule. Celui-ci est blanc, parfois nuancé de rose, non lisse, le plus souvent veiné 
ongitudinalement, nu, d'abord plein, puis lacuneux dans la vieillesse, cylindrique, rarement droit, long de 6 à 8 centimètres.

Les vers et les limaces attaquent ce champignon, qui n'est pas rare t croît, à la fin de l'été et en automne, dans les bois, et plus particulièrement dans leurs parties découvertes. Il est délicat à manger. Sa chair, blanche, cassante, est rougeâtre sous la pellicule, qui se pèle assez facilement à la circonférence et difficilement au centre; saveur agréable; odeur faible.

Ag. (Russ.) émétique ( $A g$. Riss, emeticus), Fr., Syst., 5.

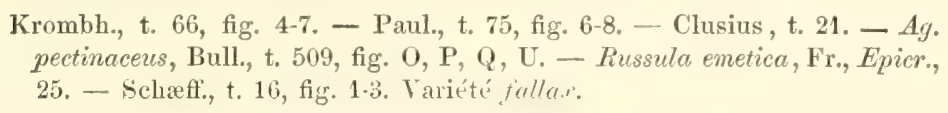

Nom vulgaire: Faux-Fayssé, dans la Meuse.

Les caractères distinctifs de cette espèce sont : un chapeau charnu, régulier, aplati ou déprimé, poli, luisant, de couleur d'abord rose, puis sanguine, et enfin fauve ou d'un blanc ochracé, dont le bord étalé est strié ou sillonné avec l'àge; une chair blanche sous une pellicule rougeâtre, qui s'en détache facilement; des feuillets libres, non adhérents, égaux, simples, larges, peu serrés, blancs, jamais pulvérulents; un pédicule spongieux, ferme, élastique, lisse, blanc ou un peu rougeâtre.

Espèce extrêmement vénéneuse. D’après les expériences de Krapf, de Vienne, son principe toxique n'est détruit ni par l'ébullition ni par la dessiccation. La chair, fragile, a une saveur âcre et repoussante, une odeur particulière. Elle croît dans les bois, à la fin de l'été et au commencement de l'automne; assez grande dimension. Très-commune.

Ag. (Russ.) fétide (Ag. Russ. foetens), Pers., Syn., 356.

$$
\begin{gathered}
\text { Sow., t. 415. - Bull., t. 292, - Krombh., t. 70, fig. 1-6. - Russula foetens, } \\
\text { Fr., Epicr., 29. }
\end{gathered}
$$

Si, comme l'affirme M. Letellier, l'Ag. Russ. foetens n'est pas vénéneux, son odeur désagréable, nauséeuse, sa saveur âcre et poivrée le rendent au moins suspect. On le trouve, en automne, dans les bois, au milieu des gazons.

Son chapeau est d'un jaune terreux, sale et tirant sur le fauve, large de 12 à 15 centimètres, d'abord convexe, puis déprimé au centre, à 
hords sinués et marqués de stries ou cannelures, qui paraissent comme articulées, enduit d'une matière gluante, peu charnu. Les lames sont rares, épaisses, inégales, assez souvent fourchues ou anastomosées à leur insejtion au pédicule, non adhérentes, d'un blanc sale, de mème que le pédicule, lequel est nu, plein ou celluleux, long de 4 à 5 centimètres, épais de 3 , s'élargissant un peu à son sommet. Chair assez ferme et cassante.

Ag. (Russ.) fragile (Ag. Russ, fragilis), Pers., Syn., 347.

Krombh., t. 64, fig. 12-18. - Barla, t. 14, fig. 10-13. - Ag. pectinacens,

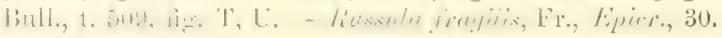

Champignon généralement de couleur rouge, mais affectant diverses nuances, toutefois plus pàle que l'agaric émétique. Chapeau charnu, mince, plan, déprimé, poli, inégal, à pellicule mince, visqueuse, à bord tuberculeux, strié; feuillets blancs, serrés, minces, ventrus, adhérents à un pédicule, d'abord plein, puis creux, luisant.

Espèce très-commune dans les bois, en automne. Chair blanche sous le pédicule; saveur âcre. Vénéneux, selon Kick. Persoon était tenté de regarder ce champignon comme une variété de l'Ag. emeticus. M. Barla dit que ce champignon se mange quelquefois dans les campagnes aux environs de Nice, après qu'on l'a fait bouillir et macérer dans l'eau.

Ag. (Russ.) à lames fourchues (Ag. Russ. furcatus), Pers., Syn., 363.

Schæff,, t. 94, fig. 1. - Buxb., t. 47, fig. 2. - Paul., t. 74, fig. 1. - Krombh., t. 62, fig. 1, 2, et t. 64, fig. 18, 22. - Barla, t.16, fig. 1-9. - Ag. bifidus, Bull., t. 26. - Russula furcata, Fr., Epicr., 9.

Nom vulgaire: Vert-bouteille.

Le chapeau, de couleur vert terne ou olivacé, est large de 8 à 10 centimètres et plus, charnu, rigide, d'abord convexe, puis plan, et enfin déprimé au centre, lisse, à surface humide dans les temps pluvieux, présentant des bords minces, recourbés en dessous, non striẻs. L s feuillets, blancs, rares, épais, tous à peu près de la même longueur, la plupart bifurqués vers le milieu ou les deux tiers externes, adhèrent au pédicule, lequel est blanc, ferme, lisse, attenué en bas, long de 3 à 5 centimètres, devenant creux ou spongieux en vieillissant.

L'Ag. furcatus croît à terre dans les bois secs et arides, en juin et en juillet. Sa chair est blanche, sèche et cassante; sa saveur, fade et 
nauséeuse dans le jeune âge, devient amère et salée dans la vieillesse ; son odeur est peu prononcée.

Il diffère de l'Ag. virescens par la pellicule du chapeau, qui ne se déchire pas en verrues, et par la bifurcation de ses lames.

On n'est pas d'accord sur les propriétés de ce champignon: ses effets seraient à peu près nuls, selon Hartig, et Reveil le déclare suspect; Paulet dit qu'essayé sur des animaux, il n'a rien produit qui fût digne d'ètre noté. J'en ai mangé impunément. Il passe toutefois pour malfaisant.

Ag. (Russ.) hétérophylle (Ag. Russ, heterophyllus), Fr.

Krombh., t. 67, fig. 12-15. - Huss., I, t. 84. - Berk1., t. 13, fig. 5. - Bull., t. 509, fig. L, M. - Noul, et Dass., t. 14, fig. A. - Battara, to 12, fig. E. Fl. dan., t. 1907, fig. 1. - Paul., t. 75, fig. 1-5. - Russula heterophylla, Fr., Epicr., 11.

Nom vulgaire: Bisotte (Paulet).

Charnu et consistant, il a le chapeau d'abord convexe, puis plan, et enfin déprimé au centre, large de 4 à 5 centimètres, uni, lisse, de couleur variable, gris de souris ou bise, plus foncé au centre, pourvu d'un épiderme, qui se détache facilement, à bord mince, lisse ou à stries fines et serrées; les feuillets, minces, très-nombreux, d'un blane pur, fourchus, quelques-uns dimidiés, attenués et atteignant le sommet du pédicule, qui est ferme, plein, quelquefois fistuleux, lisse, blanc, haut de 4 à 5 centimètres, à peu près cylindrique, un peu dilaté à l'insertion des feuillets.

A la fin de l'été et en automne on trouve ce champignon dans les bois peu couverts et les friches. Il est comestible, et on en fait une grande consommation en Bourgogne. La chair est blanche, cassante; la saveur douce, faiblement piquante, non teintée de rouge sous l'épiderme, comme celle de l'Ag. cyanoxanthus.

Il diffère de celui-ci, et par ce caractère et par ce que son chapeau n'est jamais ni rougeâtre, ni purpurescent.

Ag. (Russ.) intègre (Ag. Russ. integer), Lin., Suec., no 1230.

Schæff., t. 92. - Vittad., t. 21. - Fr., Epicr., 31. - Russula integra, Fr., Epicr., 31.

Ce champignon, comestible selon Schæffer, croit dans les bois. Il a une saveur douce, la chair blanche. 
Son chapeau est charnu, étalé ou déprimé, à pellicule visqueuse, de couleur à fond rougeâtre, mais passant au fauve, au rose sale, à bord mince, sillonné à la fun et tuberculeux. Les feuillets, à peu près libres, sont très-larges, égaux, distants, blanc, ensuite pâles, comme saupoudiés de jaune. Le pied est plein ou spongieux, lisse, blanc, ventru. Ses spores sont sub-ochracées. On le confond souvent avec l'Ag. emeticus et l'Ag. alutaceus.

Ag. (Russ.) couleur de lait (Ag. Russ. lacteus), Pers., Syn., 343. Paul., t. 74, fig. 2. - Barla, t. 15, fig. 11-13. - Krombh., t. 61, fig. 1-2.
Liéssula lacten, Fr., Evich., 21.

Chair blanche, ferme, sans odeur, comestible, de saveur douce on faiblement piquante.

Ce champignon, entièrement blane, a le chapeau charnu, compacte, à superficie sèche, non lisse, large de 6 à 8 centimètres, d'abord convexe, puis plan et quelquefois déprimé, blanc, mais prenant avec l'àge une teinte alutacée, à bord droit, lisse, souvent fendu; les feuillets épais, distants, libres ou adnés, fermes, larges, saillants, d'un blanc pâle, égaux, quelques-uns étant bifurqués; le pied spongieux au centre, compacte, fort, glabre, blane, cylindrique, long quelquefois de 12 et 15 centimètres, et épais de 4 .

Il croìt dans les bois, de hêtres surtout; rare.

Ag. (Russ.) délicat (Ag. Russ, lepidus), Fr.

(Pl. XXIX, fig. 5.)

Huss., II, t. 32. - Batsch, fig. 12. - Russula lepida, Fr., Epier., 18.

Noms vulgaires: Rouge ou Cul rouge, en Lorraine.

Le chapeau de cet ágaric est large de 8 à 10 centimètres, d'un rouge violacé (rouge-cerise) ou légèrement fulvacé, plus pâle à la circonférence, charnu, compacte, convexe d'abord, puis plan et se déprimant au centre, sub-pulvérulent, non lisse, non luisant, peu ou point strié sur la marge, se fendillant par la sécheresse; les feuillets, larges, épais, droits, non très-serrés, blanc terne ou faiblement jaunâtres, arrondis et plus larges à la circonférence, à tranchant non morfilé, sont égaux, quelques-uns parfois bifurqués; le pédicule, long de 6 à 8 centimètres, plein ou lacuneux, solide, compacte, souvent tortueux, cylindrique ou un peu renflé du haut, blanc, est presque toujours nuancé de rose ou de rouge. 
Cie champignon vient en automme, dans les bois, surtont dans les bois de hêtres. Il est comestible, excellent, de saveur douce. Il a l'odeur faible, la chair ferme, cassante, comme spongieuse, caséeuse. Le chapeau se pèle assez facilement sur les bords, difficilement au centre; la pellicule enlevée laisse une nuance rougeàtre à la superficie de la chair. Les limaces et les vers le recherchent pour leur nourriture.

L'Ag. ruber, qui est vénéneux, ressemble beaucoup à l'Ag. lepidus; celui-ci s'en distingue par son chapean sec, poli, lisse.

Ag. (Russ.) noircissant (Ag. Russ. nigricans), Bull., t. 212.

Sow., t. 30. - Huss., t. 73. - Krombh., t. 70, fig. 14, 15. - Barla, t. 17. -

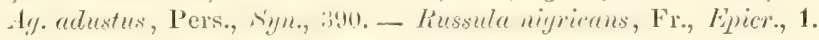

Ce champignon, d'assez grande taille, charnu, fragile, compacte, a le chapeau large de 10 à 12 centimètres, de forme arrondie d'abord, plus tard sinueux, déprimé au centre, de couleur blanc fuligineux ou olivacé-cendré et enfin noirâtre, à bords infléchis, non striés; les feuillets épais, inégaux, distants, rares, arrondis, d'un blanc pâle; le pied plein, solide, d'un blane cendré, long de 3 à 5 centimètres.

Il vient à terre, en abondance, dans les bois, en été et en automne, Sa saveur fongique n'est pas agréable; son odeur est faible.

L'Ag. nigricans passe pour malfaisant; mais son aspect ne dispose guère à en faire usage comme aliment. Sa chair et ses feuillets rougissent un peu, lorsqu'ils sont brisés. Toute la plante se dessèche, et devient entièrement noire en vieillissant, elle reste dans cet état pendant plusieurs mois. Je pense qu'on pourrait l'employer en teinture.

L'Ag. adustus est très-voisin du nigricans; il s'en distingue par ce que ses feuillets sont nombreux et généralement plus petits. Ses propriétès n'ont pas été étudiées.

Ag. (Russ.) blanc jaunàtre (A\%. Russ. ochroleucus), Pers., Syn., 355.

Buxb., t. 45, fig. 7-9. - Krombh., t. 64, fig. 7-9. - Labr., t. 19, fig. 1.

Russula ochroleuca, Fr., Epicr., 27.

Cette espèce ressemble beaucoup, par sa structure et sa nature, à l'agaric émétique : ses caractères sont d'avoir le chapeau constamment de couleur jaune pâle à bord étalé, lisse; les feuillets arrondis posté- 
rieurement, d'un blanc pâle; le pédicule légèrement réticulè, rugueux, d'un blanc cendré.

Elle vient dans les bois des montagnes, surtout les bois de conifères, les lieux humides. Malfaisante. Inodore, saveur àcre.

Ag. (Russ.) pectinacé (Ag. Russ. pectinaceus), Bull., t. 509, fig. N.

Russula pectinata, Fr., Epicr., 26.

Chapeau charriu, d'abord convexe, puis plan, déprimé ou concave, large d'environ 6 centimètres; rigide, d'abord visqueux, ensuite sec, d'un blanc jaunâtre opaque, plus foncé au centre, à bord mince strié sillonné; feuillets atténués et libres, postérieurement plus larges vers la marge, rapprochés, simples, égaux, blancs; pied plein, spongieux à l'intérieur, rigide; légèrement strié longitudinalement, blane, long de 4 centimètres. Dans les bois, en automne. Rare.

Chair blanche, jaunâtre sous la pellicule : odeur nauséeuse; saveur très-âcre. Vénéneux.

Bulliard arait réuni, sous le nom d'Ag. pectinaceus, t. 509, plusieurs espèces de Russules aujourd'hui qualifiées.

Ag. (Russ.) rouge (Ag. Russ, ruber), Fr., Syst., 9.

Larb., t. 18, fig. 7. 一 Krombh., t. 65. - Venturi, t. 7. - Vittad., t. 88, fig. 2. Schæff., t. 15, fig. 4-6. - Barla, t. 15, fig. 1-10. - Russula rubra, Fr., Epicr., 17.

Nom vulgaire: Faux Fayssẻ, dans la Meuse.

Ciette grande et belle espèce, qui vient communément en automne, dans les bois touffus, est vénéneuse. Elle a le chapeau charnu, ferme, d'ahord convexe, puis plan ou déprimé, sec, uni, lisse, non visqueux, large de 8 à 10 centimètres, rouge ou vermillon foncé, quelquefois pâle, ordinairement moins foncé sur le bord, qui est étalé, obtus, non strié; les feuillets adhérents, non décurrents, peu serrés, blanes, cassants, inégaux, entremèlés de feuillets dimidiés et fourchus; le pédicule cylindrique, plus gros près du chapeau, plein, consistant, non lisse, comme sub-cannelé, blanc ou nuancé de rose à la base.

La chair, compacte, épaisse, cassante, comme grumeleuse, rougeâtre sous la cuticule du chapeau, a une saveur très-âcre.

Il ne faut pas confondre l'Ag. miber avec l'Ag. lepidus. La saveur de ce dernier est douce. 
Ag. (Russ.) sanguin (Ag. Russ. sanguineus), Bull., t. 42.

Schæfi., t. 15, fig. 4. - Noul. et Dass., t. 16, fig. B. - Iirssula sanguinea, Fr., Epricr., 7.

Noms vulgaires: Rougetta, à Toulouse; Faux Fayssé, dans la Meuse.

Cette espèce a le chapeau charnu, compacte, de couleur rouge de sang, d'abord convexe, puis déprimé, ef Thème irrégulièrement concave, large de 8 à 10 centimètres, lisse, humide à sa surface, à bord mince, aigu, strié ou légèrement sillonné; les feuillets blanes, minces, étroits, très-serrés, très-nombreux, atténués à leurs extrémités, décurrents sur le pédicule, quelques-uns bifurqués; le pédicule long de 5 à 6 centimètres, d'abord plein, puis creux ou spongieux, nu, cylindrique, blane, et quelquefois faiblement teint de rose.

Les limaces et les vers s'en nourrissent.

Une foule d'auteurs ont constaté que ce champignon est vénéneux ou au moins suspect.

Selon MM. Noulet et Dassier, il serait vendu néanmoins sur les marchés de Toulouse, sans qu'on signale aucun cas où il ait été nuisible; la cuisson, disent-ils, faisant disparaitre son âcreté et le rendant inoffensif. Vittadini l'aurait donnè à des animaux sans qu'ils en fussent incommodés. Mais Hertwig dit qu'une once de cet agaric a occasionné à un chien des vomissements et la prostration des forces. Une chatte, à qui M. Letellier en a fait manger 125 grammes, a eu des vomissements et du dévoiement. Il sera done prudent de s'en abstenir.

Sa chair est ferme, consistante, blanche, ne changeant pas de couleur au contact de l'air; sa saveur âcre, amère, nauséeuse, son odeur faible. Il se pèle difficilement, et on peut détacher les feuillets du chapeau sans les rompre. On le trouve fréquemment, solitaire, dans les lieux humides des bois, en èté et en automne.

Ag. (Russ.) vert de gris (Ag. Russ, virescens), Schæfl., t. 94.

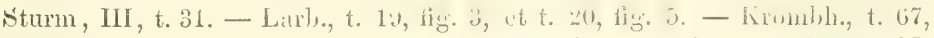
fig. 1-10. - Vent., t. 7, fig. 57, 58. - Berkl., t. 13, fig. 6. - Huss., II, t. 11. - Vittad., t. 31. - Barlit, t. 16, fig. 111-12, - 1'ers., sign., 36t. Russula virescens, Fr., Epior., 19.

Noms vulgaires: Palomet, Cruague, en Gascogne; Berdanel, Berdanello, Bordet, Bordetto, en Languedoc; Iraux-cher, Palomet, dans les Landes; Vert, Cul-vert, Vert-bonnet, dans la Meuse; Bise vraie, dans la Haute-Saòne. 


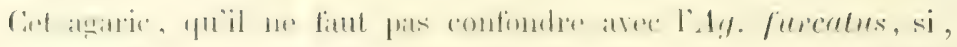

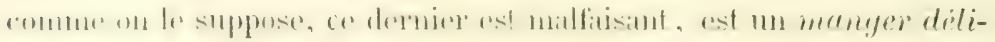
cieu. Il croit à terre, ordinairement seul, dans les bois et les friches, ì la fin de l'été et en automne. Son odeur est agréable, sa saveur douce; sa chair est blanche, cassante; son épiderme se détache difficilement au centre du chapeau.

Ce chapeau, d’abord convexe et régulier, ensuite légèrement concave et irrégulièrement arrondi, large de 8 à 10 centimètres, est de couleur vert-de-gris ou vert d'œillet, plus prononcée au centre, à superficie toujours sèche, couverte de petites verrues ou granulations verdatres, quelquefois aréolée; les feuillets droits, libres, d'un blanc assez pur, peu serrés, parfois anastomosés, atteignant presque tous le pédicule, mais non décurrents; le pédicule rarement droit, long de 4 à 6 centimètres, assez épais, cylindrique ou faiłlement renflé à sa base, plein, blanc.

\section{TCSECLE.}

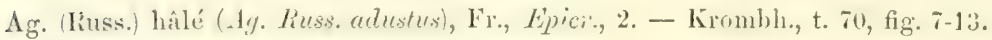
- Dans les bois.

Ag. (Russ.) alutacé (Ag. Russs. alutaceus), Pers. (décrit).

Ag. (Russ.) doré (Ag. Russ. auratus), Schæff., t. 15, fig. 1-3. - Krapf., t. 5, fig. 1-4. - Kromb!., t. 66, fig. 8-11. - Fr., Epicr., 32. - Dans les bois de pins surtout. Comestible.

Ag. (Russ.) consanguin (Aq. Russ. consobrinus), Fr.. Epicr., 28. - Dansles bois de sapins de montagnes. Suspect.

Ag. (Russ.) bleuissant (Ay. Russ. cyanescens), Kickx., Bull. de Bruxelles, 1842. - Sturm., t. 1. - Dans le nord de la France.

Ag. (Russ.) cyanoxanthe (Ag. Russ. cyanoxanthus), Pers., Syn., 360 (décrit).

Ag. (Russ.) serré (Ag. Russ. delicus), Batt., to 17, fig. A. - Paul., t. 73, fig. 1. Fr., Epicr., 4. - Dans les bois de pins. M. Léveillé doute que ce champignon soit une Russule; pour lui, ce serait un Lactaire.

Ag. (Russ.) blafard (Ag. Russ. depallens), Pers., Syn., 346. - Krombh., t. 66, fig. 12, 13. - Fr., Epicr., 12. - Dans les bois, les bruyères, les prés couverts de mousse. Comestible.

Ag. (Russ.) émétique (Ag. Russ. emeticus), Fr. (décrit).

Ag. (Russ.) chicotin (Ag. Riuss. felleus), Fr., Epicr., 16. - Paul., t. 76, fig. 4. Dans les bois de hêtres.

Ag. (Russ.) fétide (Ag. Russ. fcetens), Pers. (décrit).

Ag. (Russ.) fragile (Ag. Puss. fragilis), Pers. (décrit).

Ag. (Russ.) fourchu (Ag. Russ, furcatus), Pers. (décrit).

Ag. (Russ.) blanc de lait (Ag. Russ. galochroa), Bull., t. 509, fig. L, 'M. Batt., t. 12, fig. E. - Dans les bois de bouleaux. Variété de l'Ag. heteroihyllew.

Ag. (Russ.) gris $($ Ag. Russ. griseus), Fr., Epicr., 34. - Pers., Syn., no 358. Dans les bois de hêtres. Est peut-être une variété de l'Ag. decolorans, Fr. 
$\Lambda \mathrm{g}$. (Russ.) hétérophylle (.ly. Russ. heterophyllus), Fr. (décrit).

Ag. (Russ.) intègre (Ag. Russ, integer), Lin. (décrit).

Ag. (Russ.) lacté (Ag. Russ. lacteus), Paul. (décrit).

Ag. (Russ.) délicat (Ag. Russ. lepidus), Fr. (décrit).

Ag. (Russ.) jaune (Ag. Russ. luteus), Hudson. - Fr., Epicr., 39. - Dans les bois de hêtres, en automne.

Ag. (Russ.) nauséeux (Ag. Russ. nauseosus), Pers., Syn. 362. -- Schæff., t. 16, fig. 4. - Fr., Epicr., 41. - Dans les bois de conifères.

Ag. (Russ.) noireissạt ( $\boldsymbol{A} g$. Russ. nigricans), Bull. (décrit).

Ag. (Russ.) luisant (Ag. Russ. nitidus), Pers., Syn., 357. - Schæff., t. 254. Fr., Epicr., 35. - Berkl., t. 13, fig. 7. - En automne, dans les bois, surtout les bois de hêtres. Comestible.

Ag. (Russ.) jaune d'ocre (Ag. Russ. ochraceus), Swartz. - Fr., Epier., 38. Dans les bois de pins.

Ag. (Russ.) blane jaunâtre (Ag. Russ. ochroleucus), Pers. (décrit).

Ag. (Russ.) pectinacé (Ag. Russ. pectinaceus), Bull. (décrit).

Ag. (Russ.) jaune roux (Ag. Rirss. ravidus), Fr., Ag. pectinaceus, Bull., t. 509, fig. A. - Dans les bois de pins.

Ag. (Russ.) iosacé (Ag. Russ. rosaceus), Fr., Ag. pectindceus, Bull., t. 509, fig. Z. - Dans les bois de pins. Suspect.

Ag. (Russ.) rouge (Ag. Russ, ruber), Krombh. (décrit).

Ag. (Russ.) sanguin (Ag. Russ. sanguiners), Bull. (décrit).

Ag. (Russ.) sarde (Ag. Russ. sardonius), Schæff,, t. 16, fig. 5, 6 .

Ag. (Russ.) languissant (Ag. Russ. veternosus), Fr., Epicr., 15. - Puul., t. 74, fig. 3. - Dans Ies endroits sauvages, les buissons, en octobre et novembre. Comestible en Italie.

Ag. (Russ.) verdoyant (Ag. Russ. virescens), Schæff. (décrit),

Ag. (Russ.) pâle jaunâtre (Ag. Russ. vitellinus), Pers., Syn., 352. - Batsch, t. 72. - Dans les bois, en automne, tardivement. Variété de l'Ag. Russ. nouseosus, Fr., Epicr., 41.

\section{CHANTERLLLE, Ciantharellus.}

(K'ávoxpos, couple.)

Chapeau ou hyménophore garni en dessous de plis étroits ou de feuillets obtus sur leur tranchant; quelquefois rameux ou anastomosés entre eux; hyménophore se continuant avec le pédicule. Champignons terrestres.

Chanterelle orangée (Gantharellus aurantiacus), Fr., Epier., 2.

(PI. XXXII, fig. 2.)

Sow., t. 413. - Jacq., II, t. 14, fig. 3. - Phœb., t. 6, fig. 15-24. - Noul et Dass., t. 11, fig. B. - Berkl., t. 14, fig. 1. - Batsch, fig. 37. - Nees, fig. 233. - Merulius aurantiacus, Pers., Myc., 2.

Var. nigripes, Pers., Myc., 3. - Bull., t. 505, fig. 2.

Le Cantharellus aurantiacus ressemble quelque peu au Cantharellus cibarius, mais sa couleur est ochracée ou orangé fauve, son 


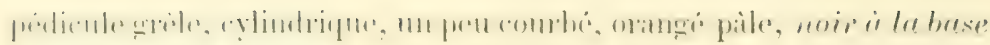

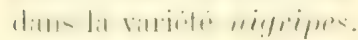

Son chapeau, peu charnu, inégal, d'abord convexe, puis déprimé

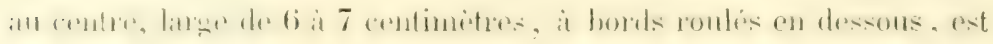
sub-tomenteux, quelquefois glabre. Ses feuillets, formant des plis étroits, seriés, droits, décurrents, bifides ou mème trifides, sont plus foncés en couleur. que le chapeau.

Il vient, à terre, dans les bois de pins, de sapins et les gazons, assez tard. Rare. Il n'a pas l'odeur agréable de la Chanterelle comestible, et de plus sa sareur est déplaisante.

Lenz le dit malfaisant; Fries le range au nombre des champignons non comestibles, et Berkeley pense qu'il l'est à peine. Bien qu'on n'apporte aucune preuve de sa nocuité, il sera prudent de s'en abstenir.

Chanterelle comestible (Cantharellus cibarius), Fr., Epicr., 1.

(Pl. XXXII, fig. 1.)

Schrff., t. n.2 et 211i. - Vaill., t. 11, fig. 14, 15. - liult., t. 62. - Suw. t. 46. - Batsch, fig. 120. - Bull., t. 62 , et t. 105, fig. 1. - Paul., t. 36 Grev., t. 258. - Krombh., t. 45, fig. 1-12, - Vittad., t. 25, fig. 1. - Vent., t. 7, fig. 66, 67. - Viriani, t. 41. - Lenz, t. 27. - Barla, t. 28, fig. 7 ì 15. - Staude, t. 2, fig. 1. - Merulius cantharellus, Pers., Myc., 1.

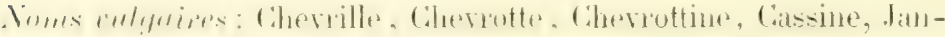
nette, Essau, Grrole, Jaunelet, Jaunire, Escraville, Roussette et Roussome, dans le Nord; Crobillo, Escrobillo, Jerilia, Aoureilleto, Tournebous, Lechocendrés, Boulingoulo, Jirbouleta, Jorilla, Girandelle, dans le Midi.

Cette plante, que l'on rencontre dans presque tous les bois, ḋ la tin de l'été et en automne, est toute de couleur jaune chamois, plus ou moins foncé. Elle a un pédicule nu, plein, charnu, glabre, épais de 10 à 12 millimètres, qui se dilate en un chapeau, toujours glabre, d'abord arrondi et convexe, puis sinueux, quelquefois lobé, creusé en entomioir, presque tonjours plus prolongé d'un còté que de l'autre, et clont le dessous est parcouru par des veines ou replis bifurqués, épais, écurtés, qui sont décurrents sur le pédicule. Elle croit assez sourent en groupes peu nombreux.

La Chanterelle est un fort Jon champignon, connu de tout le monde, et que l'on mange partout. Elle a une odeur agréable, toute particulière; une saveur un peu poivrée, lorsqu'on la mâche crue. On peut reprocher à sa chair d'ètre un peu coriace. 


\section{CIIA TETELIE.}

Ch. de la terre brûlée (C'anth. anthracophlilus), Lév. Alum. des sc nat., 1st1, t. 14, fig. 2. - Sur la terre brûlée, au printemps.

Ch. orangée (Canth. aurantiacüs), Fr. (décrit).

Ch. à pied court (Canth. brachypodes), Chev., t. 7, fig. 5. - Fr., Epicr., 4. Dans les bois.

Ch. des bryums (Canth. bryophilus), Fr., Epicr., 17. - Pers., Obs., Myc., I, t. 3, fig. 1. -- Dans les mousses; rare.

Ch. comestible (Canth. cibarius), Fr. (décrit).

Ch. cendrée (Canth. cinereus), Fr., Epicr., 9. - Krombh., t. 45, fig. 12. - Bolt., t. 34. - Dans les bois, surtout les bois de pins.

Ch. crépue (Canth. crispus), Fr., Epicr., 22. - Pers., Icon. et descr., t. 8, fig. 7. - Sur les branches du bouleau, du hêtre, en hiver.

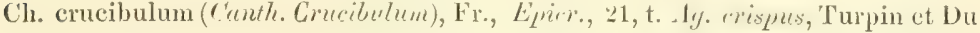
trochet. Canth. Dutrochetii, Mont. - Sur les bois, dans les lieux souterrains.

Ch. en capuchon (Canth. cucullatus), Dub., Bot. Gall., 798. Merulius cucullatus, Brond., Fl. ag., t. 2.

Ch. en cupule (Canth. cupulatus), Bull., t. 601, fig. 3. - Fr., Epicr., 11.-Dans les endroits stériles; très-rare.

Ch. en entonnoir (Canth. infundibuliformis), Fr., Epier., 8. - Sow., t. 47. Krombh., t. 4, fig. 8-10. - Vaill., t. 12, fig. 9, 10. - Dans les bois, sur la terre et les bois en décomposition.

Ch. blange enfumé (Canth. leucophares), Nouel, t. 1, fig. 2, 3. - Fr., Epicr., 10. - Sur la terre.

Ch. lobée (Canth. lobatus), Fr., Epror., 19. - Bolt., t. 177. - Fl. dan., t. 1077. Dans les lieux marécageux, au printemps.

Ch. jaunâtre (Canth. lutescens); Bull., t. 173, fig. 3. - N'est peut-être qu'une variété du Cantharellus tubceformis, Fr. - Voy. Berkeley

Ch. mélanoxère (Canth. melanoxeros), Desm. et Dub., Bot. Gall., 799.

Ch. des grandes mousses (Canth. musciyenus), Fr., Epicr., 14. - Bull., t. 288 et 498, fig. 1. - Sur les grandes mousses.

Ch. deș mousses (Canth. muscorum), Fr., Epior., 20. - Sur les mousses des trones d'arbres.

Ch. réticulée (Canth. retiruyus), Berkl., t. 14, fig. 2. - Fr., Epier., 18. - Helvella retiruga, Bull., t. 498, fig. 1. - Sur les mousses, les chaumes renversés.

Ch. roussâtre (Canth. mufescens), Paul., t. 37, fig. 2, 3. - Fr., Epicr., 3. - Dans les bois.

Ch. délicate (Canth. tenellus), Fr., Epicr., 23. - Fl. dan., t. 1295, fig. 2. - Sur les bois pourris.

Ch. en spatule (Canth. spathulatus), Fr., Epier., 13.

Ch. en tube (Canth. tubaformis), Fr., Epicr., 7. - Bull., t. 493, fig. 3. - Batt., t. 23, fig. 6. - Fl. dan., t. 2080, fig. 1. - Ditm., t. 30. -- Pers., Icon. et descr., t. 6, fig. 1. - Sur la terre et les bois pourris.

C'i. bombée (Canth. umbonatus), Pers, Disp., 27. - Jaeq., t. 16, fig. 1. - Fr., Epicr., 5. - Dans les bois, sur les places à foumeau, sur les mousses menues. 
Tableau sungtique des IBoletoidés.

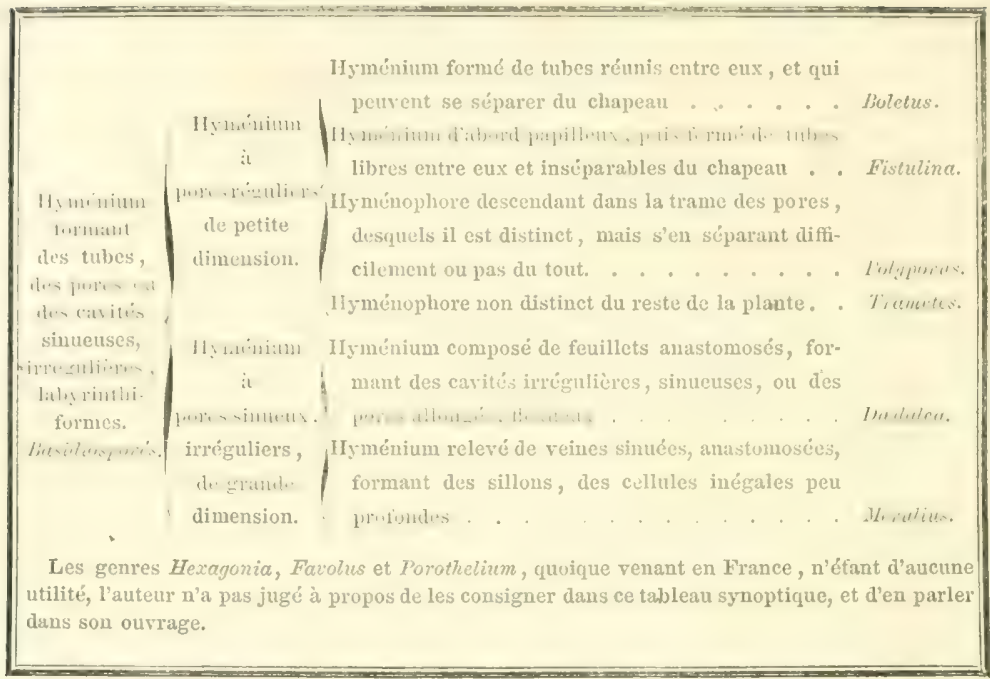

\section{ORDRE 2e. - BOLÉTOIDÉS (Boletoidei).}

Hyménium formant des tubes, des pores ou des cavités sinueuses, irrégulières, labyrinthiformes. BASIDIOSPORÉs.

FISTULINE, Fistulina (fistula, chalumeau).

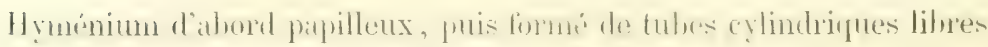
entre eux, dont l'orifice est radié et frangé.

Fistuline hépatique (Fistulina hepatica), Fr.

Tratt., t. 12, fig. 23. - Sehæfi., t. 116 et 120. - Sow., t. 58. - Fl. dan., t. 1126, 1137, - Sehm., t. 1. - Grev., t. 270. - Paul., t. 12. - Krombh., t. 44. - Vittad., t. 36. - Huss., I, t. 65. - Berkl, t. 17, fig. 1. - Bolt., t. 79. - Fistulina buglossoides, Bull., t. 74, 464 et 497. - Fr., Epicr., 1. Hypodrys hepaticus, Pers., Myc., 1.

Noms vulgaires: Langue de boeuf; Foie de bouf; Glu de chène ; Langue de chàtaignier; Bolet foie. 
Plante charnue et un peu gélatineuse, d'un rouge brun, atteignant 12 à 15 centimètres et plus de diamètre, sessile ou portée par un pédicule latéral gros et court. Sa face supérieure est toujours gluante et parsemée, dans la jeunesse, de petites protubérances, qui se détachant, plus tòt on plus tard, rendent cette surface lisse. La face inférieure, reconverte de tubes distincts, séparés les uns des autres, grêles, inégaux, très-serrés, d'abord Jlanes, puis d'un jaune pâle, un peu frangés à leur orifice.

La Fistuline hepatique croit sur les vieilles souches, le plus souvent au pied des vieux chènes, des châtaigniers, et à fleur de terre, en septembre et en octobre. Sa chair, épaisse, mollasse, fibreuse, est marbrée, plus ou moins rouge, ce qui la fait ressembler à la chair ou au foie des animaux; lorsqu'on la coupe, il en découle un suc rougeâtre; elle n'a pas d'odeur sensible, mais un goût vineux, un peu acide.

Elle fournit un aliment agréable; on préfère, pour l'usage, les individus qui ne sont pas trop avancés; un seul suffit quelquefois à faire un repas.

On zetire de ce champignon la glu, dite glu de chêne.

Bolet, Boletus (Bwitrn, nom grec d'un champignon).

Hyménium formé de tubes réunis entre eux et pouvant se séparer du chapeau.

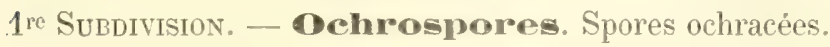

Bolet bronzé (Boletus cereus), Bull., t. 385.

Krombh., t. 36, fig. 1-7. - Fr., Epicr., 39.

Noms vulgaires: Ceps noirs; Gendarme noir, dans les Vosges; Cep, dans le Tarn.

Le chapeau du Bol. cereus est épais, orbiculaire, compacte, glabre, d'un brun olivacé ou noir bronzé, mèlé de rouge. Les tubes sont courts, serrés, à peu près libres, à orifices très-petits, de couleur jaune de soufre. Pédicule, long de 5 à 7 centimètres, à peu près égal dans toute son étendue, ferme, jaunâtre, 'réticulé de fauve à sa base.

Il est rare, et croît, à terre, en automne, dans les bois. 
Comestible; on le préfère même au Bol. edulis. Sa chair est błanche, quelquefois un peu rougeàtre vers la peau, et jaune verdâtre vers les tubes; ses pores, parfois comme obstrués, verdissent et ensuite deviennent d'un rouge brun à leur orifice, s'il est froissé.

Bolet d'été (Boletus restivalis), Paul., t. 170

$$
\text { Huss., II, t. 25. - Fr., Epicr., } 44 .
$$

Champignon de grande taille, de couleur gris de lin d'abord et ensuite d'un roux tendre ou café au lait, qui vient dans les bois du Midi de la France, en mai, juin et juillet, et que les vers attaquent facilement. Odeur et saveur agréables.

Il a le chapeau charnu, épais, large de 12 à 15 centimètres, d'abord convexe, puis étalé, doux au toucher, comme soyeux, se gerçant finement et devenant granuleux, à mesure qu'il s'étale; les tubes cylindriques, allongés, d'un blanc pâle; le pédicule fort, consistant, de la couleur du chapeau, lisse, non réticulé, haut de 10 à 12 centimètres, gros, à sa base, de 5 à 6 centimètres.

Paulet dit que c'est un manger délicieux.

Bolet orangé (Boletus aurantiacus), Bull., t. 236 et 489, fig. 2.

$$
\text { (P1. XXXVIl, fig. 2.) }
$$

Krombh., t. 32, fig. 1-11. - Barla, t. 35, fig. 6-12. - Pers., Myc., 34.

Noms vulgaires: Bolet orangé, Gyrole rouge, Roussille.

Cie champignon, commun, en automne, dans les bois, a le chapeau large de 8 à 12 centimètres, orbiculaire, convexe, épais, orangé ou rouge fative, sub-visquenx par les temps de pluie, portant le plus souvent ì son bord une sorte de frange simulant les débris d'un d'un anneau membraneux; les tubes, d'un blane terne, allongés, étroits; le pédicule, long de 10 à 15 centimètres, épais, cylindrique ou grossianant du sommet vers la base, plein, hérissé de petites aspérités rou àtres; la chair, blanche et molle, prenant une teinte vineuse, quelque tomps après avoir été entamée.

Pour quelques auteurs, ce Bolet ne serait qu'une variété du Boletus scal.cr'; mais je n'ai jamais rencontré dans le Boletus scaber le petit insecte diptère qui attaque le Bolet orangé et y creuse des galeries.

Comestible: mollasse et sans goût, lorsqu'il est vieux. 
Bolet bai brun (Boletus badius), Fr., Epicr., 8 .

Lenz, fig. 35. - Krombh,, t. 36, fig. 15.

Chapeau arrondi, convexe, mou, visqueux dans un temps de pluie, luisant par un temps sec, mais toujours lisse, large de 4 à 5 centimètres, bai fauve; ayant des tubes, adnés ou sinueux déprimés, assez larges, anguleux, d'un blanc terne, jaunàtre, passant au verdàtre; porté sur un pédicule solide, à peu près cylindrique, atténué à l'une de ses extrémités, jamais bulbeux, lisse, nu, parsemé d'une sorte de farine d'un brun plus pâle.

Est rare; vient dans les bois montueux de sapins; sa chair devient partiellement bleue près des tubes. Comestible.

Bolet des bouviers (Boletus bovinus), Lin.

Fl. dan., t. 1018. - Schw., t. 6, fig. 19. - Huss., I, t. 34. - Lenz, fig. 38. - Krombh., t. 75, fig. 1-6. - Fr., Epicr., 6, - Boletus mitis, Pers., Myc., Eur., 10, et Boletus viscosus, id. 14.

Assez commun dans les Vosges, ce Bolet croît en touffes, plus ou moins nombreuses, dans les forêts de pins. On le mange en Angleterre. Il a la chair blanche, une saveur non âcre; le chapeau, plan, ondulé, visqueux par les temps humides, glabre et brillant par les temps secs, ferrugineux roux, large de 5 à 8 centimètres; les tubes sub-décurrents, anguleux, sub-irréguliers, assez grands, d'un gris roux ferrugineux; le pied, cylindrique, lisse, unicolore, subflexueux, non pourvu de collier, long de 3 à 4 centimètres, peu épais.

Le Boletus flavidus, Fr. (B. velatus, Pers., Myc., t. 20, fig. 1-3), qui vient dans les tourbières des Vosges, ressemble au B. bovinus; il n'en diffère guère que parce qu'il n'a pas d'anneau distinct. On ne dit pas qu'il soit comestible.

Bolet calopus (Boletus calopus), Fr., Epicr., 26.

Krombh., t. 37, fig. 1-7. -- Boletus terreus, Schæef., t. 315.

Chapeau globuleux étant jeune, puis en coussin, de 6 à 9 centimètres de diamètre, sub-tomenteux dans sa jeunesse, finiment fendillé quand il est vieux, de conleur olivàtre terne; tubes petits, jaunes, adnés, anguleux à leur orifice; pied ferme, sub-égal, réticulé, d'un rouge écarlate. 
Dans les bois; août, septembre et octobre. Remarqquable par sa le:autic.

Chair spongieuse, pâle jaunâtre, plus ou moins bleuissant au contact de l'air. Inodore, point de saveur particulière. Réveil le dit vénéneux.

Bolet chrysenteron (Boletus chrysenteron), Bull., t. 490, fig. 3.

$$
\text { Huss, I, t. 5. - Krombh, t. 76, fig. 1-5. - Fr., Epier, } 21 .
$$

Chapeau convexe, à la fin un peu aplati, large d'environ 5 centimètres, de couleur brun terne, tirant sur le rouge de brique, floconneux et comme finement squameux, presque toujours fendillé en aréoles, dont les interstices sont de couleur rougeatre; tubes subadnés, assez larges, anguleux, inégaux, d'un jaune verdâtre, déprimés autour d'mn pédicule cylindrique, flexueux, rigide, fibrilleux, sub-strié ou finement ponctué, jaune, un peu renflé et souvent rougeâtre à sa partie inférieure.

Dans les bois, les prairies.

Chair jaune; rouge sous la cuticule; odeur faible, saveur peu prononcée. Suspect, dit-on. Néanmoins pour beaucoup de botanistes le Bol. chrysenteron ne serait qu'une variété du Bol. subtomentosus.

Bolet comestible (Boletus edulis), Bull, t. 60, 494.

$$
\text { (Pl. XXXIV.) }
$$

Letell., t. 614. - Sow., t. 111 et 419. - Tratt., fig. 34. - Su. bot., t. 197. - Schæff., t. 134, 135. - Lenz, fig. 34. - Staude, t. 3, flg. 3. - Huss., I, t. 81. - Berkl., t. 15, fig. 6. - Krombh., t. 31. - Vittad., t. 22。 Roq., t. 3-5. - Paul., t. 167, 168. - Pers., MIyc., nos 14, 19, 28. - Fr., Epicr., 38. - Mich., t. 68, fig. 1. - Buxb., cent. 5 et 12.

Var. A. Boletus albus, Pers., Champ. com., p. 233. - Paul., t. 177, fig. 1. Var. B. Boletus fulugineus, Fl. dan., t. 1296.

Noms vulgaires: Ceps, Cèpet, Bruguet, Bolé, Éssalon, Pṛourse, Potiron, Porchin; Aricèlous, Moussar; Nissoulous, en Languedoc; Miquemot, dans le Tarn; Michotte, Grosse queue, dans la Meuse; Polonais, dans les Vosges.

Ce Bolet s'élève à la hauteur de 15 à 20 centimètres. Son pédicule est gros, plein, cylindrique, quelquefois renflé à sa base, et alors plus court, blanchàtre, jaune ou fauve clair, réticulé. Son chapeau, épais, 
convexe, glabre, humide par les temps pluvieux, large de 15 centimètres et plus, d'un jaune terne, brun, rouge brun ou rouge cendré, ou mème blanchâtre, a des tubes allongés, petits, d'abord blancs, puis d'un jaune pâle ou jaune verdàtre. Sa chair est épaisse, de couleur blanche ou jaunàtre, assez souvent avec une teinte vineuse sous la peau, ne changeant pas lorsqu'on brise la plante. Saveur agréable; odeur nulle.

Le Boletus edulis vient à terre, dans tous les bois, depuis le mois de juillet jusqu'à la fin de septembre; il est d'un fréquent usage - comme aliment et comme assaisonnement, surtout dans le Midi de la France.

Bolet élégant (Boletus elegans), Schum.

$$
\begin{aligned}
& \text { Grev., t. 183. - Huss., II, t. 12. - Krombh., t. 34, fig. 1-10. - Fr., Epicr., } 2 . \\
& \text { Boletus armeniacus, Pers, note inédite. }
\end{aligned}
$$

Var. flaves, à tubes plus allomés, Bolt., t. 169. - Sow., t. 265.

Bolet à chapeau peu charnu, large de 8 à 10 centimètres, de forme régulière, convexe, étalé, très-visqueux par les temps humides, couleur jaune d'or ou jaune pâle, tirant sur le fauve, à bords minces. Les tubes, de la couleur du chapeau, réguliers, alvéolés, anguleux, nombreux, peu adhérents au chapeau, quelques-uns plus courts, sub- décurrents, sur un pèdicule long de 8 à 10 centimètres, plein, flexueux, cylindrique ou grossissant légèrement vers la base, ponctué ou écailleux, de la couleur du chapeau, portant, vers son sommet, les débris d'un collet aranéeux, peu consistant, plus pâle que le pédicule.

Il croît en automne, plus particulièrement dans les bois de conifẻres, seul ou en groupes peu nombreux.

Il est commun et comestible, mais non délicat à manger; chair jaune, saveur faible, odeur fongique.

Le $B$. elegans diffère du $B$. luteus par son pied beaucoup plus long, squameux, ridé, sub-réticulé, sa couleur moins foncée, sa chair jaune.

Persoon, dans une note inédite, appelle B. armeniacus, le B. élégant, à cause de sa couleur, qui est à peu près celle de l'abrịcot.

Mougeot et Berkeley regardent la variété flavus, comme formant une espèce distincte. 
Bolet à pied rouge (Boletus erythropus), Pers., Myc., 15.

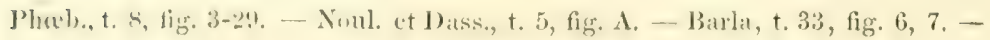
Fr., Epicr., 33.

I. Bul. enythopues vient dans les bois, en automme. Il a le chapean tomenteux, presque velonte, vispuenx par les temples de pluie, fanre roussâtre ou marron fauve, d'abord convexe, puis plan; les tubes libres, d'un rouge foncé à leur orifice; le pédicule non réticulé, mais sub-granuleux à son sommet, tantôt court, tantòt allongé, extérieurement rouge à peu près dans toute sa longueur, à l'intérieur rouge à sa base,

Sa chair jaune devient bleue lorsqu'on la coupe, et partiellement rouge; elle a une saveur acide.

Reveil regarde ce champignon comme vénéneux.

Il n'est pour quelques auteurs qu'une variété du B. luridus, espèce malfaisante aussi.

\section{Bolet granulé (Boletus granulatus), Lin.}

(Pl. XXXV, fig. 1.)

Nees, fig. 205. - Schæft., t. 123. - Lenz, fig. 51. - Letell., t. 604. Krombh., t, 34, fig. 11-14. - Barla, to 31, fig. 4-12. - Fr., Epier., 5. Boletus circinans, Pers., Myc., 5.

Cie Bolet ressemble beaucoup au $B$. luteus, et n'en diffère guère que par l'absence d'un anneau membraneux. Son chapeau, large de 8 à 10 centimètres, est d'abord hémisphérique, puis convexe, puis plan, légèrement onduleux, fauve ou brun, peu charnu, enduit à sa surface d'une matière visqueuse, surtout chez les jeunes individus. Les tubes, étroits, courts, granuleux à leur orifice, d'un blanc pâle d'abord et ensuite d'un jaune fucescent, sont adnés ou un peu décurrents sur un pédicule cylindrique, quelquefois atténué en haut, court, jaunâtre, parsemé au sommet de granulations.

On le trouve dans les gazons des bois de pins, solitaire ou en petits groupes. Souvent les individus placés à peu de distance les uns des autres forment sur le sol de longues traînées, ou même des cercles, ce qui l'a fait appeler par Persoon circinans.

Saveur un peu acide; odeur sub-vireuse. Reveil le donne pour suspect. Il passe généralement pour malfaisant; je l'ai cependant mangé impunément. 
Bolet livide (Boletus lividus), Bull., t. 490, fig. 2.

Letell., t. 606. - Fr., Epicr., 17. - Pers., Myc., 8, et Boletus brachypomus, Pers., Myc., 7.

Bolet à chapeau compacte, large de 6 à 8 centimètres, d'abord convexe, puis aplati, et quelquefois déprimé, souvent inégal, ondulé, d'un jaune livide ou fuligineux. Ses tubes sont très-courts, sub-décurrents, d'un jaune verdâtre. Le pied, lisse, épaissi par le haut, atténué en bas, souvent courbé, et d'un jaune fuscescent.

On le trouve dans les lieux humides, sub-ombragés; solitaire; assez rare. Sa chair est sub-virescente, sa saveur acide, son mycélium d'un blanc olivacé.

Alimentaire. Avancé en âge, il est dur, coriace, et donne de légères coliques.

Bolet de loup (Boletus lupinus); Fr., Epicr., 32

Boletus erythropus, Krombh., t. 38, fig. 7-10.

Chapeau arrondi, de 6 à 8 centimètres de diamètre, glabre, sec, non luissant, de couleur sale, livide avec une légère teinte verdâtre; tubes libres, petits, jaunes, d'un rouge orangé à leur orifice ; pied obèse, ovoïde, imparfaitement réticulé, de la couleur du chapeau vers le haut, teint d'un rose sanguin intérieurement.

Dans les bois, août et septembre.

Chair d'un gris jaunâtre, devenant bleuâtre au contact de l'air, et non rougeàtre.

Odeur et saveur acides. Vénéneux.

Bolet blême (Boletus luridus), Schæff., t. 107.

(Pl. XXXVI, fig. 1.)

Grev., t. 121. - Tratt., t. 9, fig. 17. - Huss., II, t. 26 et 35. - Roques, t. 4. - Paul., t. 176. - Buxb., t. 5, fig. 13. - Krombh., t. 38, fig. 11-17. Letell., fig. 32. - Berkl., t. 15, fig. 5. - Barla, t. 33, fig. 1-5. - Boletus mubeolarius, Bull., t. 490, fig. 1, et Boletus tuberosus, id. t. 100. - Fr., Epicr., 33. - Pers., Hyyc., 15.

Var. A. Boletus tuberosus, Pers. Chapeau presque hémisphérique, d'un brun olivâtre, à pied très-court, renfté en bulbe arrondi. - Bolt., t. 85. Sow., t. 150. - Batt., t. 29, fig. A, B, D. - Noul. et Dass., t. 5, fig. B.

Nom vulgaire: Bruguët fol, Cul de Saoumo, en Gascogne.

Chapeau large quelquefois de 30 centimètres, et quelquefois de 6 à 10 seulement, convexe, orbiculaire, d'abord sub-tomenteux, ensuite 


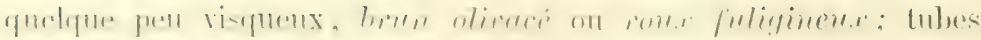
longs, petits, ronds, jamnes dans leur longueur, jaune rouge ou conleur de cimabre à leur orifice; pédicule ferme, épais, réticulé nu ponctué de rouge, cylindrique ou bulbeux.

Le Boletus luridus est très-commun, à terre, dans les bois et les pâturages des bois, à la fin de l'été et en automne. Sa chair jaune, devient promptement bleue, lorsqu'elle est coupée ou brisée. L'odeur faible, nauséeuse ; la saveur non désagréable chez les jeunes individus, léplaisante, au contraire, chez les individus adultes.

D'après les observations de Paulet et de Roques, le Bol luridus serait très-dangereux, ayant occasionné des vomissements, des convulsions et de la stupeur à des hommes et à des animaux qui en avaient mangé. Viviani raconte que, pour en avoir fait usage, une famille entière de paysans faillit périr. Il paraît cependant, au rapport de Palisot de Beaurois et d'Ascherson, qu'il est employé comme aliment dans quelques pays ; Lenz dit qu'on l'apporte, en quantité, aux marchés d'Allemagne, ¿ Olmütz et à Brünn; ce serait alors le mode de préparation culinaire qui le rendrait inoffensif en détruisant son principe actif. Lenz l'a mangé et des familles entières l'ont mangé comme lui. Trattinik dit qu'on ne le vend pas sur les marchés en Autriche, mais qu'en Pologne, les paysans le mangent, cuit sous la cendre; cependant, ajoutet-il, il est démontré que souvent son usage provoque des vomissements violents et un assoupissement profond. Reveil l'ayant donné à un chien, cru, pilé et mélangé à de la soupe, l'animal est mort le cinquième jour.

Il est probable que plusieurs espèces ont été confondues sous le nom de $B$. luridus.

Le Boletus erythropus, Pers., le Boletus lupinus, Fr., et le Boletus satanas, Lenz, ont été longtemps regardés par les botanistes comme de simples variétés du B. luridus. Aujourd'hui encore, quelques auteurs ne les admettent pas comme espèces distinctes; il est difficile, en effet, d'établir les caractères spécifiques de ces plantes.

Bolet jaunâtre (Bulctus lutcus), Lin.

(P. XXYT, fig, 2.)

Schæff,, t. 114. - Fl. dan., t. 1135. - Nees, fig. 204. - Lenz, fig. 30. Krombh., t. 33. - Barla, t. 31, fig. 143. - Fr., Epior., 1. - Boletus annulatus, Bull., t. 332. - Pers, Myc., 2.

Le Boletus luteus se distingue facilement de la plupart de ses con'génẻres par la présence d'un anneau membraneux, qui souvent 
disparaît de bonne heure, et qui est porté sur un pédicule long de 3 à 5 centimètres, peu épais, cylindrique, plein, jaunàtre, ponctué de granulations au-dessus de l'anneau.

Chapeau convexe, d'un jaune fauve ou fauve brunâtre, quelquefois tachèté de lignes roussâtres, large de 8 à 10 centimètres, enduit d'une matière visqueuse par les temps humides, a des tubes petits, ronds, quelquefois sub-décurrents, d'un jaune foncé.

Il croît communément, en automne, sur la terre, dans les bois, et plus particulièrement dans les bois de pins et de sapins.

Comestible. Sa chair, assez ferme, épaisse, blanche, chez les jeunes individus, ensuite jaunâtre, ne change pas de couleur lorsqu'on la déchire; elle a le goût d'abord un peu aigrelet, puis"suivi d'amertume.

Ce Bolet est d'un usage commun en Bavière et en Prusse. Lenz dit qu'on le consomme par milliers à Prague, en Bohème. Je l'ai mangé, et l'ai trouvé bon.

M. Letellier le déclare indigeste; 150 grammes, donnés par lui à un chat, ont occasionnè à l'animal du dégoût et du dévoiement.

Bolet obson (Boletus Obsonirum), Paul, t. 171, fig. 2, 3.

Krombh., t. 7t, fig. 12-14. - Nich., t. ws, tig. 1. - Mr., Eline, t2. Boletus leoninus, Pers., Myyco, p. 143.

Noms vulgaires: Obson, Opson (du lat. Obsonium, provision de bouche, à cause de ses bonnes qualités).

Chapeau convexe aplati, assez régulier, large de 10 à 12 centimètres, à surface sèche, douce au toucher et comme soyeuse, de couleur feuille morte ou cannelle pâle, sujette à se déchirer, surtout vers le bord, qui est mince; des tubes à demi-libres, petits, ronds, trèscourts vers la marge et le pédicule, d'abord jaunes, puis de la couleur du chapeau; pédicule plein, ferme, conique, lisse, non réticulé, plus pâle que le chapeau.

Ce champignon est un aliment de bonne qualité; sa chair, blanche, assez ferme, change à peine lorsqu'on la coupe. On le recueille, en été et en automne, à terre, dans les bois du Midi de la France.

Bolet gros pied (Boletus pachypus), Fr., Epicr., 29.

$$
\begin{gathered}
\text { Kromb., t. 35, fig. 13-15. - Huss., I, t. 22. - Letell., t. 641. - } \\
\text { Pers., Myc., 13, 16. }
\end{gathered}
$$

Bolet rare, qui vient dans les bois, et surtout les bois de montagnes, et dont le chapeau est bombé, see, sub-tomenteux, d'un fauve pâle, 


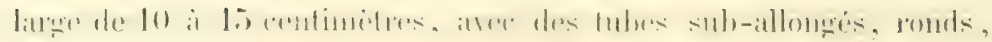

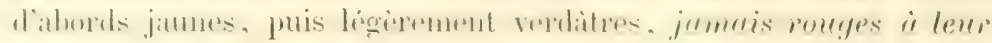
orifice, courts près du pédicule, sub-libres. Pied épais, ferme, réticulé, primitivement court, renflé à la base, plus tard allongé, presque égal, de couleur fauve, variée de rouge.

Selon Lenz et Lasch, il serait comestible, et dangereux, d'après II. Letellier. Il sera donc prudent de s'en abstenir. Sa chair, épaisse et blanche, devient légèrement bleuàtre lorsqu'elle est blessée.

Il ressemble quelque peu au Boletus edulis.

\section{Bolet poivre (Bolotus piperalus, Bull., t. 451, fï. 2}

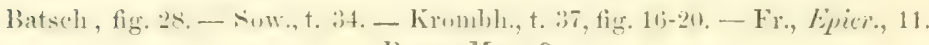
Pers., Myc., 9.

C'est dans les bois que vient ce champignon charnu, dont la chair est jaune, l'odeur faible, la saveur chaude et poivrée.

Il a le chapeau large à peine de 4 à 5 centimètres, convexo-plane, luisant, légèrement visqueux, de couleur fauve cannelle. Ses tubes irréguliers, assez grands, de couleur roux ferrugineux ou fauce rougeâtre, plus foncée que celle du chapeau, sub-décurrents. Le pédicule, long de 5 à 6 centimètres, plein, grêle, tortueux, fragile, subpulvérulent, faiblement sillonné, jaune, mais d'un fauve jounatre is sa base, qui est un peu atténuée, tandis qu'il va en grossissant légèrement à sa partie supérieure.

Fries dit qu'il est un peu malfaisant. Reveil dit l'avoir mangé, mais en petite quantité.

Bolet Satan (Boletus Satanas), Lenz, fig. 33.

(Pl. XXXVI, fig. 2.)

Huss., I, t. 7. - Krombl., t. 38, fig. 1-6. - Phøb., t. 1, 2. - Fr., Epier., 31.Boletus marmoreus, Roq., t. 6.

Le Bol. Satanas a le chapeau charnu, très-épais, convexe, large de 10 centimètres environ, glabre, légèrement visqueux, de couleur. lauve clair, faiblement nuancé de rose, comme marbré au centre, blanchàtre sur les bords; les tubes étroits, petits, allongés, libres, d'un jaune verdàtre dans leur longueur, et d'un rouge sanguin à leur orifice; le pédicule gros, ventru, long de 8 à 10 centimètres, rougecarmin ou rouge de sang, réticulé à sa partie supérieure.

Il se trouve, en automne, dans les bois des provinces méridionales the lia firance. 
Sa saveur est douce, non anı̀re; son olenr non désagréable; sa chair blanche devient rougeâtre ou violacée lorsqu'on la rompt.

Extrêmement vénéneux; Lenz a èprouvé sur lui-mème ses propriétés malfaisantes; heureusement cette espèce est assez rare en France.

Bolet rude (Boletus scaber), Fr., Epicr, 52.

(Pl. XXXVII, fig. 1.)

Sehæff., t. 104. - Fl. dan., t. 853, fig. 2, 3. - Vittad., t. 28. - Bolt., t. 8. - Krombh., t. 35, fig. 1-6. - Sow., t. 175. - Lenz, fig. 32. - Huss., I, t. 57. - Barla, t. 35, fig. 1-5. - Paul, t. 176, fig. 1-2. - Roq., t. 3. Bull., t. 132, et 489, fig. 1. - Pers., Myc., 33.

Noms vulgaires: Gyrole; Tremoulo, Tremoulen, en Gascogne.

Le Boletus scaber s'élève à la hauteur de 12 à 15 centimètres. Son pédicule est le plus souvent grèle, flexueux, cylindrique ou grossissant du sommet à la base, plein, hérissé de petites aspérités noiràtres, comme strié. Le chapeau, orbiculaire, convexe, large de 6 a 10 centimètres, est tantòt fauve jaunàtre, tantòt bistré ou fuligineux, visqueux par les temps humides. Les tubes sont petits, allongés, ordinairement d'un blanc sale, quelquefois gris

Il vient à terre dans presque tous les bois; commun à l'entrée de l'automne. Sa chair, un peu mollasse, est acidulée; cassée, elle prend quelquefois une couleur vineuse.

On le mange, lorsqu'il est jeune; le pédicule, fibreux, cassant, se rejette. Saveur un peu salée; odeur nulle.

Bolet sub-tomenteux (Boletus subtomentosus), Lin.

(Pl. XXXVIII, tig. 2.)

Sichæfi., t. 112. - Nees, fig. 206. - Lenz, fig. 36, 37. - Fl. dan., t. 1074. - Krombh., t. 37, fig. 8-11. - Bull., t. 393, fig. A. - Paul., t. 172, 173, 183. - Fr., Epicr., 22.

Cie champignon varie beaucoup pour la forme, la couleur et les dimensions. Son pédicule, grêle, long de 10 à 12 centimètres, ordinairement tortueux, le plus souvent cylindrique, aminci, d'autres fois renflé à sa base, strié, réticulé ou ponctué à sa partie supérieure, de couleur jaune, fréquemment strié de rouge, supporte un chapeau, orbiculaire, convexo-plane, sub-tomenteux, brun rougeâtre, brun olivâtre ou bronzé, ayant 8 à 12 centimètres de diamètre, sujet, dans la vieillesse, à se gercer en aréoles, dont les interstices sont de cou- 


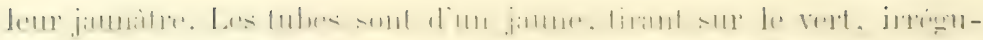
liers, larges, allongés; ceux qui raissent près du pédicule, moins longs, laissent autour de ce pédicule une sorte de vide.

Il croit communément dans les bois, à terre, en été et en automne, le plus souvent solitaire.

Sa chair, molle, cassante, d'un blanc jaunatre, quelquefois un peu changeante, et passant légèrement au bleu si on le casse, a une saveur particulière, une odeur agréable. Comestible.

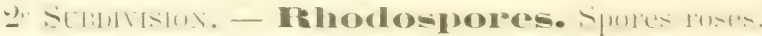

Bolet chicotin (Bolletus folleres), Bull., t. 379.

Krombh., t. 74, fig. 1-7. - - Pers., MIyc., 20. - Fr., Epicr., 56.

Chapeau convexe d'abord, puis plan, et, dans la vieillesse, recourbé sur les bords, glabre, lisse, fauve marron ou mème gris cendré; tuhes allongés, blanchàtres dans le jeune âge, ensuite couleur de chair, devenant larges et irréguliers en vieillissant; pédicule de la couleur du chapeau, grèle, cylindrique, un peu renflé à są base, réticulé à sa partie supérieure.

Ce Bolet vient dans les bois ombragés, en été et en automne.

Suspect. On est peu tenté d'en faire usage, à cause de sa saveur amère et de son odeur désagréable. Sa chair, lorsqu'on la casse, prend une teinte rosée.

3e Subdivision. - Leucospores. Spores blanches.

Bolet marron (Boletus castaneus), Bull., t. 328.

$$
\begin{gathered}
\text { Huss., II, t. 17. - Barla, t. 32, fig. 11-15. - Pers., Myyc., 22. - } \\
\text { Fr., EPicr., 58. }
\end{gathered}
$$

Ce Bolet est tout de couleur marron ou rouge brun, à l'exception de ses tubes, qui sont d'abord d'un blanc de lait, et ensuite jaunes, et des bords du chapeau, qui sont quelquefois jaunâtres. Le chapeau, d'abord convexe, puis à peu près plan, large de 5 à 7 centimètres, a un aspect velouté. Les tubes sont courts, à orifice de petite dimension. Le pédicule est mou, spongieux, ensuite creux, cylindrique, souvent renflé et crevassé à sa base, rarement droit.

Il vient solitaire, dans les bois. Rare.

Sa chair, molle, cotonneuse, de saveur agréable, ne change pas de couleur. Ciomestible. 
Bolet bleuissant (Boletus cyanescens), Bull., t. 369.

Letell., t. 654. - Krombh., t. 35, fig. 7-9. - Roq., t. 8, fig. 1, 2. - Barla, t. 37. - Fr., Epicr., 57. - Pers., MIyc., 18.

Nomes vulgaires: Somcier, dans quelques cantons; Cep-fails, dans le Tarn.

Bolet entièrement d'un blanc pàle ou blane jaunàtre, dont le chapean, "convexe, plitu, sub-toncuteux, a 5 it 8 centimètres de diamètre. Les pores sont ronds, égaux, blancs et enfin jaunâtres. Le pédicule, long de 4 à 5 centimètres, sub-tomenteux, mais non rétiticulé à son sommet, est plus gros dans le milieu qu'aux extrémités, spongieux à l'intérieur. La chair, blanche, compacte, devient, ainsi que les tubes, d'un bleu foncé, lorsqu'on la brise.

Il vient dans les bois stériles et les prés.

Le Bol. cyanescens excite des préventions à cause de sa couleu changeante; Bose assure néanmoins qu'on le mange dans le Piémont; Noulet et Dassier disent, au contraire, que, donné à des chiens, il les a incommodés. La vérité est, qu'avancé dans sa végetation, il devient dux, coriace, et donne de légères coliques. Il est donc prudent de-s'en abstenir.

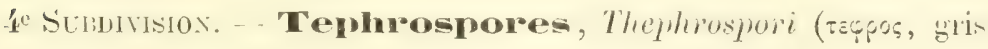
cendré, $\sigma \pi \circ p \alpha$, semence). Spores cendrées.

Bolet floconneux (Boletus floccopus), Vahl.

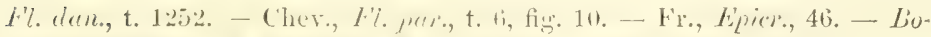

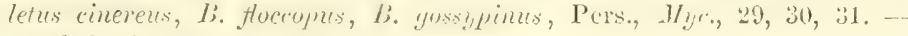
sitrobylonices floreopus, Berkl.

Ce champignon, très-rare, est remarquable par sa forme et sa couleur. Sa chair, blanche et ferme, prend une teinte rosée lorsqu'on la divise. C'est un poison violent; Reveil s'en est assuré par des expériences. Il vient dans les forèts ombragées.

Il est d'abord de couleur de cendre, ensuite noirâtre, a le chapeau convexe, charnu, large de 8 à 10 centimètres, tomenteux, aréolé, recouvert de flocons fasciculés, réunis en papilles, et formant des écailles qui recouvrent toute la surface. Les tubes sont grands, d'un blanc grisàtre, irréguliers, plus courts en arrière. Le pédicule, tantòt court, tantót long, de couleur terre d'ombre inférieurement, tomenteux, est lacuneux au sommet, et porte un anneau persistant. 


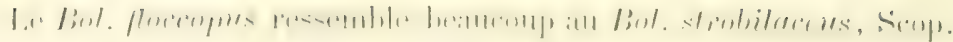
- Fr., Epror., 45. Les propriétés de ce dernier n’ont pas été étudices.

\section{EOLI: I: T}

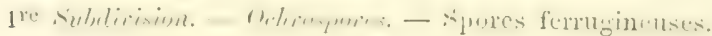

Bul. bronzé (Bol. cereus), Bull. (decrit).

B3.1. d'été (Bol. cestiralis), Paul. (décrit.)

Bul. appendiculé (Bol. appendiculatus). Schæff., t. 130. - Fr., Epicr., 25. 1):m1 lis: l, wis.

Bol. amer (Bol.amarus), Pers., Synz., 5̆11, - Peut-être est-ce une variété du Bol. pachypus.

Bol. orangé (Bol. aurantiacus), Bull. (décrit).

Bul. bai (Bol. badius), Fr. (dicrit).

Bul. des bouviers (Bol. borinus), Lin. (déerit).

13ol. beau pied (Bol. calopus), Fr. (décrit).

Bol. chrysentéron (Bol. chrysenteron), Bull. (décrit).

Bol. muqueux (Bol. collinitus), Schrefi., t. 126. - Fr., Epicr., 4. Comestible.

Bol. comestible (Bol.edulis), Bull. (décrit).

Bol. élégant (Bol. elegans), Schum. (décrit).

Bol. picd rouge (Bol. erythropus), Pers. (déerit).

Bol. jaunâtre (Bol. flaridus), Fr., Epicr., 3. - Krombh., t. 4, fig. 35-37. Bol. velatus, Pers., MIyc., t. 20, fig. 1 ct 3. - Est peut-être une variété du Bol. elegans.

Bol. flave (Bol. Alavus), With. - Sow., t. 265. - Bolt., t. 169. - Est peut-être une variété du Bol. elegans.

13ol. odurant (Bol. frayrans), Vittad., t. 19. - Fr., Epicr., 41. - Dans les bois ombragés du midi de la France. Comestible.

Bul. granulé (Bol.granulatus), Lin. (décrit).

Bul. sordide (Bol. impolitus), Krombl., t. 74 , fig. 10, 11. - Schæff., t. 108. Fr., Epicr., 43. - Daus les bois, sous les chênes. Comestible selon toutu vraisemblanec.

Bol livide (Bol. lividuss), Bull. (déerit).

13ol. du loup (Bol. lupinus), Fr., Epricr., 32, - Krombh., t. 38, fig. 7-10. - En touffes, dans les bois. Vénéneux, selon M. Crouan.

Bol. luride (Bol. luridus), Lin. (décrit).

Bol. jaunâtre (Bol. luteus), Lin. (décrit).

Bol. doux (Bol. mitis), Krombh., t. 36, fig. 15, fig. 8-11. - Fr., Eprier., 7. Dans les bois mixtes;-rare. Comestible. - N'est peut-être qu'une variété du Bol. borinus.

Bol. obson (Biol. Obsonium), Paul. (décrit).

Bol. pied épais (Bol. pachypus), Fr. (décrit).

Bol. parasite (Bol. parasiticus), Br11., t. 451. - Berk1., t. 15, fig. 4. - Fr., Epier., 12. - Sur les Lycoperdonnées.

Bol. poivré (Bol, piperatus), Bull. (décrit).

Bol. porphyrospore (Bol. porphyrosporis), Fr., Eivicr., 48. - Sur les bords sablonneux des chemins.

Bol. pruiné (Lol. pruinatus), Bull., t. 393, fig. B, C. - Fr., Epicer., 19. - Dans les prairies et les bois de hêtres ga\%omneux. 
Bol. pourpré (Bol. purpurens), Fr., Epicr., 34. - Krombh., t. 37, fig. 12-15. Dans les bois de montannes, (n antonne.

Bol. enraciné (Bol. radicans), Per's., Syn., 507. - Fr., Epicr., 24. - Krombh., t. 48, fig. 1-6. - Dans les chênaies. - Est regardé comme malfaisant.

Bol. roux (Bol. rufus), Pers., Obs., t. 2, p. 12. - Dans les bois. - Passe pour dangereux.

Bol. rugueux (Bol. rugosus), Fr., Epicr., 53. - Paul., t. 178, fig. 3. Bol. leucophous, Pers., Myc., p. 140. - C'est peut-être une variété du Bol. scaber.

Bol. chapeau rouge de sang (Bel. sanguineus), With., Arr., 4, p. 319. - Sow., t. 225. - Fr., Epier., 10. - Dans les bois; rare. - Il passe pour vé néneux.

Bol. Satan (Bol. Satanas), Lenz. (décrit).

Bol. scabre (Bol. scaber), Fr. (decrit).

Bol. bai brun (Bol. spadiceus), Schrff,, t. 126. - Krombh., t. 36, fig. 19, 20. Fr., Epicr., 23. - Sur les bois coupés, au bas des trones.

Bol. à tête sphérique (Bol. sphoerocephahus), Barla, t. 36. - Sur la sciure pourrie du bois, dans les Alpes, automne.

Bol. sub-tomenteux (Bol. subtomentosus), Lin. (décrit).

Bol. varié (Bol. variegatus), $\mathrm{F}_{1 .}$, Epicr., 15. - Krombh., t. 34, fig. 15-18, et t. 75, fig. 7-14. - Lenz, fig. 59. - Dans les bois de pins.

Bol. à peau changeante (Bol.versipellis), Fr., Epicr., 51. - Sow., t. 110. Comestible.

Bol. visqueux (Bol. viscidus), Lin, - Fr., Epicr., 47. - Dans les bois.

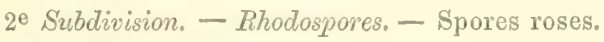

Bol. chicotin (Bol. felleus', Bull. (décrit).

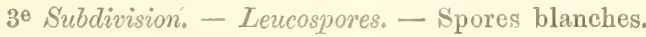

BoI. châtain (Bol. castaneus), Bull. (décrit).

Bol. bleuisant (Bol. cyanescens), Bull. (décrit).

Bol. fauve rougeâtre (Bol. fulvidus), Fr., Epicr., 59. - Krombh., t. 4, fig. 28-30. Bol. testaceus, Pers., Myc., 21. - Dans les prairies stériles.

Bol. blanc de lait (Bol. lacteus), Lér.

$$
4^{\mathrm{e}} \text { Subdivision. - Téphrospores. - Spores cendrées. }
$$

Bol. pied tomenteux (Bol. Aloccopres, Vahl. (décril).

Bol. strobilacé (Bol. strobilaceus), Scop., t. 1, fig. 1. - Pers., Myc., 32, t. 19. Krombh., t. 74, fig. 12, 13. - Dicks., t. 3, fig. 2. - Strobilomyces strobilaceus, Bérkl., p. 286. - Dans les bois, surtout de conifères. 


\section{POLYPORE Polyporus.}

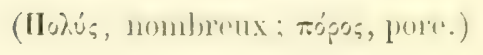

Hyménophore distinct du reste du chapeau, descendant dians la trame des pores, mais s'en séparant difficilement ou pas du tout.

fre Simiviston. - Mesopus (Mśss, milieu; noús, pied).

Champignon simple, chapeau entier, pied central, base de la couleur du chapeau.

Polypore fuligineux (Polyporus fuligineus), Fr., Epicr., 10.

$$
\text { Boletus polyporus, Bull., t. } 469 .
$$

Chapeau très-mince, charnu, mais un peu coriace, étalé, creusẻ en coupe ou déprimé au centre, glabre, d'un fauve clair, à bords sinueux, réfléchis. Les pores sont étroits, ronds, ègux, superficiels, nombrux, égaux, d'abord d'un blanc pur, puis d'un blanc légèrement cendré. Le pédicule, central, d'un jaune terreux, rougeâtre à la base, glabre, est un peu dilaté à chacune de ses extrémités.

Le Polyporus fuligineus vient à terre, dans les bois, et plus fréquemment dans les vergers, en automne; est fort rare.

Comestible, selon Fries. Chair, blanche, molle, quoique coriace.

Polypore des pacages (Polyporus ovinus), Fr., Epicr., 4.

Schæff., t. 121, 122. - Fl. dan., t. 1618. - Nees, ,t. 27. - Rostk., t. 3. Krombh., t. 52, fig. 1. - Maeq., t. 1, fig. 15. - Lenz, t. 8, fig. 24. -Pers., Myyc., 12.

Cie champignon est chamu, assez compacte, mais fragile. Son chapeau, d'un blanc pale, le plus souvent irrégulier, bientòt chargé de petites écailles, se gerce par les temps secs. Pédicule, court, inégal, blanc. Pores, petits, ronds, égaux, d'un blanc de citron.

Il est de taille moyenne, variable de forme, et mème de couleur; vu a distance, on le prendrait pour un agaric.

On le trouve dans les bois de pins, le plus souvent en groupes; il a une saveur d'amande agréable. Fries dit que dans ses excursions mycologiques, ses compagnons le mangeaient, mème cru. 
Polypore tubérastre (Polyporus tuberaster, Fr., Epicr., 2.

Mich., t. 71, fig. 1. - Batt., t. 24, fig. A. - Jacr., Suppl., 160, G. 8, 9. Nees, fig. 211. - Paul., t. 165, 166. - Pers., Myc., 13.

Ce Polypore, qui vient spontanément dans les montagnes de l'Italie centrale et méridionale, est cultivé dans une partie de l'Europe méridionale. Son mycélium, ou ce que les jardiniers appellent blanc de champignon, est ample, consistant; il englobe et lie ensemble, de la terre, des fragments de pierre et de bois, et forme ces corps fermes ou masses, connues en Italie sous le nom de Pietra fungaja, pierre à champignons.

Le Polyporus tuberaster a le chapeau charnu, mince, d'abord plan, puis déprimé ou en forme d'entonnoir, onduleux, villeux, squameux, jaunâtre ou roussâtre, large quelquefois de 15 et 20 centimètres; les pores, assez grands, égaux, sub-anguleux, ou comme finement dentés, consistants, blanchàtres, décurrents sur un pédicule, court, ferme, mince, glabre, concolore avec le chapeau.

La pierre à champignons peut se transporter d'un lieu dans un autre, et produit tous les mois, au rapport de Micheli, des champignons, qui souvent poussent én groupes. On la tient ordinairement à la cave, en ayant soin de l'arroser de temps à autre. Transportée en Suède et dans les pays froids, elle dégénère et finit par ne plus rien produire.

Le Polyporus tuberaster a une saveur et une odeur agréables, est recherché et de très-bonne qualité; on le cultive maintenant dans le midi de la France. Le chapeau seul sert d'aliment.

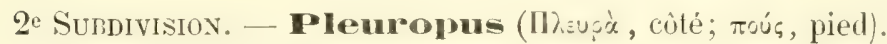

Chapeau simple, pied de côté, noir à la base.

Polypore écailleux (Polyporus squamosus), Schæff., t. 101, 102.

Sow., t. 366. - Fl. dan., t. 983, 1196. - Grev., t. 207. - Huss., I, t. 33. Rostk., t. 2. - Bolt., t. 77. - Sterb., t. 13, 14. - Paul., t. 16. - Noul. et Dass., t. 8. - Fr., Epicr., 41. - Bol. Juglandis, Bull., t. 19 et 114. Pers., Myc., 9.

Noms vulgaires: Miellin, Langon, Oreille d'orme, Oreille de Malchus; Camparol d'Oulmé, Boulet d'Oulmé, en Gascogne.

Le Polyporus squamosus croît particulièrement sur les vieux troncs du noyer et de l'orme; on le trouve aussi sur le tilleul, le saule, le peuplier, le frêne et le mûrier blanc. Il a un pédicule latéral, très- 


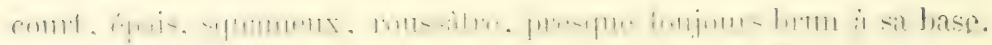
Son chapeau est dimidié, le plus souvent imbriqué, charnu, mais coriace, taillé pour ainsi dire en éventail, atteignant de 15 à 45 centimitres de diamc̀tre, jaune roux ou fauve bistré, ordinairement courert de squanes bruncities, partant de l'insertion du chapeau, et se dirigeant vers la circonfẻrence. Les tủes sont larges, courts, irréguliers, quelquefois blanes, le plus souvent de la couleur du reste de la plante, quelques-uns placés sur la tige ou décurrents.

Le poids de ce champignon est quelquefois considérable. Il exhale une odeur forte et pénétrante, qu'il serait dangereux de respirer trop longtemps. Sa chair blanche a un goût d'aloord salé, ensuite comme miclleux, assez agréable. Sa consistance, ferme et compacte, ne l'empèche nullement d'être alimentaire ; on le mange communément dans la Nièvre, mais seulement quand il est jeune et, par conséquent, encore tendre.

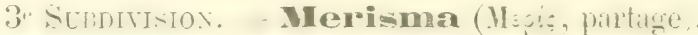

Chapeau multiple, partant d'un pédicule commun.

Polypore confluent (Polyporus confluens), Fr., Epicr., 75.

Hartz, t. 13. - Barla, t. 29, fig. 2, 3. - Staude, t. 3, fig. 1. - Pol., artemidomus, Lenz., t. 43. - Pers., IIyc., no 27, p. 47.

Ce Polypore est charnu, ferme, composé de plusieurs chapeaux, confluents, imbriqués, irréguliers, dimidiés, lobés, couleur de chair, tirant sur le roux, à surface glabre, sèche, pouvant atteindre 12 et 15 centimètres. Ses pores, d'un blanc pâle, sont très-seriés, trèscourts, peu distincts dans la jeunesse à cause de leur ténuité, sub-décurrents. Ses pédicules, blancs, courts, prennent naissance d'une souche charnue, épaisse.

Il croit, en automne, sous les pins, dans les friches, les bruyères. Très-rare en France; on le trouve en Lorraine.

Bien qu'il soit peu délicat, on le mange aux environs de Nice. Sa chair est pâle, sa saveur un peu âcre.

Polypore en crête (Polyporus cristatus), Fr., Epicr., 74 .

Rotsk., t. 16. - Schrff, t. 113. - Nees, fig. 217. - Barla, t. 29, fig. 4-7. Pers., $M_{y}$ e., 52

Ce champignon, rameux, charnu, fragile, se reconnaît aux caractères suirants : les chapeaux, les uns entiers, les autres dimidiés, le plus 
souvent irréguliers, imbriqués, déprimés au centre, sub-pulvérulents ou sub-tomenteux, ensuite ridés ou squameux, larges de 8 ou 10 centimètres, d'un roux verdatre, ont les bords légèrement roulés en dessous. Les pores, petits, anguleux, d'un blane pur d'abord, puis prenant une couleur un peu soufrée, se prolongent sur lęs pédicules, lesquels se réunissent à un tronc commun, court, blane, devenant verdâtre avec l'âge.

On trouve le Polyporus cristatus dans les Vosges; il est rare, et croît à terre, dans les liẹx ombragés des bois de hêtres. Fries le dit comestible; M. Barla dit, au contraire, qu'il n'est point comestible: dans le doute, il sera prudent de s'en abstenir.

Polypore en bouquet (Polyporus frondosus), Fr., Epicr., 72.

(PI. XXX1X, fig. 1.)

Fl. dan., t. 952. - Schæff., t. 127, 128, 129, 265, 266. - Rotsk., t. 18. Nees, t. 27. -- Sterb., t. 28. - Krombh., t. 48, fig. 17-20. - Vivian., t. 36. - Barla, t. 29, fig. 1. - Lenz, t. 9, fig. 26. - Paul., 29, 30. - Pers., Myc., 26.

Noms vulgaires : Panse de vache, dans la Meuse; Poule de bois; Couveuse, dans les Vosges; Barbasin

Le Polyporus frondosus pèse quelquefois jusqu'à 15 kilogrammes, et atteint souvent 30 centimètres d'élévation, sur autant de largeur; il est formé par la réunion d'une grande quantité de chapeaux, imbriquès, dimidiés, de 4 à 6 centimètres de largeur, lobés, mugueux, un peu ridés ou tuberculeux à la surface supérieure, d'un brun grisâtre. Ses pores sont très-petits, irréguliers, blanchâtres, de mème que le trone, duquel partent les chapeaux.

Il croît au pied des chènes, et n'est pas très-rare en Lorraine.

Sa chair, un peu coriace, a une saveur et une odeur agréables. Les gens de la campagne regardent comme tin heureux hasard de rencontrer ce champignon, puisqu'un seul pied suffit au repas d'une nombreuse famille.

Polypore chicoracé (Polyporus intybaceus), Fr., Epicr., 73.

$$
\text { Sow., t. 87. - Huss., I, t. 6. - Fl. dan., t. } 1793 .
$$

Champignon très-rameux, charnu, assez fragile, très-rare, alimentaire, dont les chapeaux, très-nombreux, dimidiés, dressés, étalés, sinueux, spatulés à la fin, à peu près lisses, d'un gris fauve, se réu- 
nissent par le pied, pour former un tronc très-court. Pores consistants

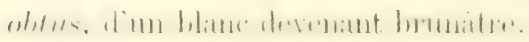

Comme le Pol. umbellatus, avec lequel on l'a souvent confondu, le Pol. intybaceus croit au pied du trone des arbres, et plus particulicrement au pied du tronc des chènes, en touffes, qui ont quelquefois 40 centimitres d'étendue sur 15 de hauteur.

On le mange en Allemagne et en Angleterre.

Polypore pied do chèvre (Polyponus pes caprex), Pers., Champ. com.,

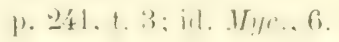

Rotsk., t. 14.-Fr., Elpicr., 76.

Nom vulgaire: Pied de mouton noir, dans les Vosges.

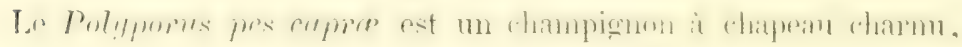
large de 8 à 10 centimètres, dimidié, brun noúrutre ou bistré noir, entier dans sa jeunesse, $\dot{a}$ squames disposées en marqueterie, assez épais vers son insertion au pédicule, dont les bords sont infléchis et ondulés. Ses pores, larges, d'un blanc jaunâtre, sont décurrents sur un pédicule latéral, long de 6 à 8 centimètres, épais de 3 à 4, lisse, ventru, de la couleur du chapeau, plus pâle à sa base.

Il vient à terre, en touffes, dans les bois de sapins, autour des bruyères, en été et en automne, dans les Vosges, et acquiert un grand volume lorsque plusieurs chapeaux sont réunis sur le mème pied.

Est comestible. Sa chair, blanche, fragile, a une saveur agréable. Il se conserve salé ou macéré dans le vinaigre.

Le Scutiger tuberosus, Paul., t. 31, fig. 1-3, dont M. Léveillé a fait le Pol. asperellus, serait, selon Paulet, fort recherché pour l'usage. On le trouve, à terre, dans les environs d'Angers, d'Angoulème, de Toulouse. Fries est disposé à le considérer comme une variété du $\mathrm{Pol}$. pes capre. Mi. Noulet et Dassier n'en font pas mention, comme venant aux environs de Toulouse.

Polypore sulfurè (Polypoms sulfureus), Fr., Epicr., 84.

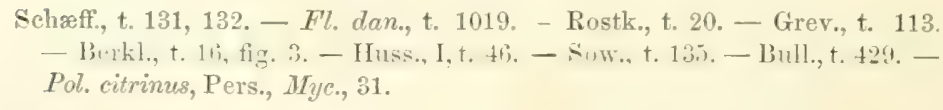

Ce Polypore est, en dessus, d'un jaune citron, tirant sur le rougeâtre, d'un jaune soufre en dessous, et de couleur chamois dans la vieillesse, glabre, ondulé, irrégulier, sessile, attachẻ par le côté; il 
aequiert quelquefois 30 et 40 centimètres de largeur. Ses tubes, trèscourts, à orifices extrêmement petits et difficiles à apercevoir, émettent, à la maturité, une poussière séminale blanche, très-abondante.

Il vient, en été et en automne, sur les cicatrices des vieux cerisiers, des chènes, des hêtres, des saules, quelquefois imbrique, et formant des touffes. Sa chair est jaunâtre, pâteuse à la bouche, et un peu aigrelette. Vieux et desséché, il devient friable et se décolore.

Les teinturiers l'emploient pour teindre en jaune. Paulet dit en avoir mangé sans inconvénient, et l'avoir même trouvé bon. Sa chair, devenant promptement coriace, il ne serait comestible que dans le jeune âge.

Le Pol. Ceratonice, Barla, t. 30, fig. 3, qui vient sur les vieilles souches du caroubier, n'est, selon toute vraisemblance, qu'une variété du Pol. sulfureus. On le récolte aux environs de Nice, et on le fait servir comme aliment, quoiqu'il soit, dit M. Barla, d'une qualité assez médiocre.

Polypore en ombelle (Polyporus umbellatus), Fr., Epicr., 71.

Schæff., t. 111, 265, 266. - Fl. dan., t. 1197. - Jacq., t. 172. - Krombh., t. 52, fig. 3-9. - Lenz, fig. 44. - Nees, t. 27, fig. 215. Pers., Mye., 25.

Champignon très-rameux, à chapeaux nombreux, de petite taille, non dimidiés, entiers, d'abord hémisphériques, ensuite plans et déprimés au centre ou en entonnoir, fibroso-charnus, de couleur fauve; pores petits, blanes; pédicules allongés, distincts, réunis à la base, blancs, tortueux, cylindriques.

Il vient, en automne, à terre, et à la base des troncs d'arbres, dans les forêts ombragées, et surtout dans les forèts de hètres. On le trouve en Lorraine; est rare dans le reste de la France.

En Allemagne et en Suède il est employé comme aliment.

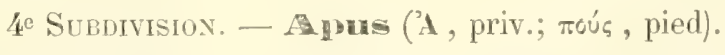

Champignon simple ou ayant plusieurs chapeaux, partant d'une base commune, rarement droit, plus souvent horizontal; absence de pédicule.

Polypore du bouleau (Polyporus betulinus), Fr., Epicr.. 139.

(Pl. XLI, fig. 1.)

$$
\begin{gathered}
\text { Bull., t. 312. - Grev., t. 246. - Rostk., t. 22. - Fl. dan., t. 1254。- } \\
\text { P'ers., IIyc., 34. }
\end{gathered}
$$

Cette plante ne croît que sur le tronc du bouleau; elle est annuelle ou bisannuelle. Son chapeau, charnu, coriace et même subéreux, de 
forme convexe, ovale ou semi-orlbiculaire, atteignant 12 i 15 centimètres, est glibre, sessile, ou porté, dans sa jeunesse, par un court pédicule, d'un blanc pur, dans le jeune àge, devenant quelquefois roussatre plus tard, et recourert d'une pellicule mince, lisse, que l'on peut enlever facilement. Les tubes, blancs, courts, petits, trèsnombreux, se séparent du chapeau sans diffieulté.

Le Polyporus betulinus se trouve assez communément, en automne, dans les bois et les chantiers.

Il a la chair, blanche, ferme et tenace, et sert, en Angleterre, à faire d'excellents cuirs à rasoirs; en Siloérie, à faire de l'amadou. Ori dit que les peuples du nord l'emploient, après l'avoir brûlé, à aromaliser le tiluac.

Polypore amadouvier (Polyporus fomentarius), Fr., Epicr., 158.

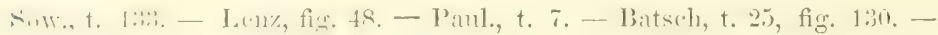
Loletus unjulatus, Bull., t. 401, fig. 6, et t. 491, fig. 2. - Pers., Myc., 92.

- Pismes fimmenturies, Fr., sinnm.

Var. A. Polyp. soloniensis, Paul., t. 9, fig. 1-3. - Parsemé en dessus de

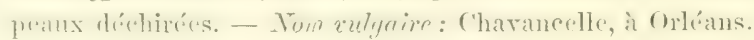

Noms vulgaires: Boula, Bolet ả amadou, Agaric de chêne, Agaric femelle.

Champignon sessile, attaché latéralement, d'abord mollasse intérieurement, ensuite coriace et ligneux, sub-triangulaire ou semi-orbiculaire, ajant alors la forme d'un sabot de cheval, et pouvant atteindre jusqu'à 50 centimètres de diamètre; la surface supérieure, d'un cendré grisütre ou fermgineux, marquée de sillons, et quelquefois de zones brunes, parallìles au bord, a, sous l'épiderme, une ècorce particulière dure et d'un noir luisant. Les tubes, étroits, très-petits, réguliers, d'abord glauques, ensuite de couleur ferrugineuse ou tannée, de même que la chair.

Le Polyporus fomentanius vit plusieurs années; à chaque année il s'ajoute une nouvelle couche de tubes aux couches anciennes. Ces différentes couches sont séparées extérieurement les unes des autres par des sillons circulaires, plus ou moins profonds. 11 croît sur les vieux trones de divers arbres, surtout sur ceux du chène et du hêtre.

C'est ce polypore qui est plus particulièrement employé dans les arts, à la préparation de l'amadou et de l'agaric des chirurgiens. 
Le Pol.soloniensis, Fr. (Paul., t. 9, fig. 1-3), employé en Sologne pour faire un excellent amadou, paraît n'ètre qu'une variété du fomentarius.

Le Pol. dryadeus, Pers. (Pol. pseudo-igniarius, Bull., t. 458. Huss., I, t. 21) peut servir aussi à faire de l'amadou.

Polypore hispide (Polyporus hispidus), Fr., Epicr., 122.

Bolt., t. 161. — Surv., t. 315. - Grey., t. 11 - Bu1l., t. 210 (t $493 .-$

Huss., I, t. 29, 31. - Krombh., t. 48, fig. 7-10. - Pers., IIyc., 40.

Var. rutilans, Pers., IIyc., t. 13.

Ce champignon, de couleur rouge fauve ou rouge de brique, devient noirâtre avec l'âge, est de consistance molle et spongieuse, en même temps que charnue dans la jeunesse, coriace et subéreuse plus tard. Son chapeau, large de 20 à 25 centimètres, compacte, épais, dimidié, forme une sorte de coussin, couvert de poils courts, mdes. Ses pores sont petits, arrondis, nombreux, jaunâtres, puis passant au fauve, et se séparant du chapeau sans trop de difficulté. Pédicule nul.

Il vient sur le tronc des vieux arbres, le pommier, le marronnier, le chêne, et plus souvent sur le noyer, en été et en automne. Saveur acide.

Le Polyporus hispidus donne une couleur jaune éclatante, aussi est-il employé pour teindre la soie, le lin, le coton.

Polypore combustible (Polyporus igniarius). Fr., Epicr., 160.

Sow., t. 132. - Mich., t. 62. - Bolt., t. 80. - Lenz, fig. 47. - Bull., t. 454, fig. A, B, D, F. - Pers., Myc., 93 et 80. - Boletus obtusus, DC., no 309. - Fomes igniarius, Fr., Summ.

Noms vulgaires: Boula, Agaric ou champignon de chêne; Esca, Sinsa, en Languedoc.

Champignon très-dur, épais, sessile, attaché par le còté, d'abord tuberculeux, puis semi-orbiculaire ou sub-triangulaire, à bord arrondi, recouvert d'une couche mince, flocculente, qui bientôt devient blanche. Sa superficie, inégale, est très-dure, de couleur cendré ferrugineux ou fauve noirâtre. Ses tubes sont courts, étroits, très-réguliers, blanchâtres dans le jeune âge, ensuite couleur de tan. Sa chair, également couleur de tan, de la consistance du liége d'abord, devient dure comme du bois. Lorsqu'on le coupe verticalement, on voit qu'il est 


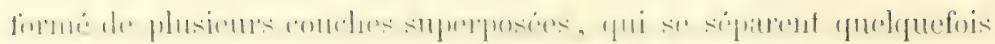
d'elles-mèmes, et indiquent l'ìge de l'individu.

Le Polyporus igniarius croit, très-communément, sur diverses espèces d'arbres et d'arhrisseaux, tels que saules, peupliers, pruniers, chènes ctc. Il vit plusieurs années, ou, du moins, il se forme chaque année une nouvelle couche de tủjes; à l'extérieur, les pousses de l'année précédente sont séparées par des sillons profonds. Le mycélium et les spores de couleur blanche distinguent le Pol. igniarius du Pol. fomentarius.

Ce Polyporus igniarius sert aux paysans pour conserver et transporter le feu; les teinturiers l'emploient pour teindre en brun fauve.

Polypore officinal (Polyporus officinalis), Fr., Epicr., 140.

Boletus Laricis, Bull., t. 296. - Jacq., t. 19, 20, 21. - Mich., t. 61, fig. 1.

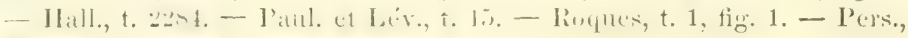
I/yr, , (i⿱ .

Noms vulgaires: Agaric blanc, Agaric des pharmaciens, Agaric purgatif.

Champignon sessile, attaché latéralement, dont la chair, d'une consistance molle et coriace, friable lorsqu'clle est sèche, ne perd jamais sa coulcur blanche. Le chapeau atteint jusqu'à 30 et 40 centimètres de diamètre, est très-épais, à peu près de la forme d'un sabot de cheval, a la face supérieure, glabre, lisse, blanche, marquée de quelques zones jaunâtres ou brunes, peu prononcées, se gerçant à la base sur les vienx individus; la face inférieure, recouverte de tubes courts, nombreux, jaunâtres, dont l'ouverture est peu distincte. Odeur de farine, se dissipant en partie par la dessiccation; saveur amère.

Il croìt, dans les Alpes et le Dauphiné, sur les vieux trones des mélèzes, mème après qu'ils ont été abattus.

On en fait usage en médecine. C'est un purgatif actif, qui excite quelquefois des vomissements; on le donne aussi comme vermifuge. Les habitants des Alpes l'emploient fréquemment contre les maladies de leurs troupeaux, et plus particulièrement des moutons; ils s'en servent aussi en guise de noix de galle, pour teindre la soie en noir, et faire de l'encre. 
5e Subuivision. - Tramètes (trumu, trame, tissil). Genre pour quelques auteurs.

Hyménophore non distinct du reste du chapeau.

Polypore (Tram.) à odeur suave (Polyporus Tram. suaveolens), Lin.

(PI. XLI, fig. 2.)

Sow., t. 227, 228. - Sterby, t. 27, fig. D. - Tratt., p. 25, fig. 1. - Fl.dan., t. 1849. - Huss., I, t. 43. - Krombh., t. 4, fig. 25. - Pers., MIyc., 64. Trametes suaveolens, Fr., Epicr., 15.

Le Polyporms sudecolens est m champignom suberenx, un peu mou, sub-tomenteux, d'un blanc de neige d'abord, et plus tard d'une teinte un peu bistrée et zonée, avec un chapeau bombé, sessile, attaché latéralement ; il peut atteindre jusqu'à 30 et 40 centimètres de diamètre, sur 3 à 5 d'épaisseur. Ses pores sont allongés, grands, irréguliers, arrondis, quelquefois inégalement proéminents, d'abords blancs, ensuite d'un blanc légèrement roussatre. Lia chair est blanche.

Il croît en automne, sur les vieux trones de saules, et surtout sur le saule blanc. Son odeur, plus prononcée chez les jeunes individus, tient de celle de la vanille et de l'anis. On pourrait en faire usage comme parfum, car il exhale une odeur délicieuse, assez persistante. Les Lapons en portent sur eux pour aller faire la cour à leurs belles; les femmes laponnes s'en servent comme parfum.

Les médecins l'ont employé contre les sueurs excessives de la nuit.

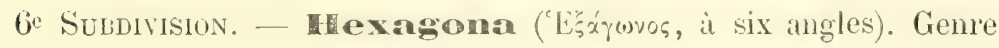
pour quelques auteurs.

Pores dilatés en alvéoles amples, sub-hexagonaux. Champignons coriaces, indurés.

Polypore Hexag. du mûrier (Polyporns Hexag. Mori), Fr., Syst., p. 34 4.

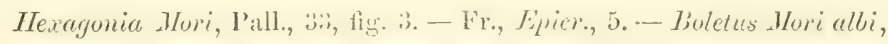
Duchesne.

Champignon sessile, subéreux, coriace, dont le chapeau est plan, glabre, lisse, de couleur jaune; alvéoles hexagones, régulières.

Il croit sur le mûrier blanc, dans le midi de la France. 


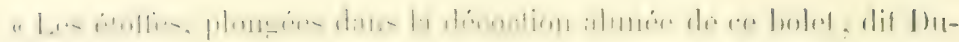
chesne, prennent les diverses couleurs, jaune verdâtre, jaune-chamois, jonruille etc., suivant le temps de macération des tissus, les proportions de bolet, la température du bain etc.; ces couleurs sont toutes très-solides. )

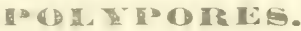

$$
1^{\text {re }} \text { Subdirision. - Mesopus. }
$$

Pol. arculaire (Pol. arcularius), Fr., Epicr., 13. - Mich., t. 70, fig. 5. Pol.

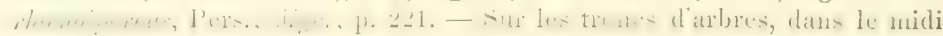
de la France.

Pol. biennal (Pol. biennis), Bull., t. 449, fig. 1 - Fr., Epicr., 24. - Sur la terre, autour des trones.

Pol. brumaire (Pol. brumalis), Rostk, t. 8. - Batsch, fig. 42. - Fl. dan., 1297. - Sur les trones de hêtres et de chênes.

Pol. fuligineux (Pot. fuliyineus), Fr. (décirit).

Pol. des trones brûlés (Pol. incendiarius), Bong. in Weinm., Ross.y p. 309. Fr., bìier., 17. - Sur les trones brûlés, après l'incendie des bois. Comestible.

Pol. déchiré (P’ol. laciniatus), Batt., 32, fig. A, B. - Buxb;, t. 3, fig. 2. Pers., Jyc., 30. - Fr., Epier., 25.

Pol. de Montagne (Pol. DTontagnei), Fr., Epicr., 26. - Ann. de la Soc. nat., 183b, no 42. - A terre, dans les bois des Ardemus.

Pol. leucomelas (Pol. leucomelas), Pers. - Fr., Epier., 5. - Dans les bois; rare.

Pol. des pacages (Pol. oxinzss), E'r. (décrit).

Pol. vivace (Pol. peremis), Fr., Epior., 28. Bolt., t. 87. - Schæff., t. 125. Rostk., t. 6. - Bull., t. 449, fig. 2. - Sur les terres stériles et même les trones; commun. Suspect.

Pol. peint (Pol. pictus), Schultz. - Bull., t. 254. - Mich., t. 70, fig. 9. - Fr.2 Epicr., 29. - A terre, en groupes serrés.

Pol. roussâtre (Pol. rufescens), Fr., Epier., 23. Sistrotrema rufescens, Pers., ex parte. - sur la terre gazonnée, les rieux trones de saules.

Pol. de Schweinitz (Pol. Schucinitaiz), Fr., Epicr., 22. - Mich., t. 70, fig. 1.Dans les bois de pins, sur les vieux tromes.

Pol. sub-squameux (Pol. suliquamosus), Lin. - Fr., Fungi vesc., t. 52. - Dans les bois de pins des montagnes. Comestible.

Pol. tacheté ( ${ }^{P}$ ol. tesoulalus), Fr., Epicr., 1. - Mich., t. 71, fig. 2. - Dans les -Alpes.

Pol. tubérastre (Pol. tuberaster), Fr. (décrit).

Pol. visqueux (Pol. viscosus), Pers., Myc., 14, Fr., Epior., 6. - N'est peut-être qu'une variété du Pol. bovinus, Fr., Epier., 6.

\section{2e Subdivision. - Pleuropus.}

Pol. anisopore (Pol, anisoporus), Del. et Mont., Ann. des se. nat., 1845; rare.

Pol. de Bouché (Pol. Boucheanus), Klotzsch. - Fr., Epicr., 42. - Sur les troucs; rare.

Pol. élégant (Pol. elegans), Bolt., t. 83. - Bull., t. 26. - Fr., Epicr., 50. - Sur les trones, de hêtres surtout. 


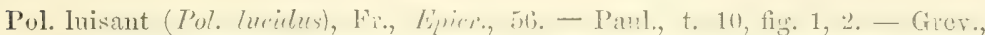
t. 245 . - Kímmbh., t. 4, fig. 222-24. - Saw., t. 134. Kiol. vbliquentes, Bull., t. 146 et 459 .

Pol. pied noir (Pol, melanopus), Rostk., t. 4. - Fr., Epicr., 44. - A terre, sux les racines, les petites branches.

Pol. nummulaire (Pol. nummularius), Bull., t. 121. - Rostk., t. 12. - Variété du Pol. eleyans, Fr., Epicr., 50.

Pol. pied couleux de poix (Pol.picipes), Fr., Epicr., 48. - Pers., Icon. pict., t. 4 fig. 1. - Sur les trones de saules.

Pol. du chêne (Pol. quercinus), Schrad., Spic., p. 157. - Fr., Epicr., 52. - Sur les trones pourris du chêne.

Pol. écailleux (Pol. squamosus) Schæff., (décrit).

Pol. varié (Pol. varius), Fr., Epicr., 49. - Batsch, t. 129. Bol. calceolus, Bull., t. 360 et 445 , fig. 2. - Sur les trones des arbres.

$$
\text { 3e Subrivisime. - Yrisuer. }
$$

Pol. acanthoïde (Pol. acanthoides), Bull., t. 337. - Fr., Fpicr., 78. - Sistrotrema rufescens, Pers., Icon. pict., t. 6. - Sur la teme et les troncs.

Pol. caséeux (Pol. casearizu), Sterb., t. 12, - Batt., t. 34, fig. A. - Fr., Elicr. 83. - Sur le trone des chênes.

Pol. confluent (Pol. confluens), Fr. (décrit).

Pol. en crête (Pol. cristatzus), Fr. (décrit).

Pol. en touffes (Pol. frondosus), Fr. (décrit).

Pol. fuligineux (Pol. futiginosus), Scop., Fr., Epricr., 91.

Pol. gigantesque (Pol. giganteus), Bolt., t. 76. - Hussey, I, t. 82. - Fr., Eprer., 77. - Rostk., t. 19. - Au bas des trones; rare.

Pol. imberbe (Pol. imberbis), Bull., t. 445, fig. 1. - A terre, ì la base des trones.

Pol. imbriqué (Pol. imbricatus), Sterb., t. 27, fig. B. - Rostk., t. 21. - Fr., Eprier., 85. - Bull., t. 366. - Sur le hêtre.

Pol. chicoracé (Pol. intybaceus), Fr. (décrit).

Pol. de Paulet (Pol. Pauletii), Fr., Eprier., 80. - Pan1., t. 31, fig. 4. - A la basc des trones, dans la France méridionale. Comestible.

Pol. pied de chève (Pol. pes caprce), Pers. (décrit).

Pol du saule (Pol. satiynus), Fr. Epior., 94. - Bolt., t. 78. - Batt., t. 38, fig. E - Sur les vieux trones morts.

Pol. sulfureux (Pol. sulfureus), Fr. (décrit).

Pol, en ombelle (Pol. umbellatus), Schæff. (déerit).

$$
\text { 4e Subdirision. }-4 \text { nes. }
$$

Pol. du sapin (Pol. abietinus), Fr., Epicr., 231. - Fl. dan., t. 2079, fig. 1, et 1298. - Grev., t. 221. - Dans los bois de pins de montagnes.

Pol. brûlé (Pol. adustus), Sow., t. 231. - Fr., Eipier., 115. - F'l. clan., t. 1850, fig. 1. - Sur les trones d'arbres.

Pol. blane (Pol. albus), Hudson. - Fr., Epior., 113. Bol.salicinus, Bull., t. 433, fig. 1. - Sur les saules et les hêtres pourris.

Pol. amorphe (Pol.amorphus), Fr., Epicr., 120. - Neos, t. 223. - Sow., t. 423. - Pers., Mye., 50 et 85. - Sur les trones de pins, dans les bois de montagnes.

Pol. antique (Pol. annosus), Fr., Epier., 188. - Sur les trones, près de la terre dans les montagnes.

Pol. apalus (Pol.apalus), Lév., Ann. des sc. nat., 1848; rare 
Pol. aplani (Pol. applanatus), Pers., Obs., Fr., Epicr., 157. - Batsch, t. 130. -

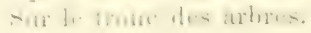

Pol. du bouleau (Pol. betulinus), Fr. (décrit).

I'ul. boréal (Pol.borealis), Fr., Epricr., 130. - Schref., t. 134. - Sur les trones 1! - situins $1 \mathrm{n}$ its.

I'ol. bleu perse (Pol. ccesius), Suw., t. 256.-Fr., Elvicr., 104. - Sur les troncs tombés à terre.

Pul. candide (Pol. candidulus), Lér., Ann. des sc. nat., 1846. - Sur les trones.

Pol. du charme (Pol. carpineus), Suw., t. 231. - Sur les charmes. - Variété du Pol. adustus.

Pol. cinabre (Pol. cinnabarinus), Fr., Epior., 193. - Jacq., t. 304. - Bull., t. 505, fig. 1. Pol. sanguineus, Paul., t. 3, fig. 3, 4. - Sur les trones des arbies.

Pol. en coquille (Pol. conchatus), Fr., Epicr., 135. - Sur Ies trones des hêtres, des saules etc.

Po1. safrané (Pol. croceus), Buxb., t. 3, fig. 1. - F1., Epicr., 107. - Sur les trones pourris du cliêne.

1'ol. des souterrains (Pol. cryptarum), Fr., Eipier., 202. — Bull., t. 478. - Nees, fig. 222. - Sur les bois de pin pourri.

1'ol. cuticulaire (Pol. cuticularis), Bull., t. 462. - Fr., Epicr., 123. - Sur les tiges de chêne, de peuplier, d'aune, de hêtre.

Pul. destructeur (Pol. destructor), Rostk., t. 27. - Fr., Epier., 106. - Krombh., t. 5, fig. 8. - Sur les bois.

1'ol. dryade (Pol. dryadeus), Bull., t. 458. - Huss., I, t. 21. - Fr., Epicr., 133. - Sur les trones du chêne, dans le Midi; rare.

P'ol. étalé (Pol. expansus), Desm. - Funy. quin., fig. 12. - Fr., Epior., 208. - Pol. meyaloporus, Pers., Myc., p. 88. - Sur les poutres.

Pol. amadouvier (Pol. fomentarius), Fr. décrit).

I'ol. du frêne (Pol. fraxineus), Fr, Epior, 177. - Bull, t. 433. - Sur les frènes.

Pol. roux (Pol. fulrus), Scop., Carn., p. 469. - Pers., Obs., 1, p. 24. - Fr., Evier., 161. - Sur les trones.

Pol. enfumé (Pol. jumosus), Fr., Epicr., 114. - Tratt., t. 3, fig. 5. - Sur les saules et en moindre quantité sur les hêtres.

Pol. gibbeux (Pol. gibbosus), Pers., Myc., 66. - Sow., t. 288. - Sur le tronc des arbres.

Pol. hérissé (Pol. hirsutus), Fr., Epicr., 221. - Sur les trones.

Pol. hispide (Pol. hispidus), Fr. (décrit).

Pol. amadourier (Pol. igniarius), Fr. (décrit).

Pol. kimatode (Pol. limatodes), Rostk., t. 24. - Fr., Epier., 119. - Sur les vieux trones morts. - A peine distinct du Pol. amorphus.

Pul. de la chèvrefeuille (Pol. Lonicerce), Weinm.

Pol. jaunâtre (Pol. lutescens), Pers., Myc., 74. - Schæff., t. 136, fig. sup. Fr., Epier., 214. - Sur les trones d'arbres.

Pol. marginé (Pol. marginatus), Fr., Epier., 170. - Sur les trones de hêtre.

Pol. nidulant (Pol. nidulans), Fr., Epicr., 109. - Dans les bois de hêtres et de chênes.

Yol. noireissant (Pol. nigricans), Fr., Eprir., 159. - Sur les bouleaux.

Pol. officinal (Pol. officinalis), Fr. (décrit).

Pol. tout châtain (Pol. olopheeus), Mont.

Pol. pâlissant (Pol. pallescens), Fr., Epicr., 145. - Sow., t. 230. - Autour des trones et des rameaux. 


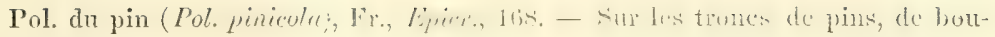
leaux etc.

Pol. du peupliex (Pol. populinus), Fr., Fpicr., 191. - Fl. dan., t. 1791. - Sur les peupliers blanes.

Pol. rheades (Pol. Rheades), Pers., MIyc., 72. - Fr., Epior., 124. -- Sur les trones d'arbres, de l'orme en particulier.

Pol. du groseillier (Pol. Ribis), Fr., Epier., 164, - Fl. clan., t. 1790. - Bull., t. 454, fig. E. - A la base des groseilliers.

Pol. rutilant (Pol. rutilans), Pers, Icon. et descr., t. 6, fig. 4. Fr., Epicr., 110. Sur l'écorce du sorbier.

Pol. en degrés (Pol. serialis), H'l., Epicr., 211. Pol. scalaris, Pers., Mye., 2, p. 90.

Pol. du saule (Pol. salicinus), Fro, Epicr., 166. - Sur les saules. Fomes salicinus, Fr., Summ.

Pol. de la Sologne (Pol. Soloniensis), Dub. - Variété du Fomentarius.

Pol. écumeux (Pol. spumeus), Fr., Elicr., 127. - Berkl., t. 16, fig. 4. - Sow., t. 211. - Sur les trones d'arbres.

Pol. stéréoïde (Pol. stereoides), Fr., Epicr., 229. - Sur les trones de sapin.

Pol. styptique (Pol. stypticus), Fr., Epicr., 99. - Sur les trones morts du pin, qui sont debout et courerts d'écorce.

Pol. de l'orme (Pol. ulmarius), Fr'. Epicr., 176. - Sow., t. 88. - Sur le trone des ormes.

Pol. ondé (Pol. undatus), Pers., Mye., t. 66, fig. 3. - Sur le bois en décomposition; rare.

Pol. velouté (Pol. velutinus), Fr., Epicr., 222. - Sur les branches mortes.

Pol. versicolore (Pol. versicolor), Batt, t. 35, fig. A. Schæff., t. 268. - Sterb., t. 27. - Huss., I, t. 24. - Fr., Evicr., 224. - Sur les troues d'arbres. Suspect, selon Réveil; vénéneux, suirant Duchesue.

Pol. zoné (Pol. zonatus), Schæff., t. 26. - Er., Epier., 223. - Batt., t. 35, fig. B. - Fl. dan., t. 2028, fig. 2. - Sur les trones de peupliers, de bouleaux.

\footnotetext{
5e Subdivision. - Resupinatus (en latin, penché, couché). - Champignon renversé, absence de chapeau.
}

Pol. entouré (Pol. circumscriptus), Léveil. - De Guernisac-Crouan, Fl. fin., p. 65. - Sur les branches mortes du châtaignier.

Pol. soyenx (Pol. bombycinus), Sow., t. 387, fig. 5. - Fr., Epicr., 254. Pol. radioides, Pers., Mye., 163. - Sur le vieux bois de pin.

Pol, tuberculeux (Pol. colliculosus), Pers., Myc., p. 103. Pol. tuberculosus, DC., Ft. fr., 5, p. 40 .

Pol. contigu (Pol. contiguus), Pers., Sym. - Fr., Epicr., 249. - Sur le chêne pourri.

Pol. brun ferrugineux (Pol. ferruginosus), Fr., Elicr., 250, - Griev., t. 155, fig. 1. - Sur le trone de l'amuc.

Pol. fauve incarnat (Pol. fusco-carneus), Pers., Alyc., p. 97. - Sur des rameaux secs; rare.

Pol. cotonneux (Pol. gossypinus), Lév, Ann. des sc. nut., 1848. - Dans les Vosges.

Pol. incarnat (Pol. incarnatus), Fr., Eyicr., 256. - Pers., Alyc., t. 16, fig. 4. Sur les trones de pins.

Pol. mie de pain (Pol. Hedulla Panis), Pers., Synz., 78. - Jacq., t. 11. - Fr., Epicr., 261. - Sur les vieux bois, quelquefois ì terre. 


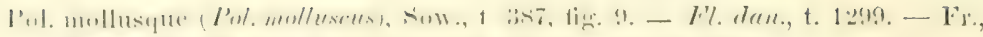

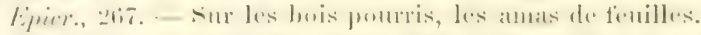

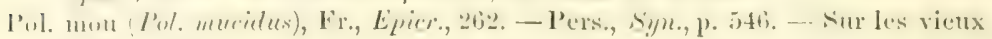
buis pustris.

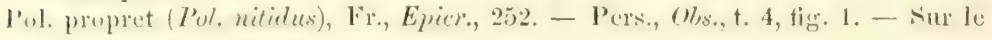
buis mort.

Pol. ochracé (Pol. ochraceus), Fr:

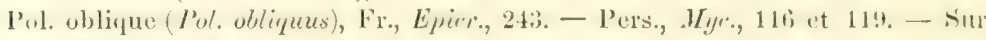
les trones; rare.

1'ol. racloir (Pol. Radula), Fr., Epier., 270. - Sur les bois et les rameaux sees.

Pol. réticulé (Pol. reticulatus), Fr., Epicr., 280. - Hoffm., t. 12. - Nees, fig. 225. - Sur le bois corrompu.

Pol lilace (Pol. rhodellus), Nr., Evier., 259. - Bull., t. 442, fig. D. - Sur le bois de hêtre; rare.

Pol. roux (Pol. rufus), Fr., Epicr., 255.

Pol. sous-spadicé (Pol. subspadiceus), Fr., Epicr., 245. - Sur les bois de hêtro pourris.

Pol. terestre (I'ol. terrestris), Fr, Epirr., zis. - I tewe, dans Ios fosscés.

Pol. uni (Pol. unitus), Pers., Mye, 117. - Fr., Eyjer., 224. - Dans les bois de sapins des Alpes, des Vosges.

Pol. de Vaillant (Pol. Veillantii), Fr., Evier., 275. - Sow., t. 326. - Sur le bois.

Pol. vaporeux (Pol.vaporarius), Fr., Epricr., 274. - Dans les bois.

Pol. violacé (Pol. violaceus), Fr., Eprer., 267. Pol. brunneus, Pers., Hyc., no 121. - Sur les bois de sapins.

Pol. vitré (Pol. vitreus), Fr., Epicr., 263. - Sur les trones pourris ot tumbés du liêtre.

Pol. vulgaire (Pol. vulyaris), Berkl., t. 16, fig. 6. - Fr., Epicr., 266. - Sur les bois et les rameaux pourris.

\section{6e Subdivision. - Traniètes.}

Pol. (Tr.) de Bulliard (Pol. Tr. Bulliardi), Fr., Epier., 17. - Paul., t. 19. Bol. suaveolens, Bull, t. 310. - Sur les vieux trones de saule.

Pol. (Tr.) de France (Pol. Tr. Gallicus), Fr., Epicr., 4. - Nees, fig. 222. Bol. favus, Bull., t. 421. - Sur les troncs et les poutres de pins.

Pol. (Tr.) gibbeux (Pol. Tr. gibbosus), Fl. dan., t. 1964. - Sow., t. 194. - Huss., II, t. 4. - Fr., Eprir., 19. Imelalen gibbose, Pers., Syn., 2. - Fur les trones de hêtres, de chênes, de saules.

P'ot. (Tr.) odorant (Pol. Tr. odoratus), Schrff., t. 106. - Wulf.; Fr., Epicr., 2. - Sur les vieux trones de sapin.

Pol. (Tr.) du pin (Pol. Tr. Pini), Fr., Epicr., 3. - Pers., Myc., 96. - Sur le trone des pins.

Pol. (Tr.) rougeâtre (Pol. Th. muescens), Fr., Epicr., 18. Dadalea rubescens, Alb. et Schw., t. 11, fig. 2. - Sur le saule et dans les lieux humides des forêts.

1'ol. (Tr.) àt odeur suave (Pol. T\%' suaveolens), Lin. (décrit).

7e Subdirisien. - Hesayonire.

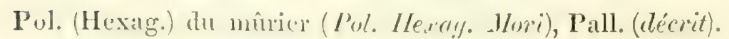




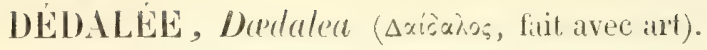

Hyménium composé de feuillets anastomosés, formant des cavités irrégulières, sinueuses, ou des pores allongés, flexueux, de grande dimension.

Dédalee du chêne (Doedalea quercina), Pers., Myc., t. 18, fig. 1.

$$
\text { (PJ. XLII, fig. 1.) }
$$

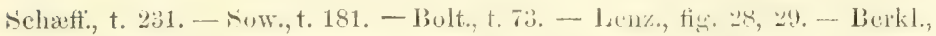
t. 19, fig. 5. - Ay. labyrinthiformis, Bull, t. 352 et 442, fig. F. - Tratt., t:2, fig. 3. - Fr., Epicr., 1. - Pers., Syn., 1.

Noms vulgaires: Labyrinthe-étrille, Peigne de loup.

Champignon d'un roux pàle ou grisitre, de forme et de dimeusion variables, coriace, tubéreux, ordinairement irrégulier, non zoné, presque toujours épais de 8 ou 10 centimètres, atteignant quelquefois jusqu'à 40 centimètres de diamètre. Le pédicule est nul, en sorte que le champignon adhère au lieu de son habitation par la plus grande partie de sa surface supérieure, l'inférieure étant garnie de lames ou feuillets épais, contournés, fréquemment anastomosés, et quelquefois de pores, larges, sinueux, ce qui le fait ressembler tantòt à un agaric, tantòt à un polypore, représentant une forme de labyrinthe.

On le trouve sur le trone des arbres, surtout celui du chène, sur les bois de charpente, dans toutes les saisons. Sa contexture est de la couleur du chapeau. Les individus qui viennent sur le sapin sont complétement noirs. Les insectes ne l'attaquent jamais.

En Autriche on en fabrique de l'amadou; en Italie, les persontes qui fréquentent les bains, s’en servent pour se décrasser la tète; dans quelques contrées de la France, il sert en guise d'étrille, pour lustrer' le poil des chevaux.

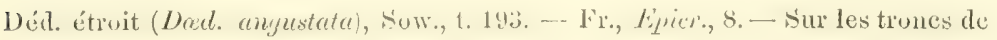
peuplier.

Déd.'doré (Deed. aurata), Battara, t. 35, fig. F. - Fr., Epier., 4. - Sur les trones de chêne, dans le Midi.

Déd. cendré (Dod. cinerea), Batt., t. 38, fig. G. - Fr., Epicr., 9. Bull., t. 537, fig. O, P, Q. - Sur le trone des hêtres.

Déd. scabreux (Dud. ronfingest), lbult., t. 160. - Suw., t. 193. -- Pers., Sym., 3. Fr., Epier., 5. - Ag. labyrinthiformis, Bull., t. 491, fig. 1. - Sur les trones d'arbres touffus.

Dẻd. très-large (Dad. Latissima), Suw., t. 424. - Fro, Eppior., 3.- - Sur les trones mousseux de hêtre; rare. 


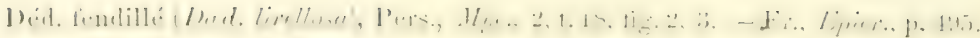
- sur l. prenplier: rar.

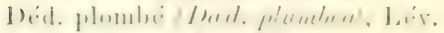

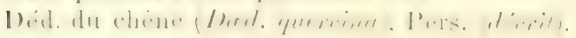

Déd. serpentant (Deed. serpens), Fr., Ëpier., 15. - Sur les trones et rameaux du

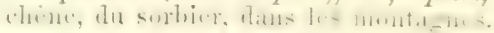

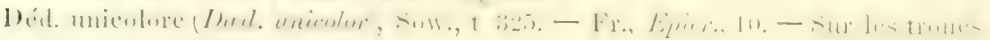
d'arbres feuillus.

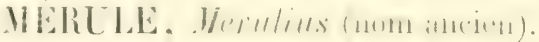

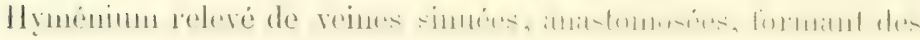
sillons, des cellules inégales, peu profondes.

Mérule pleureur (Merulius lacmymuns), Fr., Eloicr., 15.

1!. 11.11, 11\%. 2.

Wulf., t. 8, fig. 2. - Sow., t. 113, - Fl. dann, t. 2026. - Krombl., t. 46, fig. 1-2. - Huss., I, t. 3. - Berk1., t. 2, fig. 1. - Hénon, t. 2. - Hylomyzon destruens, Pers., IIyc., no 1, p. 27.

Champignon spongieux, charnu-membraneux, mince, étalé, pouvant atteindre jusqu'à 40 et 50 centimètres d'étendue, jaune ferrugineux ou orangé foncé, à marge blanche, cotomneuse, dont la surface fructifère forme un réseau à grandes mailles, ou des cellules sinuenser, sub-quadrangulaires. Son odeur est désagréable, surtout dans les individus desséchés.

Il couvre fréquemment les poutres dans les lieux humides, les celliers, et détruit des pièces de bois cntières, laissant souvent échapper des gouttelettes d'eau, l'ou lui est venu le nom de Pleureur.

Son mycélium, répandu dans les filores du Jois, souvent longtemps avant zon apparition, y reste stationnaire, altendant des circonstances farorables à son développement.

On le détruit, en grattant le bois, qu'on lave ensuite avec un pinceau, chargé d'eau, mèlée à un tier's d'acide sulfurique; il est bien pour plus de sureté de faire plusieurs lotions. On peut aussi employer la benzine.

\section{MLERTL。}

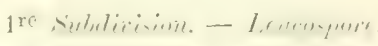

Mér. de Carmichaël (Mer. Carmichaelianus), Berk1., Outl., 8. - Grev., t. 224. Sur l'écorce et les trones pourris.

Mér. parchemin (Mer. corium), Grev., t. 147. - Sow., t. 349. - Fr., Epicr., 5. - Auricularia papyrina, Bull., t. 402. - Sur les trones et les branches des arbres feuillus. 


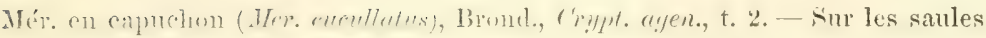

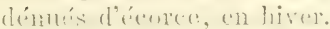

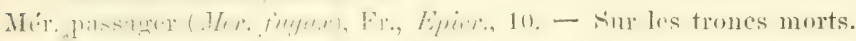

Mér. himantioüde (Mer. himantioides), Montagne, Ann. des se. nat., 1836. Fr., Epicr., 8. - Xylomyzon rersicolor, P'ers., Myc., 5, et Xyl. croceum, id., 13,

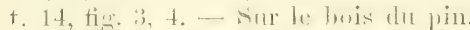

Mér. mollusque (ILer. molluscus, Fro, Exicr, 9. - Xylomyzon molluscum, Pers., Myc., 5 et Xyl. pulchrum, id., 9, t. 14, fig. 1, 2.

Mér. blane de neige (Mer. niveus), Sommerf. - Fr., Epicr., 6. - Sur Ies branches d'aune pourries.

Mér. pâle (Mer. pallens), Berk1., Outh., 7. - Sur les branches mortes.

Mér. rougeâtre (Jler. mufus), Pers. - Fr., Epicr., 12. - Xylomyzon rufum, Pers., Myyc., 8, et Mer. isopomum, 12, t. 16, fig. 1, 2. - Sur le bois carié.

Mér. porioide (IIer. porioides), Fr.., Evicr., 11. - Xylomyzon porioides, Pers., Myc., 11, et Xyl. paucirugum, id., 14, t. 14, fig. 7. - Sur le bois etl'écorce du sapin.

Mér. serpentant (Mer. serpens), Fx., Epier., 15. - Pers., nos 7, 15. - Sur les bois pourris de pins.

Mér. trémelloïde (Mer. tremellosus), Schrad., Spie., p. 139. - Huss., I, t. 10. Fl. dan., t. 1553 et 776, fig. 1. - Fr., Evier., 3. - Sur les trones d'arbres feuillus.

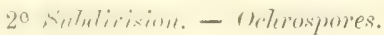

Mér. appliqué (Mes. rpplicatus), Lóv, Ann. des sc. nat., 1843, t. 7, fig. 2. - Sur les cuirs abandonnés, au printemps.

Mér. pleureur (IIer. lacrymans, F's. (déerit).

Mér. poudreux (Mer. pulverulentus), Fr., Epior., 16. - Sur les murs humides.

Mér. de Requin (Mer. Requinii).

Mér. terre d'ombre (Mer, unbrinus), Fro, Epicr., 20. - Sur les trones des conifères en décomposition.

3e Subdivision. - Favolus. (Favolus, qui a la forme d'une alvéole.) Genre pour quelques auteurs.

Alvéles amples, régulières entre elles, formées de lamelles anastomosées, rayonnantes, à parois doubles. Champignons charnus, minces.

Mér. (Fat.) d'Europe (iler. Far. Europarus), Fr., Epier, p. 498. - Mer, alveolamis, DC., Fl. fr., VI, p. 43. — Sur les trones, dans le Midi. 


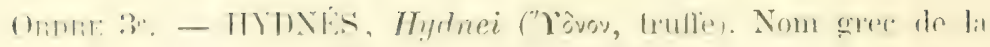

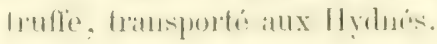

IIyménophore en forme d'aiguillons, de dents ou de papilles persistantes (BAsIDIOSPORÉS).

\section{III)XE (Hydmum).}

Plinte pourve d'uu chapeall uon toujours distinct, sarni on dessous, et quelquefois en dessus, d'aiguillons cylindriques ou coniques, distincts les uns des autres, et qui contiennent les spores ả leur extrém mité.

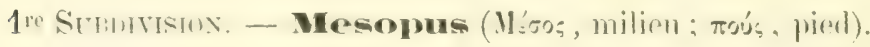

Pédicule central.

Hydne imbriqué (Hydnum imbricatum), Lin.

Schæff., t. 140. - Fl. dan., t. 176 et 1500. - Nees, t. 32, fig. 240. - Hartz, fig.t6-9. - Bolt., t. 87 . - Stande, t. 201, fig. 4. - Lonz, fig. 41. - Krombh, t. 49. - Grev., t. 71. - Noul. et Dass., t. 10, fig. B. - Barla, t. 38, fig. 1-4. - Fr., Epicr., 1. - Hydn. cervinum, Pers., Myc., 3.

Noms vulgaires: Barbe de bouc; Poucherillo, Brouquichous, en Languedoc.

Chapeau charnu, d'abord arrondi, convexe, puis plan et sub-omhiliqué, souvent difforme, large de 8 à 10 centimètres, couleur de terre d'ombre, parsemé de squames éparsses, dressées, floconneuses; aiguillons lisses, décurrents, d'un blanc cendré; pier, court, lisse.

On le recueille, en automne, à terre, dans les bois de pins et de sapins.

L'Hydnum imbricatum est comestible. Chair d'un blane pâle, ferme.

Hydne en entonnoir (Hydnum infundibulum), Swartz.

$$
\begin{gathered}
\text { Shro. Bot, t. 492. - Fr., Epier., 6. - Pers., Myc., 4. - Hyd. fusipes, } \\
\text { Pers., Myy., 12, t. 20, fig. 4-6. }
\end{gathered}
$$

Champignon de taille moyenne, croissant à terre, le plus souvent en touffes, dans les hois de pins et de sapins des Vosges, et ayant un chaреaи charm, fibren, flexible, lisse, glabre, infundibuliforme, ir- 
régulier, fauve ou blanc grisitre, des aiguillons décurrents, nombreux, d'un blanc pâle; un pied, inégal, atténué en bas, de la couleur du chapeau.

Il exhale, lorsqu'il est desséché, une odeur forte, analogue à celle du céleri. Comestible.

\section{Hydne lisse (Hydnum loevigatum), Swartz.}

Mich., t. 72, fig. 1. - Paul., t. 34. - Barla, t. 38, fig. 5, 6. - Fr., Epier., 5. Hyd. bubalinum, Pers., Myc., 9.

On reconnait ce champignon comestible, mais de qualité médiocre, à son chapeau charnu, mollasse, glabre, lisse ou faiblement rugueux, sinueux, irrégulier, de forme variable, fauve cendré, non squameux; à des aiguillons très-grêles, nombreux, d'un blanc cendré, aigus au sommet; à son pied, de la couleur du chapeau, ferme, inégal, lisse.

Sa chair, blanche, épaisse, ferme, a une saveur agréable.

On le trouve, à terre, dans les bois de pins.

\section{Hydne sinué (Hydnum repandum), Lin.}

(PI. XLIII.)

Vaill., t. 14, fig. 5-8. - Fl. dan., t. 310. - Sow., t. 176. - Schæff,, t. 318. - Bull., t. 172. - Krombh., t. 50, fig. 1-9. - Vittad., t. 25, fig. 2. Paul., t. 35, fig. 1, 2. - Staude, t. 2, fig. 3. - Huss., I, t. 16. - Berkl., t. 17, fig. 2. - Noul, et Dass., t. 10, fig. A. - Pers., Myc., 8. - Fr., Epier., 8.

Noms vulgaires : Erinace, Chamois, Chevrelle, Ursin; Rignoche, Lurchon, Penchenilla, en Gascogne; Arresterou, dans les Landes; Mouton, dans la Meuse; Pied de mouton blanc, Barbe de vache, dans les Vosges.

L'Hydnum repandum, très-commun au commencement de l'automne, dans les bois, à terre, épars ou en séries très-longues et mème circulaires, est entièrement de couleur jaune-chamois ou incarnat pâle, de grandeur moyenne. Il a le chapeau charnu, compacte, irrégulier, sinué, non-zoné; les aiguillons inégaux, tubulés, fragiles, quelques-uns s'avançant jusque sur le sommet d'un pédicule, plein, irrégulier et presque toujours excentrique. Chair ferme, cassante; saveur légèrement amère et un peu acerbe.

Comestille, et d'm nsage très-fréquent. 


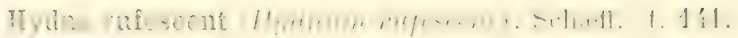

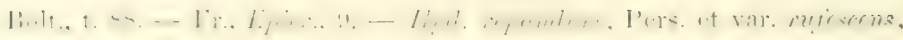
Mijc., 8; Ieon., t. 19, fig. 1

LiHydinum mescens est regardé par Persoon et Berkeley comme une simple variété de l'Hydnum renandum; il n'en diffèreguère que par ce qu'il est génératement plus petit. Son chapeau est mince, subtomenteur, ochiacé, roussatre, irrégulier. Les aiguillons sont minces, égaux; de couleur incarnat ochracé. Pied grèle, à peu près égal.

Il croit, à terre, dans les bois. Comestible.

Hydne écailleux (Hydnum squamosum), Schæff., t. 273.

Barla, t. 39, fig. 10-12. - Fr., Epier., 2. - Hyd. eucopus, Pers., Myyc., 2.

Ce champignon, comestible, assez rare, qu'on trouve, à terre, dans les bois de pins, a la chair d'un blanc jaunàtre, molle; le chapeau charnu, large de 6 à 8 centimètres, campanulé, puis déprimé, irrégulier, lisse, fauve fuligineux, courert de squames ou écailles ivégulieres; les aiguillons, grêles, d'un gris fanve, hlanchàtres au sommet.

L'Hydnum squamosum n'est, pour M. Barla, que la var. mufescens, Pers., de l'H!yd. repandum.

Hydne en forme de coupe (Hydnum scrobiculatum), Fr., Epier., 21.

Mich., t. 72, fig. 7. - Hyd. cyathiforme, Bull., t. 156. - Schæff., t. 139.

Bien qu'il soit coriace, quelques personnes n'hésitent pas à manger ce champignon; il nait, à terre, dans les bois, en groupes plus ou moins nombreux, est de couleur tannée ou ferrugineuse. Son chapeau estsulbérenx, coriace, d'rabord armondi, puis plan, et enfin creusé en entonnoir, mince, zoné, comme squameux; aiguillons trẻs-courts; pédicule ne s'élerant pas au delà de 3 centimètres, nu, pourvu de racines.

Hydne sub-squameux (Hydurum subsquamosum), Batsch, t. 10, fig. 43.

Paul., t. 33, fig. 1. - Fr., Eprer., 3. - Hyd. badium, Pers., Myyc., I, t. 21 - Hyrl. squamosum, Bull., t. 409.

Noms vulgaires : Chevrotine écailleuse, grande chevrette.

Champignon de grande taille, ayant le chapeau charnu, plan, irrégulier. suh-ombilicqué, frue fermginenx, tacheté de squames super- 
ficielles ou marqué de fissures de couleur fauve foncé; les aiguillons, d'abord d'un blanc cendré, ensuite légèrement fauves; le pied, court, cylindrique, inégal, de la couleur du chapeau.

Il croìt en touffes, à terre, dans les forèts de pins et de sapins, et n'est pas rare dans les Vosges et le Jura.

L'Hydnum subsquamosum acquiert quelquefois 25 centimètres de diamètre; est comestible. Chair ferme, d'un blanc jaunâtre.

Hydne violace (Hydnum violascens), Alb. et Schw.

Paul., t. 35 bis. - Pers, Myc., 10. - Fr., Epicr., 12.

L'Hydnum violascens a le chapeau, fibreux, charnu, d'abord convexe, puis plat, puis déprimé au centre, le plus souvent irrégulier; une surface tomenteuse, donce au toucher, sub-zonée, de couleur violet sale; des aiguillons égaux, cylindriques, aigus, violacés, décurrents sur un pédicule ferme, souvent courbé, inégal.

A terre, dans les bois. Rare.

Est comestible, mais peu recherché pour l'usage alimentaire, malgré son goût et son odeur agréables.

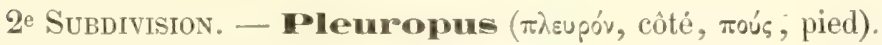

Pédicule latéral.

Hydne cure-oreille (Hydnum Auriscalpium), Lin.

Schæff., t. 143. - Fl. dan., t. 1020, fig. 1. - Grev., t. 196. - Krombh., t. 50, fig. 15-17. - Sow., t. 267. - Bull., t. 481, fig. 3. - Fr., Epicr., 34.

Ce champignon, d'un brun roussâtre, croît sur les cônes de pin tombés à terre. Son chapeau, mince, coriace, tomenteux, semi-orbiculaire ou réniforme, atteint rarement au delà de 2 centimètres de diamètre; il est garni, en dessous, de petits aiguillons nombreux, égaux, et attaché, par le côté, au sommet d'un pédicule grêle, droit, velu, plein, long de 4 à 5 centimètres.

Bien qu'il soit coriace et de très-petite taille, on le mange en Gascogne et en Toscane; c'est un aliment peu digne d'ètre recherché. 


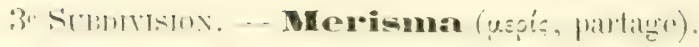

Tiris-irmentr.

Hydne tête de Méduse (Hydnum caput Medusce), Bull.

Fr., Eprior., 41. - Clararia reput Meduset, Bull., t. 412. - IFeririum eapul Medusce, Pers., Myc., 10.

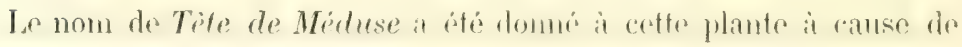
son aspect entragere, fout heriscie.

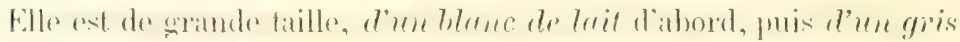

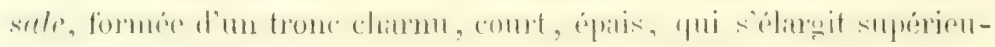
rement et se termine par de nombreux aiguillons grèles, allongés, simples, pointus, dirigés d'abord verticalement, puis tout à fait pendants, ondulés, rassemblés en touffes et insérés sans ordre.

L'Hydnum caput Medusce croit, à la fin de l'été, sur les troncs de bois morts. Rare.

On le mange fréquemment en Italie; il a une odeur et une saven' agréables.

\section{Hydne coralloïde (Hydnum coralloides), Scop.}

(Pl. XLIV, fig. 1.)

Mich., t. 64, fig. 2. - Boccone, t. 303, fig. 7. - Schæff., t. 142. - Nees, t. 33, fig. 249. - Sow., t. 252. - Krombl., t. 51, fi. 4-7. - Lenz., t. 53.

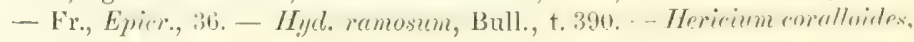
Pers., Myc. 1.

Nom vulgaire: Hérisson coralloïde.

On trouve, en automne, sur les vieux troncs d'arlores encore vivants et principalement sur le chène, un champignon sessile, d'abord blanc, puis jaunatre, et qui, dans sa jeunesse, ressemble à une tète de choufleur. De sa base, tendre et charnue, partent un grand nombre de rameanx flexueux, entrelacés, rapprochés en touffes, portant, au sommet de chacune de leurs divisions, une houppe de longues pointes ou aignillons, d'abord droits, puis pendants, et mème recourbés en dessous et se terminant par étages.

L'Hydnum coralloïdes n'est pas très-rare en Lorraine. C'est un ali ment délicat.

Fries raconte, qu'étant avec sa mère, à l'âge de 12 ans, à cueillir des fraises dans $m$ bois, il vit avec admiration $m$ bel exemplaire d'Hydne 
coralloïde, qui, tout d'abord, fit naître en lui uu si vif désir de connâ̂tre les champignons, que deux ans après (1808), bien qu'il fût en pension dans une école, et par conséquent rarement libre de sortir, il avait appris à en connaitre 300 ou 400, auxquels il donnait des noms fictifs, n'ayant pas de livres pour le guider dans son étude.

\section{Hydne hèrisson (Hydnum Erinaceus), Bull., t. 34.}

$$
\text { (PI. XLIV, fig. 2.) }
$$

Tratt., t. 18, fig. 35. - Buxh., t. 56, fig. 1. - Krombh., t. 51, fig. 1-3. Vittad., t. 26. - Fr., Elirr., 40. - Hericium Fimarenes, Pers., Mlyc., 7.

Noms vulgaires: Houppe des arbres, dans les Vosges; Penchinilia, mil Languedoc.

L'Hydnum Erinaceus, l'un des plus grands du genre, croît dans les cicatrices des vieux chênes, et quelquefois de hètre. Il est charnu et entièrement d'un blanc jaunâtre, sessile ou à pédicule court, simple. latéral, irrégulièremeut cylindrique et recourbé à son sommet, lequel se dilate en une espèce de chapeau, qui émet une multitude d'aiguillons minces, allongés, toujours pendants et se terminant par étages.

Champignon très-bon à manger, d'une consistance tendre et char-nue, de la saveur du champignon de couche.

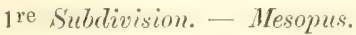

II. orangé (Hyd. aurantiucum), Alb. et Schw. - Fl. dan., t. 1439. - Fr., Epirr, 16. - Dans les bois de pins.

H. cendré (Hyd. cinereum), Bull., t. 419. - Krombh., t. 70, fig. 13, 14. - Dans la France méridionale.

H. compact (Hyd. compactum), Batsch, fig. 221. - Krombh., t. 50, fig. 12. Fr., Epier., 15, - Dans les bruyères, sous les bouleaux, même dans les taillis de pins.

H. jumeau (Hyd. connatum), Schultz. - Fx., Epicr., 23. - Hydnum scutatum, Pers., Mye., p. 170. - Dans les bois de chênes.

H. couleur de rouille (Hyd. ferrugineum), Krombh., t. 50, fig. 10, 11. - Fr., Epicr., 17. - Hyd. hybridum, Bull., †. 453, fig. 2. - Dans les bois de pins.

H. à odeur forte (Hyd. graveolens), Delast. - Fr., Epirr., 26. - Hydnum leptopus, Pers., Myc., 23. - Dans les bois de pins.

H. imbriqué (Hyd. imbricatum), Lin. (décrit).

H. en entonnoir (Hyd. infundibulum), Swartz (décrit).

H. lisse (Hyd. lovigatum), Swartz (décrit).

H. noirâtre (Hyd. melaleucum), Fr., Epier., 27. - Schæff., t. 272. - Dans les bois de coniferes.

H. noir (Hyd. nigrum), Fr., Epicr., 25. - Mich., t. 72, fig. 5. - Dans les bois de pins. 


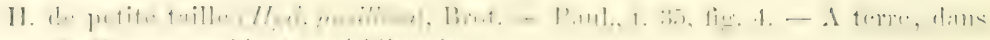

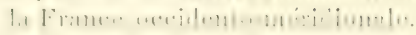

II. sinué (Hyd. repenutum), Lin. (décrit).

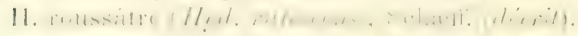

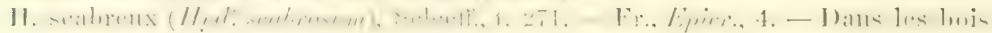
de conifères, sur les montagnes; rare. Comestible.

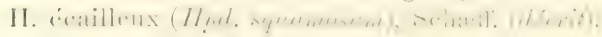

H. en coupe (IIyd. scrobiculatum), Fr. (dicrit).

H. odorant (Hyd. sucureolenss), Scop. - Fr., Epicr., 13, - Variété Cceruleum. IF. dan., t. 1374. - Dans les bois de pins.

H. sous-écailleux (IIyd. subsquamosum), Batsch (décrit).

H. drapé (Hyd.tomentosum), Lin. - Schrff., t. 139. - Fl. dan., t. 1020, fig. 2. - Dans les bois de pins.

H. velouté (Hyd. velutinum), Mich., t. 72, fig. 4. - Fr., Epicr., 20. - IIyd. hyGridum, Bull., t. 453. - Dans les bois de pins.

II. violacé (IIyd. violaceum), Alb. et Schw. (décrit).

H. zoné (IIyd. zonatum), Batsch, t. 224. - Nees, fig. 212. - Fr., Epier., 22. Dans Ies chênaies des champs.

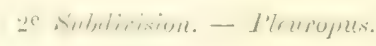

H. blane verdâtre (Hyd. albo-virens), Vill.

II. cure-oreille (Hyd. Auriscalpium), Lin. (d'crit).

II. occidental (Hyd. occidentale), Paul., t. 32, fig. 1, 2. - Fr., Epior., 32. - Au bas des trones, dans la France occidentale; rave. Paulet le regarde comme malfaisant.

H. parasite (Hyd. parasiticum), Vill.

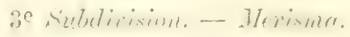

H. tête de Méduse (Hyd. caput Medusce), Bull. (décrit).

H. coralloïde (Hyd. coralloides), Scop. (décrit).

H. hérisson (Hyd. Erinacens), Bull. (décrit).

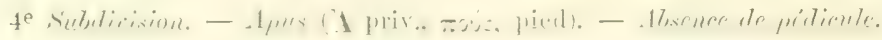

H. en vrilles (Hyd. cirratum), Pers., Syn., 9. - Fl. dan., t. 1789, fig. 2. - Fr., Epicr., 47. - Sur les trones.

H. gélatineux (Hyd, gelatinosum), Scop. - Fl. dan., t. 717. - Jacq., t. 239. Schæff., t. 144. - Krombh., t. 50, fig. 18-22. - Sur les trones de sapins.

I. hérissé (IIyd. hirtum), Fl., Epier., 56. - Hyd. lutescens, Pers., Myc., 31. Sur les trones.

H. jaune d'ocre (Hyd. ochraceun), Pers., Syn., 13. - Sow., t. 15. - Fr., Epicr. 61. - Sur les trones du pin.

H. gentil (Hydt.putorinum!, Fl., Epicr., 60.-Hyd. dichroum, Pers., Myc., p. 213. - sur les trones cariés du chêne.

\section{5e Sublivision. - Resupinatus (en latin, penché, couché). - Étalé horizontalement.}

H. diaphane (IIyd. diaphanum), Sehrad., t. 3 fig. 3. - Fr., Epier., 90. - Sur le trone des arbres feuillus. 


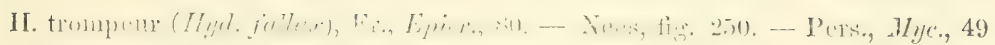

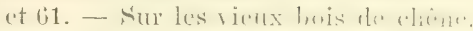

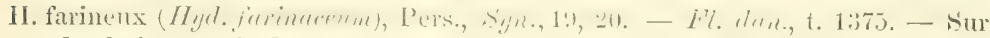
les bois pourris de pins ete.

H. en fascicule (Hycl. fasciculare), Alb. et Sehw., t. 10, fig. 9. - Sur les trones putréfiés du pin.

H. ferrugineux (Hyd. fermginosum), Fr., Epior., 71. - Nees, Syst., fig. 248. Schrad., t. 4, fig. 2. - Sur les bois pourris, sous les écorces.

H. fragile (Hyd. frogile), Pers., Syn., 16. - Fr., Epricr., p. 518. - Sur les trones de pins.

H. membraneux (Hyd. membranaceum), Bull., t. 481, fig. 1. - Sow., t. 327. Fr., Epicr., 67. - Sur les bois pouris.

H. moisi (Hyd. mucidum), Pers., Syn., 18. - Frr., Epicr., 89. - Sur les trones du chêne, du sorbier, du luêtre.

H. blane (Hyd. niverm), Pers., Disp., t. 4, fig. 6, 7. - Fr., Epicr., 91. - Nees, fig. 246. - Sur les bois.

H. du pin saurage (Hyd. pinastri), Fr., Epicr., 77. - Hyd. abietinum, Duby, Bot. Gall. - Sistotrema pinastri, Pers., Jyje., 19.

H. rude (Hyd. mude), Duby, Bot. Gall. - Sistolrema mude, Pers., Synn., p. 553.

H. grêle (Hyd. subtile), Fr., Epicr., 95. - Hycl. acutum, Per's., Myc., 42. - Sur le bois et les écorces.

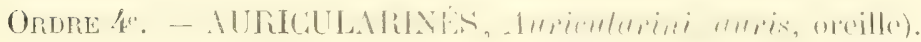

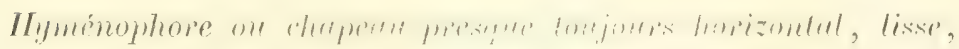
rarement veiné; hyménium inférieur ou amphigene continu avec l'hyménophore. BAsIDIosporés.

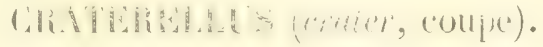

Champignon charnu membraneux, hyménium inférieux se continuant avec l'hyménophore, lisse, glabre, et enfin rugueux. Putrescent en vieillissant. Très-voisin du genre Cantharellus.

Craterelle en massue (Craterellus clavatus), Fr., Epicr., 9.

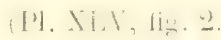

Sehrff., t. 164 et 276 , fig. 4. - Schmid., t. 60. - Jacq., t. 12, fig. 3. Krombh., t. 45, fig. 13-17. - Hoffm., t. 6. - Staude, t. 2, fig. 2. - Lenz, t. 8, fig. 40. - Gomphus truncetus, Pers., MIyc., 1.

Champignon difforme, charnu, simple ou sub-rameux, ayant un chapeau turbiné, tronqué, déprimé, flexueux, non lisse, sub-flavescent à la surface supérieure, purpurascent, lisse, ridé en dessous, atténué en un pied solide. 


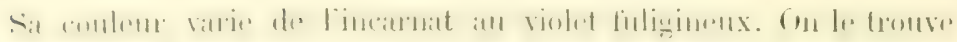
dans les bois, surtout les bois de sapins. Rare.

Comestible. Sa chair est blanche et épaisse.

Craterelle corne d'abondance (Craterellus comncopioides), Pers., Myc., 1.

1'. XLV, lig. 1.)

Mich., t. 82, fig. 5, 6. - Fl. dan., t. 384 et 1260. - Schæffo, t. 165, 166. Sow., t. 74. - Vaill., t. 13, fig. 2, 3. - Nees, t. 165. - Bolt., t. 103. Bull., t. 150 et 498 , fig. 3 . - Krombh., t. 46 , fig. 10. - Berkl., t. 19, fig. 6. - Huss., II, t. 37. Fr., Epicr., 4. Peziza cornucopioides, Lin.

Le Craterellus cornucopioides a des rapports avec les Pézizes et les Helvelles, mais il se rapproche davantage des Chanterelles. Sa forme est à peu près celle d'un entonnoir ou d'une trompette. Il a le chapeau sub-menbraneux, noir fuligineux, peluché ou légèrement squameux, avec des bords sinueux, lobés, réfléchis en dessous; la surface inférieure, plus pàle que la supérieure, est d'un fauve cendré, marquée de veines anastomosées, peu saillantes. Pied noir, creux jusqu'à la base.

Il vient en groupes peu nombreux, dans les bois, à terre, en été et en automme, surtout lorsque le temps est pluvieux.

Comestible. Son peu de chair et sa couleur sombre n'invitent guère à le manger.

\section{Craterelle.}

C'r. en massue (Crat. clavatus), Fr. (décrit).

Cr. corne d'abondance (C'rat. cornucopioides), Pers. (déerit).

Cir. crépue (Crat. crispus), Sow., t. 75. - Huss., II, t. 18. - Bull., t. 465. - Fr., Eprer., p.533. - Helvella crispa, Bull., t. 465, fig. 1. - Dans les bois.

C'r. jaunâtre (Crat. lutescens), Fr., Epier., 2. - Schrff., t. 157. - Bolt., t. 105, fig. 2. - Merulius xanthopus, Pers., Mye., t. 13, fig. 1. - Dans les lieux humides et les bois de pins de montagnes.

Cr. mélanoxéros (Crat. melanoxeros), Desm.

C'r. ocracée (Crat. ochreatus), Per's., Mye., 2, t. 13, fig. 2. - Fr., Epier., 3. Recueillie aux environs de Paris.

Cr. pilon (Crat. pistillaris), Schæff., t. 290. - Fr., Epicr., 12, - Dans les bois épais de sapins, la mousse.

Cr. petite taille (Crat. pusillus), Pers., Wye., p. 6. - Fr., Epicr., 8. - Cantharellus Kunthï, Chev., Fl.paris., t. 7, fig. 6. - Dans les bois de hêtres.

Cr. sinueuse (Crat. sinuosus), Fr., Epior., 7. - Vaill., Bot., t. 11, fig. 11-13. Dans les chênaies hunides. 


\section{OruRe 5". - CLAVARES (Clatariei).}

Hyménium occupant it peut près toule la surface d'un hyménophore certical, lisse on ì peine ride, amphigène. BasmossPORÉS.

\section{CLAVAIRE (Clavaria).}

(Clava, massue, de la forme de quelques espèces.)

C'hampignon à réceptacle ou hyménophore allongé, simple ou ra-meux, charnu ou coriace, ordinairement droit, confondu avec le pédicule, recouvert en grande partie de l'hyménium. Pas de chapeau distinct.

L'âge, le'sol, l'exposition et d'autres circonstances locales font varier la plupart des Clavaires dans leurs dimensions, leurs formes, leurs conleurs. Peut-être en a-t-on trop multiplié les espèces.

\section{1we Truti. Framosa (en rumeatux). fre Sumpinsios. - Leucospones.}

Clavaire améthyste (Glavaria amethystea), Bull., t. 496, fig. 2.

(Pl. XLVI, fig. 3.)

Schæff., t. 172. - Nees, 2, t. 16, fig. 151. - Berkl., t. 18, fig. 2. Bolt., t. 1-6. - Pers., Myc., 14. - Fr., Epicr., 3.

La Clavaire améthyste est entièrement de couleur violacée ou lilas, de taille variable, mais atteignant quelquefois 8 centimètres et plus; fragile, très-rameuse. Ses rameaux, grands, lisses, non ondulés, obtus, sont très-simples, parfois hauts de moins d'un centimètre.

Elle est comestible, d'un goùt très-fin, et vient, à terre, dans les bois, en automne.

Clavaire en grappe (Clavaria botrytis), Pers., Comment., p. 41.

(Pl. XLVII, tig. 2.)

S'ehæft., t. 176 et 288. - Jueı., t. 13. - Tratt., p. 159, fig. 13B. - Necs, t. 150. - Fl.dan., t. 1303. - Bolt., t. 113, fig. $a_{*}$ - Krombh., t. 53, fig. 1-4. - Vittad,, t. 29. - Vent., t. 12, fig. 111. - Hartz., t. 57. Staude, t. 1, fig. 6. - Barla, t. 40, fig. 1-3. - Fr., Epicr., 2. *

Noms vulgaires: Barbe de chèvre ou de bouc, Pied de coq, Ganteline, Tripette, Mainotte, Manetas. 


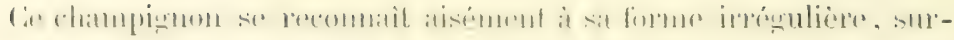

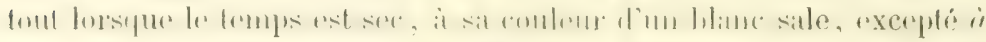

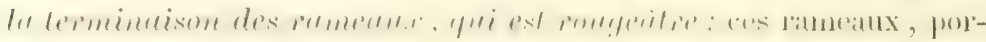
tés par un tronc charnu, gros, sont nombreux, courts, épais et serrés, inégaux, sub-rugueux, denticulés et légèrement comprimés au sommet. Il a l'aspect d'un chou-fleur.

On le recueille daus les bois, en été et en automne.

Il est comestible ef d'un usage fréquent dans la Carinthie. Chair blanche; goût agréable; odeur faible.

\section{Clavaire cendrée (Clavaria cinerea), Bull., t. 354.}

$$
\text { (I'. XLl1, fig. 2.. }
$$

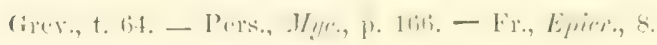

Nom vulgaine: Menotte cendrée, dans les Vosges.

C'est dans les bois que vient ce champignon fragile, de couleur cendrée, très-rameux; à pied court, épais; à rameaux et ramuscules, irréguliers, difformes, un peu ridés, obtus. Il pèse quelquefois près d'un kilogramme.

Comestible, mais nuisible si l'on mange une certaine quantité. J'en ai fait l'expérience.

Clavaire coralloide (Clavaria coralloides), Lin.

Batt., t. 1, fig. A. - Ifulnisk., t. 12. - Sum., t. 278. - Fr., Eprir., 7. -

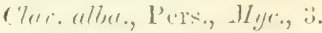

Clavaire de couleur blunche, passant au gris, sub-fragile, ayant une tige creuse en dedans, assez épaisse, irrégulièrement rameux; les rameaux, très-nombreux, forment des faisceaux inégaux, serrés, aigus.

Elle se rencontre dans les bois humides, surtout dans les bois de sapins. Comestible.

\section{Clavaire fastigiee (Clavaria fastigiata), Lin.}

Bull., t. 358, fig. D, E. - Holmsk., I, p. 90. - Fl. dan., t. 836, fig. 2. Vaill., t. 8, fig., 4. - Raj., t. 24, fig. 5. - Fr., Epicr., 4. - Clav. pratensis, Pers., Clav., t. 4, fig. 5; id., Myc., 27.

Ciette Clavaire, de couleur jaune, très-rameuse, s'élève à peine à 3 centimètres. Ses rameaux partent d'une tige très-courte, mince, 
sont divariqués, glabres, disposés en faisceaux obtus, et se terminent à la mème hauteur.

Elle est assez commune, en automne, dans les pâturages, les Jruyères, au bord des chemins, et se plait surtout dans les gazons et les mousses. Comestible.

Glavaire jaunâtre (Cilacaria flava), Pers., Comment., p. 42.

$$
\text { (Pl. XLVI, fig. 1.) }
$$

Schæff., t. 175 et 285. - Lenz, fig. 54. - Krombh., t. 53, fig. 8. - Barla, t. 4, fig. 5. - Clav. coralloides, Bull., t. 496, fig. 3, t. 222 et 358, fig. B, E. - Fr., Epicr., 1.

Noms vulgaires: Menotte ou Mainotte, Gallinette, Espignette, Barbe de chèvre, Poule, Buisson, Tripette etc.

Excellente à manger et très-recherchée en Allemagne; cette Cliavaire croit dans les bois ombragés.

Elle est de grande taille, charnue, fragile, de couleur jaune; a le trone épais, droit, blanc, très-rameux; les rameaux cylindriques, lisses, disposés en faisceaux, obtus, de couleur jaune. Variable en intensité.

Les Clavaires rameuses portent différents noms, selon les provinces : celui de Mainotte ou Menotte leur a été donné, sans doute, à cause de leurs ramifications.

2. Subdivision. - Uchrospreses.

Clavaire dorẻe (Clavaria aurea), Schæff., t. 287.

Tratt., t. 2, fig. 4. - Clav, coralloides, Bull., t. 222. - Fr., Epicr., 19.

- Clar. flara, Pers., Myr., 4.

Les noms vulgaires du Clavaria aurea sont ceux du Clavaria flava, bien que ces deux plantes soient distinctes.

La Clavaire dorée est de couleur jaune, haute de 8 à 12 centimètres. Son trone, épais, élastique, pâle, se sübdivise en rameaux nombreux, dichotomes, inégaux, droits; chaque subdivision, obtuse, sub-dentée. La base ou pédicule est souvent allongée, mais quelquefois peu évidente.

Cette Clavaire, excellente dे manger, vient, dans les bois, en octobre et en novembre. 
Clavaire élégante (Clavaria formosa), Pers., Icon, et descr., t. 3, fig. 6.

Batsch, fig. 48. - Krombh., t. 53, fig. 5-7, et t. 54, fig. 21, 22. -

Barla, t. 40, fig. 4. - Fr., Epier., 20.

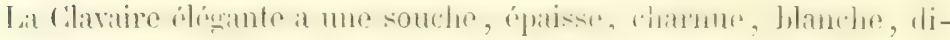
visíc en rameaux, épais, cylindriques, allongés, serrés, de couleur jaune orangé ou orangé rose, subdivisés en petits rameaux, obtus, flavescents, réunis en faisceaux, et terminés par deux ou trois dents "11 puinte? 111 pr'ti obtuse.

kille se recueille, en automne, dans les pacages, les friches et les beis.

On l'apporte aux marchés de Nice. Sa chair, comeslible, trèsblanche, at un gonit delinat.

Clavaire grise (Clavaria grisea), Pers., Comment., p. 43.

Krombl., t. 53, fig. 9, 10. - Barla, t. 41, fig. 1, 2. - Fr., Epicr., 25.

La Clavaire grise a la chair ferme; le trone épais, d'un blane sale; les rameaux, sub-rugueux, atténués, subdivisés en ramuscules, inégaux, obtus, de couleur cendré fuligineux.

Est comestible, et vient, à terre, dans les bois et les friches, en automne.

Le Clav. mifo-violacea, Barla, t. 11, fig. 3-12, comestible aussi, n'est peut-ètre qu'une variété du Clav. grisea.

\section{Trult: Simplex - -implu.

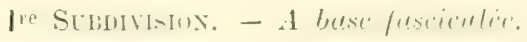

Clavaire vermiculee (Clavaria vermiculata), Scop.

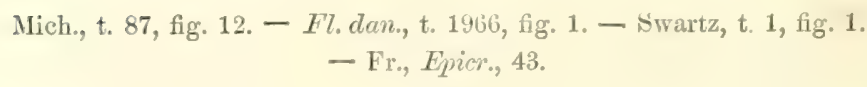

Cette plante, qui vient en touffes, dans les gazons et les bois, en automne, et forme, dit Berkeley, des groupes, ressemblant à des paquets de petites chandelles, est commune, fragile, de couleur blanche; elle a l'aspect de petites massues, pleines, cylindriques, souvent courbées ou flexueuses, terminées en pointes. Comestible. 
2. Subdiniston. - Séparies a la base.

Clavaire pilon (Clavaria pistillaris), Lin.

Sow., t. 279. - Fl. dan., t. 1255. - Bull., t. 244. - Huss., I, t. 62. -

Holmsk., t. 504, fig. 1, 2. - Krombh., t. 54, fig. 1-11. - Pers., Myc., 39. - Fr., Elicr.2 49.

Champignon simple, ayant la forme d'une massue ou d'un pilon, long de 10 à 15 centimètres, plein, charnu, arrondi au sommet, de couleur fauve ou terreuse.

Il croît, en automne, dans les bois fourrés, les gazons, solitaire ou en groupes peu nombreux. Comestible.

Les paysans Polonais, Russes et Allemands, mangent cette Clavaire. En France, elle n'est nullement recherchée, à cause de sa chair ferme, un peu coriace, et de sa saveur légèrement amère.

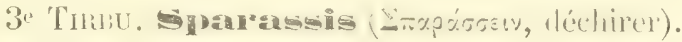

Champignon à réceptacle ou hyménophore très-rameux, confondu avec le pédicule, à rameaux foliacés, laciniés, couverts partout de l'hyménium. Pas de chapeau distinct. Genre pour quelques auteurs.

Clavaire (Spar.) crépue (Clavaria Spar. crispa), Jacq., t. 14, fig. 1. (Pl. XLVII, fig. 1.)

Schæff., t. 163. - Paul., t. 189, fig. 6. - Krombh., t. 22, fig. 1. - Lenz, fig. 56. - Pers., Mye., 1. - Sparassis crispa, Fr., Epier., 1.

Champignon charnu, fragile, crépu, très-rameux, de couleur blanc jaunâtre, de forme arrondie, atteignant quelquefois le volume de la tête d'un enfant. De son pédicule, épais, court, solide, plein, attenué à sa base, partent des rameaux nombreux, glabres, entrelacés, recourbés au sommet, et comprimés en forme de laines crépues et denticulées.

De loin la Clavaire crépue a assez bien l'aspect d'un arbrisseau; elle vient en automne, dans les bois de sapins, au pied des arbres.

Comestible et d'excellent goùt; on la mange en Alsace.

Clavaire (Spar.) lamelleuse (Clavaria Spar. laminosa), Fr.

Sparassis laminosa, Fr., Epicr, 2. - Spar. brevipes, Krombh., t. 22, fig. 3, 4.

La Clavaire lamelleuse est de la taille de la Clavaire crépue. C'est une plante très-rameuse, hémisphérique, de couleur paille, à rameaux 


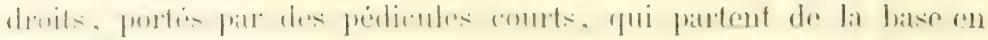
rayonnant, et deviennent plus considérables, larges et droits au sommet.

On la recucille au pied des sapins et des chênes. Comestible, et d'excellent goût.

$$
\begin{aligned}
& \text { 1re Trist. - liameuses. } \\
& \text { 1re subdicision. - Leucospores. }
\end{aligned}
$$

Cl. améthyste (Cl. anzethystea), Bull. (décrit).

Cl. en grappe (Cl. Botrytis), Pers. (décrit).

('l. ecentréc (1\% rinerea), Bull. (diritit).

C1. coralloïde (Cl. coralloides), Lin. (décrit).

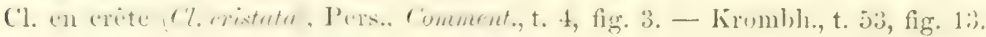
- Grev., t. 190. - Hulmsk., p. 92. - Fl. dan., t. 1304, - Pers., Myc., 16, 19, 20. - Dans les bois.

C1. fastigiée (Cl. fastigiata), Lin. (décrit).

Cl. jaunâtre (Cl. flava), Pers. (décrit).

Cl. de Kunze (Cl. Kunzei), Fr., Epicr., 12. - Bull., t. 358, fig. C, maxima. - Dans les bois feuillus, humides.

Cl. mousse ( $(l$. muscoides), Lin. - Schæff., t. 173. - Fl. dan., t. 775, fig. 3. Krombh., t. 53, fig. 22, 23. - Bull., t. 496, fig. O, Q. - Jacq., t. 16, fig. 1. Dans les prairies.

Cl. palmée (Cl. palmata), Pers., Comment. - Crouan, Fl. fin., p. 62. - Dans les chemins creux.

Cl. en forme de boîte (Cl. pyxidata), Pers., Comment, t. 1, fig. 1. - Fl. dan., t. 1304, fig. 1. - Sur les bois pourris.

Cl. rousse-tiolacée (Cl. mufo-violacea), Barla. - Champ., t. 41, fig. 3-13. - Automme, dans la mousse, le gazon, sur le penchant des collines. Comestible.

C1. rugueuse $(C l$. rugosa), Bull., t. 48 , fig. 2. - Krombh., t. 54, fig. 18-17. Bolt., t. 115. - Fl. dan., t. 1301. - Berkl., t. 18, fig. 3. - Grev., t. 328. Dans les lieux humides. Comestible.

Cl. ténue (Cl. subtilis), Pers., Comment., t. 4, fig. 2. - Dans les buis.

\section{0 sublirision. - Ochruspores.}

C1. du sapin (Cl. abietina), Fr., Epicr., 22. - Fl. dan., t. 2030, fig. 2. - Grev. t. 117. - Dans les bois de sapins.

C1. dorée ( $C l$. aurea), schæeft. (décrit).

C1. à radicule byssoïde (Cl. byssiseda), Pers., Comment., t. 3, fig. 1. - Fl. dan., t. 1967, fig. 1. - Sur les bois de chênes, de hêtres.

C1. coquette (Cl. crispula, Fr., Epror., 31.-Cl. muscoides, Bull., t. 358, fig. A, B. - Cl. Syringarum, Pers., Jlye., 9. - A terre, à la base des trones.

(1. safranée (G\%.crocea), Pers., Icon. et descr., t. 11, fig. 6. - Dans les bois de liêtres.

Cl. sub-épineuse (Cl. spinulosai, Pers., Obs., 2, t. 3, fig. 21. - Fr., Epricr., 21. Dans les bois de conifères.

C1. élégante (Cl. formosa), Pers. (décrit).

Cl. grise (Gl. grisea), Pers. (décrit). 
Cl. contractée ( 7 . stricta), Pers., Comment., t. 4, fig. 1. - Schæff., t. 286. Krombh., t. 18, fig. 5. - Sow., t. 157. - Sur les vieux trones de hêtres.

C1. de la Suède (Cl. Suericaj, Fr., Epier., 26. - Krombh., t. 54, fig. 23. - Dans les bois de coniferes.

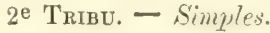 \\ $1^{\text {re }}$ Sublivision. - A base fasciculée.
}

Cl. argillacée (Cl. argillacea), Fr., Epicr., 42; Obs., t. 5, fig. 3.-Fl. dan., t. 1852, fig. 2, et 1962, fig. 2. - Pers., Comment., t. 1, fig.4. - Schm., t. 15. - Sur la terre, dans les endroits stériles, la terre glaise.

Cl. fragile (Cl. fragilis), Holmsk., 1, p. 7. - Bolt., t. 111, fig. 3. - Fl. dan, t. 775, fig. 2. - Mich., t. 87, fig. 6 et 10. - Sow., t. 90 et 232. - Vaill,, t. 7, fig. 7. - Clavaria cylindrica, Bull., t. 463, fig. B, N, O. - Cl. Helvola, Pers., Syn., 35; Cl. pistilliforma, Pers., Myc., 59. - Dans les bois de hêtres, à terre, en touffes.

Cl. fusiforme (Cl. fusiformis), Sow., t. 234. - Bolt., t. 110. - Dans les gazons. - Comestible, d'après Réveil.

Cl. inégale (Cl. incequalis), Fl. dan., t. 836, fig. 1. - Grev., t. 37. - Huss., I, t. 18. - Sow., t. 253. - Pers., Comment., t. 1, fig. 3. - Bull., t. 264. - C7. fasciculata, Vill., 1054. - Dans les gazons.

Cl. vermiculée (Cl. vermiculate), Scop. (décrit).

$2^{e}$ Sublivision. - Séparées ì la base.

C1. aiguë (Cl. acuta), Sow., t. 333. - Fr., Epicr., 61. - Sur la terre ombragée.

C1. canaliculée (C7. canaliculata), Fr., Epicr., 56. - Bull., t. 496, fig. L, M. Bolt., t. 110. - Sur la terre, dans les broussailles des forêts.

Cl. dichotome (Cl. dichotoma), Desm., Cat. - Dans le nord de la France.

Cl. en forme de faulx $(C l$. falcata $)$, Pers., Comment., t. 1, fig. 3. - Fr., Epicr., 57. - Sur la terre humide.

Cl. fistuleuse (Cl. fistulosa), Fr., Epicr., 54. - Fl. dan., t. 1100, fig. 3, et t. 1255. - Krombh., t. 5, fig. 19. - Sur les petites branches, les pailles.

Cl. pied fauve (cl. fuscipes), Pers., Myc., 75. - Sur les rameaux sees.

Cl. petit jonc (Cl. juncea), Fr., Epicr., 55. - Mich., t. 87, fig. 7. - Fl. dan., t. 1257. - Bull., t. 463, fig. H. - Pers., Myc., 45, 48, 67. - Sur les feuilles tombées à terre, près des hêtres.

Cl. de petite taille (Cl. minor), Lév., Ann. des se.nat., XX, t. 7, fig. 2.

Cl. humide (Cl. mucida), Pers., Comment., t. 2, fig. 3. - Fl. dan., t. 1376. Fr., Epicr., 60. - Sur la terre et les bois mousseux.

Cl. pilon (Cl. pistillaris), Lin. (décrit).

Cl. onciale (Cl. uncialis), Grev., t. 98. - Fr., Epicr., 63. - Sur les tiges et tuyaux des herbes, dans les régions alpestres.

3e Tribu. - Sparassis.

C1. (Spar.) crépue (Cl. Spar. crispa), Jacq. (décrit).

C1. (Spar.) lamelleuse (Cl. Spar. laminosa), Fr. (décrit). 
ORIRE 6. - TREMELLINES (Tremellini).

Plante chamue, gélutineuse (BASIDIOSPORÉS).

\section{TREMELLE, Tremella (tremulus, tremblant).}

Expansion gélatineuse, tremblante, distendue, de forme indéterminée, immarginée, dont l'hyménium recouvre tonte la superficie, lisse, ridée, non papilleuse.

Trémelle frangée (Tremella fimbriata), Pers., Myc., 14.

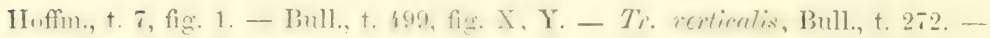
Fr., Epicr., 1. - Tr. tinctoria, Pers., JYye., 8.

La Trémelle frangée affecte toujours une direction verticale. Elle est gélatineuse, mollasse, élastique, de couleur violacée ou olivacé fuligineux, dilatée dans le haut, ondulée ou diversement plissée en lobes flaccides, comme incisés sur les bords, et atteint 6 à 8 centimètres d'ètendue.

Elle pousse, en automne, quelquefois en touffes, dans les endroits humides des bois, sur les vieilles souches, les branches mortes, plus particulierement sur celles de l'aune. Assez rare. Comestible.

On pourrait l'employer utilement en teinture. Elle donne, dit Bulliard, une couleur d'un beau Jistre rougeàtre, très-solide, et qui porte sa gomme. Plongée dans l'eau, lorsqu'elle est desséchée, elle reprend la forme qu'elle avait avant la dessiccation.

Trémelle jaunâtre (Tremella lutescens), Fr., Epicr., 4.

(Pl. XLVIII, fig. 1.)

Pers., Icon., t. 8, fig. 9. - Tr. mesenterica, var. B, Pers., Myc., 4. -

Tr. mesenteriformis, Bull., t. 406, fig. C, D, et t. 499, fig. U, V.

Plante d'un jaune pàle, de consistance charnue, tremblante, ondulée, contournée, formée de lobes serrés, entiers.

Commune sur les vieux trones.

Elle peut se manger, de même que le Tremella mesenterica, auquel elle ressemble beancoup. 
Tramelle mésentérique (Tremella mesenterica), Pers., Syn., 1.

(Pl. XLVIII, fig. 2.)
Vaill., †. 14, fig. 4. - Jacq., 1, t. 13. - Schæff., t. 168. - Engl. bot., t. 709. - Huss., I, t. 27. — Fr. Epier., 7.

Plante d'une belle couleur jaune orange, gélatineuse, acsez souvent coriace, grande d'environ 3 centimètres, ascendante, diversement lobée ou plissée, lisse, simple ou composée de plusieurs individus réunis.

Elle vient très-communément en automne et en hiver, sur les vieux troncs, les branches tombées à terre, et même les bois travaillés.

Comestible. On en fait usage en Allemagne, oì on la conserve comme les Morilles, dont elle a à peu près le goût.

TIE EMELLA.

'Trém. blanchâtre (Trem. albidal, Fr., Epier., 9; Huds. - Trem. cerebrina, Bull., t. 386 , fig. A. - Sur les ranucaux.

Trém. en massue (Trem. clavata), Pers., Icon. pict., t. 10, fig. 1. - Sur les branches et les rameaux tombés.

Trém. exiguë (Trem. errigua), Desm. - Temospore grisen, Cord., Icon., 3, fig. 68. - Sur les rameaux morts de l'ajonc.

Trém. de Dufour (Trem. Dufourii), Brond., 1854.

Trém. frangée (Trem. finbriata), Pers. (décrit).

Trém. foliacée (Trem. foliacea), Hers., Obs., 98. - Bull., t. 406, fig. A. - Sur les trones d'arbres.

Trém. touffue (Trem.frondosa), Fr., Epicr., 2. - Bull., t. 499, T. - Sur le trone des hêtres, des chênes.

Trém. perlée (Trem. gemmata), Lév., Toyage Demidoff, t. 4, fig. 4.

Trém. sans beauté (Trem. indecorata), Sommerf. - Fr., Epicr., 11. - Sur les peupliers et les saules, dans les contrées alpestres.

Trém. gonflée (T'rem. intumescens), Sm., Engl. bot., t. 1870. - Fr., Epicr., 10. Sur les trones pourris et les branches tombées.

Trém. jaunâtre (Trem. lutescens), Fr. (décrit'.

Trém. mésentérique (Trem. mesenterica), Pers. (décrit).

Trém. sarcoìcle (Trem. sarcoides), Engl. bot., t. 5450. - Schæff., t. 323, fig. 1-3, 6. - Berkl., 2, fig. 7. - Trenella amethystea, Bull., t. 499, fig. 5. - Sur les trones.

Trém. tortueuse (Trem. torta), Willd. - Dacrymyces tortus, Fr., Epicr., 9. - Sur le bois en décomposition.

Trém. Thurétienne (Trem. Thuretiana), Lév., Ann. des sc.nat., 1848.

Trém., en vessie (Trem. vcsicaria), Bull., t. 427, fig. 3. - Engl. bot., t. 2451.A terre.

Trém. verdâtre (Trem. virens), Fr., Epicr., 12. - Math., Fl. de la Belgique. Sur les troncs moisis, pendant l'automne et l'hiver. 


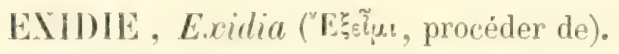

Expansion gélatineuse, tremblante, marginée, en forme de coupe ou d'oreille; hyménium recouvrant seulement la surface supérieure, plus ou moins ridée, les interstices étant lisses, non papilleux; sur face inférieure veloutée; consistance cornée, lorsque le champignon est sec.

Exidie oreille de Judas (Exidia auricula Juda), Fr., Epicr., 1.

$$
\text { (Pl. XLVIIl, fig. 4.) }
$$

Batt., t. 3, fig. T. - Bolt., t. 107. - Huss., I, t. 58. - Engl. bot., t. 2447. - Krombh., t. 5, fig. 50. - Hart\%, t. 45. - Barlal, t. 44, fig. 17, 18. Ifirneola auricula Juda, BerkI., t. 18, fig. 7. - Tremella auricula Judre, Lin. - Bull., t. 427, fig. 2. - Auricularia Sambuci, Pers., Myc., 2.

Var. nidiformis, Léveillé, Ann. des sciene. nat., t. 4, fig. 10.

Nom vulgaire: Oreille de Judas.

Plante de consistance gélatineuse, mais ferme et élastique, composée de deux lames, appliquées l'une sur l'autre. Elle est sessile, mince, ètendue horizontalement, très-irrégulière; a presque toujours une grande échancrure, qui lui donne la forme d'une oreille d'homme, large de 6 à 9 centimètres, haute de 3 à 4. La surface supérieure d'un brun rougeâtre, creusée en soucoupe, veinée ou diversement plissée, glabre; la surface inférieure, plus pâle, pulvérulente, comme tomenteuse, parsemée de veines saillantes et divergentes.

L'Oreille de Judas ne croit que sur les vieux trones d'arbres, et plus particulièrement sur ceux du sureau.

On l'employait autrefois en médecine, à titre de purgatif. Il est douteux qu'elle ait la propriété laxative. S'il faut en croire Rabelais, elle figurait sur table, en salade, comme plat d'entrée $\left({ }^{1}\right)$.

Exidie glanduleuse (Exidia glandulosa), Fr., Epicr., 7.

(Pl. XLVIII , fig. 3.)

Engl. bot., t. 2448 et 2452. - Fl. dan., t. 884. - Huss., I, t. 42\% - Tremella glandulosa, Bull., t. 420, fig. 1. - Tr. spiculosa, Pers., Myc., 13.

L'Exidia glandulosa se rencontre communément, en automne, sur le tronc et les branches mortes du chêne; il sort d'entre l'écorce,

(1) C'est une sorte de Funges, issaux des vieulx suzeaulx.

(Rabelais, Pantagruel, liv. TV, chap. LX.) 
d'abord arrondi, devient aplati et sinueux, est noir ou noirâtre, glabre en dessus, hérissé en dessous de petites papilles coniques, cendré et un peu tomenteux.

Il donne à l'eau une couleur brune, brillante; on pourrait donc l'employer en teinture.

Ex. oreille de Judas (Ex. aurimle Jud (w), Fr. (dírit).

Ex. glanduleuse (Ex. glandulosi), Fr. (dicrit).

Ex. forme de pezize (Ex. perizeformis), Lév., Ann. des sc. nat., 1848. - Dans la France méridionale.

Ex. tronquée (Ex. recisa), Fr., Epicr., 5. - Ditm., t. 13. - Engl. bot., t. 1819. Exidia gelatinosa, Dub. - Pezisa gelatinosa, Bull., t. 460, fig. 2. - Sur les branches de saules; en abondance, pendant l'hiver.

Ex. saccharine (Ex. saccharina), Fr., Epicr., 8. - Sur les vieux trones de pins.

\section{Section II.}

\section{Hyménomycètes exospores; hyménium à surface ou membrane sporophore placée extërieurement. Quatre spores portées par des basides.}

\section{BASIDIOSPORÉS.}

Champignons pourvus d'un volva; hyménium ou membrane sporophore mucilagineux, se réduisant en une liquide fétide.

\section{Ordre 7e. - PHALLOIDES (Phalloidei).}

Chapeau ou piléole non cancellé, pourvu d'un pédicule; un volva.

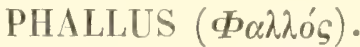

Champignons pourvus d'un chapeau perforé à son sommet, et réticulé ou marqué d'enfoncements polygones, d'où sort une liqueur visqueuse, dans laquelle sont engagées les spores; marge ou bord du chapeau libre.

1 re Tribu. Phallus (type).

Satyre impudique (Phallus impudicus), Lin.

$$
\text { (PI. XLIX.) }
$$

Mich., t. 83, - Fl. dan., t. 175. - Schæff., t. 196, 197, 198. - Bolt., 2, t. 92. - Bull., t. 182. - Bail., t. 25. - Grev., t. 213. - Tratt., t. 9, fig. 18. Nees, fig. 259. - Hartz, t. 66. - Cordä, t. 7, fig. 50. - Krombh., t. 18, fig. 10-15. - Berkl., t. 20, fig. 3. - Barla, t. 46, fig. 1-4. - Paul., t. 191. Pers., Syn., p. 242.

Noms vulgaires : Enfant du diable, Impudique, Satyre. 
Cielte plante, dont le nom indique la forme, a un chapeau conique, asscz court, perforé à son sommet, traversé par le pédicule, auquel il n'idhère pas par' sa base, creusé de cellules polygonales irrégulières, remplies d'une substance verdìtre, excessivement fétide, qui, à une certaine époque, se résout en une liqueur glaireuse. Son pédicule, long de 12 à 14 centimètres, blanchìtre, fistuleux, percé à jour d'une infinité de trous, est entouré à sa base d'un large volva, qui enveloppait le champignon dans son jeune âge.

Le Satyre impudique vient à terre, dans les bois, à la fin de l'été et cn automme. Son odeur le fait découvrir de loin; cette odeur attire les mouches et d'autres insectes, qui dévorent la pulpe contenue dans les alvéoles.

Il passe pour malfaisant; au rapport de Krombholz, il aurait occasionné des accidents. Ascherson dit n'avoir rien trouvé qui prouve qu'il soit nuisible. Paulet doute qu'il soit pernicieux, puisque les bètes fauves et les sangliers le mangent lorsqu'il est encore en boule, et que les chats en sont friands, lorsqu'il a atteint son entier développement. Fût-il hon à manger, il ne figurera jamais sur les tables, à cause de son orleur infecte.

En Allemagne, les habitants de la campagne le font sécher avant qu'il soit entièrement développé, le donnent réduit en poudre et mêlé à (puelque liqueur, aux bestiaux et aux chiens, pour les exciter à l'accouplement; des femmes mème en ont pris, comme provocateur des règles, mais, le plus souvent, il a produit un effet nuisible. Les anciens l'employaient contre la goutte.

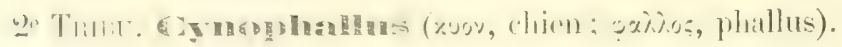

Chapeau arlné, adhérent au pédicule, non perforé, inégal, raboteux; un volva. Gene pour guelques auteurs.

Phallus (Cyn.) de chien (Phallus Cyn. caninus), Huds.

Schreff, t. 330. - Batt., t. 40, fig. E, F. - Sow., t. 330. - Entre les feuilles tombées, dans les bois. 


\section{Ordre 8e - CLATHRACÉS (Clathracei).}

Chapeau ou piléole cancellé, dépourvu de pédicule; un volva.

(Basidiosporés.)

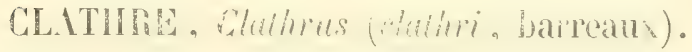

Champignon sessile, ovoïde ou globuleux, formé de rameaux charnus, anastomosés en grillage, émettant, de tous les côtés, une humeur dans laquelle sont enveloppées les spores.

\section{Clathre cancellè (Clathrus cancellatus), Lin.}

(Pl. L.)

\footnotetext{
Batt., t. 2, fig. 2. -- Nens, fig. sti1. - Nomm\}., †. 19, fig. 1-9. -- IJus., I, t. 86. - Corda, t. 6, fig. 49. - Barla, t. 45, fig. 5-12. - Paul., t. 204, fig. 8. - Sterb., t. 30 , fig. N, O. - Cl. volvceceus, Bull., t. 440. - Cl. ruber, Pers., Syn., 1.
}

Noms vulgaires : Cran, Cranca, Cancer, dans les Landes.

Le Clathre cancellé vient dans les bois secs et les lieux stériles du Midi de la France. C'est une plante sessile, charnue, globuleuse ou ovoïde, vide dans le centre, haute de 5 à 10 centimètres, de couleur rouge de feu, quelquefois orangée, jaune ou blanche, dont les rameaux anastomosés entre eux, forment une espèce de voûte, percée de part en part de larges trous carrés ou en losanges, et dont les semences sont mèlées à une substance très-puante, qui, à une certaine époque, tombe en déliquescence et les entraịne. A sa base, se trouve un volva ou enveloppe blanche, ordinairement lisse, quelquefois plissée par petits carreaux, qui la contenait dans sa jeunesse. Elle ne tient à la terre que par une petite racine.

Paulet rapporte un fait qui prouve que ce beau et singulier champignon est pernicieux. Ses effets sont ceux des poisons narcotiques. Dans le département des Landes, les habitants, dit Thore, s'imaginent qu'il donne le cancer à celui qui le touche. Son odeur n'est pas moins fétide que celle du Phallus impudicus.

\section{Clathius.}

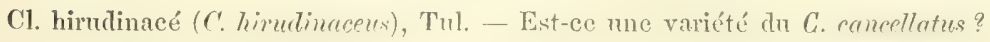




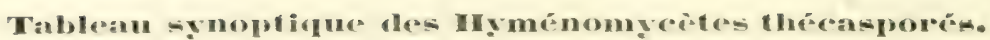

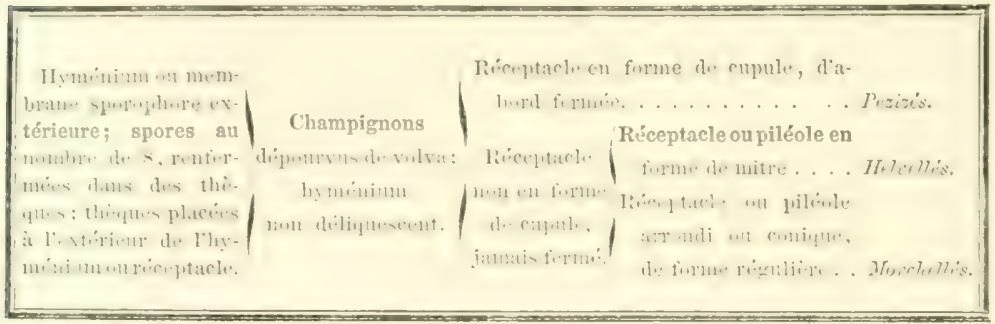

\section{SEction III.}

\section{Hyménium à surface ou membrane sporophore placée extérieurement.}

Spores contenues dans des thèques (THÉcasporés).

$$
\text { OrdRE 1\% - MORCHELLE (Morchellei). }
$$

Champignon dont la membrane sporophore recouvre un réceptacle marqué de nervures sinueuses, formant des cellules irrégulières ou aliéoles, lisses ou à côtes.

Genre MORILI.E, Worchellu (Yurrel, all., nom de la plante).

Champignon dont le chapeau ovoïde, globuleux ou conique, pédonculé, imperforé au sommet, est relevé extérieurement de nervures anastomosées, qui forment de larges alvéoles, recouvertes par l'hỵménium. Toutes les Norilles viennent à terre et sont comestibles.

Morille à côtes (Morchella costata), Pers., Myc., 9.

Mich., t. 85, fig. 3. - Schæff,, t. 300, fig. 1. - Vittad., t. 13, fig. 6, 7, et t. 14 , fig. 6 .

Var. Deliciosa, Weinm, t. 533, fig. 1.

La Morille à côtes atteint 10 et 12 centimètres de hauteur, sur $\mathbf{5}$ d'épaisseur. Son chapeau, de forme et de couleur variables, a ordinairement une forme ovale ou conique, une couleur brune ou fuligineuse, noiràtre ou cendré verdâtre; il est marqué de côtes longitudinales pres que paralleles, entrecoupées de plis transversaux, formant des cel- 


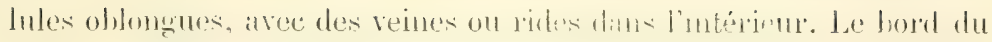
chapeau adhère au pédicule, lequel est d'un blanc pâle, creux, épais, habituellement cylindrique, comme farineux en dedans, et présentant souvent au dehors de petites squames transversales, surtout vers le sommet.

Cette Morille vient au printemps, dans les lieux humides, autour des fossés, parmi les graminées.

Alimentaire. On la vend sur les marchés d'Italie. Elle est moins estimée que la Morille comestible; sa chair, peu épaisse, a l'aspect de de la cire.

Morille comestible (Morchella esculenta), Pers., Syn., 1.

$$
\text { (I'I. LI, fig. 1.) }
$$

Batt., t. 2, fig. F. - Bolt., t. 91. - Schæff., t. 199, 298, 299 et 300. - Sow., t. 51. - Huss., I, t. 13. - Krombh., t. 16, fig. 3-6. - Hartz, t. 50. Roq., t. 1, fig. 4, 5. - Bull., t. 218. - Letell., t. 104. - Lenz, t. 13, fig. 36, 37. - Ventux., t. 11, fig. 10, et t. 109. - Barla, t. 42, fig. 1-7. Vittad., t. 13, fig. 1-5, et t. 14, fig. 5. - Paul., t. 7-11. - Fr., Syst., p. 6. - Pers., Myc., 7.

Var. A. grisen.

Var. B. conica, Pers., Mye., 8. - 'Tratt., t. 6, fig. 11. - Staude, t. 1, fig. 4, 5 . - Barla, t. 42, fig. 8-10. - Krombh., t. 16, fig. 7-16.

Noms vulgaires: Mourillon (Languedoc), Merigoule (Gascogne), Morchelon.

La Morille comestible a un pédicule le plus souvent cylindrique, presque toujours creux à l'intérieur, long de 4 à 5 centimètres, d'un blanc pàle, lisse, assez épais; un chapeau de forme arrondie, ovoïde et même conique, creusé en dessus de cellules polygones irrégulières, ef dont les bords sont adhérents au pédicule. Ce chapeau, blanc ou grisàtre dans la jeunesse de la plante, devient plus tard tantôt d'un blanc sale, tantôt d'un bistre foncé, et tantòt noirâtre, ce qui constitue plusieurs variétés, qui croissent toutes dans les bois, les prés et les gazons, en avril et en mai.

C'est un aliment délicat et généralement recherché.

On mange la Morille fraiche ou desséchée; son odeur est faible, assez agréable. 
Morille à moitié libre (Norcholla semilibera), DC.

$$
\text { 11. I.1. 4i:... }
$$

Mich., t. 84, fig. 3. - Grev., t. 89. - Letell., t. 696. - F'r., Syst., 8. - M. rete,

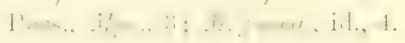

Var. A. M. crecsipes, Per's., Hyc., 5, - Sow., t. 238

Var. B. II. mesomorpha, Pers., IIyc., 6. - Sow., t. 51, fig. media. - Tratt., t. 6 , fig. 12.

Var. C. M. rimosipes, DC., F'l. fro, $57 \pm$ - Harz, t. 78.

Cette Morille est alimentaire; on la confond presque toujours avec la Morille comestible. Elle a une odeur particulière, une saveur non désagréalje. On la troure, au printemps, sur les bords des bois, des fossés, des laies, dans les licux ombiagés un peu humides.

Le chapeau, ayant ordinairement la forme d'un còne aigu, long de 3 centimètres, adhère an stipe par sa partie superieure seuiement; il est creusé de sillons allongés ou de cellules de forme irrégulière, de couleur jaune påle ou fauve. Pied fistuleux, long de 8 à 10 centimètres, d'un blanc pâle, ordinairement granuleux à son sommet.

Mor. de Bohème (7orch. Bohenica), Kromluh., t. 15, fig. 1-13, et t. 17, fig. 8. Terpa dubia, Lér., Ann. des se. nut., 1846. - Rare.

Mur. conique (Morch. conica), Per's., Myco, 8. - Champ. com. - Variété de l'esculenta.

Mor. à côtes (Morch. costata), Pers. (décrit).

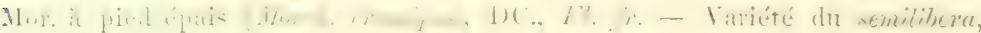
Pers., dans une note manuscrite.

Mor. délicicuse (Morch. deliciosa), Fr. S'yst. - Myc., 8. - Variété de l'esculenta.

Mor. comestible (Morch. esculenta), Pers. (décrit).

Mor. fauve (Morch. Jusca), Pers., Myc., 4. - Mitrophora fusca, Lév., dnn. des sc. nat., 1846. - Variété du semiliberce.

Mur. géante (Morch., giyas), Pers., Myc., 1, no 1.. - Mich., t. 84, fig. 1. - Mirtrophora jiyas, Lér., Ann. des sc.nat., 18t6. - Verpa speciosa, Vittad., t. 15 , fig. 4

Mor. Jiémale (Jorch. Tiemalis), Fr., Syst., 4. - Ball., t. 11, fig. 4.

Mor. hybride (Jorch. Tyyrida), Pers., Syn., 6. - Sow., t. 238.

Mur. étendue (Jorch. patula), Pers., Syn., 2. - Sow., t. 51, en partie. - Mitrophora patula, Lév., Lim. des se. nat., 1816.

Mor. pubescente (Horch. pubescens), Pers., Myen, p. 207. - Dans les bois du Jura.

Mor. à pied crevassé (Morch. rimosipes), DC., Fl. fr., 574. - Mitrophora rimosipes, Lév., dun. cles sc. nut., 1S \pm 6 . - D'ans les bois.

Mor. à moitié libre (Horch. semilitera), DC., (décrit).

Mor. trémelloïde (Forch. tremelloides), DC., Fl. fr., 572. - Phallus esculentus, Bull., t. 218, fig. F.

Mor. ondoyante (Morch. undosa), Pers., IIyc., 2. - Mich., t. 84, fig. 2, - MFitrophora undosa, Lér., Ann. des sc.nat., 1846. 


\section{Orure 2)" - IIELTELLES (Holedlei.}

Champignons dont l'hyménium recouvre la face supérieure d'un réceptacle ou piléole membraneux, irrégutier, divisé en lobes pliés et rabattus, libres ou adhérents. (THÉGASPORÉS.)

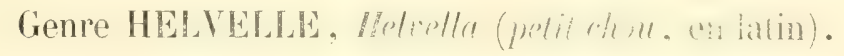

Champignon ordinairement pédiculé, dont le chapeau membraneux, presque toujours plissé irrégulièrement, lisse en dessous, porte les spores à la surface supérieure seulement.

\section{1re Tribu. Helvelle (type).}

Chapeau membraneux, plissé, irrégulièrement suspencidu sur le pédicule.

Helvelle crépue (Helvella crispa), Fr., Syst., p. 14.

(Pl. LII, fig. 1.)

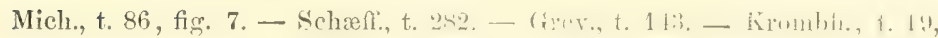
fig. 27-29. - Roq., t. 1, fig. 3. - Letell., t. 37, fig. 2. - Lenz, t. 1t, fig. 40. Vittad., t. 30, fig. 1. - Ventur., t. 11, fig. 110. - Sow.. t. ร9. - Barla, t. 43, fig. 1-5. - Tratt., t. D D. - Helv. leucophece, Pers., MIyc., 2. Helr. mitra, Bull., t. 4iti.

Cette espèce, une des plus grandes du genre, a le chapeau libre, c'est-à-dire non adhérent au pédicule par ses bords, couªbé de différents côtés, lobé et quelquefois comme crispé, de couleur d'un blane pâle en dessus, devenant roussàtre par la dessiccation, et très-légèrement fuscescent en dessous. Son pédicule est glabre, blanc, fistulenx, lacuneux ou cannelé, à lacunes profondes et complicuées. On la trouve, en octobre et en novembre, dans les bois, parmi les mousses et les gazons.

Comestible. Odeur peu sensible, chair blanche, élastique.

Helvelle èlastique (Helvella elastica), Bull., t. 242. (Pl. LII , fig. 3.)

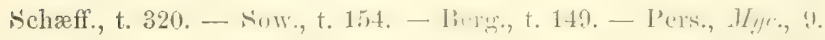

Chapeau libre, rappelant la fome d'une mitre, devenant lobé avec l'âge, gris cendré, uni en dessus et en dessous; le pied allongé, grêle, long de 8 à 10 centimètres, non lacuneux, creux à l'intérieur, pruineux, plus pâle que le chapeau. 


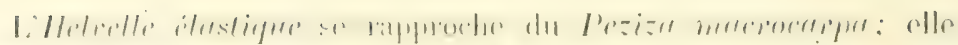

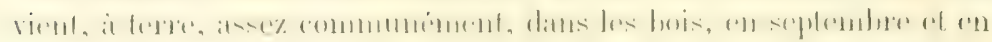

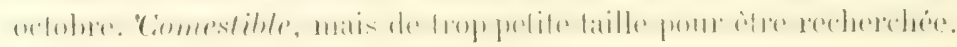

Helvelle haute taille (IIelvella grandis), Gumino, t. 2.

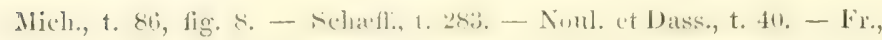

$$
\begin{aligned}
& \text { Syst., 2, p. 118. - Pers., Hyye., } 5 .
\end{aligned}
$$

Nom vulgaire: Morille, en Languedoc, où l'on confond les deux plantes.

L'Helvella grandis atteint jusqu'à 16 centimètres de hauteur; son chapeau, tantòt d'un brun fuligineux, tantòt violacé ou fauve, blanc en dessous, est formé de trois ou quatre lobes, recourbés, distincts, à surface lisse, irrégulièrement sinueux sur les bords, souvent marqués d'une ligne blanchàtre. Le pédicule, lisse ou raxement sillonné, épais, solide, est parfois traversé de perforations, qui lui donnent l'aspect d'un pédicule qui serait formé de plusieurs pédicules soudés ensumble.

Cette Helrelle, à l'état frais, rappelle l'odeur du cuir tanné; elle se trouve solitaire, dans le Midi de la France, au printemps, après les pluies, et en automne, à terre, dans les lieux découverts et sablonneux des bois. Rare. Comestible. Sa saveur est agréable.

Helvelle en turban (Helvella Infula), Schæff., t. 150.

$$
\begin{aligned}
& \text { Krombh., t. 21, fig. 14-17. - Barla, t. 43, fig. 14-16. - Mouzel, t. } 6 . \\
& \text { T-- Fl. dan., t. 835. - Fr., Syst., 2, p. 17. - Pers., Mye., 6. }
\end{aligned}
$$

Grande espèce, dont le chapeau, irrégulier, de forme variable, réfléchi, lobé, lisse, glabre, est large de 6 à 8 centimètres, brun rougeàtre ou cannelle, à face inférieure légèrement veloutée, d'abord blanche ou rousse, et par la suite plus ou moins violacée, adné à un pédicule, long de 6 à 8 centimètres, épais, non sillonné, blanchâtre ou d'un roux clair, plein dans le jeune âge, fistuleux lorsque l'individu arrive à son entier développement, lisse, mais quelquefois couvert d'une efflorescence pruineuse.

L'Helvella Infula est comestible, non très-rare dans les Vosges, où on l'appelle Morille d'automne; il croit, en automne, dans les friches et les bois montueux; sa texture est très-élastique. 
Helvelle lacuneuse (Helvella lacunosa), Afzel.

$$
\text { (Pl. LII , fig. 2.) }
$$

Schæff., t. 154 et 162 . - Krombh., t. 19, fig. 18-21, 22-26. - Grev., t. $30 .-$ Fl. dan., t. 24. - Berger, t. 147. - Cheval., t. 6, fig. 5. - Michel,, t. 86' fig. 7. - Holmsk. t. 24. - Barla, t. 43, fig. 6-11. - Fr., Syst., 2, p. 115. - Helv. mitra, Pers., Myc., 1. - Bull., t. 190.

Noms vulgaires : Mitre d'évèque, Morille en mitre.

Ce champignon a le chapeau formé de deux ou trois lobes, réfléchis, ondulés sur les bords, qui, en se recourbant, ressemblent à une mitre, et sont tantòt d'un gris cendré, tantôt d'un brun fauve, adnés au pédicule, lequel est fistuleux, blanchâtre, profondément sillonné et lacuneux, consistant.

L'Helvelle lacuneuse croit, au printemps et en automne, dans les mousses, le gazon, et plus particulierement sur les sols sablonneux.

On la mange en Provence et dans le Piémont.

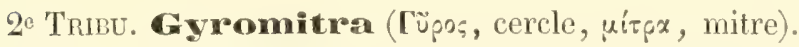

Chapeau renflé, raboteux, inégal, arec des còtes saillantes, grosses et formant des circuits. Genre pour quelques auteurs.

Helvelle (Gyr.) comestible (Helvella Gyr. esculenta), Scheff., t. 160, et t. 300 , fig. 2.

Fl. dan., t. 116. - Tratt., t. CC. - Krombh., t. 20, fig. 6-12. - Vittad.. t. 32. - Lenz, t. 15. - Barla, t. 43, fig. 12, 13. - Ntaule, t. 1, fig. 3. Pers., Champ. com., t. 4; it. Myge, 7. - Fre, Syst., 4. - Eyromitra escut lenta, Str., in Flora, 49.

Nom vulgaine: Mouricaude, dans les Vosges.

Ce champignon sert en quelque sorte de transition entre les Helvelles et les Morilles; il diffère des Morilles en ce qu'il n'a pas d'alvéoles, mais seulement des plis contournés au chapeau, et rentre dans la classe des Helvelles par ce qu'il est entièrement lisse. Son chapeau, large de 6 à 8 centimètres, de couleur bai brun, tantòt sub-orbiculaire, tantòt sub-lobé, ondulé ou plus ou moins plissé, blanc et villeux en dessous, adhère à un pédicule creux, assez court, lisse, non sillonné, d'un blane incarnat ou roussâtre. 


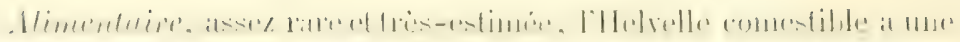

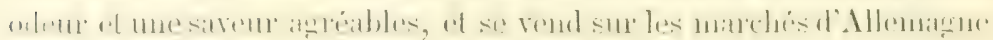
inmume les valies Morilles.

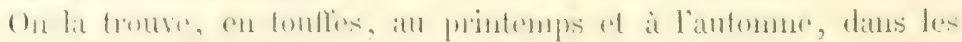
pays élevés, sur le bord des chemins et dans les friches.

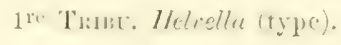

II. ì stipe court (Helv. brevipes), DC., Fl. fr., VI, p. 28. Helvella leucopus, Pers., Myc., 8. - Sur la terre un peu humide, dans les bois; trìs-rare.

II. crépue (Itelv. crispa), Fr. (décrit).

II. comestible (Helv. esculenta, Schæff. (décrit).

II. élastique (Helv. elastica), Bull. (décrit).

II. forme de selle (Helr. Ephippium), Lér., Ann. des sc. nat., 1841, XVI, t. 15, fig. 7. - Dans les bois, sur la terre; parmi les gazons, au mois d'août.

II. haute taille (Helv. grandis), Cumino (déerit).

II. en mitre (Helv. Infula), Schæff. (décrit).

II. lacuneuse (Helv. laeunosa), Afzel (décrit).

II. capuchonnée (Helv. Monacella), Fr., Syst., 6. - II. spadicea, Schref., t. 283. - Dans les bois montucux, au printemps,

11. noirâtre (Helv. pulla), Holmsk., t. 26. - Fr., Syst., t. 10. - Dans les bois, sur la terre humide.

II. sinueuse (Helv. simuosa), Brond., t. 3, fig. 5. - - Dans la France méridionale,

II. sillonnée (Helv. sulcata), Afzel., in Act., 305. - Schreff., t. 352. - Sur la terre humide des bois.

$$
\text { 2e Trist. - Gigrumitra. }
$$

II. (Gyr.) comestible (Helv. Gyr. esculenta), Schæff. (décrit).

\section{TERPA (rieus mot latin, synonyme de Phallus.s.}

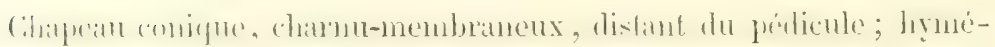
nium ruguleux, mais non à côtes saillantes.

Verpa en forme de dé (Verpa digitaliformis), Pers, Myc., t. 7, fig. 1-3.

$$
\text { (Pl. LIII, fig. 1.) }
$$

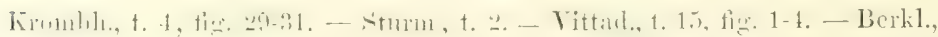
t. 12, fig. 6. - Barla, t. 44, fig. 1-6. - Fr., Syst., 2, p. 24.

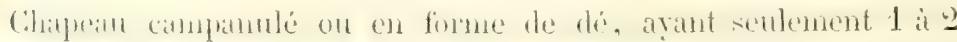
centimètres de haut et autant de large, irrégulier, libre en dessous, inséré au sommet du pédicule, lisse en dessus ou seulement un peu rugueux, brun à la partie supérieure, d'un blane grisâtre à la partie inférieure; pédicule sub-cylindrique, long de 3 à 5 centimètres : ondulé, marqué de flocons transversaux, creux en dedans. 
Bien qu'il ait peu de goût et que sa chair soit mince, ce champignon se mange en Italie comme la Morille. Il vient au printemps et n'est pas commun.

V. agaricoïde (V. ayaricoides), Pers., Myc., 2, t. 7, fig. 4-5. - Morchella agaricoides, DC., $F$ \% fr., 569. - Dans les bois.

V. digitaliforme ( $\boldsymbol{V}$. diyjtaliformis), Pers. (déerit).

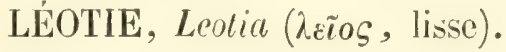

Réceptacle ou chapeau supporté par un pédicule central, à bord enroulé, recouvert d'un hyménium ou membrane sporophore, luisant et un peu visqueux.

Léotie lubrique (Leotia lubrica), Pers., Myc., t. 9, fig. 4-7.

$$
\text { (Pl. LIII, fig. 2.) }
$$

Mich., t. 82, fig. 2. - Vaill., t. 13, fig. 7-9. - Sow., t. 70. - Fl. dan., t. 719. - Nees, fig. 144 B, et fig. 162. - Hoffm., t. 6, fig. 1. - Berkl., t. 22, fig. 1. - Grev., t. 56. - Helvella gelatinosa, Bull., t. 473, fig. 2.

La Léotie lubrique a la consistance molle, presque gélatineuse; elle est d'un jaune tirant sur le vert. Son pédicue, grêle, fistuleux, le plus souvent cylindrique, long de 4 à 6 centimètres, supporte un chapeau convexe, arrondi ou légèrement déprimé, lisse, large de 2 centimètres seulement, irrégulier, ondulẻ sur ses bords, qui sont roulés en dessous.

Elle croit, en été et en automne, à terre, dans les bois; le plus ordinairement en touffes; n'est pas rare.

Comestible; mais sa petite taille, son peu de chair, son aspect peu attrayant feront qu'elle ne sera jamais recherchée.

L. noir foncé (Leot. atrocivens), Pers., Myc., 8, t. 9, fig. 1. - Dans les bois et les lieux humides.

L. formant cerele (Leot. circinans), Pers., Icon. et descript. t. 5, fig. 5-7. - Dans les forêts de sapins, en cercle.

L. lubrique (Leot. lubrica), Pers. (décrit).

L. pied comprimé (Leot. platypoda), Fr., Syst., 28. - Helvella platypoda, DC., $F^{\prime} l$. fr., VI, p. 29. - A terre, dans le midi de la France. 


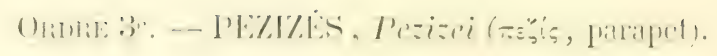

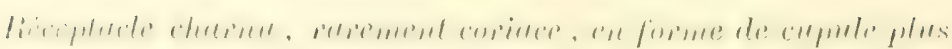

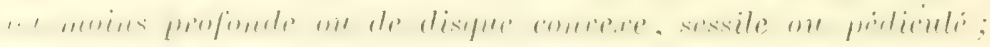
lugménium couvrant le dessus de la cupule (TIIÉcasponés).

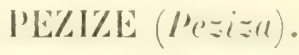

(Pezicce, nom latin d'un champignon).

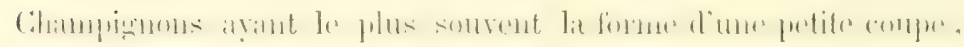
d'abord fermée, dont la surface supérieure est lisse et porte des spores,

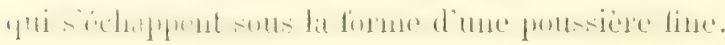

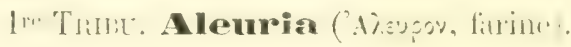

Capsules charnues ou carnoso-membraneuses, fragiles, extérieurement pruincuses ou floconneuses, de grande dimension; presque toutes terrestres.

Toutes les espèces de Pezizes, de la section des Aleuria, paraissent etre de nature alimentaire. Les plus grandes pourraient figurer sur nos tables, à côté des Morilles et des Helvelles. En général, les Pezizes sont peu recherchées.

\section{Pezize en coupe (Peziza Acetabulum), Lin.}

$$
\text { ('l. LIT, fig. 1.) }
$$

Vitill., t. 13, fig. 1. - Sow., t. 59 -- Mich.., t. \&, fig. 1. - Bull., t. 45,

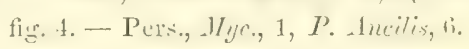

Cette Pezize, l'une des plus grandes du genre, puisqu'elle atteint jusqu'à 6 centimètres, a la forme d'une coupe ou d'un entonnoir, est mince, fragile, de couleur fuligineuse. Son pédicule, assez court, épais, blanchâtre, est marqué de sillons assez profonds et de côtes rameuses, divergentes à leur sommet. Sa consistance est celle de la cire.

Elle croit au printemps, à terre, dans les lieux ombragés.

Rare. Couleur d'abord faure, puis d'un brun plus ou moins foncé. Comestible. 
Pezize orangée (Peziza aurantia), Oed., Fl. dan, t, 657, fig. 2.

$$
\text { (Pl. LV, fig. 2.) }
$$

Pers., IIys., no 6, p. 222. - Sichxfl., t. 148. - Sow., t. 78. - Batt., t. 10. - Holmsk., t. 7. - Nees, fig. 279. - Inss., I, t. 37. - Krombh., t. 54, fig. 30. - IIartz, t. 72. - Barla, t. 44, fic. 13-16. - Er., Siyst., 1. 49. $P$. eoccinea, Bull, t. 474 .

Cette Pezize, qui attire l'attention par sa couleur d'un rouge orangé très-vif, est sessile ou sub-sessile, mince, fragile, irrégulière, évasée en cupule ou en coquille de limacon, large de 2 à 8 centimètres, glabre en dessus, pulvérulente et plus pâle en dessous.

Elle croît à terre, le long des chemins ombragés, dans les pelouses, le plus souvent solitaire, quelquefois en séries ou formant des cercles.

Comestible; saveur peu prononcée.

Le célèbre Persoon, étant encore enfant, fut frappé d'admiration à la vue de la Pezize orangée, et dut à cette circonstance le goût de l'étude des champignons, étude à laquelle il s'adonna tellement, qu'il devint le premier mycologiste de son époque.

Pezize baie (Peziza badia), Pers., Obs.

ILuss., II, t. 13. - BerkI., t. 22, fig. 4. - Vaill., t. 11, flg. 8 .

Plante de couleur variable, grande, sessile, entière, flexueuse, ordinairement brune, ayant le bord enroulé; plus pâle et prenant une nuance olivàtre, comme poudreuse extérieurement.

Est comestible; vient dans les jardins, les bois, sur les bords des étangs, en été et en automne.

Pezize en limaçon (Peziza cochleata), Lin.

Bull,, t. 154. - Berg,, t. 175. - Sow., t. 5. - Schæff., t. 155 et 274. - Vaill., t. 11, fig. 8. - Hartz, t. 72, fig. A. - Barla, t. 44, fig. 11, 12.

Var. A. P. alutacea, Pers., Myc., 3, p. 221.

Var. B. P. umbrina, id., p. 220.

Pezize de grande taille, sessile, minse, fragile, contournée et comme partagée en deux lobes latéraux, roulés en spirale. Elle atteint 3 cert timètres de hauteur el 6 de diamètre; elle est farineuse extérieurement. Sa couleur, d'un blanc jaunâtre, puis d'un fauve peu prononcé, devient brunâtre dans la vieillesse. 


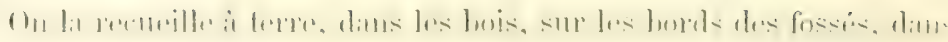
les jardins et les gazons, en été et au commencement de l'automne;

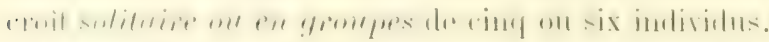

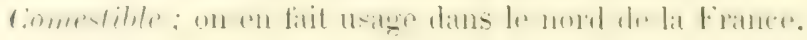

Pezize léporine (Peziza leporina), Batsch.

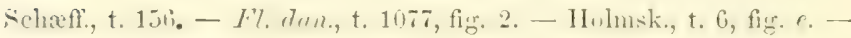
Fr., Syst., p. 47. - Pers., Myyc., 8, et P. felina, 9.

Champignon de couleur cannelle, sub-stipité, haut à peine de 4 centimètres, dimidié en forme d'oreille, farineux extérieurement, lisse interieurement.

Plus petit que le $P$. onotica, il a presque la même forme.

Comestible. Il croit le plus souvent en touffes, à terre, dans les bois de pins.

Pezize pédiculèe (Peziza macropus), Pers., Obs. Myc., t. 1, fig. 3.

Fr., Syst., p. 57. - Sehæff., t. 152 et 166. - Fl. dan., t. 12, fig. 2.

P. stipitata, Bull., t. 457, fig. 2.

Ciette Pezize de grande taille est remarquable par son pédicule trèslong, attenué en bas, un peu flexueux, souvent lacuneux, s'élargis sant en une cupule de forme d'abord hémisphérique, puis étalée, cendrée, atteignant jusqu'à 8 centimètres, tomenteuse en dessous. Les bords sont irréguliers, légèrement ondulés.

Elle croit sur la terre dans les bois ; est comestible. Les paurres la mangent.

Pezize oreille d'âne (Peziza onoiica), Pers., Myc., 7.

(Pl. L.IV, fic. 2.)

Dittm., t. 16. - Sow., t. 79. - Fr., Syst., p. 48.

Nom vulgaire: Oreille de lièvre.

Ce champignon, de grande taille, est stipité, dimidié, légèrement allongẻ d'un còté, en forme d'oreille, farineux et jaunâtre à l'extẻrieur, rose ou orangé en dedans, et finissant par devenir plissé ou rugueux. Pare.

Croìt à terre, dans les bois ; est comestible et d'une beauté remarquable. 
Pezize vésiculeuse (Pe:iza vesiculosa), Bull., t. 457, fig. 1, et t. 44 .

$$
\text { (Pl. LII, fig. 2.) }
$$

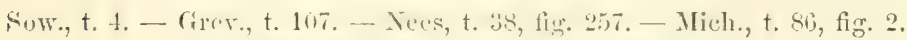
- Barla, t. 4t, fig. 7-10. - I'ers., Myy., 25.

Champignon commun sur les fumiers et sur les terreanx gras, dans les jardins, au printemps et en automne, croissant quelquefois solitaire, mais le plus souvent en groupes de cinq ou six individus; il est sessile, d'abord globuleux et creusé en gobelet, il prend ensuite la forme d'une bourse ou d'une petite coupe à ouverture rétrécie, dont les bords sont crénelés et sinués, plus ou moins contournés; n'a habituellement que 2 à 3 centimètres de diamètre, mais peut atteindre jusqu'à 6 et 8 centimètres. Sa couleur varie du blane jaunàtre out léģèrement bistré, au blanc ferrugineux; sa surface externe est comme granuleuse, subtomenteuse à la base. Il a l'aspect, la demi-transparence et la fragilité de la cire. Très-commun.

La Pezize vésiculeuse est comestible; je l'ai mangée crue. Sa saveur est faible, agréable.

P. d'Abbot (P. Lbbotimet), Sow., t. 389, fig. R. - Aujourd'hui c'est le Leranora cerina, Ach.

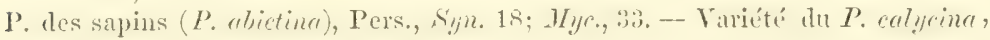
Schum. - Dans les bois de pins.

P. en coupe (P. Acetabulum), Lin. (décrit).

P. aiguille (P. arumu), Alb. et Fichw. - Fr., Syst., 1. 95. - Sur les aiguillons du sapin, dans les bois humide's.

P. opprimée ( $P$. adpressa), Wallr., Crypt. - Sur les tiges sèches de l'Hélianthe annuel.

P. blanc de chair (P. albo-carnea), Crouan. Fl. fin., p. 52. - Sur le Funcus ylomeratus.

P. vert de gris (P. aruginosa), Pers., Syn., 105. - Chlorosporium oruginosum, Tul. - Sur les bois morts humides.

P. blanc sale (P. albo-fusca), Crouan, Fl. fin., p. 54. - Sur les crottes de mulot.

P. agyrioïde ( $P$. agymoides), Desm., Ann. des sc. nat., 1837, t. 2, fig. 2.

P. blanc testacé (P. albo-testacea), Desm., Ann. des sc. nat., 1843.

P. blanc violacé ( $P$. albo-violascens), Alb. et Schw., t. 8. fig. 4. - P. relutina, Desm., Catal., et P. fallax, Pers., Myc. - Sur divers arbres, hiver et printemps.

P. des chatons (P. amenti), Batsch, fig. 148. - Pers., Myc., 264. - Sur les capsules des chatons du saule.

P. amorphe (P. amorpha), Pers.; Thelephora amorpha, de Fries. - Sux l'écorce des sapins morts.

P. agrandie (P. ampliata), Pers., Icon. et deser., t. 8, fig. 6. - Sur les trones,

$P$. très-grande $(P$. amplissima $)$, Balb.

P. petit bouclier (P. ancitis), Pers., Myc., 6. - A terre dans les bois. 


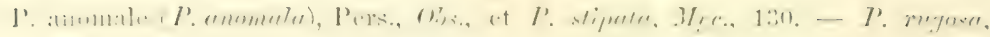
Sow. t. 369, fig. 3. - Sur les rameaux tombés, surtout du cerisier.

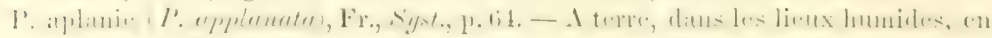
septembre et octobre.

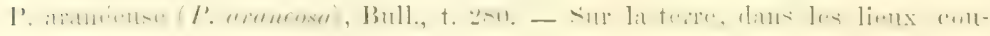
verts; en septembre et octubre.

P. clu sable (P. arcnicola), Lév., Ann. des sc. nat., 1848. - Champs sablonneux du littoral.

P. coulcur d'abricot (P. armeniaca), Pers., Myc., 124. - Sur les bois desséchés.

P. du roseau (P. Arundinis), Fr., Syst., p. 105. - Sur les chaumes desséchés de

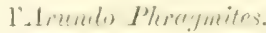

$P$. en forme d'ascobole ( $P$. ascobolimorpha), Crouan, $F l$. fin., p. 54. - Sur les fumiers d'étable.

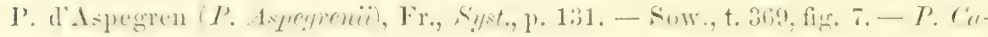
licium, Pers., Myc., 165.

P. âpro ( $P$. aspera), Pers.; Excipula aspera, Fries.

I'. noire ( $P$. atra), Desm. - Sur les gousses pourrissantes des hricots to mbés à terre.

P. noirâtre (P. atrata), Pers., Syn., 128. - Sur les trones, les tiges des plantes, au printemps.

P. noir verdâtre (P. atrovirens), Pers., Syn., 13. - P. seriata, id., Myc., 305. Coryme virescens, Tul. - Sur les bois en décomposition.

P. orangé ( $P$. aurantia), Ed. (décrit).

P. aurélie (P.aurelia), Pers., Mye., 129. - P. Mauchï, Grev. - Sur les feuilles tombées du hêtre, du chêne, au printemps.

P. aurore ( $P$. aurora), Crouan, $F$. fin., p. 53.- - Sur les bouses de vaches anciennes.

P. azuréc ( $P$. azurea), Lév., Ann. des se. nat., 1841, t. 15, fig. 9. - Dans les bois, à terre, au printemps.

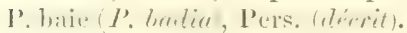

I. barbue ( $P$. barbata), Kunze. - P. pellita, Pers., Myc., 110. - Sur les rameaux du chèvre-feuille.

P. avenante ( $P$. benesuada), Tul., Bot. Zeit., 1853.

P. de l'épine-vinette ( $P$. Berberidis), Pers., Syn., 55. - Sur les rameaux secs dc l'épine-vinette.

P. de Berkeley (P. Berlieleii), Blox. - Sur l'Angelica sylrestris.

P. du bouleau ( $P$. betulce), Pers. - Stictis betule, de Fries.

I. de Bioxam (P. Bioxami), Berkl. - Sur le trone du prunelier.

P. bicolore (P. bicolor), Bull., t. 410, fig. 3. - P. quercina, Sow., t. 17. - Sur les rameaux tombés, au printemps.

P, bolaire (P. bolaris), Batsch, t. 23, fig. 155. - Sur les rameaux.

I'. brune (P. brunnea), Alb. et Schw., t. 9, fig. 8. - Sur la terre brûlée et au bord des chemins.

I'. noir brun (P. brunneo-atra), Desm., Ann. des sc. nat., 1836.

P'. brunâtre (P. brunneola), Desm., Ann. des sc. nat., 1842.

P. bulbeuse (P. bulbosa), Nees, fig. 289. - A terre, dans les bois. N'est peut-êtro qu'une variété du $P$. macropus.

P. du byssus (P. byssiseda), Fr., Syst., p. 107. - P. testacea, Pers, - Sur les bois putrides souvent humectés.

P. du cacalia (P. Cacalice), Pers., Myc., 174. - Sur les tiges des plantes composées. 
I'. en calice ( $P$. calycina), Schum. - Fr., s'yst., p. 91. - P. cherysophlethalma, P'rers, Myc., 97. - Sur les rameanx putrescents.

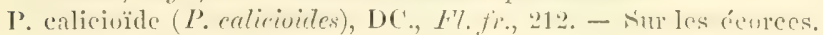

P. petite-coupe (P. calyculus), Sow., t. 116. - Sur les branches mortes décortiquées.

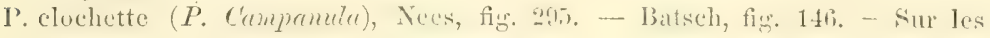
chaumes, les stipules putrescentes.

P. dos champs ( $P$. campestris), Crouan, Fl. fin., p. 23. - Champs cultivés. '

1. du cherreuil (I'. C'apreuli), P'ers., Myr., 214. - I'. limberte, Wallr. - Sull Ies crottes de chêvre, de cerf ctc.

P. chanterelle ( $P$. Cantharella), Fr., Syst., p. 48. - A terre, dans les bois.

P. du carex ( $P$. Caricis), Desm.

P. chair pâle ( $P$. cameo-pallida), Desm.

P. charnue ( $P$. carnosa $)$, Bull., t. 396, fig. 1.

$P$. de Caroline (P. Carolince), de Guernissac-Crouan, $F l$. fin., p. 49. - Sur les ramules mortes de l'érable.

I'. du charme (P. conpinea), Pers. - Tulueventaria mlyaris, Tode. - Sur les charme, en automne.

P. carpoboloïde $\{P$. carpoboloides $)$, Crouan, Fl. fin., p. 50. - Sur une corde pourrie.

P. coupe (P. Catinus), Holmsk, t. 8. - P. cerea, Bull., t. 44, fig. 6. - Sur les trones pourris.

P. bocal (P. Caucus), Reb. - Pers., Myc., 168. - Sur les chatons tombés du peuplier blanc.

P. des tiges (P. cantincola), Fr., Syst., p. 94. - P. Scrratulce, Pers., Myc., et P. albo-marginata, id. - Sur les tiges des plantes, hiver et printemps.

P. des céraistes (P. Cerastionm), Fr., Sys.t, p. 153. - Sur les tiges et les feuilles des céraistes.

P. céracée (P. cerea), Pers., Myc., 32. - Sow., t. 3. - Sur les terres fumées, les couches, en automne.

P. couleur de cire (P. cerinea), Pers., Syn., 62. - Sur les bois putrescents.

P. de Cesati (P. Cesatii), Mont.

P. blane de neige (P. chioncea), Fr., Syst., p. 132. - Sur les feuillos de pin, an printerups.

P. chrysocome (P. chrysocoma $)$, Bull., t. 376, fig. 2. - P. aurea, Pers., Myge, 231. - Sur les bois de pin pourri.

P. à bord cilié $(\boldsymbol{P}$. ciliaris), Sclirad. - Sur les fenilles tombées, à terre.

P. cendrée $(P$. cinerella $)$, Crouan, $F l$. fin., P. 51. - Sur les tiges mortes de la ronce.

P. cendrée (P. cinerea), Batseh, t. 137.-- P. callosa, Bull., t. 416, fig. 1. - Sur les bois et les rameaux putréfiés.

P. cannelle (P. cinnamomea), DC., Fl. fr., TI, p. 23. - Pers., Mz, c., 124. - Sur les rameaux des chênes, parmi les lichene.

P. à frange ( $P$. cirrata), Crouan, Fl. fin., p. 51. - Sur l'écurce de l'Eupatorium cennubinum.

P. citrine (P. citrina), Batsch, fig. 218. - Pers., Syn., 106. - Sow., t. 150. Sur les trones et les rameaux putrescents, en automme.

P. clandestine (P. clandestina), Bull., t. 416, fig. 5. - Sur les ramesux tombés, au printemps.

P. des clavaires (P. Clavariarum), Desm, Ann. des se. nat., 1837.

P. massette (P. clavata), Pers. - Sur les tiges des grandes herbes.

P. coccinée (P. coccinea), Jacq., t. 169. - P. epipendra, de Bull., t. 467. - Sur les rameaux putrides tombés à terre. 


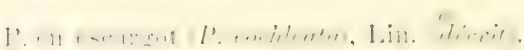

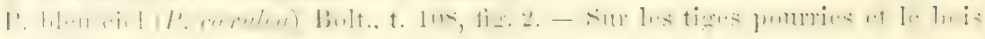

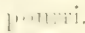

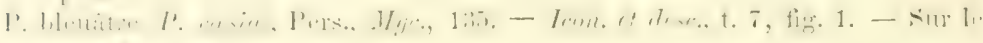

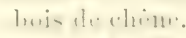

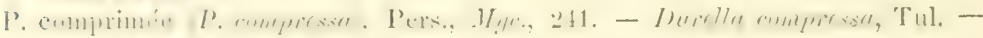

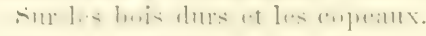

P. parée (P. concinna), Pers., $M Y_{y}$. . 5. - Sur les feuilles de chêne tombées.

P. poudrée (P. conspersa), Pers., Myc., 184. - Thelebolus hirsutus, DC., F\% fr., 729.

P. en couronne (P. coronata), Bull., t. 416, fig. 4; P. radiata, de Pers., Myr., 179. - Sur les tiges des grandes herbes, ortie, chanvre ete.

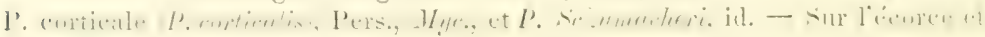
le bois mort de divers arbres.

P. corbeau (P. corina), Pers, Myc.. 65. - Sur les rameaux et les bois.

P. de Créc'hquérault ( $P$. C'rec'hqueraultii), Crouan, F'. fin., p. 55. - Sur la terre de bruyère.

P. barbue (P. crinita), Bull., t. 416, fig. 2. - Pers., Myc., 88. - Sur les bois putrides.

P. safranée (P. crocinc $)$, Mont., Ame. des sc. nat., 1836.

I. du chanme (P. culmicola), Desm., Ann., des sc, nat., 1836. - Sur les tiges mortes de diverses plantes herbacées.

P. des céréales (P. culmigena), Fr., Syst., p. 127. - Sur les chaumes desséchés.

P. du cyprès (P. C'upressi), Batsch. $-P$. cupressina, Pers., Myc., 187. - Sur les feuilles martes du cyprès.

P. en cupule ( $P$. cupularis), Lin. - P. crenata, Bull., t. 396, fig. 3. - Vaill. 11, fig. 1-3. - Pers., Ob.s., t. 4, fig. 6, 7. - En été, sur la terre brûlée et les bois pourris.

P. de Currey (P. Curreyi), Berk1. - Sur les fiuits morts du Juncus effisus.

P. cyatoïd (P. cyathoidea), Bull., t. 416, fig. 3. - Pers., Myc., 171. - Sur les tiges des herbes et surtout de l'asperge.

$P$. de la dentaire (P. Dentarice), Chaill, - Sur les tiges de la dentaire.

$I^{\prime}$. dentée ( $P$. dentata), Pers, Icon., t. 1, fig. 6, 7; id., Myc., 267. - Sur le bois carié.

P. diaphane (P. diaphana), Pers., Myc., 271. - P. hyalina, Hoffm,, t. 6. - Sur les poutres, dans les galeries des mines.

P. lavée $(P$. dilutella), Fr., Syst., p. 148. - Sur les tiges mortes du Lychnis dioica.

P. diminuée ( $P$. diminuta), Desm., Ann. des sc. nat.. 1849. - Sur le chaume des joncs, en été.

P. diplocarpa (P. diplocarpa), Curr.

P. diversicolore $(P$. dizersicolor), Fr., Syst., p. 88. - P. chlorina, Pers., J/y.c., 84. - P. papillata, id., 83. - Sur les fientes, le fumier.

P. des buissons (P. dumetorum), Desm., Ann. des sc. nat., 1850.

P. iroire (P. eburnea), Desm., Am. des sc.nat., 1851. - Sur les feuilles des graminées.

P. ćchimophile (P. echinophila), Bull., t. 600, fig. 1. - Dans l'enreloppe dés cluâtaignes tombées.

P. disparaissant (P. effugiens), Desm., Ann. des sc. nat., 1858. - Sur les graminées, au printemps.

P. épiphylle (P. epiphulla), Pers., Mys., 203. - Sur les feuilles putrescentes de divers arlures. 
P. sulvillouse (P. eriotoma), Fre, Syst. - Sur les ramules morts de l'brien cinerea.

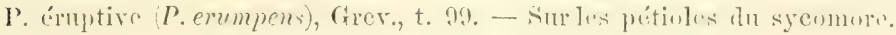

P. marquée de rouge ( $P$. enythrostigma), Mont., Ann. des sc. nat., 1842.

P. très-belle (P. eximia), Dur. et Lév.

P. du hêtre (IP. fougineu), l'ers., Myc., 205. - Sur l's péricarpes du hôtre.

P. trompeuse (P. fallax), Desm., Ann. des sc. nat., 1845.

P. en faisceaux (P. fascicularis), Alb. et Schw., t. 12, fig. 2. - Sow., t. 425, fig. 1, 2. - P. populnea, Pers., Syn., 135.-DC., Fl. fr., VI, p. 27. - Sur les trones pourris des peupliers, des saules et quelquefois des frênes.

P. ferrugineuse ( $P$. ferruginea), Schum; $P$. lenticularis penediculata, de Bull., t. 300 .

P. ferme ( $P$. firma), Pers., Mye., 150. - Sur les trones et les rame aux tombés et putrescents.

P. fendue (P. fissa), Fr., Syst., p. 75. - Sur les rameaux, en hiver.

P. flamme (P. flanmea), Alb. et Sehw., t. 11, fig. 7. - Pers, Myc., 277. - Sur les vieux bois dénudés, du charme, du pommier.

P. jaune ferrugineux (P. Alavo-ferruginea), Alb. - Sur le bois, les fenilles.

P. jaune fuligineux (P. Aavo-fuliginea), Alb. et Schw., p. 319, t. 11, fig. 7. Sur les feuilles en décomposition.

P. fauve verdâtre (P. flavo-virens), Pcrs., Myc., 486. - Sur les bois putrescents, dans les endroits humides.

P. flexueuse (P. flexella), Fr., Syst., p. 152. - P. salicaria, Pers., MIyc., 244. Sur les bois cariés du saule, du pin etc.

P. de la bourdaine (P. Frangulce), P'ers. - Tympanis Frangule, Fr., Syst., 174.

P. des fruits $(P$. fructigena $)$, Bull., t. 228. - P. salicina, Pers., Sym., 104. - Sur les rameaux tombés, les glands, Ie péricarpe du hêtro, du châtaignier ete.

P. brillante (P. Fulgens), Pers., Mye., 46. - A terre, dans les forêts de sapins.

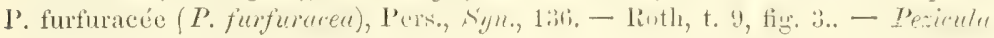
Coryli, Tul.

P. fusarioïde (fusarioides), Berk1., no 12, - Calloria fusarioides, Tul. - Sur les tiges mortes de l'ortie dioïque.

P. basanée ( $P$. fusca), T'ers. - Sur les boịs pourris.

$P$. jaune de terre $(P$. geochroa), Pers., Myc., 2. - Dans les bois.

P. de Godron (P. Godroniana), Mont. - P. tricolor, Sow., t. 369, fig. 8.

P. glume (P. glamaarum), Desm., Ann. des sc. nat., 1841.

P. hémisphérique (P. hemispharica), Wigg., Schæff., t. 319. - Sow., t. 147. - Fl. dan., t. 656, fig. 1. - P. Labellum, Bull., t. 204.- P. lanuginosa, id,, t. 396, fig, 2. Comestible. - Commune, ì terre, dans les bois humides.

P. des graminées (P.graminis), Desm., Ann. des sc.nat, 1841. - Sur les chaumes des graminées, en hiver.

P. granulée (P. granulata), Bull., t.4*8, fig. 3.-P.granulosa), Pcrs., Myc., 14. - Sur les bouses, en automne.

P. des herbes (P.herbarum), Pers., Myc., 202. - Sur les tiges sèches des grandes herbes, automne et hiver.

P. de l'hiver, (P. hiemalis), Weinm. - Sporonema hiemalis, Desm.

P. hérissée (P. hirte), Schum. - Mich., t. 36, fig. 14. - Pers., Myc., 58. - A terre, dans les bois, parmi les mousses humides.

P. hispidule (P. hispidula), Schrad. - Pers., Myc., 64. - Sur les trones et les rameaux tombés, en hiver.

P. légèrement hérissée ( $P$. horrilula), Desm., Ann, des sc. nat., 1847. - Sur les chaumes des graminées. 


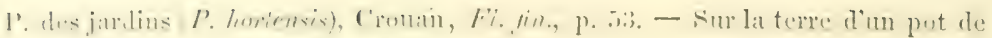
H.

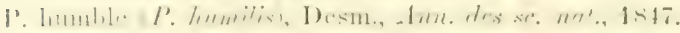

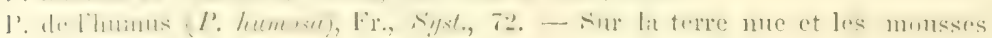
liumides.

I'. hyaline (P. hyalina), Pers., Myc., 78. - Sur les trones putreseents du pin et du sapin.

P. soucoupe (P. hypocrateriformis), Wahl., 498. - P. stipitata, Bull., t. 457, fig. 2.

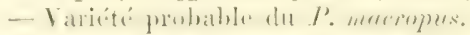

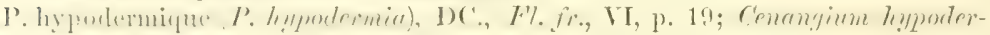
miem, 1) 1:l,y.

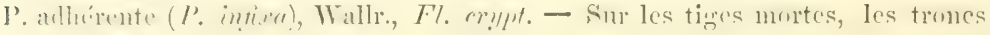
pumris.

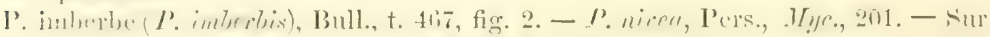
les rieux bois, presque toute l'annéo.

P. infléchic ( $P$. inflexa), Batt., t. 106, fig. 2. - Sow., t. 306. - P. coronilla, Pers., Myc, 180. - Sur les tiges de l'ortic dioïque.

$P$. insidicuse ( $P$. insidiosa), Desm.; Spleceria craterium, DC. - Sur les feuilles du lierre, en automne.

I'. violette (P. ianthina), Fr., Syst., p. 130. - Hedw., t. 8, fig. A. - Sur les vieux trones de saule.

P. très-agréable ( $P$. jucundissima), Desm., Ann. des sc. nat., 1847.

P.des jones (P.jumcina), Pers, Mryc., 261. - Sur les tiges sèches des jones.

P. des jongermames (P. Jungermanie ), Fr. - P. bryophila, Pers., Myc., 235. - Sur les jongermannes.

P. de Kneiff (P. Kneiffi), Wallr. - Xyloma arundinaceum, DC. - Sur les tiges mortes des roseaux.

P. à deux lèvres ( $P$. labiatc), Desm., Ann. des sc. nat., 1847. - Sur le chardon Iioland.

P. à duret coart (P. lachnobrachys), Desm., Ann. des sc.nat., 1851.

P. des lacs (P. tacustris), Fr., Syst., p. 143. - Sur les chaumes des scirpus, des roseanx.

P. couleur de brique ( $P$. lateritia), Pers., Mye., 139. - Sur Ies bois; très-rare.

P. lécidée (P. lecideola), Fr., Obs., t. 4, fig. 1. - Pers., Myc., 248. - Sur les bois.

P. Ienticulaire (P. lenticularis), Bull, t. 300, fig. B, D. - P. citrina, var. lenticularis, Pers., Myc., 197. - Sur les trones vieux et détériorés, en automne.

P. élégante ( $P$. lepida), Pers., Myc., 314. - Sur les tiges des plantes.

$P$. léporine ( $P$. leporina), Batsch (décrit).

P. soie blanche (P. leucocoma), Pers., Mye., 79. - Sur les bois cariés.

P. bordée de cils blanes ( $P$. leucoloma $)$ Reb. - Hedw., t. 4, fig. A. - Entroles mousses et sur les murs, en automne.

P. blancnoir (P. leucomela), Pers., Myc., 5. - P. sulcata, id., Syn., 38, t. 5. Nur les branches sèches du coudrier.

P. chevelure blanche ( $P$. leucotricha), Alb, et Schw., t. 7, fig. 5.-A terre, dans les endroits ombragés. - Pers., Consp., t. 7, fig. 5.

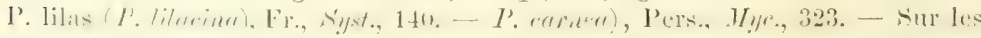
trones d'arbres coupés.

P. des rivages (P. littorea), Fr., Syst., p. 121. - Sur le chaume des roseanx, hiver et printemps.

P. pédiculée ( $P$. macropus), Pers. (décrit). 
P. maritine (I'. maritina), Desm.

1'. forme de bourse (I'. mursupium), Pers., syne, 30. - N'est peut-être qu'une variété du $I^{3}$. vesirulosere, de Bull.

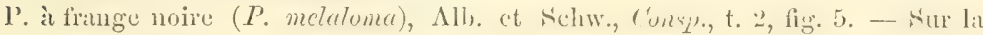
terre brûlée.

P. noirâtre (P. melana), Fr., Syst., p. 60. P. melania, Pers., Myc., 41, ct P. vorgesiaca, id. - $\Lambda$ terre et sur les débris de hois pourris, les nousses, en avril et en mai.

P. châtain noir (P. melanophaca), Fr. - Exciputa melanophoca, id., Syst., p. 190. - Sur les cônes tombés des pins.

P. melanosperne (P. melanospermum), Crouran, Fl. fin., p.50. - Sur la terro brûlée.

P. mélastome (P. melastoma), Sow. t. 149. - Pers., Mye., 40. - Sur les racines découvertes des vieux trones.

P. jaune noir ( $P$. melaxantha), Fr., Syst., p. 150. - Sur les bois morts.

P. excrémenteuse ( $P$. merdaria), Fr., Elench. - Sur les excréments de l'homme.

P. micacée (P. micacea), Pers., Myc., 123. - Sur les tiges du Carduns mutans.

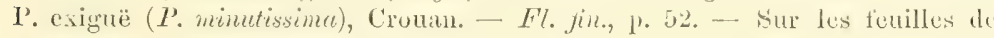
chêne à moitié pourries.

1. menue (P. minuta), Lamarck, Encycl., 5, 215.

P. pauvrette (P. misella), Desm., Ann. des sc. nat., 1847. - Sur la face inféricurd des feuilles de ronce.

P. de Mougeot (P. Mougeotii), Pers., Myc., 186, t. 12, fig. 2. - Biatora campestris, Fr. - A terre.

P. des mousses ( $P$. muscomm), Holmsk., t. 21. - Sur les feuilles et les mousses putréfiées, en automne.

P. négligée ( $P$. neglecta), Lib. - Sur les tiges sèches de l'ortie dioïque.

P. petit nid (P. nidulus), Pers., Myc., 79. - Sur la tige du muguet multiflore, au printemps.

P. négrette ( $P$. nigrella), Pers., Syn., 52. - A terre, dans les bois de pins, tard, en automne.

P. blane de neige $(P$. nivea), Fr., Syst., p. 90. - Fl. dan., t. 1440, fig. 2; $P$. clandestina, de Bull., t. 416, fig. 5. - Sur les bois et les rameaux putrescents.

P. œdème (P. Qddema), Desm., Ann. des sc. nat., 1850.

P. olivacéc $(P$, olivacea $)$, Batsch. - Sur les branches de chêne tombées à terre.

P. ombiliquée ( $P$. omphalodes), Bull., t. 485, fig. 1. - P. confluens, Per's., Obs., t. 5, fig. 6, 7. - Pyronema confluens, Tul. - Sur les places à foumeau dans les bois.

1'. oreille d'âne ( $P$. onotica), Pers. (décrit).

P. des chaumes (P. palearnm), Desm., Ann. des sc, nat., 1846. - Sur les chaumes.

P. de couleur pâle (P. pallescens), Pors., Myc., 198. - P. citrina, Sow., t. 151. - Sur les souches pourrissantes du coudrier.

P. des marais (P. palustris), Desm., Inn. des sc. nat., 1847.

P. à papilles (P. papillaris), Bull., t. 467, fig. 1. - Sow., t. 177. - Sur les bois pourris, en automne.

P. boutonné (P. papillata), Pers., Syn., 64. - Nees, fig. 276. - 1scobolus papillatus, Wallr. - Sur le fumier, en automne.

P. patène (P. patellaria), Pers., MIyc., 238. - Patellaria atrata, Fr., Syst., p. 160. - Sur less tronces, an printrmps. 


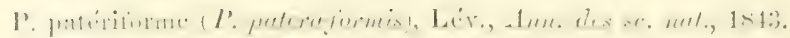

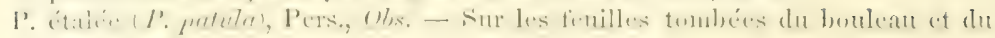
penplin.r.

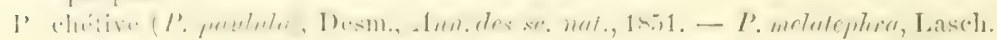

I'. de Persoon (P. Persoonii, Muugcot. - Pers., IIye., 183, t. 12, fig. 1. - Iy. coperdon Equiseti, Hofhim., t. 5, fig. 1. - Sur les tiges des prêles.

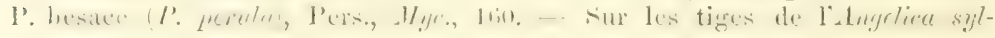
inalivi:

P. des pétioles (P. petiolonum), Desm., Amn. des sc. nat., 1812.

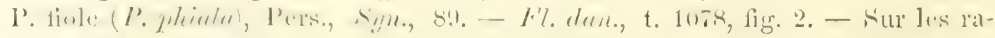
meaux putrescents de l'aulne et du boulcau.

P. safrané ( $P$. pileo crocata), Crouan, $F l$. fin. - Sur l'écorec et la tige de diverses plantes.

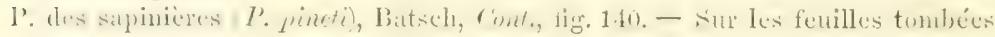
du pin.

P. phyllophile (P. phyllophila), Desm., Ann. des sc. nat., 1812.

P. du pin (P. pinicola), Fr., Syst. - P. farinacea, Pers., Syn., - Sur los côncs tombés du pin.

P. tomnear (P. pithia), Pers., Icon. et deser., t. 11, fig. 2; id., Myc., 96. - Nece, fig. 877. - P. helotium pithium, Fr., Syst., p. 155. - Sur les tiges, les feuilles mortes du Pinus picea.

I'. pulytrique (l'. Polytriehie, schum, - Fre, syst., p. 70. - I terre, au milieu des polytrichum.

P. jaune orangé (P. pseudo-aurantia), Crouan, Fl., fin., p. 54. - Champs sablonneux maritimes.

P. roisine (P.propinqua), Grogn. - Sur le bois mort.

P. pseudo farineux (P. pseudo farinacea), Crouan, $F l$. fin., p. 52. - Sur Ies ramules tombés du pin maritime.

P. de la fougère (P. Pteridis), Alb. et Schw., t. 12, fig. 7. - Pers., Myc., 220; id., Consp. fung., t. 12, fig. 7. - Sur les tiges putrescentes de la fougère.

P. des ptéris $\langle P$. pteridicola $)$, Crouan, Fl., fin., p. 50. - Sur la base du Pteris aquitina.

P. punctiforme (P. punctiformis), Fr., Szst.. p. 105. P. dryophila, Pers., M $M_{3 c}$, 116. - Sur les feuilles putrescentes de divers arbres.

P. pourpre ( $I^{\prime}$. purpurascens), Pers., $H_{y j}$., 48, t. 2, fig. 10. - A terre.

P. pustulée (P. pustulata), Pers., Myc., 18. - J'eziza plicata, id., 16, et P. spurcata, id., 17. - A terre, lieux humides.

P. bouche de feu ( $P$. pyrostoma), Mont., Ann. des sc. nat., 1845,

P. à radicule (P. radiculata), Sow., t. 114. - P. Souerbea, Pers., Mryc. - Sur la terre ombragée.

P. de Randan (P. Randanensis), Lecoq (Recherches sur Randan).

P. ratissoire ( $P$. radula), Berkl. - Sur la terre, dans les bois.

P. radis ( $P$. rapulum), Bull., t. 485, fig. 3. - Nees, fig. 291. - Molmsk., t. 9. -. A terre, au printemps.

P.relicine (P. reticina), Fr., Syst., p. 103. - P. Atrope, Pers., Myc., 70. - Sur les tiges de diverses plantes.

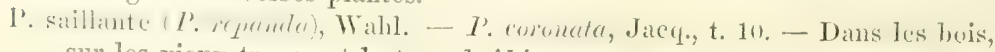
sur les rieux trones et la terre brûléc.

P. rhabarbarina (P. rhabarbarina), BerkI.; P. ardennensis, de Mont.

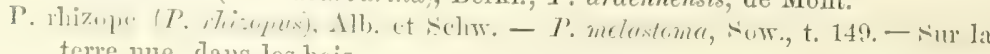
terre nue, dans les bris. 
I. du riceia (P. Riecier), Crouan, $F$ r. fin., 54. - Sur les feuilles vivantes du likceire glaucel.

P. des ruisseaux (P. rivularis), Crouan, Fl., fin., p. 55. tableau supplémentaire. - Sur les branches mortes et sulumergées du saule.

P. humide (P. roseola), Fr., Syst., 60. - Sur les rameaux morts du pin, du nuyer.

P. Roberge (P. Robergei), Desm., Ann. des sc. nat., 1815.

I'. de la rose (P. Rosce), Pers., Mye., 136. - Tympanis obtente, Walli. - Sur les rameaux des rosiers.

P. rougette ( $P$. rubella), Pers., Myc., 230. - Sur les écorces et les bois putrides.

P. roux olivître (P. mufo-olizacea), Alb) et śchw., t. 11, fig. 4. - Siur les xameaux des ronces.

P. rutilante ( $P$. rutilans), Fr., Syst., p. 68. - Dans les prés et les pâturages. $P$. ericetorum, Pers., Myc., et P. polytrichina), Pers., id.

P. rouge sang (P. sanguinea), Pers., Myc., 140. - Nees, t. 37, fig. 271. - Sur les bois desséchés.

P. sanieuse (P. saniosa), Schrad. - Sur la terre, parmi le Bryum argenteun.

$P$. à bouche divisée (P. schizostona), Richon, Soc. des arts etc., de Vitry-leFrançois. - A terre, bois de pins; Champagne.

P. de Schenk (P. Schenliii), Batsch, t. 12, fig. 52. - Pers., Myc., 58. - A torre, parmi les mousses.

P. en seatelle $(P$. scutellata $)$, Lin. $-P$. aurantiaca, Bull., t. 10. - P. livida, Schum. - Sur les bois putrescents, en été.

P. sébile (P. scutula), Pers., Myc., 171. - Nees, t. 38, fig. 282. - Sur les tiges sèches des plantes.

P. des haies (P. sepium), Desm., Ann. des sc. nat., 1850.

P. tardive (P. serotina), Pers., Syn., 98. - Bolt., t. 98. - Sur les tiges et les feuilles putrescentes, tard, en automne.

P. soyeuse $(P$. setos $\alpha)$, Nees, fig. 275 . - Sur les trones cariés.

P. rouge brun (P. spadicea), Per's., Mye., 76. - Sur le peuplier tremble.

P. émeraude (P. smaragdina), Lév., Am. des sc, nat., 1846.

P. de la spirée (P. Spircece), Kirch. - Sur les tiges et les feuilles mortes du Spiraca Ulmaria.

P. des fumiers $(P$. stercorea), Pers., Mye., 62. - P. citiata, Bull., t. 438, fig. 2. $P$. equina, $F$ l. dan., t. 779, fig. 3. - Sow., t. 382. - Sur le fumier, les terres grasses, presque toute l'année.

P. striée (P. striata), Fr., Syst., p. 122. - P. Urtico, Pers., Hyc., 176. - Sur les tiges de l'ortie dioïque, au printemps.

P. brunâtre (P. subfusca), Crouan, Fl. fin., p. 53. - Sur l'album grecum.

P. hirsuteuse (P. subhirsuta), Schum. - P. hirtella, Pers., Myc. - Sur la terre, parmi les petites mousses.

P. des cônes $(P$. strobilina $)$, Fr., Syst., p. 125. - Sur les cônes de sapins.

P. subulaire $(P$. subularis $)$, Bull., t. 500, fig. 2. - P. subulipes, Pers., Myc., 166. - Sur les semences à demi-décomposées des hélianthes et des bidens.

P. sillonnée ( $P$. sulcata), Pers., Syn., t. 5, fig. 1. - Dans les forêts de hêtres.

P. sulfureuse (P. sulfurata), Fr., Syst.. 74. - P. theiochroa, Pers., Mye., 296.

P. sulfurée (P. sulfurea), Pers., Mryc., 72; Icon. et descr., t. 8, fig. 4, 5. - Sur les tiges des grandes plantes.

P. couleur de cendre (P. tephrosia), Pers., Myc, 133. - P.porinaformis, DC, Fl. fr., VI, p. 26. - Sur les bois it temi-pourris. 


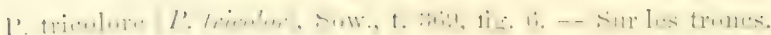

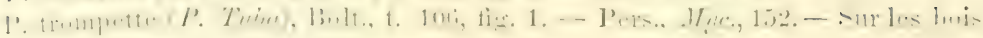
et les rameanx putréfiés.

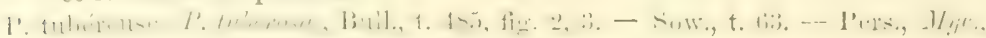
36. - Dans les bois et les prés humides.

1'. enflée ( $P$. tumida), Pers., Myc, 127, - Sur les sarments de vignes.

P. de l'ulex (P. Llicis), Crouan, Fl. fin., p. 52. - Sur les branches mortes do

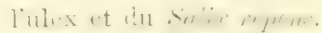

P. de l'orme ( $P$. ulmicola), Crouan, Fl. fin., p. 52. - Sur l'écorce morte de l'orme.

I'. tumidule ( $P$. tumidula), Desw., Ann. des sc.nat., 1851.

P. bombée (P. umbonata), Pers., Icon. et descr., t. 9, fig. 5; Myc., 265. -- Sur les rameaux, les fruits, les feuilles, les chatons.

P. ombrinclle (P. umbrinella), Desn., Am. des se. nat., 1843. - Sur les tiges sècles de la verge d'or.

P. couleur variće (P. variceolor), Pers., Icon. et descr., t. 8, fig. 4, 5. - Sur les bois putrides.

I'. veinéc (P. venosa), Pers., Mig., 7. - Wulf. in Jacq., t. 17, f.g. 1. - Sur les feuilles pourries, dans les bois.

1'. gentille (P. venustula), Desm., Ann. des sc. nat., 1840.

I'. printannière (P. vernalis), Schum. - Fr., Syst., p. 89. - Sur les tiges tombées à terre.

P. versicolore (P. versicolor), Desm., Ann. des sc. nat., 1858. - Sur les tiges de la fougère.

P. changeante (P. versiformis), Pers., Myc. - Helotium, Berkl., Outl., t. 2, fig. 6. - Sur la terre.

1'. vésiculeuse (P. vesiculosa), Bull. (décrit),

I'. velue ( $P$. villosa), Pers., Syn., 76, et P. granuliformis, id., 64. - P. sessilis, Sow., t. 389, fig. 1. - Sur les tiges des herbes.

P. vineuse ( $P$. vinosa), Alb. et Schw., p. 308. - Sur les rameaux tombés et les tiges des plantes.

P. violacée ( $P$. violacea), Pers., Myc., 49. - A terre et surtout sur les places à fourncaux et les trones cariés.

I. rerdâtre ( $P$. virescens), Alb. et Schw. - Sur les ramules pourris d'ulex.

P'. virginale (P. virginea), Batsch. - Pers.- Myc., 104. - P. lactea, Bull, t. 576 , fig. 3. - Holmsk, t. 14 - Sur les bois, les écorces, les feuilles.

1'. jaune d'œuf ( $P$. vitellina), Pers., MIyc., 91. - A terre.

I'. viticole ( $P$. viticola), Pers., IIyc., 249. - Dans les fentes des rameaux de la rigne.

I'. vulgaire (1'. vulyaris), Fr., Syst., p. 146. - Sur l'écorce des rameaux desséchés.

I'. ¿̀ taches dorées ( $P$. xanthostigma), Fr., $S_{y s t}$., p. 146. - Sur le bois de sapin putrescent. 


\section{BLLGARIE, Bulyaria (bulya, mot gaulos, signifiant bourse de cuir).}

Iiéceptucle d'abord orbiculaire, ensuite tronqué, gébatinenx od list: à l'intérieur, rugueux à l'extérieur, d'abord fermé, puis ouvert. Hyménium lisse, persistant.

Bulgarie salissante (Bulgaria inquinans), Fr., Syst., p. 167.

(PI. 55, fig. 3.)

Batsch, t. 11, fig. 50. - Fl. dan., t. 464. - Sow., t. 428. - Nees, t. 39, fig. 296. - Huss., I, t. 32. - Berkl., t. 22., fig. 7. - Peivia nigra. Bull., t. 11 et t. 460, fig. 1. - P. inquinans, Pers, Myc., no 279.

\section{Nom vulgaire : Pezize noire.}

Le Bulgaria inquinans se distingue facilement des Pezizes proprcment dites par sa consistance gélatineuse, élastique et épaisse ; sa conleur, d'un brun noiràtre en dessus et en dessous, ou noirâtre seulement en dessus et rouillée en dessous. Elle est sessile, en forme do còne renversé ef tronqué, rarement large de plus de 3 centimètres. La face supérieure, d'abord creusée en soucoupe, s'aplatit avec l'àge, et finit mème quelquefois par devenir convexe; l'inférieure est peluchée et rugueuse.

Elle croìt, au printemps et surtout en automne, dans les temps humides, sur les bois morts, principalement sur les troncs de chènes coupés et exposés à l'air.

Les soldats de l'armée d'occupation russe, cantonnés en Lorraine en 1816 et 1817, faisaient de cette plante une assez grande consommation. Elle est donc comestible, mais peu recherchée à cause de sa couleur noire. Elle produit abondamment une poussière qui tache le linge et les doigts, et que l'on pourrait employer comme substitut de la sépia, dans la peinture à l'aquarelle; délayée, elle donne à l'eau une couleur vineuse.

Bulg. salissante (Bulg. inquinans), Fr.(décrit).

Bulg. sarcoïle (Buly. sarcoides), Fr., Syst., p. 118. - Pexiza sarcoides, Pers., $1 / y c$., s82. - Acliafi., t. 327 , fig. 2-7, ut t. 324. - I'. tremelloides, Bull., t. 410 , fig. 1. - sur les vicilles sonchus. 


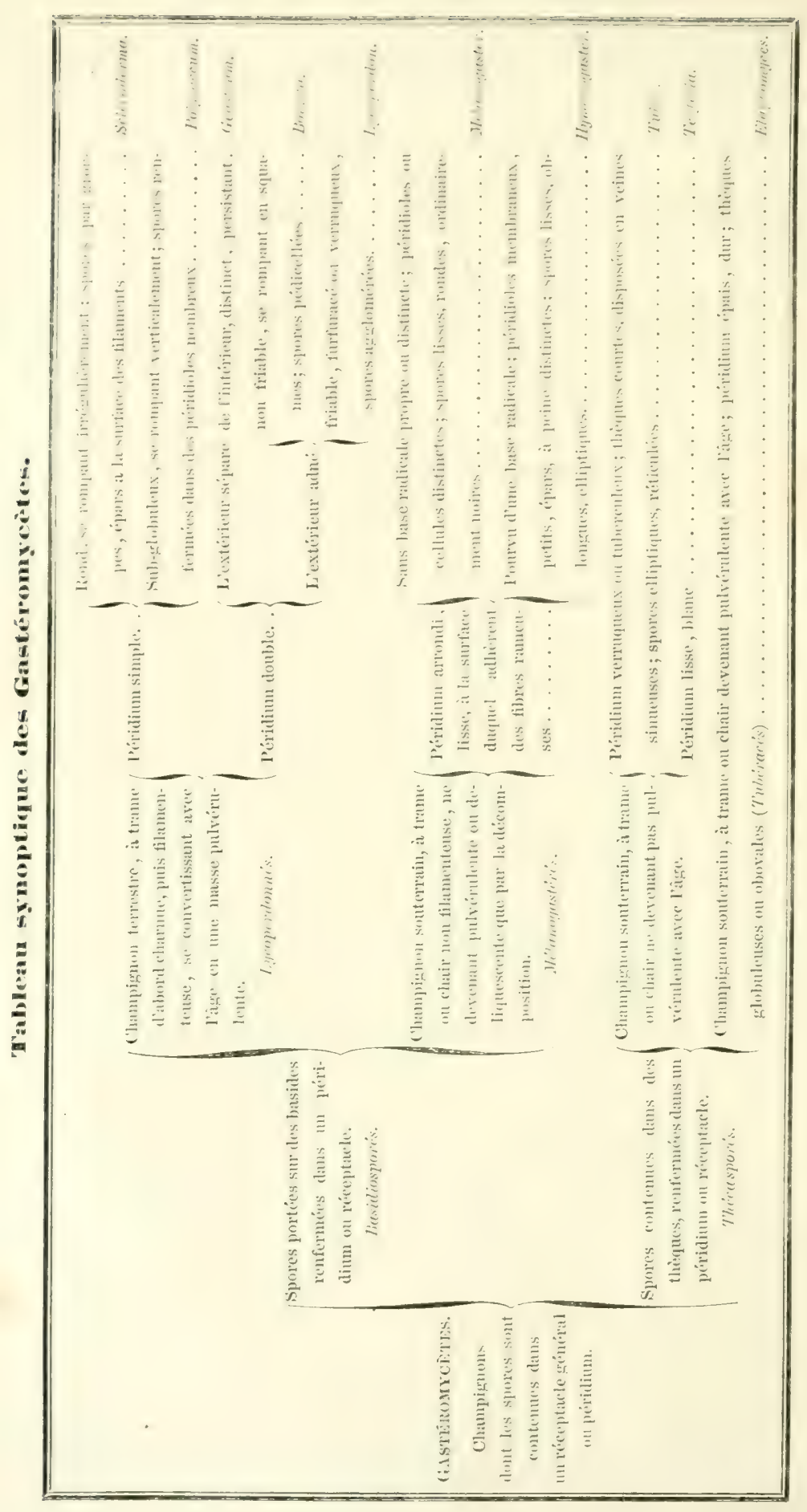




\section{CLASSE II. - MASTÉROHYCÉTES.}

\section{CHAMPIGNONS DONT LES SPORES SONT CONTENUES DANS UN RÉCEPTACLE COMMUN OU PÉRIDIUM, FERMÉ de TOUTES PARTS AU MOINS DANS LE JEUNE AGE.}

ORDRE Ier. - LYCOPERDONNÉS (Lycoperdonnei).

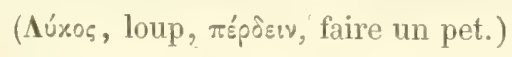

Champignons le plus souvent de forme globuleuse, dont les spores sont renfermées dans un réceptacle ou péridium commun, fermé de toutes parts, au moins dans le jeune âge de la plante; trame ou chair se transformant en poussière.

\section{Basidiosporés.}

GÉASTRE, Geaster ( $\boldsymbol{\Gamma} \tilde{\eta}$, terre; $\alpha$ tríg, étoile).

Péridium double, l'extérieur distinct, persistant, se déchirant en plusieurs lobes étoilés.

Gèastre hygrométrique (Geaster hygrometricus), Pers., Syn., 6.

(Pl. LVI, fig. 1.)

Bolt., t. 179. - Lycoperdon stellatum, Bull., t. 238, fig. A, B, C, D. Schm., t. 26, fig. 27. - Nees, fig. 127. - Vittad., t. 1, fig. 8. - Barla, t. 46, fig. 1-3.

Le Géastre hygrométrique doit son nom à la propriété que possède son péridium ou enveloppe extérieure, de s'étaler ou de se recourber en dessous, selon que le temps est sec ou humide.

Ce péridium est divisé en six ou sept segmenls ou rayons, épais, coriaces, de couleur marron. L'enveloppe intérieure, également de couleur marron, est sessile, sphérique, large de 2 à 3 centimètres, sub-réticulée, se déchirant irrégulièrement au sommet, et répandant une poussière abondante d'un brun roux.

Il croit communément, en automine, sur la terre, dans les bois sablonneux.

Ce champignon est un véritable hygromètre, par la propriétè qu'ont les rayons de l'enveloppe extérieure de s'infléchir en dessous par les 


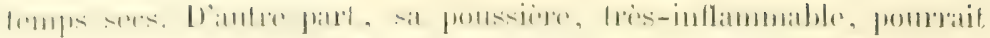

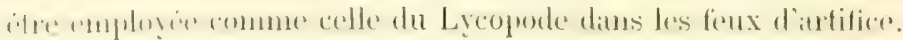

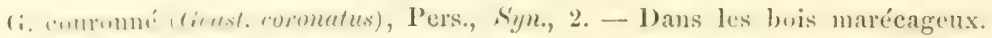

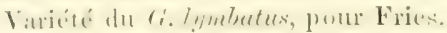

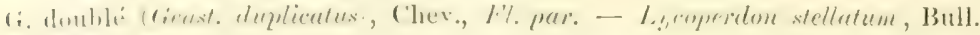
t. 471, fig. O, P. - Dans les grands bois.

(i. frangé fienst. fimbrietus, Fr., signt., 7. - Mich., t. to0, fig. 1. - suw., t. 81. - Berkl., t. 20, fig. 4. - Dans les furêts de sapins.

(†. ceintré (Geast. fornicatus), Fr., Syst., 2. - Batt., t. 39, fig. 1-4. - Sow., t. 198 - Feliafi.. t. 183. - A terre, suus les sapins.

G. Iyygrométrique (G'east. hygrometricus), Pers. (décrit).

(i. limbe (ieust. limbutux), Fr., Syst., 5. - sow., t. 312. - IIuss., I, t. 2. - Sur la terre.

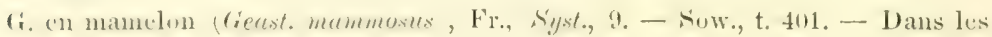
forêts et les bruyères, été et printemps; rare.

G. ¿̀ plusiens pieds (lienst. multifidus), liabh., $1 \%$ den., t. $360 .-\Lambda$ terre, dans les bois de sapins. Variété du G. limbatus, pour Fries.

G. Toux (Geast. rufescens), Fr., Syst., 10. - Mich., t. 100. - Lyc. stellatum, Bull., t. 238, fig. G, H. - Dans les bois de pins et de chênes. N'est pour De Candolle, Fl.fr., 721, qu'une variété du G. hygrometrieus.

G. strié (Geast. striatus, DC., F'l. fr., 718. - Fr., Syst., 3. - G. badius, Pers., Joum. de botan., t. 27. - A terre, dans les lieux sees, le sable.

G. tunicellé (Geast. tunicatus), Vittad., t. 3, fig. 1. - Geast. fimbriatus, Tul., Ann., t. 5, fig. 8.

\section{BOTISTE. Boristu (Bofist en allemand, resseloup).}

Peridium de forme globuleuse, semblable à du papier ou à du car'ton, persistant; écorce distincte, se détachant à la fin en peaux, el tombant en écailles; capillitium égal, attaché sur tous les côtés à l'inlérieur du péridium; spores pédicellées.

Le genie Bucistu eat-il bien different du genie Lygoperdon:"

Boviste noirâtre (Bov. nigrescens), Pers., Syn., 1.

Berkl., t. 20, fig. 5. - Lycoperdon globosum, Bolt., t. 118.

Champignon sessile, de forme globuleuse ou oblongue, ayant de $3 \dot{a}$ 4 centimètres de diamètre, pourvu de deux enveloppes ou péridium, l'extérieur blanchàtre se détachant par lambeaux, lisse; l'intérieur, coriace, papyracé, devenant à la fin de couleur noire. Sa chair, à la maturité, est d'un pourpre hrun, de mème que les spores.

On le trouve, non rarement, en été et en automne, dans les prés et les patturages.

Hussey et Bolton le disent comestible. Sa poudre est employée en Angleterre, pour arrèter le sang des petites plaies. 
Bov. couleur de plomb (Bov. plumbea), Pers., Syn., 2).

(Pl. LVI, fig. 2.)

Berkl., t. 20, fig. 6. - Batsch, t. 29, fig. 166, - Iyroperdon plumbeum, Vittad., Lyc. ardosiacum, Bull., t. 192.

Le Bovista plumbea diffère si peu du B. nigrescens, que, pour Lenz, ils ne forment qu'une seule espèce.

Il a à peine 3 centimètres de diamètre, est sessile, de forme arrondie, pourvu de deux enveloppes ou péridium; l'extérieur, très-blanc, se détruit en totalité ou en partie; l'intérieur, lisse, papyracé, devient couleur de plomb à la maturité. Chair d'abord citrine, ensuite d'un brun fauve, de même que les spores.

Est assez commun et comestible, mais dèdaigné à cause de sa petite taille.

Il vient, à terre, en automne, dans les pâturages.

B. des sables (Bov. ammophila), Lév., Ann. des sc. natur., 1848, t. 9, fig. 5.

B. noirâtre (Bov, nigrescens), Pers. (décrit).

B. des marais (Bov. paludosa), Lév., Ann. des sc.natur., 1848, t. 9, fig. 5. Dans la France méridionale.

B. couleur de plomb (Bov. plumbea), Pers. (décrit).

B. subéreux (Bov. suberosa), Fr., Syst. Myc., 6. - Lycoperdon Corium), DC., Fl. fr., II, p. 598. - Dans les friches, les bruyères, les mousses.

VESSELOUP, Lycoperdon ( $\lambda v x o s$, loup, $\pi \varepsilon \dot{\varepsilon} \delta \varepsilon \omega$, faire un pet).

Péridium de forme globuleuse, membraneux, dont la chair, ferme et blanchâtre dans la jeunesse, se change ensuite en une poussière abondante, de couleur fauve ou verdàtre, entremêlée de filaments; à la maturité, le péridium s'ouvre ordinairement an sommet, pour donner passage aux spores ou poussière séminale; écorce adnée, sub-persistante, se détachant en verrues ou écailles; capillitium adné, arhérent au péridium et à une base stérile.

Vesseloup ciselée (Lycoperdon colatum), Bull., t. 430.

(Pl. LVII , fig. 1.)

Schæff., t. 189, 190. - Vaill., t. 16, fig. 4. - Huss., II, t. 23. - Berkl., t. 20, fig. 7. - Hartz, t. 74. - Krombh., t. 30, fig. 7-10. - Barla, t. 46, fig. 4, 5. - Fr., Syst., 2. Lyc. Bovista, Pers., Syn., 2.

Cette Vesseloup, un peu moindre de volume que la Vesseloup géante, tient à la terre par une large touffe de fibres badicales: ello 
est scsile, mais rétrécie vers sa base et crrondie au sommet. Sa surface, d'abord blanche, puis cendrée ou rousse, et enfin plus ou moins brune, est ordinairement surmontée de verrues ou tubercules aplatis à leur base, ou crevassée en étoiles qui la font paraitre comme ciselée; quelquefois elle est lisse. La chair, d'abord blanche, puis un peu jaunâtre, finit par se changer en une masse de poussière brune. Le péridium s'ouvre irrégulièrement au sommet.

On la trouve dans les mêmes lieux que la Vesseloup géante, mais plus communément; elle possède les mèmes propriétés et peut servir aux mêmes usages. Les lièvres, dit Ascherson, la mangent avec avidité.

Vesseloup gemmifère (Lycoperdon gemmatum), Batsch, 147.

(P1. LVII, fig. 2.)

Fl. dan., t. 1140. - Huss., I, t. 54. - Lyc. hirtum, Bull., t. 340, et t. 475, fig. A, B, C, D, F, G, H, I, M, N. - Lyc. perlatum, l'ers., Syn., 7. Lyc. echinatum, id., 9. - Lye. Proteus, DC., Fl. fr., 714. - Lyc. excipuliforme, Scop.

Noms vulgaires: Vesseloup hérissée, Loufa de loup.

Plante globuleuse, d'abord blanche, ensuite fauve ou brune, large de 4 à 6 centimètres, dont la base se prolonge plus ou moins en forme de pédicule, et dont le péridium ou la surface est recouvert de vermes ou papilles fragiles, allongées et fort apparentes sur certains individus, souvent même comme digitées ou lacérées au sommet, à peu près nulles sur d'autres. La chair est blanche et ferme dans le jeune âge, et se convertit à sa maturité en une poussière brunâtre, qui s'échappe du sommet du péridium.

Commune à terre, en été, dans les bois, les friches.

Selon Bulliard, on s'en nourrit, en beaucoup d'endroits, pendant qu'elle est jeune. Probablement que la plupart des Vesseloups proprement dites sont comestibles dans le jeune âge; Micheli en indique onze espèces que l'on mange à Florence. Toutefois il faut s'en défier lorsqu'elles sont arrivées à maturité, car alors elles passent pour vénéneuses. A la vérité, cette propriété n'a pas été constatée par des expériences suivies; il est au moins certain que leur poussière, lancée dans les yeux, occasionne des ophthalmies graves, et que, respirée par le nez, elle provoque des éternuments violents et quelquefois même des hérnorhagies. 
Vesseloup géante (Lycoperdon giganteum), Batsch, t. 20, fig. 165.

Schæff., t. 191. - Paul., t. 200, fig. 1, et t. 201, fig. 4. - Grev., t. 336. Huss., I, t. 26. - Fr., Syst., 1. - Pers., Syn., 1, Lycoperdon Bovista, Lin. - Bull., t. 447. - Borista gigantea, Nees, fig. 124.

Noms vulgaires: Pisse-loup, Vesse-loup des Bouviers, Vesse-deloup citrouille, Boulet d'Agnel, en Languedoc.

Cette espèce, qui acquiert jusqu'à 30 et 40 centimètres de diamètre, est constamment arrondie, sub-sessile. Son réceptacle ou péridium est blanc, fragile, souvent lisse, mais plus ordinairement peluché ou floconneux, blanchâtre dans la jeunesse, puis ochracé pâle, et enfin cendré. Sa chair, d'ahord blanche, passe peu à peu au jaune verdâtre, puis au gris brun, et finit par se convertir en une masse de poussière brun fuligineux, après quoi le péridium se gerce et s'ouvre à son sommet en aréoles irrégulières, et bientòt il ne reste de la plante que la base, dont la consistance et la légèreté rappellent celles de l'éponge.

Le Lycoperdon giganteum a la racine extrêmement petite, et croìt à terre, en automre, dans les friches et les pàturages. Dans le jeune àge, il a l'odeur et le goût d̦ champignon de couche; à la maturité, ce goût et cette odeur deviennent très-désagréables.

On le mange lorsqu'il est jeune, c'est-à-dire tant que la chair reste ferme et blanche; il fournit mème, dans ces conditions, un aliment excellent, recherché en Italie. La chair, devenue grise, n'est plus alimentaire; on peut alors en fabriquer un très-bon amadou.

Les Finlandais font prendre de la poussière de cette plante, mêlée avec du lait, aux veaux qui ont la diarrhée. On peut en obtenir, à l'aide de précipités, diverses nuances de couleurs brunes, utilisées en teinture; on emploie sa fumée comme anésthésique.

V. noir pourpre (Lyc. atropurpureum), Vitt., Mon., t. 2, fig. 6. - Sur le terreau de feuilles de sapin.

V. ciselée (Lye. culatum), Bull. (décrit).

V. gemmifuere (Lyc. yemmatum), Batsch (décrit).

V. géante (Lyc. giganteum), Batsch (décrit).

V. commenteuse (Lyc. gossypinum), Bull., t. 486, fig. 1. - Sur les trones pourris.

V. d'hiver (Lye. hiemale), Dur. et Mont. - Lyc. Proteus, Bull., t. 72, fig. B, $\mathrm{D}, \mathrm{E}$, et t. 475 , fig. E.

V. grosse racine (Lyc. macrorhizon), Pers., Desv. Journal, t. 1, fig. 6.

V. de Michéli (Lyc. michelianum), Balb., Fl. Lugd., 216. - Dans le centre de la France. 


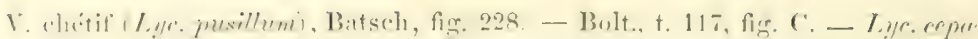
forme, Bull., t. 435, fig. 2. - Dans les bruyères et les terres sablonneuses.

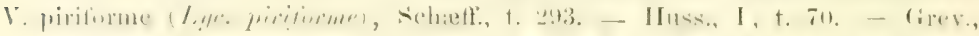

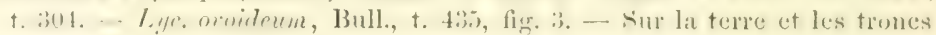
pulluris.

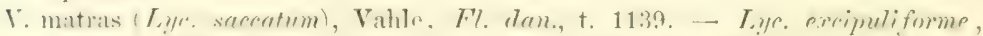

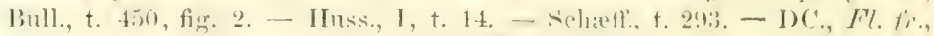
709. - Dans les bois, les gazons. Rare.

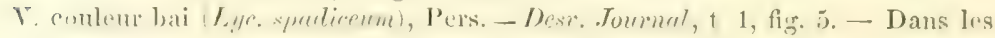
juris.

V. forme d'outre (Lye. utriforme), Bull., t. 450, fig. 1. - Sur la terre; assez commune.

De Candolle, dans la Flore française, range sous le nom de Lycoperdon Proteus les L. cepreforme, Bull., ovoiteum, Bull., piriforme, Bull., hiemale, Bull., Tronnosum, Bull., hirtum, Bull. Cette espèce s'offre, dit-il, sous une multitude d'aspects ; peut-être la Vesseloup ciselée et la Vesseloup gigantesque n'en sontelles que de simples variétés.

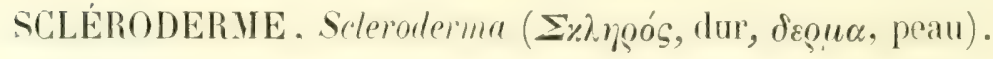

Péridium ferme, avec une écorce simple, se déchirant irrégulièrement; flocons adhérents de tous còtés au péridium, et formant des reines distinctes dans la masse centrale; spores grandes, granulées.

\section{Sclèroderme à verrues (Scleroderma verrucosum), Pers., Syn., 8.}

$$
\text { (PI. LVIII, fig. 1.) }
$$

Vaill., t. 16, fig. 7. - Batt., t. 31, fig. C. - Grev., t. 48. - Huss., I, t. 17, fig. 1. - Barla, t. 47, fig. 3-10. - Scl. spadiceum, Pers., Sym., 9. - Iyjcoperdon verrucosum, Bull., t. 24.

Le Scleroderma vermecosum a le péridium arrondi, épais, ferme, persistant, quelque peu stipité, large de 4 à 9 centimètres, de couleur blane sale d'abord, fauve ou brun jaunatre ensuite, garni de nombreuses écailles ou verrues peu proéminentes, brunes. Sa chair, primitivement blanche, puis bleu lilas, et enfin brune, se réduit avec l'ìge en une poussière d'un brun pourpre. Son pied, épais, creusé de sillons et comme plissé, est soutenu par une racine composée de prolongements qui se réunissent en larges touffes.

M. Barla considère, avec raison peut-ètre, le Scleroderma vermcosum comme une variẻté du Scl. vulgare.

On le trouve fréquemment, à terre, en automne, dans les bois ef Jes endroits montueux. 
Sa poussière, dit Bulliard, lancée dans les yeux, cause des ophthalmies violentes. S'il fallait en croire Vaillant, ce Scleroderma, pris intérieurement, serait mortel. Toujours est-il qu'il passe pour dangereux.

Sclëroderme commun (Scleroderma vulgare), Fr., Syst., 2.

F\%. dan., t. 1969, fig. 2. -- IIuss., I, t. 17, fig., 2. - Berkl., t. 15, fig. 4. -

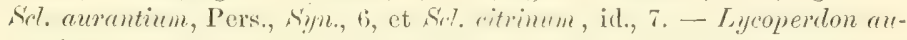
rantium, Bull., t. 270. - Bolt., t. 116. - Vaill., t. 16, fig. 5, 6, 8.

Champignon de forme arrondie, à peu près sessile, irrégulier, ayant un péridium épais, ferme, coriace, légèrement tuberculeux et quelquefois seulement aréolé, ou mêmeà peu près lisse, jaune brun ou jaune citron, se terminant par une racine formée de prolongements réunis en touffe, percé en plusieurs endroits, à la maturité, de trous qui laissent échapper les spores, lesquelles sont de couleur brune. Sa chair, d'abord blanche, devient d'un bleu d'ardoise, quelquefois mar bré de pourpre, et enfin brune.

Il croit à terre, et, communément, sur le bord des bois, en automne. Sa grosseur varie de 10 à 14 centimètres. Son odeur est forte.

Vittadini dit que, dans quelques pays, les paysans récoltent ce champignon et le mangent. Arrivé à sả maturité, il n'est plus comestible et passe même pour vénéneux.

Sel. des bouviers (Scl. Bovista), Fr., Syst., 48. - Lycop. irregulare, DC., Fl. fr., VI, p. 102. - Dans les terrains sablonneux.

Sel, cuir (Scl. Corium), Grav. - Barla, t. 47, fig. 1, 2. - Iycoperdon Corium, DC., Fl. fr., supplém. - Dans les terrains sablonneux ou argileux; en automne.

Scl. géastre (Scl. Geaster), Fr., Syst., 46. - Scl. polyrhizum, Pers., Syn., 11. Sel. polyrhizon, Léveillé, Ann. des sc. nat., 1848, t. 7, fig. 1-4. - Dans les champs, les bruyères.

Scl. verruqueux (Scl. verrucosum), Pers. (déerit).

Scl. vulgaire (Scl. vulgare), Frr. (décrit).

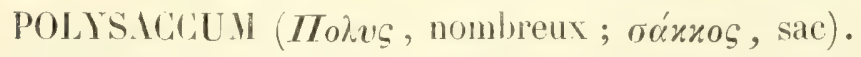

Péridium simple, non flexible, se déchirant irrégulièrement; masse intérieure partagée en cellules distinctes, remplie de petits péridiums; spores mêlées avec les filaments. 
Polysac pied épais (Polysaccum Crassipes), DG., Fl. fr., VI, p. 103.

$$
\text { (1). 1.1111, lig. 2.) }
$$

Mlich., t. 98, fig. A, B. - Paul., t. 99, fig. 5, 6. - Krombh., t. 60, fig. 1, 2.

- Barla, t. 47, fig. 11-13. - Scleroderma tinctorium, Pers., Syn., 4.

Péridium irrégulièrement arrondi, bosselé, d'abord roussâtre, puis brun, ayant de 5 à 7 centimètres de diamètre, rempli, à sa maturité, d'une poussière brune, extrèmement abondante. Pédicule épais, compacte, allongé, souterrain, divisé en grosses ramifications radicales, long de 15 à 20 centimètres, épais de 3 . Spores fauves, rondes.

Le Polysaccum crassipes vient, à la fin de l'été et en automne, dans les champs, les friches, les terrains sablonneux. En Italie, on le mange lorsqu'il est jeune.

Les habitants des campagnes, dit Saint-Amans, teignent leur fil en brun violet avec la poussière de cette plante.

Pol. à pied épais (Pol. crassipes), DC. (décrit).

Pol. pisocarpe (Pol. pisocarpium), Fr., Syst, 5. - Pol, acaule, DC., Fl. fr., VI, p. 103. - Dans les sables.

\section{OrdRE 2e. - MÉLANOGASTÉRÉS (Melanogasterei).}

Champignon souterrain à trame ou chair non flamenteuse, ne devenant pulvérulente ou déliquescente que par la décomposition.

\section{Basidiosporés.}

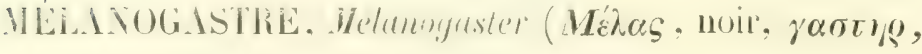 ventre).}

Champignons à péridium arrondi, lisse, à la surface desquels adhèrent des fibres rameuses, sans base radicale propre ou distincte; péridioles ou cellules distinctes; spores lisses, rondes, ordinairement noires.

Mélanogastre varié (Melanogaster variegatus), Tul., t 2. fig. 4 ,

$$
\begin{aligned}
& \text { it } 1 \text { lo, fig. } 6 \text {. } \\
& \text { II. I.X. fiw. I.) }
\end{aligned}
$$

Mich.. t. 98, fig. 2, C. - Sow., t. 426. - Nees, t. 23, fig. 2. - Noul. et Dass., t. 42 , fig. B. - Octariana variegata, Vitt., t. 3, fig. 4. - Tuber moschatum, Bull., t. 479. - Pers., Syn., 2.

Le Melanogaster variegatus est un champignon de forme ovale, arrondie, d'abord ochracé, puis d'un rouge ferrugineux, et plus tard 
d'un brun noirâtre, tant à l'intérieur qu'au dehors. Sa surface est constamment lisse, légèrement veloutée, dit Berkeley. Sa chair, mollasse, noire, parsemée de veines d'un blanc sale, exhale, lorsqu'elle est fraîche, une odeur de musc, qui se perd par la dessiccation.

Il vient en terre, à la profondeur de 15 à 18 centimètres, dans les bois découverts et sur les coteaux; on l'a trouvé aux environs d'Agen, et mème de Paris.

Comestible, mais non délicat. Les paysans le mángent cuit et même cru, à Sainte-Foi-de-Jérusalem, dit Saint-Amans.

En Angleterre on le vend au malché de Bath, sous le nom de truffe noire. La surface se plisse profondement par la dessiccation.

Mél. ambigu (Mel. ambiguus), Trıl., Amn., t. 17, fig. 24, et Funji hyp., t. 2, fig. 5 , et t. 12 , fig. 5. - Dans le terreau des bois.

Mél. rougeâtre (Mel. rubescens), Tul., Fungi hypog., t. 2, fig. 6, t. 12, fig. 7 .

Mél. varié (Mel.variegatus), Tul. (décrit).

\section{HYILNOGisTLR, Mymenogaster (Yucvıov, petite mem- brane, yactŕo, ventre).}

Péridium arrondi, sessile, se terminant par une base radicale, mais non pourvue de racine: péridioles nombreux, globuleux, remplis de spores elliptiques, à peu près lisses.

Hyménogastre de Klotzsch (Hymenogaster Klotzschii), Tul., t. 10, fig. 2.

$$
\text { (Pl. LIX, fig. 2.) }
$$

Staude, t. 1, fig. 1, 2 - Sterb., t. 32, fig. A A. - Noul. et Dass., t. 42 , fig. A. - Tuber album, Bull., t. 404, - Pers., Syn., 4. - Rhizopogon albus, Fr., Syst., 1.

Tubercule arrondi, difforme, d'abord blanc, puis légèrement fauve en vieillissant, ayant un péridium lisse, quelquefois un peu rugueux ou silonné; muni à sa base d'un plateau radical. A l'intèrieur, sa chair est ferme, blanche, avec des veines rougeâtres. Ses spores sont petites, elliptiques, obtuses à chaque extrémité, à peu près lisses.

Ce champignon croìt presque à la surface du sol, dans les bois et les friches, surtout dans les terrains sablonneux. Son odeur nauséabonde n'empêche pas quelques personnes de l'employer comme aliment. Les sangliers en sont très-avides. Il n'est pas rare dans le Languedoc; a été trouvé à Agen et à Rambouillet.

On pourrait la confondre avec la truffe comestible; mais celle-ei n'a jamais de base radicale. 
Iym. des subles (Hym. arenarizs), Tul., Funji hypp., t. 10, fig. 2.

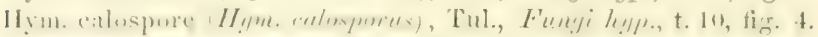

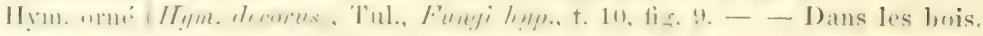
IIym. de Klotzsch (Hym. Klotzschii), Tul. (décrit).

Hyı. lilacé (Hym. lilacinus), Tul., Fungi hyp., t. 1, fig. 2, et t. 10, fig. 8.

Hym. jaunâtre ( $H_{i y m}$. luteus', Vittad., t. 3, fig. 9. - Corda, t. 8, fig. 81. - Dans les bois.

IIym. des peupliers (Hym. populetorum), Tul., Fungi hyp., t. 10, fig. 10. Corda, t. 8 , fig. 83.

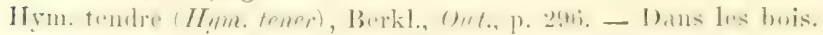

Hym. vulgaire (Hym. vulgaris), Tul., Fungi hyp., t. 10, fig. 13. - Ann. des se. nat., 19, t. 17, fig. 1-3. - Corda, t. 8, fig. 84. - Dans les bois.

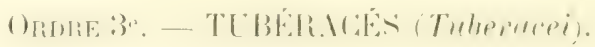

Chrempignons dont la membrane sporophore est contenue drens un péridium souteriain, charm, exactement fermé.

THER

ELIPIOMYCES ('Ehaqos, (ert. ur\%), champignon).

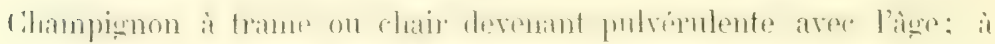
pridiun épais, dur; it the ques globulenses on obovales.

Ėlaphomyce granulé (Elaphomyces gramulatus). Fr., Syst., 1.

(Pl. LIX, fig. 1.)

Mich., t. 99, fig. 4. - Paul., t. 199, fig. 1, 2. - Chev., t. 10, fig. 6. - Tul., Ann., t. 2, fig. 7, et t. 4, fig. 3 ; id., Fungi hyp., $2^{\mathrm{e}}$ série, t. 1, fig. 3. Nees et Henry, t. 10, et Nees, t. 15, fig. 147. - Scleroderma cervinum, Pers., Sym., 12, t. 4, fig. 2.

Ce champignon souterrain est de forme ovoïde ou globuleuse, de la grosseur d'une cerise ou d'une petite noix, dépourvu de racines. Son péridium est dur, ferme, d'un roux sale ou brunàtre, entièrement couvert de petites verrues, anguleuses ou obtuses. Sa chair, d'un blanc rougeàtre d'abord, ensuite brune, finit par se transformer en une poussière d'un brun pourpre, entremêlee de filaments blancs.

Il croit, sous terre, au printemps, de féłrier à juin, et même en automne, dans les forêts de sapins, et dans les terrains montueux et sablonneux. On prétend que les cerfs, les sangliers et les lièvres le déterrent pour le dévorer.

L'Ẻlaphomyces granulatus tient le milieu entre les Vesseloups et les Truffes; à l'éłat sec, il devient fragile et pulvérulent.

Passe pour malfaisant. On lui attribue néanmoins une vertu éminemment aphrodisiaque, qui l'a fait vendre très-cher en Allemagne. Odeur vireuse; goût désagréable. 
Les Élaphomyces ne sont pas d'un usage alimentaire, mais rien no prouve qu'ils sont malfaisants. MM. Tulasne en ont fait prendre des quantités considérables à des oiseaux et à des grenouilles, et ces animaux n'ont pas paru en souffrir.

E1. à pointes (Elaqh. aculeatus), Vittad., t. 3, fig. 13.

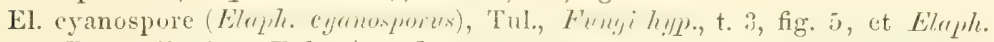
Persoonii minor, Tul., Ann. des se. not., 16, t. 1, fig. 7, et t. 2, fig. 1-12.

E1. hérissé (Elaph. ectinatus), Vitt., t. 3, fig. 6. - Elaph. aculeatus, Tul., t. 1, fig. 5 , t. 2 , fig. 6 , et t. 3 , fig. 3 .

El. granulé (Elaph. gramulatus), Fr. (décrit).

E1. lisse (Elaph. levigatus), Desportes.

E1. de Léveillé (Elaph. Leveillei), Tul., t. 3, fig. 7, et t. 19.

E1. murex (Elaph. nuricatus), Fx., Syst., 2, - Vitt., t. 4, fig. 6.

El. panaché (Elaph. variegatus), Vittad., t. 4, fig. 4. - Elaph. hirtus, Tul., Ann., t. 841 , t. 1, fig. 6 ; t. 2, fig. $3-10$; t. 4, fig. 2 . - Berkl., t. 23, fig. 3 .

\section{TRUFEE, Tuber (not latin signifiant truffe).}

Péridium verruqueux ou tuberculeux; thèques courtes disposées en veines sinueuses; spores elliptiques, réticulées.

Truffe d'étè (Tuber oestivum), Vittad.

Berkl., t. 23, fig. 2. - T. albidum, Cæsalp., 616. - Fr., Syst., 2.

Nom vulgaire : Truffe de la Saint-Jean.

Truffe arrondie, de la grosseur d'une noix, d'un noir brun, marquée de verrues très-grandes, à polygones pyramidaux, striés transversalement, dont la chair, blanchâtre d'abord, puis d'un jaune d'argile ou d'un bistré clair, tirant sur le brun, est parcourue de veines blanchâtres, très*nombreuses, entremêlées d'espèces d'arborisations. Sporanges de quatre à six spores, elliptiques, brunes, réticulées, alvéolées, les alvéoles étant peu amples.

Elle vient, en été et en automne, dans les forèts de la France centrale et méridionale; odeur aromatique de ferment.

Le Tuber astivum est moins délicat que les Tuber cibarium et brumale. En Angleterre c'est la Truffe commune des marchés.

Truffe comestible (Tiuber cibarium), Sibth., p. 398.

$$
\text { (Pl. LX, fig. 2.) }
$$

Mich., t. 102, fig. 4. - Nees, fig. 147. - Tul., t. 7, fig. 2, et t. 17, fig. 3.Paul., t. 198, fig. 5, 6. - Krombl., t. 59, fig. 1-11. - Barla, t. 44, fig. 19, 20. - Corda, t. 17, fig. 125, 126. - Huss., I, t. 11. - Tub. nigrum Bull., t. 356. - Lycoperdon Tuber, Lin.

Noms vulgaires: Truffe noire; Truffe d'hiver; Truffo, en Langueloc; Riablassa, en Provence. 
Fongosité irrégulièrement arrondie, de couleur noirâtre, dépourvue de racines, à surface comme chagrinée ou recouverte de petites éminences, à peu près de forme prismatique, souvent crevassée à la maturité, ayant ordinairement la grosseur d'une noix ou d'un ouf', mais quelquefois beaucoup plus grosse, puisqu'on en a vu du poids d'un kilogramme. A l'extérieur, sa couleur varie du brun violet ou brun cendré; à l'intérieur, elle est blanchâtre dans la jeunesse, puis d'une teinte gris foncé, interrompue par des lignes d'un blanc roussâtre, nombreuses, disposées en réseau à la maturité.

Le Tuber ,cibarium se trouve à la profondeur de 8 à 10 centimètres, et plus, dans les terrains légers et sablonneux, surtout dans les bois de chènes et de chàtaigniers des départements du sud et de l'est de la France. Odeur et saveur très-agréables.

Les Truffes fournissent un aliment et un assaisonnement des plus recherchés; on les sert fréquemment sur les tables somptueuses. Les plus estimées sont celles du Périgord, de l'Angoumois et du Quercy.

Truffe magnate (Tuber magnatum), Picn, p. 79.

Vittad., t. 1, fig. 4 , et t. 2 , fig. 9. - Tul., t. 6 , fig. 3 , et t. 17, fig. 6 . Corda, t. 29, fig. 136. - de Borch, t. 1, 2. - Krombh., t., 59, fig. 12-18. Barla, t. 44, fig. 21-24. - Paul., t. 198, fig. 1, 2. - Tub. griseum, Pers., Syn., 2.

Nom vulgaire: Truffe grise.

Tubercule charnu, ayant de 6 à 8 centimètres de diamètre, et même davantage lorsqu'il est parvenu à son entier développement, de forme irrégulière, arrondie, et quelyuefois aplatie, diversement lobée, à surface lisse ou très-faiblement papilleuse, de couleur jaune sale, blonde ou gris terreux. Sa chair, compacte, tendre, d'un blanc jaunâtre, et plus tard d'un roux ferrugineux ou rosé, est parcourue, dans tous les sens, de veines blanches, très-déliées, réticulées.

Il croît à l'ombre des saules, des peupliers, et surtout des chènes. Rare en France; il a été trouvé aux environs de Tarascon et d'Arignon.

Cette Truffe est delicate et très-recherchée; son odeur rappelle celle de l'ail.

Truffe à spores noires (Tuber melanosporum), Vittad., t. 2, fig. 111, et $t$. 3 , fig. 20 .

Tul., Pungi hyp., p. 136. - Tub. cibarium, Turpin, Dict. des sc. nat., Atlas, p1. 1. - Roques, Champ., t. 24, fig. 1, 2.

Nom vulgaire: Truffe violette ou du Périgord. 
Trufle d'un noir roussâtre, couverte d'aspérités, dont les verrues polygones sont marquées de taches rubigineuses. La chair mûre est d'un noir tirant sur le rouge foncé ou d'un violacé noir, parcourue par des veines blanches, marquées des deux còtés d'une ligne translucide, devenant enfin rougeâtre. Sporanges de quatre à six spores, qui sont elliptiques, oblongues, hẻrissées, opaques.

Abondante dans le midi de la France et particulièrement recherchée; odeur et saveur très-agréables.

Le Tuber melanosporum se distingue du Tuber brumale par la couleur noire ou violacée de sa chair, ses veines blanchittres, fines et nombreuses. Le Tuber brumale a la chair grise ou bistrée, marbrée de veines, plus rares, nettes et d'un blane mat.

Truffe mésentérique (Tuber mesentericum), Vittad., t. 3, fig. 19.

Tul., p. 40. t. 3, fig. 19. - Tub. cibarium, Corda, t. 5, fig. 46.

Noms vulgaires: Truffe grosse fouine et petite fouine, en Bourgogne et aux environs de Paris; Truffe samarquo, dans le Condomois. Confondue avec la Truffe d'été, dont elle est très-voisine.

Truffe globuleuse, d'une taille moyenne, noire, raboteuse, à verrues anguleuses de grosseur moyenne, ayant une chair gris fauve ou brun grisâtre, dont les veines forment des lignes ou sinuosités obscures, très-contournées, rappelant d'une manière remarquable celles du mésentère. Sporanges de quatre à six spores, elliptiques, réticulées, alvéolées, brunes. Odeur et saveur fortes.

Cette Truffe, non rare dans le centre et le midi de la France, dans les environs de Paris, en automne et en hiver, est comestible, mais peu recherchée.

On la confond souvent avec le Tub. cibarium. Très-voisine de la Truffe d'èté, elle s'en distingue par une chair plus obscure, d'un gris fauve, de nombreuses lignes noiràtres, étroites, qui décrivent des tours nombreux et irréguliers, parallèlement aux veines blanches, d'où le nom de mésentérique lui a été donné. Elle présente vers sa base une large anfractuosité, qui semble caractéristique.

Tr. affine (Tub. affine), Corda, Icon., t. 19, fig. 140.

Tr. d'été (Tub. ostivum), Mich. (décrit).

Tr. asa (Tub Asa), Tul., Fungi hyp., t. 5, fig. 2.

Tr. automnale (Tub, brumale), Vittad., p. 135.

Tr. comestible (Tub. cibarium), Sibth. (décrit). 


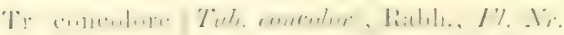

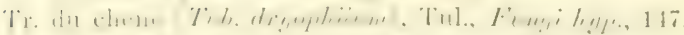

Tr. creuse (Tub. excaratum), Vittad., t. 1, fig. 7.

'Tr' filamenteuse (Tub. filamentosum), Tul., Fungi Typp., 151.

Tr. fétide (Tub. foetidum), Vittad., t. 1, fig. 8, et t. 3, fig. 11 .'

Tr. de Lespiault (Tub. Lespiaultii), Tul., Fungi hyp., 91. - Corda, t. 16, fig. 119.

Tr. magnate (Tub. magnatum), Pieo. (décrit).

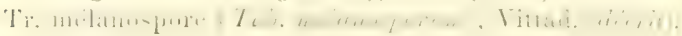

'Tr. mésentérique (Tub, mesentericum), Vittad. (décrit).

Tr. Iuisante (Tub. nitidum), Vittad., t. 2, fig. 10. - Corda, t. 6, fig. 117. Dans la terre de bruyères.

Tr. pannife'e (Tub. panniferum), Tul., Fungi luyp., t. 3, fig. 3, et t. 17, fig. 4.

Tr. odeur de rave (Thb. rapceodorum), Tul., Fungi hyp., t. 5, fig.4, et t. 18, fig. 1.

Tr. de Requien (Tub. Requieni). Tul., Fungi hyp., t. 19.

Tr. rousse (Tub. mufum), Pico. - Dans les vigines et les buis.

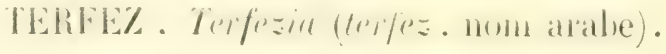

Péridium blane, lisse; chair non veinée.

Terfézie Leonis (Terfezia Leonis), Tulasne, Fungi hyp., t. 7, fig. 5, et t. 15 , fig. 3 (Pl. LX, fig. 3).

Zobel, t. 16, fig. 122. - Krombh., t. 59, fig. 19-24. - Tuber niveum, Dest.

- Choiromyces Leonis, Expédit. scient. de l'Alyérie, t. 24, fig. 22-30.

Toms vulgaires: Terfàs, Terfez, Tirfàzen (Algérie).

Champignon souterrain, globuleux, quelquefois piriforme, lissc, entièrement blanc à l'extérieur et à l'intérieur, ayant le volume d'une noix et mème d'une orange.

Rare dans le midi de la France; il est commun en Algérie, dans les terrains sablonneux, après les pluies.

Les Arabes le mangent acec délices, cuit à l'eau ou avec du lait. Des tribus entières, dit W. H. Duveyrier ${ }^{1}$, en font une grande consommation. En France, ce champignon est d'une qualité inférieure, aussi n'est-il pas recherché.

Terf. odeur de berberis (Terf. berberidiodora), Tul., Funyi hyp., 176.

Terf. Leonis (Terf. Leonis), Tul. (décrit).

Terf. leptoderme (Terf. leptoderma), Tul., Funyi hyp., 175, t. 15̆, fig. 4.

Terf. olbiensis (Terf. olliensis), Tul., Fungi hyp., 176, t. 15, fig. 5 .

Terf. olignsperme (Terf. oligosperma), Tul., Fungi hyp., 176, t. 21, fig. 15.

C'es espèces, toutes assez rares, ont été signalées en France par M. Tulasne. On ne dit rien de leurs propriétés.

1 Henry Duveyrier, Exploration du Sahara, p. 208.

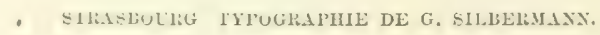




\section{GLOSSAIRE.}

Acaule, qui n'a pas de tige, de support.

acotylédone, dépourvu de cotylédons.

scuminé, qui se termine insensiblement en pointe.

Adné, qui fait corps ou paraît faire corps avec l'organe yoisin.

Igame, plante dont les organes reproducteurs sont inconnus.

Mgloméré, rassemblé en nombre.

Igrégé, en faisceau.

Niterne, disposé alternativement.

Alutacé, qui a l'aspect de la peau.

stvéolé, qui a la forme de cellules alvéolaires.

Inastomose, réunion, entrelacement de nervures.

Anneau, débris d'une enveloppe partielle qui reste sur le pédicule en forme de bague.

Anthéridie, cellule saillante à la surface fructifère des champignons.

Apode, qui n'a pas de pédicule ou stipe.

spre, rude au goût ou au toucher.

Aranéeux ou Arachnoide, qui est formé de filaments très-fins, figurant par leur entre-croisement une toile d'araignée.

Aréole, cercle coloré de petite dimension.

Arqué, courbé en arc.

Iscendant, qui est courbé à sa base et s'élève ensuite verticalement.

Ascus, utricule, petite outre dans laquelle les spores sont renfermées.

Atténué, qui est insensiblement aminci ou rétréci.

waside ou Easidie, utricule qui porte les spores sur un filament.

sifide, bifurqué, divisé en deux.

hourse, enveloppe membraneuse des champignons.

Eubeux, qui a la forme d'un bulbe ou oignon.

Cadue, qui n'est pas persistant.

Campanulé, en forme de cloche.

Capillitium, nom donné aux filaments renfermés dans les lycoperdons.

Careithe, nom donné par quelques auteurs au blane de champignon.

Cellule, vacuole formée dans les tissus.

cendré, couleur de cendre.

Chapeau, sorte de réceptacle qui porte la membrane fructifère de certains champignons.

Charnu, qui a la consistance, l'aspect de la chair.

Claviforme, qui a la forme d'une massue.

Clinode, utricule saillante qui porte les spores.

collet, Collier ou collerette, sorte d'anneau qui se voit sur le pédicule de divers champignons.

conceptacle, lieu où une chose est contenue.

concolore, d'une même couleur, à des nuances différentes.

Confluent, dirigé vers un même point.

Continu, qui ne présente aucune interruption.

convergent, qui se dirige vers un même point. 


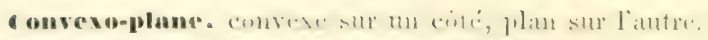

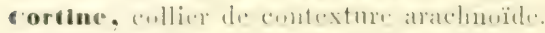

coronneus, yni a lisspect du cotur.

corgledon, lube mininal des plantes.

crypte, follicule glambleuse donf liorifice forme une petite fossese.

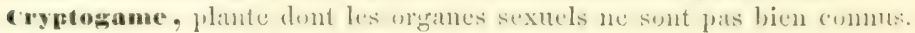

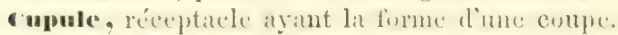

сориiforme, en firme de contur.

cylludrague, qui a la furme d"un cylimtre.

cyotide, cellule arrondic ou ovale, faisant saillie au-dessus de l'hyménium.

becurent, qui est aign "n arriere et se prolonges sur la tige, le pédicule.

beliqueseent, qui se liquéfic.

Déprimé, qui est comme affiassé sous le poids d'une pression.

Dichotome, divisé plusicur's fois, successivement, en deux branches,

bicotyledone, plante pourvue de deux cotylédons.

bimidié, semi-orbiculaixe, comme divisé en deux parties. On dit des feuillets qu'ils sont dimidiés quand ils se terminent à une égale distance du bord du chapeau et de la tige.

Discolore, qui présente deux couleurs différentes.

Divariqué, écarté.

mivergent, qui s'écarte de la ligne droite.

ícalleux, couvert d'écailles.

Endospore, dont les spores sont logées intérieurement.

vinroulé, roulé en dedans.

Épiderme, membrane mince qui recouvre diverses parties des végétaux.

Épiphyte, qui pouse sur un autre végétal.

Esculent, luon ì manger.

Nipece, végétal qui a sa forme, son organisation propre.

Excentrique, qui part hors du centre.

crospore, dont les spores sont placées extérieurement.

Exotique, étranger au climat où il est né.

Famule, association de végétaux ayant des organes situés les uns relativement aux autres d'une manière uniforme.

Fascieulé, qui pousse en petites touffes.

Wastigié, qui s'élève en pointe et se termine à la mểne hauteur.

Feuillet, lame disposée en rayon, et particulière aux agarics.

ribreux, composé de fibres ou filaments déliés.

Fibrilleux, couvert de filaments ou de petites stries.

Fistuleux, creusé en tuyau, en flûte.

vlabellforme, qui a la forme d'un éventail.

-lavescent, jamnâtre.

vlocon, petite touffe ressemblant à de la laine.

Fongueux, qui a la forme ou la consistance d'un champignon.

Frange, qui a le bord semblable ì unc frunge.

wance, qui ne dure qu'un temps très-court.

vuligineux qui est couvert d'une sorte de suie.

vuscescent, brun, basané.

vusiforme, rqui a la forme d'un fuseau.

4ćlatineux, qui a la consistance d’une geléc.

cenre, réunion d'un certain nombre d'espèces ayant des caractères commmins.

Gabre, qui est lisse et sans poils ou aspérités. 
Glande, organe qui súcrete un liquide.

chanduleux, qui tient de la nature de la glande.

Alauque, de couleur vert blanchâtre.

alebe, petite boule, sphiere.

Gongyle, spore, semence des champignons.

Congylifère, qui porte des gongyles.

Granulenx, couvert de saillies ou rugosités en forme de gianules.

Inabitat, demeure.

Inispide, couvert de poils longs et rudes au toucher.

עу уоториае, qui est comme transparent.

Iy yénium, membrane fructifère des champignons.

пуме́uophore, organe qui supporte l'hyménium.

Iypha, tissu, toile.

IIy pogé, qui vient sous terre.

Imbriqué, composé de parties qui se recouvrent les unes les autres comme les tuiles d'un toit.

Immarginé, non entouré d'un bord.

Indigène, qui est natif du pays.

Individu, être particulier d'une espèce.

Infundibuliforme, qui est creusé en entonnoir.

Lacteseent, qui donne un suc laiteux.

Lacume, creux, enfoncement.

Lacuneux, qui a des creux, de petites cavités.

Lamelle, feuillet disposé en rayon à la partic inféricuro du chapeau ou hyménophore.

Libre, distinct, indépendant, qui n'est pas soudé.

ligneux, qui a la consistance et le tissu du bois.

Mamelonné, qui présente à la partie supérieure une petite élévation que l'on pourrait comparer à un mamelon.

varcescent, qui, après s'être flétri, se conserve desséché.

Marginal, placé au bord.

Varginé, qui a une bordure.

verisma, division; qui est partagé.

vonocotylédoné, qui est pourvu d'un seul cotylédon.

Mitre, receptacle ou chapeau ayant la forme d'une mitre.

vucilage, mucosité, humeur visqueuse.

Mycélium, blane de champignon, filaments produits par la germination des spores.

vareotique, qui produit le sommeil, l'assoupissement.

vervare, filament rameux et saillant.

Nu, qui est privé d'appendices ou d'enveloppes.

Deracé, de couleur de jaune d'ocre ou de limon de terre.

Dmbiliqué, qui présente un petit renfoncement à son centre.

Ondulé, dont le bord ou la surface forme de petits plis arrondis.

Opposé, disposé par paires, les unes vis-à-vis des autres.

orbiculaire, arrondi, fait en rond.

Dvoïle, en forme d'ouf.

Palmé, qui représente une palme, une main.

Trapaphse, excroissance, thèque avortée.

Parasite, qui croît sur une plante vivante.

Parenchyme, partie de la plante formée de tissu ecllulaire seulement.

Pédicule et pédieclle, support ou pied du chapeau. 
Pedilum. enrelople extéricure des urganes de la firetification, conme dans les lycopuchelinés.

E'hanerogame, dint les urganes sexucls sont apparents.

Dibiole, partic renflée en forme de chapeau, lequel purte la membranc fructitile.

I'Purope. qui a le pied latéral.

pore, olifice des tubes des bolétoídes.

Port, aspect général.

rruineux, qui a l'aspect du givre, d'une gelée blanche.

pubenceut, couvert de duvet.

pulpe. substance charnue du champignon.

pulpeux, charnu, succulent.

pulvérulent qui est couvert de poudre.

Pulvine, qui a la forme d'un coussin.

Famification, distribution en rameau.

Itéceptacle, partie du champignon qui porte ou renferme immédiatement les organes contenant les séminules.

Itencichi, replié en dehor's ou en dessous.

téniforme, en forme de rein.

мésupiné, renversé, étalé et portant l'hyménium en dessus.

Itéticulé, dont la surface est couverte de ramifications sous forme de réseau.

thomboilal, qui a la forme d'un losange.

ruile, âpre au toucher.

mugueux, qui est ridé, plissé.

scabre, qui porte des aspérités, rude au toucher.

séminifère, qui porte les semences ou spores.

séminule, graine ou semence des champignons.

sessile, qui n’est pas supporté par un pied ou pédicule.

solide, plein, non creusé d'une cavité.

sous-ligueux, qui a presque la consistance du bois.

spatule, qui a la forme de linstrument appelé spatule.

spécifique, appartenant à l'espèce.

spieule, nom donné par quelques auteurs au stérigmate.

sporange, vésicule dans laquelle les spores ou séminules sont contenues.

spore et sporule, organe reproducteur ou semence des champignons.

sporophore et sporulifere, qui porte des spores ou sporules.

siyuamifère, qui porte des écailles, qui ressemble à des écailles.

stérigmate, filament qui porte la spore des basidies.

stipe, le pied, le support des champignons.

stipité, qui est pourvu d'un pied.

strie, petite ligne longitudinale.

strić, marqué de stries, de cannelures.

stroma, tubercule plus ou moins saillant, qui sert de base ou de support aux sporidies de la plupart des champignons épiphytes.

subereux, qui a la consistance et l'aspect du liége.

subulé, on forme d'alène.

succulent, rempli d'un sue aqueux ou mucilagineux.

Theque, utricule dans laquelle les spores sont contenues.

Tomenteux, cotonneux, couvert d'une sorte de duvet.

Trame, le tissu, la substance intermédiaire entre l'hyménium et les feuillets des agarics et les pores des polypores.

Tube, partie cylindrique et creuse. 
Tubéreux, renflé en tubercule.

cnilatéral, disposé ou dirigé d'un seul côté.

ctrleule, petite outre ou cellule dans laquelle les spores sont renfermées.

varlété, individu qui diffère de l'espèce ordinaire, par suite de circonstances extérieures.

Veine, nervure peu proéminente et flexueuse.

velouté, couvert d'un duvet court et doux au toucher.

velum, enveloppe partielle, de texture floceso-farineuse, qui entoure le réceptacle de certains champignons dans le premier temps de leur développement.

villeux, garni de poils très-rapprochés.

visqueux, gluant à la superficie.

Volva ou Volve, enveloppe générale, membraneuse ou quelquefois gélatineuse, de divers champignons dans le premier temps de leur développement.

zoné, qui est marqué de zones. 


\section{BIBLIOGR APIIIE.}

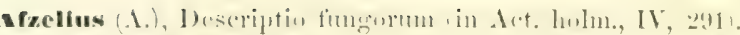

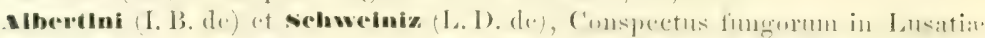

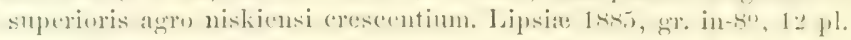

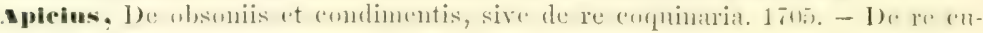
lintria on de arte copruinatria. Milan 147 s.

annales des sciences naturelles. P'aris.

snnules de chimie et de physique. J'aris.

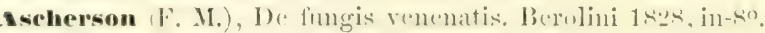

Mhone. I dipunsulistes.

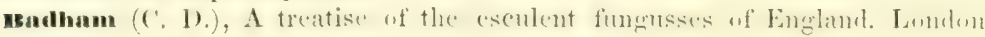
1517.

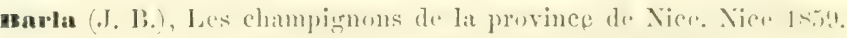

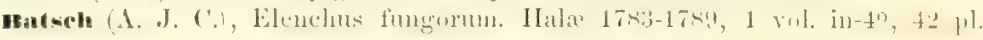
collol:

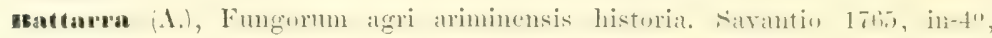
1.2 1, I,

mayle-marelle $(G$. $)$, Descrizione e fatta dei funghi nocivi e sospetti. Milano 1808 , fin. cul.

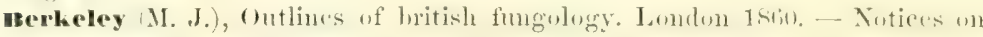

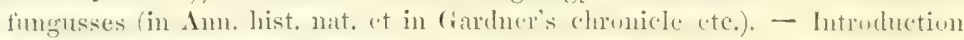
to cryptonamic botany. Lundun 1857 , in-80, fig.

Eertoloni (D. A.), Flora italica cryptogamia, 1833 et suiv., in-80.

Eolton (J.), Historia fungorum circa Halifax sponte nascentium. 4 vol. in-8o. Berlin.

morch ( $\mathrm{Ph}$. de), Lettres sur les truffes du Piémont. Milan 1780, in-80, avee 3 pl. color.

nose, Sur quelques champignons de l'Amérique septentrionale, in-40, fig.

wouchardat, Annales des sciences naturelles, II, liv. XVI, 1841, p. 27.

mouillon-Lagrange, Annales de chimie, t. XLVI et LI.

uraconnot, Annales de chimie et de physique, t. LXIX, p. 434.

Erongniart (A.), Dictionnaire des sciences naturelles, in-80. Levrault - Dictionnaire classique d'histoire naturelle. Paris 1822. - Essai d'une classification naturelle des champignons. Paris 1825 , in- 80 .

urondeau (L. de), Recueil de plantes cryptogames de l'Agenais. Agen 18291830 , in- 80 .

mrayerin (J. B.) (Bruyerinus), De re cibaria. De fungis, liv. IX, chap. XIX. Francfort 1600 et 1606. Périgueux 1560.

mulliard $(P$.$) , Histoire des champignons de la France ete. Paris 1791-1798.$

แแxbaum (J.), Plantarum minus cognitarum, centurix V. Potropoli 1728. Enumeratio plantarum in agro halensi crescentium. Halæ 1721. - De propagatione fungorum ete.

celse, De re medica.

Chevallier (F.), Flore générale des environs de Paris. Paris 1836, 2 vol, in-80.

curtis, Flora Iondinensis, in-fo, 1817-1828. 
mesconrtilz (E.), Des champignoms comestibles, suspects et vénéneux. Paris 1827 , in-8o, et atlits.

Gesmazières (J. B.), Anmales des sciences natur. etc. - Plantes cryptogames du Nord, in- $4^{\circ}$.

Dutrochet, Mémoires pour servir à l'histoire anatomique et physiologique des végétaux et des animaux. 1837,2 vol. in- $8^{\circ}, \mathrm{pl}$.

Desfontaines $\left(\mathrm{R}_{\text {. }}\right)$, Flora atlantica, sive historia plantarum quæ in Atlante etc. Paris 1798-1800, 2 vol. in-40, pl. 261.

Ehrenberg (C. G.), Sylvæ mycologicæ berolinenses, Berolini 1818.

Ilora danica, Icones plantarum in Dania, sponte nascentium edid. Eder, Müller, Vahl etc. Copenhague 1862, fasc. 45, in-fol., pl. col.

Flora danica, in-fol, 1761 etc.

Fries (E. M.), Systema mycologium. Gryphiswaldiæ 1821-1832, 3 vol. in-80. Epicrisis systematis mycologiæ seu Synopsis hymenomycetum. Upsaliæ et Lundæ 1836-1838. - Fungi resci et nocivi Suecir. Upsalix 1836. - Monographia hymenomycetum Sueciæ. Upsaliæ 1857 etc.

Cresalpin (A.), Traité des plantes. Florence 1583.

Clusius (1'Echse), Rariorum plantarum historia, commentariolum de fungis continens. Antuerpiæ 1601, in-fol.

Corda (A. C. J.), Icones fungorum hucusque cognitorum. Pragæ 1837, 5 vol, in-fol., $44 \mathrm{pl}$. etc.

mecandolte (A. P.) of Buby (J. E.), Botanicon gallicum. Paris 1818, 2 vol. in-80.

Dioseorides (P.), De medicinali materia libri sex, J. Ruellio interprete. Francofurti 1543 , in- $4^{\circ}$, fig.

Galien (C.), Eurres. Leipzig 1832.

Grleditsch (J. G.), Methodus fungorum etc. Berolini 1753, in-80, 6 pl.

Gobley, Recherches chimiques sur les champignons rénéneux. Paris 1865, in -80 .

Greville (R. K.), The scottish cryptogamic flora. Edinburgh 1829, 360 pl. gr. in- 8 .

Moffunun (G.), Vegetabilia cryptogama, in-40, 1787-1790.

Holmskiold (T.), Beata ruris otia fungis danicis impensa. Havniæ 1816, in-fol. Hussey (Mrs T. J.), Illustrations of british mycology, 2 séries in-4o, pl. Londres 1849-1855.

sacquin (P, F. de), Flora austriaca, in-12, fig. 1773-1787.

Jacquin (N. J.), Miscellanea austriaca, in-4o, 1778-1781.

mughhu, in Linnæa, vol. V, 1830.

kiekx (J.), Flore cryptogamique des Flandres, 2 vol, in-80. 1867.

Klotzseh, Fungi, in- $4^{\circ}$, broch.

n rombhola (J.), Naturgetreue Abbildungen der essbaren, schitdichen und verdächtigen Schwæmme. Pragæ 1831-1849, in-fol., 70 pl. color.

Lamarek (J. B. de) et Bbecantholle (A. P.), Flore fronçaise, Paris 1815,6 vol. in-s?.

Laterade (J. F.), Flore bordelaise et de la Gironde. Bordeaux 1829, in-12.

Lavale $\left(J_{.}\right)$, Traité pratique des champignons ete. Dijon 1852, in-80.

Genz (F. A.), Die nützlichen und schädlichen Schwrmme. Gotha 1862.

de Bulliard. Paris 1834-1846, in-fol., 108 pl. color, - Dissertation sur les propriétés alimentaires ete. des champignons. Paris 1827. - Histoire et description des champignons alimentaires etc. Paris 1826, in-8o. - Journal de pharmacie, t. XXIII, 18:37. 
a.velié (J. H.), Annales des seiences naturelles. 1825-1851 etc. - Dictionnaire universel d'histoire naturelle. - Iconographic des champignons de l'aulet. Paris 1855 , in-40.

rink (H.), Observationes mycologicæ (Ann. d. Naturgesch.). 1791. - Nova genera plantarum e classe fungorum (Schrader's Jourm.).

anue (C.), Flora succica, iu-80.1755. - Systema vegetabilium, in-80.

varsillus (L. F.), De generatione fungorum. Romæ 1714, in-fol., pl.

wathiole (P. A.), Opera qux extant omnia; hoc est: Commentarii a C. Bauhino infinitis locis aucti. Basileæ 1598, in-fol., fig. - Commentaires de la matière médicale de Dioscoride, traduit du latin par Penet. Lyon 1680, in-fol.

Mérat (F. V.), Nouvelle flore des environs de Paris. 1837.

wehell (P. A.). Nova ptantarum genera. Florentia 1729.

Montagne (J.F.C.), Sylloge generum specierumque cryptogamarum etc. Paris 1556 .

Moynier (M. M.), De la truffe. Traité complet de ce tubercule. 1856 ; 1 vol. in- $8^{\circ}$.

vecker (E. J.), Traité sur la mycétologie. Mamncim 1783, in-80.

vees von Esenbeck (C. G.), Das System der Pilze und Schwrmme. Würzburg 1847, fig. col., in $-4^{0}$.

vees von Esenbeck ( $F$. T. , wenri et Bail, Das System der Pilze. Bonn 1837-1859, in-80, pl.

voulet et massier, Traité des champignons comestibles, suspects et vénéneux qui eroissent dans le bassin sous-pyrénéen. Toulouse 1838.

Eder (G. Ch. de), vahl, Hornemann etc., Flora danica. Harniæ 1761-1845, 15 vol. in-fol.

Parmentier, Recherches sur l'usage et les effets des champignons. 1782

Paulet (J. J.), Traité des champignons. Paris 1793-1835, avec atlas in-fol. Mémoires de la Société royale de médecine. 1776, in-fol., fig.

Paulet (J. J.) et Lévellé, Ieonographie des champignons. Recueil de 217 planches dessinées d'après nature et coloriées. 1855, in-fol.

rennier de congchamps (P. B.), Dissertation physico-médicale sur les truffes et les champignons. Avignon 1766.

Persoon, Observationes mycologicæ. Lipsiæ 1796. - Commentatio de fungis clavæformibus. Lipsiæ 1797. - Icones et descriptiones fungorum minus cognitorum. Lipsiæ 1798-1800, - Synopsis methodica fungorum. Gottingx 1801, in-12. - Icones pietæe rariorum fungorum. Paris 1803-1806. - Traité sur les champignons comestibles. Paris 1818. - Mycologia europæa. 1822 1828, 3 vol. in -80 aree $30 \mathrm{pl}$. color.

Pico (V.), Meletemata inauguralia de fungorum generatione et propagatione.

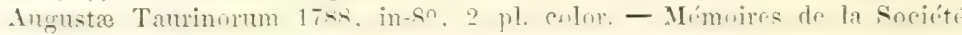
de médecine. 1781.

Platine, De obsoniis.

Pline (C. P. S.), Histoire naturelle en 37 lives.

Pouchet, Expériences sur les champignons vénéneux. - Journ. des connaiss. méd. prat. et de pharmacologie, $6^{\mathrm{e}}$ vol.

Kavel (M.), Culture de la truffe. Paris 1857 , in-80.

Roques (G.), Histoire des champignons comestibles et vénéneux. Paris 1841, in-8o, pl. - Plyytographie médicale. 1821, 2 vol. in-4o, pl.

saint-Lmans (A. de), Flore agenaise. Agen 1821.

schaffer (J. X.) Fungorum qui in Bararia et Palatinatu cirea Ratisbonm nascuntur, icones. Ratisbonæ $1762-1774,4$ vol, in-4o. 
Sehmid (J.), De fungis esculentis et venenatis. Vindebonæ 1836.

schrader, Spicilegium, in-80. 1794.

schummel (E.), Ueber die giftigen Pilze etc. Breslau 1840.

scopoll (J. A.), Flora carniolica. Viennæ 1772, 2 vol. in-80, pl, - Plantæ subterraneæ. Pragæ 1772.

seerétan, Myeographie suisse, in-80. 1833.

serini (Fr. V.), Funghi sospetti e venenosi del territorio senese. Torino 1868, 2 , via del soccorso.

๙ommerfelt, Supplementum floræ lapponicæ, in-8, 1836.

sowerby (G.), Coloured figures of english fungi or mushrooms. London 1797-1815, $400 \mathrm{pl}$.

Tessier, Expériences sur la carie des blés. 1785, in-80.

Théophrasti, De historia plantarum libri decem, græce et latine. Amstelodami 1644, in-fol., fig.

Thore (G.), Essai d'une Chloris du département des Landes. Dax 1803.

Tode (H. G.), Fungi mecklenburgenses selecti. Luneburgi 1790-1791. 1 vol. in $-4^{\circ}, 17 \mathrm{pl}$.

Tonini (F.), Prospetto chromo-lithografico confrontativo tutto dal vero dei funghi mangerecei e dei funghi velenosi e sospetti i piu communi. Como 1848.

Trattinick (L.), Fungi austriaci delectu singulari iconibus 40 observationibusque illustrati. Vindobonæ 1809-1830, $20 \mathrm{pl}$.

Tulasne (L. R. et C.), Fungi hypogæi. Histoire et monographie des champignons hypogés. Paris 1862, gr. in-4º, pl. - Selecta fungorum carpologia, gr. in $-4^{\circ}, 1861-1866$.

vallant (S.), Botanicon parisiense. Leyde et Amsterdam 1727, in-fol., pl.

vauquelin, Annales de chimie, liv. XXX, 33 ete.

vittadini $\left(C_{\text {. }}\right.$ ), Descrizione dei funghi mangereci piu communi dell' Italia et de velenosi, che possono co' medesimi confondersi. Milan 1835, fig. Monographia tuberacearum. Milan 1831. fig. in- $4^{\circ}$.

wallmoth (C. F.), Flora eryptogamica Germanix. 1831-1833, in-12.

weinmann (J. A.), Hymeno- et Gasteromycetes, 1836, in-80.

willdenow (C. L.), Floræ berolinensis prodromus. Berolini 1787.

withering (W.), Butanical arrangement. 1796, in-so. 


\section{TABLE DES NOUS VULGAIRES.}

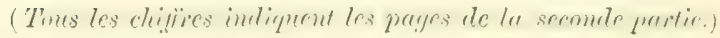

1hi1) 111.

Agarie alliace, 6.t. - lilane, 156. - du chine, 154, 155. - à petite coiffe, 13. - femelle, 155. - meurtricr, 113. - aux mouches, 6. - des phimaciens, 15t), - porrean, 62. purpatif, 156.

Aoureilleto, 130

Aomeillo dimalmé, s.

Aricélous, 136.

Arresterou, 167.

Barbasin, 151.

Barle de bone, 166, 175. - de chievre, $167,175,177$. - de vache, 167.

Beigoula, 78 .

Bcrdanel, 127.

Berdanello, 127.

Bérigoule, 78.

Bise rouge, 120. - verte, 38. - vraie, 127.

Bisotte, 123.

Blavet, 31

Bulé, 136.

Bolet à amadou, 154. - foie, 132. orangé, 134.

Bordet, 127.

Bordetto, 127.

Bouche de lièvre, 000 .

Boula, 154, 155 .

Boulé, 6.

Boule de neige, 88 .

Boulet d'agnel, 215. - d'oulmé, 149.

Boulingoule, 78.

Boulingoulo, 130 .

Bousiquet, 89.

Bouterot, 20.

Braquet, 29.

Brigoule, 78.

Briqueté, 110.

Brouquichous, 166.

Brugaizello, 20.

limguët, $136 .-\mathrm{fol}, 139$

Buisson, 177.

Caberlas, 87 .

('atran, 4.

Calalos, 113, 114.

Campagnol, 4.

Campagnola, 89.

Campaønoulé, 89.

Camparol d'oulmé, 149.

Cancer, 187
Capellan, 20.

Cassenado, 37, 39, 42

Cassine, 130 .

Caussetta, 22

Cep, 133.

Cépet, 136

Ceps, 133, 136.

Ceps-fails, 145 .

Ceps noir, 136.

Chageran, 4.

Chair de Bavière, 84 .

Chamois, 167.

Champignon des bruyères, 88. - du chêne, 155. - de couche, 89. - do fumier, 89. - jaune des sables, 46. - museat, 29. - de l'olivier, 79. du peuplier, 24. - des prés, 89.

Charbonnier, 120.

Chavane, 111

Chavancelle, 154.

Chénier ventru, 41.

Chevrelle, 167.

Chevrette' (grande), 168.

Chevrille, 130.

Cheviotte, 130.

Chevrottine, 130. - écaillcuse, 168.

Chic-t̀-la-bague, 20.

Chogeran, 4.

Cloroson, 20.

Clorosse, 20

Coche, 20 .

Cocherelle, 20.

Colombette, 20.

Commère, 20.

Comparol d'oulmé, 82.

Coquemelle, 6.

Corgne, 78 .

Cormelle, 20

Concoumèle, 12, 13. - blanche, 6. - grisette, 12. - jaune, 12. - orangée, 12. Couderlo, 78.

Coulemèle d'cau, 17

Couleuvrette, 20.

Coulsé, 20.

Courdelou, 36.

Couveuse, 151.

Couvrose, 80 .

Cran, 187.

Cranca, 187.

Crobillo, 130.

Crusagne, 000.

Cul d'ours, 20. - rouge, 124. - de saoumo, 139. - vert, 127 
Darmas, 23.

Dorade, 4.

Dorgne, 4.

Doumergal, 4 .

Eauburon, 111

Enfant du diable, 185.

Envinassa, 89.

Erinace, 167.

Esca, 155 .

Essalon, 136.

Escoubarbe, 36 .

Escraville, 130.

Escrobillo, 130.

Escumelle, 20.

Espignette, 177.

Essau, 130.

Fausse golmelle, 6,17 .

Faux fayssé, 121, 126, 127.

Faux jaseran, 6 .

Faux missie, 6.

Faux mousseron, 63 .

Fayssé, 120.

Foie de bouf, 132.

Frigoule, 39.

Gallinette, 177

Ganteline, 175.

Gendarme noir, 133.

Gingoule, 78,

Glu de chêne, 132 .

Golmelle franche, 9. -- de voyen, 20.

Golmotte, 9

Grisette, 12, 20.

Grosse queue, 136.

Gyrandelle, 130,

Gyrole, 130, 143. - rouge, 143.

Hérisson coralloïde, 170.

Houpale, 20.

Houppe des arbres, 171

Impudique, 185.

Irandja, 4.

Iraux-cher, 127.

Jannette, 130

Jaseran, 4.

Jaune d'œuf, 4.

Jaunet, 46.

Jaunelet, 130

Jaunire, 130 .

Jerilia, 130.

Jirbouleta, 130.

Jorilla, 130.

Labyrinthe étrille, 163.

Lactaire doré, 116.

Lamburon, 111.

Langue de bouf, 132. - do châtaignier, 132.
Langon, 149.

Latheron, 111.

Lechocendrés, 130.

Loufa de loup, 214.

Lurchon, 167.

Macaron des prés, 23.

Mainotte, 175,177

Manetas, 175 .

Menotte, 177. - cendrée, 176

Merigoule, 189.

Michotte, 136 .

Miellin, 149.

Miquemot, 136.

Missie, 9 .

Misseron, 29, 89 .

Mitre d'évêque, 193

Morchelon, 189

Morille, 189, 192. - en mitre, 193.

Morton, 114

Mouricaude, 193.

Mourette, 000 .

Mourillon, 189.

Moussaỉrigo, 34.

Moussaïron, 29, 34.

Moussar, 136.

Mousseron, 29, 31, 34, 44, 47. - d'automne, 63. - de Dieppe, 63. - faux, 63. - godaille, 63. — pied dur, 63.

Mouton, 167. - zoné, 114.

Mujalo, 4. - folo, 6

Nissoulous, 136.

Nouret, 80 .

Obson, 141.

Opson, 141.

Oburon, 000 .

Oronge (fausse), 6, - (vraie), 4.

Oreille, 44. - de chardon, 78. - de Judas, 184, - de lièvre, 193, - de Malchus, 149. - de nouret, 80. d'orme, 82, 149.

Oreillette. $36,44,78$.

Ounégal, 4.

Palombette, 31.

Palomet, 31, 127.

Panichaon, 78 .

Panse de vache, 151.

Parasol, 20.

Paturon, 20, 89. - blanc, 88

Peigne de loup, 163.

Penchenilla, 167.

Penchinilia, 171

Pezize noire, 209.

Piboulade, 24, 42.

Pied de coq, 175. - de mouton blane, 167. - de mouton noir, 152.

Pinédo, 37.

Pisseloup, 215. 
l'ivoulade, 24. - l'comse, 39, 42. - Sinsa, 155.

de saule, 24, 85 .

Poivré, 111.

l'olumais, 136 .

Purchin, 1:3t.

Putiron, 88, 89, 136.

Poucherillo, 166 .

Poule, 177. - de bois, 80, 151.

Pradélos, 89.

Prourse, 136

Quiche, 44.

Quiuinal d'azé, 106.

Rabassa, 221.

Raffoult, 113, 114.

Ragoule, 78.

Rignoche, 167.

lingoule, 78 .

Rouge, 124.

Rougetto, 89,120

Rougillon, 110 .

Roumanel, 4 .

Roussette, 130.

Roussille, 134.

Roussillous, 117

Roussonne, 130 .

Rouzillon, 110.

Saint-Martino, 20.

Satyre, 185

Saussiron, 89.

Sauzénado, 22, 24, 42.

sécadon, fis.
Sorcier, 145

fouquarel, 22.

Tathyoun, 111 .

Terfâs, 224.

Terfez, 224.

Tirfâzen, 224.

Tournebous, 130.

'Tremoulen, 143.

Tremoulo, 143.

Tripette, 175.

Truffe, 221. - fouine (grande), 223.fouine (petite), 223. - grise, 222. d'hiver, 221. - noire, 221. - du Périgord, 222. - de la Saint-Jean, 221. - samarquo, 223. - violette, 222.

Truffo, 221.

Tue-mouches, 6.

Ursin, $\_67$

Vache JIanche, 111. - ronge, 110, 113.

Vachotte, 116.

Vélo, 116 .

Vert, 127.

Vert bonnet, 127.

Vert bouteille, 122.

Vesseloup des bouviers, 215. - citronille, 215. - hérissée, 214.

Viau, 116.

Videau, 46.

Vinois, 89. 


\section{TABLE DES 60 CHRONOLITHOGRAPHIES.}

I. - Agaricus cæsareus.

II. - Agaricus muscarius.

III. - Agaricus Mappa. - Agaricus pantherinus.

IV. - Agaricus phalloides.

V. - Agaricus vaginatus. - Agaricus vaginatus, ver. lividus.

VI. - Agaricus speciosus. - Agaricus parvulus.

VII. - Agaricus colubrinus.

VIII. - Agaricus melleus.

IX. - Agaricus albellus. - Agaricus graveolens.

$\mathrm{X}$. - Agaricus fusipes.

XI. - Agaricus eburneus. - Agaricus virgineus.

XII. - Agaricus Orcella. - Agaricus Prunulus.

XIII. - Agaricus crustuliniformis. - Agaricus rimosus.

XIV. - Agaricus seorodonius. - Agarieus peronatus. - Agaricus vreades.

XV. - Agaricus Catinus. - Agaricus fragrans.

XVI. - Agaricus tigrinus.

XVII. - Agaricus involutus.

XVIII. - Agaricus tessulatus. - Agaricus ulmarius.

XIX. - Agaricus conchatus. - Agaricus stypticus.

XX. - Agaricus campestris. - Agaricus arvensis.

XXI. - Agaricus præstans.

XXII. - Agaricus violaceus. - Agaricus armillatus.

XXIII. - Agaricus viscidus.

XXIV. - Agarieus atramentarius.

XXV. - Agaricus deliciosus. - Agaricus plumbeus.

XXVI. - Agaricus subdulcis. - Agaricus volemus.

XXVII. - Agaricus torminosus. - Agaricus theiogalus.

XXVIII. - Agaricus piperatus. - Agaricus vellereus.

XXIX. - Agaricus lepidus. - Agaricus alutaceus.

XXX. - Agaricus cyanoxanthus.

XXXI. - Agaricus vireseens.

XXXII. - Cantharellus cibarius. - Cantharellus aurantiacus.

XXXIII. - Fistulina hepatica.

XXXXV. - Boletus edulis.

XXXV. - Boletus granulatus. - Boletus luteus.

XXXVI. - Boletus luridus. - Boletus Satanas.

XXXVII. - Boletus scaber. - Boletus aurantiacus.

XXXVIII. - Boletus chrysenteron. - Boletus subtomentosus.

XXXIX. - Polyporus frondosus. - Polyporus sulfureus.

$\mathrm{XL}$. - Polyporus fomentarius.

XLI. - Polyporus betulinus. - Polyporus suaveolens.

XLII. $\rightarrow$ Dædalea quercina. - Merulius lacrymans.

XLIII. - Hydnum repandum. 


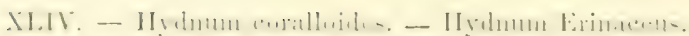

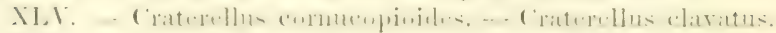

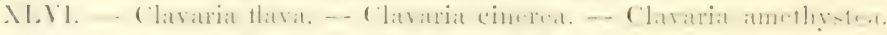

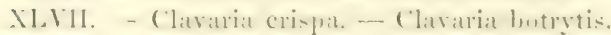

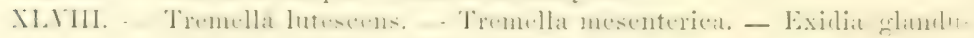
lusat. - Exidia anriculat Judar.

Ml.IX. - I'hallus impruliens.

L. - Clattrus canctliatus.

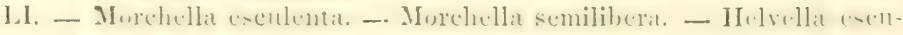
l.nitil.

LII. - Helvella crispa. - Helvella lacunosa. - Helvella clastica.

L.11. - Verpar digitalifirmis. - Lontia hubica.

LIV. - Pezizar acetalunlum. - P'eziza onstica.

LV. - Peziza aurantia. - Peziza vesiculosa. - Bulgaria inquinans.

LVI. - Fraster hygmetricus. - Buvista plumbea.

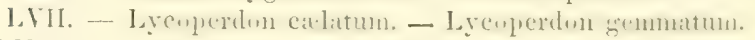

LVIII. - Seleroderma verucosum. - Polysaccum erassipes.

LLX. - Elaphomyces granulatus. - Hymenogaster Klotzschii.

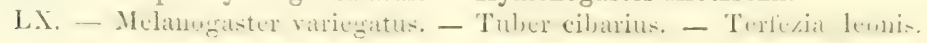




\section{TABLE ALPIIABÉTIQUE.}

Achorion Schonleinii, Remat:.

\section{asaric.}

AGARICLNÉS

$\Lambda$ garicus baceatus, irich.

bicolor, Pers. . . . . . 
Amaricus appendiculatus, bull. applicatus, Jiatiseh.

Iquifulii, I'aul.

arachnostrephus, Letell.

araneosus, Bull.

araneusus violacens, biull.

argentatus, Pers.

arenarius, Latern.

arenatus, l'ers.

armeniacus, Schaeff.

armillatus, $F r$.

armoricanus, Crouan

arvensis, Schaeft:

asper, l'ers.

aspideus, $F_{r}$.

atomatus, $F r$.

atramentaxius, Bull.

atrorufus, Schaeff. .

atrutumentosus, Batsch

attenuatus, $D C$.

augustus, $F$ r..

aurantiacus, Bull.

aurantiacus (Fl. dan.)

aurantius, Schaeff:

auratus, Krombh

auratus, Schaefi.

aureus, Matt.

Auricula, $F r$.

Auricula, Pers.

aurivellus, Batsch

azonites, Bull.

Cacabus, $F r$.

cæprstipes, Som.

casareus, frop.

caligatus, Vivian.

caliginosus, Jungh.

callochrous, Pers.

callosus, Fr. .

calopus, Pers.

campanella, Batsch

campanulatus, Lin.

campestris, Lin.

\section{THEX \\ $1 \mathrm{r}^{\mathrm{c}}$}

110,111

110,11

$43,45,52$

$\left\{\begin{array}{c}43,52,1 \\ 116\end{array}\right.$

camphoratus, Bull.

campylus Otto

camulus, $F_{2}$. ${ }^{\circ} \cdot{ }^{\circ} \cdot{ }^{\circ} \cdot$

candicans, Pers. . . . . . .

Candollianus, $F_{r}$. . . . . . .

caninus, $F r$. . . . . . . . .

capillaris, Schum.

Carcharias, Pers.

Carpini, Fr. . . . . . . . .

castancus, Fr.

castancus, Bull.. . . . . . .

Catinus, $F r$.

caudatus, $F r$.

cepaceus, $F r$.

ceratopus, Pers.

cernuus (Fl, dan.). riagt:

is

")

"

,

",

",

,

")

,

45, 46

")

")

$59,9 \%$

(1)

")

",

$"$

"

$n$

"

"

")

21

1(i)

")

,

")

"

89,93

\begin{tabular}{c} 
TE. \\
\hline 1 \\
\hline 1 \\
77 \\
11 \\
10 \\
10 \\
10 \\
10
\end{tabular}

100,104

88,93

16,27

108,118

105,107

24,23

21,27

109,119

17,27

4,15

22,27

93,95

109

100,104

101

48,119

69,75
$\mathrm{Xx}$

85

(1)

XXIV

15
77

93

1

$11 !$

31

128

28

$30^{2}$

28

(i)

96

102

68

75

916

118

103

75

94

103

66

27

80

XV

XXII

$\mathrm{XX}$$$
\text { I }
$$

is

66

95 
TABLE ALPHABÉTIQUE.

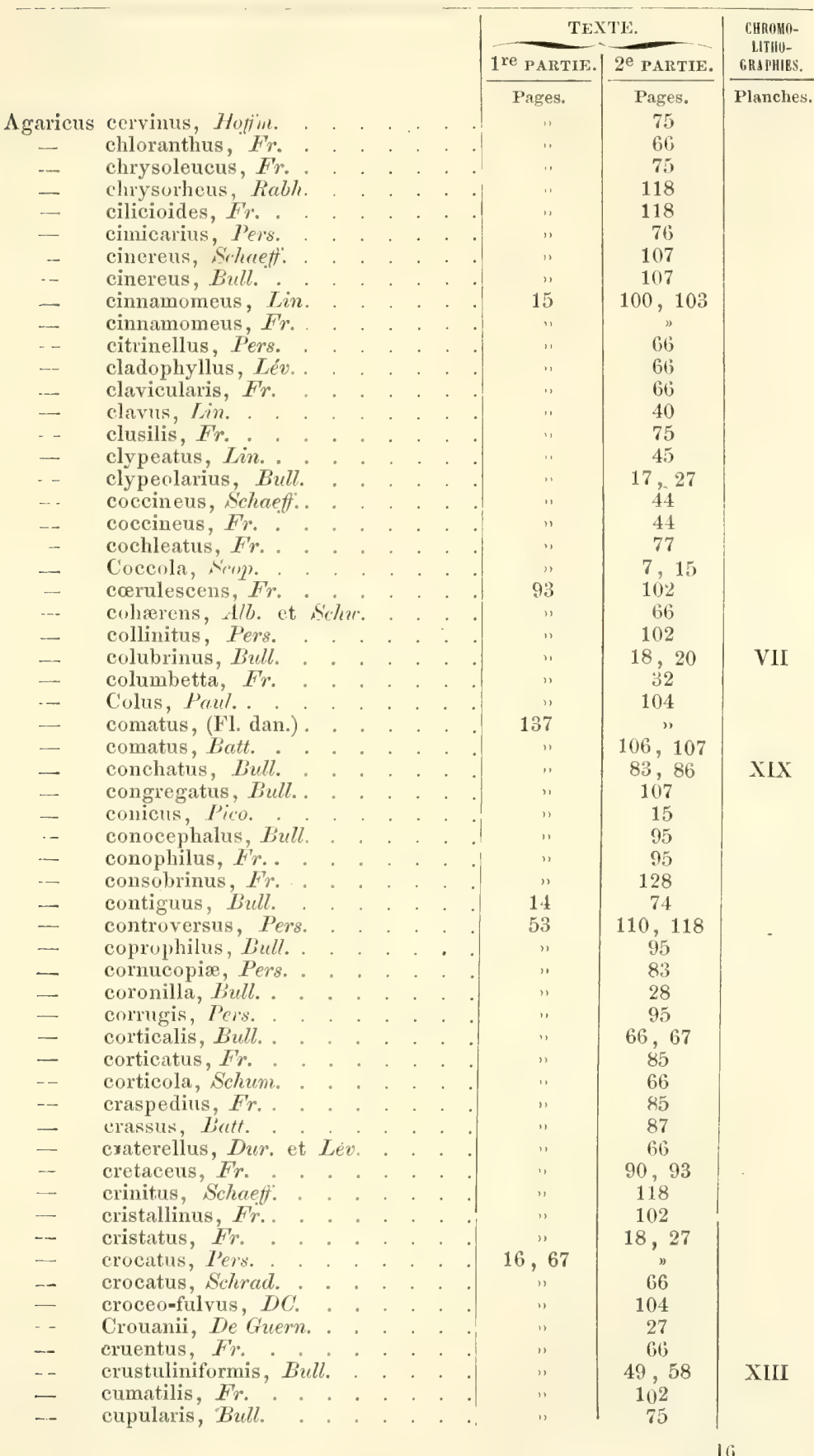


Agaricus cyanescens, Firhx.

cyaneus, Bull.

(rancus, Pers.

cyanites, Secr.

cranites, $F r$.

cyanoxanthus, Pers.

cyanmxanthus, Scleafit.

cyathiformis, Schaefi.

cylindraceus, $F r$.

erphellatormis, Berki.

D)actyli, Croucun.

debilis, bull.

Delastrii, Mont.

deliciosus, Lin. .

deliciusus, Fr.

delicus, Batt.

deliquescens, $F r$.

denigratus, Pers.

depallens, Pers.

depluens, Batsch.

destruens, Brand.

dictyorhizus, $D C$.

digitaliformis, Bull.

digitalis, Batsch.

dilatatus, $F r$.

dimidiatus, Bull.

discopus, Lév.

disseminatus, Pers.

domesticus, Pers.

dryinus, Pers.

dryophilus, Bull.

Dunalii, $D C$.

dyemogalus, Bull.

eburneus, Bull.

eburneus, $F r$.

echinatus, Roth.

echinocephalus, Titfoit.

edulis, Bull.

elatior, Pers.

encticus, Fr.

ephemeroides, Bull.

ephemerus, Bull.

epibryus, Weinn.

epichysium, Pers.

epiphyllus, $F r$.

epipterygius, Scop

epixanthus, Paul. .

ericetorum, Bull.

ermineus, $\mathrm{Fr}$.

Eryngii, $D C$.

erythrocephalus, $D C$.

erythropus, Pers.

esculentus, Jacq.

eumorphus, Pers.

excelsus, $\boldsymbol{F r}$.

excoriatus, $F_{r}$.

expalllens, Pers.

exstinctorius, Paul.

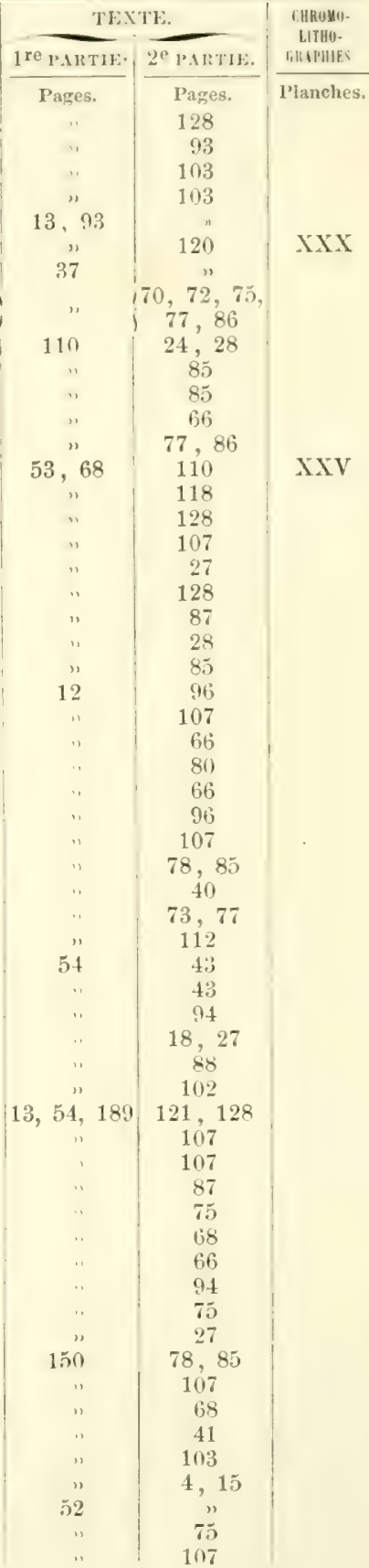




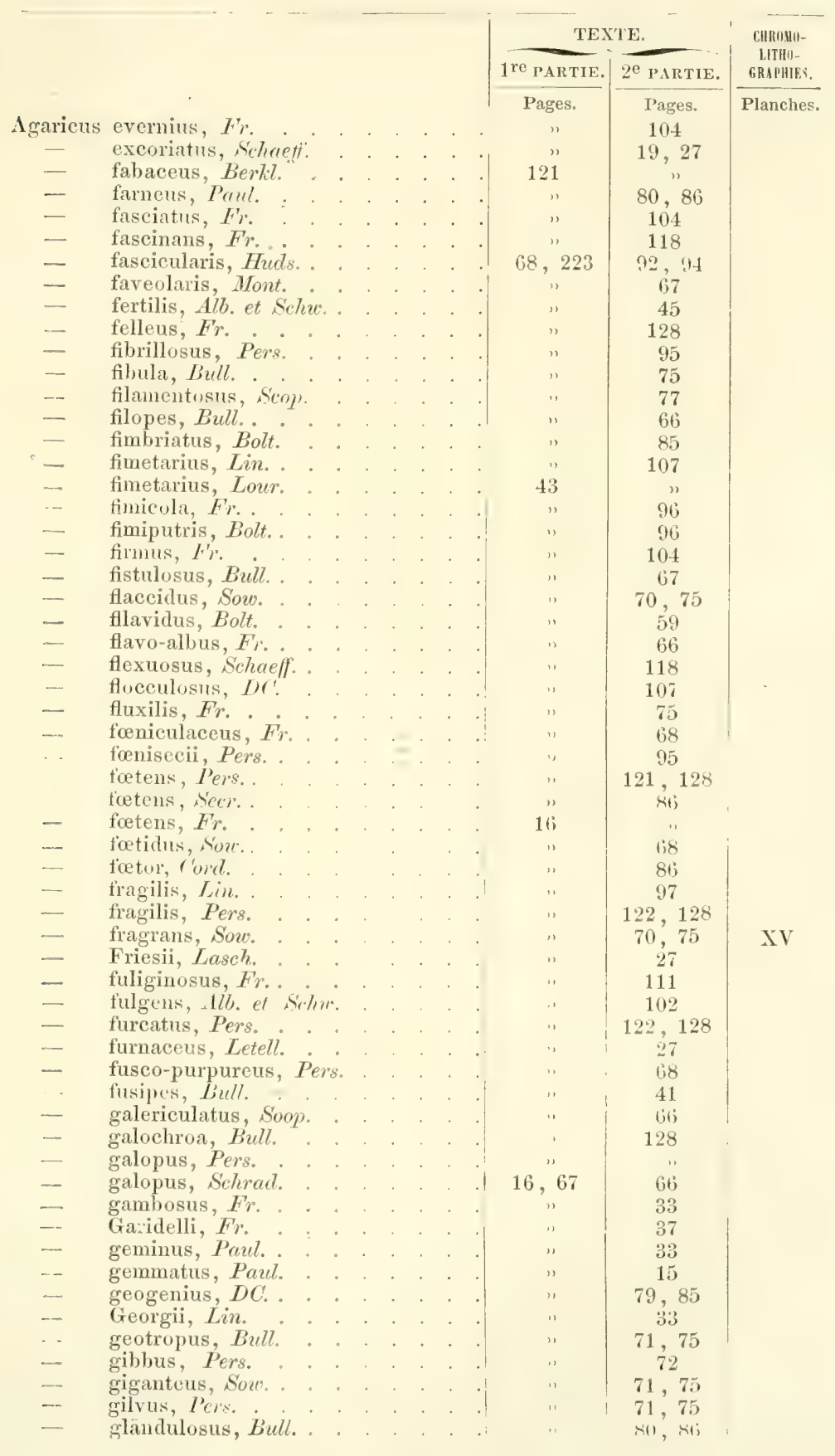


A:-iricus glaueopus, Schaeff. gloiocephalus, $D C$.

- glutinosus, Schaeti.

- glyciosmus, Len\%.

(iimpluts, l't,...

gossypinus, Bull.

iracilis, $1 \%$

gracillimus, Teinn

gramimun, Lil,

grammopodius, Bull.

granulosus, Batsch.

graveolens, Pers.

griseo-fuscus, $D C$.

griscolus, P'er.

griseo-pallidus, Desm.

griscus, Fr.

grmnopodius, Bull.

grisielss, livell.

gyrinus, Bull.

gyroflexus, Paul.

hariolorum, Bull.

hrematocephalus, Jont.

hæmatopus, Pers.

hrmatospermus, Bull.

hedeosmus, Pers.

helvolus, Bull.

helvolus, Pers.

hemitrichus, I'tr.

Hendersonii, Fr.

hepaticus, Batsch.

hercinicus, Pers.

heterophrllus, Fr.

hiascens, $F r$.

himmlens, sor.

humescens, LEU.

Hudsuni, l'is.

hydrogrammus, Bull.

hydrophilus, Bull.

hydrophorus, Bull. .

hyemalis, Osbeck.

- hypnicola, Pers.

ichoratus, Batsch. .

ilenpudins, $F \%$.

iliciuns, $L C$ :

-.. imbricatus, $F r$.

incisus, $F$.

inconstans, Pers.

- infractus, Pters.

- infundibuliformis, Bull.

infundibuliformis, Schaeti.

insillinsts. I, foll.

insititius, Taill.

insulsus, $F r$.

integer, $F r$.

integer, Lin. .

integrellus, Pers.

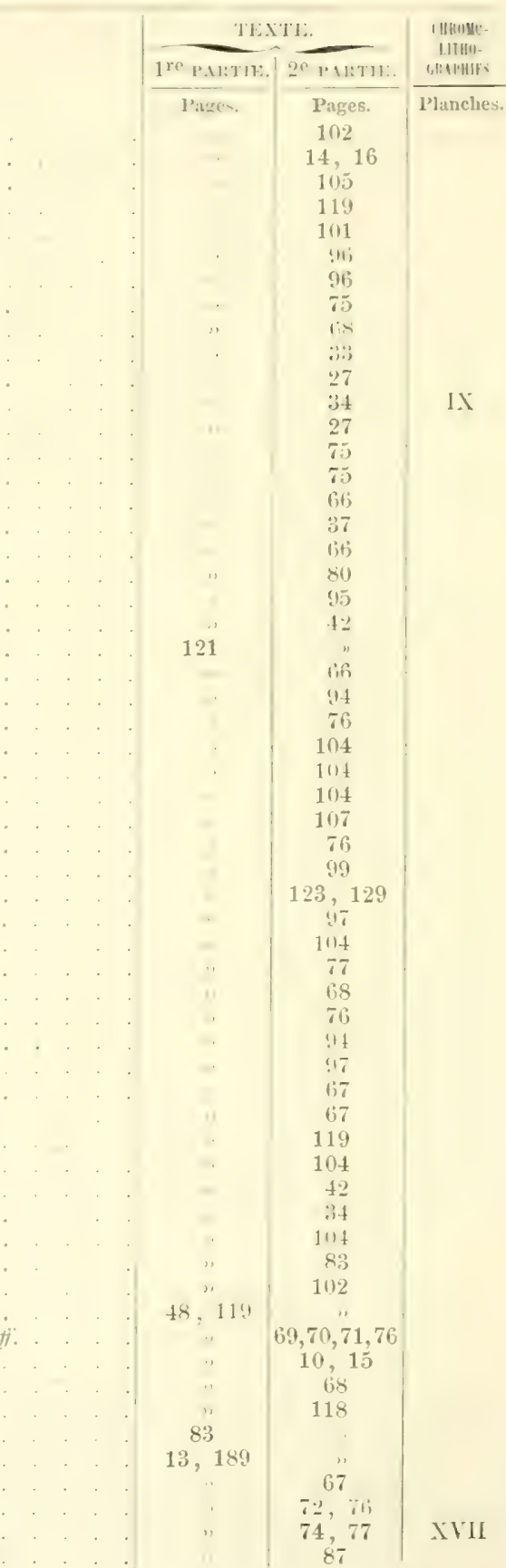

inversus, scop.

- involutus, Batsch.

- jonquilla, Lí et $P^{\prime}($ iul 


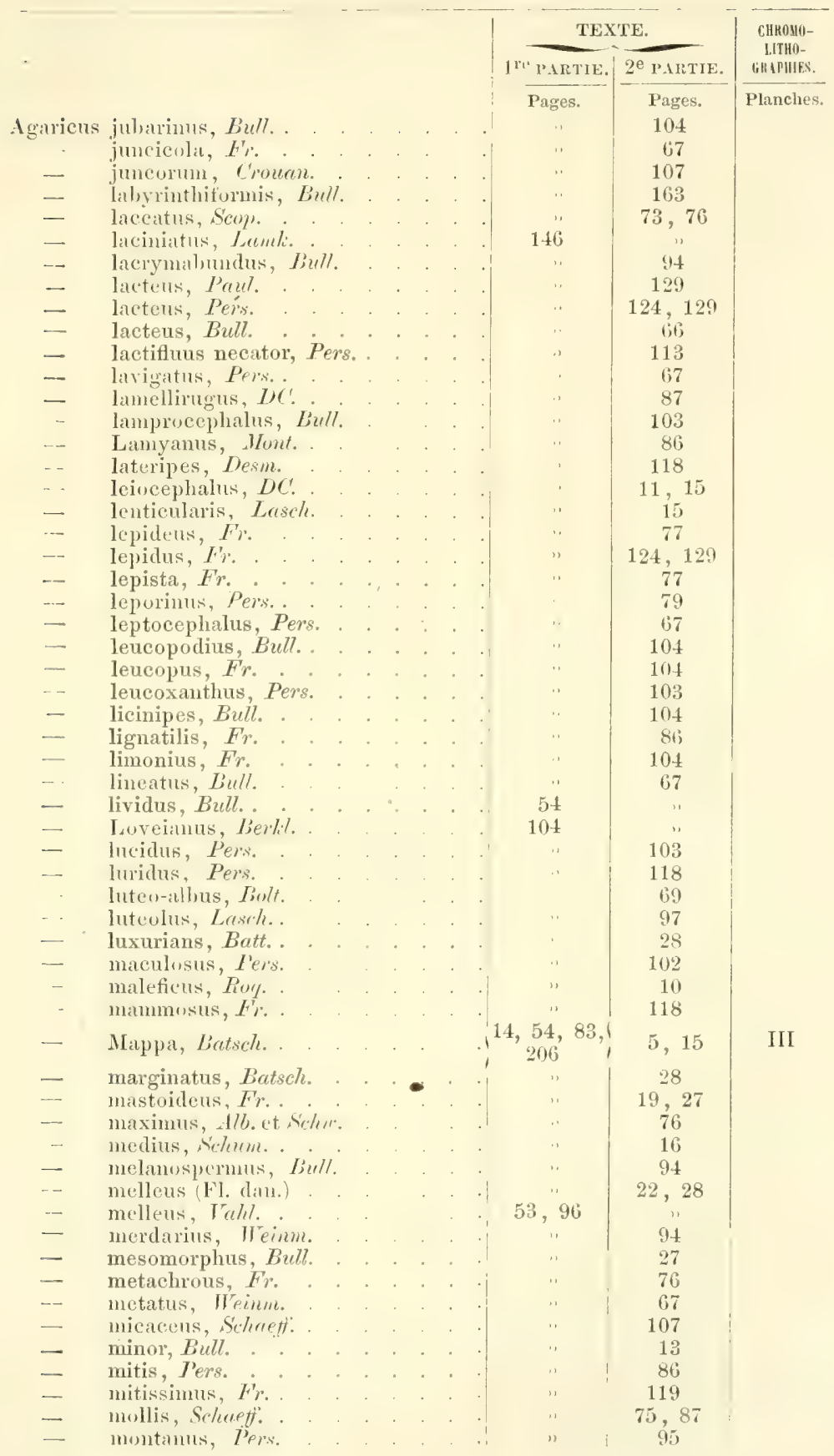


Astrima Mari, liall.

mucidus, Sclirad.

Mucor, Batsch.

mucosus, Bull.

mulleus, $\boldsymbol{F r}$. .

multiformis, $F r$.

muralis, Stearts.

muricatus, $F_{r}$.

murinaceus, Bull.

murinus, Roq.

muscarius, Lin.

mustellinus, Mich.

mustaus, $F \%$.

mutabilis, Schreti.

- mycenoides, $F r$.

- Mimus, limll.

- Nitus, Fr.

- naucinus, $F$ r.

nauseosus, Pers.

neapolitanus, P'ers.

nebularis, Batsch.

necator, Pers.

necator, Bull.

nidulans, F'ers.

niger, schuein.

nigricans, Bull.

nigricans, $F_{r}$.

nitinns, limll.

nitidus, Schaeti.

nitidns. $F_{i}$.

nitidus, Pers.

nitidus (Fl. dan

niveus, Pers.

nóctilucens, Lér.

notatus, Pers.

nudus, Bull.

nyethemerus, $F$ \%

obbatus, Buxb.

oblinaus, Pfis.

obturatus, $F r$.

obtusatus, $F_{r}$.

ochraceus, Startz. .

ochroleucus, $F r$.

ochroleucus, Pers. .

odorus, Pers.

olearius, $D C$.

Oniscus, Fr... .

ophites, Lév. et Paul.

Orcella, Bull.

oreades, Bolt.

orellanus, $F r$.

ostreatus, Jac\%.

ovatus, Schaeff.

ovoides albus, Bull.

ovoideus, $D C$.

pallidus, Pers.

palmatus, Bull.

pantherinus, $D C$ :

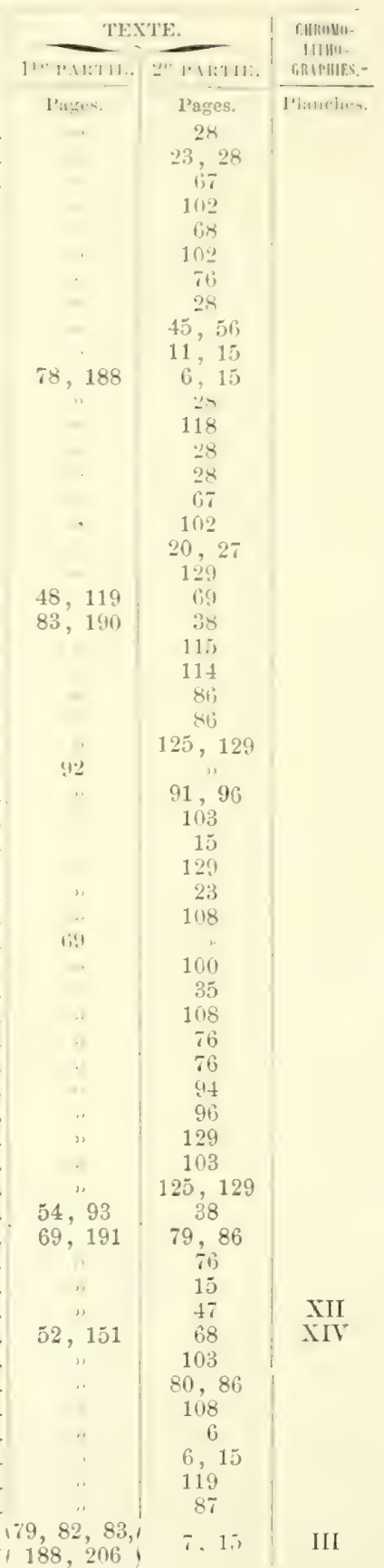




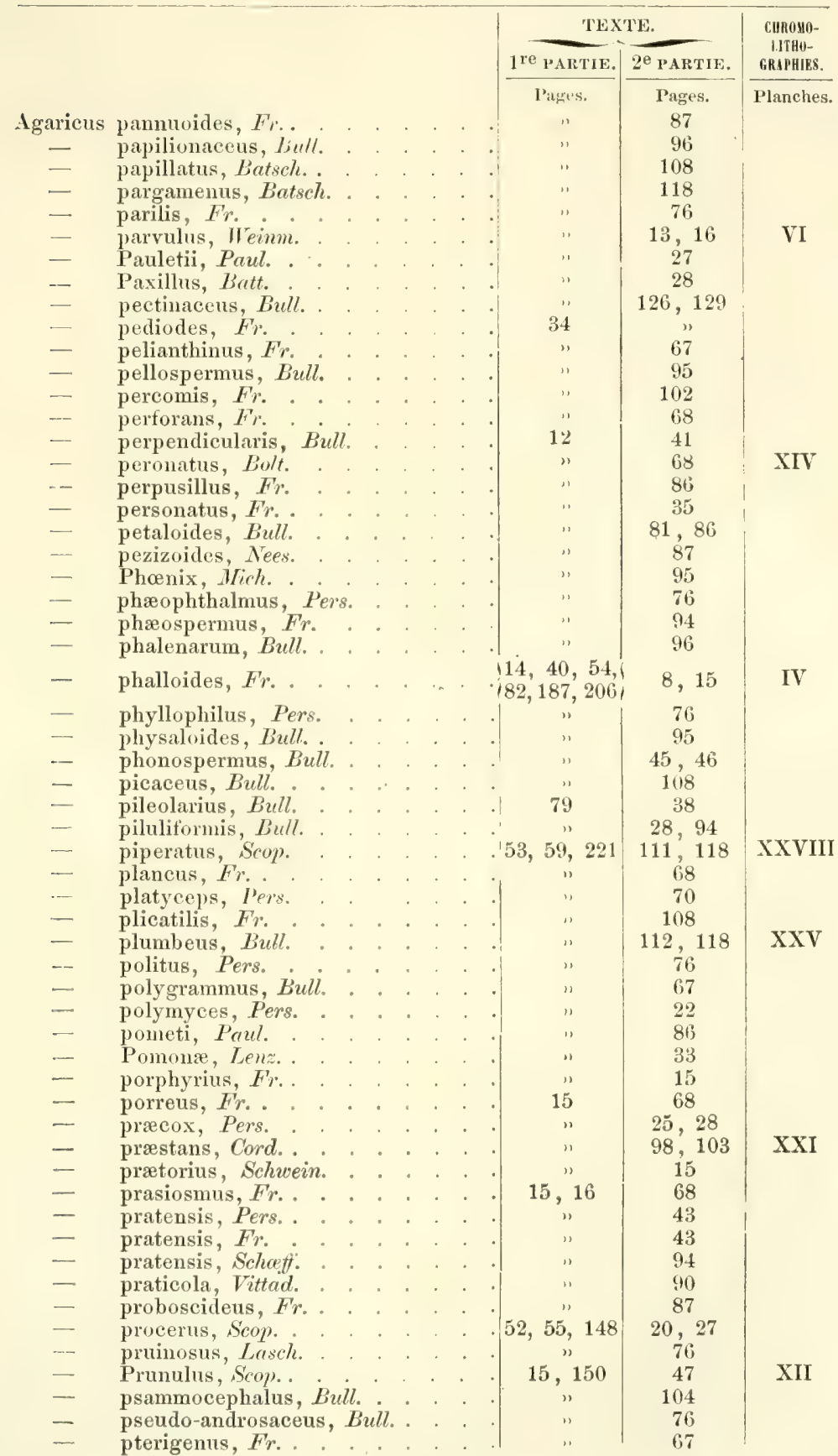


Agaricus pudicus, Bull. pulvemulentus, Bull. pumilus, Bull. pronctatus, l'eis. purpurasens, $F$. purts, Pess. pusillus, Hofime. pyramidalis, Scop. . pivougalus, liull. pyxidatus, Buell. quietus, $F r$. . . racemosus, Pers. radians, Desm. . radiatus, Bolt. radicosus, Bull. raphamides, l'erw ramealis, Bull. . ramentaceus, Bull. ravidus, Bull. recutitus, $F r$. regius, Porta. resimus, $F r$. rachudes, Tittuil. rhagadiosus, $F r$. rhodopolius, $F r$. rimosus, Bull. robustus, Alb. et Schw. rosaceus, $F r$ rosellus, Pers. rotula, scop. ruber, Fr.

rubescens, Pers.

nubro-marrinatus, $F i$.

rugosus, Bull.

Russula, schereti.

rusticus, $F r$. .

saccharinus, Batsch.

sailor, $F r$.

salignus, $F r$. .

salignus, $A l b$.

sanguifluus, Paul.

43

113,119

34
67

54

35

76

69

103

sanguineus, Bull.

sanguineus, Irult. .

sanguinolentus, $A l b$. et Sehro

sareocephalus, $F r$.

81,86

sardonius, Schaeff.

scurudunius, Fi.

scrubiculatus, scrop.

scruposus, Fr.

scyphiformis, $F r$.

scyphoides, $F r$.

semiglobatus, Batsch

separatus, $\operatorname{Lin}$.

septicus, Fr.

serifluus, $D C$.

119

$13,54,189$

127,129

67

103

95

129

129
69
118

118

23,28

76

76

91,94

96

86 
Agaricus serotinus, Schrad. setiger, Paul.

sctipes, $F r$.

silacens, Pers.

sinnatus, $F r$.

soboliferus, Hoffm.

sucialis, $D C$ !

solitarius, Bull. .

spadiceo-griseus, schene it

spadiceus, Schaetf.

spathulatus, Pers.

speciosus, $F r$.

spectabilis, $F r$.

sphagnicola, Berlil.

sphaleromorphus, Bull.

spissus, $F$,

splendens, Pers.

spodoleucus, $F r$.

spodophyllus, Krombh.

squamosus. Pers.

squamosns. Bull.

squamulosus, Pers.

squarrosus, irull

stanneus, Iraill.

stipatus, Per's.

stercorarius, $F r$

stercorarius, Bull.

stercricus, Scop.

stereopus, Pers.

sterquilinus, $F r$.

strangulatus, $F$ r.

streptopus, Pers.

striatulus, $F r$.

striatus, Bull.

strubiliformis, Tittred.

strobilinus. Sow.

stylobates, Pers.

stypticus (Panus), $F r$.

stypticus, Bull.

suaveolens, Schum.

suavis, Pers. . .

subatratus, Batsch.

subduleis, Bull.

subferrugineus, Batseh

sublateritius, Schaeff. .

subnotatus, Pers.

subtilis, F'r.

suffrutescens, Brot.

sulfureus, Bull.

supinus, Lin.

sylvaticus, Schaeff:

sylvicola, Vittad.

tabularis, Pers.

tabularis, $F r$.

tardus, Pers. .

tegularis, Schum

tentatula, Bull.

tergiversans, $F^{\prime} r$.

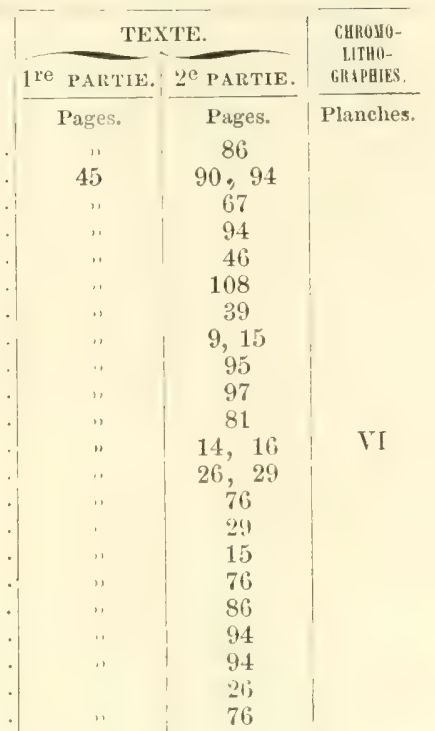

26,29

67

94

94

108

108

76

108

16

76

86

97

10,16

ii7

$(59,68,191$, , 205,224 .

93

119,148

84,86

76

72

97

113,119

104

92,94

108

97

77

36

67

91,94

45

90
33
103
70
95
67
108

XIX

xxYl 


\begin{tabular}{|c|c|c|c|c|c|c|c|}
\hline & & & & & TE: & KTE. & 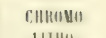 \\
\hline & & & & & fre pAITIF. & 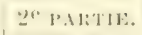 & Golumes. \\
\hline & & & & & liaters. & larges. & P'lane-1e. \\
\hline Istuicus & tessulatus, liull. & & & & $n$ & 82,86 & XVIII \\
\hline- & theiogralus, liull. & . & & . & $5 ! !$ & 114,119 & XIVII \\
\hline - & tigrinus, Bull. . & & & & " & 73,77 & \\
\hline & tintinnalulım, l'uul. & . & . & & .. & तi. & \\
\hline & tithymalimus, Sirop. & & & & . & $11 !$ & \\
\hline- & titulitus, liull. . & & . & . & $\therefore$ & 97 & \\
\hline- & togularis, Bull. . . & . & & . & . & 29 & \\
\hline - & tomentusis, liull. & & & & ," & 1118 & \\
\hline$\ldots$ & torminusus, sirleney. & . & & . & $.53,76,22: 3$ & 114,118 & XXVII \\
\hline - & torquatus, Fr. . & . & & . & . & 69 & \\
\hline 一 & torulosus, Nees. . & & . & . & $"$ & 84,86 & \\
\hline - & torrus, $1 \%$. & . & & . & " & 104 & \\
\hline - & traganus, $F r$. & & & . & " & 103 & \\
\hline- & translnceus, $J)($ : & & & . & .. & 85,87 & \\
\hline - & tremulus, Scleaeti. & & & & ." & Sij & \\
\hline- & trichutis, Pers. . & & & . & ." & 85 & \\
\hline & truncormu, sicherfi. & . & . & & ." & 108 & \\
\hline - & Tuba, Paul. . . & . & & & ." & $\pi i$ & \\
\hline & tumescens, Tiviun. & & & . & " & 91 & \\
\hline & tubrrusus, bull. & . & . & & 15 & " & \\
\hline & turbinatus, Bull. & . & . & . & " & 98,102 & \\
\hline - & turpis, Weinm. & . & . & . & " & 115,118 & \\
\hline & typhoides, limll. & & . & . & . & 106 & \\
\hline- & diliginosus, liertil. & & . & . & . & 103 & \\
\hline$\cdots$ & "lmarins, bull. . & & & . & 44 & 82,86 & XVIII \\
\hline$\rightarrow$ & umbellatus, $F r .$. & . & . & . & " & 74 & \\
\hline - & umbelliferus, Jin. & & . . & . & . & $7 i$ & \\
\hline - & umbilicatus, liull. & & & & . & 75 & \\
\hline -.. & umbilicatus, schaeji. & & & & . & 76 & \\
\hline - & umbratilis, Fr. & & . & . & . & 76 & \\
\hline - & umbrinus, Pers. & & . & . & .. & 118 & \\
\hline- & unguicularis, $F r$. & & & & " & $86 j$ & \\
\hline- & urens, Bull. . & & . & . & 52 & 65,69 & \\
\hline & uvidus, Fr. . & & & . & $"$ & 119 & \\
\hline - & udus, Pers. . & & & . & " & (4) & \\
\hline - & vatginatus, bull. & . & & . & .. & 12,16 & \\
\hline - & Vaillantii, $F r$. & & & & .. & 69 & \\
\hline- & validus, Bertil. . & & & . & .. & 16 & \\
\hline$\cdots$ & vaporarius, Kromisi. & . & . . & . & 45 & " & \\
\hline - & vaporarius, Otto. . & & . & . & $n$ & 90 & \\
\hline - & variabilis, Pers. . . & & . & . & , & 87 & \\
\hline - & variegatus, Pers. & & . & . & $" 1$ & 67 & \\
\hline - & varius, Schoeff. . . & & . & . & $n$ & 102 & \\
\hline - & vellereus, $\dot{F} r$. & . & . & . & 190 & 115,118 & \\
\hline - & velutinus, Pers. . & & . & . & " & 95 & \\
\hline - & ventosus, $F r$. & . & . & . & " & 77 & \\
\hline - & vernus, Bull. . & & . & . & " & 8,16 & \\
\hline 一 & verrucosus, Bull. & & . & . & " & 9 & \\
\hline - & veternosus, $F r$. & & & . & $"$ & 129 & \\
\hline - & viberinus, Fr. . & & & . & $"$ & 77 & \\
\hline - & vibratilis, Fr. & & . & . & $"$ & 103 & \\
\hline - & villaticus, Brond. & & . & . & 45 & 90 & \\
\hline - & viulacen-cinereus, f'e & & & . & $"$ & 99 & \\
\hline- & viulacen-fulvus, Lat & she. & & & " & 87 & \\
\hline - & violaceo-lamellatus, & I) : & . & & " & 94 & \\
\hline - & violaceus, Lin.. & & . & . & $"$ & 99 & XXII \\
\hline - & viperinus, $F r_{.}$. & & . & . & , & 15 & \\
\hline 一 & virescens, Schaetf. & & . & . & 54,115 & 127,129 & XXXI \\
\hline- & virescens Fl. diall.). & & & & " & & \\
\hline
\end{tabular}


Agaricus virgineus, $l r$.

virgineus, Jarr.
- viridis, Paul.
virosus, Paul. .
viscidus, Lin..
vitellinus, Pers.
vitilis, Fr. Moret.
Vittadini, Mr.
- volemus, Fr.
- $\quad$ volvaceus, Bull.
- vulgaris, Pers. .
- vulpinus, Fr.
zonarius, Bull.

Amanita.

Amanita alba, Pers.

- ampla, Pers.

- citrina, Pers.

incarnata, Pers.

- pusilla, Pers.

- umbrina, Pers.

- venenosa Pers.

- virgata, Pers.

\section{Armillaria}

Ascobolus papillatus, Walle.

Aspergillus flavus, Wied. nigricans, $\Pi_{\text {ied }}$

Auricularia papyrina, Bull. Sambuci, Pers.

Adricularinés.

Basidosporís.

Biatora campestris.

\section{Eolbitius.}

Eolet

BolétuÏLES

Boletus æreus, Bull. .

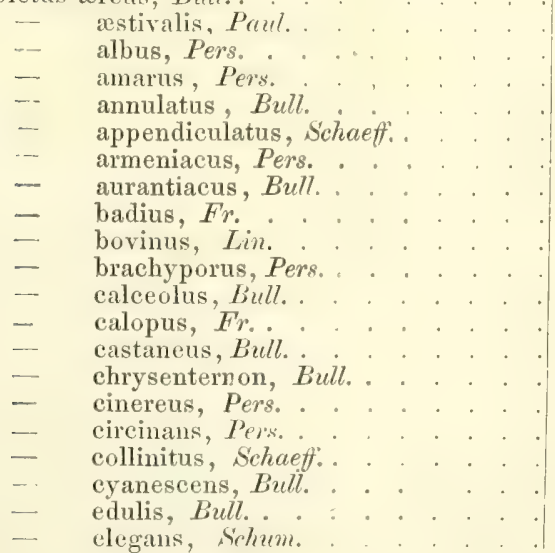

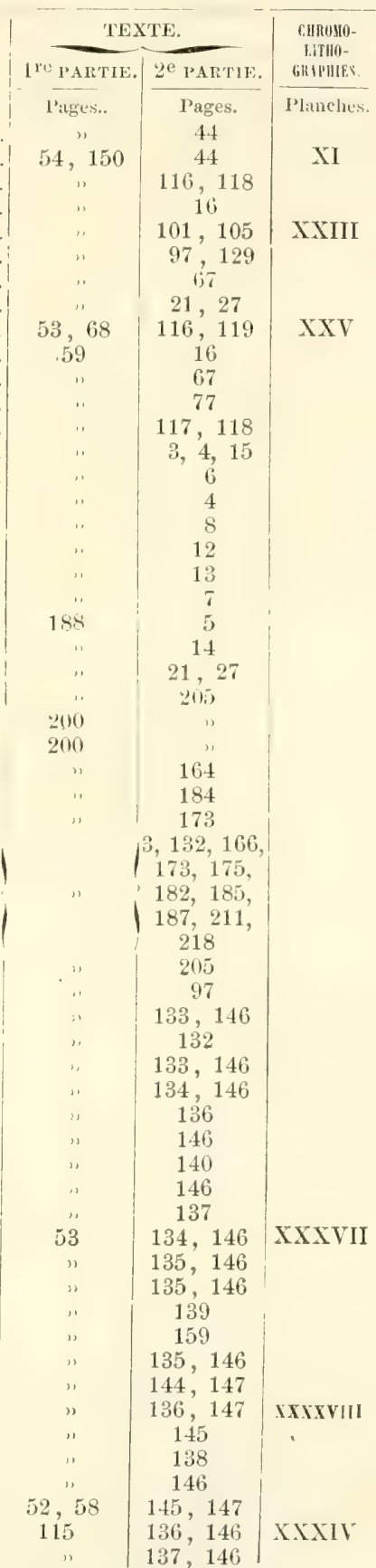




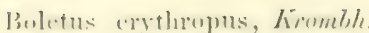
revthupus, I'te. li.iluns, lieill.

flavidus, $F_{i}$.

flavus, Bolt

flavus, With.

Hoceopris, Halli:

fragrans, Tittad.

- fuligineus (Fl. diul.)

- fulvidus, Fr. .

- gossypinus, Pers.

- granulatus, Lin.

- impolitus, Krombli.

- Juglandis, Bull.

- lacteus, Lév.

- Laricis, Bull.

- leoninus, Pers.

lenenplians, Ifrix

- lividus, Bull.

- lividus, $r \%$

- lupinus, $F r$.

- luridus, Schaft.

luteus, Lin

marmureus, lioy

melampus, Rostl:

mitis, Pers.

mitis, Krombl.

- moschocaryanus, Rumph.

nummularius, Bull. .

- (1)sonium, P'aul.

- motusus, IJC. pachypus, $F r$.

parasiticus, Bull.

piperatus, Bull.

polyportss, Bull

porphyrosporus, $F r$.

- pruinatus, Bull.

purpureus, $F r$.

radicalls, limll.

radicans, Pers.

ruhenlirius, Bull.

mufic, I'eris.

motest: Fr.

saguarius, Rumple.

sanguineus, With.

salicinus, Bull.

Satanas, Fr.

scaber, $\mathrm{Fr}$.

spadiceus, schaeti.

sphærocephalus, Barld

strubilaceus, siou.

suaveolens, Bull.

subtomentosus, Lin.

terreus, Schaeff. .

- testaceus, Pers.

tuberosus, Bull.

variegatus, $F_{2}$.

velatus, Pers.

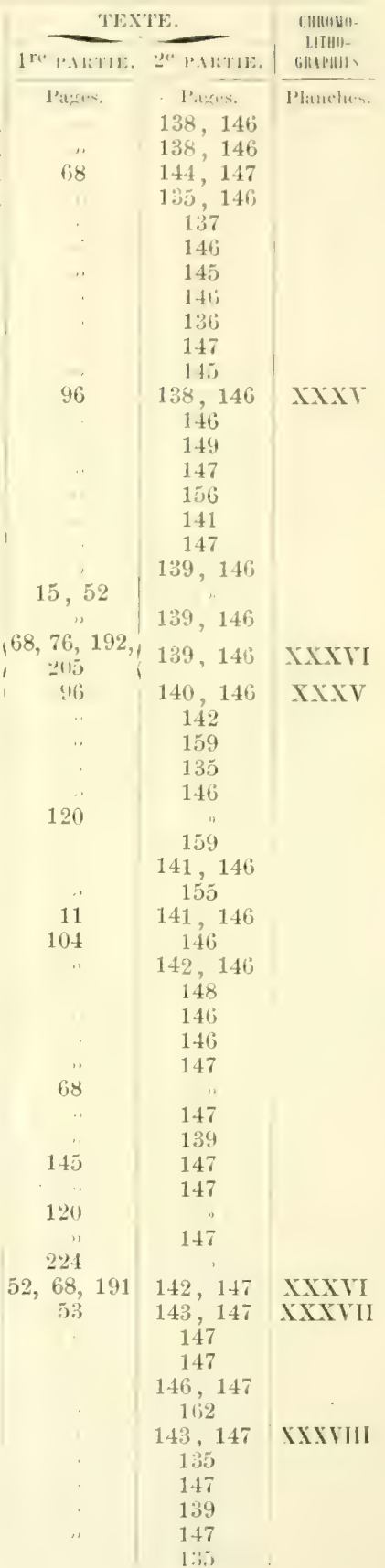


Boletus versipellis, $F r$. viscidus, $\operatorname{Lin}$.

- viscosus, Pers

Botrytis bassiana, Bals.

Bovista ammophila, Lér.

- gigantea, Nees. nigresecus, Pers.

- paludosa, Lév.

- plumbea, Pers.

buviste

suberosa, Fr.

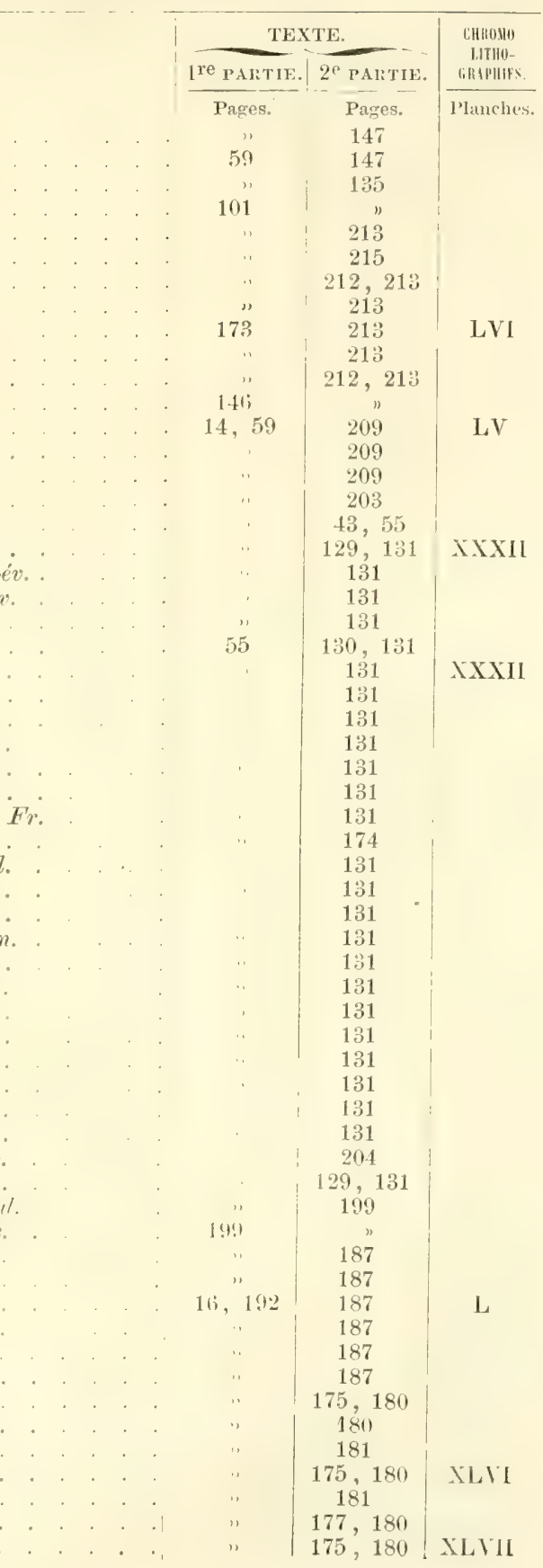

Cenangium hypodermium, Dub.

\section{Chanterelle.}

Chlorosporium æruginosum, Tul.

Cladosporium herbarum, Link.

C'lathracés.

Clathre.

Clathrus cancellatus, $\operatorname{Lin}$.

- hirudinaceus, Tul.

ruber, Pers. .

Clavaire

volvaceus, Buil 
Clavaria byssiseda, Per:

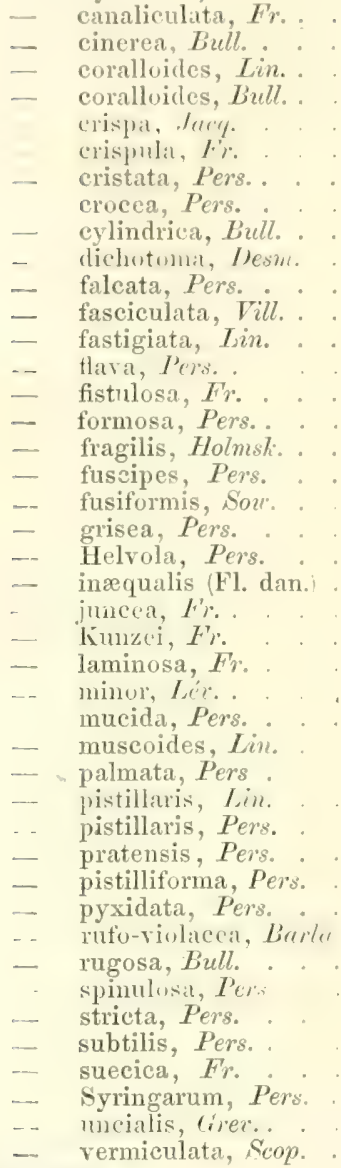

('LATILIÉ

\section{Clitocybe \\ collybia \\ coprin. \\ Coprinaire \\ Coprinarius: \\ coprinus}

Coprinus atramentarius, Bull, comatus, $F r$.

fucescens, $F r$.

Cordiceps entoaurriza, $F_{\gamma}$. militaris, Lint.

\begin{tabular}{|c|c|c|}
\hline \multicolumn{2}{|c|}{ TEXTY: } & \multirow{2}{*}{ 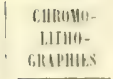 } \\
\hline 1PR.MITH. & :" PARTHA. & \\
\hline l'ages. & P'it:s.s. & I'lanches. \\
\hline " & 180 & \\
\hline$"$ & $1 \leqslant 1$ & \\
\hline$\cdots$ & 176,1811 & XKVI \\
\hline$\cdot$ & 176,180 & \\
\hline & & \\
\hline & 179,181 & Xlatil \\
\hline$\ldots$ & $1 \leqslant 1$ & \\
\hline 333 & $\begin{array}{l}180 \\
180\end{array}$ & \\
\hline 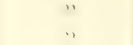 & $\begin{array}{l}180 \\
181\end{array}$ & \\
\hline ." & 181 & \\
\hline & 181 & \\
\hline$"$ & 181 & \\
\hline 34 & 176,180 & \\
\hline$"$ & 177,180 & XLVI \\
\hline " & 181 & \\
\hline$"$ & 178,180 & \\
\hline - & 181 & \\
\hline & 181 & \\
\hline & 178,180 & \\
\hline & 181 & \\
\hline & 181 & \\
\hline & 181 & \\
\hline ". & 180 & \\
\hline " & 179,181 & \\
\hline " & 181 & \\
\hline$\cdots$ & 181 & \\
\hline 93 & 180 & \\
\hline & $\begin{array}{c}180 \\
179,181\end{array}$ & \\
\hline & 181 & \\
\hline & 176 & \\
\hline$"$ & 179,181 & \\
\hline$\therefore$ & 180 & \\
\hline ". & 178,180 & \\
\hline & 180 & \\
\hline . & $\begin{array}{l}180 \\
181\end{array}$ & \\
\hline & 180 & \\
\hline & 181 & \\
\hline & 180 & \\
\hline & 181 & \\
\hline " & 178,181 & \\
\hline & 175 & \\
\hline ' & 36,52 & \\
\hline & 47,57 & \\
\hline & 40,53 & \\
\hline ,. & 105 & \\
\hline ,. & 96 & \\
\hline . & 105,107 & \\
\hline ". & 105 & \\
\hline ") & 106 & \\
\hline$"$ & 106,107 & \\
\hline $\begin{array}{l}102 \\
102\end{array}$ & $n$ & \\
\hline & $97,102,103$ & \\
\hline & 1014 & \\
\hline
\end{tabular}




\section{Cortinariws.}

Cortinarius violaceo-cinereus, $\dot{F}_{\gamma}$. violaceus, Fr. .

\section{Craterelle}

Cratarellus clavatus, $F r$.

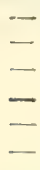
cornucopioides, Pers. crispus, Sou. lutescens, $F r$ melanoxeros, Desm. pistillaris, Schaeff. pusillus, Pers.

\section{Crepidotus} sinuosus, $\mathrm{Fr}$.

\section{cymophallus}

Cyttaria Daywin, $B$ re

Dacrymyees tortus, $F r$.

Dædalea angustata, Sou.

- aurata, Batt.

- cinerea, Batt.

- confragusa, Bolt.

- gibbosa, Pers.

- latissima, Sor.

- lirellosa, Pers.

- plumbea, Lér.

- quercina, $F r$. rubescens, Alb. et sicho.

Dédalée serpens, $F r$.

bermocybe .

Durella compresisal, Tir.

Elaphomyee

Elaphomyces aculeatus, Vittad.

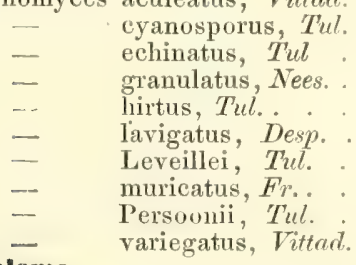

Entolonı

Exidie.

Exidia auricula Judæ, Fr.

- gelatinosa, $D u b$.

- glandulosa, Fr.

- pezizæformis, lér.

- recisa, Fr.

- saccharina Fr.

Fxcipula aspera, $F r$.

Favolus europæus, $F$,

Fistulina buglossoides, Bull.

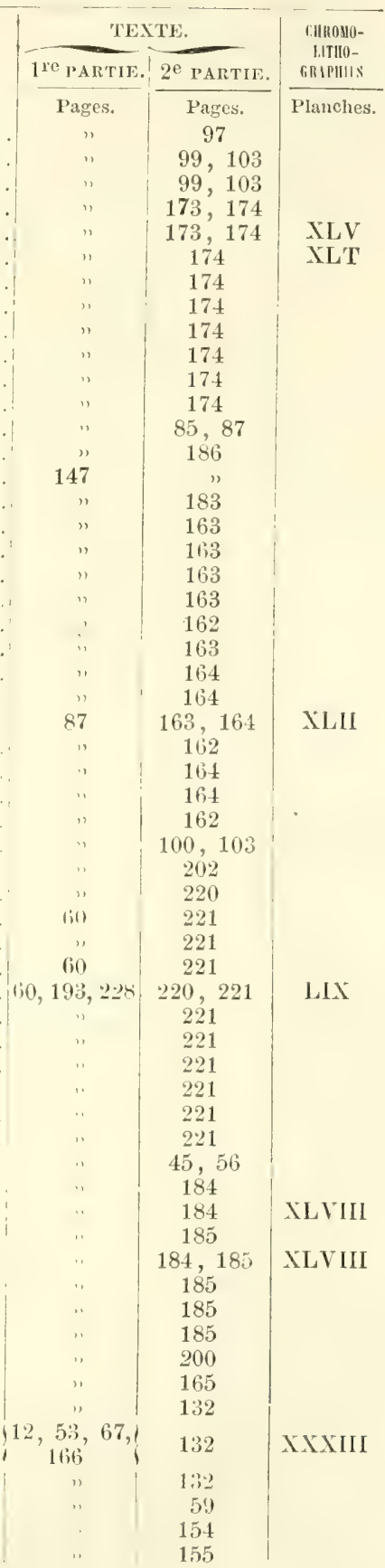

\section{Fistuline.}

Tlammula

Fomes fomentarius, $F_{2}$. igniarius, $F ?$ ? 
Fomes salicinns, fro

\section{fatera}

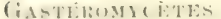

Gasteromycetes badius, Pers. (u) unatus, Pers. duplicatus, Chev. fimbriatus, $7 r$ fornicatus, $F \%$ hrerometricus, l'er: limbatus, $F r$. . mammosus, Fr. multifidus, Finlit.

- rufescens, Fr.

- striatus, $D C$.

- tunicatus, Tittad.

(ieaster badius, Pers.

coronatus, Pers.

duplicatus, Chev.

fimbriatus, $F r$.

fornicatus, $F r$.

hygrometricus, Pers

limbatus, $F_{r}$. . .

mamnusus, $F$

multifidus, Rabh.

xufescens, Fr. .

striatus, $\nu r^{\prime}$

tunicatus, Vitted.

Géantre

Geoglassum hirsutum, Pers.

\section{somphidius}

Gomphidius viscidus, $F r$.

Gomphns truncatus, Pros

\section{Gyninope}

(i)mulu)us

Gyromitra esculenta, Str. .

\section{webeloma}

Ilelotium versiforme, Berkl.

IItlvella anura, Lour. .

brevipes, $D C$.

- crispar, $\mathrm{Fr}$.

- elastica, Buil.

- Ephippium, Lév. .

- esculental, Solurio.

- gelatinosa, Bull.

- grandis, Cumin.

- infula, Schereff.

- lacunosa, Afz.

- leucophra,Pers

- leucopus, Pers.

Mitra, liull.

-. Mitra, Pers.

- Monacella, Fr.

- platroudar Ior

millia, Metmeli.

- sinuosa, Bro

\section{Helvelle.}

$$
\text { sulcata, } A, \%
$$

IIELvelifis

Iericium caput Medusar, Pers.

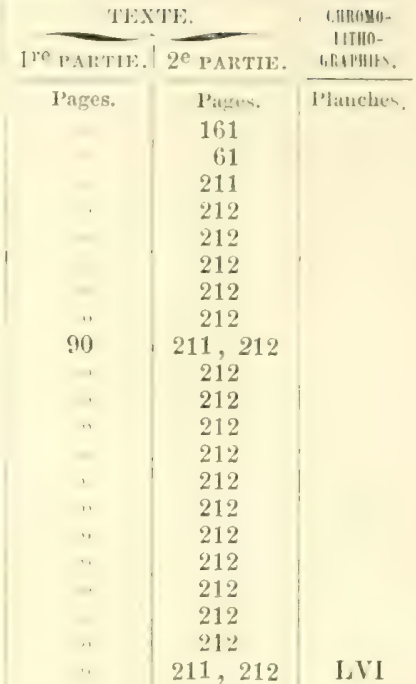

212

212

212

212

212

212

211

1111

101

173

29,50

29

193,194

48,58

208

194

191,194

191,194

194

193,194

195

192,194

192,194

193, 194 191

194

117

LII

LII

LII 
Herieinm coralloides, Scop.

$$
\text { - Erinacens, Perx. }
$$

Hexagona Mori, Ball. .

Himenla amicula Judie, lierlil.

\section{Myalne.}

\section{Hydines}

Itydnum alho-rirens, Iill.

:urantiacum, $A b b$. et sshm.

Anriscalpinu, Lim. .

hadium, Pers.

- Dubalinum, Pers.

eaput Medusæ, Bull. .

cervinum, Pers.

cinerenm, bull.

compactum, Batsch

comnatum, schults.

eoralleides, sirop.

eyathiforme, Bull.

Erinaceus, Bull.

ferrugineum, Krombl.

frisipes, Pers.

cravedens, Jelost.

hybriclum, líll.

imbricatum, $\operatorname{Lin}$

- Infundibulum, Suarts

- Irvigatum, Swart:

leptopus, Pers.

melalencum, $F_{r}$.

nigrum, $F$ '

occidentale, Paul.

parasiticum, Fill.

pusillum, Brot.

ramosum, Bull.

- repandum, Jin.

mufescens, Schreft'.

seabrosum, sicherit.

scrobiculatum, $F$.

scutatum, Pers.

sqamosum, Scherfi.

suaveolens, Pers.

subsquamostum, Batsch.

tomentosum, Lin.

velutinum, ir.

violascens, $A l b$, et Schm.

zonatum, Batsch.

\section{Hygrocybe}

\section{Tily yrophorus}

IIYMFNOMYCETES

Ilymenogaster arenarius, 'I'il.

calosporis, T'tel.

decorus, Tul.

Klotzschii, Tul.

lilacinus, Tul.

luteus, Vittad.

- populetorum, Tul.

tener, Berk.

vnlgaris, Tul.

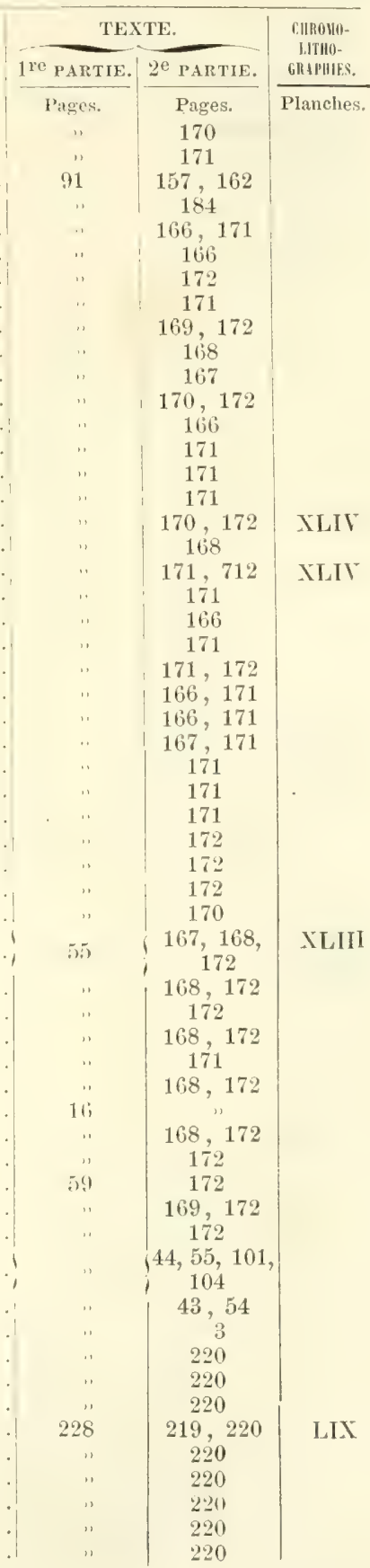




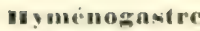

\section{I1 viluoloma.}

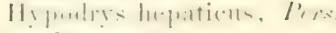

\section{ขัตรо⿴⿻儿口}

\section{vactaire}

\section{quetarius}

Lactarins aspideus, $l \%$. .

- azonites, $F r$.

- (:um)luitus, lint

- contruversus, $F_{7}$.

- deliciosus, $I r$.

- fuliginosus, $F$.

- piperatus, $F r$.

- plumbeus, $F_{r}$.

- rutus, $F r$.

- subdulcis, $F r$.

$\longrightarrow$ theiogalus, $F v$.

- torminosus, $F r^{\circ}$.

- turpis, Fr.

- rellereus, Fr.

- virilis, $1 \%$

- volemus, $F_{r}$..

Lccanora zonarius, $r$.

erina, Ach.

\section{centinus.}

Lentinus suavissimus, $F$

tigrinus, Bull.

Leotia atrovirens, Pers.

riwinans, I'ers.

lubrica, Pers.

platypoda, $F r$.

Détie.

cepiota

I.piote

acetonia.

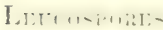

Iimucism

1. venurertur

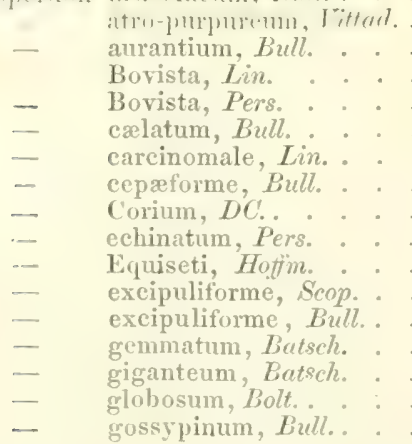

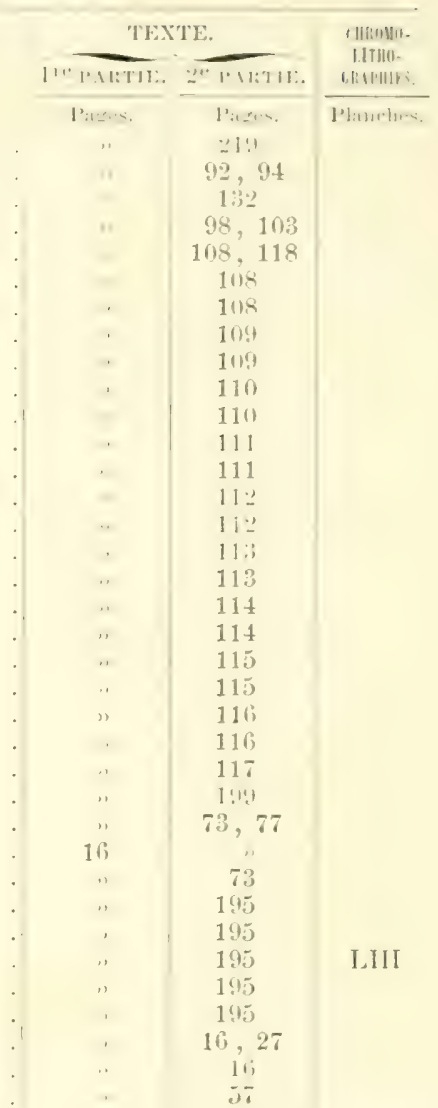

$4,15,16,29$ 161, 69, 77 $83,85,86$, $1+1,1+7$, 164,175 $4:$, it ㄴ1:3

215

217

$21 . i$

$\because 1: ;$

213,215

L. VII

216

217

214

200

214

211

214,215

215

219

.13 
Lycoperdon hiemale, Dur. et Ilont. .

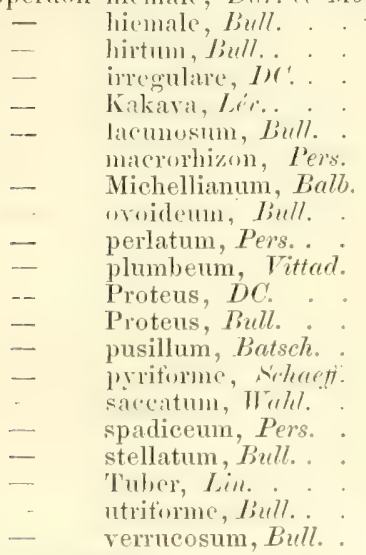

L Y YOPPERDONES

\section{Lasurus Mokusin, (ih}

\section{varasmius}

Marasmins meus

Melanogaster ambiguus, Tul.

$$
\text { - rubescens, Tul. }
$$

Métaruliastérés

\section{Mélumogastre.}

\section{MéLafospores.}

Mentagrophytes, Gisub.

\section{Mérule}

Merulius alveolarius, $D C$.

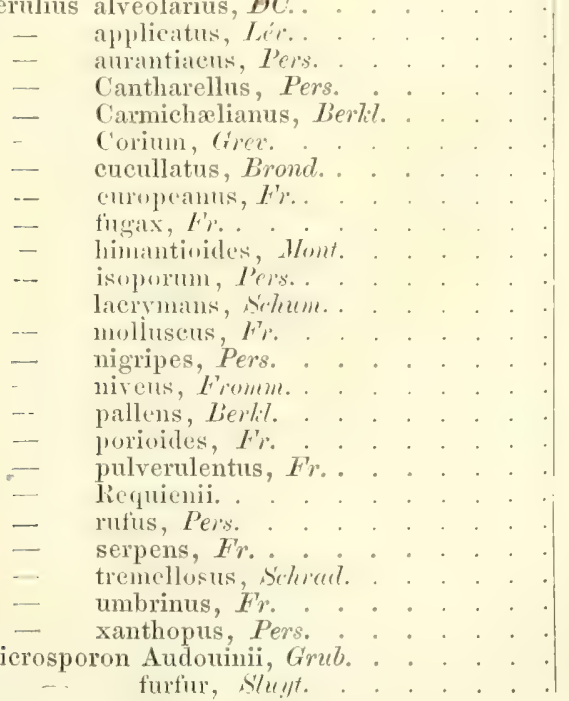

18040-

$\sin 10-2$

RAIIIE:

$$
1 \text { ret }
$$

Pages.

Pages.

Planches.

216

214,216

217

228

216

215

215

216

214

213

214,216

216

216

211 i

216

216

211,212

221

216

216

211

62,68

(ii)

219

219

218,219

218

218

96,105

164

165

165

129

130

$16 \pm$

164

165

165

165

165

165

164,165

165

129

165

165

165

165

165

165

165

165

165

174 


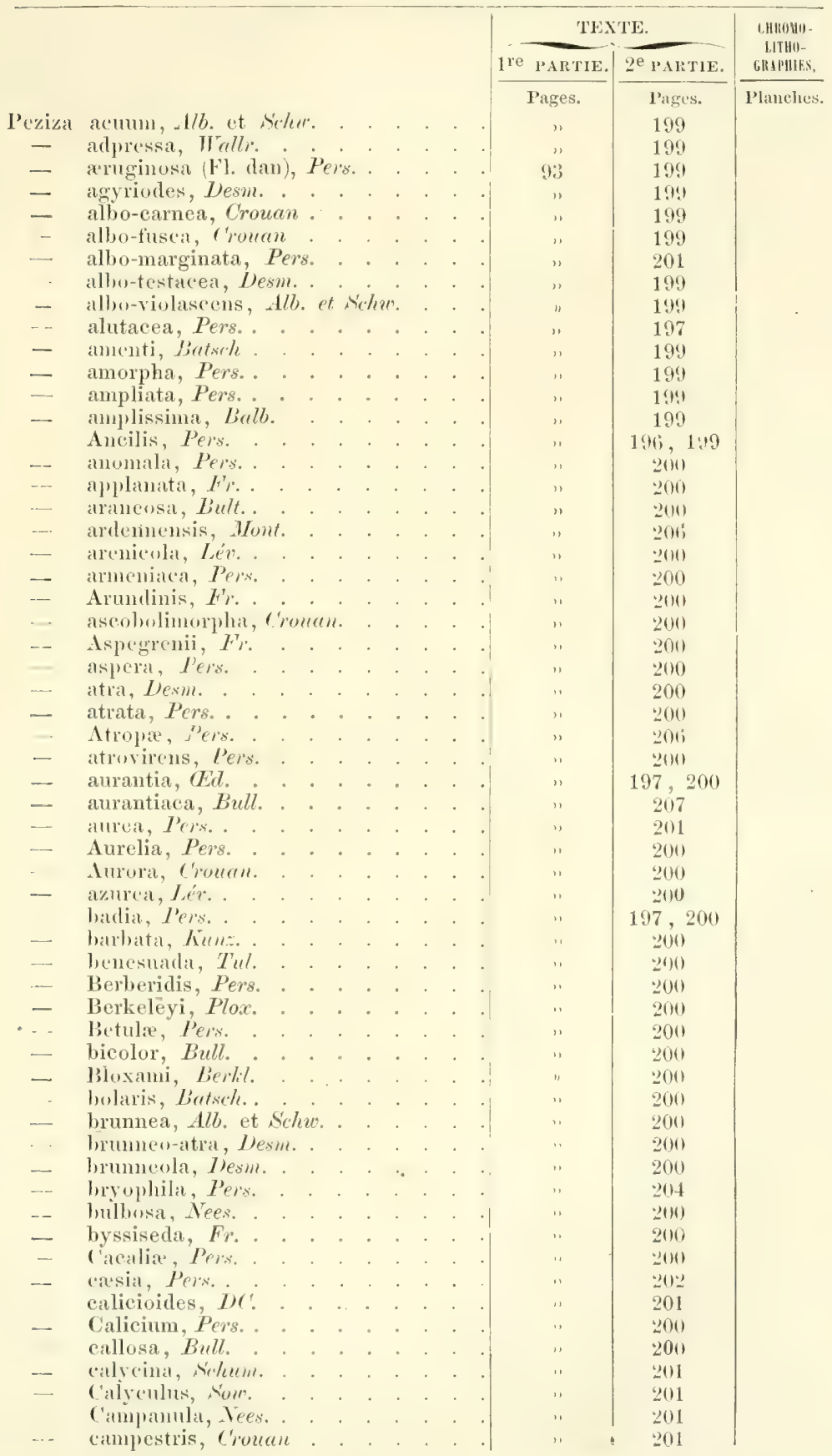




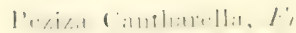

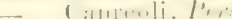

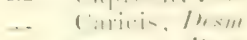

( $, 1111+\cdots 1, \quad / 1, \cdots$

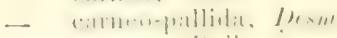

allum-il, liull.

- Carulinx, de Guernissac-Crouan.

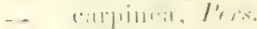

- carpoboloides, frot.

- 1 inlonis, lith

- amlinemlit, $l \%$ :

Critstiollum, $F$

-

- ("rill, I', l.

- Iisitii, Hunt.

- chionea, $F r$.

- chlorima, I's is.

elursuphthalunal, l's is.

ciliaris, sirlenel.

- viliatil, liull.

- cinerella, Crouan

- cinerea, Batsch.

cimnamomea, $D C$.

cirrhata, Crourn.

- citrinil. I't...

ritrillal, sirr.

clabdestina, Bull.

C'lavariarum, Desm.

(1itvittil. I'ris.

coccinea, Bull.

cochleata, Lin.

- corrulea, liult.

- compressa, Pers.

- concinna, Pers.

- confluens, Pers.

- conspersa, Pers.

- cornucopioides, Lin.

(rurusatal, liull.

- Corrullata, Jire\%

- Coronilla, Pers.

- corticalis, Pers.

$\longrightarrow$

- Crec'lqueraulti

- crinita, Bull.

- (rur.ina, Hunt.

- culmicola, Desmo.

- culniprua, F'.

- Cupressi. Batsch.

- cupressina, Pers.

- (-11)ularis, lin.

- Cirmevi, firlil.

- cyathoidea, Bull.

- Dentaria, Chaill.

- dentatit, l're.

- diaphana, l'f-...

- dilutella, $F r$.

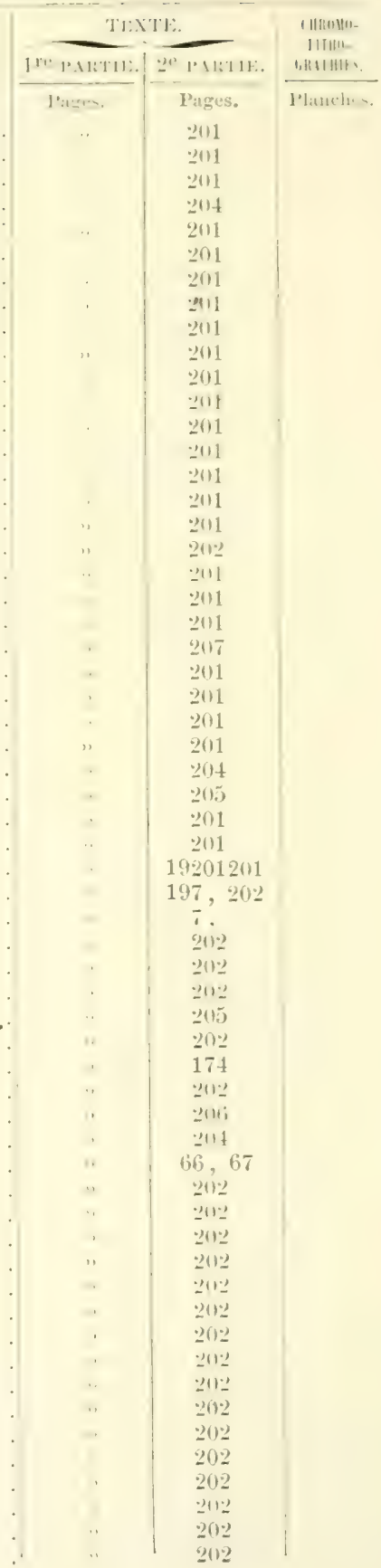


TABLE ALPIABETLCE.

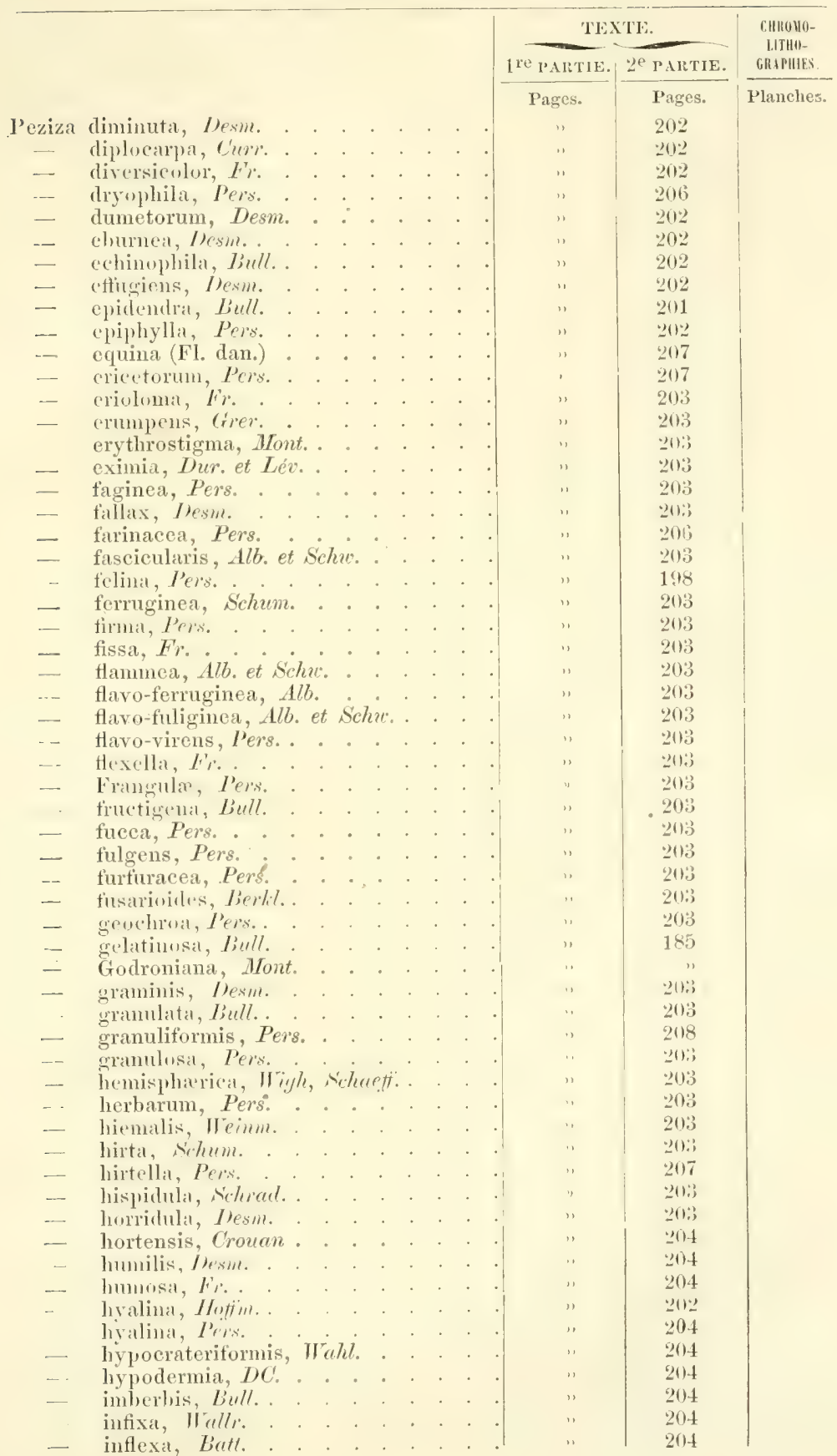




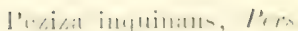

\begin{tabular}{|c|c|c|}
\hline \multicolumn{2}{|c|}{ TE:XTL: } & \multirow{2}{*}{ 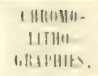 } \\
\hline 1WPARTIE. & $2=1.18 T 11:$ & \\
\hline Pages. & P:a:.... & Platuditen, \\
\hline & 209 & \\
\hline & 2614 & \\
\hline & 2114 & \\
\hline & 204 & \\
\hline & 2644 & \\
\hline & 204 & \\
\hline .. & 20.4 & \\
\hline & :11:; & \\
\hline & 204 & \\
\hline & 204 & \\
\hline & 2118 & \\
\hline. & 204 & \\
\hline & 203 & \\
\hline & 204 & \\
\hline .. & 2114 & \\
\hline & 203,2014 & \\
\hline
\end{tabular}

198,204

204

204

(1). 1

204

(2). 1

901

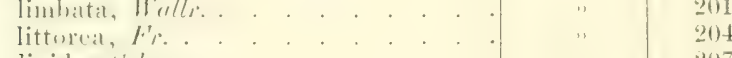

207

- mavida, selltm.

maritima, lexm.

Marsmpium, fers.

198,204

205

205

205

20.5

203

.05

205

20.5

201

205

205

205

205

20.

2115

205

$3(1$.

205

2015

201

201:

$\because 04$

211.

205

205

$-205$

198,20

1.11

mivaleat, Batsitle.

uluticia. Je's.

- baluarm, Itesm.

- pallescens, Pers.

billnstris, lirsm.

205

205

205

205

202,205

- papillaris, liull. 


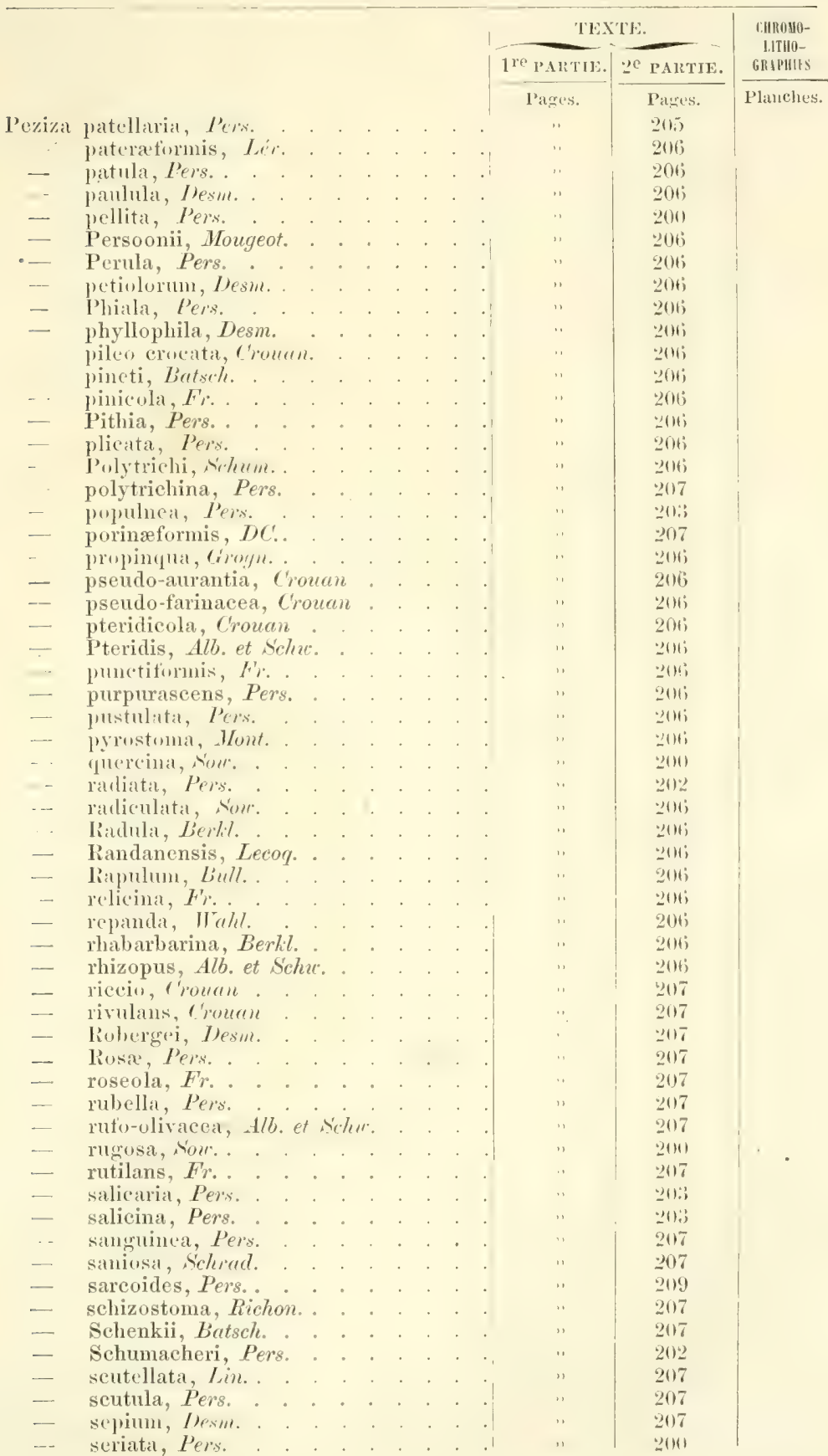


l'eziza serotina, l'ers.

- serratula, Per's.

si.cilis, sum.

st tusal, Jits.

- smaragrlina, Lé

- Suwerbea, Pers.

- Spirea, Hirch

spureata, Pers.
stelenea. I's

stipata, Pers.

- stipitata, Bull.

strittit, $Y$.

- strobilina, $F r$

- sulfinsea, Groum .

subhirsuta, fichum.

subularis, Bull.

subulipes, Pers.

sulcata, Pers.

- sulfurata, $F r$.

- sulfurea, Pers.

- theiochroa, Pers.

- tephrosia, Pers.

testacea, Pers.

tremelluides, liull.

- tricolor, Sow.

Tulua, lialt.

- tuberosa, Bull.

- tumida, Pers.

- tumidula, Desm.

- Elicis, Crouan.

- ulmicola, C'rouan

immlinuatil, l'tes.

- umbrina, Pers. .

- nubrinella, Desm.

Irtice, Pers.

- variacolor, Pers.

- velutina, Desm. .

vinusi, $P$ ' is.

- vemustula, Desm.

- versicolor, Desm.

- vesiculosa, Bull.

- vesiculosa, Pers.

- villosa, Pers.

- vinosa, Alb. et schu.

- violaces, Jers.

- virescens, $A l b$. et Sstur.

- virginea, Batsch.

- vitellina, Pers.

- viticola, Pers.

- vogesiaca, Pers.

- vulgaris, $F_{j}$.

- Wanchi, Grex.

\section{$11 \mathrm{~T} 1 \%$}

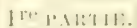

l'a:es.

1.11:111:

I': $:=$

2117

201

2115

2117

닏

2(1)i)

2117

2117

$\because 114 i$

2017

네시

198,2014

2017

2117

2117

2117

$\because 117$

2117

201,207

2417

내

2117

2017

2(11)

209

군, 2115

2018

2115

2018

2018

चा18

चार

208

197

ㄴiा

2117

2118

$13: 4$

2018

2018

2018

2018

-118

199,208

$17 !$

2)

2019

2018

2118

2415

2118

$2(18$

211.1

2)(1.

2(1)

패

196,199

196

185

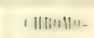

I.ITHII.

1.1611.113

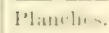

Pézize

I'I:BHE-

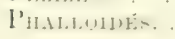




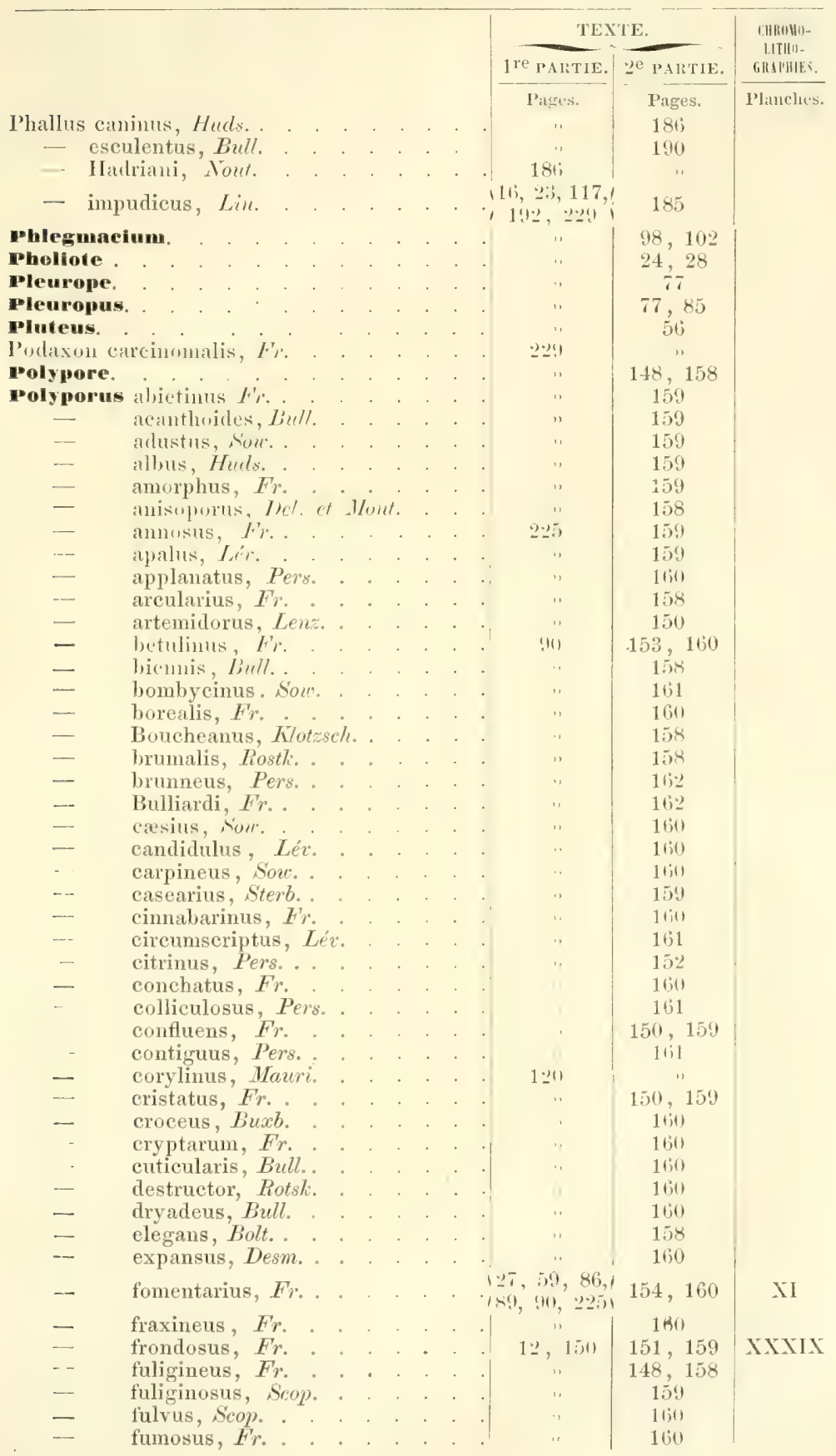


polyporus fissu-cillatlls, l'ris.

Gallicus, $F r$.

gihbosus, Pers.

wilhusis Fl. wall.

giganteus, Bolt.

unstuinus, lii,

hirsutus, $F r$.

lispidus, $F r$.

lispidhs, liull

igniarius, $F^{\gamma}$.

imbertis, Bull.

imbliteatus, Ster,

inte:triatus, $F$

intruliatrins, limey

inthlater, $1 \%$.

kimitudes, linetl:

latriniatus, liett.

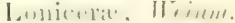

lucidus, $F r_{r_{1}}$. .

lutescens, $T_{t}$ is.

marginatus, Fro;

merlullat l'anis. l'te.

menilupurus. I'tix.

malluscos, sim.

Muntanei, $F$

Mori, $\mathrm{Fr}$.

Muri, I'all.

mucidus, $F r$. .

nidulans, $F r$.

nitoricius . Fi,

nitidus, $F$

"Hliquatus. Lutl.

obliquus, $F_{7}$. .

odoratus, Scherti

ofticinalis, $F r$.

"Wupheus, Mtout.

ovinus, $F r$.

pallescens, $F_{r}$.

Pauletii, $F r$.

perennis, $F r$.

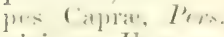

piexus $F y$

jictiln, sidenle.

Pini. F'.

pinicola, $F_{r}$.

f', jullinus, $F \%$

Riadula, $\boldsymbol{F}$.

retionlatus, $F$

lihristes, I'tor.

thodellus, $F$ \%

rhombiporeus, Pers.

Ribis, Fr.

mhermas. F

muti-atems

rufus, $F \%$.

mitilass, Ima

sacer, $F r$

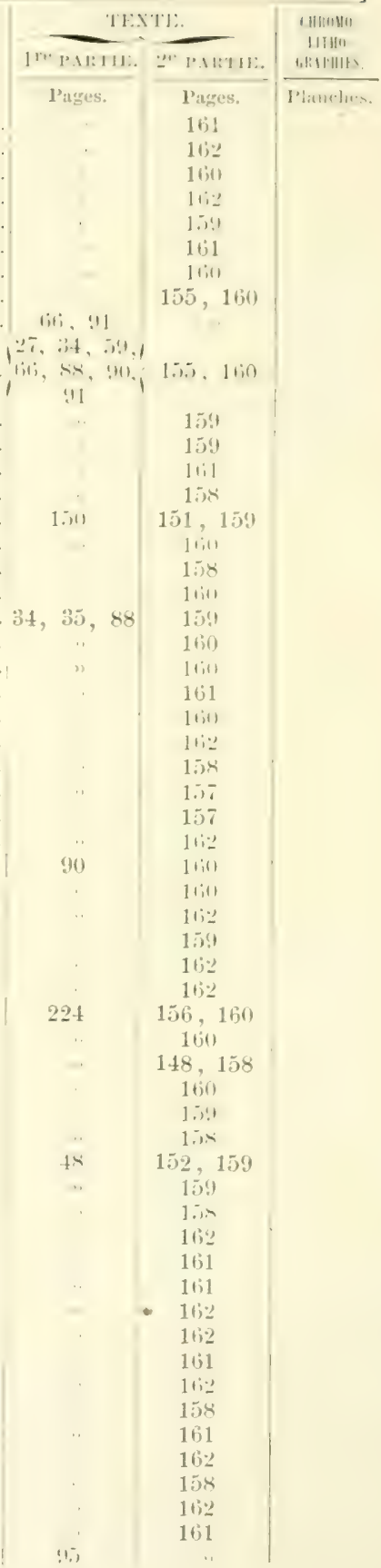


Polyporus sanguineus, Paul. salieinus, $F r$. salignus, $F r$. scalaris, Pers.

Schweinizii, $F r$. serialis, $F r$

serpentarius, Pers.

Soloniensis, Dub.

Soloniensis, Paul.

squamosus, Fr.

squamosus, Schaff.

stereoides, $F r$.

stypticus, $F r$.

suaveolens, $\operatorname{Lin}$.

subspadiceus, $F_{r}$.

subsquamosus, Lin.

spumeus, $F r$.

sulfureus, $F r^{\circ}$

terrestris, $F r$.

tessulatus, $F x$.

tuberaster, $F r$.

tuberculosus, $D C$

ulmarius, $F$ ?

- umbellatus, $F r$.

undatus, Pers.

ungulatus, Bull.

unitus, Pers.

Vaillantii, $F r$. .

vaporarius, $F r$.

varius, $F r$.

velitinus, $F r$.

versicolor, $F r$.

versicolor, Batt.

violaceus. Fr.

viscosus, Pers.

vitreus, $F_{r}$.

- vulgaris, Berlil.

zonatus, Schetit.

Polysaceum acaule, Ju':

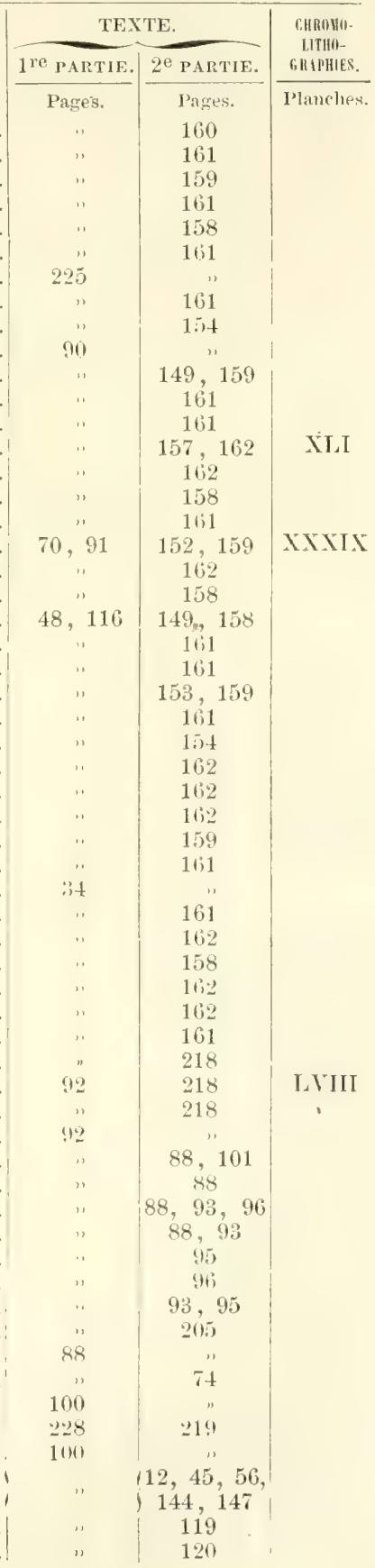

P'orityrospories.

crassipes, $D C$

- pisocarpium, $F$.

pratella

Pratelle.

Psalliota .

Psathyra

Esathyrella.

Psilocybe

Pyronema confluens. Tul.

Racodium cellare, Pers.

Rhimovis involuta, Rabh.

Rhizoctonia Crocorum, $D C$.

Rhizopogon albus, Fr.

Ritomospores.

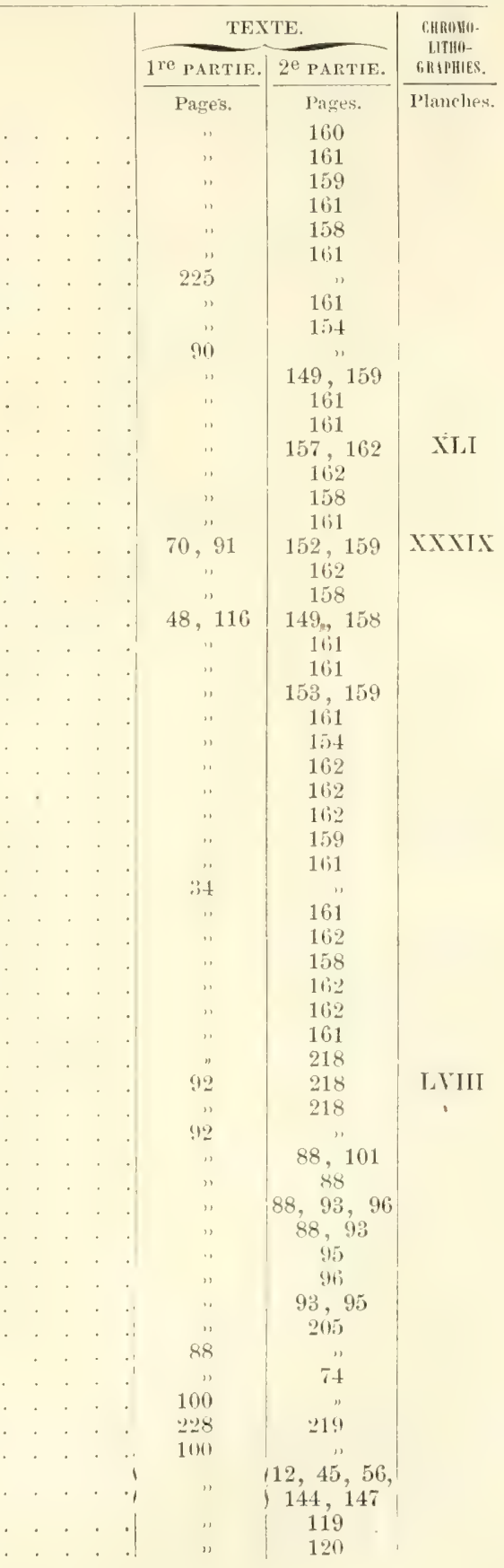


вunala cyanoxantha, Pers. .

fortens, $F r$.

fragilis, $F v$.

filleittit, $F$

('miticis, li,

heterophylla, $F$ \%

lactea, $F r$.

- lepida, Fr.

nigricans, $F r$

ochrolenca, $F r$.

pectinata, $F r$.

rubra, $F r$.

sanguinea, $F$

\section{IRussule}

virescens, $F r$.

\section{Sittrit.}

Schizophyllum commune, $F r$.

Seleroderma aurantium, J'ers.

$$
\begin{aligned}
& \text { citrinum, Pers. } \\
& \text { - Bovista, Fr. } \\
& \text { - Corium, Grav. } \\
& \text { - Geaster, Fr. } \\
& \text { - polyrhizum, Pers. } \\
& \text { - } \quad \text { spadicemm, Pers. } \\
& \text { - timctorium, Pers. } \\
& \text { - verrucusin, I'r. }
\end{aligned}
$$

seléroderme.

Sclerotium Clavus, $\dot{D} C$.

ristotrema rufescens, Pers.

Sparassis crispa, Fr.

- brevipes, Krombh.

$$
\text { - laminusil, } I^{*} \% \text {. }
$$

Sphacelia segetum. Lê.

iphæria militaris, Ehrh.

$$
\text { eraterium, } D C \text {. }
$$

Sporisorium Maydis, Link.

spoxonema hiemalis, Desm

Stachylidium Bassianum, Mont.

Ftrmulitis wata, Pers.

Stictis betulæ, Ir. . . .

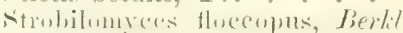

Syzygites megalocarpus, Ehr.

\section{relamonia}

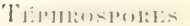

Terfezia berberidiodora, $T u l$.

$$
\begin{aligned}
& \text { Lumis, Tul. } \\
& \text { - leptoderma, 'Tul. } \\
& \text { - mbiensis, Tul. } \\
& \text { nliguspremat Tul. }
\end{aligned}
$$

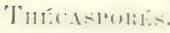

'Thelelulus hirsutus, J)(

Thelephora amorpha, $F r$.

$$
\text { - terrestris, Pers. }
$$

Tilletia Caries, Tu?.

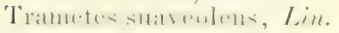

$$
\text { - odorata, Fr. }
$$

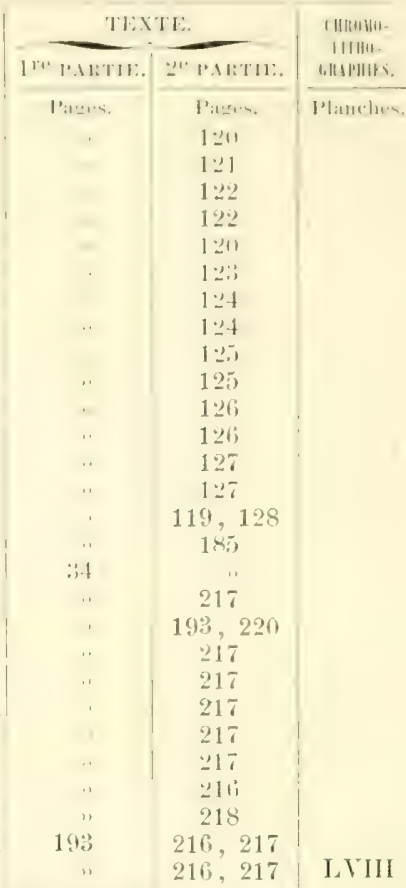

98,198

102

$1 ! 11 ;$

101

$1 ! 11 i$

$1 !$

$1+$

100,104

145,147

$\because 24$

224

224

224

224

1 188,191

196

202

199

34

98,195

15), $16 \%$ 
Tremella albida, $F_{3}$.

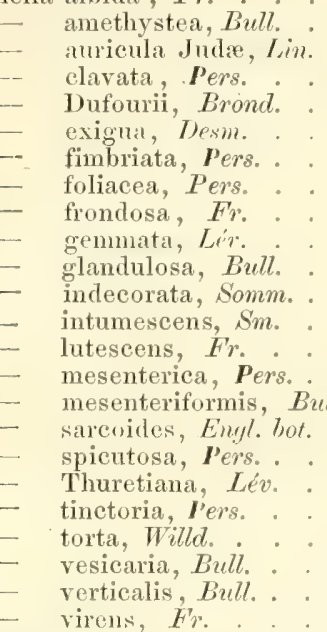

\section{Trémelle.}

\begin{tabular}{|c|c|c|}
\hline TEX & TE. & CIIrovII- \\
\hline $1^{\text {Te PAITIE. }}$ & בе l'ARTIE. & galapilifs. \\
\hline Pages. & Pages. & $\overline{\text { Planches. }}$ \\
\hline " & 183 & \\
\hline " & 183 & \\
\hline ". & 184 & \\
\hline ". & 183 & \\
\hline " & 183 & \\
\hline ". & 183 & \\
\hline 92 & 182,183 & \\
\hline ", & 183 & \\
\hline$"$ & $\begin{array}{l}18: 3 \\
183\end{array}$ & \\
\hline " & $\begin{array}{l}183 \\
184\end{array}$ & \\
\hline ." & 183 & \\
\hline ., & 183 & \\
\hline ". & 182,183 & XLVIII \\
\hline " & 182,183 & XLVIII \\
\hline$"$ & 182 & \\
\hline$"$ & 183 & \\
\hline i' & 184 & \\
\hline ". & $\begin{array}{l}183 \\
182\end{array}$ & \\
\hline ". & 183 & \\
\hline ". & 183 & \\
\hline " & $18:$ & \\
\hline ". & 183 & \\
\hline " & 182,183 & \\
\hline 98,197 & 182 & \\
\hline 98,198 & 201,50 & \\
\hline 2011 & $"$ & \\
\hline ", & 221 & \\
\hline ", & 223 & \\
\hline ", & 221,223 & \\
\hline ". & 221 & \\
\hline "1 & 219 & \\
\hline ". & 223 & \\
\hline $59,65,228$ & $\begin{aligned} 20: 3 \\
\prime \prime \prime\end{aligned}$ & \\
\hline , & 221,223 & $I T$ \\
\hline ". & $22: 3$ & \\
\hline ". & 222 & \\
\hline "" & $\begin{array}{l}224 \\
221\end{array}$ & \\
\hline "' & 224 & \\
\hline , & 224 & \\
\hline .. & 224 & \\
\hline ." & 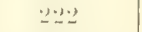 & \\
\hline ") & 224 & \\
\hline " & 222,224 & \\
\hline$"$ & 222,224 & \\
\hline " & 223,224 & \\
\hline " & 218 & \\
\hline ", & $\begin{array}{l}221 \\
224\end{array}$ & \\
\hline$"$ & $\begin{array}{l}224 \\
224\end{array}$ & \\
\hline "1 & 224 & \\
\hline " & 224 & \\
\hline$"$ & 224 & \\
\hline " & 224 & \\
\hline$"$ & 220 & \\
\hline
\end{tabular}

Trichobasis Rubigo vera, Lév. . . . . . . 98, 197

\section{Tricholoma}

Trichophyton tomsurans, Habrust.

\section{Truffe}

Tuler affine, (combl.

- astivum, Jittrel.

-. albidum, C'rsalp..

- allimm, linll.

- Asa, Tul.

- brumale, Tittad.

- cibarimm, Lin.

- $\quad$ S. Sibth.

- $\quad$ - Comd.

- comcolor, liabh. dryopliilum, 'Tul.

- excavatum, Vittad. fatidum, Tittad.

- griseum, Pers.

- Lespiantiii, Tul.

- magnatum, Pico. $\dot{\text { - }}$ -

- mesentericum, Irittarl.

- moschatum, Bull.

- nigrum, Bull.

- nitidum, Iittred.

- niveum, Desfi. .

- panniferm, Tul.

- rapæodorum, Tul.

- rufum, P'ico.

Tiberrackes

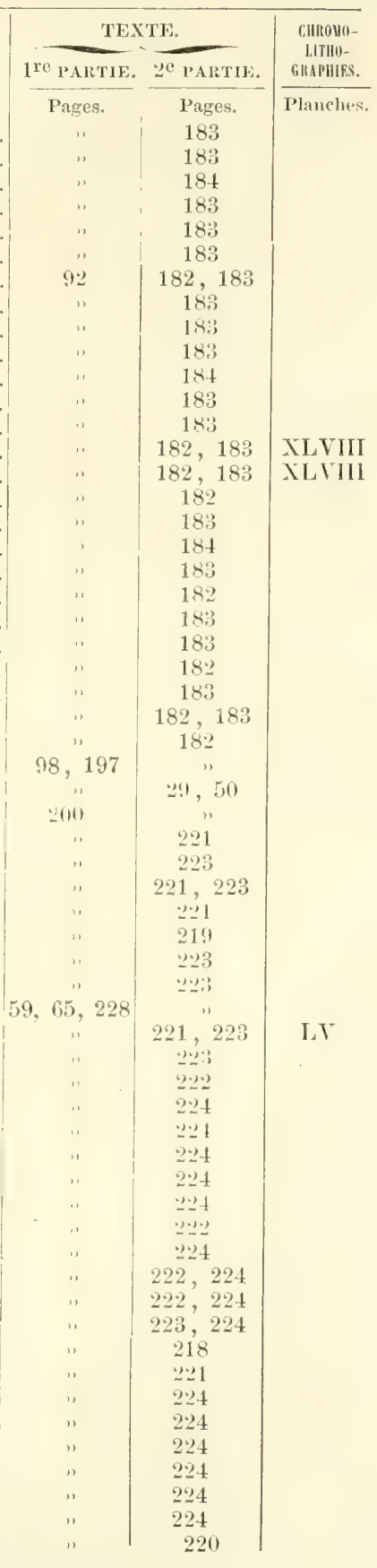


Tubrenlatria rulganis. Turte Tympanis Frangulæ, Fr.

linelu ciulics, lu.

- Rubigo vera, DC.

Ĺstilago hypodytes, Trél. .

$$
\text { Milyiis, Tul. }
$$

- segetum, Ditm.

Terpa agaricoides, Pers.

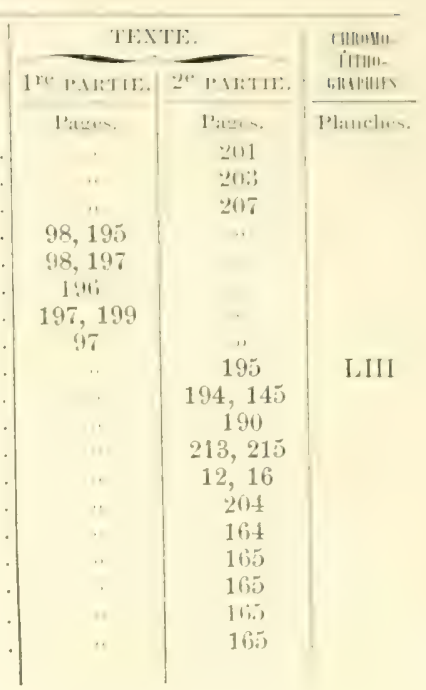

Sissclinu.

\section{volvaria.}

Xrloma arundinaceum, $D C$.

Xylomyzon destruens, Pers.

molluseum, Pers.

pattcirmgunt, l'res.

puricides, I'es.

julchmon, Pers. 


\section{TABLE DES IITIËRES.}

\section{TABLE DE LA PREMIÉRE PARTIE.}

CHapre 1 - De l'organisation des champignons. Pages

2. - Propriétés physiques des champignons . . . . . 10

3. - Physiologie des champignons . . . . . . . . 19

4. - Géographie des champignons . . . . . . . . . . 32

5. - De l'influence de la saison, du climat, du sol, de l'habitat, de la culture. . . . . . . . . . 37

6. - Des moyens de distinguer les champignons alimentaires des champignons vénéneux. . . . . . . . 50

7. - De la composition chimique des champignons. . . . 59

8. -De la possibilité d'enlever aux champignons vénéneux leur principe toxique . . . . . . . . . 76

9. - De l'emploi des champignons dans l'industrie et l'économie domestique . . . . . . . . . 86

10. - Dommages causés par les champignons . . . . . 97

11. - De la récolte des champignons . . . . . . 105

12. - De la culture des champignons . . . . . . . 109

13. - Culture de la truffe. . . . . . . . . . . . 123

14. - Moyens de conservation des champignons . . . . 132

15. - De l'emploi alimentaire des champignons . . . . 142

16. - De la préparation eulinaire des champignons . . . . 148

17. - De l'effet des champignons vénéneux sur l'économie animale. . . . . . . . . . . . 185

18. - Des symptômes de l'empoisomnement par les champignons. . . . . . . . . . . . . . 205

19. - Des moyens de rémédier aux accidents produits par les champignons délétères . . . . . . . . 209

20. - De l'emploi des champignons en médecine . . . . 218 
TABLE DE LA DEUNiEME PARTIE

1). scriptions.

Pite-

Milussitire . . . . . . . . . . . . . 225

libliugraphic . . . . . . . . . . . . . . . 2301

Table des noms vulgaires. . . . . . . . . . . . . . . 234

Table des 60 Chromolithographies. . . . . . . . . . . . . 237

Talile alphabétique de tous les noms cités dans l'unrage. . . . . 239

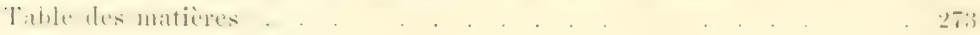

IIN WH 1. WTHALE: 


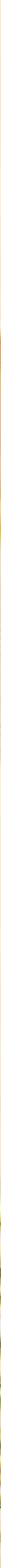





\section{LES CHAMPIGNONS DE FRANCE.}
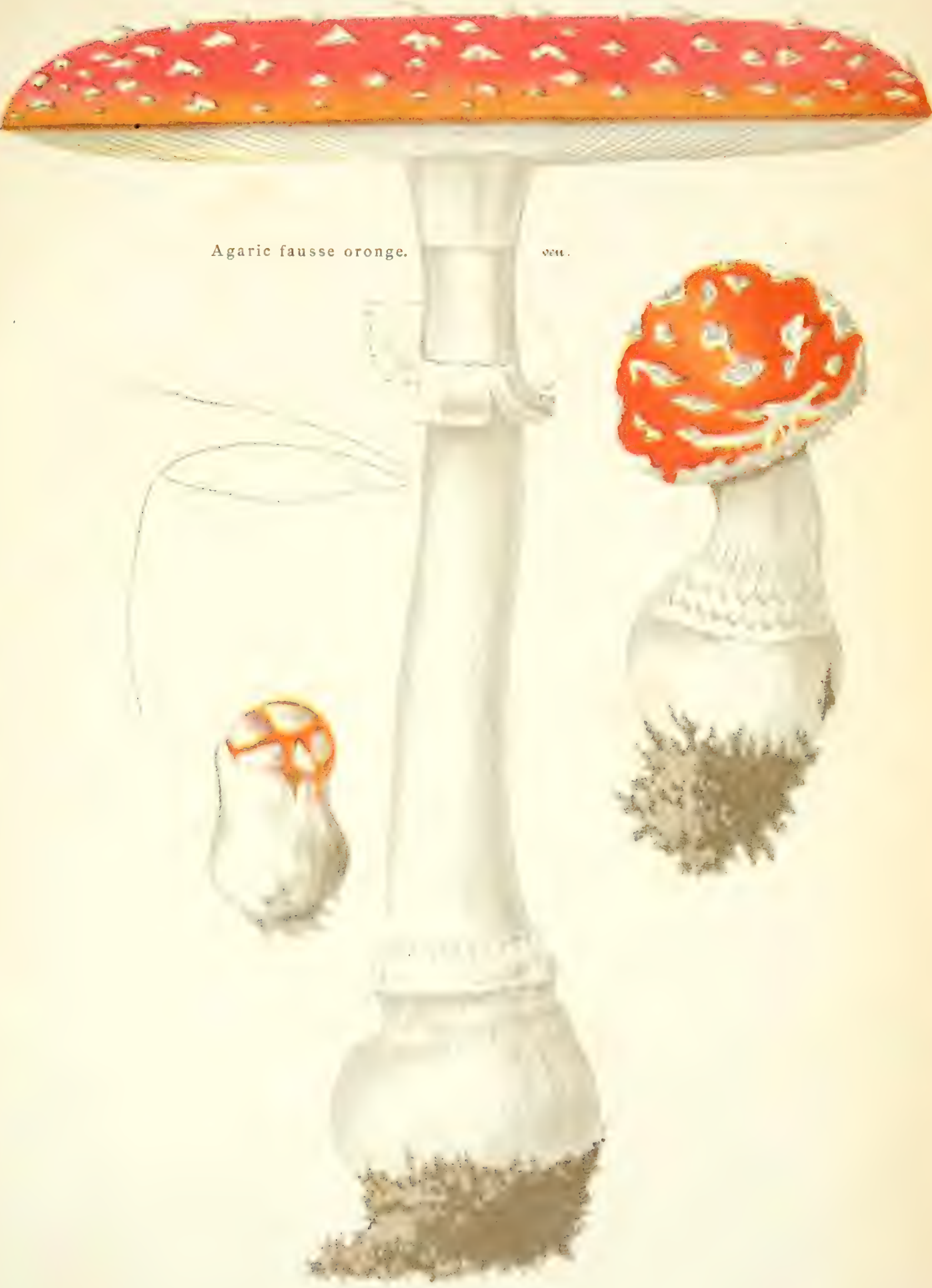

AGARICUS MUSCARIUS, LIN.

PI. II. 


\section{LES CHAMPIGNONS DE FRANCE.}

I. Agaric mappa. ven

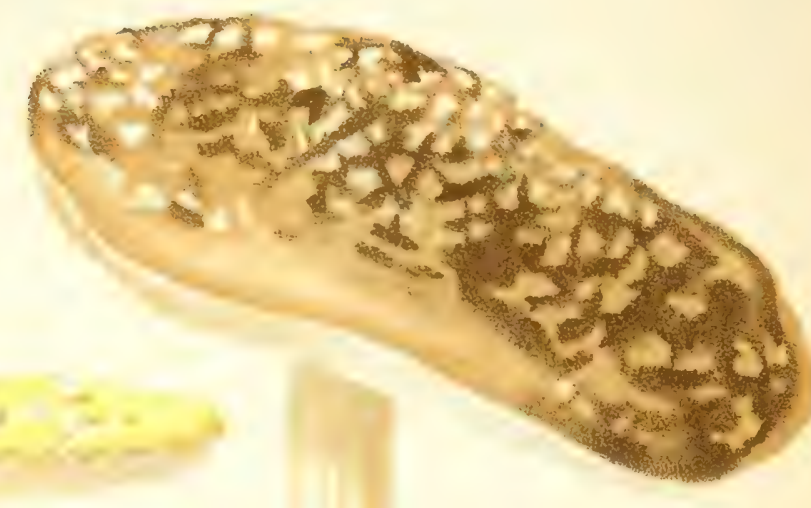

2. Agaric panthère. ven.

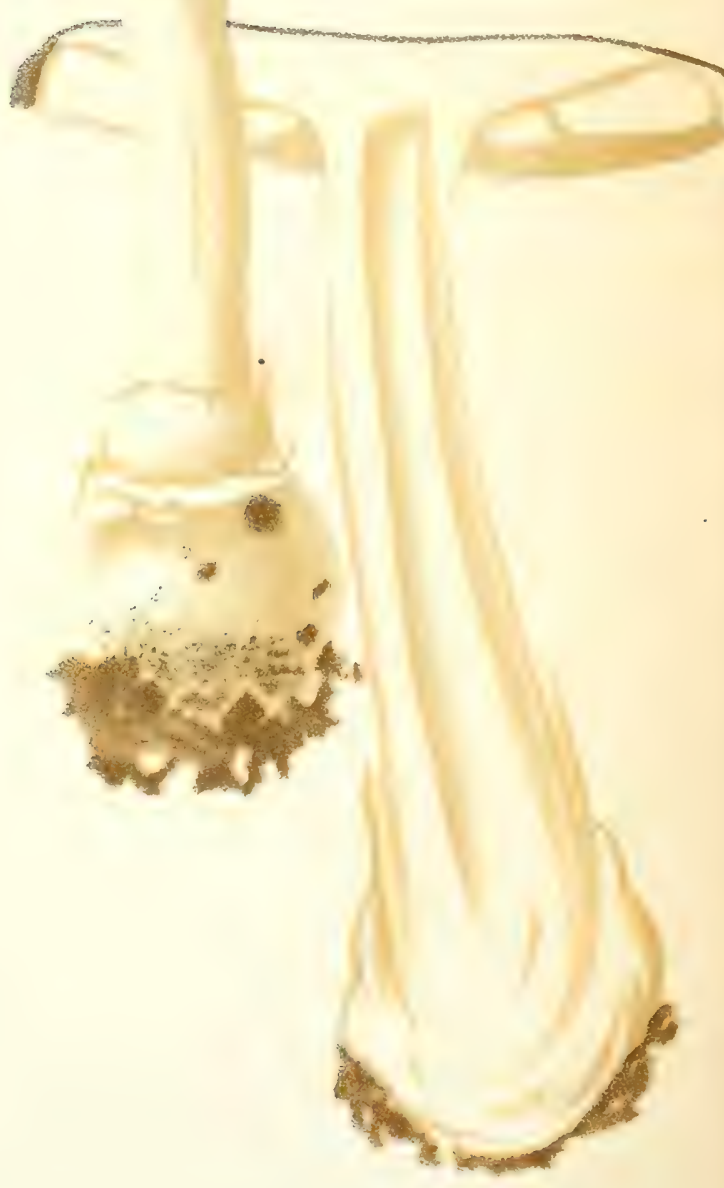

1. AGARICUS MAPPA. BATSCH. 2. AGARICUS PANTHERINUS. DEC.

PI. III. 



\section{LES CHAMPIGNONS DE FRANCE.}

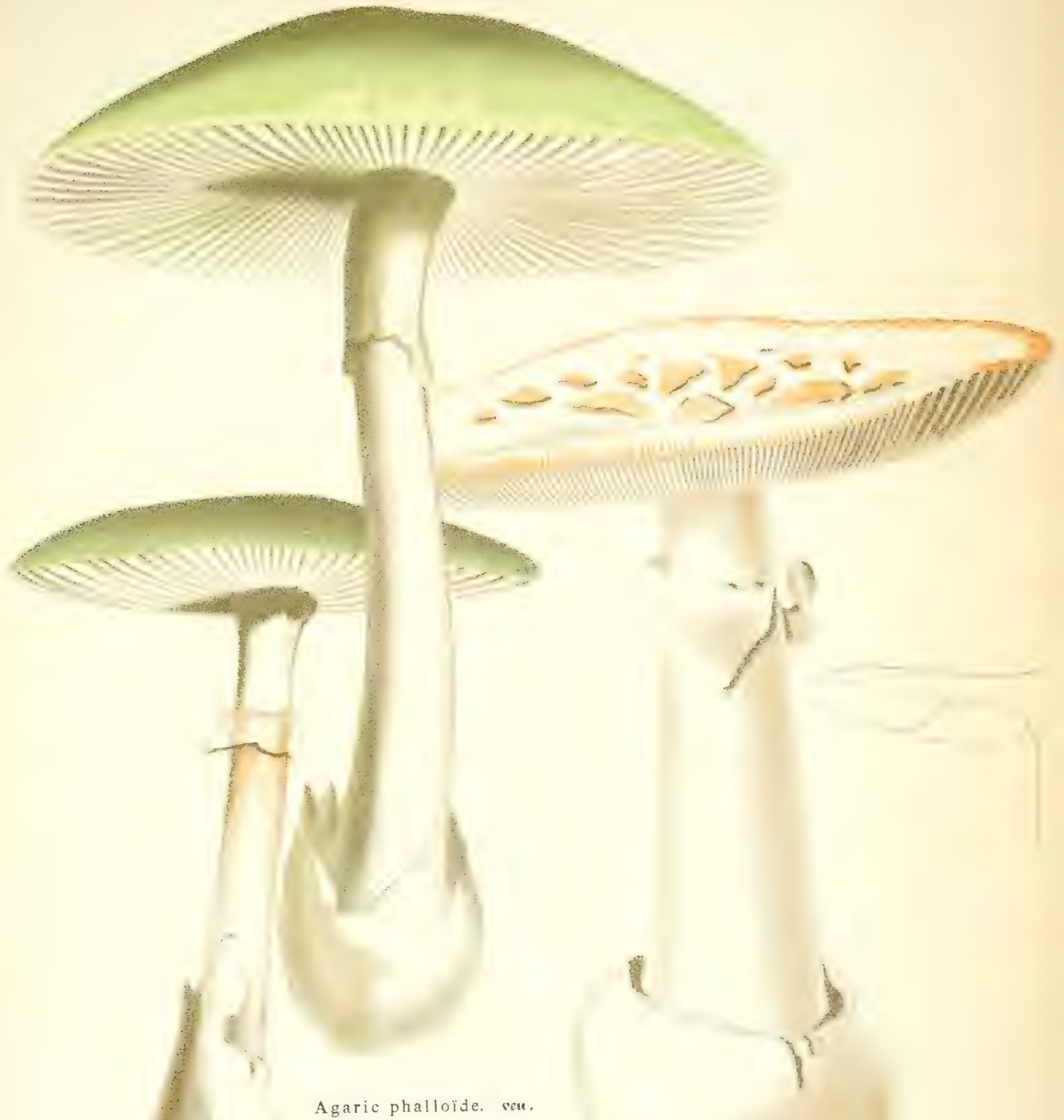

Agaric phalloüde. sen.

AGARICUS PHALLOIDES. $F \boldsymbol{R}$.

PI. IV. 



\section{LES CHAMPIGNONS DE FRANCE.}

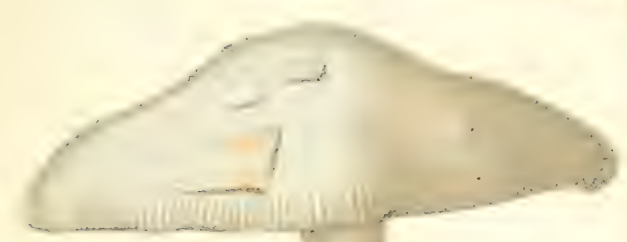

a. illir.

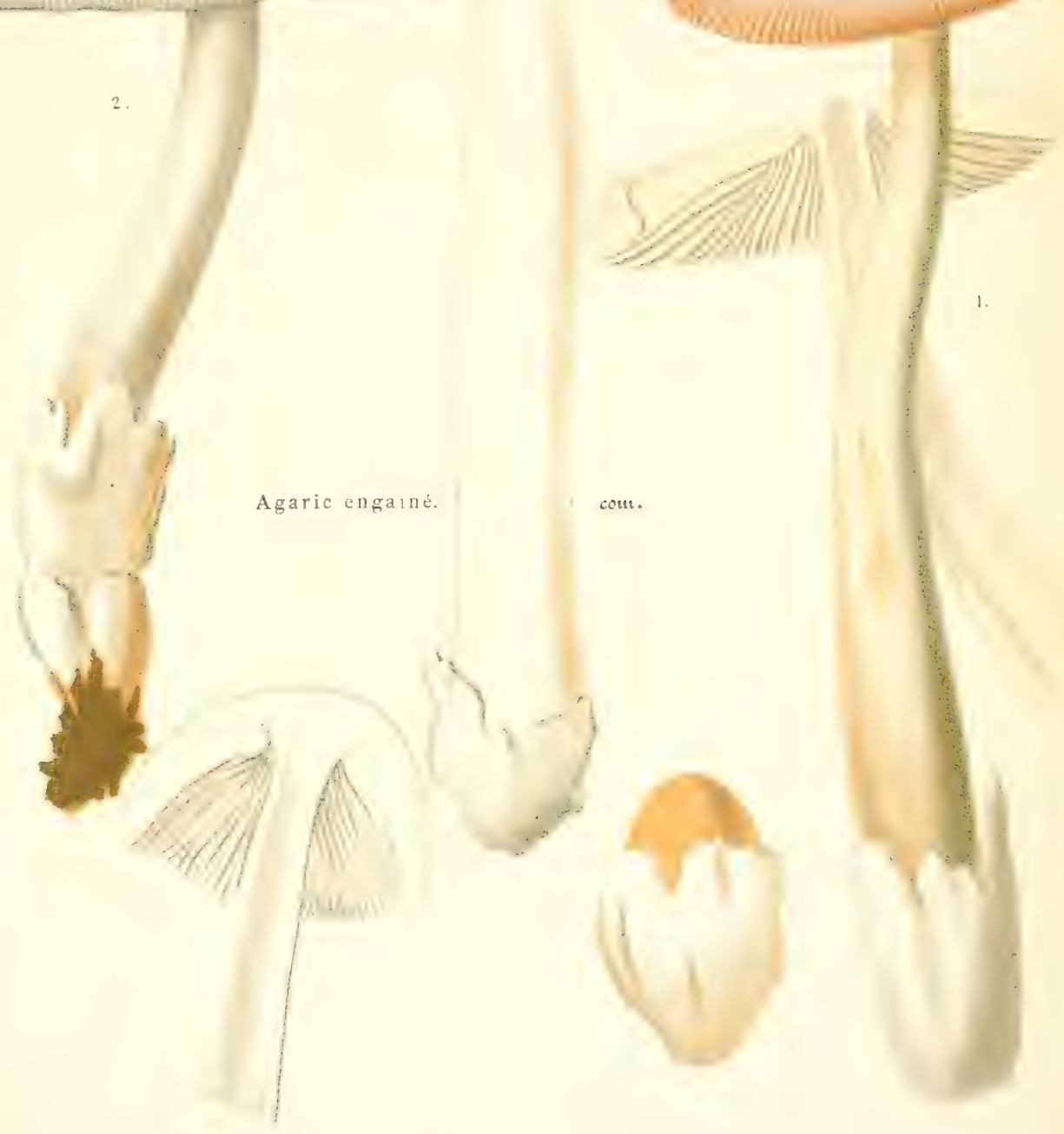

1. AGARICUS VAGINATUS. B BULL.

2. Var. : LIVIILS suop

Pl. V. 



\section{LES CHAMPIGNONS DE FRANCE.}

1. Agaríc spécieux. ven.

2. Agaric petite taille, ven.

I. AGARICUS SPECIOSUS. FR. - 2. AGARICUS PARVULUS. WEIN.

PI. VI. 



\section{LES CHAMPIGNONS DE FRANCE.}

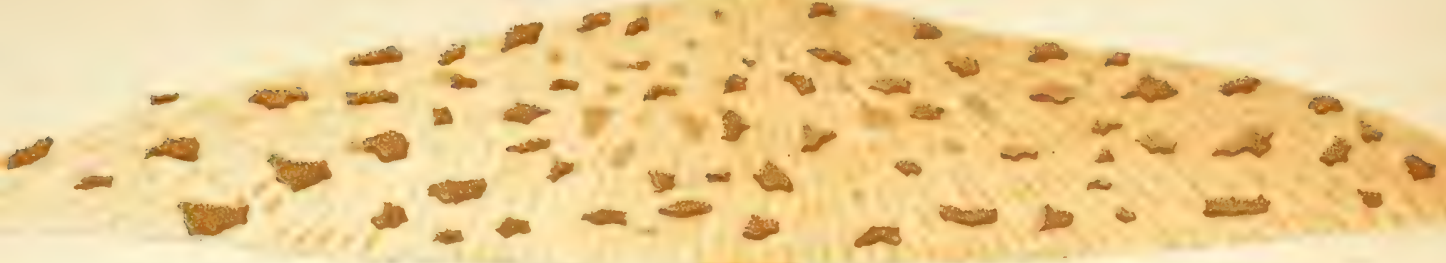
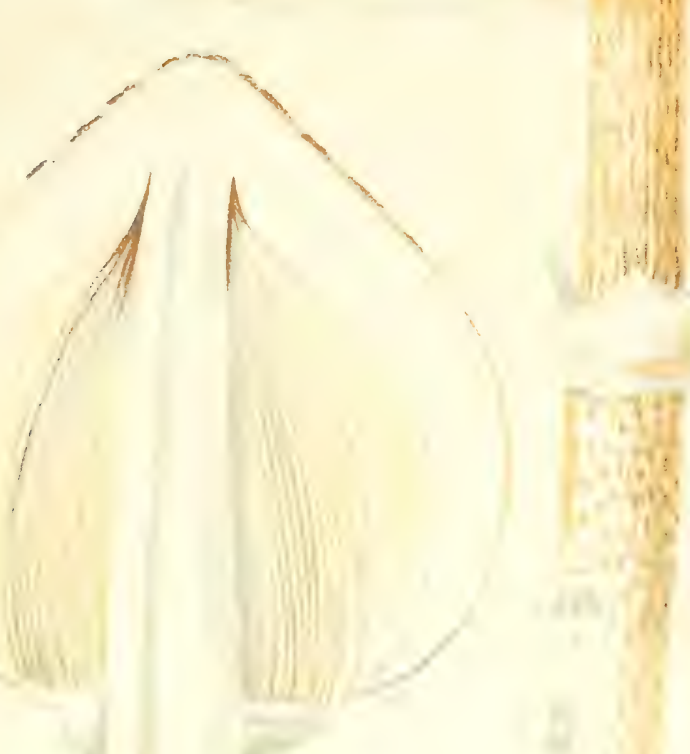

Agaric couleuvré.
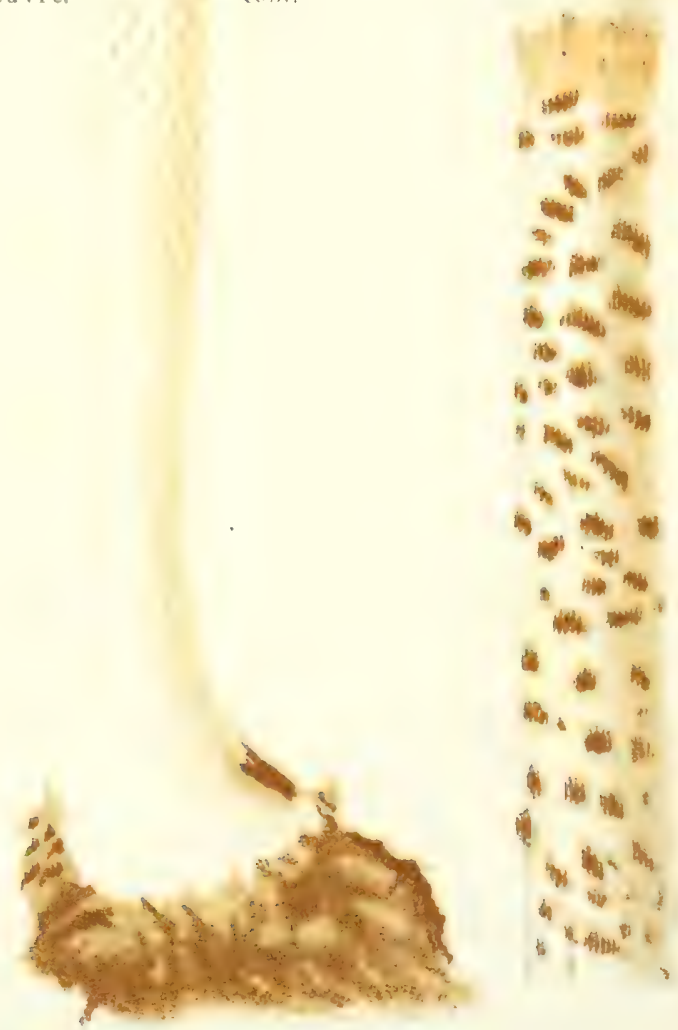



\section{LES CHAMPIGNONS DE FRANCE.}

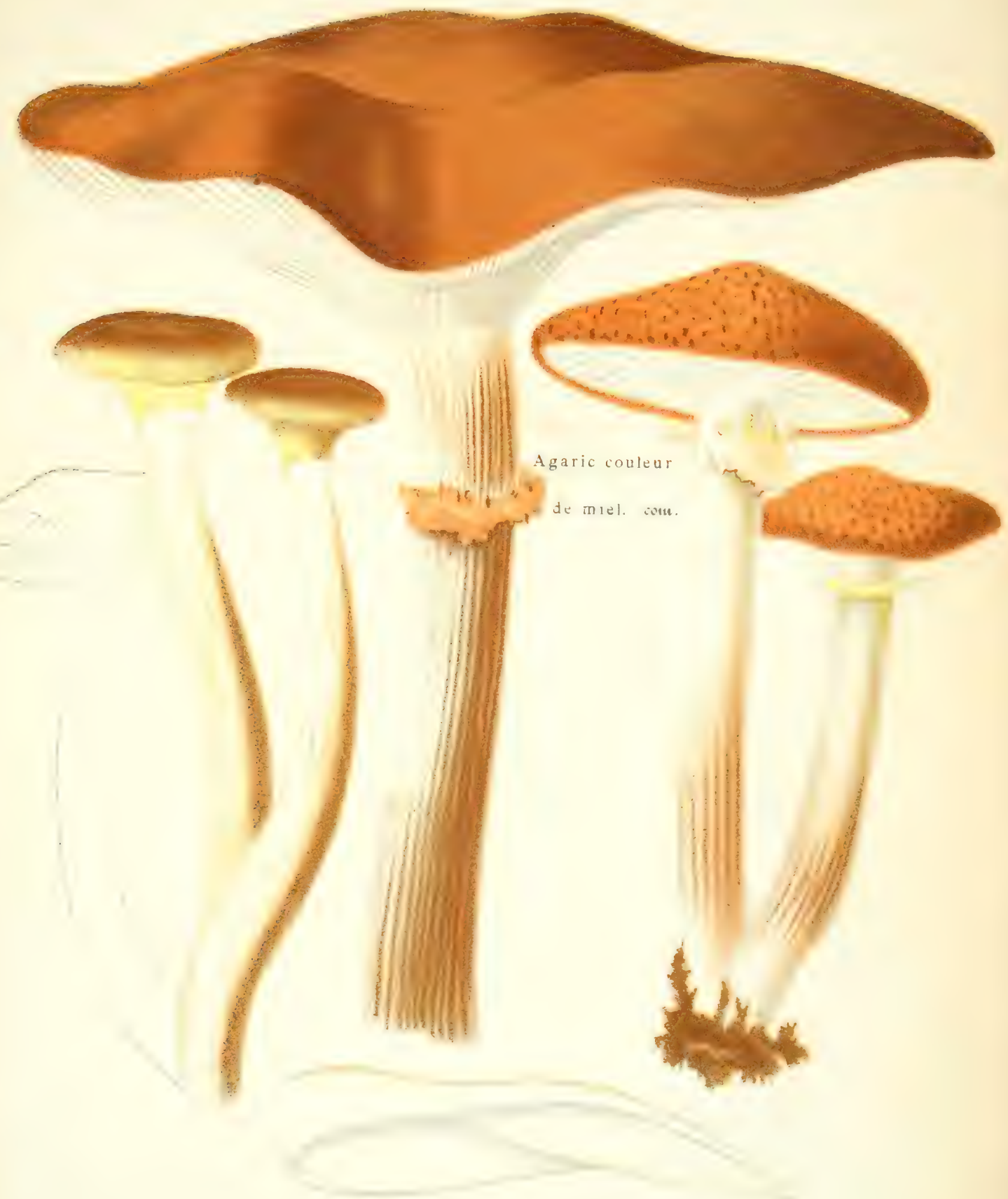

AGARICUS MELleUS. F $\boldsymbol{F}$. DAN

PI. VIII. 



\section{LES CHAMPIGNONS DE FRANCE.}
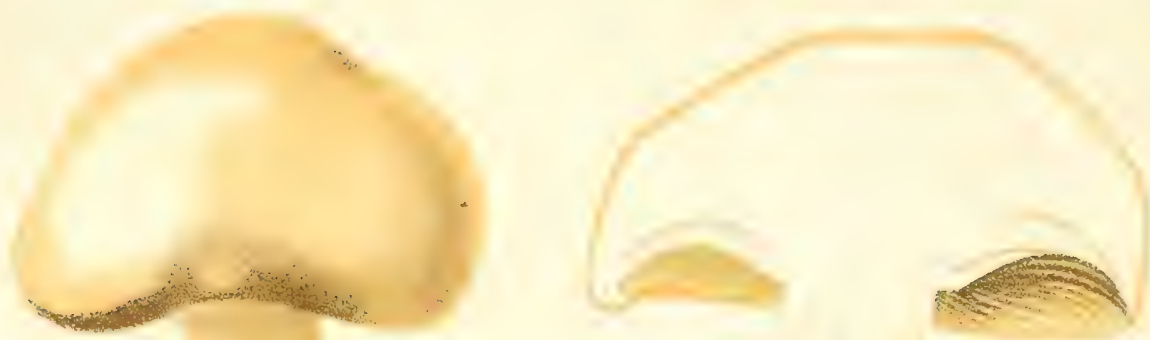

1. Agaric mousseton. com.
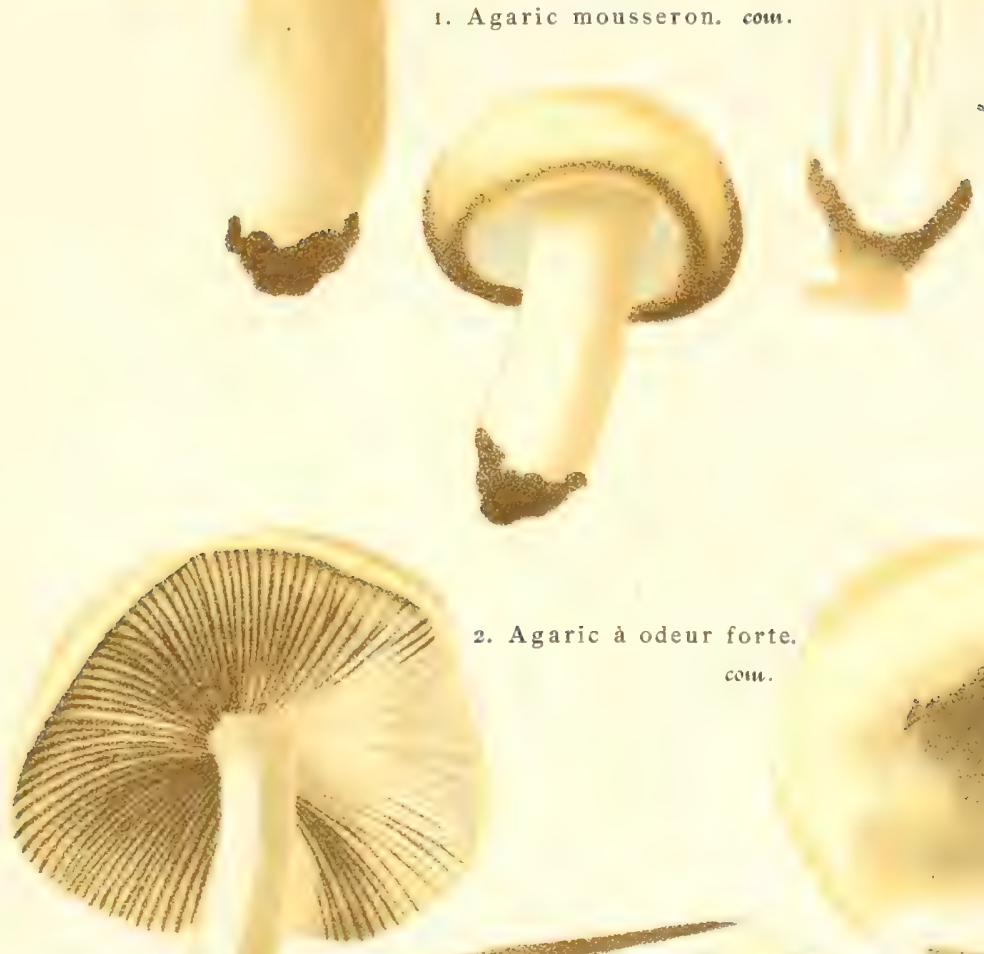

2. Agaric à odeur forte.

coti.
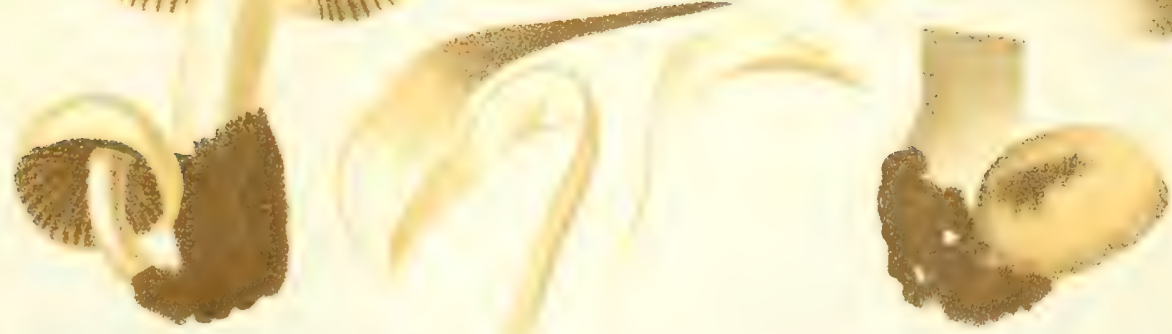

I. AGARICUS ALBELlUS. $D E C$. - 2. AGARICUS GRAVEOLENS. PERS.

Pl. IX. 

LES CHAMPIGNONS DE FRANCE.

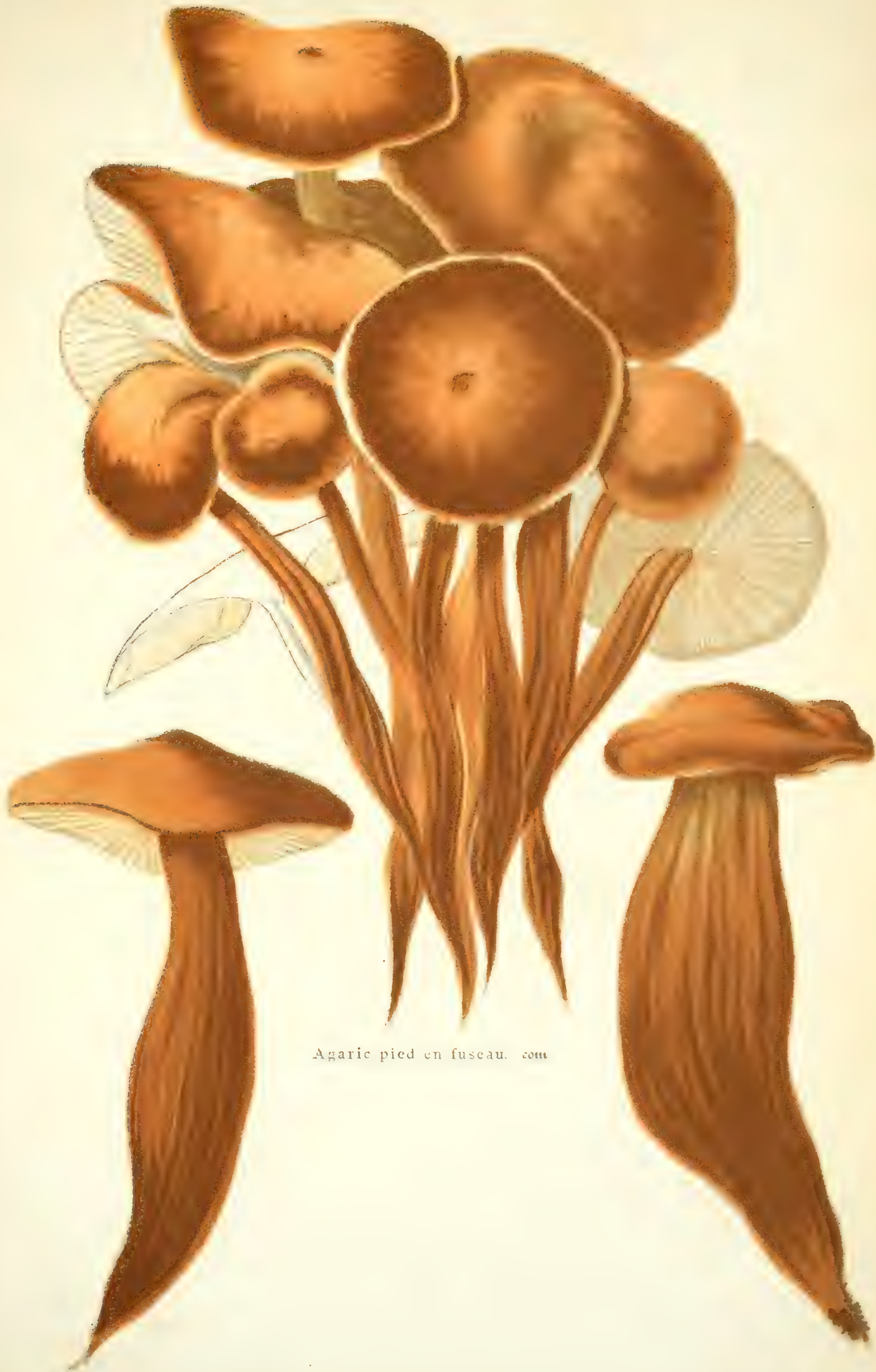

PI. X. 



\section{LES CHAMPIGNONS DE FRANCE.}
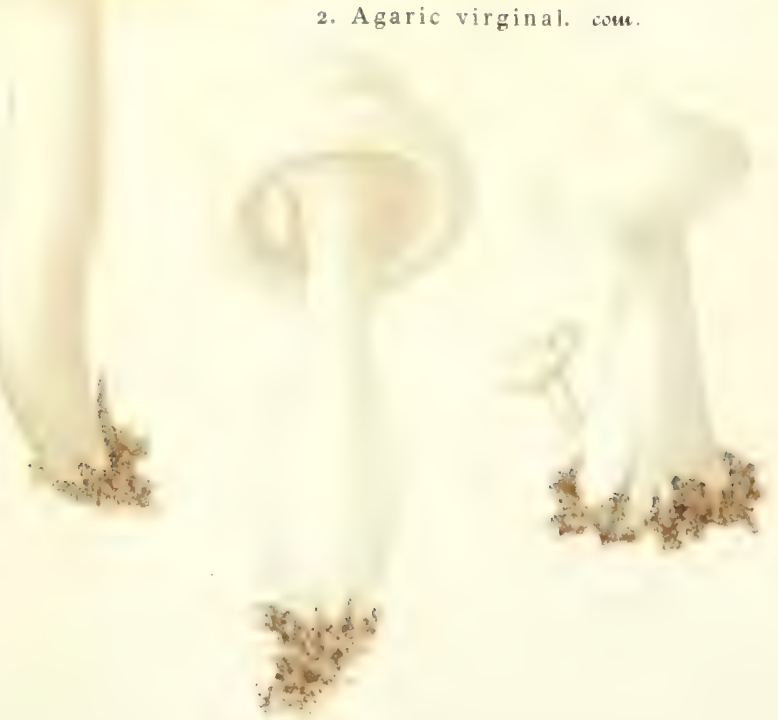

3. AGARICUS EBURNEUS. BULl. - 2. AGARICUS VIRGINEUS. WULF. PI. XI. 



\section{LES CHAMPIGNONS DE FRANCE.}
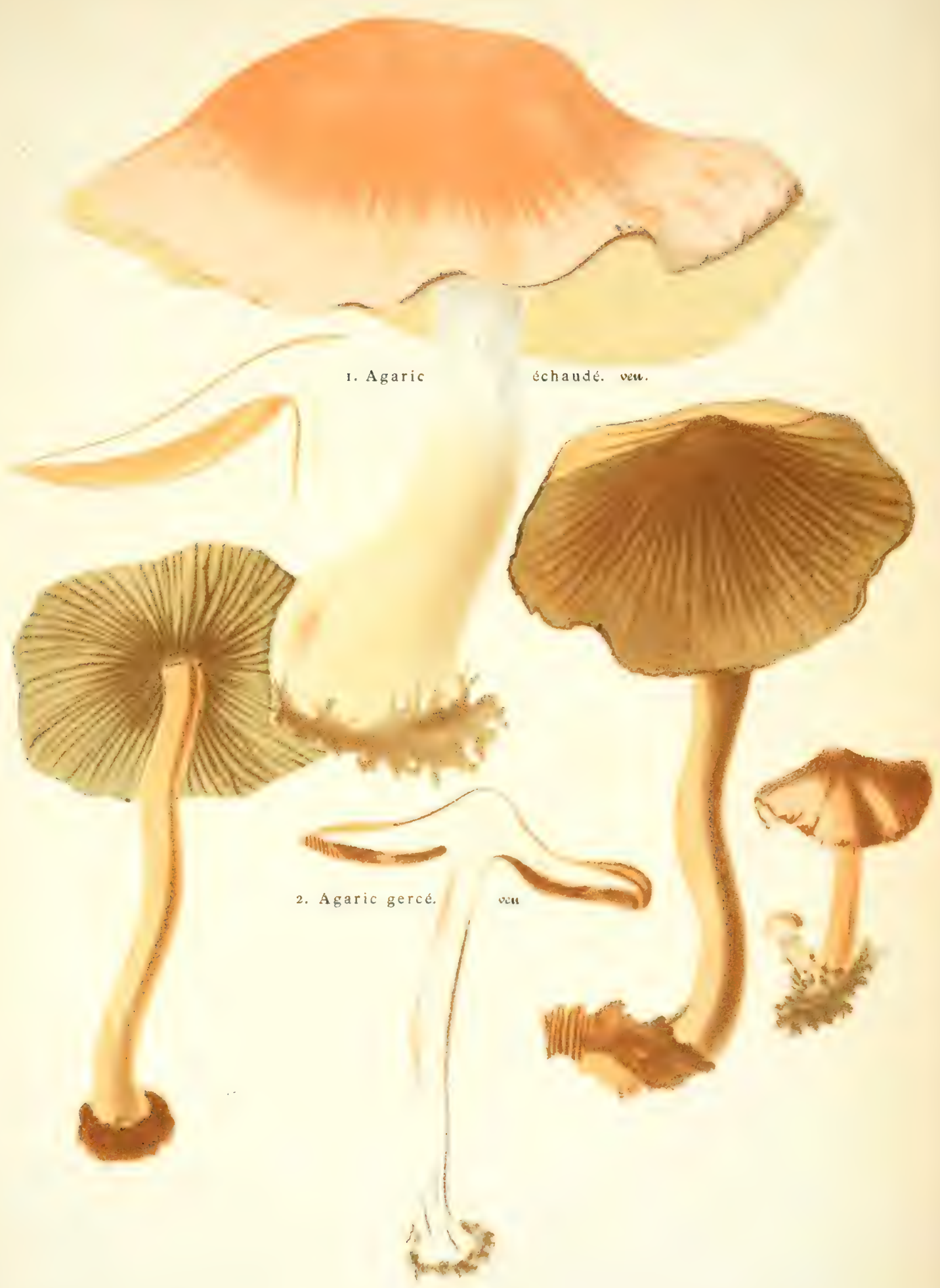

1. AGARICUS CRUSTULINIFORMIS. BULL. - 2. AGARICUS RIMOSUS. BELL.

PI. XIII. 



\section{LES CHAMPIGNONS DE FRANCE.}

1. Agaric échalotte. com.

2. Agaric chaussé. com.

3. Agaric faux mousseron. com.

I. AGARICUS SCORODONIUS. F $F$ - 2. AgARICUS PERONATUS. BoLt.

3. AGARICUS OREADES. BOLT.

PI. XIV. 



\section{LES CHAMPIGNONS DE FRANCE.}

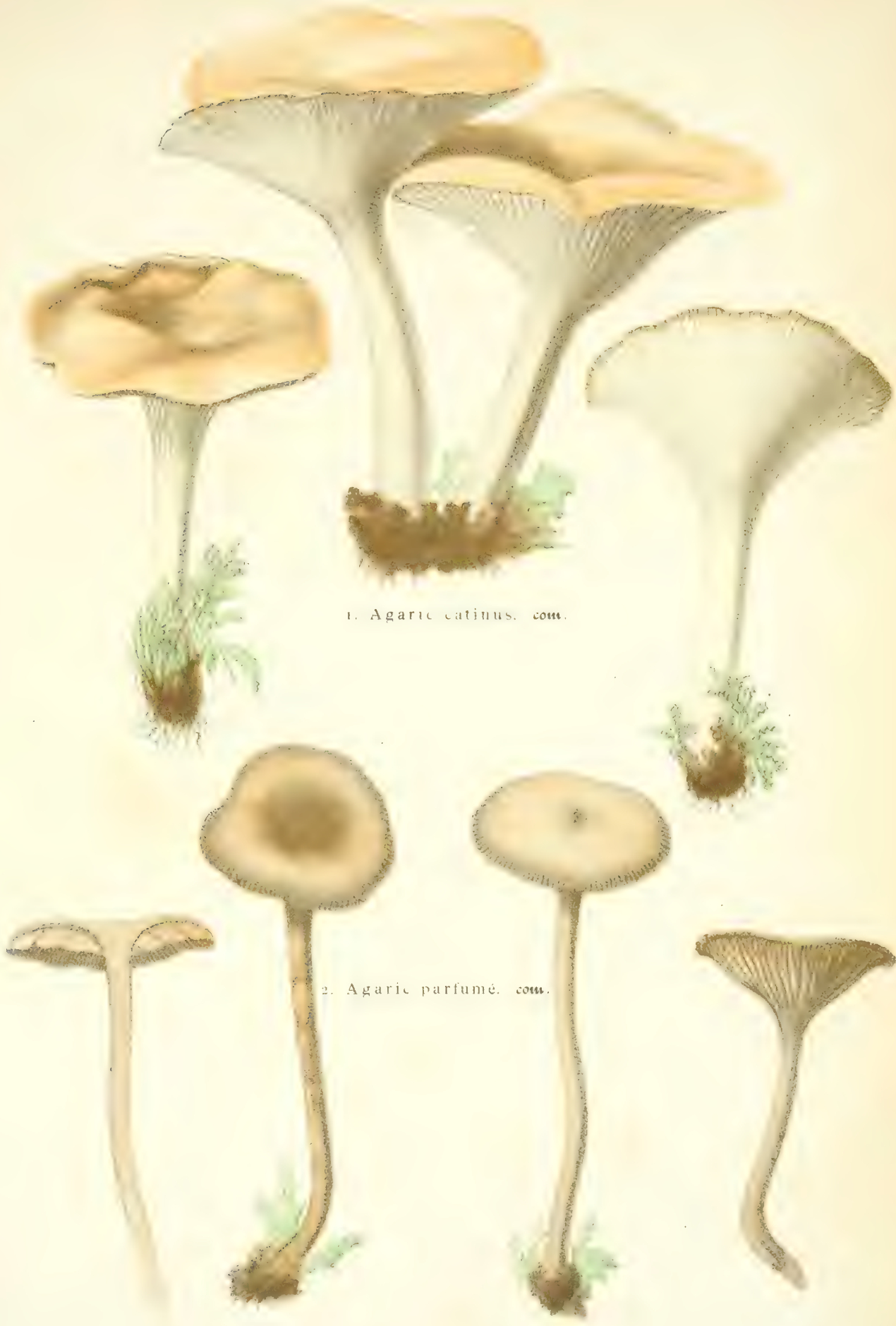

I AGARICUS CATINUS. $F_{k},-2$. AGARICUS. FRAGRANS. $\quad F R$.

PI. XV. 



\section{LES CHAMPIGNONS DE FRANCE.}

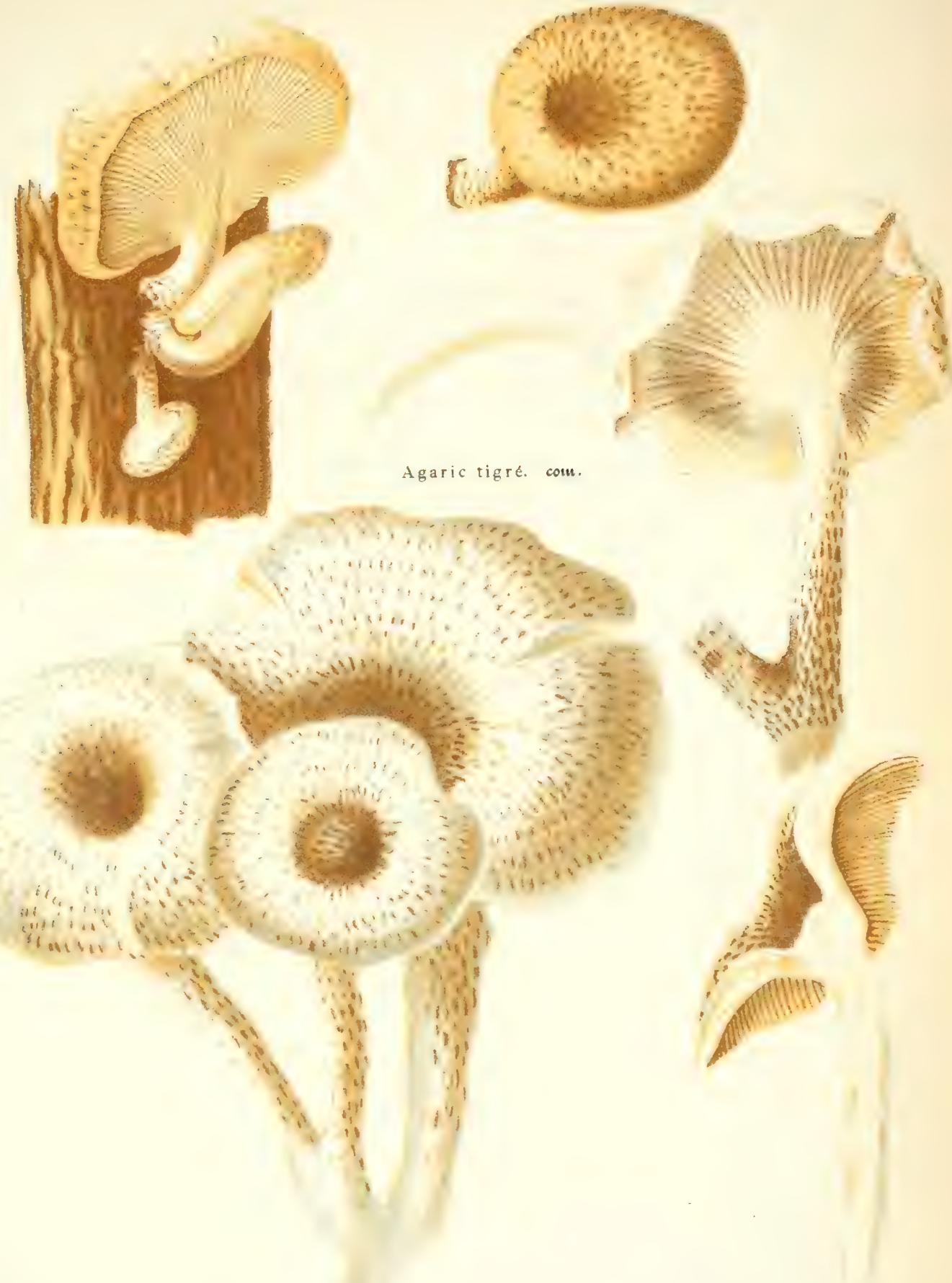

Pl. XVI. 

LES CHAMPIGNONS DE FRANCE.

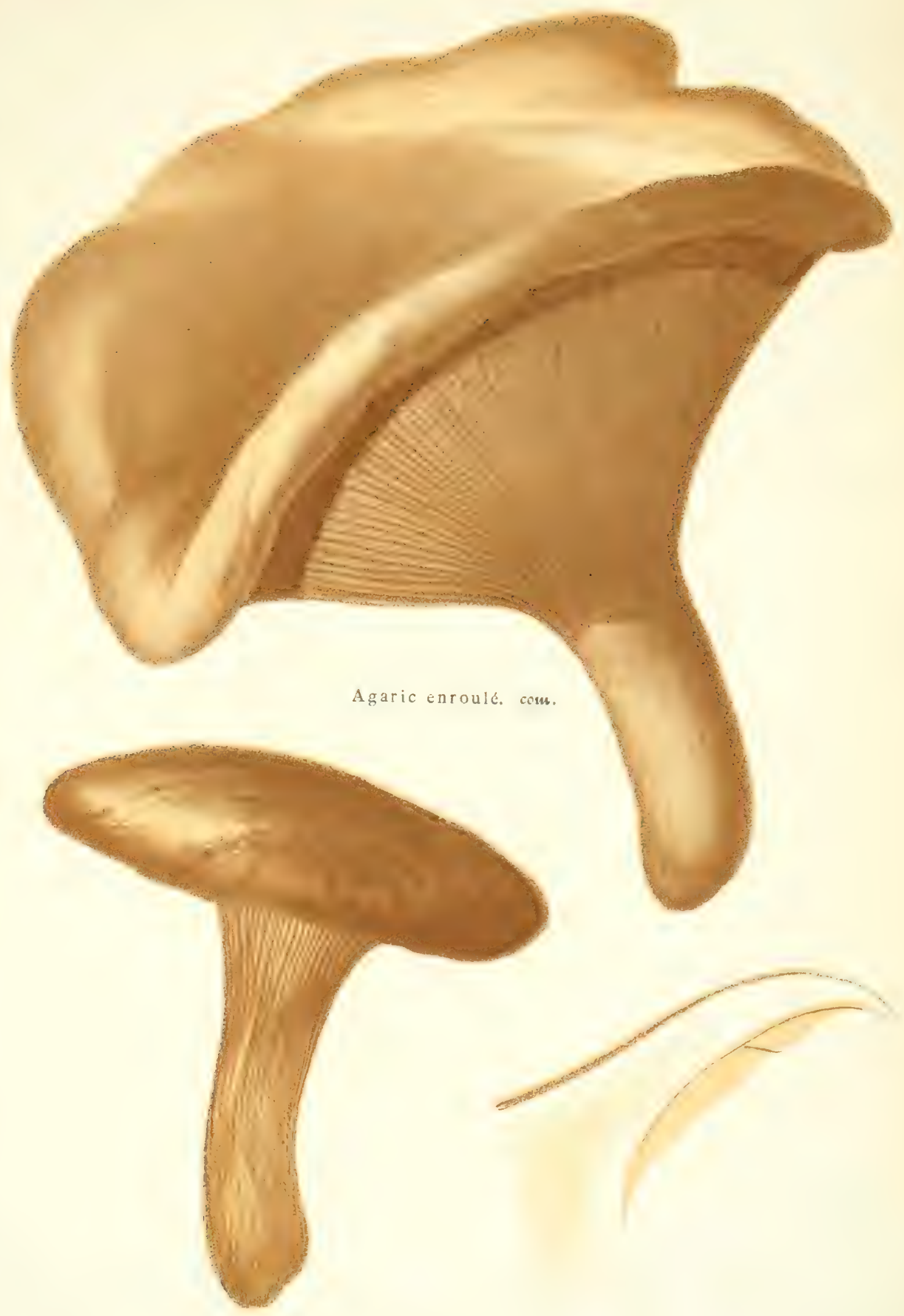

AGARICUS INVOLUTUS. BATSCH.

Pl. XVII. 



\section{LES CHAMPIGNONS DE FRANCE.}

1. Agaric marqueté. com.
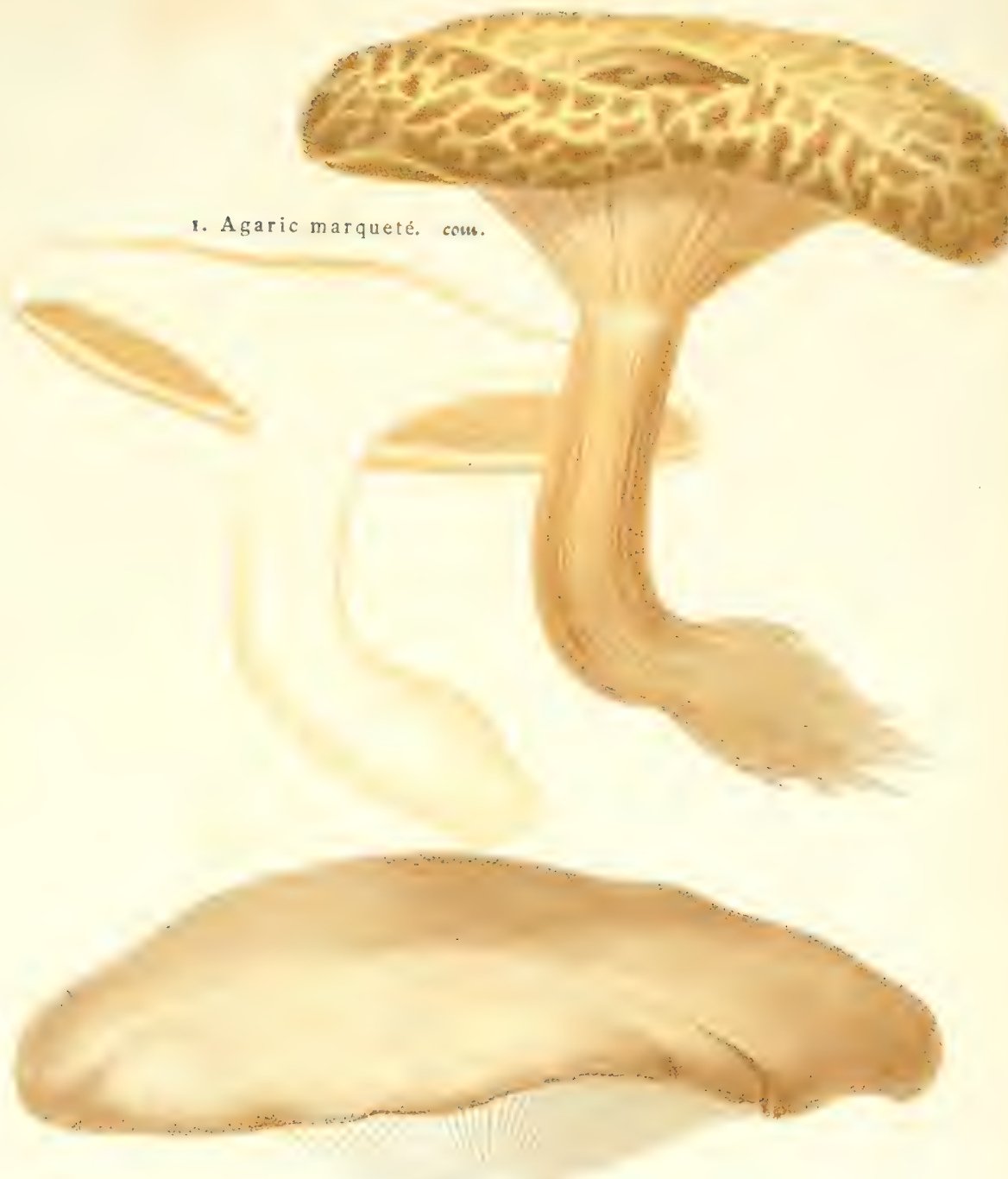

2. Agaric de l'orme. com.

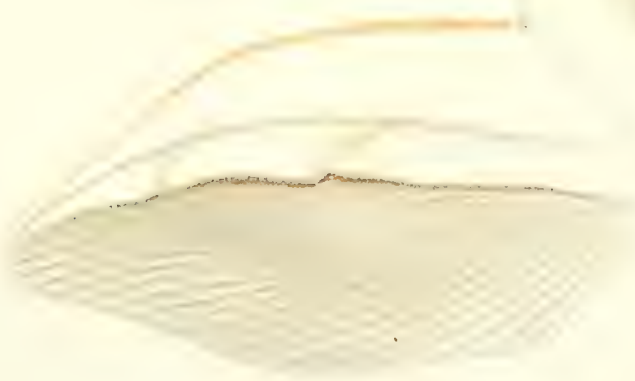

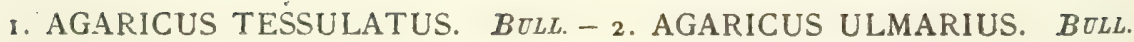

Pl. XVIII. 

LES CHAMPIGNONS DE FRANCE.

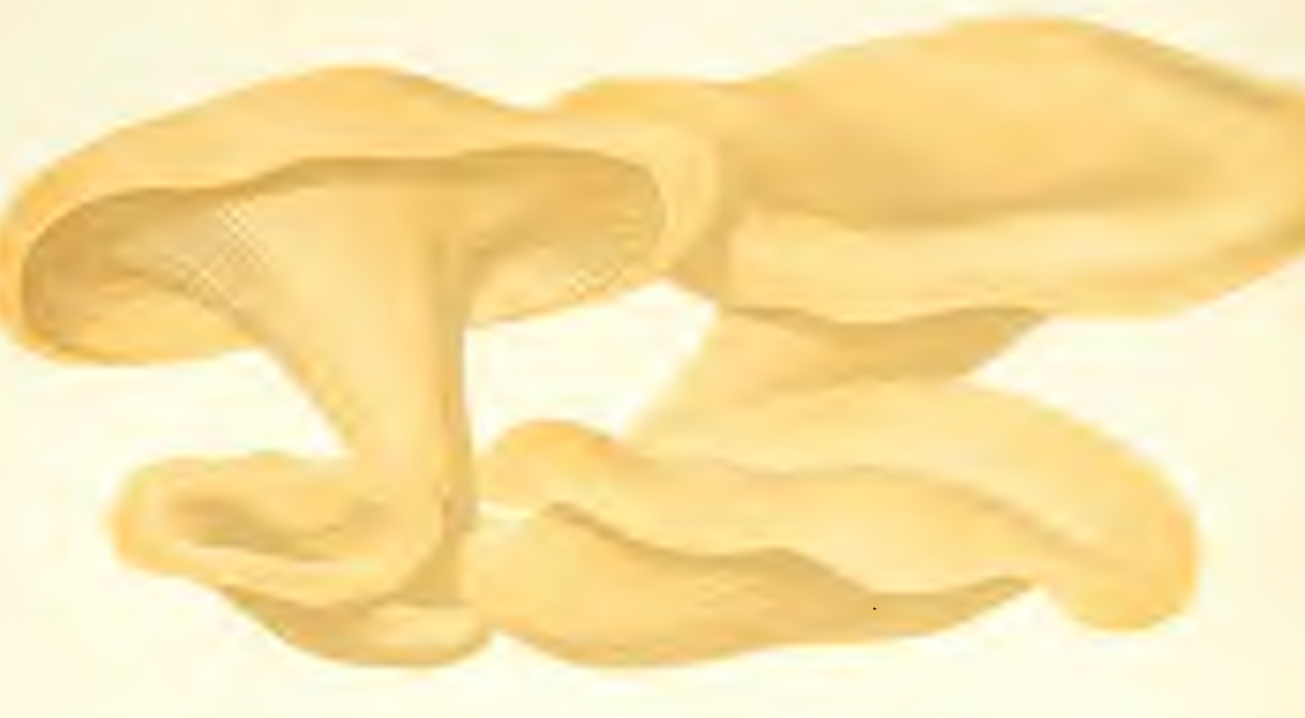

1. Agaric en conque. com.
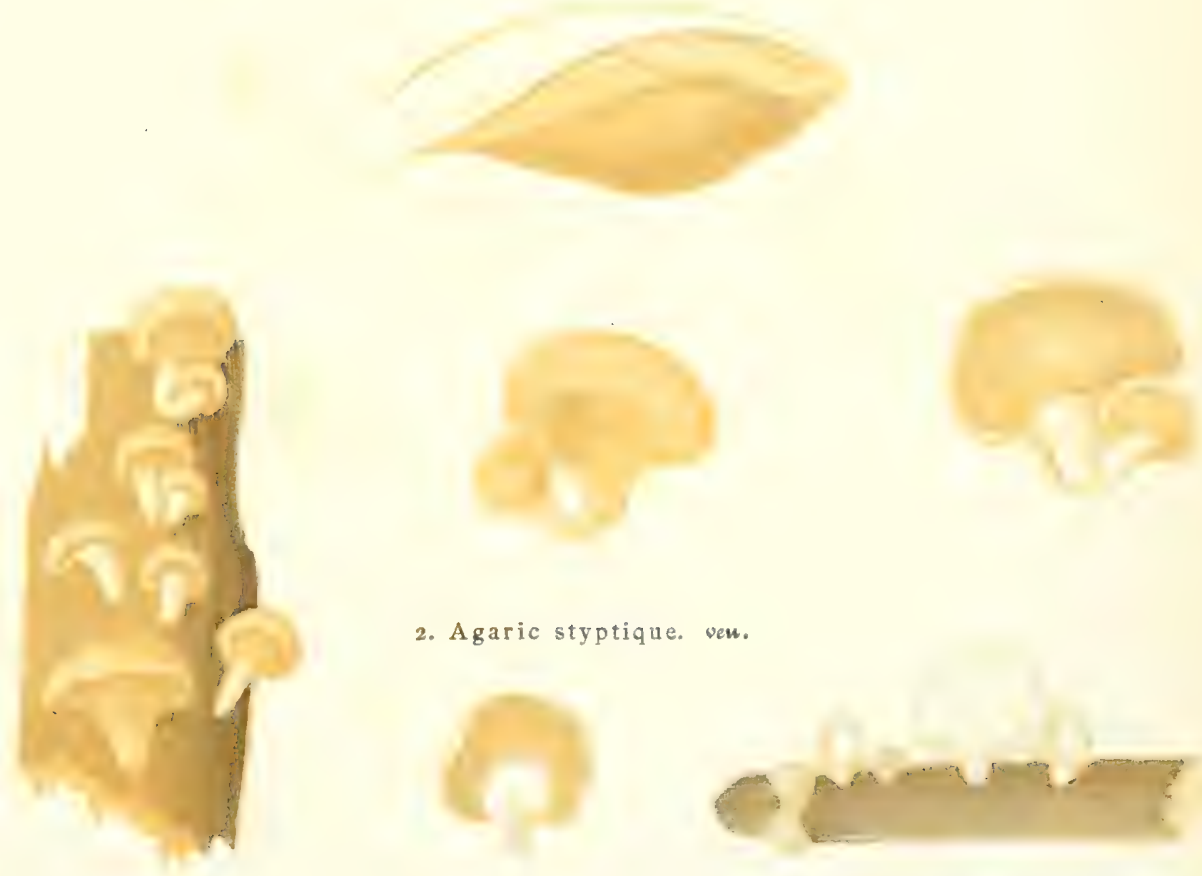

2. Agaric styptique. ven.
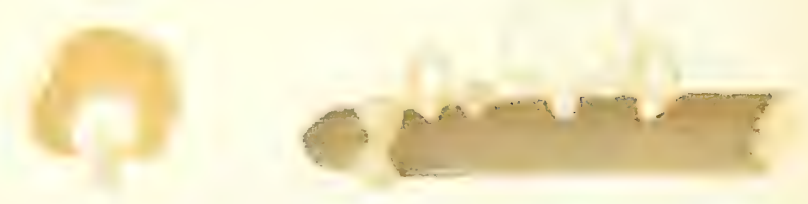

1. AGARICUS CONCHATUS. BULL. - 2. AGARICUS STYPTICUS. BULL.

PI. XIX. 



\section{LES CHAMPIGNONS DE FRANCE.}

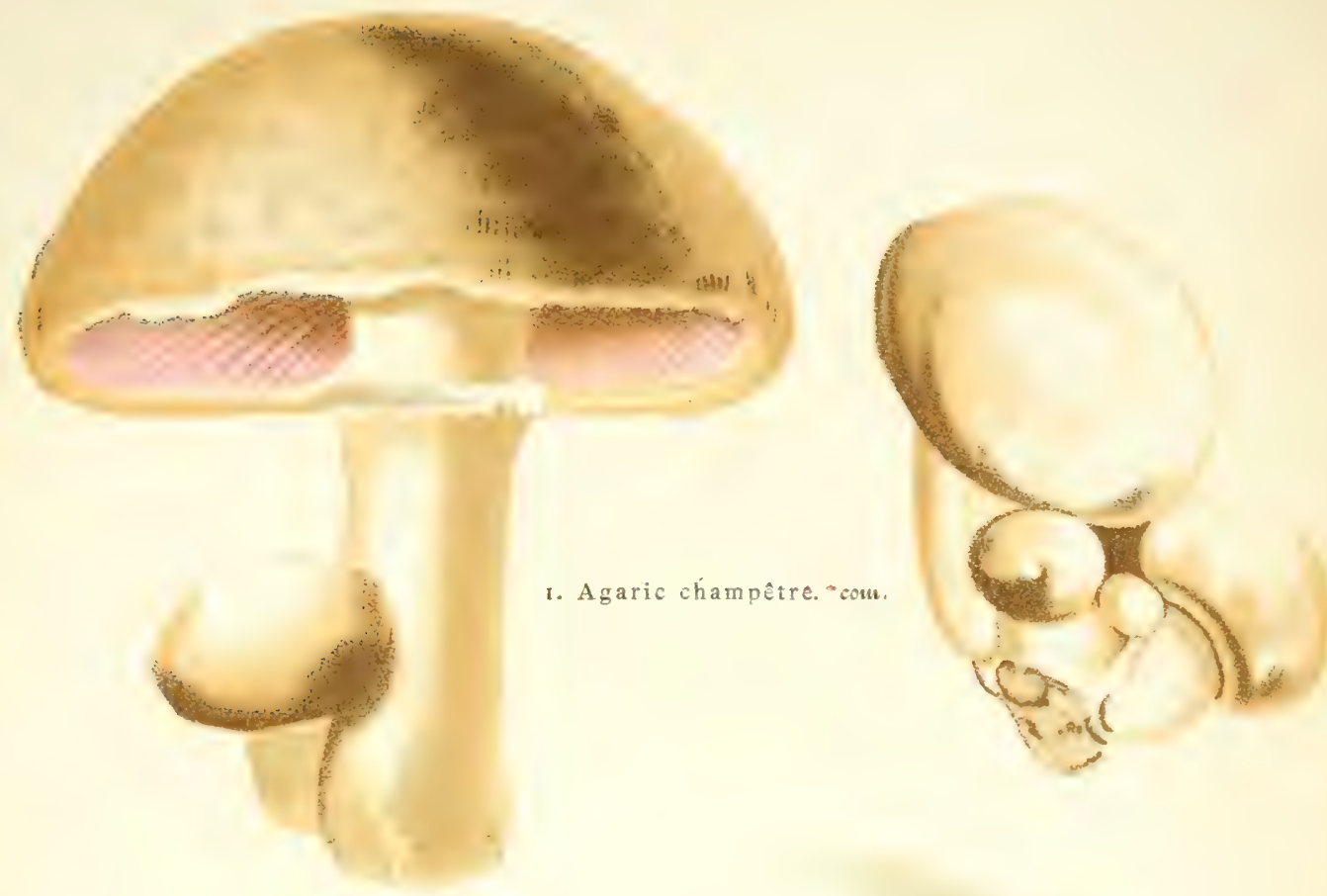

2. Agaric boule de neige. cou.
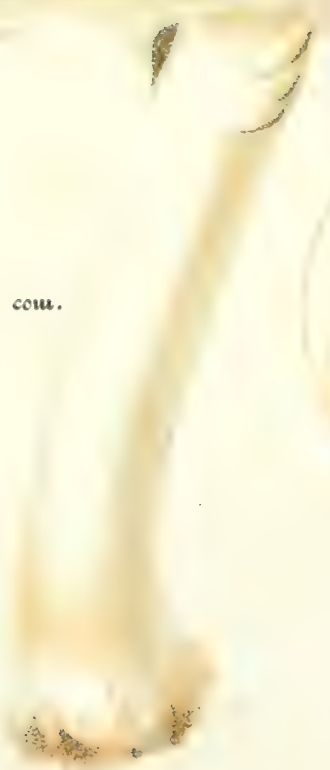

I. AGARICUS CAMPESTRIS. LIN. - 2. AGARICUS ARVENSIS. SCHEFF.

PI. XX. 

LES CHAMPIGNONS DE FRANCE.

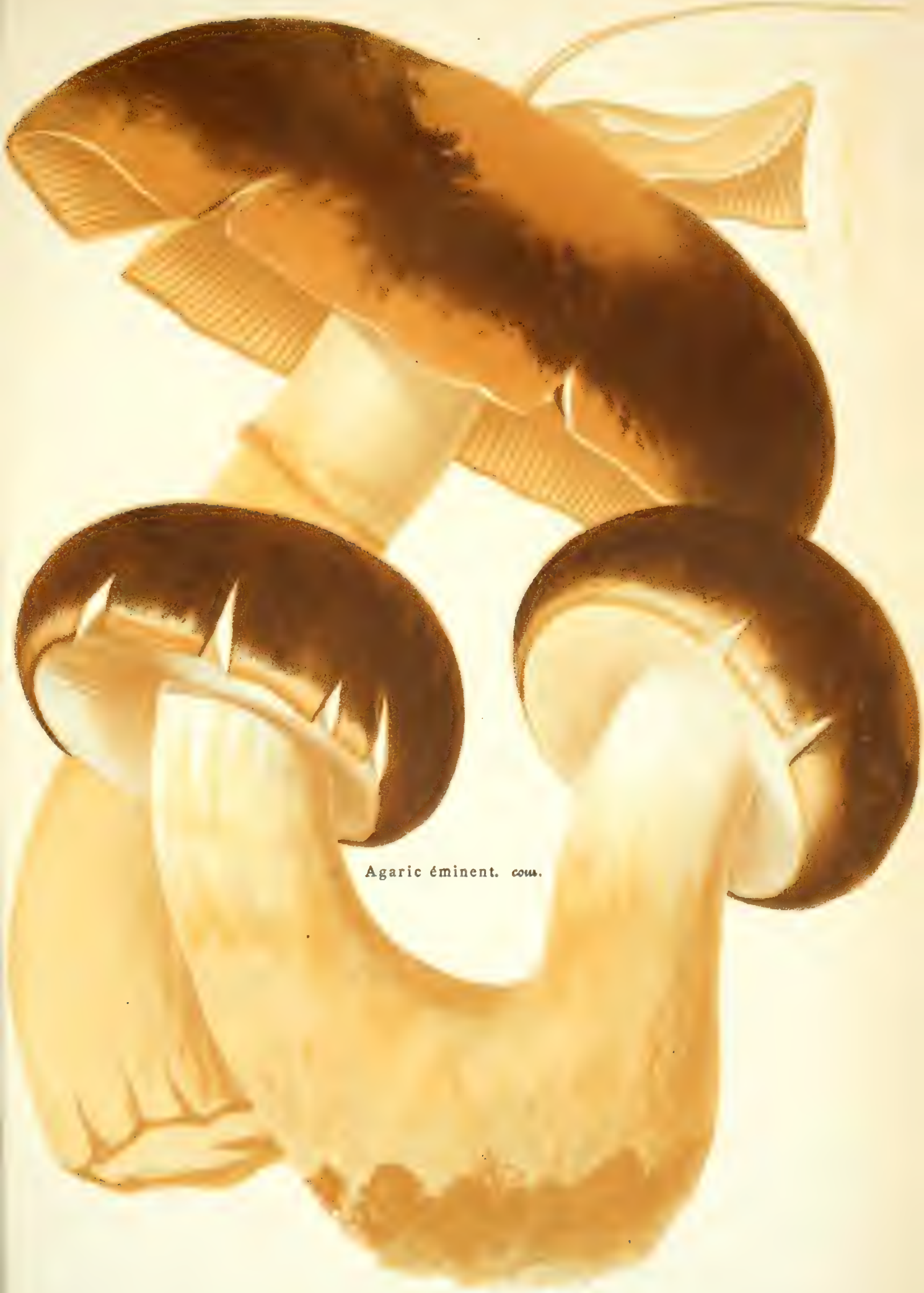

AGARICUS PRESTANS. CORDE.

Pl. XXI. 



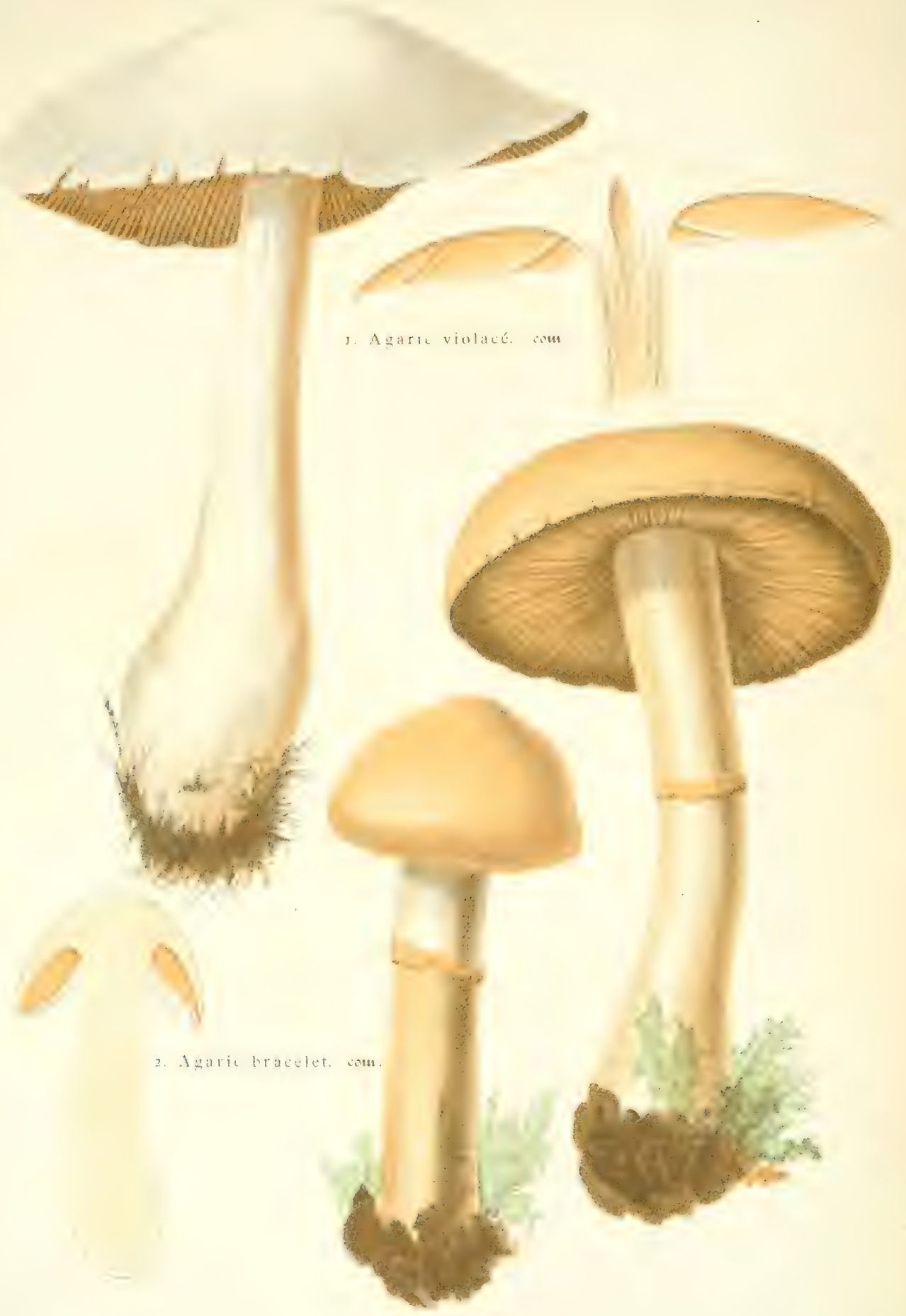

1. AGARICUS VIOLACEUS. BvLl- -2 , AGARICUS ARMILLATUS $\boldsymbol{F}_{R}$.

PI. XIII. 



\section{LES CHAMPIGNONS DE FRANCE.}

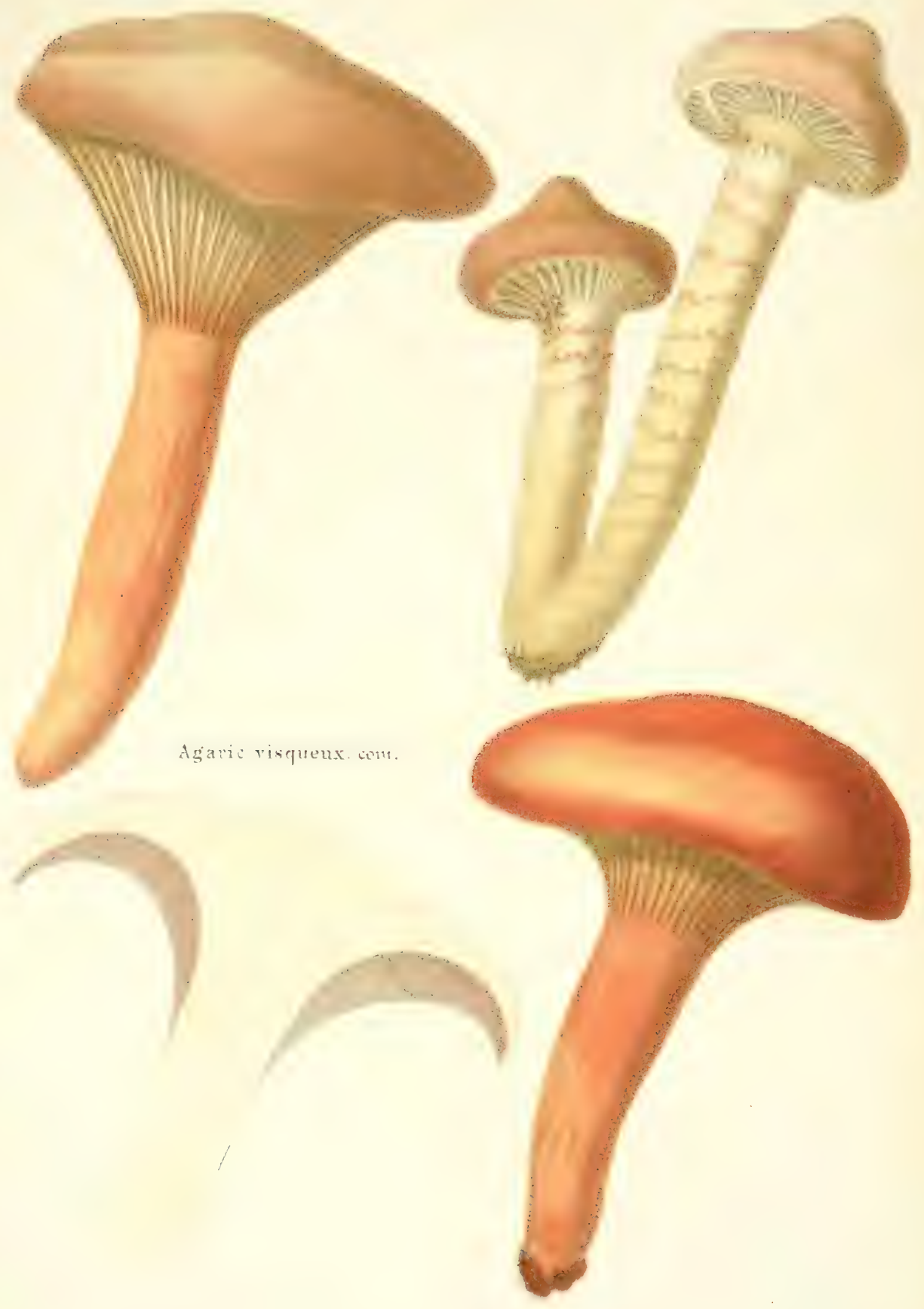

AGARICUS VISCIDUS. LIN.

PI. XXIII. 

LES CHAMPIGNONS DE FRANCE.

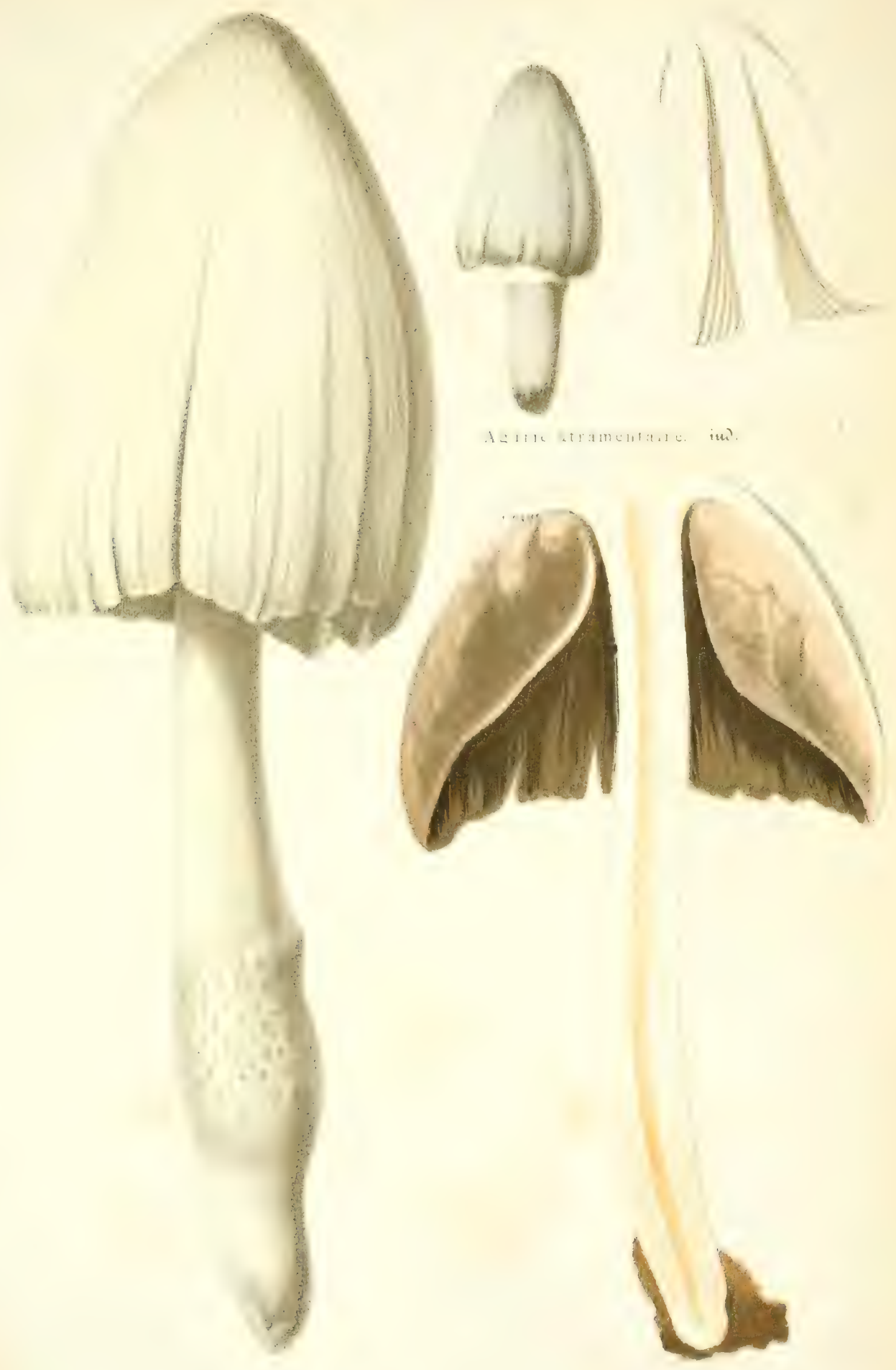

AGARICUS ATRAMENTARIUS. BULL.

Pl. XXIV. 



\section{LES CHAMPIGNONS DE FRANCE.}
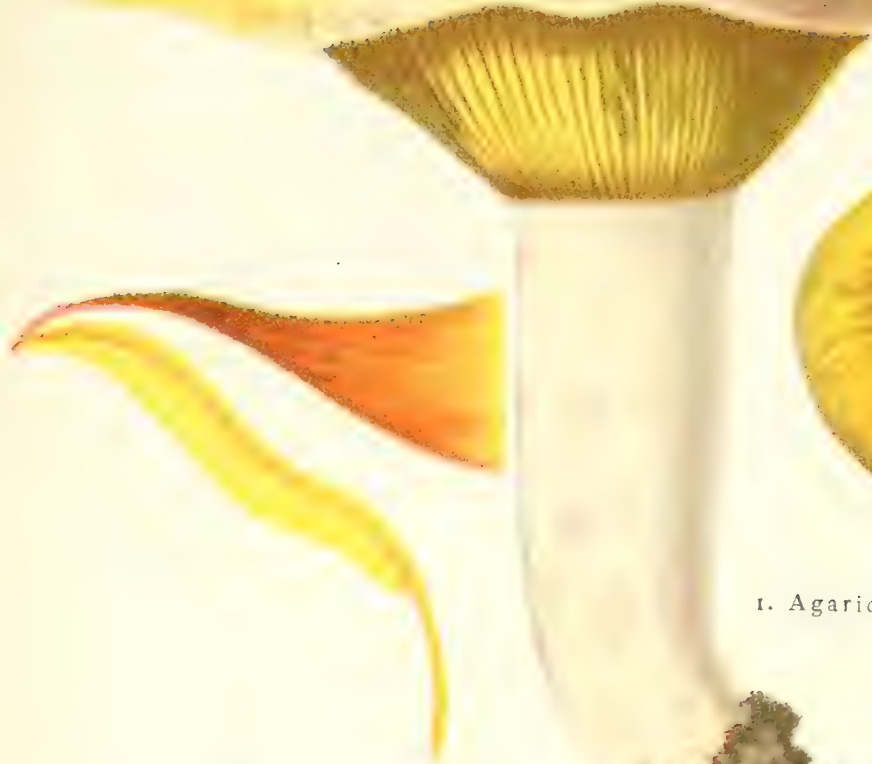

I. Agaric délicieur.

coit.

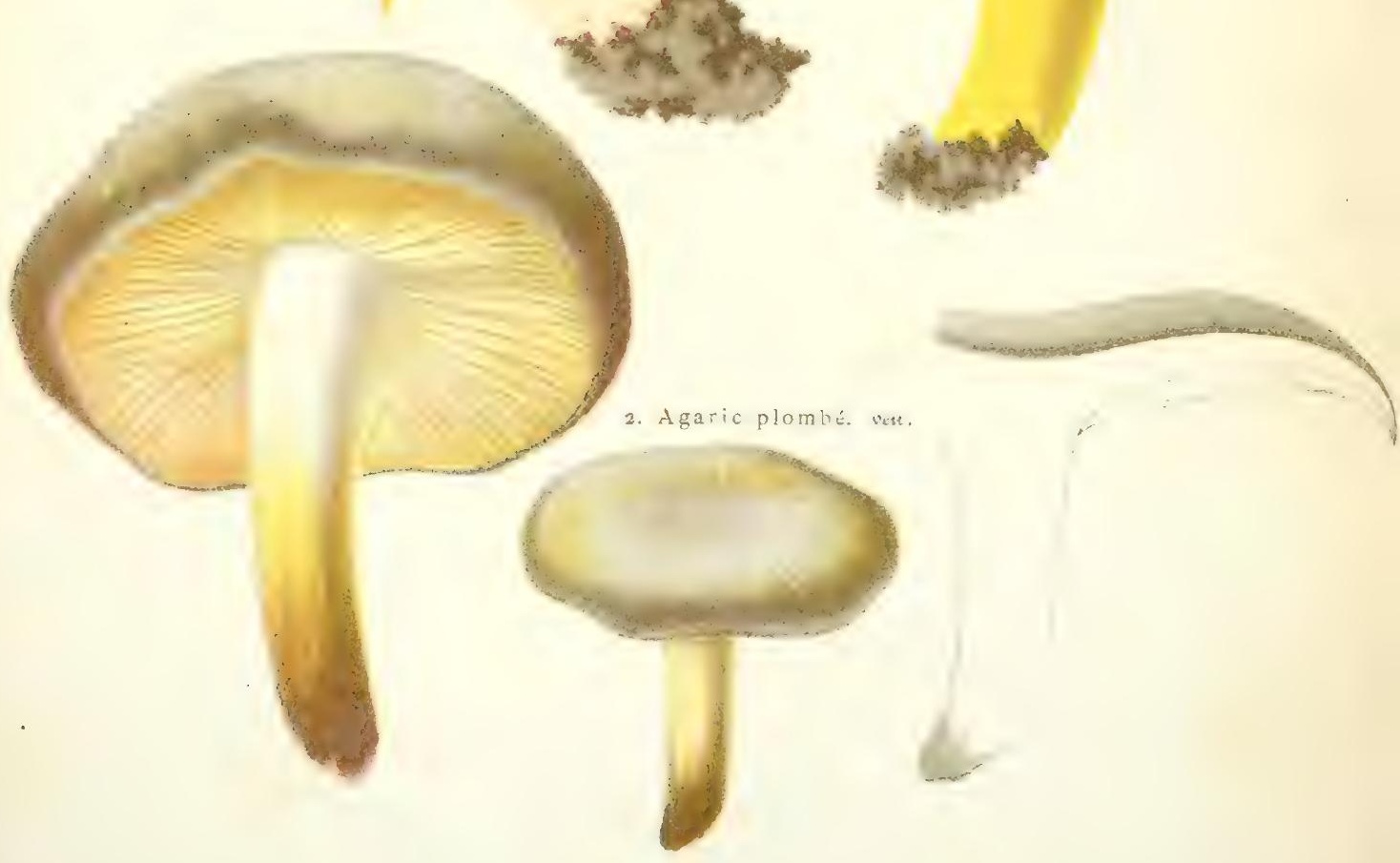

i. AGARICUS DELIC JSUS. LIN. - 2. AGARICUS PLUMBEUS. BULL.

PI. XXV. 



\section{LES CHAMPIGNONS DE FRANCE.}

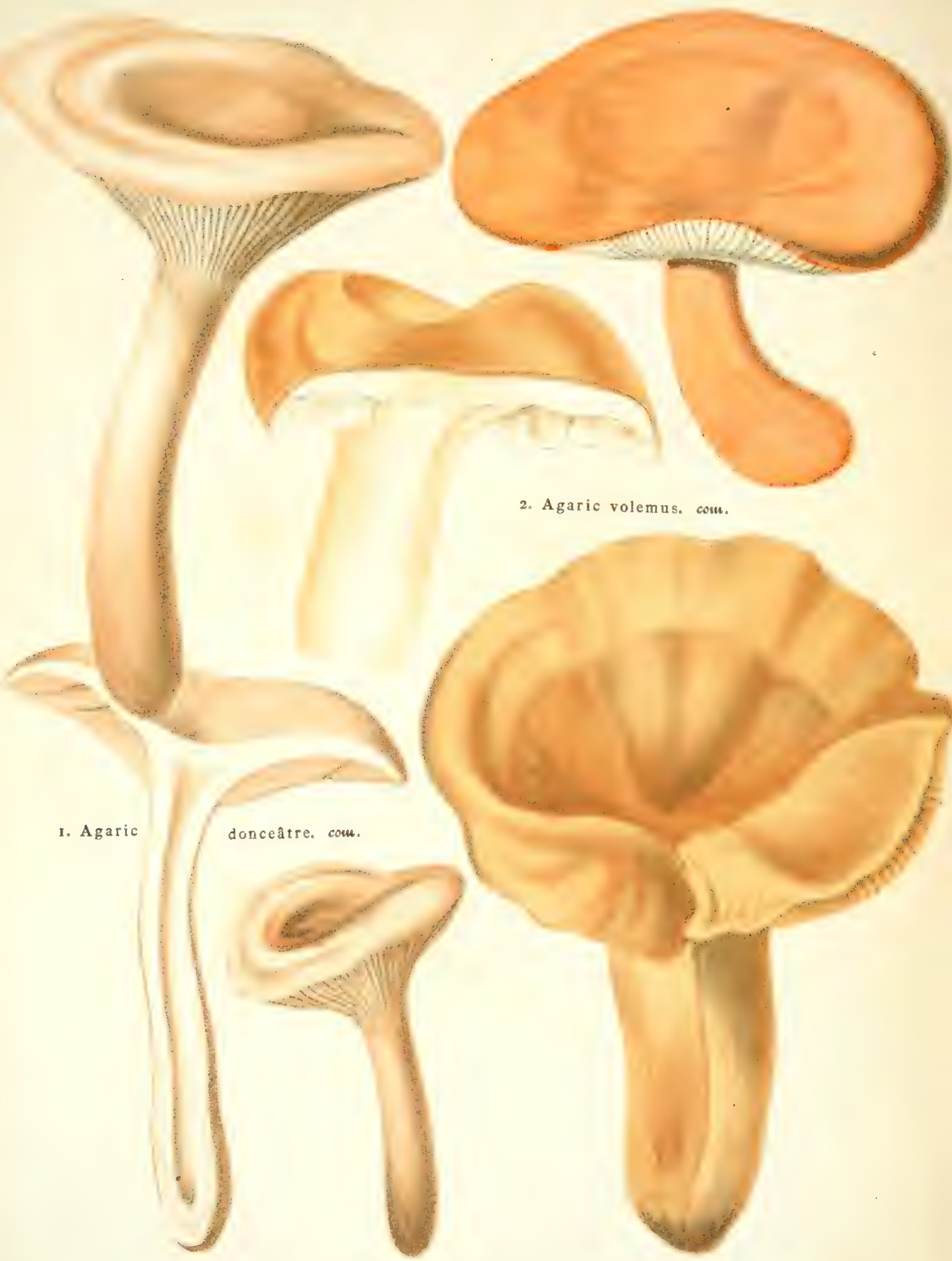

r. AGARICUS SUBDULCIS. BULL. - 2. AGARICUS VOLEMUS; $F \boldsymbol{R}$

PI. XXYI. 



\section{LES CHAMPIGNONS DE FRANCE.}

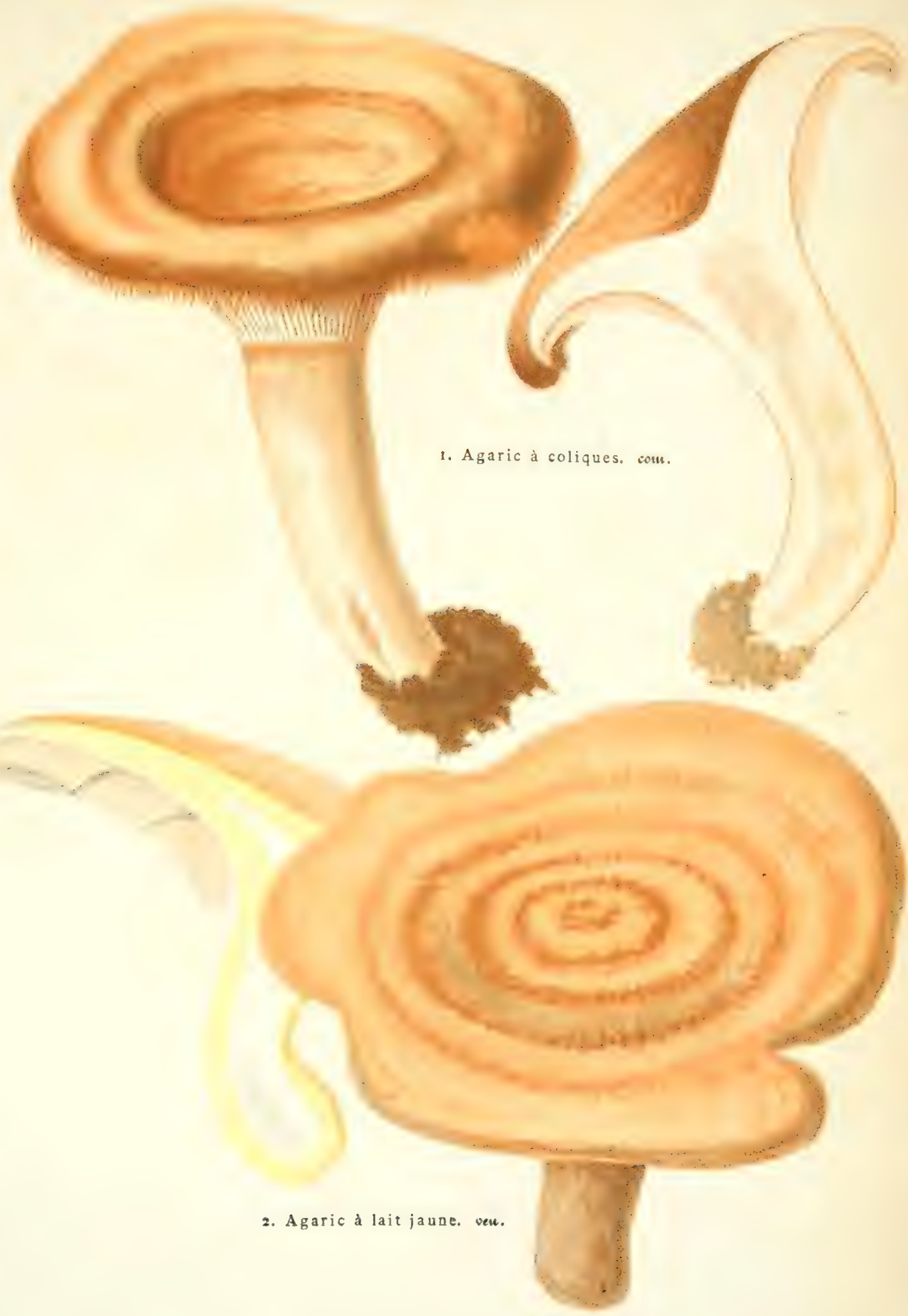

I. AGARICUS TORMINOSUS. SCHAEF. - 2. AGARICUS THEIOGALUS, BULL.

PI. XXVII. 



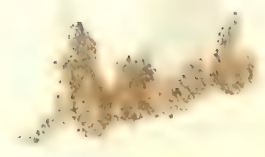





\section{LES CHAMPIGNONS DE FRANCE.}

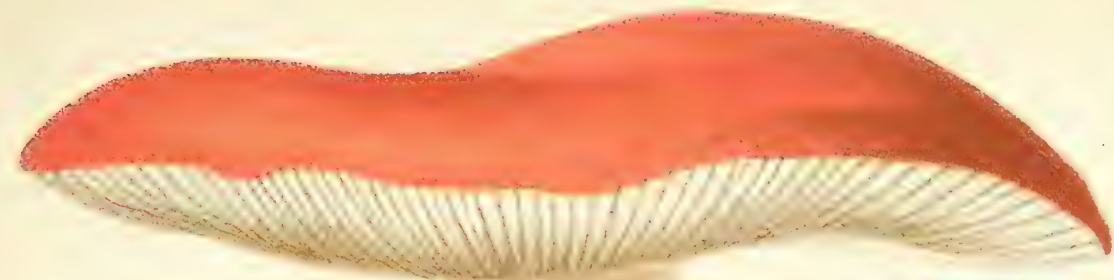

1. Agaric lépide.

coms.
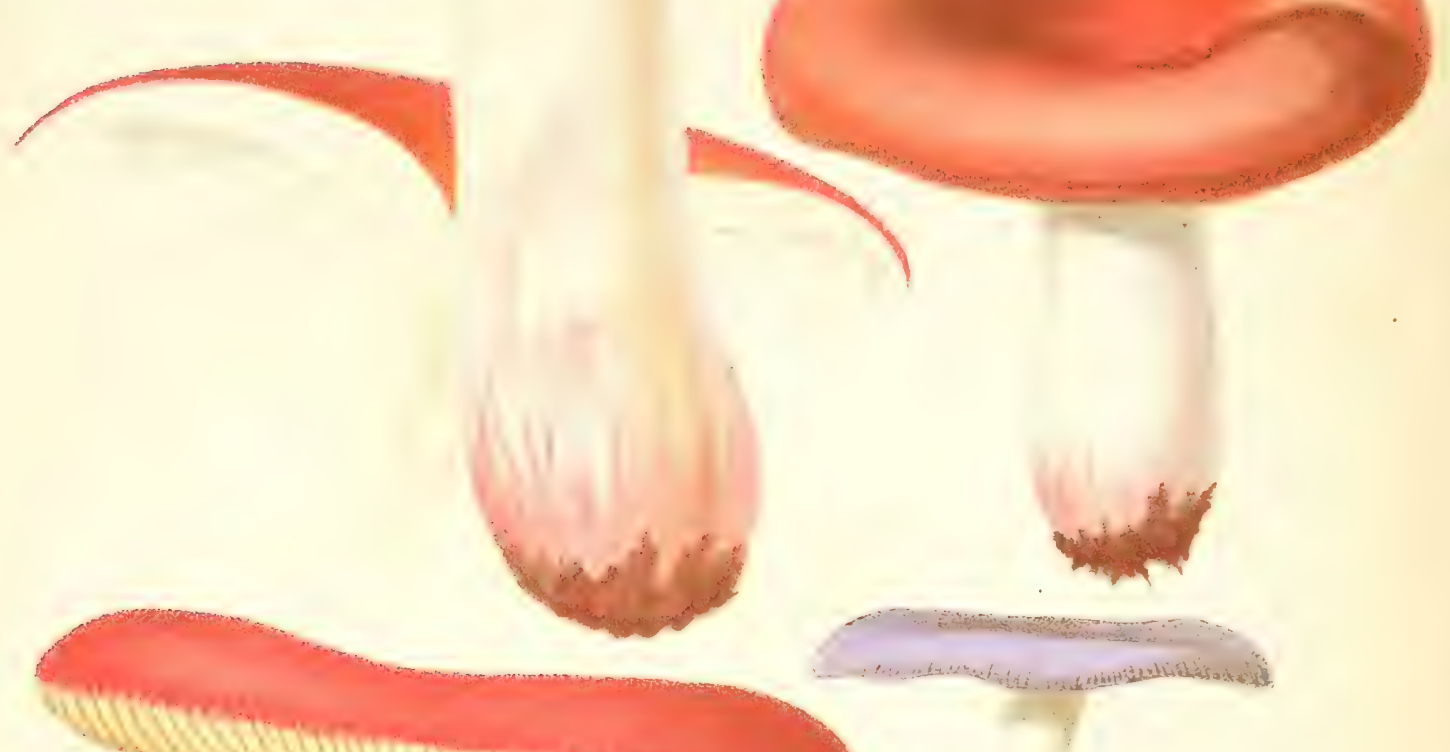

2. Agaric alutacé. com.
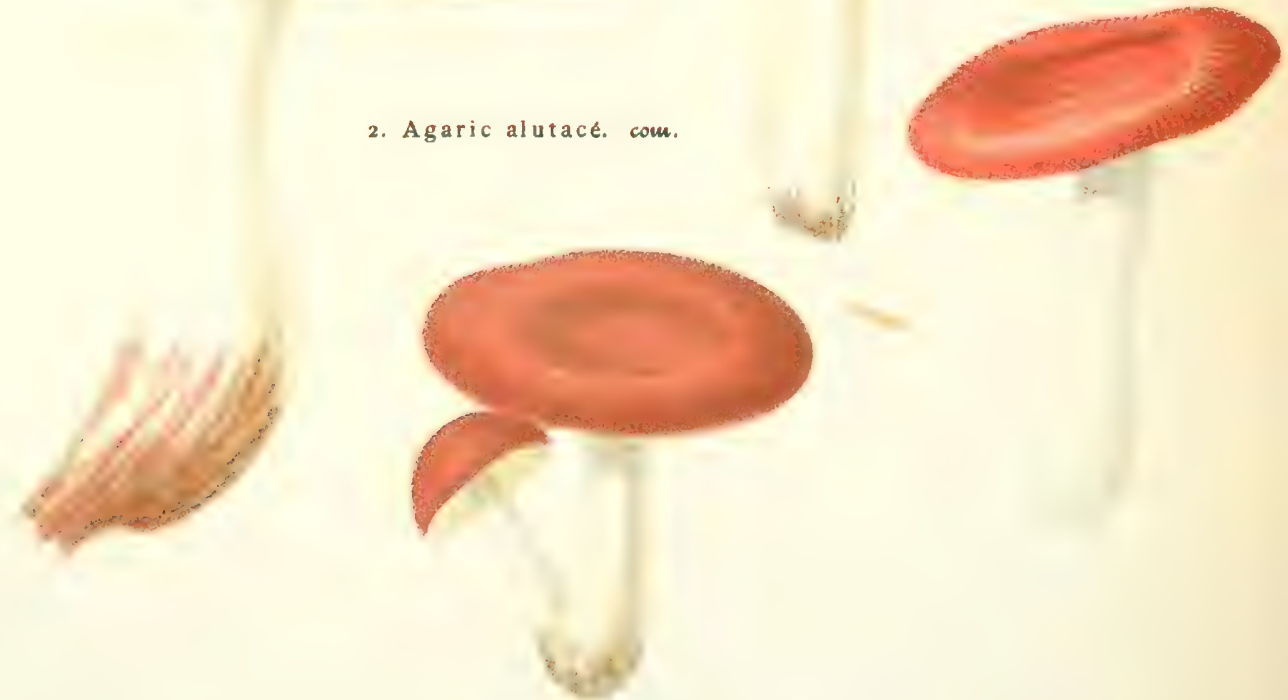

1. AGARICUS LEPIDUS. Fr. - 2. AGARICUS ALUTACEUS. PERS.

PI. XXIX. 



\section{LES CHAMPIGNONS DE FRANCE.}
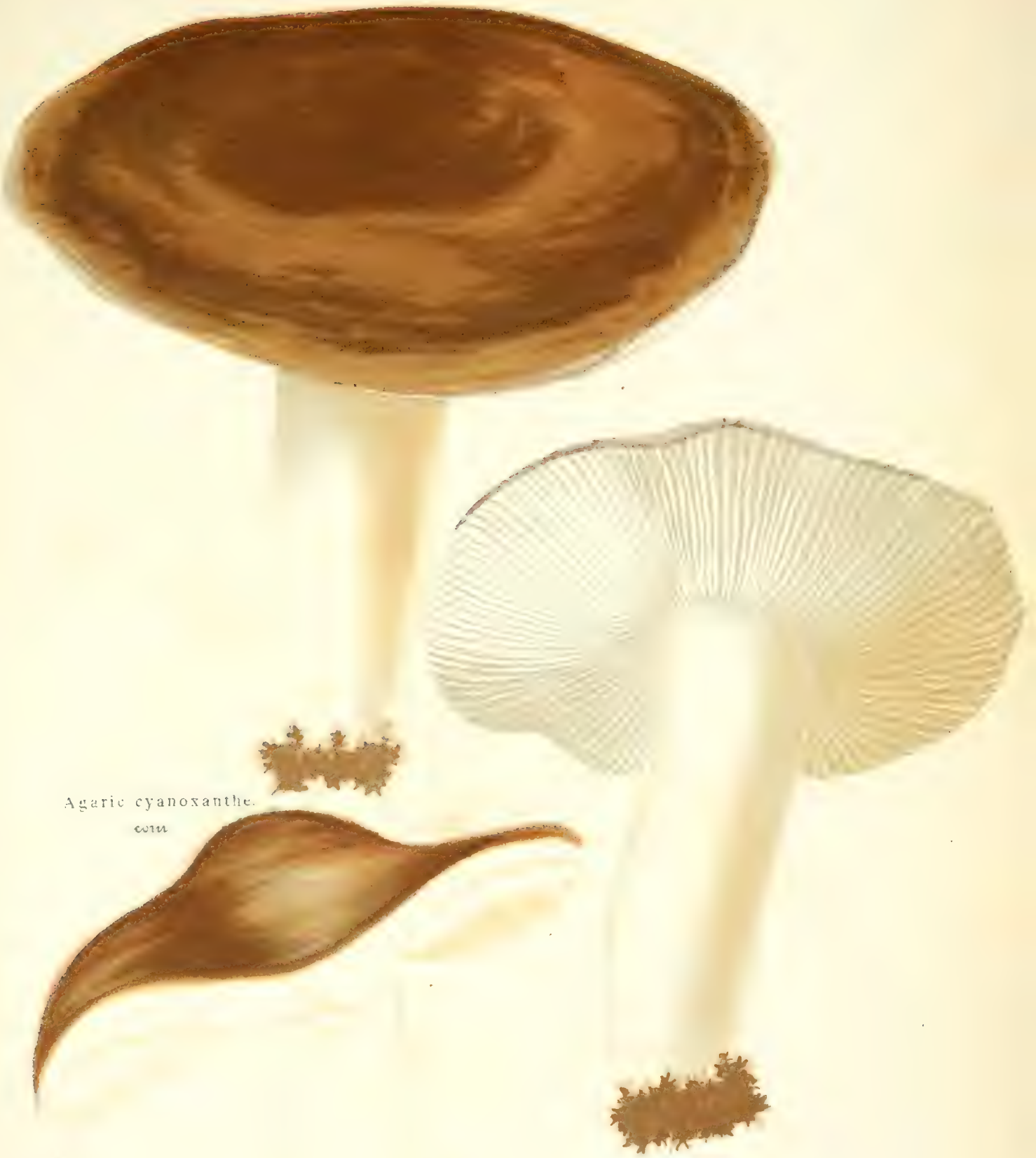



\section{LES CHAMPIGNONS DE FRANCE.}

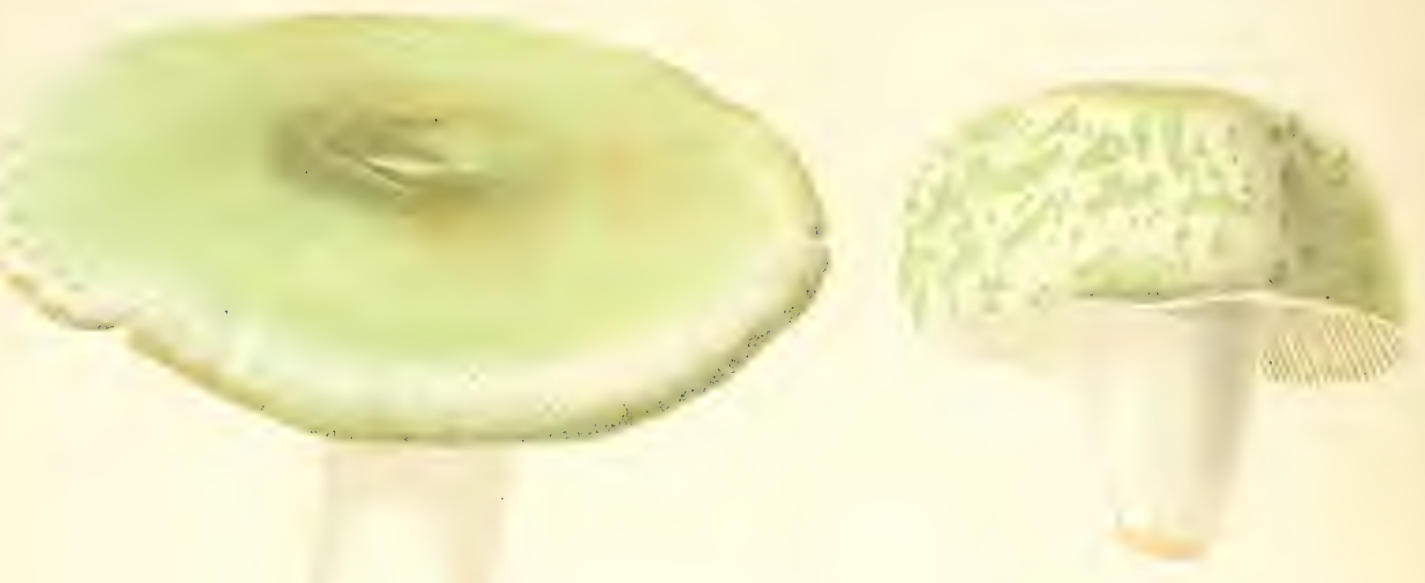

Agaric verdoyant. com.

AGARICUS VIRESCENS. $F_{k}$

PI. XXXI. 



\section{LES CHAMPIGNONS DE FRANCE.}

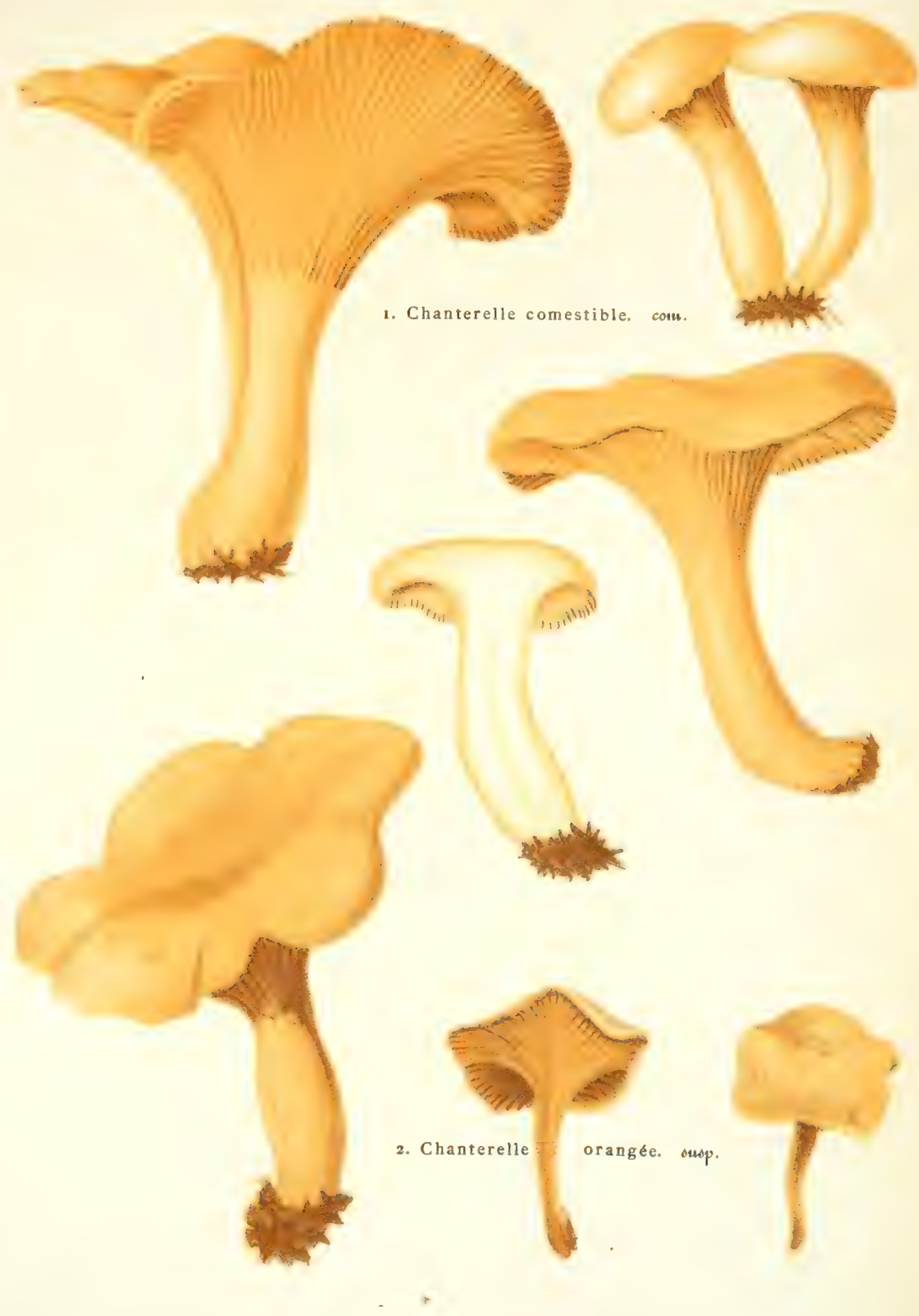

1. CANTHARELLUS CIBARIUS. $F \boldsymbol{R} .-2$. CANTHARELLUS AURANTIACUS. $\boldsymbol{F} R$. PI. XXXII. 



\section{LES CHAMPIGNONS DE FRANCE.}

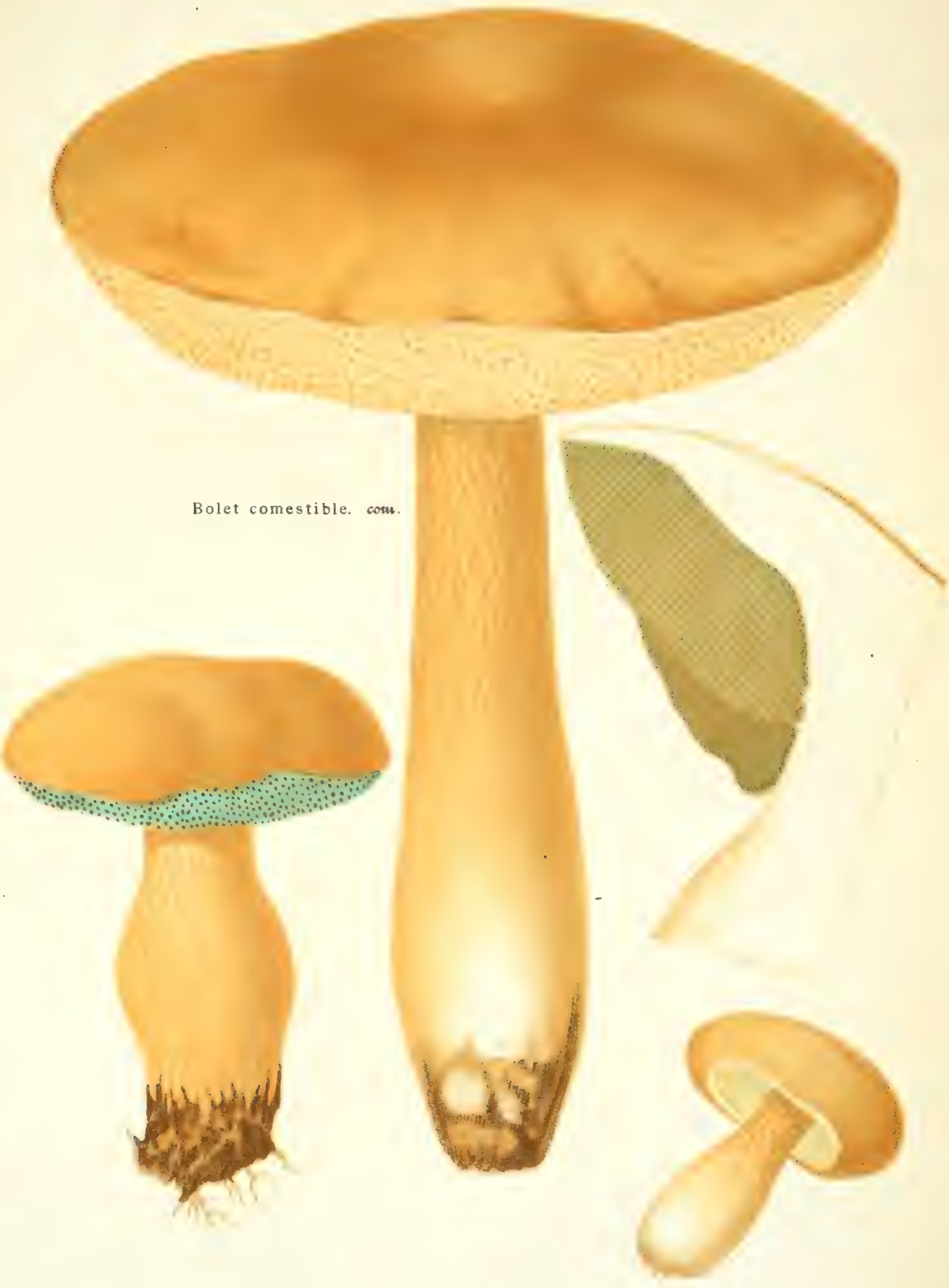

I. BOLETUS EDULIS. BULL.

PI. XXXIV. 



\section{LES CHAMPIGNONS DE FRANCE.}
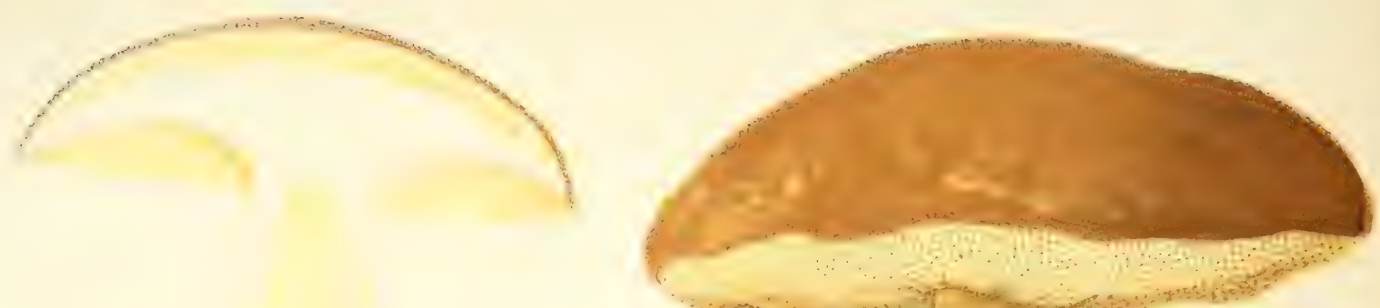

2. Bolet jaune. coum.

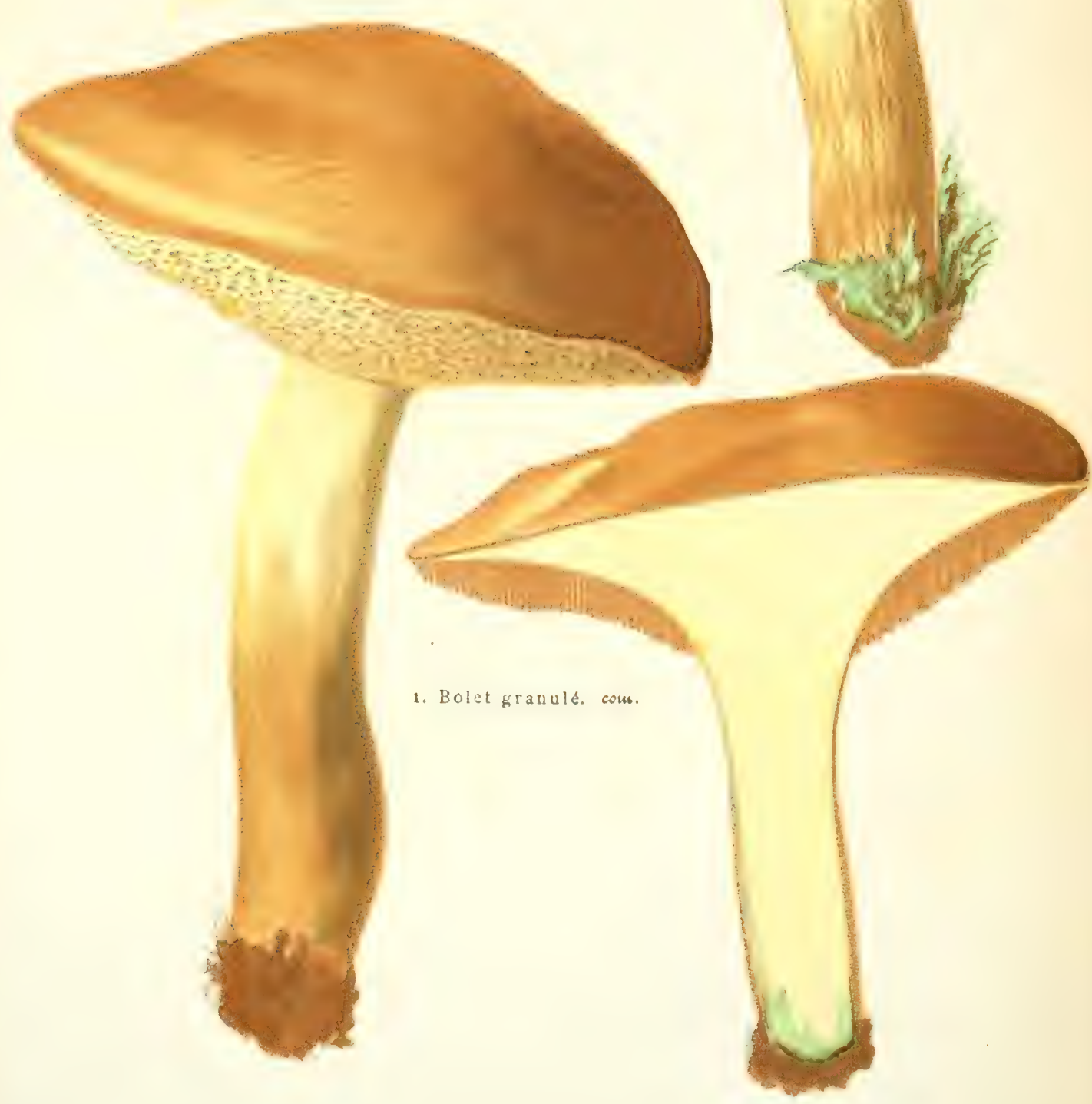

I. BOLETUS GRANULATUS. LIN. - 2. BOLETUS LUTEUS. LIN.

PI. XXXV. 



\section{LES CHAMPIGNONS DE FRANCE.}

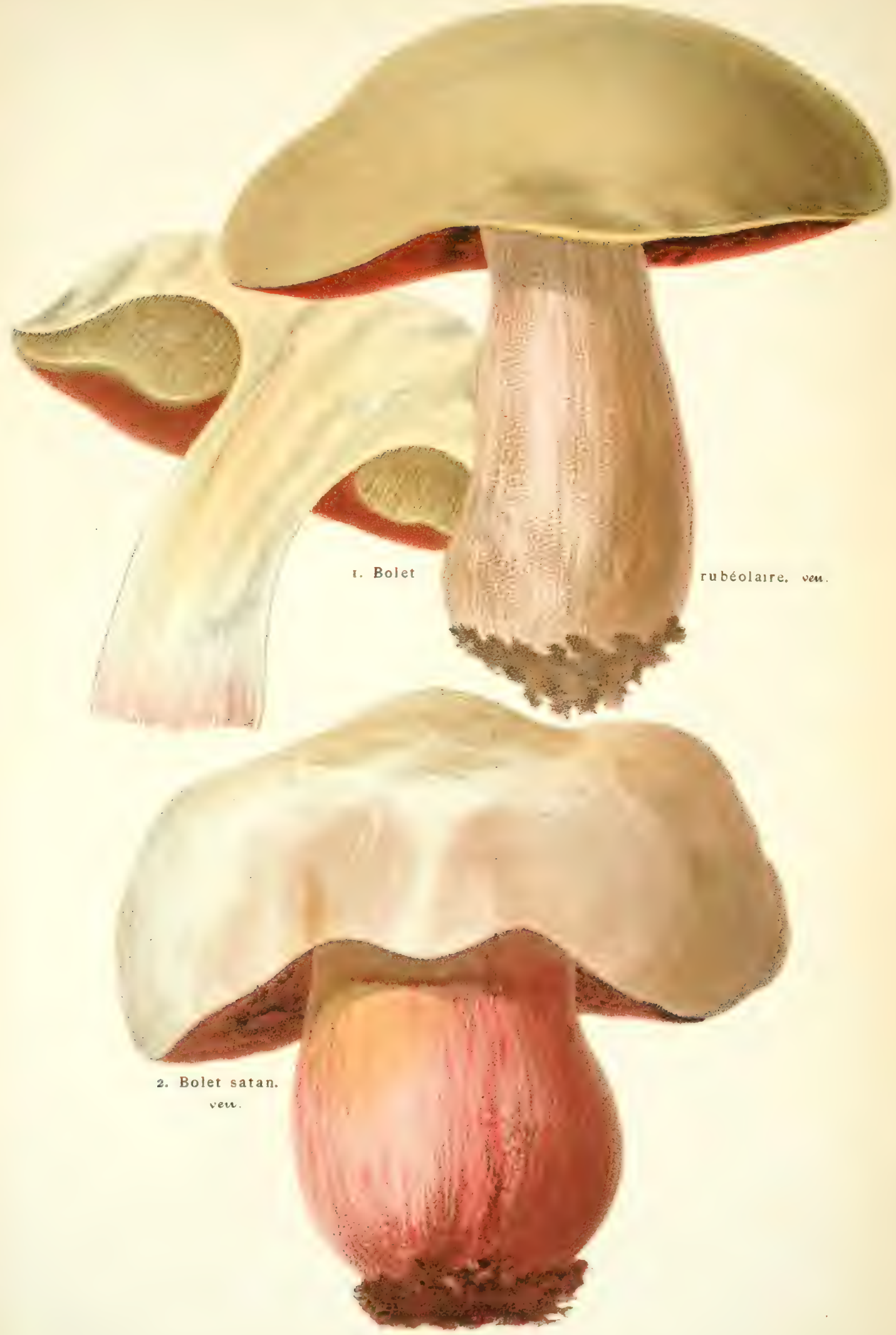

I. BOLETUS LURIDUS. $F R .-2$. BOLETUS SATANAS. LENZ.

PI. XXXVI. 



\section{LES CHAMPIGNONS DE FRANCE.}

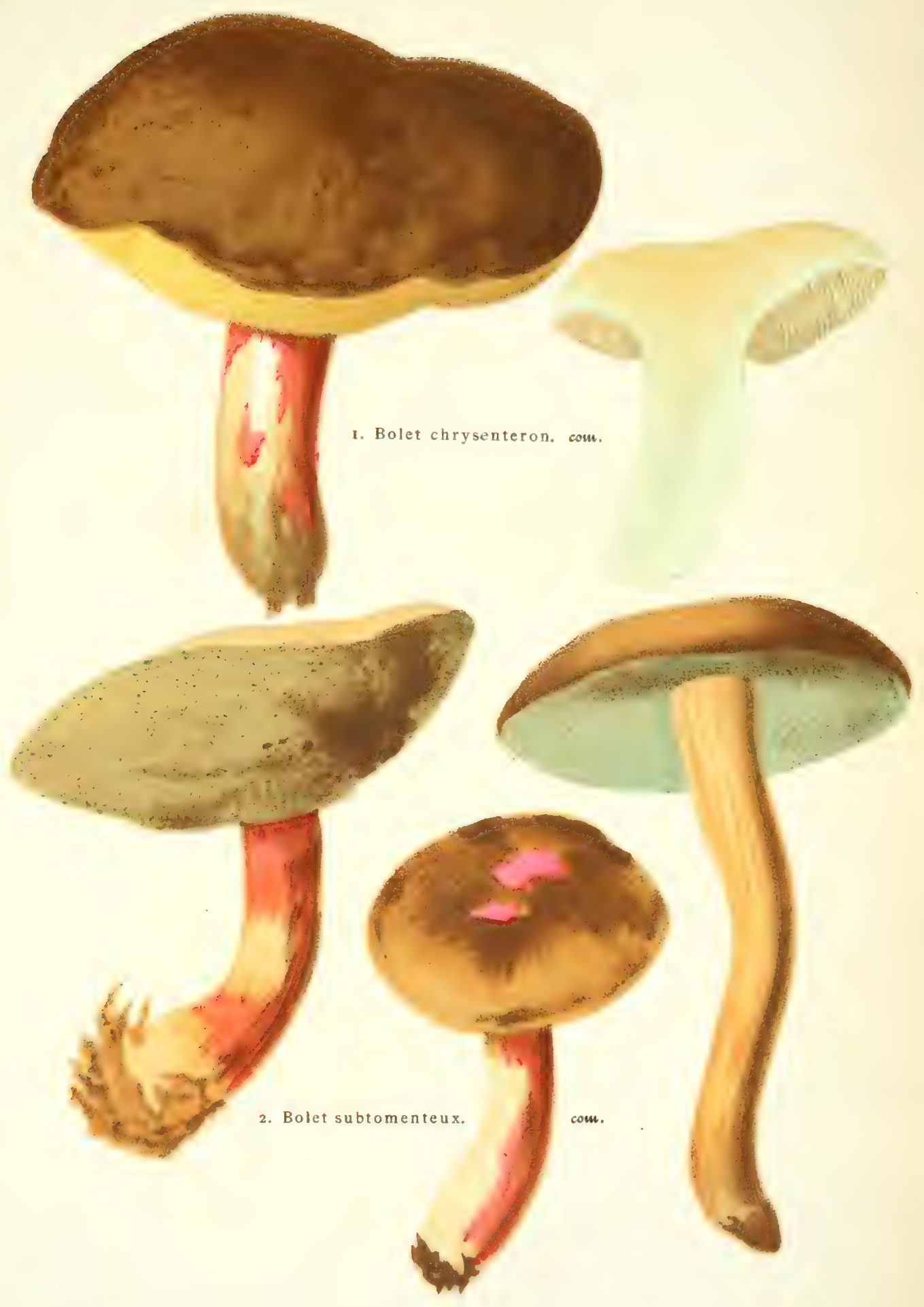

I. BOLETUS CHRYSENTERON. BULL. - 2. BOLETUS SUBTOMENTOSUS. LIN. PI. XXXVIII. 



\section{LES CHAMPIGNONS DE FRANCE.}

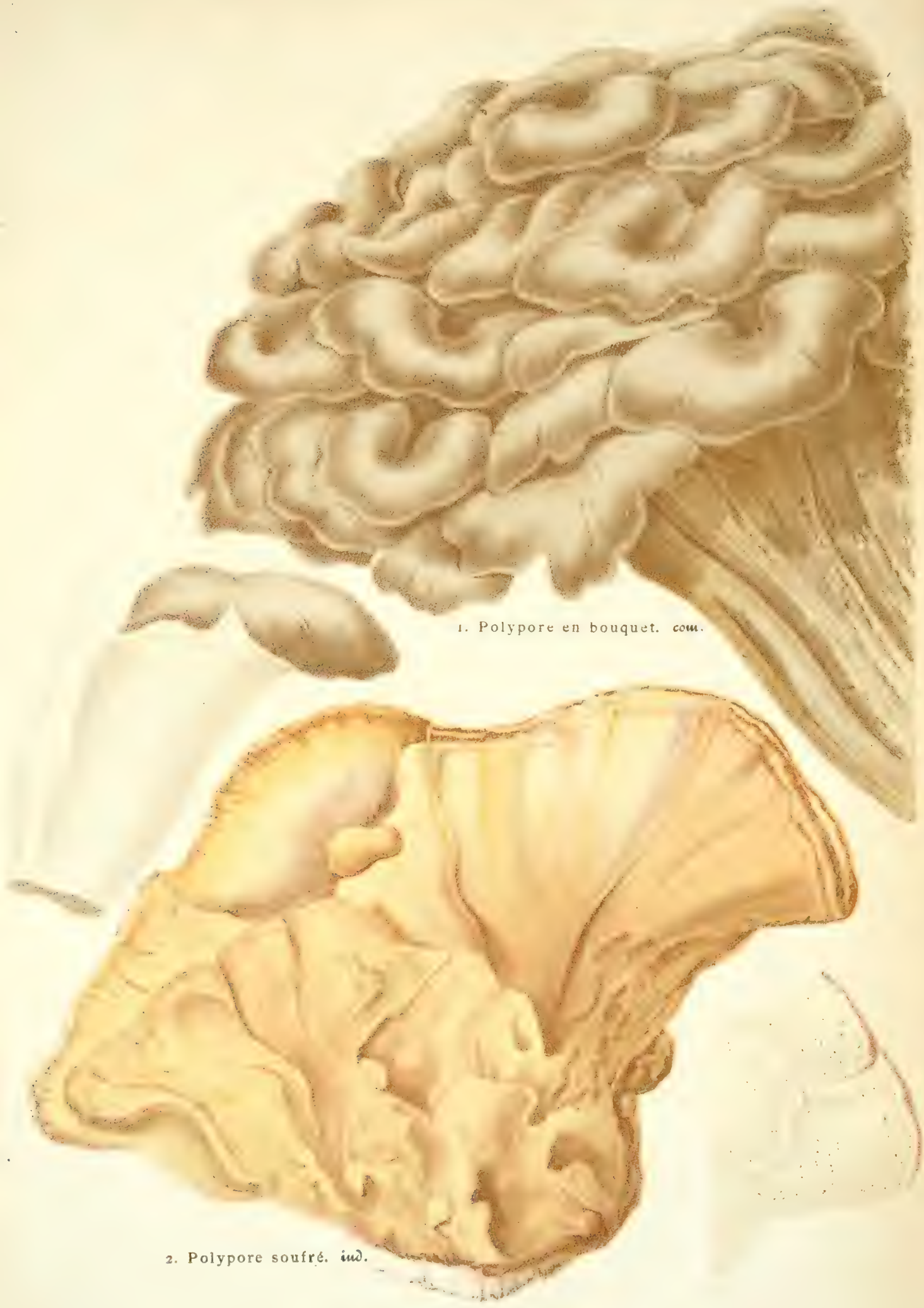

POLYPORUS FRONDOSUS. PERS. - 2. F OLYP('RUS SULFUREUS. $\dot{B} U L L$

PI. XXXIX. 

LES CHAMPIGNONS DE FRANCE.

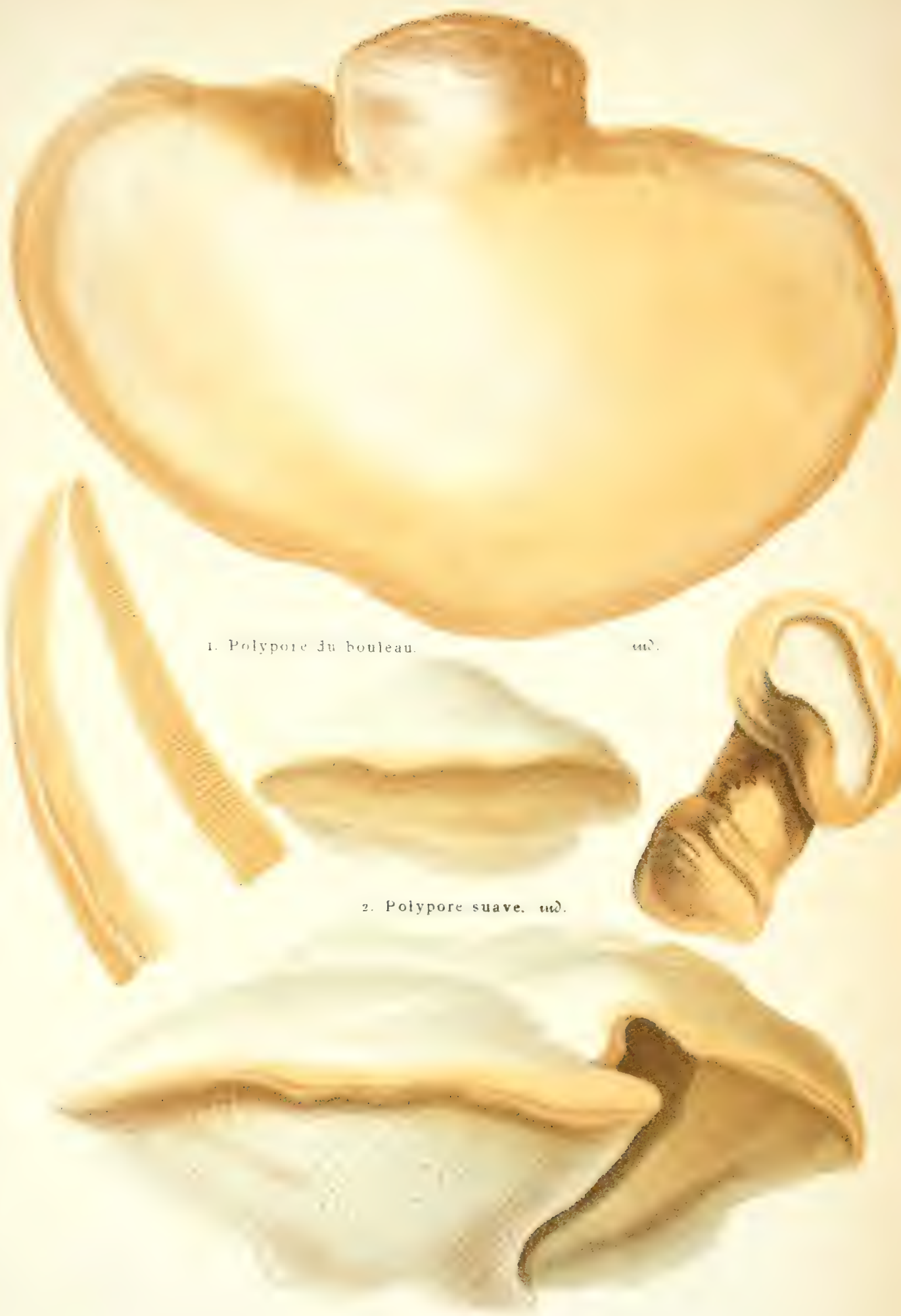

1. POLYPORUS BetUlinUS. BULl. - 2. POLYPORUS SUAVEOLENS: $\boldsymbol{F}$. P]. XLI. 



\section{LES CHAMPIGNONS DE FRANCE.}

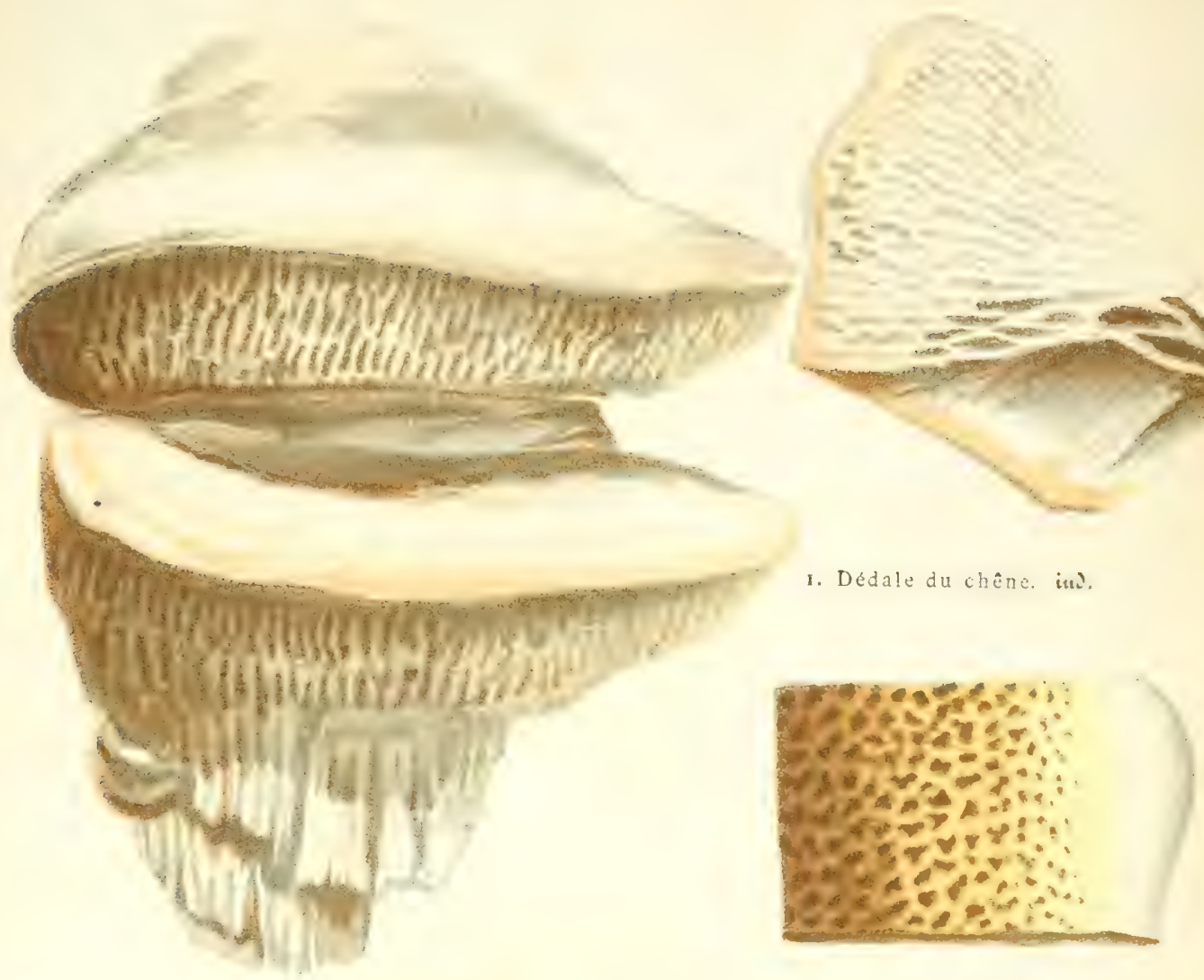

2. Mérule pleureur. com.

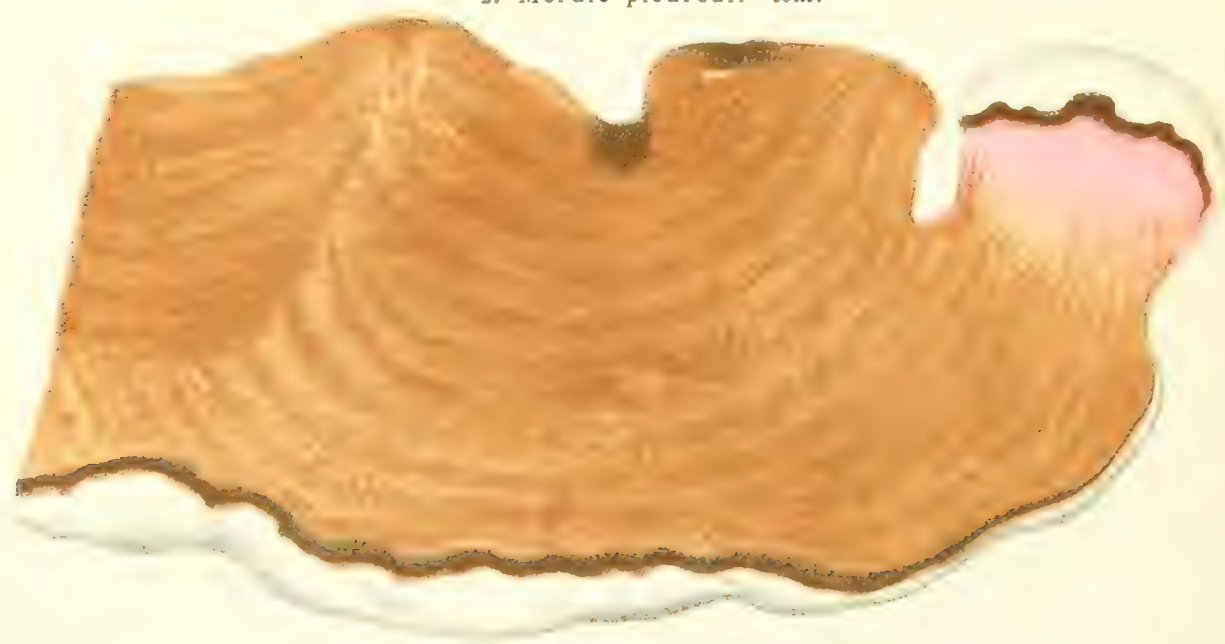

1. DeEdalea QUercina. PERs. - 2. MeruliUs lacrymans. $F r$.

Pl. XLII. 

LES CHAMPIGNONS DE FRANCE.

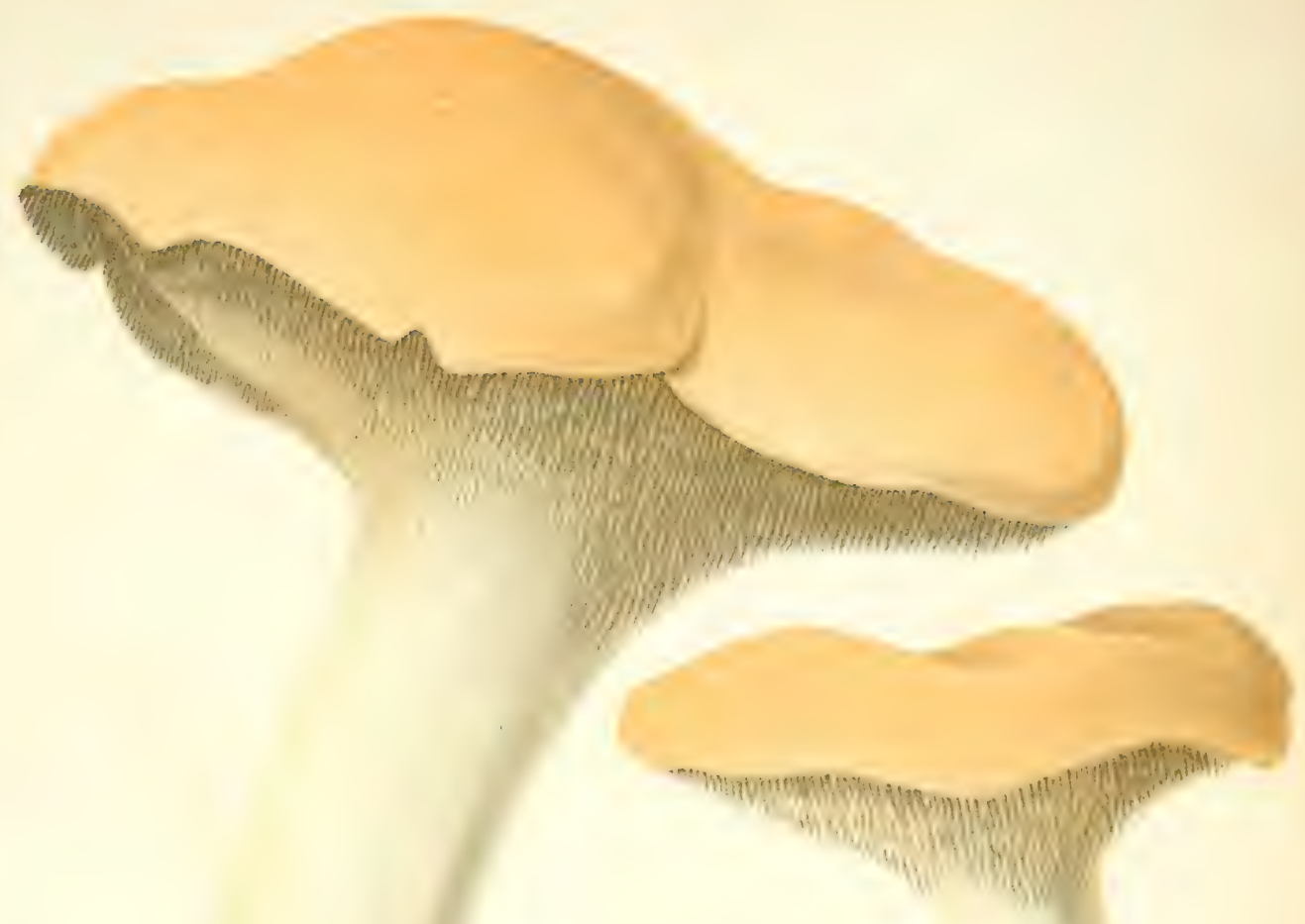

Hydne srume. :om

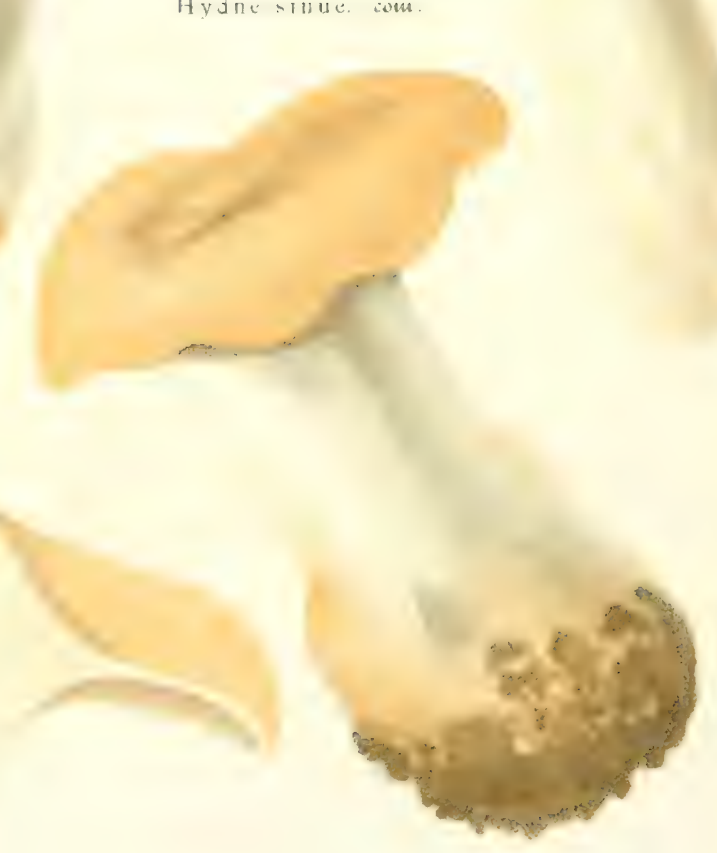

HYDNUM REPANDUM. LIN.

Pl. XliIII. 



\section{LES CHAMPIGNONS DE FRANCE.}

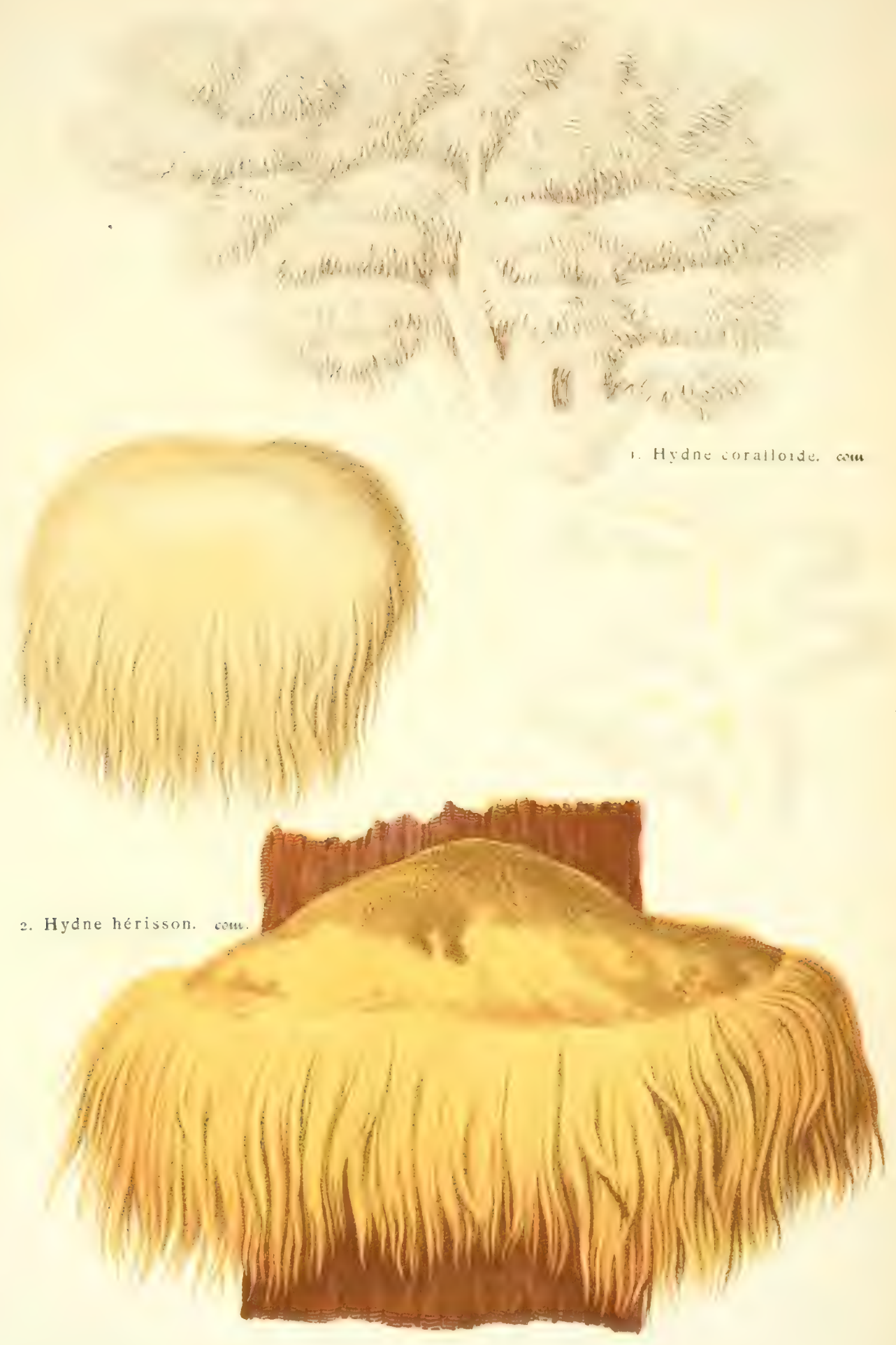

1. HYDNUM CORALLOIDES. SCOP. - 2. HYDNUM ERINACEUS. BULL.

PI. XIII. 



\section{LES CHAMPIGNONS DE FRANCE.}

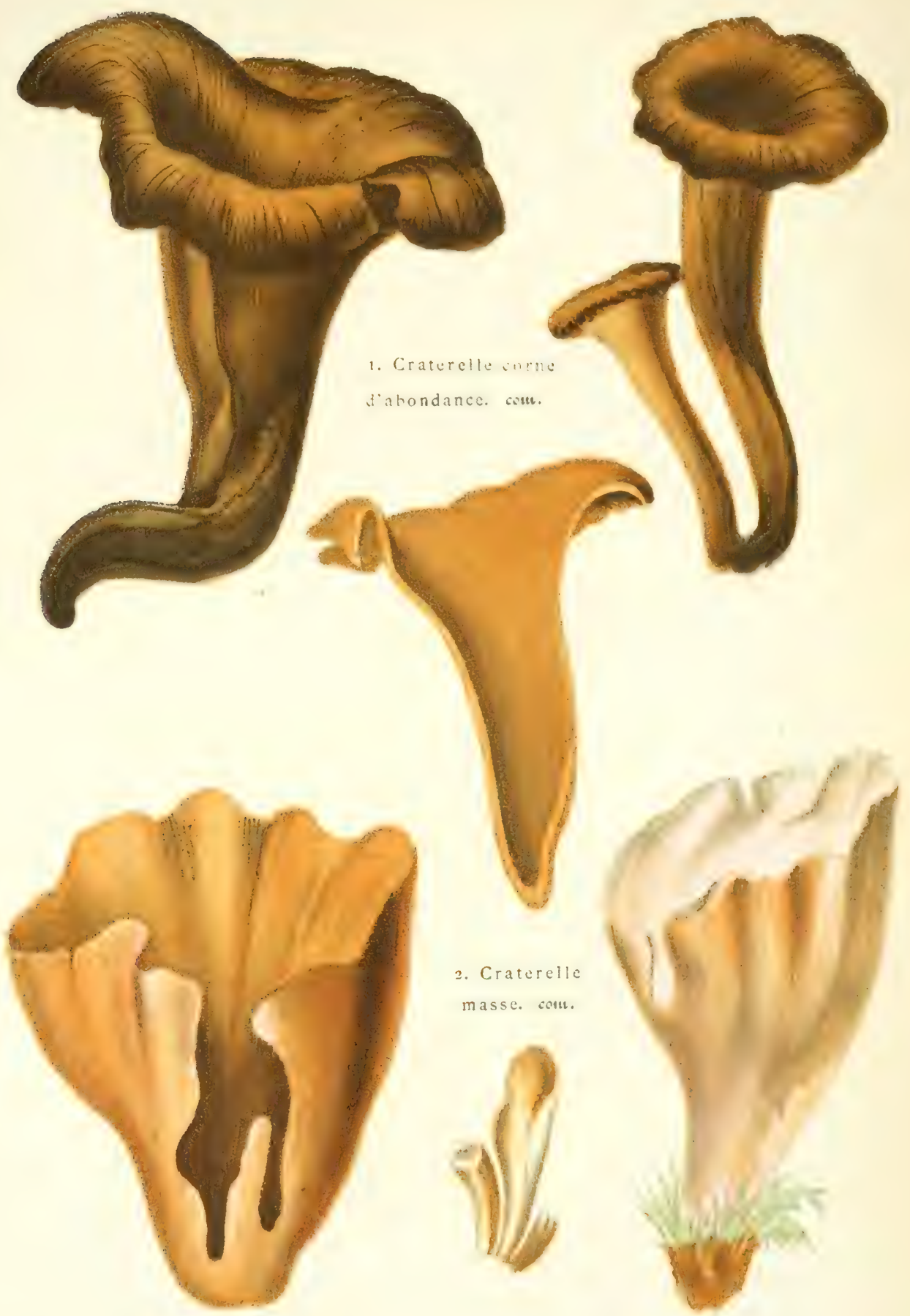

1. GRATERELLUS CORNUCOPIOIDES. PERS. - 2. CRATERELLUS ClAVATUS. Fra PI. XLV. 



\section{LES CHAMPIGNONS DE FRANCE.}

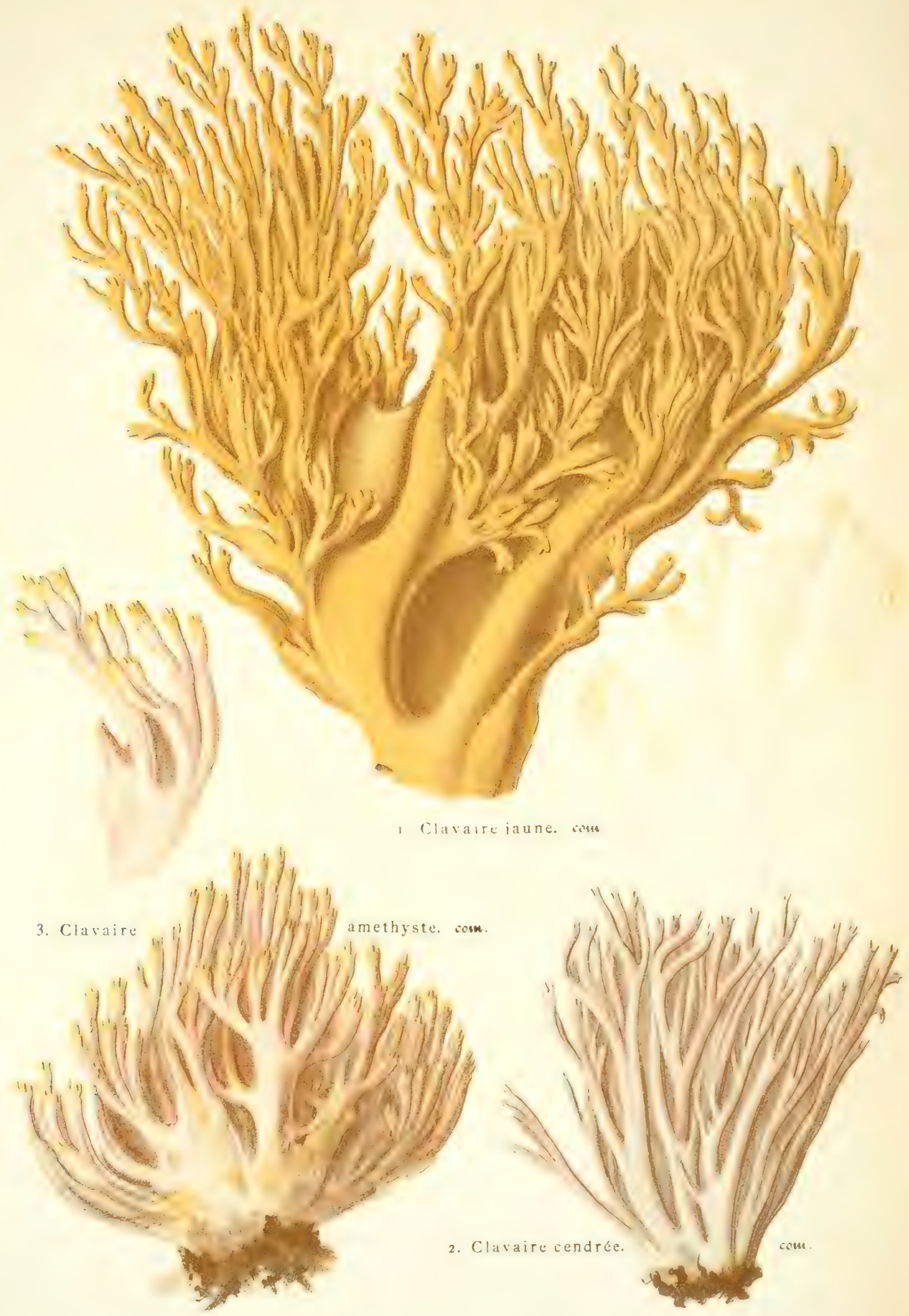

1. Clavaria Flava. PERS. - 2. Clavaria CiNerEa. Bull.

3. CLAVARIA AMETHYSTEA. BULL.

PI. XLY. 



\section{LES CHAMPIGNONS DE FRANCE.}
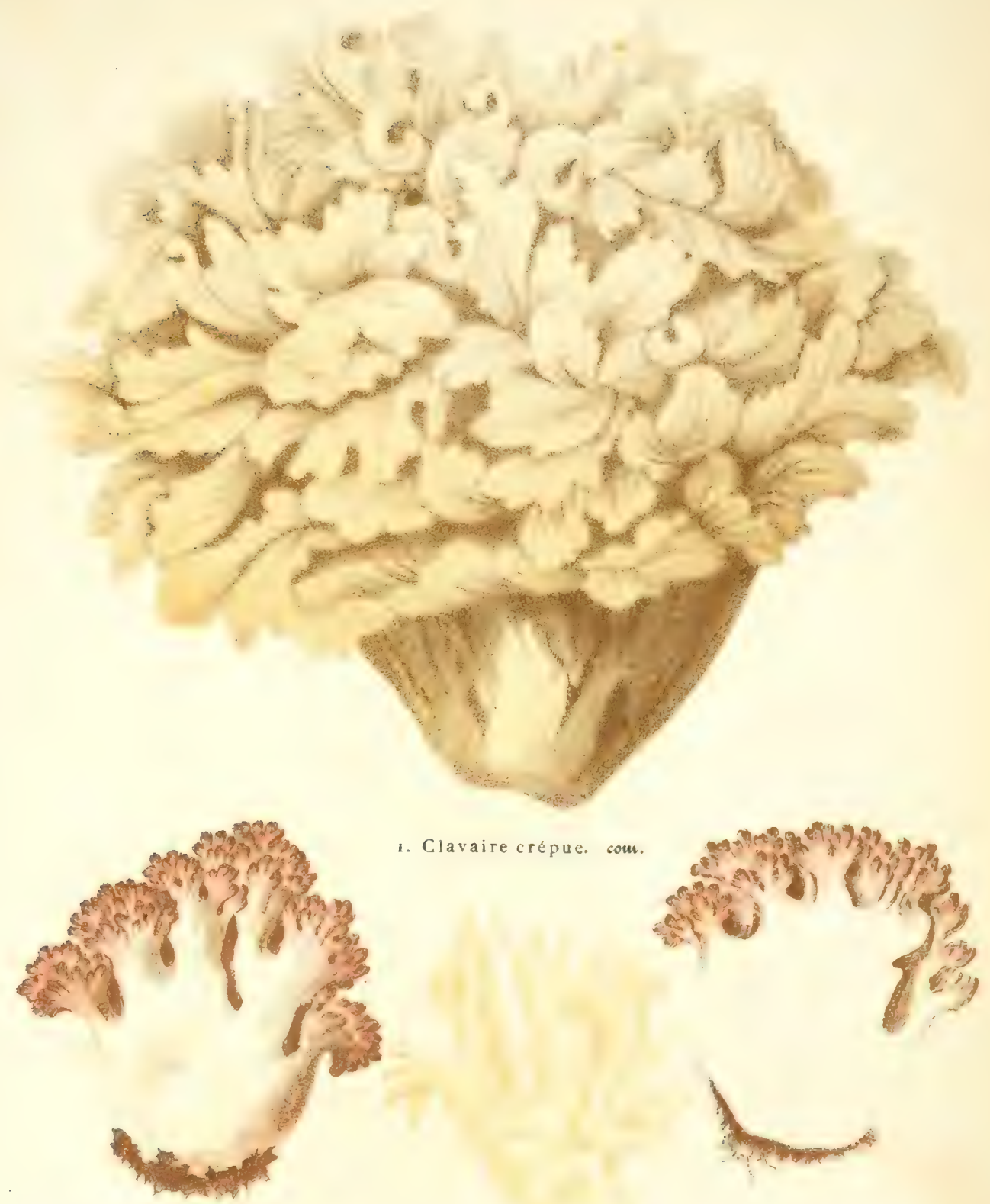

2. Clavaire botryoïde. com.

I. Clavaria CRISPA. $F r$. -2 . Clavaria BOTRYTIS. PERS.

PI. XLVII. 



\section{LES CHAMPIGNONS DE FRANCE.}
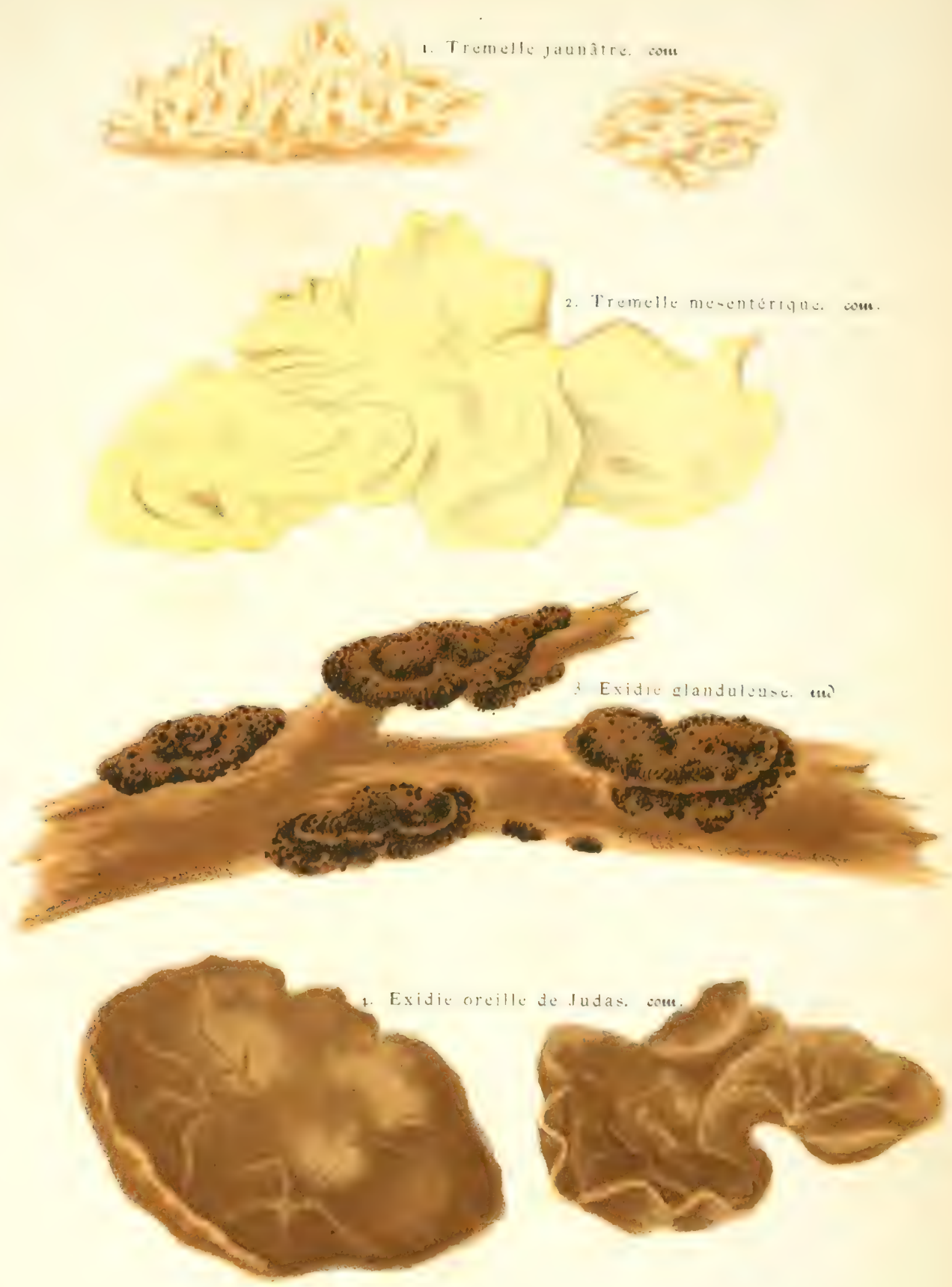

I. TREMELLA LUTESCENS. $F R$ - 2. TREMELLA MESENTERICA. REtz. 3. EXIDIA GLANDULOSA. FR. - + EXIi)A AURICULA JUDE. FR. PI. Xl, IIII. 


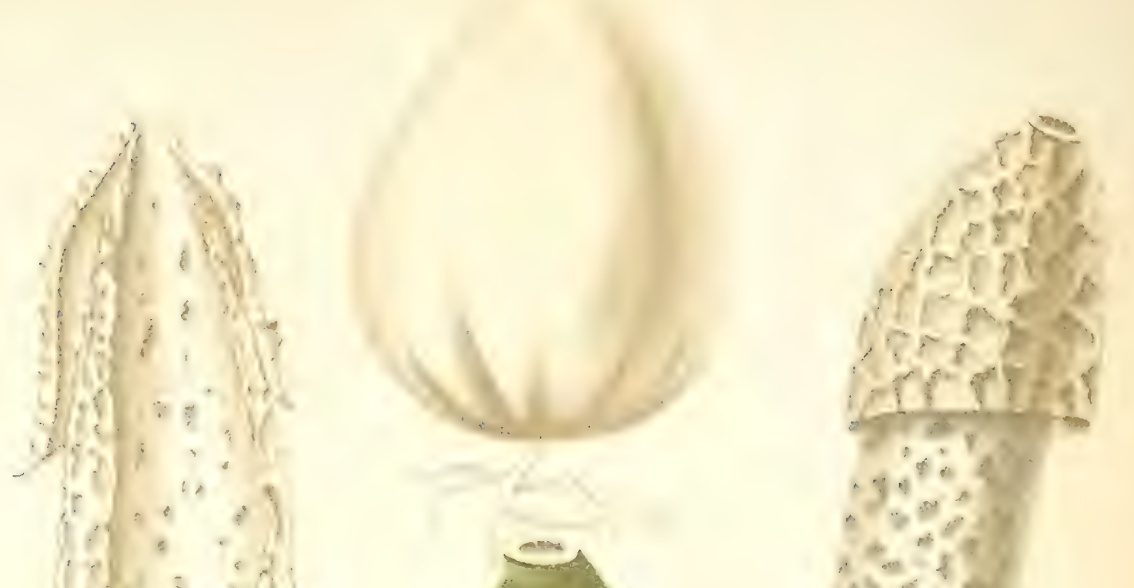

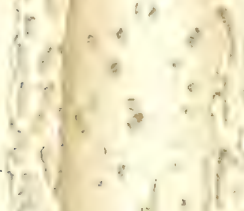

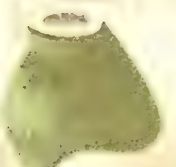

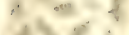

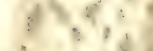

40,11

$8,9,5$

ifo

$42 * 2,32$

i. 1 if

$26=-b^{2}$

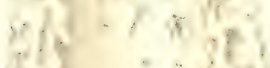

$\because 2, \therefore 80^{\circ}$

(1) $1,1,\{0\}$

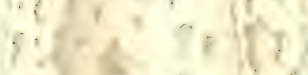

$3 \times 18,89$

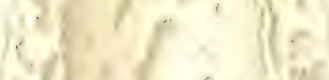
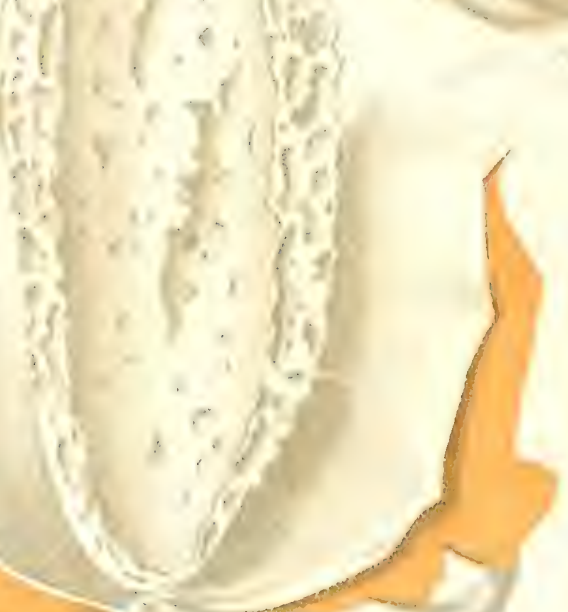

Satyre impudique. ven.

PHALLUS IMPUDICUS. LIN.

PI. XLIX. 



\section{LES CHAMPIGNONS DE FRANCE.}

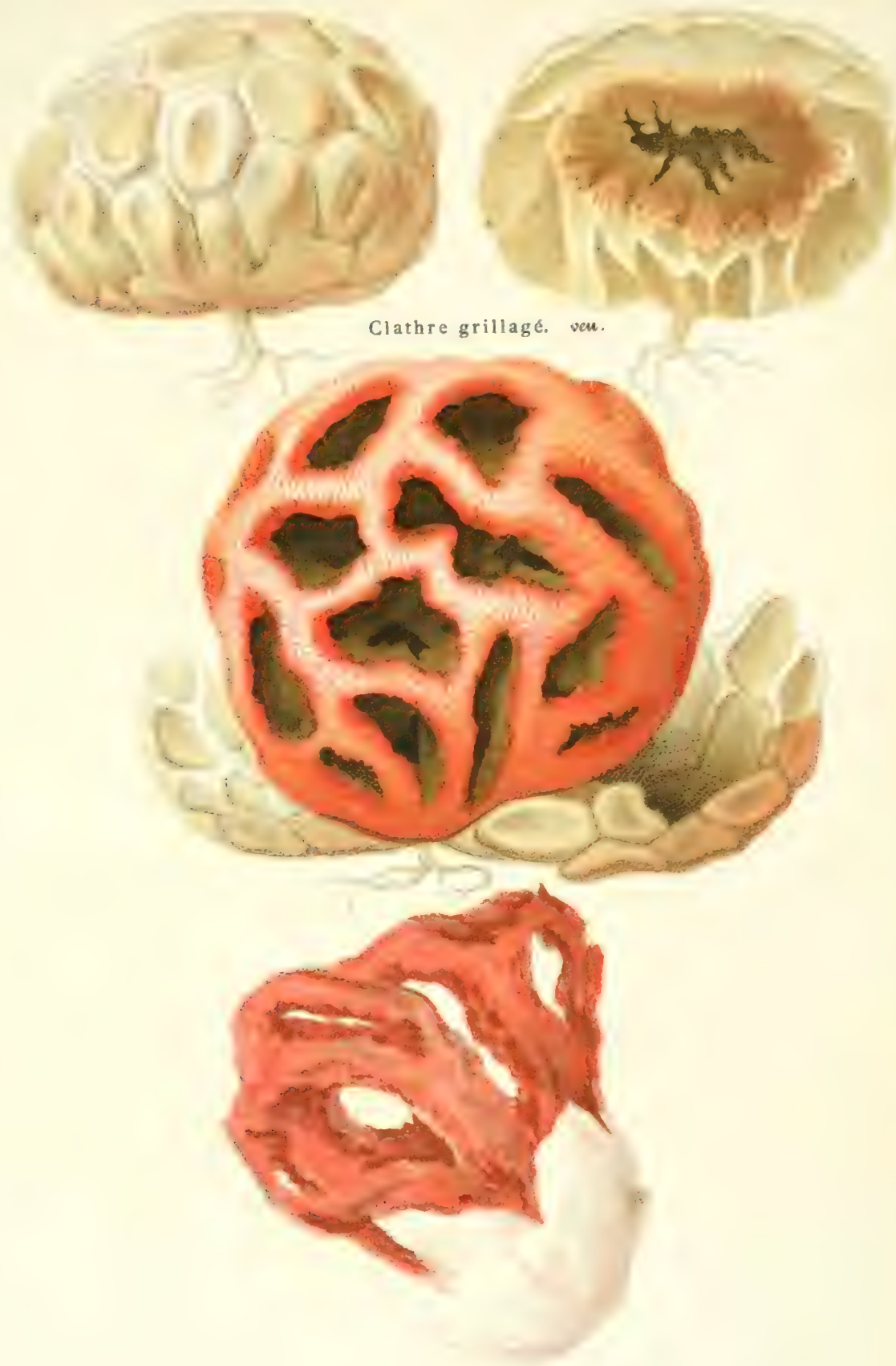

CLATHRUS CANCELLATUS. LIN.

Pl. L. 

LES CHAMPIGNONS DE FRANCE.
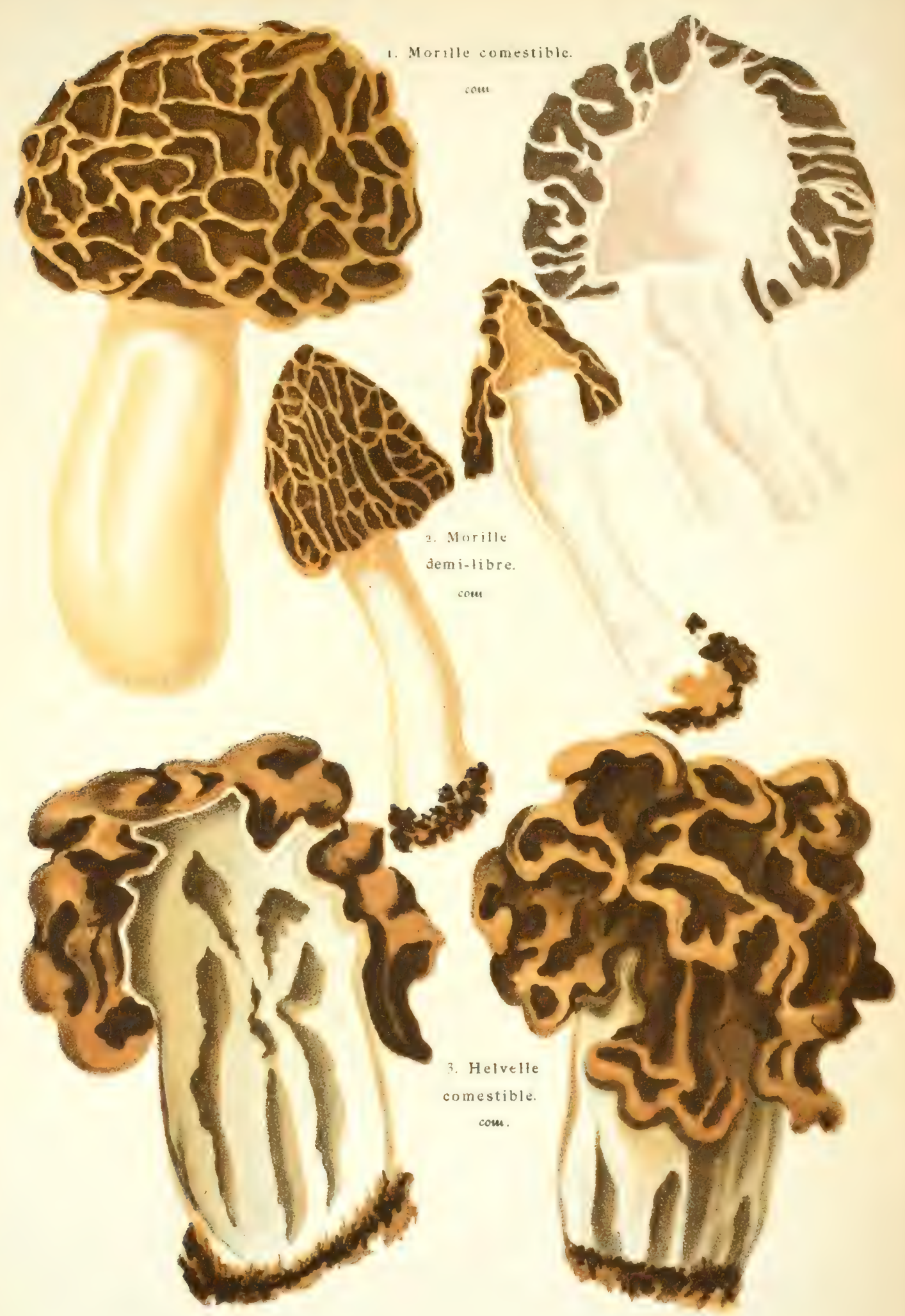

I. MORChElla ESCULENTA. PERS. - 2. MORCHELla SEMI LIBERA DEC.

3. HELVELLA ESCULENTA $F_{R}$.

Pl. U. 



\section{LES CHAMPIGNONS DE FRANCE.}

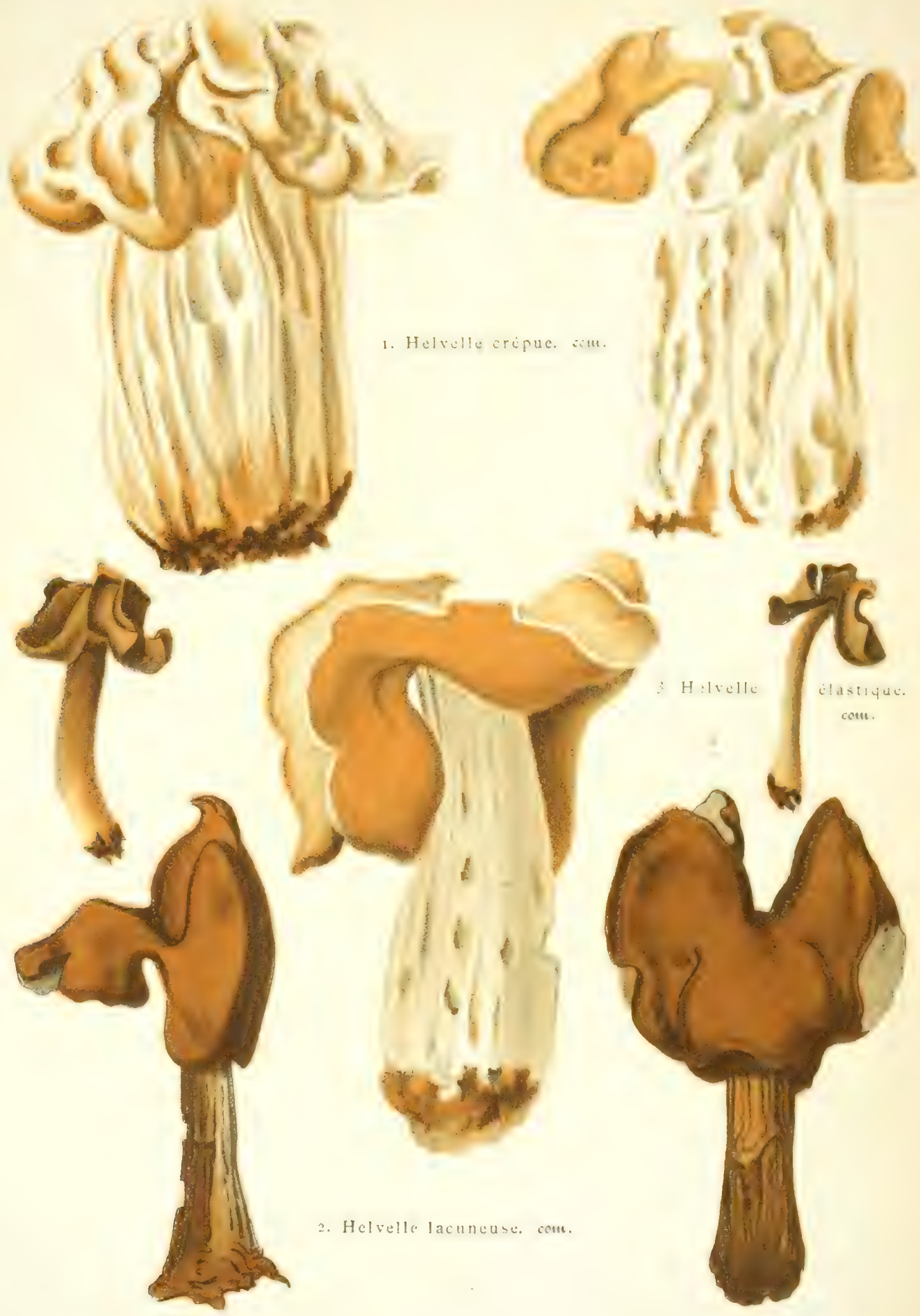

1. HELVELla CRISPA. FR. - 2. HELVELlA LACUNOSA. AFZELL.

3. HELVELLA ELASTICA. BuLL. 

LES CHAMPIGNONS DE FRANCE.
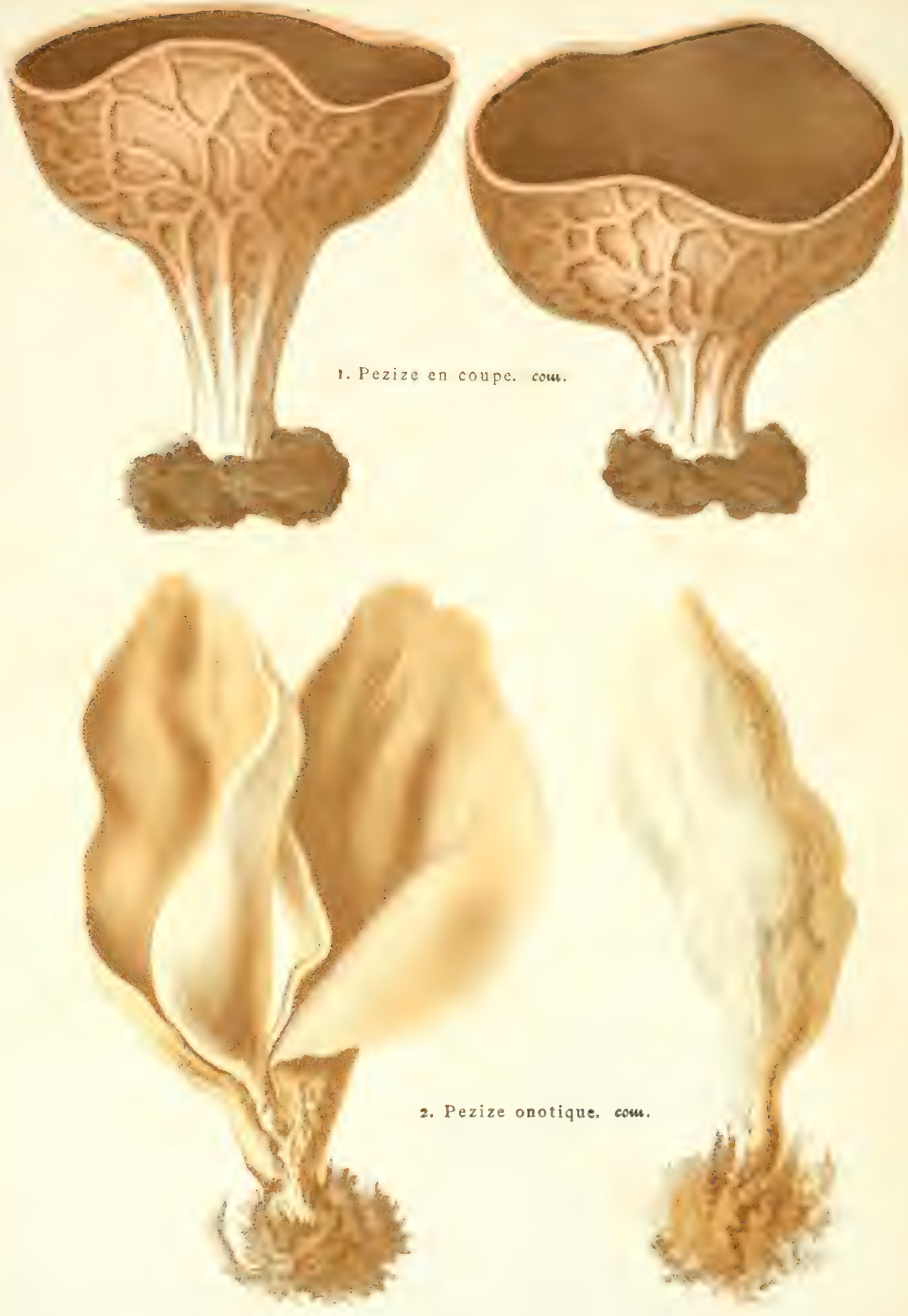

1. PEZiza ACETABUlum. LiN. - 2. PEZIZA ONOTICA. Pers.

Pl. LIV. 



\section{LES CHAMPIGNONS DE FRANCE.}

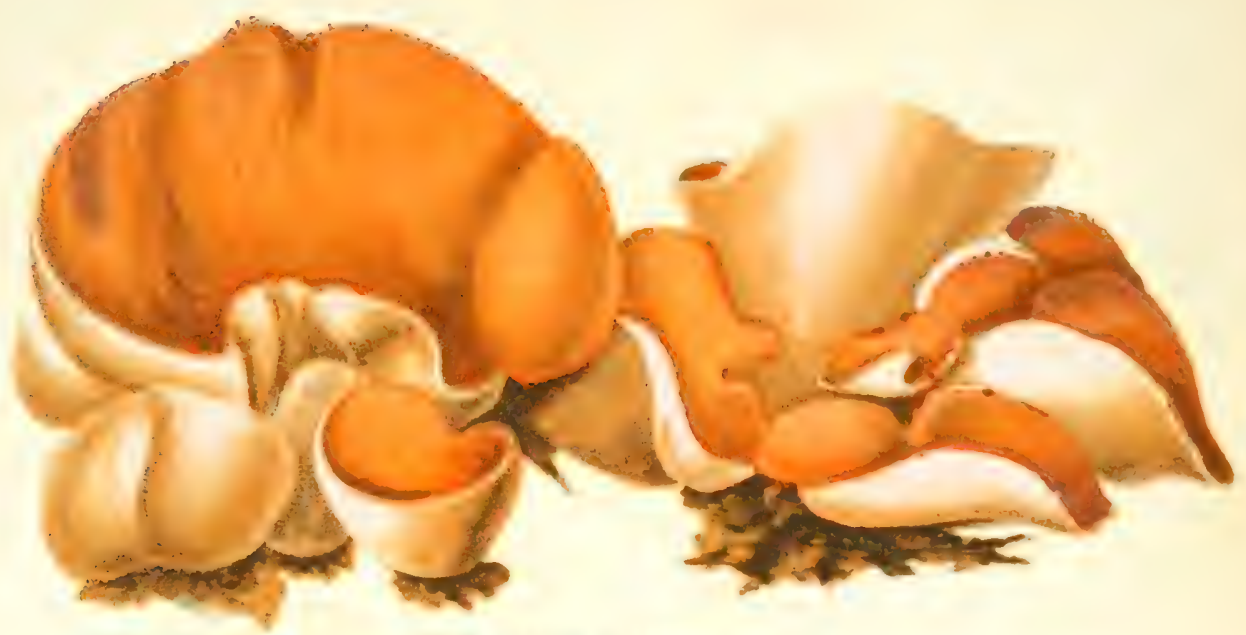

1. Pezize orangéc. sou.

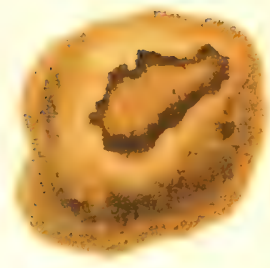

2. Pezize vesiculeuse.

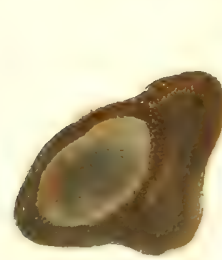

3. Bulgariesalissante. cous.
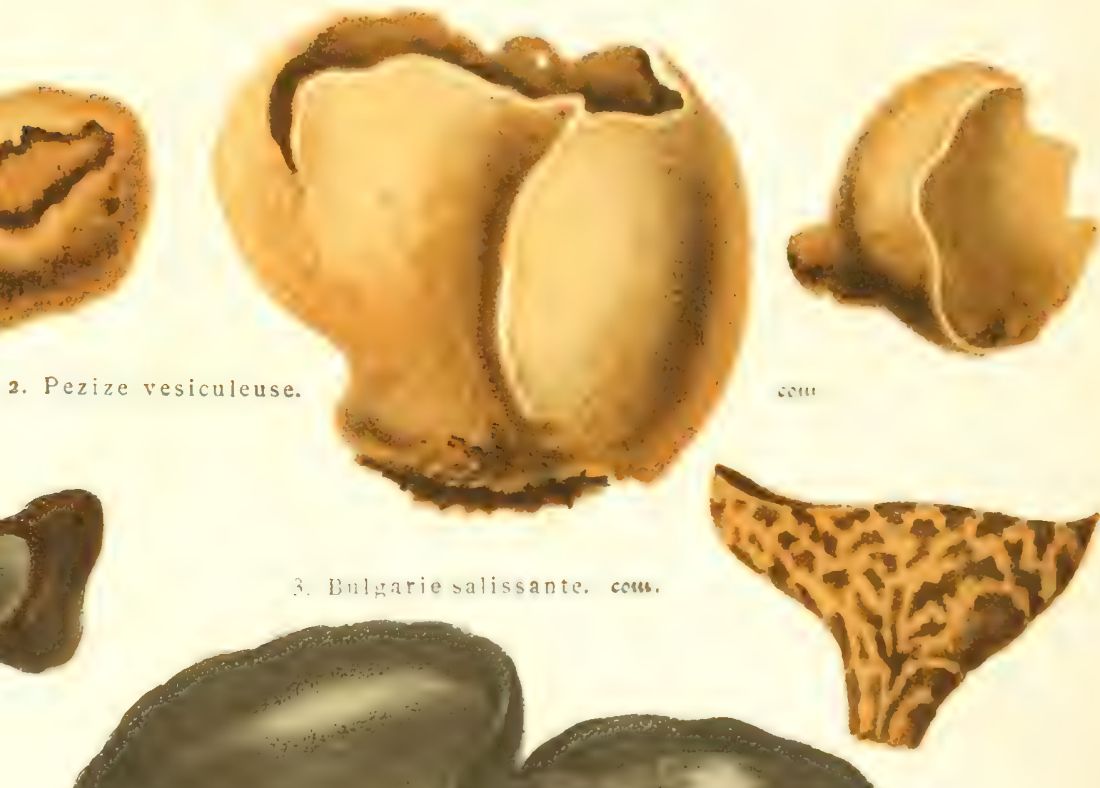

I. PEZIZA AURANTIA. $F R$. -2 . PEZIZA VESICULOSA. BULL.

3. BULGARIA INQUINANS. FR.

P!. LV. 

LES CHAMPIGNONS DE FRANCE.
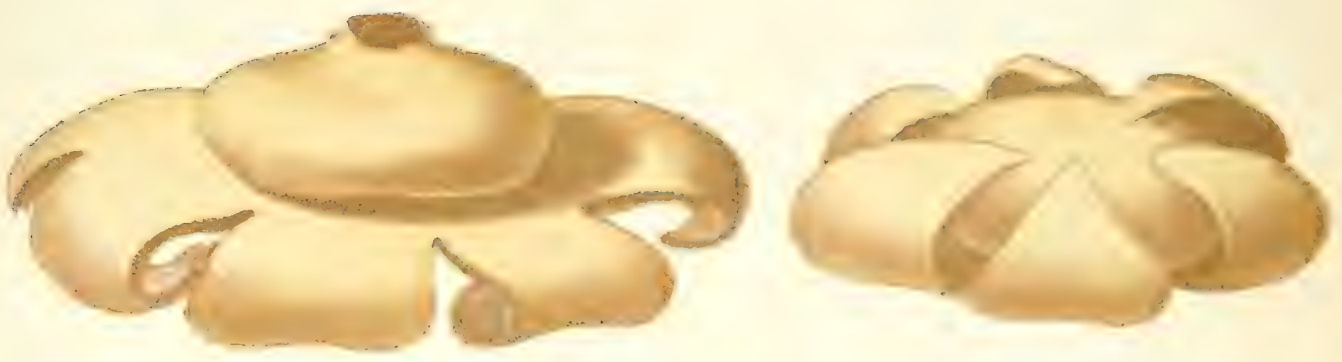

1. Géa-ter hytrotnétriyuc. me
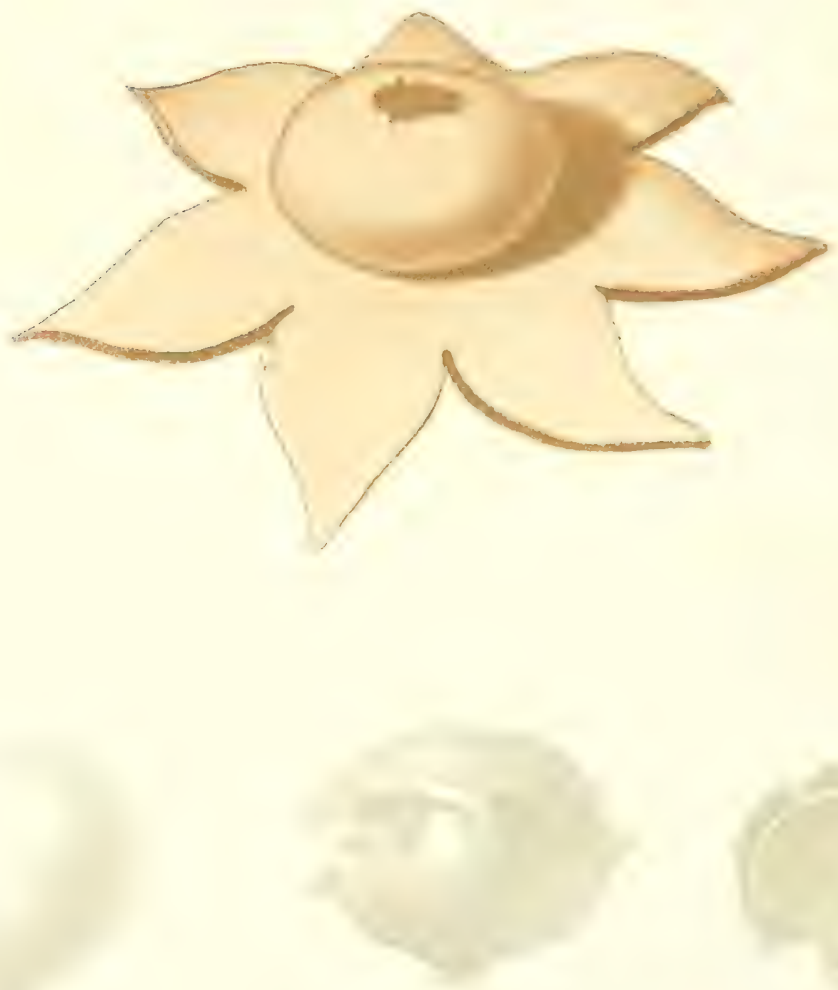

2. Boviste plombc. com

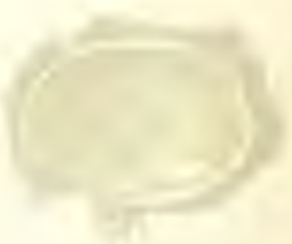

1. GEASTER HYGROMETRICUS. PERS. - 2. BOVISTA PLUMBEA. PERS.

Pl. LVI. 


\section{LES CHAMPIGNONS DE FRANCE.}

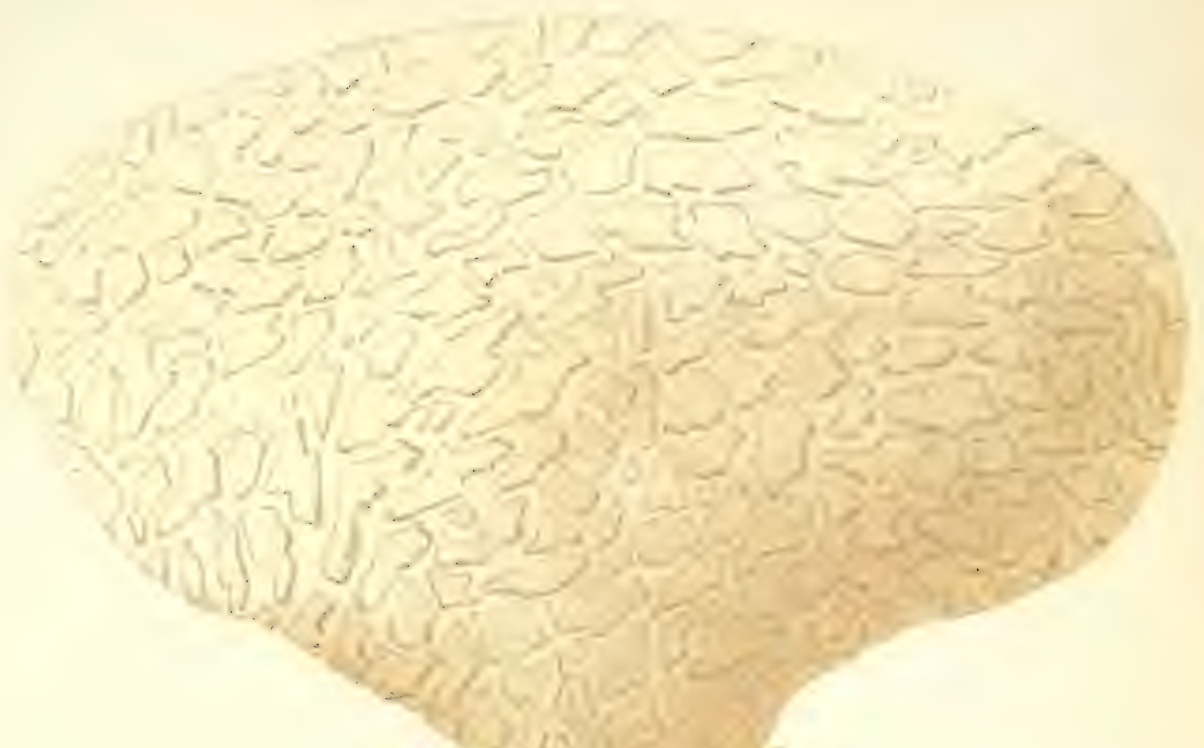

1. Vesseloup ciselée.
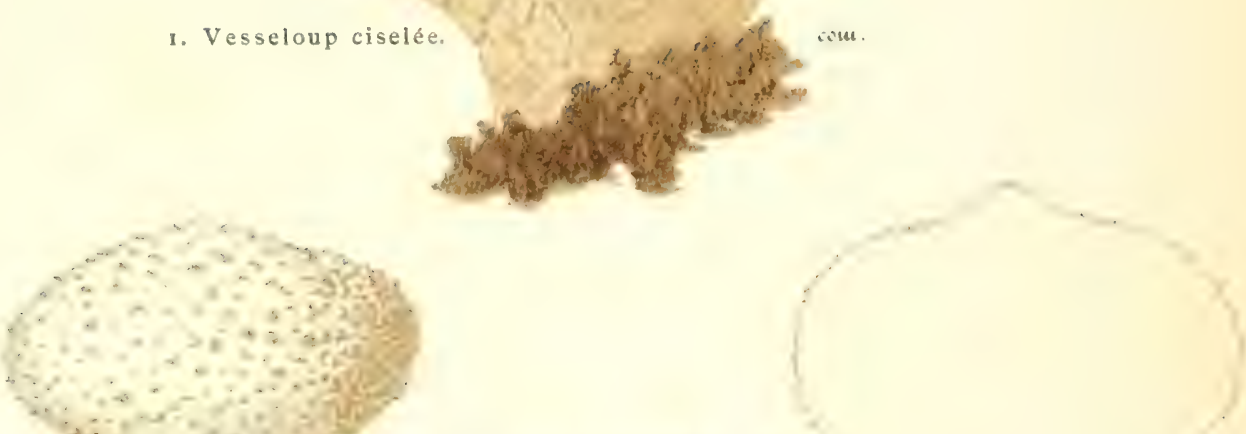

2. Vesseloup gemmiferc. conu
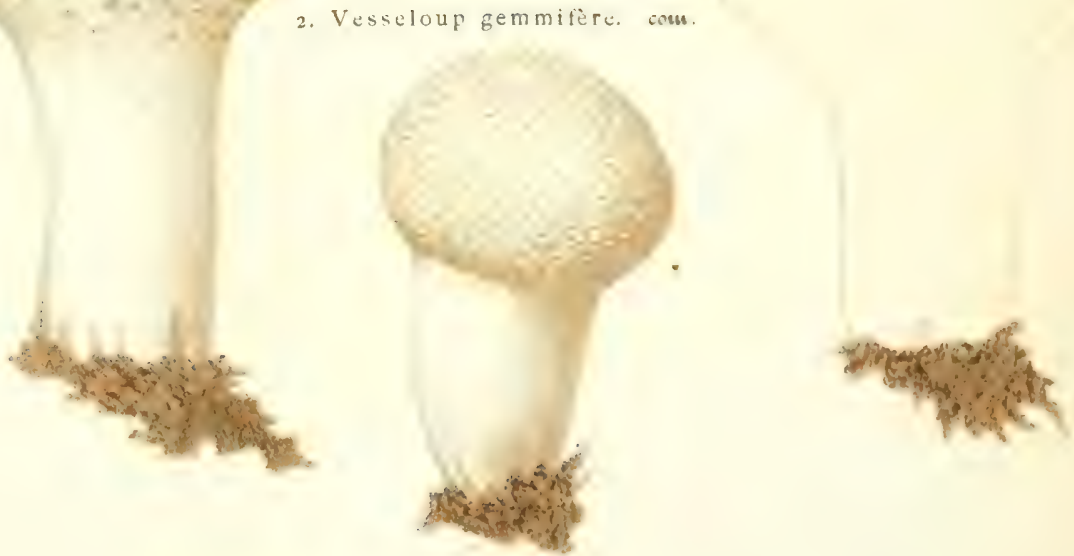

1. LYCOPERDON CELATUM BULL. - 2. LYCOPERDON GEMMATUM. SCOP. PI. LVII. 



\section{LES CHAMPIGNONS DE FRANCE.}

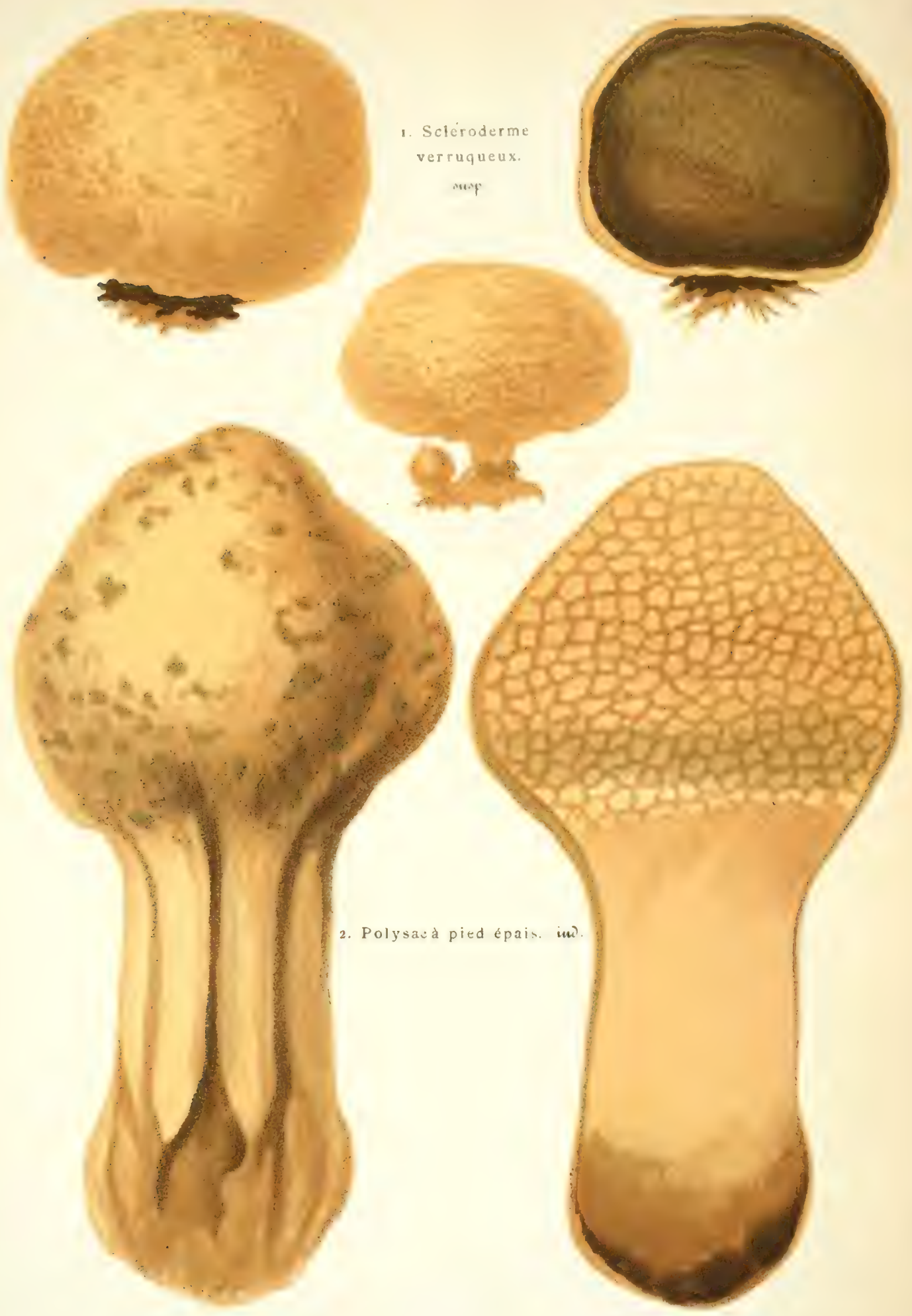

1. SCleroderma VERRUCOSUM. PERS. - 2. POLYSACCUM CRASSIPES. DEC.

PI. LIIII. 



\section{LES CHAMPIGNONS DE FRANCE.}
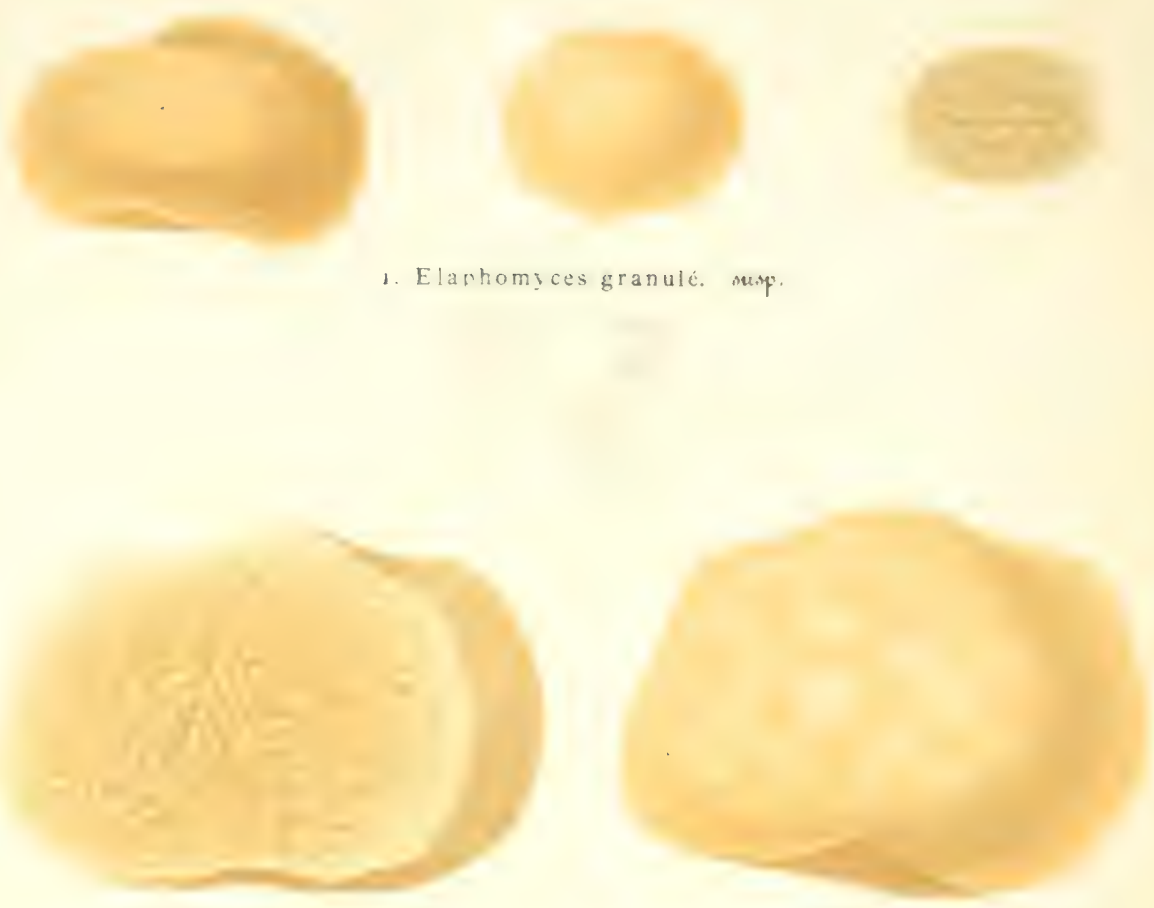

2. Hymenogaster blanc. com.

1. ELAPHOMICES GRANULATUS. $F R .-2$. HYMENOGASTER KLOTZSCHII. TUL.

PI. LIX. 

LES CHAMPIGNONS DE FRANCE.
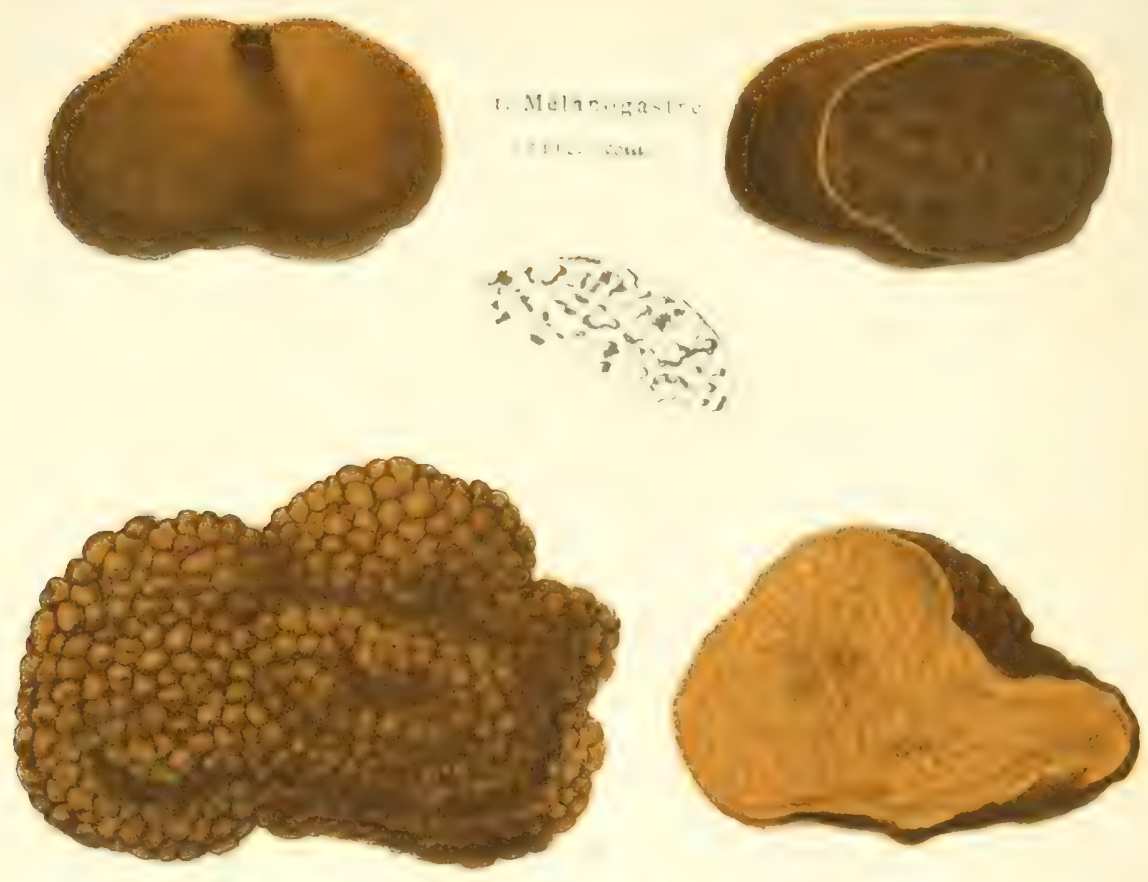

2. Truffe comestitle.

$\cos$ in $\quad$ in

and
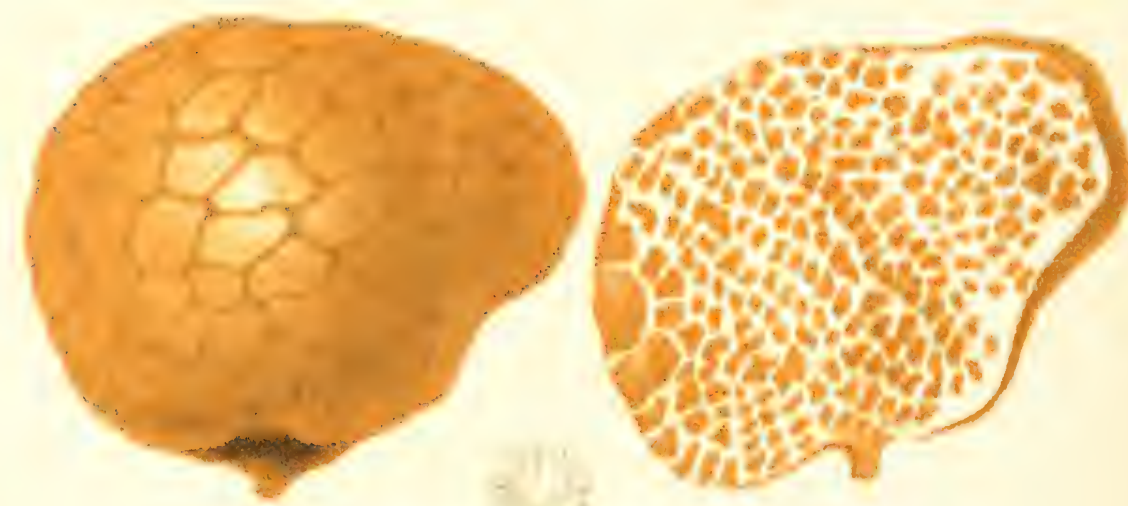

3. Terfezie leonis. com.

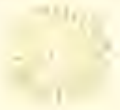

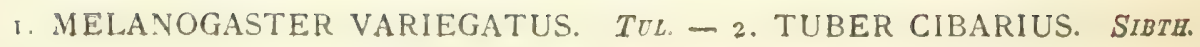

3. TERFEZIA LEONIS, TLL.

PI. LX. 




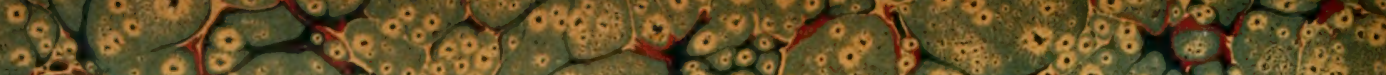

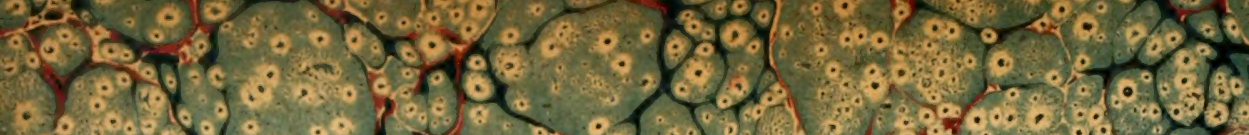

N: $10^{\circ}$

$37^{2}-25$

$10.60 \%$

H.

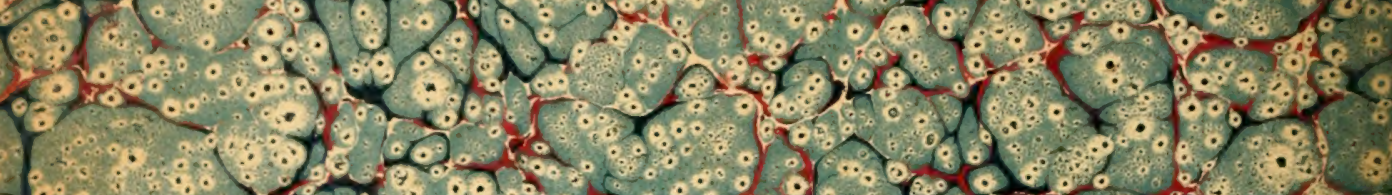

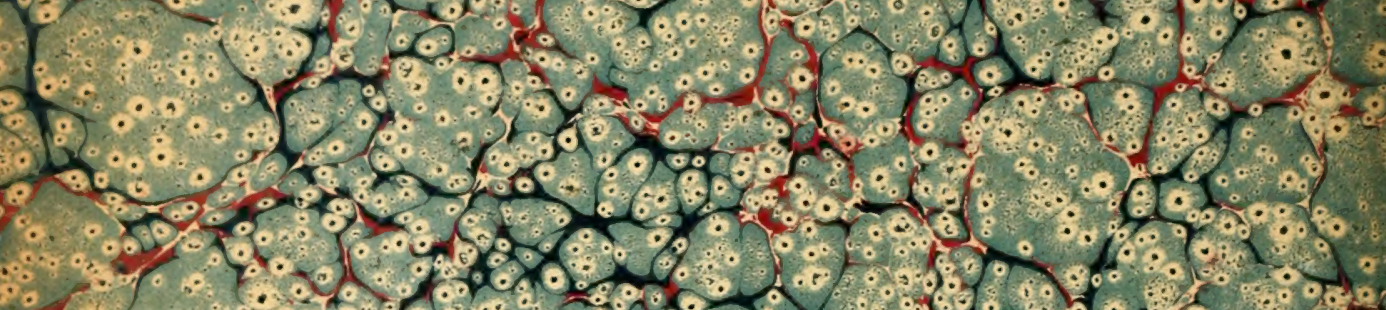

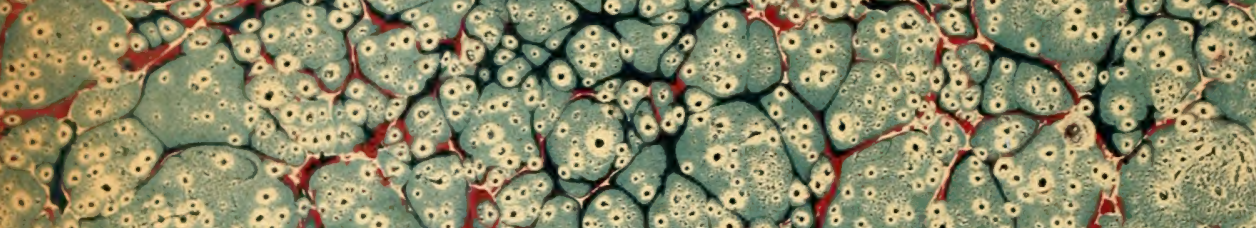

.

$\therefore: 1 \%$

.

ise

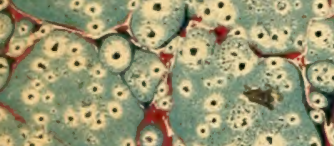

e.

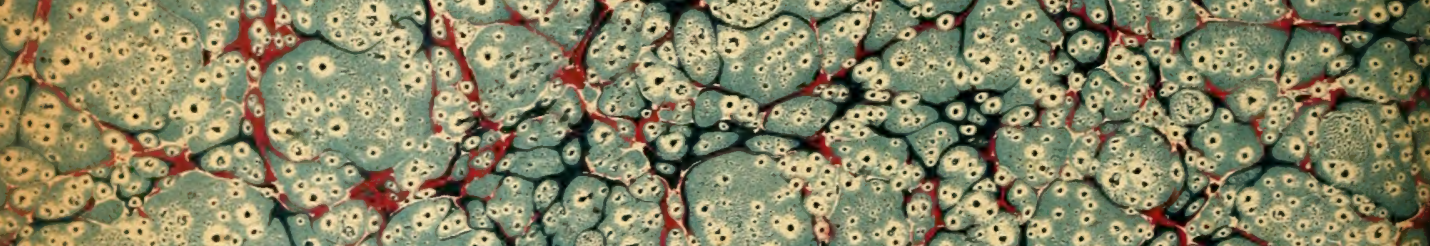

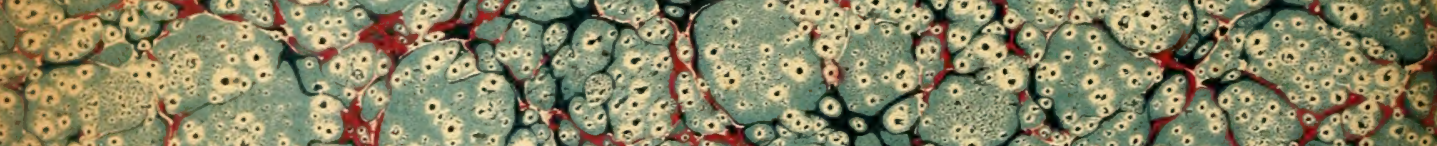

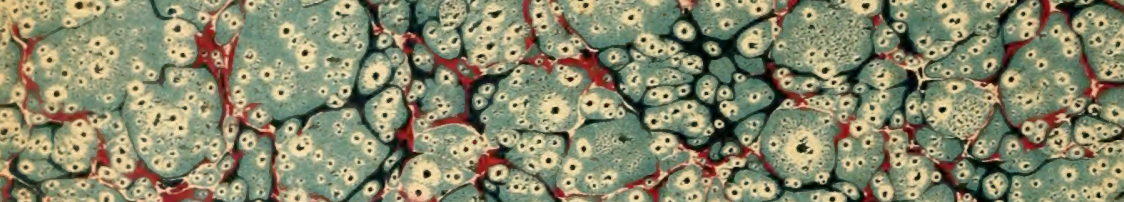

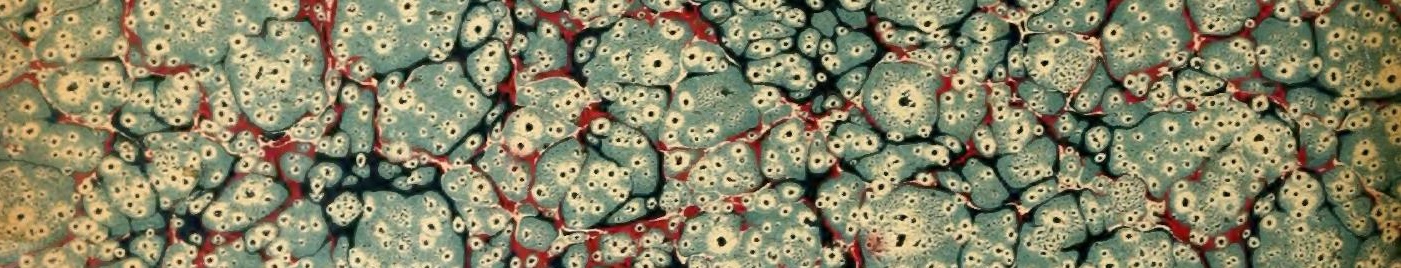

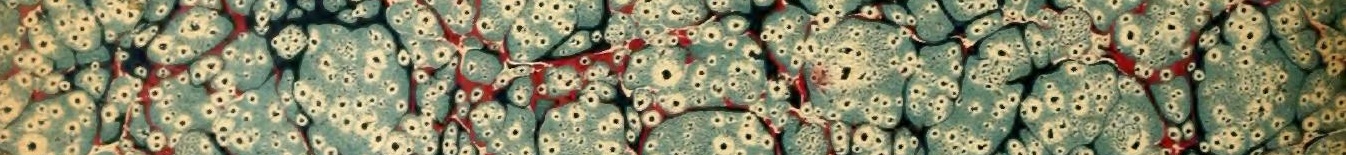
a

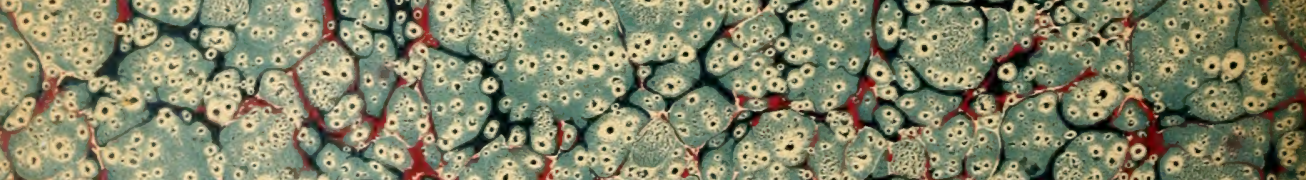

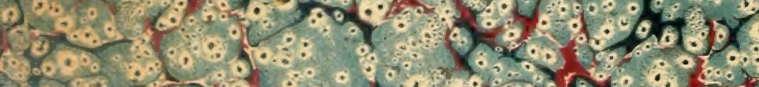

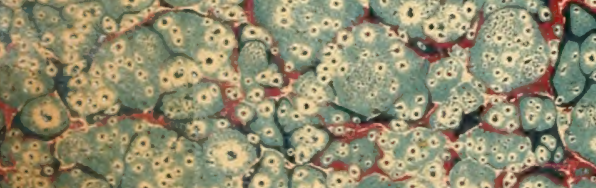
36

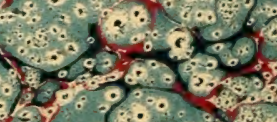
$6 \%$

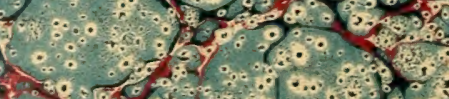

(v) $2 \%: \%$

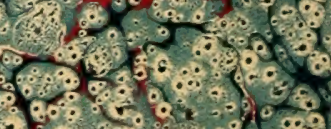

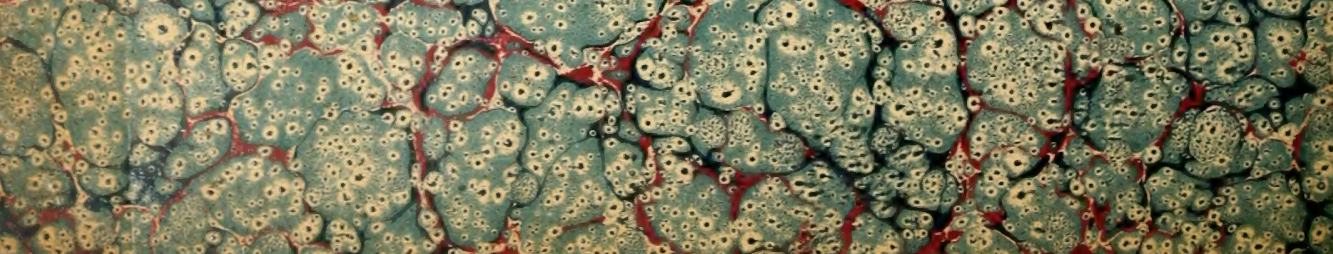




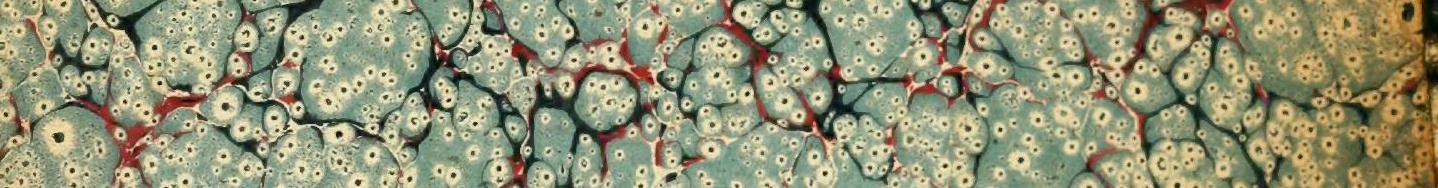

?

O. $0.5 \times$ t. 24

$\because$

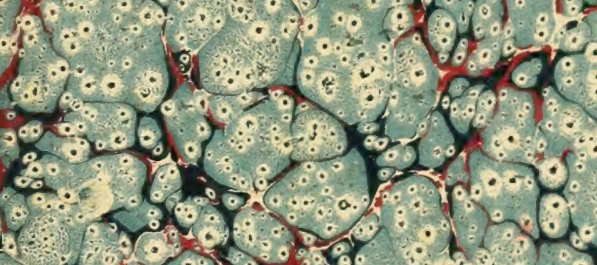
r.

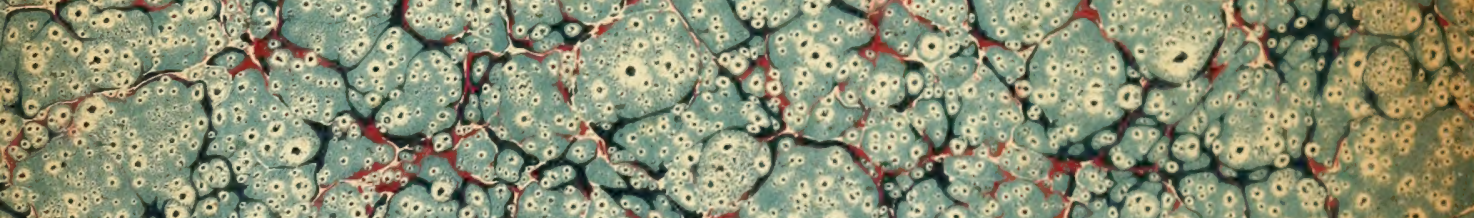

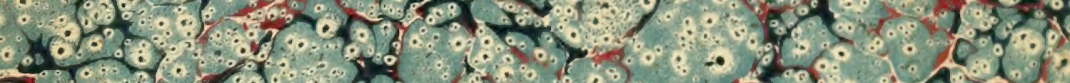




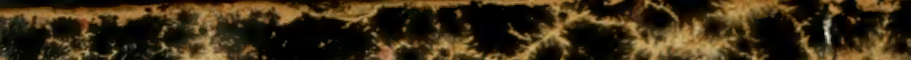

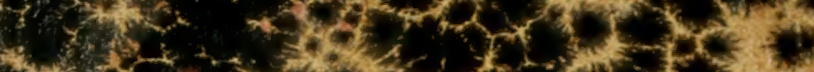

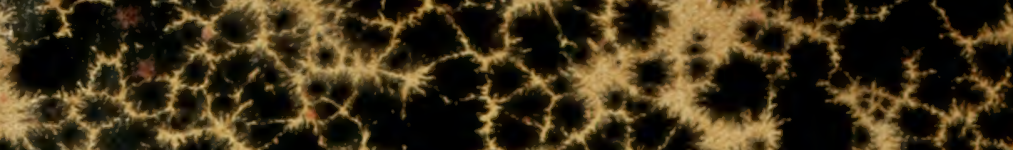

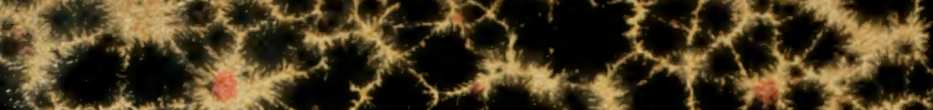

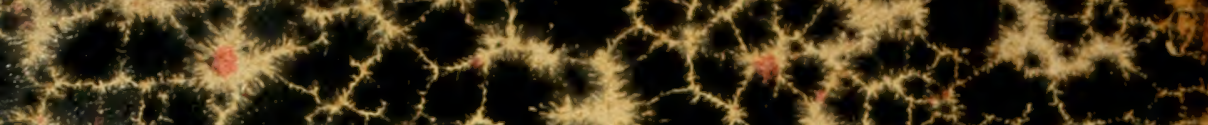

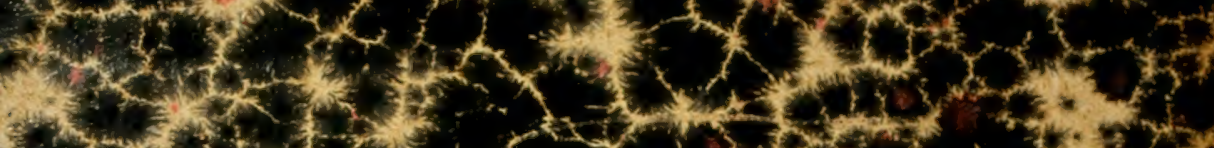

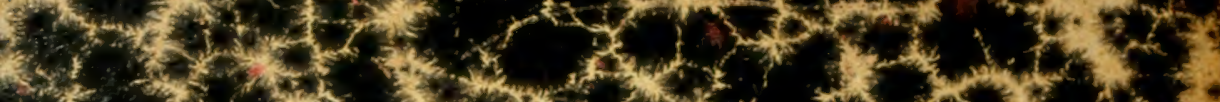

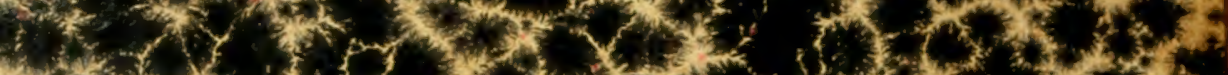

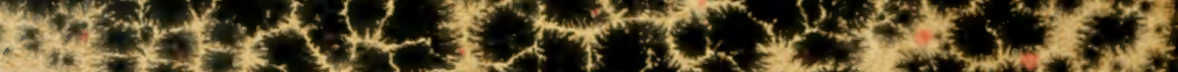

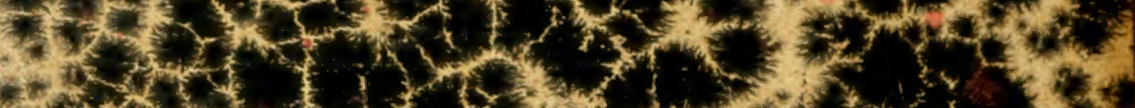

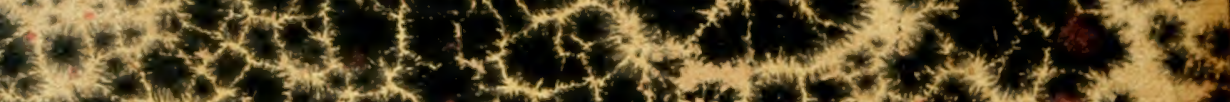

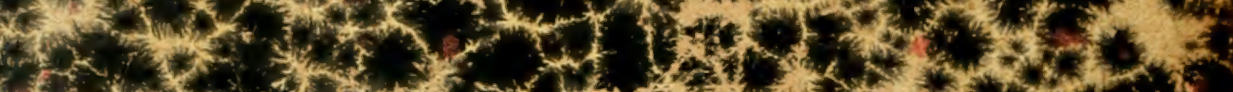

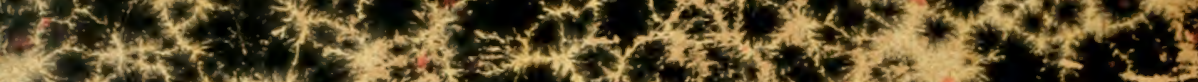

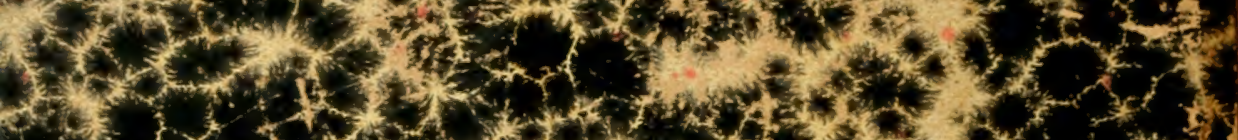

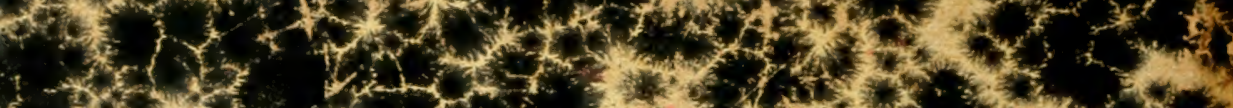

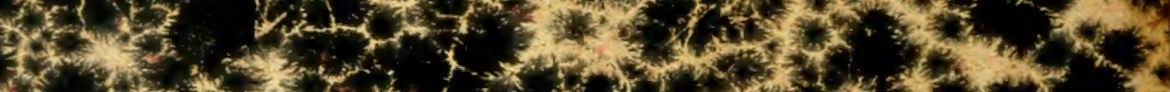

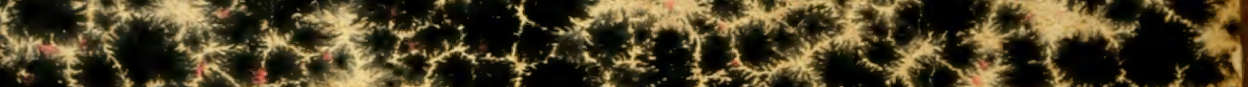
(5)

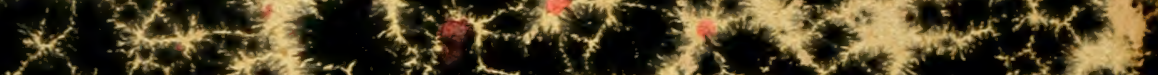

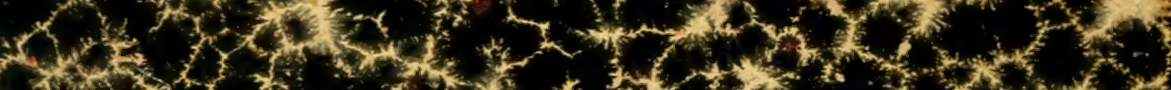

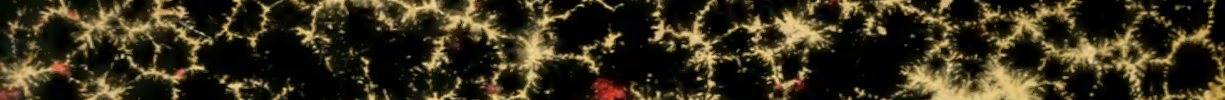

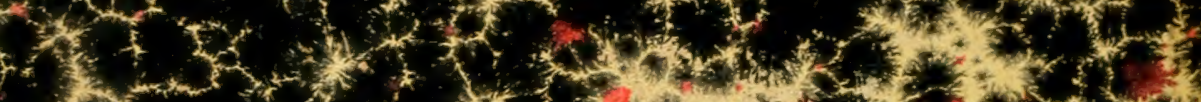
anding

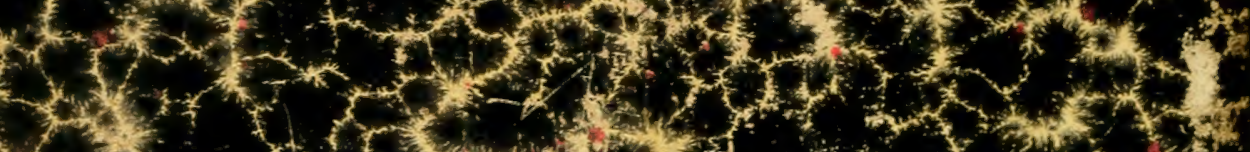

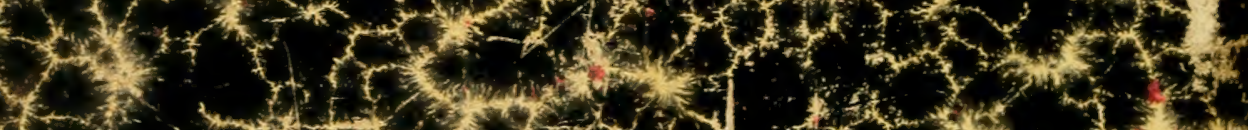

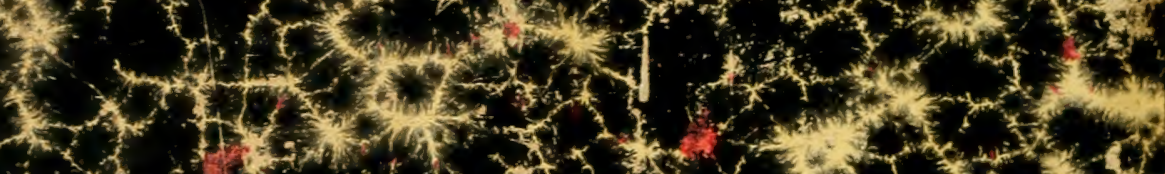

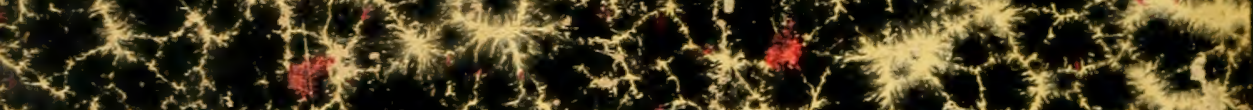

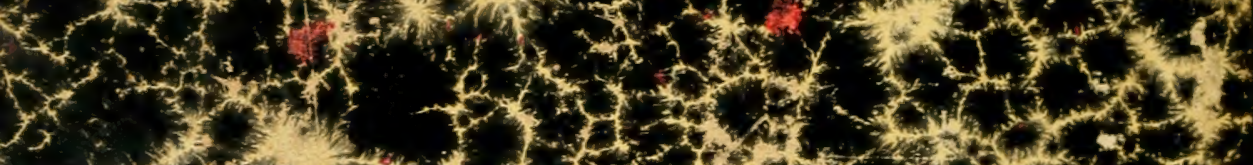

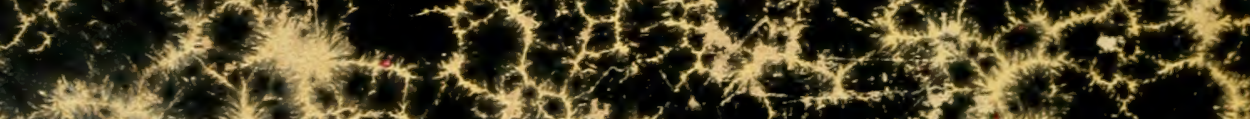

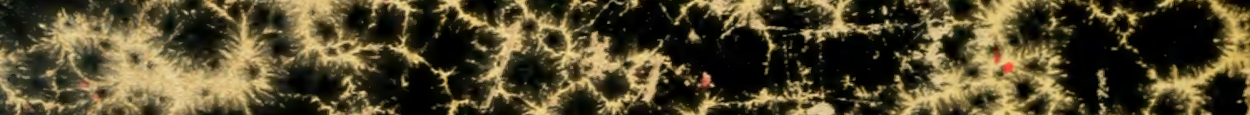

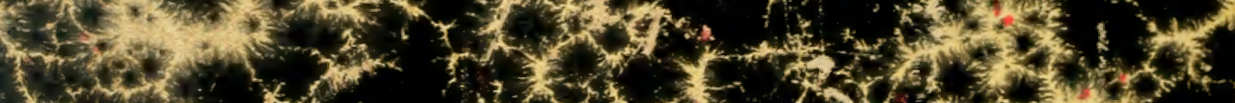

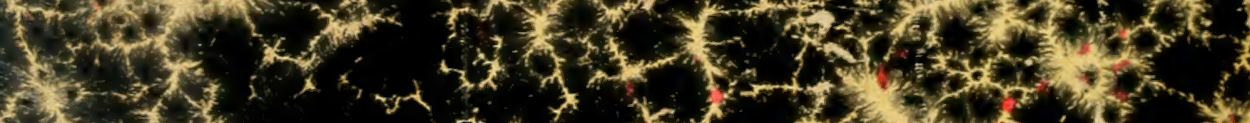

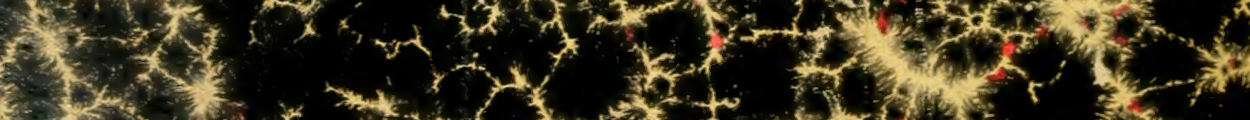

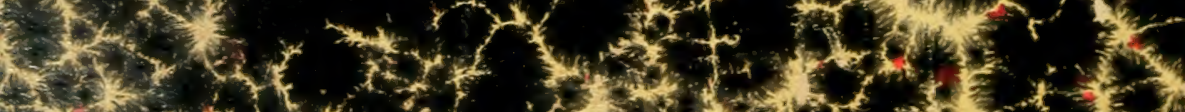

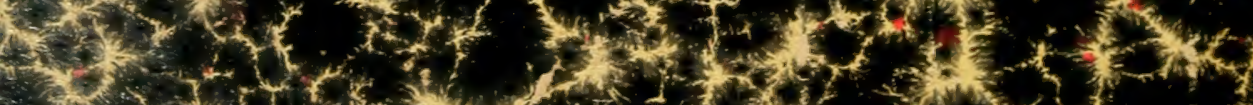

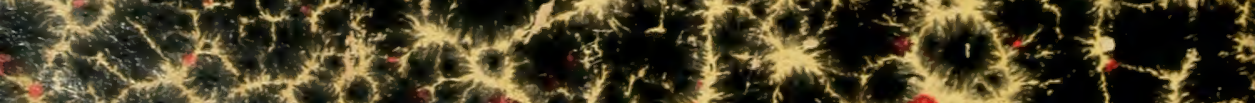

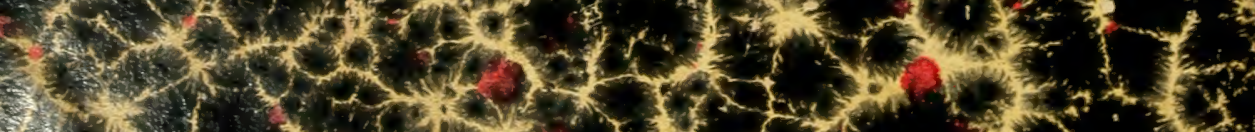

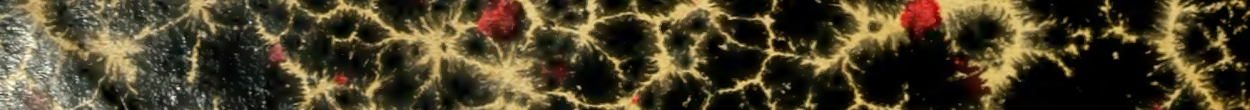

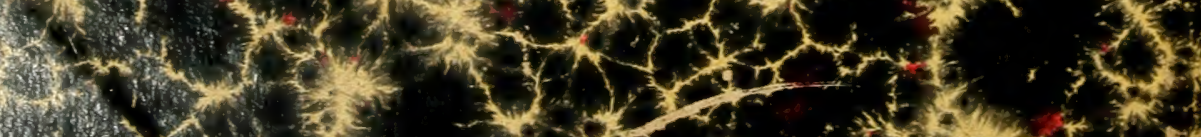

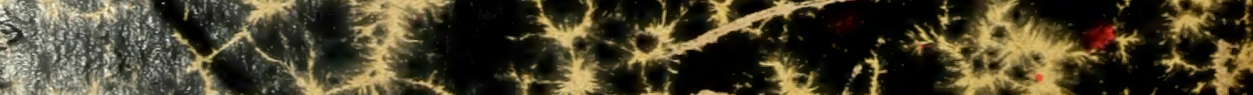

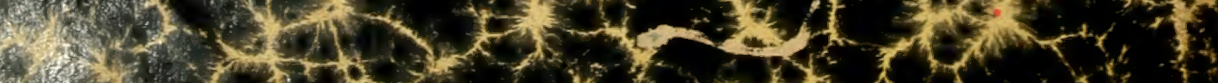

